


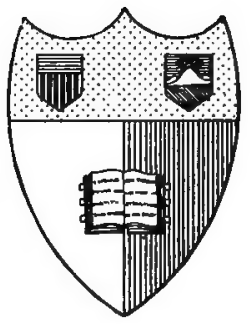

\section{Avew 1 grack \\ State Gallege af Agriculture}

At Urarnell Jlninersity

Jthara, 2ิ.

\section{Tibrary}




\section{QL 48.N62 1888}

Text-book of zoology for junior students

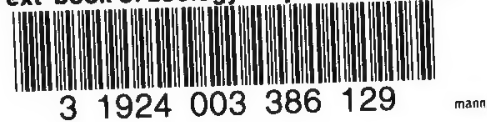




\section{Cornell University Library}

The original of this book is in the Cornell University Library.

There are no known copyright restrictions in the United States on the use of the text. 




\section{TEXT-B00K OF Z00LOGY}





\title{
TEXT-BOOK OF ZOOLOGY
}

\section{FOR JUNIOR STUDENTS.}

B Y

\section{HENRY ALLEYNE NICHOLSON,}

\author{
M. D., D. Sc., Pн. D. (Götт.), F. L. S., F. G. S.,
}

REgIU⿴ PROFESSOR OF NATURAL HISTORY IN THE UNIVERSITY OF ABERDEEN.

FOURTH EDITION,

REVISED AND ENLARGED.

NEW YORK:

D. APPLETON AND COMPANY,

1, 8, AND 5 BOND BTREET.

1888. 



\section{PREFACE TO THE FOURTH EDITION.}

$\mathrm{W}_{\text {ITH }}$ regard to the present Edition of this work, the Author has only to say that he has submitted it to a thorough revision, and, to the best of his ability, has brought it up to the present standard of our knowledge. As the work is strictly elementary, and is intended solely for the use of Junior Students, it has not been deemed advisable to make fundamental alterations in its general plan, or to materialiy change the classification followed in previous Editions, save in those instances in which there is now a general consensus of opinion. The more important recent additions to our acquaintance with the existing or extinct fauna of the world have, however, been noticed in the text, and fresh illustrations have been introduced where this appeared to be desirable.

\section{UnIversity, AberdeEn,}

December 1885. 



\section{ONTENTS.}

\section{INTRODUCTION,}

Definition of Biology and Zoology-Characters of dead and unorganised bodies-Characters of living and organised bodies -Differences between animals and plants-Conditions of Life-Principles of Zoological classification - The great Physiological Functions-Homology and Analogy-General divisions of the Animal Kingdom-Invertebrata and Vertebrata-Distribution in Space-Distribution in Time,

CHAPTER I.

General characters of the Protozoa-Classification of the Protozoa -Gregarinida, .

\section{CHAPTER II.}

General characters and orders of the Rhizopoda-Monera-Anatomy of the Amobea-Foraminifera-Distribution of the Foraminifera in space and in time-Radiolaria-Acanthometro-Polycystina-Thalassicollida-Heliozoa, . .

CHAPTER III.

General characters of the Infusoria-Ciliated Infusoria-Anatomy of Paramceium-Vorticella_Flagellated Infusorians; .

CHAPTER IV.

General characters of the Porifera--Structure of a typical Sponge - Reproduction of Spongilla - Distribution of Sponges in space, . . . . . . . , 


\section{CHAPTER Y.}

General characters of the Coclenterata-Divisions of the Colenterata-General characters of the Hydrozoz-General terminology of the Hydrozoa, . . . . .

CHAPTER YI.

Divisions of the Hydrozoa-Hydroida-Hydrida-Anatomy of Hydra-Corynida-Reproduction in the Corynida and in the Hydroid Zoophytes generally-Alternation of generationsSertularida_Campanularida-Medusidæ, . . .

CHATTER VII.

Siphonophora cr Oceanic Hyclrozoa-Calycophoridæ-Physophorida,

CHAPTER VIII,

Lucernarida - Hidden-eyed Medusæ-Development of Lucernarida-Rhizostomida-Graptolitidæ--Hydrocorallina, .

\section{CHAPTER IX.}

General characters of the Actinozoa-Zoantharia-Anatomy of a Sea-anemone - Zoantharia sclerodermata - Sclerodermic and Sclerobasic Corals-Coral-reefs-Zoantharia sclerobasica - Alcyonaria - Gorgonida - Red Coral - Helioporida Rugose Corals-Ctenophora-Anatomy of Pleurobrachia, .

\section{CHAPTER $\mathrm{X}$.}

General characters of the Echinodermata-Divisions of the Echinodermata-Echinoidea-Anatomy of Echinus-AsteroideaOphiuroidea-Crinoidea-Cystoiclea and Blastoidea-Holothuroidea,

\section{CHAPTER XI.}

General characters and divisions of the Annulosa-General characters of the Sculecida-Divisions of the Scolecida-Treniada -Development of a Tape-worm-Cystic worms-Trematoda -Turbellaria - Acanthocephala - Gordiacea - NematodaRotifera,

CHAPTER XYL.

General characters of the Anarthropoda-Gephyrea-AnnelidaDivisions of the Annelida-Hiruclinea--Oligochæta-Polychreta, . 


\section{CHAPTER XIII.}

General characters of the Arthropoda-Divisions of the Arthropoda - General characters of the Crustacea-DecapodaMacrura - Anomura - Brachyura-Stomapoda-IsopodaAmphipoda-Lamodipoda-Merostomata-Trilobita-Phyllopoda-Cladocera, Copepoda, and Ostracoda-Ichthyophthira-Cirripedia-Rhizocephala,

CHAPTER XIV.

General characters of the Arachnida-Podosomatid-Acarina-

Pedipalpi-Araneida, . $151-156$

\section{CHAPTER XV.}

General characters of the Myriapoda-Centipedes-Millipedes-

Pauropoda-Onychophora,

\section{CHAPTER XVI.}

General characters and anatomy of Insects-Metamorphosis of Insects, . $160-167$

\section{CHAPTER XVII.}

Orders of Insects-Anoplura-Mallophaga-Collembola--Thysanura - Hemiptera -- Orthoptera - Neuroptera-Aphaniptera-Diptera-Lepidoptera-Hymenoptera-StrepsipteraColeoptera, .

\section{CHAPTER XVIII.}

General characters of the Mollusca--Primary divisions of the Mollusca, - $183-186$

\section{CHAPTER XIX.}

Molluscoida-General characters of the Polyzoa-General characters of the Tunicata-General characters of the Brachiopoda, 187-195

\section{CHAPTER XX.}

Classes of the Mollusca proper-General characters of the Lamellibranchiata—General characters of the Gasteropoda-Nudibranchiata-Heteropoda-Air-breathing Gasteropods-Pteropoda, 


\section{CHAPTER XXI.}

General characters of the Cephalopoda-Reproductive process in the Cuttle-fishes-Shell of the Cephalopoda-Dibranchiata -Tetrabranchiata-Orthocerata-Ammonites,

\section{CHAPTER XXII,}

General characters of the T'ertebrata-Skeleton of VertebratesStructure of a vertebra-Vertebral column-Limbs of Vertebrates-Digestive system -Circulatory system-Respiratory system - Nervous systen - Reproduction - Primary divisions-Ichthyopsida-Sauropsida-Mammalia, .

\section{CHAPTER XXIII.}

General characters of the Fishes-Scales-Endoskeleton-Limbs - Tail-Digestive system--Circulation-Respiration-Nervous system-Organs of hearing and smell-Reproduction, . $228-236$

\section{CHAPTER XXIV.}

Orders of Fishes-Pharyngobranchii-Marsipobranchii-Teleostei -Sub-orders of the Teleostei-Ganoidei-ElasmobranchiiSub-orders of the Elasmobranchii--Dipnoi, . $23 i-248$

CHAPTER XXV.

General characters of the Amphibia-Orders of the AmphibiaOphiomorpha-Urodela-Anoura-Labyrinthodontia, $249 \cdot 256$

\section{CHAPTER IXVI.}

General characters of the Reptilia-Circulatory and Respiratory systems-Divisions, .

CHAPTER XXVII.

Orders of Reptilia-Chelonia-Ophidia_Lacertilia-CrocodiliaIchthyopterygia - Sauropterygia - Pterosauria-Anomodontia-Deinosauria-Theriodontia,

\section{CHAPTER XXVIII.}

General characters of the class Aves-Feathers-Vertebral column -Anterior extremity and pectoral arch-Posterior extremity and pelvic arch-Digestive system - Respiration - Circulatory system-Nervous system-Organs of the senses-Migrations of Birds, . 


\section{CHAPTER XXIX.}

Divisions of Aves-Cursores-Natatores-Grallatores-Rasores

-Scansores-- Insessores-Raptores-Odontornithes, . . $290-308$

\section{CHAPTER XXX.}

General characters of the class Mammalia-Skeleton-TeethDental formula-Digestive system-Heart-Lungs-Nervous system-Integumentary appendages-DevelopmentPrimary divisions, $309-318$

\section{CHAPTER XXXI.}

Orders of Mammalia-Monotremata-Marsupialia-EdentataSirenia - Cetacea - Ungulata - Dinocerata - Tillodontia Toxodontia-Hyracoidea-Proboscidea-Carnivora-Rodentia - Cheiroptera - Insectivora — Quadrumana-Bimana, . 319-360 



\section{Z 00 L 0 G Y.}

\section{INTRODUCTION.}

\section{Definition of Biology and Zoology.}

ALt natural objects may be roughly divided into three groups constituting the so-called Mineral, Animal, and Vegetable kingdoms. The objects comprised in the mineral kingdom are all devoid of life, and they exhibit the following characters: $\alpha$. Their chemical composition is simple. They consist of either a single element, as is the case, for instance, with native gold ; or, if combined, they almost always occur in nature in the form of simple compounds, composed of no more than two or three elements-as, for example, common salt, limestone, plaster of Paris, and many others. $b$. Mineral bodies are, when unmixed, composed of similar particles, which have no definite relations to one another ; or, in other words, they are homogeneous. $c$. The form of mineral bodies is either altogether indefinite, when they are said to be "amorphous"; or, if they have a definite shape, they are crystalline, in which case they are usually bounded by plane surfaces and straight lines. $d$. When mineral bodies increase in size, as crystals may do, the increase is produced simply by the addition of particles from the outside (technically called "accretion"). *. Mineral bodies exhibit no phenomena which are not purely physical and chemical, and they show no tendency to periodic changes of any kind.

All the bodies which exhibit these characteristics properly belong to the mineral kingdom, and fall to be treated of by the sciences of Geology, Mineralogy, Chemistry, and Physics. It should be borne in mind, however, that in the case of what are called "fossils" or 
"petrifactions," we have mineral bodies which owe their existence and characters to living beings which existed at former periods in the history of the earth. For this reason, fossils, though composed of mineral matter, cannot be said properly to belong to the mineral kingdom.

On the other hand, the objects which belong to the animal and vegetable kingdoms differ from those which are comprised in the mineral kingdon in the following points : $\alpha$. They are composed of few chenical elements, of which carbon, hydrogen, oxygen, and nitrogen are the most important; and these elements are combined to form complex organic compounds, which always contain a large proportion of water, are very unstable, and are prone to spontaneous decomposition. $b$. They are composed of diverse or heterogeneous parts, which have usually more or less definite relations to one another. These heterogeneous but related parts are termed "organs," and the objects possessing them are said to be "organised." Some of the lowest forms of animals have bodies composed of so uniform a substance that they cannot be said to be organised, as they exhibit no definite organs. This exception, however, does not affect the general value of this distinction. c. They are always nore or less detinite in shape, presenting concave and convex surfaces, and being lwonded by curved lines. $d$. When they increase in size, or "grow," they do so, not by the addition of particles from the outside, but by the reception of foreign matter into their interior and its assimilation tbere (technically called "intussusception"). e. Lastly, they invariably pass through certain periodic changes in a definite and discoverable order, - these changes constituting life.

All the objects, then, which fulfil these conditions, are said to be alive; and they all belong either to the animal or to the vegetable kingdom. The study of living oljects of all kinds, irrespective of which kingdom they belong to, is conveniently called by the general name of Biology (Gr. bios, life ; and logos, discurrse). As all living objects, however, may be referred to one or other of these two kingdoms, so Biology may be divided into the two sciences of Boten.", which treats of plants, and Zoology (Gr. zrmin, animal ; logos, discourse), which treats of animals. The term Natural History, again, is generally understood nowadays as being equivalent to Zoology alone, though originally it was applied to the study of all natural objects indiscriminately.

\section{Differences between Antmals ayd Plants.}

It now becomes necessary to inquire into the differences which subsist between animals and plants, and which enable us to separate 
the kindred sciences of Zoology and Botany. It might have been thought that nothing could be easier than to determine the animal or vegetable nature of any given organism; and such, indeed, was the alınost universal belief of older observers. In point of fact, however, no hard-and-fast line can be drawn, in the present state of our knowledge, between the animal and vegetable kingdoms, and it is often a matter of extreme difficulty, or even wholly impossible, to decide positively whether we are dealing with an animal or a plant. In the case of the higher members of the two kingdoms there is no difficulty in arriving at a decision. The bigher animals are readily, separated from the higher plants by the possession of a distinct nervous system, of locomotive power which can be voluntarily exercised, and of an internal cavity fitted for the reception and digestion of solid food. The higher plants, on the other hand, possess no nervous system or organs of sense, are incapable of voluntary changes of place, and are not provided with any definite internal cavity, their food being wholly fluid or gaseous.

The lower animals (Protozoa) cannot, however, be separater in many cases from the lower plants (Protophyta) by these distinctions, since many of the former have no digestive cavity, and are destitute of a nervous system, and many of the latter possess the power of active locomotion. In determining, therefore, the nature of these ambiguous organisms, the following are the chief points to be attended to :-

Firstly, As to mere form or external configuration, no certain rules can be laid down for separating animals and plants. Many of the lower plants, either in their earlier stages of existence or when grown up, are exactly similar in form to some of the lower animals. This is the case, for example, in some of the Algoe, which closely resemble some of the Infusorian animalcules. Many undoubted animals, again, are rooted to solid objects in their ardult state, and are so plant-like in appearance as to be always popularly regarded as vegetables. This is the case with mary of the so-called Hydroid Zoophytes, such as the Seafirs, and also with the much more highly organised Sea-mats ( $F / u s t r a)$, all of which are usually regarded as sea-weeds by seaside visitors. This is also, but less strikingly, the case with the Corals and Sea-anemones, of which the latter are often spolsen of as "sea-flowers."

Secondly, No decided distinction can be drawn between animals and plants as to their minute internal structure. Both alike consist essentially of minute solid particles (molecules or granules), of cells, or of fibres.

Thirdly, As regards chemical composition, there are some decided, though not universal, differences between plants and animals. As a general rule, it may be stated that plants exhibit a decided predominance of what are known to chemists as "ternary compounds"- that is to say, compounds which, like sugar, starch, and cellulose, are composed of the three elements, carbon, hydrogen, and oxygen. They are, comparatively speaking, poorly supplied with "quaternary" compounds, which contain the fourth element, nitrogen, in addition to the three first mentioned. Animals, on the other hand, are rich in quaternary nitrogenised compounds, such as albumen or fibrin. Still, in both kingdoms we find nitrogenised and non-nitrogenised compounds, and it is only 
in the proportion which these bear to one another in the organism that animals differ in any way from pliats. The most characteristic of all vegetable compounds is the one known as cellulose, very nearly allied in its chemical composition to ordinary starch. As a general rule, it may be stated that the presence of an exterual envelope of cellulose in any organism raises a strong presumption as to its vegetable nature. Still cellulose is not exclusively confined to plants, as was at one time believer. It is now well known that the outer covering of the so-called Sea-squirts or Ascidian Molluses contains a large quantity of cellulose (as much as 60 per cent in some cases). Another highly characteristic vegetable product is chlorophyll, the green colouring-natter of plants. Any organism which exhibits chlorophyll in any quantity as a proper elenient of its tissues is most probably vegetable. In this case also, however, the presence of chlorophyll cannot be regarded as a certain test, since it occurs regularly in some undoubted animals (e.g., Stentor amongst the Infusoria, and the Hydra viridis, or green Fresh-water Polype, amongst the Celenterata).

Fourthly, As regards locomotive poner, or the ability to effect changes of place at will, the results of observation are singularly at variance with our preconceived notions. Before the invention of the microscope, no instances of independent voluntary novements were known in plants, if we except the voluntary opening and closure of flowers and their turning towards the sun, the drooping of the leaver of sensitive plants under irritation, and some other phenomena of a like nature. Now, however, we know of many plants which are endowed, either when young or throughout life, with the power of effecting voluntary morements apparently as spontaneous and independent as those exhibited by the lower animals. In some cases the niovements are brought about by means of little vibrating hairs or cilia, with which a part or the wlinle of the surface is furnished. When it is added that many animals are permanently fixed and rooted to solid objects in their fully-grown condition, it will be seen that no absolute distinction can be drawn between animals and plants merely on the ground of the presence or absence of independent locomotive power.

Fifthly, We have shortly to consider one of the most reliable of all the tests by which an animal may be separated from a plant-namely, the nature of the food, and the products which are formed out of the food within the body.

The differences between animals and plants in this respect may be roughly stated as follows:-

1. Plants live upon purely inorganic substances, such as water, carbonic acid, and ammonia-and they have the power of making, out of these, true organic substauces, such as starch, cellulose, sugar, \&c. Plants, therefore, take as food very simple bodies, and manufacture them into much more complex substances, so that plants are the great producers in nature.

2. All plants which contain green colouring-matter (chlorophyll) in the process of digestion break up carbonic acid into the two elenents of which it is composed-namely, carbon and oxygen, keeping the carbon and setting free the oxygen. As carbonic acill occurs always in the air in mall quantities, the result of this is that plants renove carbonic acid from the atmosphere and give out oxygen.

3. Animals, on the other hand, have no power of living on inorganic matters, such as water, carbonic acid, and ammonia. 'They have no power of converting these into the complex organic substances of which their bodies are composed. On the contrary, animals require to be supplied with ready-made organic com- 
pounds if their existence is to be maintained. These they can only get in the first place from plants, and therefore animals are all dependent upon plants for food either directly or indirectly. Animals, therefore, differ from plants in requiring as food complex organic bodies which they ultimately reduce to very much simpler inorganic bodies. Whilst plants, then, are the great manufacturers in nature, animals are the great consuners. Another distinction arising from the nature of their food is, that whilst plants decompose carbonic acid, keeping the carbon and setting free the oxygen, animals absorb oxygen and give out carbonic acid, so that their reaction upon the atmosphere is the reverse of that of plants. It should be added, however, that there are organisms which are genuine plants so far as concerns their mutritive processes, but which, nevertheless, exhibit other characters which would place them among animals. Examples of such organisms are found in Volvox and its allies.

As regards these general distinctions between plants and animals, there are two points which should be renembered :-

1. That even if universally true, these distinctions can often not be applied in practice to the ambiguous microscopic organisnis about which alone any doubt can be entertained.

2. These general laws are certainly not of universal application in the case of plants. Thus, plants which do not contain chlorophyll (e.g. Fungi) do not possess the power of decomposing carbonic acid under the influence of sunlight, but are like animals in requiring organic compounds for their food.

\section{Conditions of Life.}

Certain conditions are necessary for the manifestation of life or vitality, as, indeed, is the case with every known force. Some of these conditions, though very generally present, are not absolutely indispensable; but there is one condition which appears to be essential, and that is, that the living body must be composed of a certain material. This material forms the essential and fundamental parts of every living being, whether vegetable or animal, and it is usually known by the technical name of "protoplasm" (Gr. protos, first; and plasso, I mould). Living beings. may, and often do, contain in their bodies many other substances besides "protoplasm," but it is in this substance that vitality seems alone to be inherent; and we are consequently justified in saying that life is only found in connection with protoplasm. It is, however, still a matter of opinion whether the protoplasm of all aninals and plants is precisely the same, and under any circumstances we may believe that this substance is simply the medium or vehicle through which vital force manifests itself. Using the term in its general sense, "protoplasm" is chemically related in its nature to albumen or white-of-egg, and generally has the character of a jelly-like, semi-fluid, transparent material, which does not in itself exhibit any definite structure. When heated to a certain temperature, it solidifies or "coagulates," just as the white of an egg does when 
boiled. In its living state also, protoplasm appears invariably to have the power of movement. Thus, any little mass of living protoplasm, if free to do so, has the power of throwing ont processes of its own substance, and thus of moving and changing its place. It has, also, the power of increasing in size or of maintaining its existence by "assinilating "fresh and foreign material ; and it may detach portions of its own substance which rnay become developed into fresh masses of protoplasm.

In some cases, though protoplasm be present, there is no external and visible manifestation of life, as is the case with eggs and seeds, which exhibit what is called a "dormant" vitality. This condition nay remain for a long time unchanged, until the external circumistances are altered, and then the organism passes from a state of clormant into one of artive life.

As a general rule, therefore, it is necessary for certain external conditions to be present before any external vital phenomena can be manifested ; and usually life itself, even in a dormant state, cannot be maintained in the absence of these conditions. Thus, the presence of atmospheric air (or rather of free oxygen) is in an ordinary way essential to active life. The higher manifestations of vitality, again, are only possible between certain limited ranges of temperature, varying from near the freezing - point to about $120^{\circ}$ Fahr. Water, again, is an essential constituent of protoplasm in its living state, and is therefore absolutely essential to the carrying on of vital processes of all kinds. Hence the mere drying of an animal or plant will in most cases kill it outright, and will always suspend all visible vital phenomena.

Lastly, the great majority of living beings are organised that is to say, they are composed of different parts, or orgors, which hold certain relations with one another, and which discharge different functions. It is not the case, however, that organisation is a nesessary accompaniment of vitality, or that all living beings are organised. Many of the lower forms of life exlibit absolutely no visible structure, and cannot, therefore, be said to be "organised"; but they nevertheless discharge all their vital functions just as well as if they possessed special organs set apart for the performance of each. Animals, therefore, are organised, or possess structure, because they are alive; they do not live because they are organised.

\section{Classification.}

By the term classification is understood the arrangement of a number of dissimilar objects of any kind into larger or smaller groups according as they exhibit more or less likeness to one an- 
other. The number of different animals is so enormous, that it was long ago perceived that some classification of them, or method of arranging them into groups, was absolutely indispensable. Without some such arrangement it would have been utterly impossible to have ever acquired a clear notion of the animal kingdom as a whole. In forming such a classification, we might take some one chiracter, such as the possession of wings, the number of legs, or the like; just as we might divide mankind into groups according to the colour of the hair, the shape of the nose, or some other trivial feature. Classifications of this kind, however, are "artiticial," and do not express the real relationships of animals; hence they are now universally discarded by naturalists. The true method of forming a classification is to compare different animals with one another as regards all the features which they present; and in this way we obtain what is called a "natural " classification. It is to be remembered, however, that a thoroughly natural classification of animals would imply that our knowledge of all their characters was contplete; and as that is not the case, no known classification can be regarded as more than approximately true.

(A natural classification, then, is founded upon a comparison of different animals with one another as regards all their essential characters; and these characters are of two kinds. Firstly, we have to look to the laws, form, and arrangement of the structures of the organism.) This constitutes what is called "Morphology," or the science of form and structure (from the Greek words morphe, shape or form; and logos, a discourse). Secondly, we have to study the vital actions performed by the living organism, and the functions. discharged by each portion of the body. This constitutes the science of "Physiology."

Morphology.-As we have just seen, Morphology, as a general science, deals with the mere form and structure of the organism, irrespective of function or ase; but it admits of a more or less artificial division into subordinate departments. Thus the study of the form and structure of living beings in their fully developed condition constitutes the science of Anutomy. The term Human Anatomy is given to the morphology of man, and the term Comparative Anatomy is applied to the study of the structure of animals in general, as compared with one another and with man.

Morphology, again, not only deals with the organism as a fully developed whole, but is also concerned with the changes through which every living being has to pass in reaching its mature or fully-grown condition. This constitutes a special branch of the subject to which the term "Development" is applied.

Finally, a separate department of the subject is sometimes consti- 
tuted under the name of "Jinute Anatomy," to designate those morphological studies which are specially concerned with the inves: tigation of the miuute or microscopic structures and tissues of which living beings are composed, apart from the grosser and more palpable features of form and structure.

Physiology.-In its broadest sense, Physiology may be stated to be the science of life aind vital phenomena,--understanding by "science," knowledge methodised and reduced to its principles. In other words, Physiology deals with the functions exercised by living , bodies, or by the various definite parts or "organs" of which most living beings are made up. Morphology teaches us the structure of 'the animated machine; Physiology shows us what the machine can do, and what are the use and purpose of the various parts of which the machine is composed.

The study of the functions discharged by the human organism constitutes a distinct branch of Physiology to which the name of Human Physiology is applied; whilst Comparative Physiology is concerned with the study of the vital phenomena exhibited by the lower animals.

All the vital actions of the organism-in other words, all physiological phenomena-may be roughly divided into the following three groups :-

1. Functions of nutrition, comprising the various functions by which the organism is enabled to live, grow, and maintain its existence as an individual.

2. Funtions of reproduction, comprising those functions whereby fresh individuals are produced, and the perpetuation of the species is secured, whilst the original individual perishes.

3. Functions of relation, comprising all those functions (such as sensation and the power of voluntary movement) whereby the outer world is brought into relution with the organism, and the organism in turn is enabled to react upon the outer world.

The functions of nutrition and reproduction are essential to bare existence, and are sometimes spoken of collectively as the "vegetative" functions, as being common to animals and plants alike. On the other hand, the functions of relation are often spoken of as the " animal" functions, since they are most highly developed in animals. Various plants, however, are endowed with the power of movement, and exhibit sensibility equal in amount and apparently similar in kind to that manifested by many of the lower animals; so that the functions of relation, though more characteristic of animals than of plants, are not peculiar to animals.

It should also be borne in mind, that though the alove grouping of the physiological functions is convenient, it is to a certain extent 
arbitrary, and that the groups of functions run into one another, and are most intimately connected. Thus, for example, in the higher animals, some or all of the functions of relation are secondarily functions of nutrition, and vice versit, since the integrity of both groups is essential to the working of either. If the aninal be deprived of the powers of vision and locomotion, it camnot obtain food; and if its nutrition be interfered with, its functions of relation will be destroyed.

HomologY AND AvalogY.-These are two terms which are employed to express, respectively, the morphological and physiological likenesses between the organs and parts of different animals.

When we find the same morphological structure or organ in two different animals, however much altered or disguised in form, then we have to deal with a case of homology; the two organs are homologous; and the one is said to be the homologue of the other. And

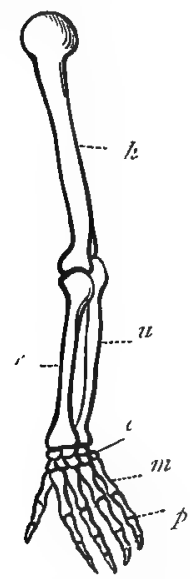

A

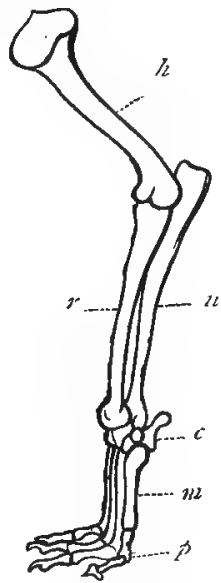

B

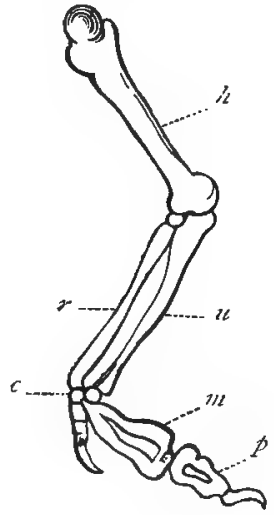

$\mathrm{C}$

Fig. 1.-A, Arm of Man. B, Fore-leg of Dog. C, Wing of Bird. $h$ Humerus, or bone of upper aru ; $r$ and $u$ Radius and Ulna, or bones of the fore-arm; $c$ Carpus, or bones of the wrist; $m$ Metacarpus, or bones of the root of the hand; $p$ Phalanges, or bones of the fingers.

it is not in the least degree necessary that the two homologous organs should perform the same function or discharge the same work. On the contrary, they may be fitted for very different purposes, and it is simply necessary that they should be formed on the same fundamental plan of structure. For example, the arm of man, the foreleg of the dog, and the wing of a bird, are constructed upon the same morphological type, and are therefore homologous - as will readily be seen by referring to the annexed illustration, where cor- 
responding parts are lettered with corresponding letters. They perform, however, totally different functions, the first being an organ of prehension, the second being devoted to terrestrial progression, and the third being an organ of flight.

On the other hand, whenever we find in different aninials, organs fulfilling the same purpose and doing the same work, then we have to deal with a case of anulogy-the organs are analogous, and the one is said to be the anclogue of the other. In other words, those parts or organs are cnalogous which resemble one another physiologically and discharge the same functions, wholly irrespective of what their fundamental structure may be. In most cases the organs which would ordinarily be called "analogous" are such as differ from one another in structure, at the same time that they discharge the same duties. Thus the wings of a hird and the wings of an insect are analogous organs, since they are both organs of flight, and serve to sustain their possessor in the air. They are, however, in no way similar to one another except when regarded from this physiological point of view; and they differ altogether from a morphological aspect, being in no way formed on the same fundanental plan. It often happens, however, that "analogous" organs have the deeper relation to one another of being constructed upon the same morphological plan, in which case they are both analogous and homologous. Thus, the leg of man and the hind-leg of a dog are both analogous and homologons, since they are constructed upon the same plan and discharge sinilar functions.

It need only be added in this comnection that sound classification hepenuls on a correct discrimination between likenesses of homology and likenesses of analogy. Likenesses of analogy-that is, likenesses depentent solely upon the possession of organs discharging the same physiological function-are to be disregarded. Thus, the Bird and the Butterfly are not to be grouped together simply because both possess rroins of flight. On the other hand, likenesses of homology - that is to say, likenesses dependent on identity of structural plin-ire a safe guide to real aftinity, enabling us to trace the gremine relationships which may subsist between animals out witrdly very dissimilar, and affording to us the foundation of a common type capable of almost endless moditicatiou. ; Whilst the therny of philosophical classification is thus clear, it may be further said that great difficulties attend the carrying ont of the admitted theory into actual puretice. This arises chiefly from the difficulty which is met with when we come to disentangle the homological from the merely analogical likenesses of animals; and it is in overcoming this difficulty that a great portion of the laboturs of the philosophical zoologist consists. 


\section{General Divisions of the Amimal Kingdom.}

Acting upon the principles above indicated, and by a careful comparison of the morphological and physiological differences between different animals, naturalists have divided the entire animal kingdom into a number of divisions, the general arrangement of which may be very briefly indicated. Firstly, the whole aninal kingdom may be divided into two great sections, known respectively as "Invertebrate Animals" or Invertebrutre, and "Vertebrate Animals" or Vertebrata. The leading characters which distinguish these two great sections are exhibited in the subjoined diagram, and may be shortly stated as follows: In all Invertebrate animals, the body, if divided transversely or cut in two, shows only a single tube/ containing all the vital organs (fig. 2, A). These organs in the higher Invertebrata consist of a digestive or alimentary tube; a circulatory system, by which the vital fluids are distributed through
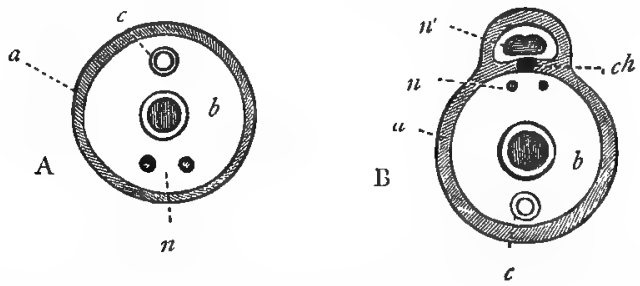

Fig. 2.-A, Diagranmatic section of one of the higher Invertebrita. B, Section of one of the Vertebrata (slightly altered from Huxley): $a$ Wall of tlıe body; $b$ Alinentary canal ; $e$ Circulatory system ; $n$ Nervous system ; $n^{\prime}$ Brain and spinal cord of the Vertebrata, enclosed in a separate tube; ch Notochord or chorda dorsalis.

the body; and a nervous system, by which the animal is brought into relation with the outer world. Any or all of these vital organs, however, may be wanting, or may be imperfect or rudimentary. When there is any skeleton, this is usually external, and is mostly nothing more than a hardening of the skin, produced by the deposition in it of horny matter, of lime, or of flint. The limbs, when present, are turned towards that side of the body upon which the main portions of the nervous system are situated. In the Vertebrata, on the other hand, the body, if transversely divided, exhibits two tubes (fig. 2, B). In the one is placed the main mass of the nervous system (the brain and spinal cord). In the other tube are the alimentary canal, the main organs of the circulatory system, and certain other portions of the nervous system, which are 
known as the "sympathetic" system of nerves. Further, in the Tertebrata there is always an internal skeleton, the central stem of which is usually constituted by a true backbone or "vertebral column." When this is nnt present, there is a structure which will be afterwards described as the "notochord" or "chorda dorsalis." Lastly, the limbs of Vertebrate animals, when present, are never more than four in number, and they are always turned away from that side of the body on which the main masses of the nervous system are placed.

The subdivision of the Invertebrate animals is divided into five great groups or "morphological types," which are known as subkingdoms. ${ }^{1}$ These primary types of structure are known to natuxalists under the technical names of the Protozoa, Colenterata, Echinodermata, Annulosa, and Mollusca. Their distinguishing characters and more important subdivisions will be spoken of hereafter, and need not, therefore, be noticed here. The division of the Vertebrate animals constitutes by itself a sixth sul.kingdom, which is simply known under the name of V'ertebrata. There are, therefore, six primary types of structure or sub-kingdoms, to one or other of which all known animals may be referred. The highest of these forms alone the division of the "Vertebrate Animals," whilst the five lower sub-kingdoms are grouped together under the collective name of "Tnvertebrate Animals."

Each sub-kingdom, therefore, comprises a group of animals which are constructed upon a common plan or type, however greatly this type may be modified; and each is, in turn, broken up into subdivisions which are termed "rlasses." Each "class," again, is divided into "orders," each "order" into "families," each "family" into "generc," and each "genus" into "species." To define the term "species," which is the smallest definite division accepted by naturalists, is, in the light of recent researches, no easy matter. -We may, however, consider that each "species," or, as we should lcommonly say, "kind," of animals consists of such individuals as resemble one another in all the essential characters of their structure, and are able, directly or indirectly, to produce other fertile individuals like themselves. Even in the above definition, we must recollect that the individuals of a species are not precisely alike, and it commonly happens that a number of the individuals of a species have some special peculiarity or peculiarities, by which they can readily be separated from the rest. When this is the case, the individuals thus distinguishable constitute what is called a "variety,"

1 Many naturalists regard the Sponges as forming a sixth division, to which the name of Porifera is often given; but this division is larlly equivalent in rank to a sub-kingdom. 
and if their peculiarities are pernanent, and are handed down conlstantly by inheritance, then we get a "puce." Thus we may suppose (though some doubt it) that all known dogs belong to and constitute one species. But we know that individual dogs, such as the greyhound, the mastiff, the terrier, the bull-dog, and the like, differ from one another so greatly that we can always recognise them with certainty. These, therefore, constitute so many varieties of the dog. It need only be added that the greatest of all difficulties which the practical naturalist has to confront is the difficulty of determining precisely what constitutes a species as distinguished from a variety. In other words, there are innumerable cases in which it is almost impossible to tell whether we are dealing with two closely allied species, or with a species and its variety; and in no case can any definite rule of guidance be laid down by which this difficulty can be got rid of.

The classification now adopted by naturalists will perhaps be better understood if we take an actual example, and see how it is applied in practice. If we regard the domestic dog, with all its subordinate varieties, as a single speries, we have to notice, in the first place, that it is known technically by a double name, and is called the Cunis familueris. All species are thus known by "binomial" desiguations, the secmul name being like a man's Christian name, and being distinctive of the individual, whilst the first name is like a man's surname, and indicates the group, or, technically, "genus," to which the individual belongs. The dog, then, whilst individually recognised by the epithet "famitiar.s," belongs to the "genus" Canis, in which are included other related species, such as the Wolf (Canis lupus) and the Jackal (cturis arureus). The genus Canis, again, belongs to the "family" Crride, including other genera, such as the Foxes (Julpes). The family Canida, again, is one of a number of families, such as the Lions, Tigers, and Cats (Felidoe), the Bears and Racoons (Lrridce), the Hyænas (Hyanidoe), \&c., which together constitute the "order" of the Camivora or Beasts of Prey. The Carnivora, again, constitute one of nuany orders of Quadrupeds, which are distinguished by suckling their young and by other common characters, and which collectively constitute the "class" Mummulir. Finally, the class Mammalia is united with the classes of the Birds, Reptiles, Amphibians, and Fishes, to constitute the great primary division of Vreverretu or "Vertebrate Animals;" since all these classes agree with one another in the fundamental character of possessing a backbone or "vertebral column," or an equivalent structure.

Condensing the above, the zoological position of the Log, expressed in full, would be as follows :-- 


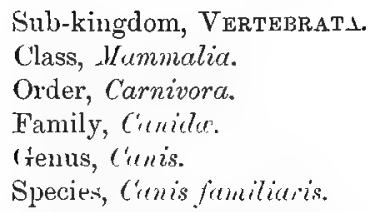

In an ordinary way, however, it is quite unnecessary to employ in practice any of the above names except the last or sprcifir name, since that implies all the other's.

The remainder of this work will be occupied with the consideration of the chief characters of the more important groups into which the animal kingdom has been divided, omitting those which are not of paramount interest; but it will be necessary first to say a few worls as to the distribution of animals in siace and in time.

\section{Distribution of Aximils in Sipace and in Time.}

Distribution in Space. - The distribution of animals in space, or their geographical distribution, is a department of zoology which is concemed with determining the limits within which each species of animal is at the present lay confined. Save man, and his faithful attendant the dog, no species of animal can be said to have anything like a universal distribution; and each species, as is a matter of common observation, belongs to a certain region, and is confined within wider or narrower limits. Thus the Giraffe, for example, is not known to exist out of Africa ; the Kingaroos belong to A ustralia ; the Armadillos do not occur out of South America,-_and so on. Further than this, it is possible to divile the earth's surface into a certain number of gengraphical regions or "sorteyirel provines," each of which is characterised by the occurrence in it of certain associated forms of animal life. Under the heal, therefore, of "distribution in space," come two different but allied branches of intuiry. Firstly, we have to inquire as to the geographical range enjoyed by each individual species of animal; and secondly, we have to deternime what general assemblages of animals characterise certain large areas or provinces, and this alone demands a brief consideration here.

The geographical distribution of land animals is conditionea partly by the existence of suitable surromulings, and partly by the presence of barriers preventing nigrations. Thus, certain contignous regions might be equally suitable for the existence of the same animals, but they might belong to different zoological provincess if sepruated by any impassable barrier, such as a lofty chain of mountains. Uwing to their power of flight, the geographical distribution of birds is much le s; limited than that of Mammals; and many migratory birds may 
be said to belong to two zoological provinces. In spite of their powers of locomotion, however, birls are limited by the necessities of their life to definite areas, and a zoological province may be marked by its birds just as well as by its quadrupeds.

The geographical distribution of an animal at the present day by no means necessarily coincides with its former extension in space. Many species are known which now occupy a much more restricted area than they did formerly, owing to changes in climate, the agency of man, or other canses. Similarly, there are species whose present area is much wider than it was originally.

At the present day, naturalists usually adopt the arrangement of the dry land into zoological provinces, which was originally proposed by $\mathrm{Mr}$ Sclater. In this arrangenent the earth's surface is divided into the following six provinces, each of which is characterised partly by the presence of a particular "fauna," or characteristic assemblage of animals, and partly by the absence of certain other characteristic animals :-

I. The Pulcarctic Province, including Europe, Africa north of the Atlas Mountains, and Northern Asia. Among the more characteristic animals of this province are Bears, Sheep, Goats, Catarhine Monkeys, and Pheasants.

II. The Ethiopian Province, including Africa south of the Atlas Mountains, aud Southern Arabia. Among the more characteristic animals are the African Elephant, the Hippopotanus, Giraffe, Hyrax, Aardvark, numerous Antelopes, Baboons, the Lion, and the Ostrich. There is a characteristic absence of Bears, Deer, Goats, and Sheep.

III. The Oriental or Indian Province, including Asia south of the Himalaya Mountains, Burmah, Siam, Southern ('hina, and the Indian Archipelago (Java, Sumatra, Borneo, \&c.) Characteristic animals are the Chevrotains, Indian Buffalo, Indian Elephant, Tiger, Hornbills, Pea-fowl, and Jungle-fowl.

IV. The Australian Province, including Australia, Tasmania, New Guinea, New Zealand, and most of the islands of the Pacific Ocean. Characteristic aninals are the Duck-mole and Spiny Ant-eater (Echidna), numerous Marsupials, Birds of Paradise, Cockatoos, and the Australian Mud-fish (Ceratodus). There is a remarkable absence of most orders of the Placental Mammals, of Vultures, Woodpeckers, and Tailed Amphibians. New Zealand is peculiar in not having any Marsupials nor Monotremes; in having no Reptiles except Lizards; and in the possession of the curious Aptery:x and the extinct Dinornis.

V. The Nearctic Province, including North America down to the centre of Mexico. Characteristic animals are the Prongbuck, the 
Musk-rat, the American Buffalo, Tree-Porcupines, and the Turkey. The Beaver, Reindeer (Caribou), Sheep, and Bears are types common to this and the Palæarctic Region.

VI. The Meotropiral Province, including the whole of South America, Central America, aud Southern Mexico, together with the Antilles. 'Chariuteristic animals are the Platyrhine Monkeys, Llamas, Peccaries, C'ivies, Sloths, Ant-eaters, Armadillos, Trogons, and Curissows. There is an absence of Insectivorons Mammals, I foits, Antelopes, Oxen, Cranes, \&c. The Opossums are common to this anr to the Nearctic Province.

Leaving the dry land, we find that even in the ocean animals are not distributed at rindom, but have, on the contrary, a more or less definite range. Without entering at length into this very interexting subject, two or three of the more important facts connected with the distribution of nuarine life may be stated here. In the first place, certain marine animals affect that portion of the seashore which lies between tide-narks, and is therefore more $\because r$ less completely uncovered twice a-day by the retirement of the tide. Technically, naturalists call the tract letween tide-marks the "Littoral Zone" (Latin, litus, the shore). In the second place, we find other aninuals which do not like to be uncovered by the retiring tide, and which live, therefore, just below the limit of low water, and usually extend their range till the sea becomes about fifteen fathoms in depth. Within these limits the great Tangle ( Laminuria) flourishes in profusion, and hence this is called the "Laminarian Zone." Beyond the Laminarian Zone are other regions of different depths, which can usually be recognised more or less distinctly by the animals which inhabit then. Finally, by the researches of Carpenter, Wyville Thonson, (iwyn Jeffiers, Wallich, Liars, Pourtales, Agassiz, and other olservers, we know that the "deep sea" properly su cilled, extending frum a depth of 300 futhoms up to at least 3000 or 4000 fathons, is tenanted by a vast number of animals, constituting a very remarkahle and peculiar life-assemblage. We also know now, that, cxcept in viry limited depths, the distribution of marine animals is conditioned nut by the depth of the water, but loy its imumerese. Sinilar forms of narine life are therefore found inhabiting areas in which the bottom-temperature is the same, irrespective of whiat the deptl of the water mily be. And it may happen that two neighlouring areas of the sea-bottom may be inhallited ly different assemblages of animals, in spite of their being close together, provided ine area is swept lyy a current of warm water, whilst the other has its temperature lowered by the influx of a cold current.

Distribution in Time.-The distribution of animals in past 
time, or their "geological distribution," belongs to the science of "Palcoontology" (Gr. palaios, ancient; oniu, beings; logos, a discourse), and constitutes a sulject so vast that nothing more can be done here than to indicate one or two of the most elementary considerations relating thereto. In the first place, Geology shows us that a very large portion of the crust of the earth is composed of rocks which existed originally in the form of sand, mud, clay, or ooze, and which formed the floor of the ocean. Other rocks can be shown to have been originally formed by lakes or rivers, and sometimes we find what may be regarded as old land-surfaces or soils. These various kinds of rock, in the second place, often contain in their interior what are called "fossils" or "petrifactions,"--in other words, the remains or traces of animals and plants which lived at the time when the rocks were in actual process of formation. In rocks which have been formed in the sea, the fossils consist chiefly of the skeletons of shell-fish, corals, sea-urchins, and other marine animals; in rocks which have been formed in lakes or rivers, we have chiefly fresh-water shells and the skeletons of fresh-water fishes; and in ancient soils we find the remains of plants, along with air-breathing animals, such as insects, spiders, or quadrupeds.

We see, then, that animals existed upon the earth for a long period before the appearance of such forms as are now familiar to us ; and we have to note, in the third place, that not only are existing animals in many cases different from those which immediately preceded them, but that the globe has really passed through a succession of periods, during each of which there flourished an assemblage of animals more or less peculiar to the period. In the later periods of the earth's history, the animals which lived in the sea or in lakes and rivers, or which roamed upon the land or disported themselves in the air, present a general likeness to the animals now in existence, though not identically the sane. In the earlier periods, again, the animals are not only "extinct," or, in other words, no longer existent, but they are very unlike any animals which we see at the present day, and the older the period the greater is this unlikeness.

We have, finally, to remember, that though many extinct animals are so peculiar that we have to place them in distinct families or orders, there is at present no known fossil w hich cammot be referred to one or other of the existing sub-kingdoms. We have therefore, so far as our present knowledge goes, no proof of the former existence and disappearance of any "morphological type." 


\section{INVERTEBRATE ANIMALS.}

\section{STB-KINGIONAL I. PROTOZOA.}

\section{CHAPTER I.}

\section{General Characters of the Protozon. 2. Classification.}

\section{Gregarinida.}

THE sub-kingdom Protozoa (Gr. protos, first; and zoön, an animal), as the liame implies, is the lowest division of the animal kingdom, and its limits are therefore necessarily not yet strictly defined. The Protozoa comprise an enormous number of aninals, which are mostly so small is to be invisible to the naked eye, and can only be satisfactorily exanined under pretty high powers of the microscupe. For this reason, and because they are almost universally found in water, these creatures, often populariy called "animalcules," are almost unknown to the majority of people. The microscopical furms of the Protustu swarm in most stagnant pools, and in all waters charged with organic matter so as to afford them food. Every worker with the microscope is familiarly acquainted with them, and they exhibit phenomena which in many cases render them objects of the highest interest. From their low position in the animal scale, it arises that the Protwom are mainly characterised by the absence of organs and structures which oceur in higher beings, and they possess few positive characters by which they can be distinguished.

The Irratosom ma be defined as animals, generally of a very minute size, "unt anmposed of unmorlified or slightly modition protoplasm. The typiral members of the group rere "unictlular," the primitive mass

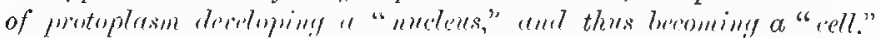

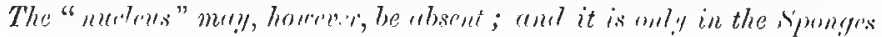


that the protoplasm becomes converted into an aggregate of cells. There is no definite internal cavity ("body-cavity"), and no nervous system is developed. Definite digestive organs are wanting, or present only in rudimentary form.

If we except the Sponges--which many naturalists regard as a separate division - the Protozoa do not rise, morphologically, above the condition of which is called a "cell." That is to say, a typical Protozoön consists of a mass of protoplasm, surrounded by a thickened layer or "wall," and enclosing a central solid or vesicular body or "nucleus," often containing in its interior, or attached to its exterior, a still smaller body or "nucleolus." The outer layer of the protoplasm may, however, remain unchanged, not becoming differentiated into a "wall," and the "nucleus" and "nucleolus" may be wanting. In such cases, the organism constitutes what is usually called a "cytode," rather than in "cell."

On the other hand, in the Sponges the organism becomes "multicellular," the primitive protoplasm becoming ultimately divicled into a larger or smaller number of separate "cells." For this reason it is not unusual to associate the sponges with the whole series of animals higher than the Protozoa, and to speak of them collectively as the Metazoa.

The substance of which the body of any Protozoün is composed is of the nature of protoplasm, usually very slightly differentiated or altered in any way, and commonly known as "sarcode" (Gr. savir, flesh; eidos, form). Viewed under the microscope, the sarcode appears as a transparent, colourless, or variously coloured viscid substance, exhibiting numerous minute darker particles or granules scattered through it, these being probably of a fatty nature. Along with these dark granules and molecules there can generally be observed a larger or smaller number of varionsly sized round clear spaces, which are known by the name of "vacuoles." Some of these "vacuoles" seem to be constantly present; but many are of mere temporary occurrence, and these seem to be merely little drops of water included in the soft protoplasm, and sometimes surrounding a particle of food. Often one of the vacuoles is not only permanent and fixed in position, but is much larger than the rest, and is "contractile," having the power of dilating and contracting at definite intervals. This is known as the "contractile vesicle" (fig. 3, A), and may, perhaps, be looked upon as a rudimentary organ of circulation. Sometines there are two or more contractile vesicles.

Very commonly the external layer of sarcode composing the body of a Protozoün is comparatively dense and free from granules, while the internal protoplasm is softer and more fluid, and is charged with grunules and vacuoles. Thus the protoplasm may be distinguished 
in many cases into an "ectosarc" and "endosarc." In the endosare in most Profosm is found the solid or hollow body, known as the "nucleus" (fig. 3, A), and this may have a still smaller brody, the "nuclenlus," attached to its external surface, or embedded in its interior. The "nucleus" and "nucleolus" have often been supposed to have a reproductive function; but there appears to be insufficient evidence for this conjecture.

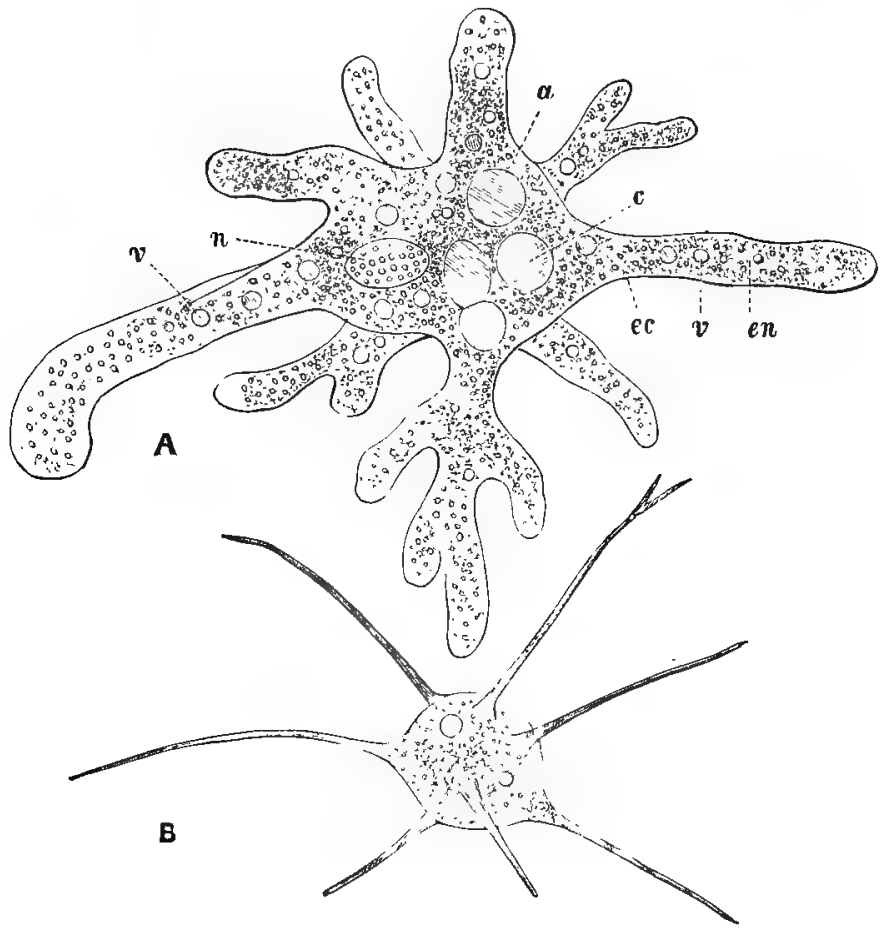

Fig. 3.-A, Amatuc proters, with the psetdopodia protiuder, enlarged 200 dianteters (after Leldy): $u$, Nucleus; $c$, Contractile w'sicle; $r$, (In of the larger food-vacuoles; en, The granular endusaro; $e c$, The transparent ectosare; $\pi, A$ coll of an Alga taken in as forcl (other cells of the same Alga are obliquely elariad). B, - Lme hu molirise, enlarged 500 diameters (after Leidy). The bouly sliows two large vacuoles, but no nuclens or coutractile vesicle. The long and delicate pseudopodia are protruded.

In one division of the l'mitnom (the Lufusoria) there is a permawent month and a short gullet, but in all the others there are no detinite argans connected with the process of digestion. In no l'o- 
tozoön, however, without exception, have any traces of a nervous system been hitherto detected; and in none, even in those which possess a mouth, is there any distinct and definite cavity or chamber within the body in which the particles of food are received. No organs of sense (except, perhaps, occasionally very rudimentary ones) exist in any of the Protozoa - that is to say, there are no distinct organs fitted for the reception of impressions produced by light or sound; but the general surface of the body appears capable of receiving the impressions produced by contact with foreign bodies, and therefore acts as an organ of touch. The power of active locomotion is enjoyed by most of the Protozoa; but in some cases this is very limited, and in other cases the animal is permanently fixed in the adult condition. The apparatus of lncomotion in the Protozoa is of a varied nature. In many cases, especially in the higher forms, movements are effected by means of little hair-like processes, which are called "cilia" (Lat. citium, an eyelash), and which have the power of vibrating or lashing to and fro with great rapidity. In other cases the cilia are accompanied or replaced by one or nore long whip-like bristles, which act in the same fashion, and are known as "flagella." Amongst the lower Protozoa the most characteristic organs of locomotion are the so-called "pseudopodia" (Gr. pseudos, falsity; podes, feet). These consist of variously shaped filaments, threads, or finger-like processes of sarcode (fig. 3), which the animal can thrust out from any or every part of its body. They are not, however, definite and permanent organs like the cilia, for they can be produced at will, and when they are again withdrawn they simply melt into the sarcode of the body, and leave no traces of their existence.

The three principas groups of tne Protozoa are known as the Gregarinida, the Rhizopoda, and the Infusurir. The riponges will be here regarded as a special division of the Animal Kingdom, to which the name of Porifera may be applied.

Class 1. Gregarinida.-The Gregarinicla may be defined as parasitic Protozoa which have no mouth, and have no pouer of giving out pseudopodia. They are usually looked upon as forming the lowest class of the Protozoa; but in all probability much of their degraded character, as we shall see in other cases, is due to the fact that they are mostly internal parasites, and are therefore not dependent on their own exertions for food. They vary in size from less than the head of a small pin up to nearly balf an inch in length, when they look something like small worns; and they are found living in the interior of various animals, especially the cockroach and the earth-worm.

In anatomical structure a Gregarina usually prescuts the appear- 
ance of it single cell, consisting of an iil-defined membranous envelope, filled with c more or less granular sarcode containing fatty granules, and having in it a little central bladder or vesicle-the "nucleus"--which in turn encloses a solid particle or "nucleolus" fig. $4, a$ and $b$. The outer covering or cuticle with which the

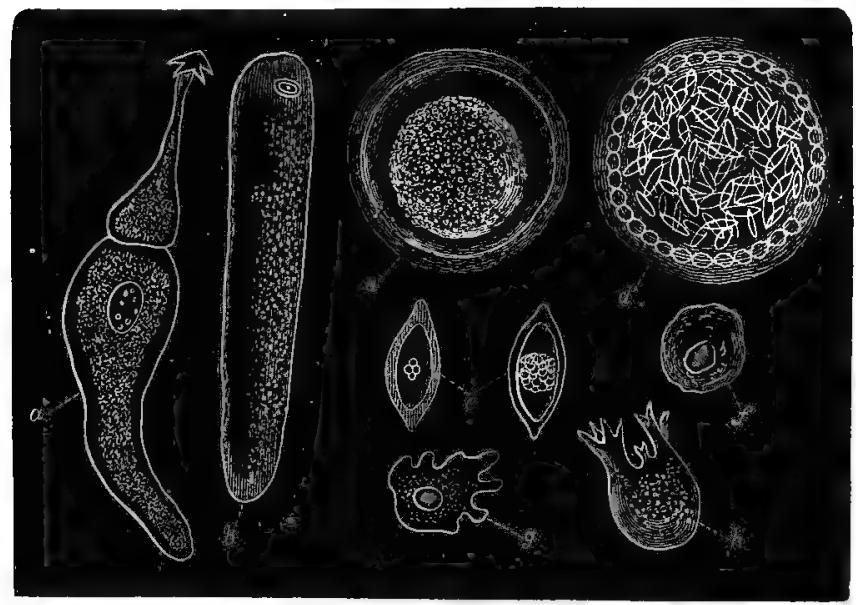

Fig. 4.-Morphology and development of fregrrinida (after Stein and Lieverkuhn). a stytrhynchus oligacanthws, a "dicystidean" Gregarine; b Gregarine of tlie earth-worm ("monocysticlean"); $c$ The same encysted; $d$ Further stage of the same, with the contents divided into "pseudonavicelle"; e Free "pseudonavi"ellar"; $f$ Amobiform mass of protoplasm liberated from a pseudonavicella; a and $h$ Active forms of $f$. All the figures are greatly enlarged.

protoplasmic lorly is enclosed may be quite smooth, or it may be furnished with bristles or spines, and in some cascs even cilia have been olmerved. Beyond the nneleus and nucleolus no definite

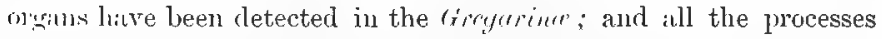
of assimilating form and getting rid of waste or injurious poduct. must be effecterl hy the general surface of the borly. As we shall see, howerer, this is common in internal pirisites, which are not Jerensitaterl to live nom solid forl, but which are enalled to sulsirt sinuly l,y imhiling the nutritive juices of their lust...

The following is a brief ontline of the process of reprotnetion, as it has been oherved in the firemeriuer, sonetimes in a single intlividual, sonetines in two indivitluals which have come together and completely conlesserl and nelterl into one altother. The rirmfrmm becomes completely motionless, assumes a globular form, and develcps round itself a thick structureless cont or envelope, 
when it is sail to ho "encysted" (fig. 4, c). The uucleus then disappears, and the sarcode of the body breaks up into little masses, which are at first rounded, but afterwards become pointed at both ends, when they are called "pseudonavicelle" (fig. 4, d). The eyst then breaks and the pseudonavicellre escape, when they give origin to little masses of sarcode, which have the power of active movement and of throwing ont pseudopodia, thus coming closely to resemble the animalcnle which will be directly described as the Amoha (fig. 4, $g$ and $h$ ). These little amoba-like masses, if they find a suitable locality, are finally developed into new Grogtrince. 


\section{CHA P TER II.}

\section{RHIZOPODA.}

Tre next class of the Profrion which we have to consider comprises the most characteristic and typical forms of the whole sub-kingdom. The name of Iihionorli, or "l'oot-footed" animalcules (from the Greek, rhiza, ront; and podes, feet), is derived from the fact that they all possess the power of throwing out at will from various parts of the body the processes of sajcode which hive been already spoken of as pseudopodia, and by which they both move and obtain food. In fact, the Rhisoprot" may be shortly defined as Protwsure which have no mouth, and whirle possess the pur $;$ of giving out pseudopodia. The pseudopodia vary a good deal in shape and in other characters in

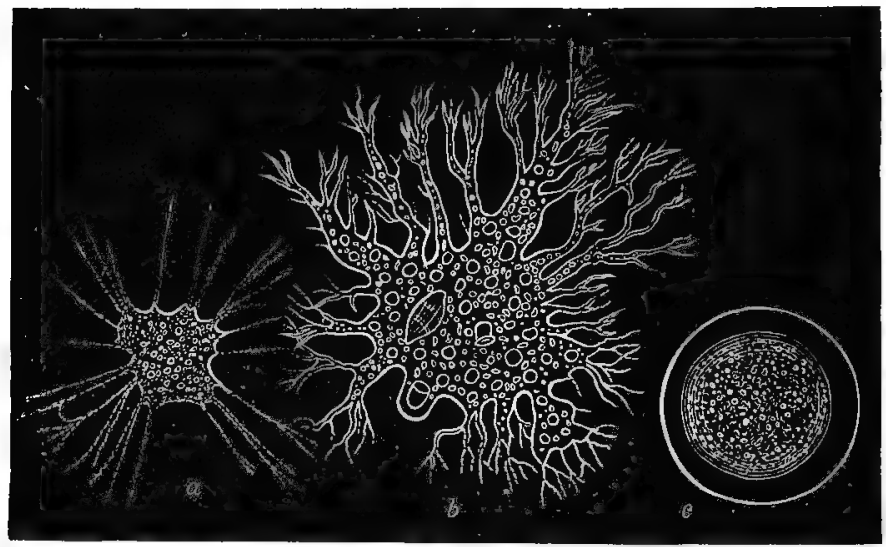

Fig. 5.-Mophlology of Monera. a Protamolu porrecta: $b$ Protomyxa aurantiaca; $c$ The same in an cincysted condition. Greatly macnified.

different orders of the Rhisopoln, but they have invariably the character of being nothing more than temporary threads or finger-]ike 
processes of sarcode, which can be thrust out at will, and which melt again into the substance of the body when they are withdrawn.

Four principal types of structure are known in the Rhizopoda, and these constitute as many distinct orders, which are known by the names of the Monera, Amobea, Foraminifera, and Radiolaria.

\section{Order I. Monera.}

This name has been proposed for a small group of organisms which are not only the lowest types of the Rhizopods, but may be regarded as the most elementary forms of animal life known to us. The Monera are minute protoplasmic organisms in which the sarcode-body is neither defended by a thickened external envelope, nor furnished with the structures known as the "nucleus" and "contractile vesicle." Vacuoles and granules are present in the sarcode, and the pseudopodia emitted by the soft and mutable protoplasm of the body are delicate and thread-like, or may be ranified and variously interlaced (fig. 5). No hard covering or shell is ever developed. The Moners inhabit water, and are mostly marine.

\section{Order II. Amqebea.}

This order is characterised by the fact that the pseudopodia are mostly blunt and finger-like in shape, and that the sarcode of the body contains the structures knoun as the "nucleus" and "contractile vesicle."

As the type of the order may be taken the 1 maba or Proteusanimalcule, so called because of the incessant and varied changes of form which it exhibits (Gr. amoibos, changing). The Amoeba is a little microscopical creature which may commonly be detected in stagnant water, especially where there is decaying vegetable matter. When examined under the microscope, all that would probably be seen at first would be a shapeless or irregularly spherical mass of gelatinous, jelly-like sarcode, containing scattered granules. Soonthe creature might be observed to push out a finger-shaped prolongation of its own substance; and it would soon be found that similar processes or pseudopodia could be pushed out at will from almost any point of the body and again retracted within it without leaving any trace behind. As a result of this, the form of the animal is constantly changing, and hence its common name of Proteus-animalcule (fig. 3 and fig. 6 B). By means of these temporary processes of sarcode, the Amoba both moves and obtains food. Locomotion is effected in a kind of creeping manner, the animal pushing out the pseudopodia in one direction and then 
pulling the body in the same direction. In the same way, when any minute particle of food, such as a microscopic plant, comes within its reach, the Amoba wraps of pseudopodinm round it, and then withdrawing the psendopodium, lodges the nutrient particle securely in the substance of the body. It follows from this that the lom lu bas no permanent mouth-no aperture, that is, which is especially employed in the admission of fond. Any part of the surface can be pushed out into a pscudorodium, and therefore any

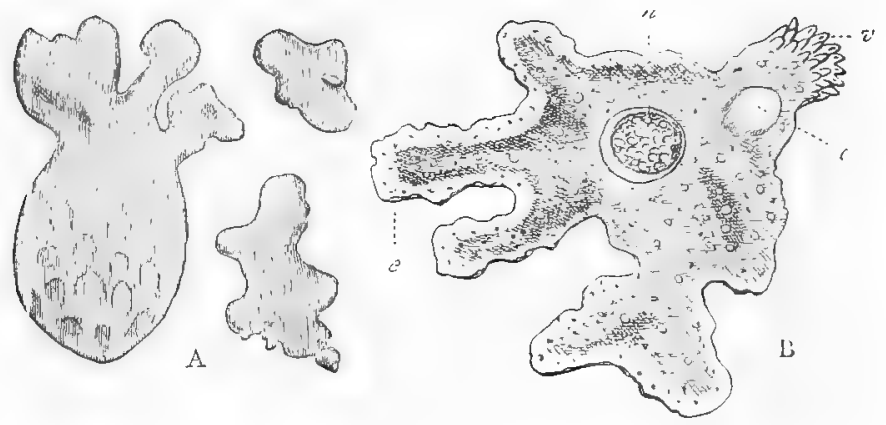

Fig. 6.-Anwbea. A, small Amr be developer in organic infusions, areatly magnitied. B, Amoha wincers: $n$ Nucleus; c Cortractile vesicle; $v$ Region of the body where incligrestible matter's are tlirust ont.

part of the surface an be extemporised into a mouth. The process of taking fouml, in fact, in the slumblu, has been aptly compared to thrusting a stome or any other solid body into a lump of dough. The central portion of the body of the animal is softer and more fluid than the outer linyers, and the particles of fork, on reaching this point, undergo a sort of digestion, and are subjected to a species of norement or rotation in the interion of the animal. Eich prorticle of forml, in the process of lyeing taken into the body, usually carries with it a little drop of water; and in this way a number of clear sprices are fornerl, which are usually quite round, and look like distinct carities. These spaces are called "vacuoles"; but they are not distinct organs of any kind, though formerly regarded as distinct stomildis. Having undergone digestion, any portions of food which may be imligestible or insoluble are simply thrust out again through the walls of the hody. This appears to be effectel at one particular lint of the bridy; but there is no permanent aperture for the purlose. There ate no distinct vessels which serve to convey the nutritive fluid derived from the digestion; but there does appear tr) be a rudimentary organ by which this fluit is driven through 
the body. If we watch an Amoeba (fig. 6, B) carefully, there is usually no difficulty in observing that every now and again there appears at one particular place a clear spot, "like a window," which slowly expands to its full extent, and then usually contracts slowly till it disappears altogether. This process of gradual expansion and contraction is what is called "rhythmical"- that is to say, it is repeated at tolerably regular intervals, perhaps twice a-minute. In some cases the vesicle, when contracted, remains so for a long time, but it always reappears in the same place. It is known as the "contractile vesicle"; and there can be little doubt that it is a permanent orgin. It is, in fact, a little clear space or cavity in the substance of the body, filled probably with the nutritive fluid derived from the digestion, and no doubt serving by its contraction to drive this fluid to various parts of the body. In its function, then, the contractile vesicle of the Amoba is to be looked upon as the first indication which we have in the entire animal kingdom of that most important organ, the heart.

The Amaba possesses no breathing-organs of any kind, and 111 excretory organs, so that these functions nust be performed by the general surface of the body in a manner somewhat the same as the exhalation from the skin which takes place in the higher animal:. There are, also, no traces of a nervous system, and no organs of sense, and the only other structure of any kind is what is known as the nucleus. The nucleus (fig. 3 and fig. $6 n$ ) is simply a small rounded or oval, granular mass, and there may be more than one in the same individual. Its function, however, is quite unknown, though it is probably connected with reproduction. The mean: employed by the 1 moeba to perpetuate the species are various, but the only one which need be mentioned is the process by self-division. This is what is technically called "fission" (Lat. findo, I cleave), and it consists in a gradual division or cleavage of the body into two parts, each of which then becomes a separate and independent individual. In some cases this process is slightly varied, a single pseudopodium alone being cast off and becoming a fresh Amoba, but this does not differ essentially from the former.

Regarding the Amoba from a physiological point of view, we see that, though the animal nourishes itself and maintains its existence perfectly, the process of nutrition is carried on in the simplest possible manner, and with the sinplest possible apparatus. There is no permanent mouth, no stomach or alimentary canal of any kind, no respiratory or excretory organs, and even no distinct aperture for the extrusion of indigestible food. The only distinct structure which is at all concerned in nutrition is a rudimentary contractile cavity, the first foreshadowing of the heart in the higher animals. 
As regards the functions of relation, it is questionable how far the Amceba can be said to have distinct perceptions or sensations of any kind. It has no nervous system or organs of sight or hearing, and in all probability it has nothing more than a general sensibility to light. It appears, however, to be fully aware when any object comes in contact with a pseudopodium, and even to have some idea whether this is fit for food. Locomotion,

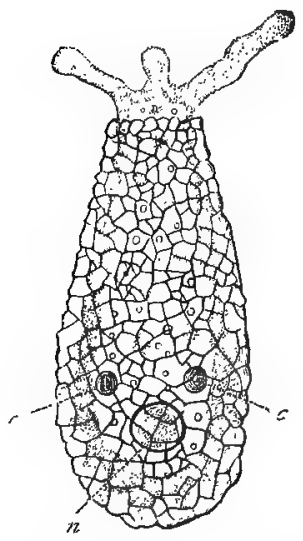

Fig. 7. - Diffugin pyriformis, greatly enlarged. (Altered slightly from Carter.) The case is composed of angular grains of transparent quartz, within which is the transparent outer layer of the lurily, lined by the finely granular inner layer: $n$ Nucleus; $c c$ Contractile vesicles. as we have seen, is entirely effected by the temporary processes of sarcode, or pseudopodia, and there are no permanent organs set aside either for locomotion or for prehension-that is, for seizing external olijects.

Many other Rhizopods, more or less closely related to the $A m \propto b a$, have been described. firme of these, though resembling the 1 moelsa in general structure, and in the form of the psendopodia, have the soft protoplasnic body enclosed in a kind of shell or "test." A good example of these shelled I mobea is the little Diff ugia (fig. 7), a not uncommon inhabitant of fresh water. In this form the body is enclosed in a sort of shell, composed of sand-grains and other foreign particles cemented together by a kind of horny secretion. The animal can retire within its shell, one end of which is open, so as to allow of the protrusion of the pseudopodia. In walking, the animal creeps about "hear-downwirds," so to speakthat is to say, with the closed end of the shell elevated above the surface on which it is moving.

\section{Order ili. Foraminivera.}

The next order of the likimpola is that of the Foraminifera, comprising animals wbich at first sight alpear to be highly complex, but which are really less highly urganised than the Amoeba. The Fora-

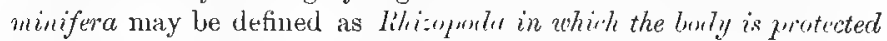
by a shell or "test"; a merlous and contractile vesiti" are "sually present; and the mendopritio we entremely long and threat-like, and interlace with one another so us to form a neturork.

The most obvious and striking character of the Foraminiftra is 
the possession of an outer case or shell, and for a long time they were known to naturalists by their shells alone. As the shell or test is usually very beautiful and often very complex, the Foraminifera were consequently placed at first amongst the true shell-fish (Mollusca), very much in advance of their true position. When, however, the anatomical structure of the group came to be investigated, it was soon found that they were really referable to the Protozoa, and that

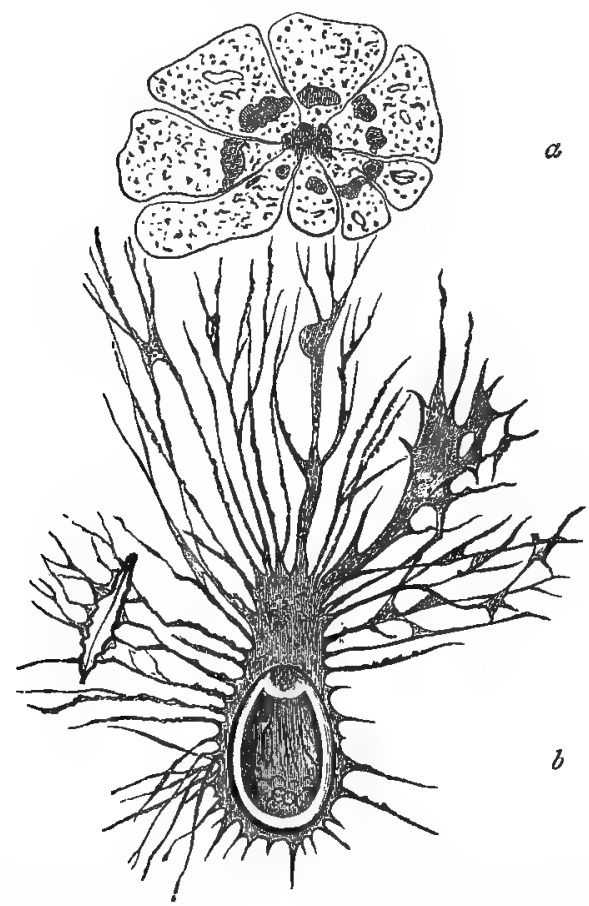

Fig. 8. - Foraminifera. $a$ The animal of Nonionina, after the shell has been removed by a weak acid; $b$ Gromia (after Scluultze), slowing the slicll surrounded by a network of filanents derived from the body-substance.

in point of fact they even occupy a low position in this sub-kingdom. However elaborate and complicated the shell may be, the body of the contained animal is composed simply of granular gelatinous sarcode, highly elastic and contractile, and usially reddish or yellowish in colour (fig. $8, a$ ). This sarcode not only fills the shell, but alsn in many cases gains the exterior by means of little perforations in its walls, and forms a thin film over its onter surface. Wherever 
the sarcode is exposed, whether this be only at the mouth of the shell, as in Miliulu (fig 9, b), or whether it be over the whole surface, as in Discorbina (fig. 9, $c$ ), it has the power of giving off pseudopodia. The psendopodia, however, differ greatly from those of the Imecbu, and they show some remarkable characters. They are extremely long thread-like processes, instead of being blunt and finger-shaped (fig. $8, b$ ), and they have the curious property that they run into one another and interlace towards their extremities, so as to form a network which has been aptly compared to an " animated spider's web." Lastly, the microscope reveals in the pseudopodia
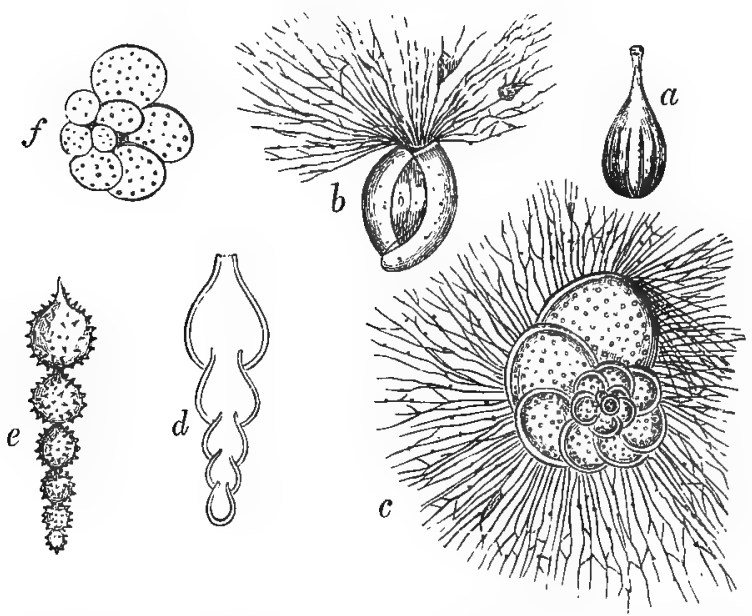

Fig. 9.-Morjhology of Foraminifera. a Lagena vulgaris, a monuthalamous Foraminifer; $b$.Hiliola (after Schultze), showing the pseudopodia protruder from the oral aperture of the shell; c Discorbina (after Schultze), sliowing the nautiloid shell vith foranina in the shell-walls, giving exit to pseudoporaa; a Section of Nodosaria (after Carpenter); " Notlostria hivpida ; flobigerina bulloides.

a very curious circulation of minute solid particles or granules, which travel in all directions through the pseudojodial network. Internally, the sarcode-body of the Forceminifires is of a very simple structure; but a nucleus and contractile vesicle are usually, if not invariably, present.

Simple as is the sarcode-lonly of the Foraminifore, it has in all cases the 1 wwer of secreting in skeleton or shell, which is technically called the "test" (Lat. testu, a shell). The shell is usually " calcareous "-that is to sily, composed of ciulsonate of lime; but it is sometimes "arenaceous," or compused of particles of sind mited tugetlicr 
firmly by a horny cement, and it is in some cases simply membranous. In rare cases, the shell may be siliceous. In any case, the shell may exhibit one or other of two very distinct types of structure. In the one type (as in Miliola, fig. 9, b), the shell-walls are not perforated with holes, and the pseudopodia are therefore all emitted from the mouth or "oral aperture" of the shell. In the other type (as in Discorbina, fig. 9, c), the shell-walls are perforated with a number of little apertures or "formina," from which the order derives its name. These foramina are the moutbs of tubes which pierce the walls of the shell, and thus establish a free communication between the interior and exterior. In this way the sarcode which fills the inside of the shell is enabled to reach the outer surface, so as to form a tiln, from any part of which the pseudopodia nay be given off. The presence or absence of foramina is believed to constitute a true structural distinction, and the Foraminifera may be thereby divided into two great and natural groups (Perforata and Imperforata).

According to the form of the shell, also, the Foraminifera may be conveniently, though arbitrarily, divided into two sections. The simplest form of shell is seen in such an example as Lagena (fig. 9, $a$ ), where the shell consists of but a single chamber ; and the animal, in fact, is nothing more than a little mass of sarcode, surrounded by a calcareous envelope. Lagena, then, may be taken as the type of what are called the "monothalamous" Foraminifera (Gr. monos, single ; thalamos, a chamber) - that is to say, of those forms in which the animal consists of a single segment, and the shell of a single chamber. All the Foraminifera, without exception, commence life as "simple" or "monothalanous" forms, like Lugenu, but it is comparatively seldom that they retain this simplicity throughout life. In the great majority of cases the primitive mass of sarcode undergoes constriction or segmentation, according to a determinate law, the segments thus produced remaining in organic connection. In this way we get ultimately a compound organism, composed of a number of little masses of sarcode, all permanently united to one another, and all enclosed in a common shell. In this way are produced forms like Nodosaria (fig $9, d, e$ ), which may be regarded as a good example of these so-called "compound" or "polythalamous" Foraminifera (Gr. polus, many; thalamos, a chamber). The exact form of shell which is produced by this process will depend upon the direction in which the segments are given off by the primordial segment. If the segments are developed in a line, we get such a form as Nodosaria. If they are given off in a spiral direction, each succeeding segment being a little larger than the one before it, and the coils of the spiral all lying in one plane, then we get such a shell as Discorbina (fig. 9, c). This is one of the commolrest forms of 
shell amongst the foraminifir, and it is often called the "nautiloid" shell, from the close resenblance which it bears in shape to the well-known shell of the Pearly Nautilus. It was, in fact, this external sinilarity which induced the older naturalists to place the Foraminifere anongst the Mullusca in the neighbourhood of the Cuttle-fishes. There are numerous other types of shell, all of which can be referred to the manner in which the prinordial segment becomes constricted or segmented; lut the two forms above mentioned nuay be taken as sufficient examples. It may be mentioned, however, that there are forms in which the new segments are added in a very irregular manner, and the resulting shell has no very definite shape.

The great majority of the Froraminifera are inhabitants of the sea, and they are mostly very minute. A few living forms may

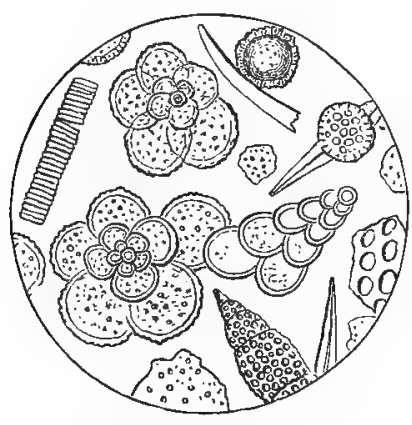

Fig. 10.-Organisms in the Atlantic Ooze, chiefly Foraminifera (Globigerino and Textularict), with Polycystina and spronge-spicule's; highly magnificd.

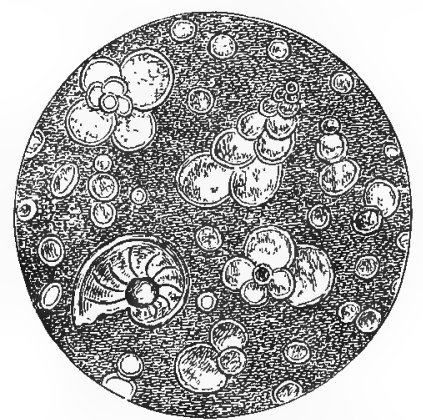

Fig. 11.-Section of Gravesend Chalk, cxamined by transmitterl light and highly magnified. Besicles the entire shells of Globigerina, Rntalia, and Textularia, numerous detached chambers of Glolitgerina are seen.

reach a quarter of an inch, half an inch, or even more than an inch in diameter. The commoner forms nay usually be found by examining with a lens the sand of the sea-shore in places where there is a large intermixture of broken shells and frisments of other marine aninals. Many forms live in the open ocean floating near the surface of the water. Others live on the bottom of the sea up to the greatest depths which have yet been exanined by the dredge. At great dej,ths in the sea-iteths, it may be, of orer two or three thousind fithoms-the bottom is often found to be cuvered with a whitish chalky mud, which is seen muder the microseope to be almost entirely made up of the shells of various Firrominifera, and 
especially of the shells of Globigerina (fig. 10). The name of "Globigerina nud" is often given to this deep-sea ooze, and it is remarkable as having a close resemblance to the well-known White Chalk. Thus, if we examine chalk under the microscope, we find that it is also composed to a large extent of the shells of Foraminifera, and especially of the shells of Globigerina (fig. 11). We may therefore regard the "Globigerina ooze" of the deep Atlantic and Pacific as a modern representative of the great geological formation known as the White Chalk-a formation which may be r.any hundreds of feet in thickness, but is nevertheless principally made up of the accumulated shells of these minute organisms. Many of the massive limestones of the earth's crust are, in like manner, largely made up of the shells of Forrminifera. A striking example of this is found in the so-called "Nummulitic Limestone," which owes its name to the fact that it is largely made up of the coin-shaped shells of a large Foraminifer, termed the Nummulite. Nummulites (fig. 12) vary in size from the size of a split pea up to an inch in diameter, and they are now almost wholly extinct.

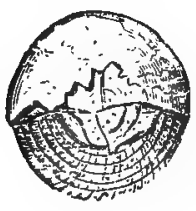

$\mathbf{I}$

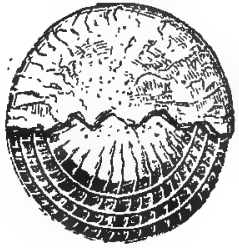

2

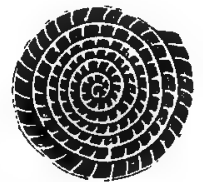

3

Fi.r. 12.-Nummulites levigatus.

The Nummulitic limestone stretches from France on the west to the frontiers of China on the east, and is almost everywhere readily recognisable as a distinct formation. It attains in places a thickness of several thousand feet, and is especially largely developed in the Alps. It has an historic interest from the fact that the Pyramids are built of it, and that the Nummulites in it were noticed by Herodotus, " the father of history."

\section{Order IV. Radiolaria.}

The third order of the Rhizopoda is that of the Radiolaria, essentially distinguished by the fact that the sarcode-body has generally the power of secreting a "siliceous" or flinty skeleton, either in the form of a shell, or of detached spicules or needles; whilst the pseudopodia are long and thread-like, and stand out from the body like rays. In this last character the Radiolaria approach very 
closely to the Foraminifin; and the resemblance between the two groups is still further increased by the fact that the pseudopodia often run into one another so as to form a network, and sometimes show a circulation of granules along their edges. There is generally a central cipsule surrounded by a layer of sarcode exteriorly, and the latter usually contains coloured cells. A contractile vesicle is usually wanting. Four principal groups of organisms have been described as belonging to the Radisluriu, and we may briefly notice an example of each of these.

In the first family we have organisms like Acanthometra (fig. $13, a$ ), in which the body is composed of sarcode, supported by a framework of siliceous or flinty rods, which all meet in a common centre. The spines or rods are all perforated by canals, and each conveys a pseudopodium, which is protruded from an aperture at its
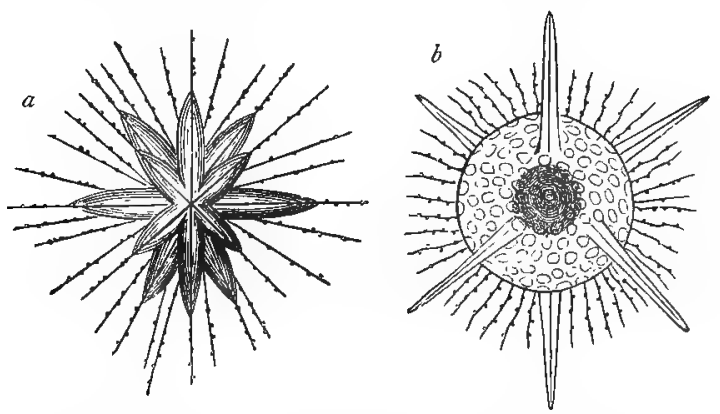

Fig. 13.- a Acenthomet ru lanceolata; b II fliomma hexasanthum, one of the Polycystina (after Aluller).

apex. Many pseudopodia, however, are given off from the surface of the body directly, and are not enclosed in the spines. The Acanthometres are all minute, and are found floating near the surface in the open ocean, sometimes in great numbers.

In the second family (Polycystine, fig. 13,b) we have a number of

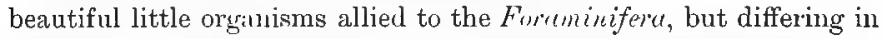
the fact that the body is enclosed in a glassy shell composed of flint. The shell is perforated hy numerous holes through which the pseudopodia are emitted, and it is usually of extreme beauty, being sculptured in various ways, and of ten adorned with spines. The sarcode of the body is usually olive brown in colour, and often does not quite fill the shell.

The pseudopodia are filamentous, and exhibit a slow circulation of granules along their vorders, but they do not rum into one another. 
All the Polycystina are microscopic, and they are all inhabitants of the sea. They are best known to students of the microscope as the "Fossil Infusoria of Barbadoes" (fig. 14), as they occur in incalculable numbers in a sandstone in that island.

They are, however, in no way related to the "Infusoria" properly so called, having much stronger affinities with the Foraminifera. We know, also, now, that deposits of the flinty shells of these beautiful microscopic organisms are in process of formation in our oceans at great depths.

In the third family (Collozoa) are included in number of singular gelatinous organisms which

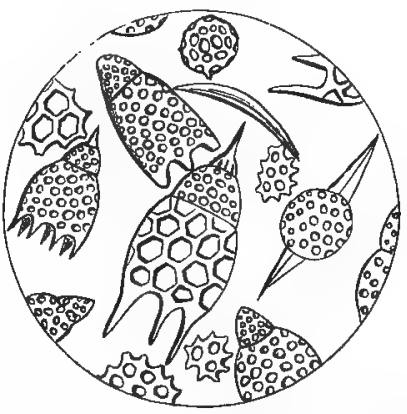

Fig. 14.-Shells of Polycystina from the "Barhadoes Earth," greatly magnified. (Original) may be as large as an ordinary marble, but are often hardly visible to the unassisted eye. They are found floating passively at the surface of most seas; and they may either have no skeleton, or may secrete a flinty framework, which may give rise to a fenestrated
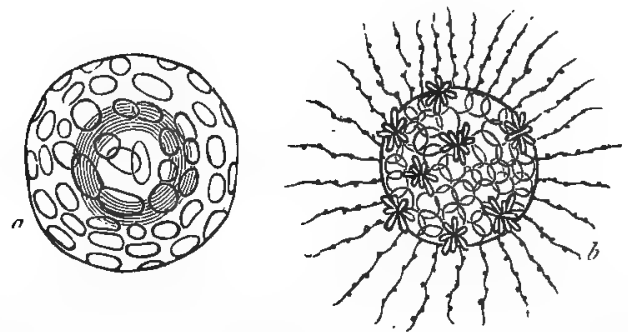

Fig. 15. - $a$ Siliceons shell of Collosphcera; $b$ Sphorozoum, showing the radiating pseudopodia and gromps of siliceous spicula (ufter Milller).

shell, as in Collosphoera (fig. 15, $a$ ), or may remain in the form of scattered spicules, as in Spharozoum (fig. 15,6 ). In Thalassicolla the skeleton is wanting.

A fourth family has been constituted under the name of Heliozoo, for a number of singular and beautiful microscopic organisms, which mostly occur in fresh water, and which cannot be regarded as typical Radiolarians, though more closely allied to this group of the Pro- 
tozod than to any other. In these forms (fig. 16) the body is provided with long filamentous pseudopodia, which stand out like rays, and which may anastomose with one another. The body may be quite soft, as in the common "Sun-animalcule" (Actinophlirys), but

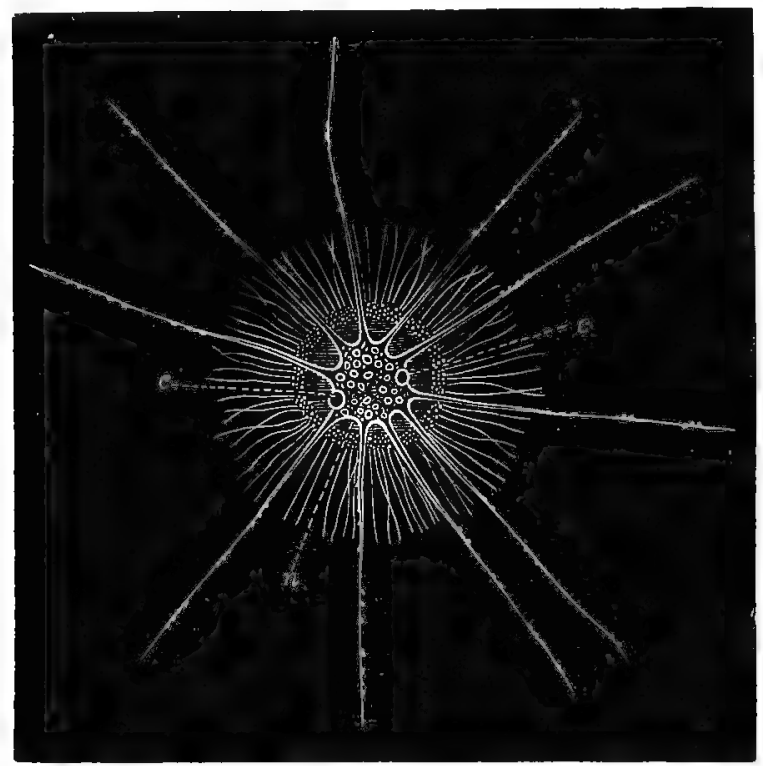

Fig. 16.-Heterophry/s spinifera, one of the Heliozod, greatly enlarged (after Hestwig and Lesser). c c Contractile vesicles.

there may be, and often are, delicate spines of fint radiating from the central sarcodic mass, and there is sometimes a regular siliceous skeleton. The Heliozoia are further furnished with the structures which aro known as the "contractile vesicle" and "nucleus." 


\section{CHAPTER III.}

\section{INFUSORIA.}

The Infusorian Animalcules are minute Protozoa of almost universal distribution, abounding in almost all collections of fresh or salt water in which organic matter may be present. They commonly have the power of becoming "encysted," and of remaining dormant, when deprived of water or of other conditions necessary to their active existence, the external layer of the body forming a kind of case within which the soft central protoplasm is enclosed. Their desiccated bodies, or their similarly desiccated germs, may thus be carried through the atmosphere from place to place, and may at any moment pass into a condition of active life, if they should meet with favourable conditions. Hence, whenever water containing organic matter in solution is freely exposed to the air, it will almost certainly be found to be charged with a larger or smaller number of these minute organisms. It is for this reason that the name of Infusoria was originally applied to this group of the Protozoa; it having been observed that "organic infusions"-i.e., water in which an animal or vegetable substance had been boiled-very commonly came to contain Infusorian Animalcules after exposure to the air for a limited period.

Morphologically, the Infusorian Animaleules are unicellular animals, consisting of a primitive mass of soft protoplasm, provided with an outer membranous wall, and furnished with one or more nuclei. Very usually the outer wall of the body is pierced by a definite oral opening; and they are sometimes for this reason collectively spoken of as the "stomatode," or mouth-bearing, Protozoa. There are, however, certain groups of the Infusoria in which there cannot be said to be any proper mouth.

There are two principal groups of the Infusoria, known as the Ciliated Infusorians and the Flagellated Infusorians; the former (fig. 17, A, B, C) having the external surface covered with vibrating cilia, in part or wholly ; whilst the latter (fig. 17, D and $\mathrm{E}$ ) have one or more long lash-like filaments or "Hlagella," and are usually destitute 
of cilia. There is a third smaller group-the Suctoria-in which the body is furnished with contractile tentacle-like filaments, which end in little dises, and are used as sucking-tubes. It will not be necessary to do more than mention the Suctorial Infusoria here; but the two groups of the C'itiata and Flagellata require more detäiled attention.
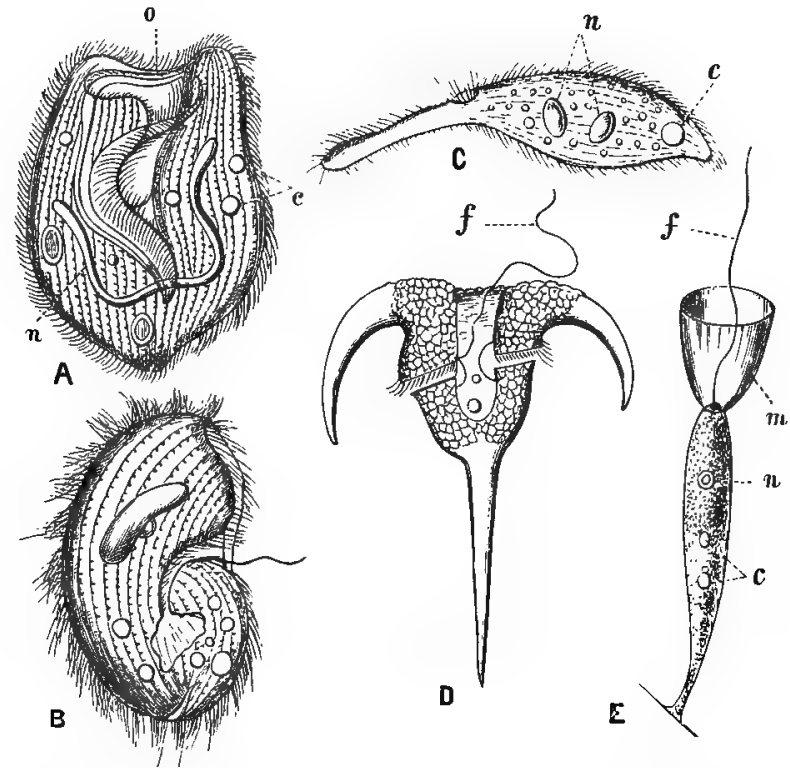

Fig. 17.-Ciliated and Flagellate Infusoria. A, Bursaria truncatella, enlarged 50 times. B, Nyctotherus cordiformis, enlarged 150 times. C, Amphileptus anser, enlarged 120 tmes. D, Cerutium tripos, enlarged 250 times, with its carapace and single flagellum. E, Monosiga angnstotu, enlarged 2.500 times: $n$ Nucleus; $c$ Contractile resicle; $f$ Flagellum; $m$ Menloranous collar surrounding the base of the flagelium. (After, or copied from, Saville Kent.)

The Ciliated Infesoriu may be defined as Protozoa which are provided with a mouth, and usically a short gullet and a distinct anues. Their bodies wnesist of soft semi-fluid protoplasm (" "endoplusm") enclosed by a more or less complex extemal layer ("exoplasm"); and the external surface is partly or whlly covered with vibrating cilia. They are mostly simple free-swimming organisms; but they sometimes furm colonies by budding, and are fixed to some solid object in their adult condition. As types of these two sections of the $I_{n-}$ fusoria, we may take respective'y l'tramcerium and Iorticella. 
Paramoecium (fig. 18) is a benutiful slipper-shaped little creature, which may be found commonly in stagnant waters or in artificially prepared infusions. The body is nearly quite transparent, and consists of three layers-1, a structureless, transparent, external film or pellicle, called the "cuticle"; 2 , a central mass of soft semi-fluid sarcode which receives the particles of food; and 3 , an intermediate layer of firm and consistent sarcode, which is called the "cortical layer" (Lat. cortex, bark). The external membrane or cuticle is richly covered with minute vibrating hairs or cilia, which in this particular type are of approximately equal length, and are arranged in close-set longitudinal rows. In many of the Infusoria, however, the cilia in the neighbourhood of the mouth are much longer than those covering the general surface. The cuticle is also perforated by the aperture of the mouth, which is continued into a short funnelshaped gullet (fig. 18, $m g$ ). The gullet, however, is not continued into any distinct stomach, but opens directly into the soft semi-fluid sarcode (endoplasm) which constitutes the central mass of the body. The particles of food on passing through the gullet are directly received into the central mass of diffluent sarcode, where they undergo a kind of slow circulation or rotation. As in the case of the Amoeja, each particle of food generally carries with it a little water, so that the appearance is produced of a number of little clear

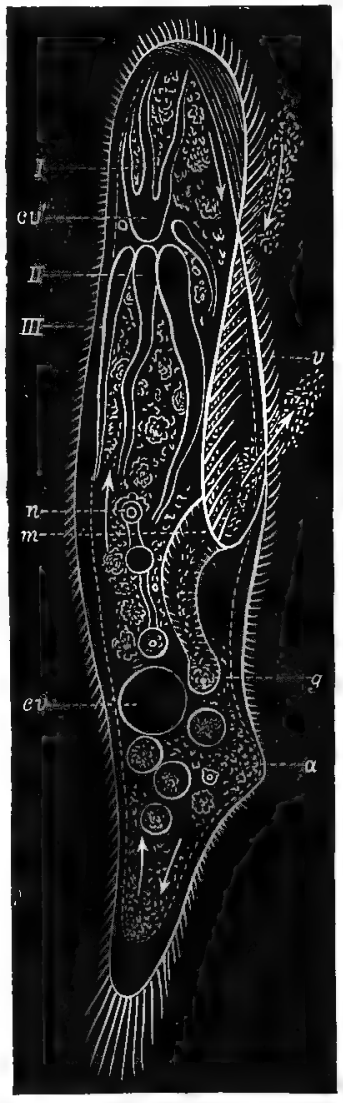

Fig. 18. - Paramacium, viewed dorsally, and greatly magnified. $m$ Mouth; $m$ to $g$ Gullet; $a$ Anus ; $c v^{\prime}$ and $c v$ The contractile vesicles; I, II, III, Canals proceeding from the anterior contractile vesicle; $n$ Nucleus; $v$ Large cilia bounding the depression ("vestibule") leading to the mouth. The arrows indicate the course in which the particles of fnod circulate in the semi-fluid protoplasm of the interior of the body. (After James-Clark.)

spaces in the central sarcode. These are now called vacuoles, or food-vacuoles; but they were originally described by Ehrenberg, the 
famous Prussian microscopist, as so many distinct stomachs, in consequence of which he named the Infusoria the Polygastrica (Gr. polus, many ; and gestr', stomach). The vibrating cilia which clothe the surface of l'tramocium serve partly to drive the animal rapidly through the water, and partly to set up currents by means of which food is conveyed to the mouth. All the nutrient particles obtained in this way undergo the circulation in the central sarcode above spoken of, where they are partially or completely digested. The indigestible portions of the food are got rid of by a second aperture (anus) placed near the nouth (fig. 18, $a$ ). The only other organs possessed by Paranocium are the so-called nucleus and nucleolus, and the contractile vesicle (or vesicles), all of which appear to be situated in the cortical layer of the body. The nucleus is a little solid body, composed of an external membrane, with granular contents, and having the nucleolus (or paranucleus) firmly attached to its exterior

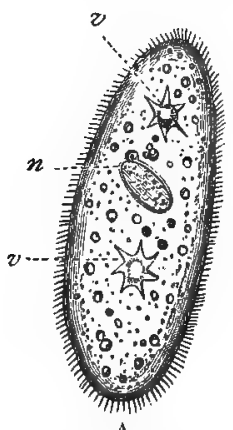

A

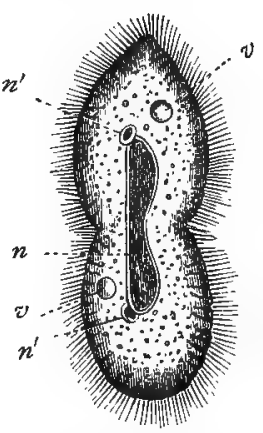

B

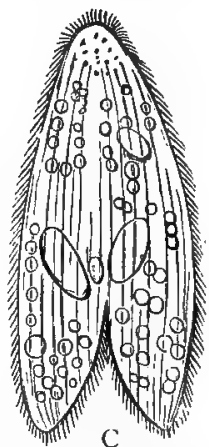

C

Fig. 19.-Ciliated Infusoria. A, Paramacium, showing the nucleus ( $n$ ) and two contractile vesicles (v). B, Puramcecium bursaria (after Stein), dividing transversely : $n$ Nucleus; $n$ 'Nucleolus; $v$ Contractile vesicle. C, Paramorium aurelia (after Elrenberg), undergoing "conjugation," two individuals being partially united by their ventral faces.

in the form of a little spherical particle. The nucleus and nucleolus used to be regarded as corresponding with the reproductive organs of the higher animals; but this view is now known to be without foundation. The contractile vesicle has essentially the same structure as in the Amoluc. It is a little wall-less space in the protoplasm, which is filled with a transparent fluid, and contracts and dilates at intervals. Sometimes it assumes a stellate form (fig. 19, A), or irregular radiating canals can be traced proceeding from it; while a communication with the exteriur has been stated to exist in some cases. Not uncommonly two vesicles are present. It is not 
improbable that the contractile vesicles should be looked upon as corresponding with the water-vessels of the lower groups of Worms, and as having the function of excretory, rather than of circulatory organs.

Reproduction in Paramocium may be effected simply by transverse cleavage or fission of the body into two portions (fig. 19, B). In other cases "conjugation" of two Paramoecia takes place. In this process two individuals come together, and adhere closely to one another by their ventral surfaces, in such a way that they present the appearance of a single individual undergoing longitudinal fission (fig. 19, C). Partial fusion of the conjugating individuals takes place, and the nucleus and nucleolus pass through certain curious changes. Ultimately, the conjugating individuals separate again, and each probably then undergoes repeated fission, and thus gives rise to fresh Paramocia.

As a common and beautiful example of the Stalked Infusoria, we may take the so-called Bell-animalcule (Vorticella, fig. 20, C), which
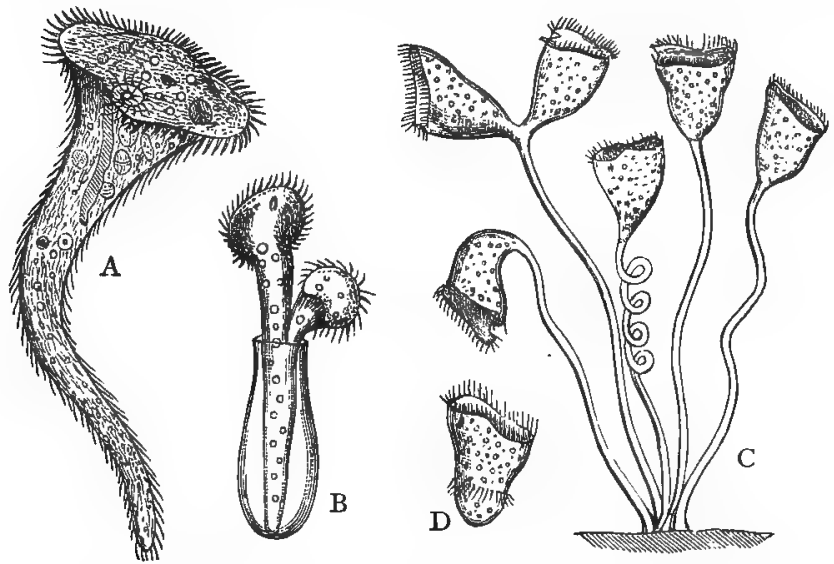

Fig. 20.-A, Stentor Mülleri. B, Vaginicola erystallina. C, Group of Vorticella.

D, Detached burl of Vorticella, showing the posterior circlet of cilia.

may be found in any stagnant pool attached to the stems of aquatic plants. The body in Vorticella forms a kind of cup or "calyx" supported upon a long stalk, which is in turn fixed to some solid object. The sten contains a contractile fibre in its interior, and the animal can by this means push itself out or coil itself up with the utmost rapidity. The vibrating filaments or cilia are not scattered over the whole surface of the bell-shaped body, but are collected to form a 
kind of fringe or circle round the mouth of the calyx. Nearly in the centre of this ring, or on one side, is placed the aperture of the mouth, which leads by a short gullet straight into the central soft sarcode of the interior of the body. A nucleus and contractile vesicle are also present, so that in the essential points of its anatomy Vorticella does not differ from a free-swimming Infusorian such as Paramocium. Indeed, a transition between the two forms is found in the so-called Trumpet-animalcule or Stentor (fig. 20, A), which can detach itself and swim about at will, at the same time that it is ordinarily fixed by its thinner extremity to some solid object. In Vaginicola (fig. 20, B), again, we have an animalcule closely related to Stentor, but having the body protected by a horny or membranous sheath.

The group of the Flagellated Infusoria is distinguished from that of the Citiata, by the fact that the body is furnished with one or more long lash-like filaments or flagella, usually without any cilia. A mucleus and contratile vesicle are present. The flagella of these singular Infusorians are the main locomotive organs, serving by their lash-like movements to drive the animal through the water, as also to set up currents by means of which food is brought to the organism. In many instances, the latter is their principal function, as the animal is fixed by a stalk in its adult condition. A few forms have a mouth (e.g., Euglena); but most have no distinct oral aperture, the inception of food being limited to a definite discoidal area surrounding the base of the flagellum. This area is enclosed by a delicate membrane, which is prolonged upwards round the lower part of the flagellum as a kind of cup or "collar" (fig. 17, $\mathrm{E})$. The movements of the flagellum produce a kind of miniature whirlpool inside the collar, and the animal is thus supplied with food. These "collar-bearing" Infusorians possess, as will be subsequently seen, a striking resemblance to certain of the cells which form the body of a sponge. A number of the Flagellated Infusorians possess a limited number of cilia, in addition to the flagellum. This is the case, for example, in the curious forms known as Peridininm and Cerutium (fig. 17, D), in which the body is enclosed in a kind of horny shell with long projecting processes.

In their internal structure, the Flagellated Infusorians do not differ essentially from the Ciliated forms. They occur both in fresh and in salt water, and often form colonies. They are mostly of very minute size; and it is difficult to separate certain forms from certain groups of plants (Alge $)$. 


\section{CHAPTER IV.}

\section{PORIFERA (SPONGES).}

Originally regarded as being of a vegetable nature, the Sponges are now universally admitted to be animals; and are by many naturalists associated with the Sea-anemones and Corals (Coelenterata). They have, however, many remarkable points of relationship to the typical Protozoa, and particularly to the Flagellated Infusoria. Upon the whole, therefore, it may be as well to treat them here as a special group, intermediate between the Protozoa and Colenterata, under the name of Porifera.

The Sponges may be defined as multicellular protoplasmic masses, supported in most cases by a framework of horny fibres or of calcareous or finty needles, and traversed by canals which open on the surface, and are dilated at intervals into chambers lined by flagellate cells.

In the first place, then, a Sponge differs from the typical Protozoa, and agrees with all the higher animals (1/ctu:oa), in the fact that the body is multicellular, being composed of a vast number of separate protoplasmic units, which may be termed "sponge-particles" or "sarcoids," and each of which may be regarded as being a single cell. In the second place, this protoplasmic aggregate is almost always, though not invariably, strengthened and endowed with a definite form, by the presence in it of a "skeleton," consisting of horny fibres, or of "spicules" of lime or silica. In the third place, the entire organism is traversed by a complicated "canalsystem," which opens on the surface by two sets of apertures ("pores" and "oscula"), and the branches of which are dilated at intervals into "ciliated chambers." There is no distinct mouth, no digestive system, no circulatory or definite nervous organs, and no body-cavity; but we must consider in greater detail the characters and structure of the "sponge-flesh," the "skeleton," and the "canal-system."

If we take the ordinary horny sponges of commerce, what we call the "sponge" is, of course, nothing but the skeleton of the 
sponge-colony, comprised of innumerable horny fibres interlaced into is continuous network, in such a way as to leave innumerable holes and canals between its bundles. In the living condition, the

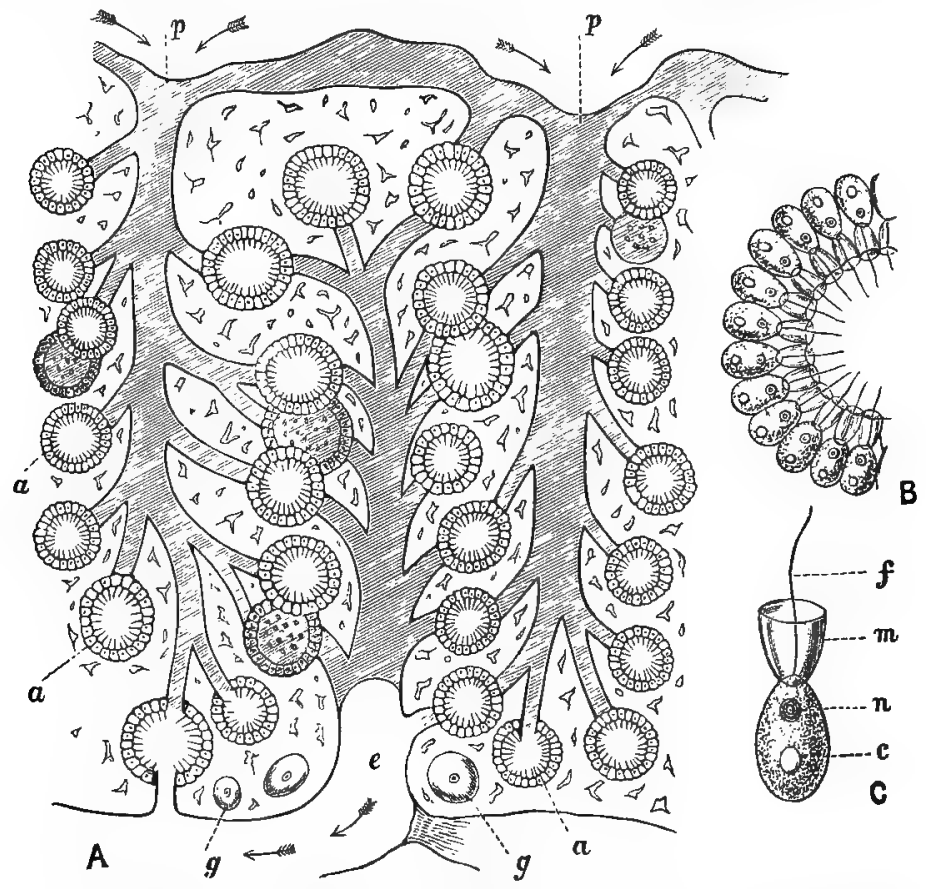

Fis. 21.--Structure of Spongida A, Yertical section of the outer layer of Halisarta lobularis, a Spontre in which the skeleton is wanting, enlarged 75 times (after F. I Schultze) : $p p$ "Pores," or openings of inhalant canals by which water" is conducted tri the ciliated chambers $(a a)$; e Commencement of a larger exllalant canal, conducting from the ciliated chambers to the deeper canals, by which the witt'r is finally "irriph off to be expelled from the "osenla"; $g$ g Young stages of the reprotuctive bodies or spores. B, Part of a single ciliated chamber of the same sponge, transversely divillal, and enlarged s00 diameters (after siville Kent), showing the flagellate "ells or " "Imnge-particles," with their inwardly directed lligeth. C, A single flagellate coll of the same, still further enlarged: $f$ Flagellum; $m$ Collar round the base of the flagellum: N Nucleus; $c$ Contrartile vesicle.

whole of this skeleton is corered externally and internally with a soft protuplasmic material, which has been often termed the "sponge-flesh," as it represents the soft parts of the sponge. Examined microscopically, the "sponge-flesh" is found to be compused of an cnormous number of minute protoplasmic bodies or 
cells - the "sponge-particles" or "sarcoids"-which differ in their characters in different parts of the sponge. Some of the spongeparticles are very like Amobce, since they consist of little masses of granular protoplasm, furnished with a nucleus, and capable of throwing out pseudopodia (fig. 22, C), by means of which they feed. In the outer layer of the sponge, these sponge-particles may be arranged so as to form a kind of membrane; and at other times they become more or less coalescent, giving rise to a common gelatinous matrix, and losing their separate distinctness. Other spongeparticles, again, instead of being like Amobo, are closely similar to those Flagellate Infusoria which possess a collar round the flagellum. These flagellate sponge-particles (fig. 21, C, and fig. 22, B) possess a nucleus and one or more contractile vesicles, and they are arranged within the so-called "ciliated chambers" (fig. 21, $a$ a) of the canal-system.

The entire aggregate of sponge-particles is so arranged as to be traversed by a series of canals, which convey water in and out of the organism, and are connected with respiration and the procuring

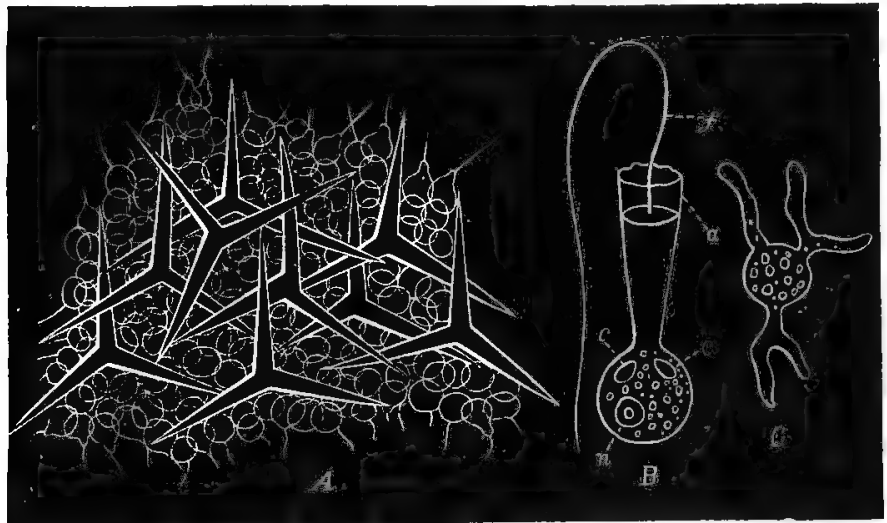

Fig. 22.-A, Portion of Grantia, highly magnified, showing the spicules and the sponge-particles. B, A single sponge-particle of Grantia compressa, greatly enlarged, showing the membranous collar $(a)$, the flagelum $(f)$, the contractile vesicles $(c c)$, and the nucleus $(n)$. C, A sponge-particle of Grantia compressa, with the pseudopodia protruded and without the flagellum, greatly enlarged. (B and $C$ are after Carter.)

of food. Looking at the skeleton of the dried sponge, the most obvious sign of the existence of this "aquiferous system" that we see is the presence of one or more large openings (fig. 23, A), together with a vast number of much smaller apertures. These latter 
are termed the "pores"; and though permanently present in the skeleton, they are only temporarily present in the sponge-flesh, being produced afresh, when required, as openings between the sponge-particles which form the outer layer of the sponge. The "pores" are the external openings of a series of canals which ramify in every direction through the sponge, and which are usually called "inhalant canals," as it is through these that the outer water is conveyed into the interior of the sponge. The "inhalant canals" ultimately open into a second series of canals, which converge to form one or more large tubes which open on the surface by a corresponding number of large apertures. These large tubes carry the water out of the organism again, and they are hence called "exhalant canals" (fig. 21), while their surface-openings are the "oscula."

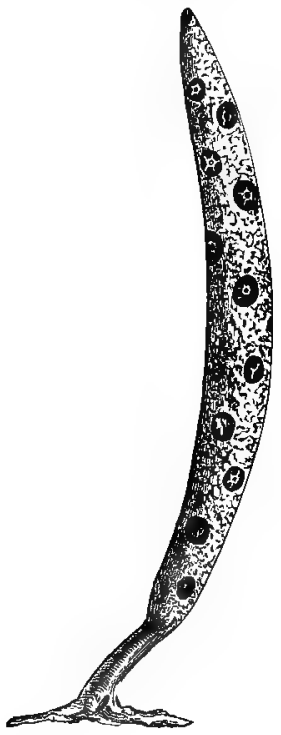

A

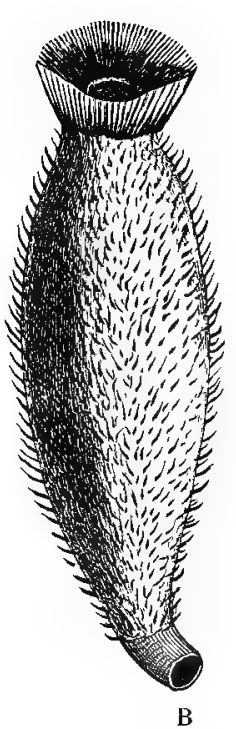

B

Fig. 23. - A, Axinelle polypoides, a fibrous sponge showing oscula and pores. B, Sycandra ciliata, a calcareous sponge, enlarged, showing the single terminal osculum. (After Schmidt.)

The "oscula" are permanent (fig. $23, \mathrm{~A}$ ), and are often placed on chimney-like elevations. If there is only one osculum, it is placed at the apex of the sponge (fig. 23, B). What we usually call a sponge may consist of only a single excretory opening or "osculum," 
together with the pores belonging to this (fig. $23, \mathrm{~B}$ ); or it may consist of a larger or smaller number of such "oscula," each with its proper complement of "pores" (fig. 23, A). In the latter case, there is produced what is commonly called a "sponge-stock."

In a living sponge, in its active condition, a circulation of water is kept up throughout the organism by means of this canal-system. The water is admitted by means of the "pores" (fig. 21, A, p p), is driven into the interior of the sponge, and is finally expelled in steady streams from the osculum or oscula. The mechanism by which this circulation of water is effected was long unknown. It is now known, however, that the circulation of water is maintained by the vibrations of the flagella, with which we have seen certain of the spongeparticles to be provided. In some cases, the entire system of watercanals seems to be lined with these flagellate sponge-particles. More commonly, the "inhalant canals" are dilated at intervals into globular chambers (fig. 21, A, $a \alpha$ ), which are lined with flagellate sponge-cells. These sponge-particles are so arranged that all their flagella point inwards into the centre of the chamber (fig. 21, B), and in their structure they precisely resenible Flagellate Infusoria. The flagella within these so-called "ciliated chambers" all work towards the interior of the sponge, and thus supply the motive power needed for the keeping up of the water-currents. By means of these watercurrents the organism obtains oxygen, and gets rid of waste matter;
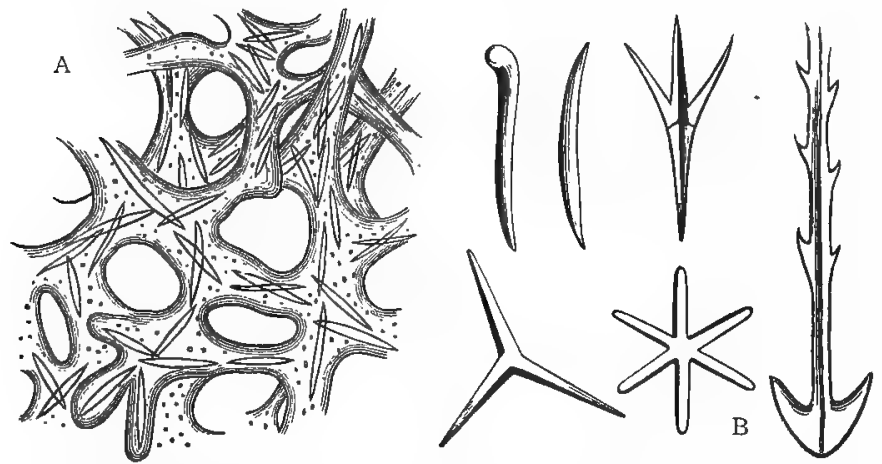

Figr. 24.-A, Fraginent of the skeleton of a liorny sponge (after Bowerbank), showing interlacing horny fibres with spicula. B, Different forms of the spicules of sponges, much nagnified.

while the individual sponge-particles appropriate the minute particles of nutrient matter which may be carried in suspension in the water. 
Such, then, are the general phenomena exhibited by any sponge, and the principal point which still remains for consideration is the nature of the hard structures which form the "skeleton" of the Sponges. Sume sponges (such as Hulisarca) have no skeleton; and when a skeleton is present, it varies much in its constitution. In the sponges of commerce (Euspongicl) the skeleton consists solely of hollow horny fibres, which are interlaced with one another so as to form a close reticulation. In many other common sponges, a horny skeleton is also present, but it is associated with, and sometimes largely replaced by, microscopic needles or "spicules" of flint. These spicules (fig. 24, B) are of very various shapes in different sponges, and they maty be either scattered through the sponge-flesh, or contained in the interior of the horny skeleton-fibre, which they often extensively replace. In the so-called "Siliceous" Sponges, or " (thass Sponges," no horny fibre is developed, but the whole skeleton is composed of spicules of flint, which are often soldered together so as to form a continuous framework, which looks like a lattice of spun glass. The beautiful Venus's Flower-basket (Explectellı) and the Bird's-nest Spronges (Holtenia) are examples

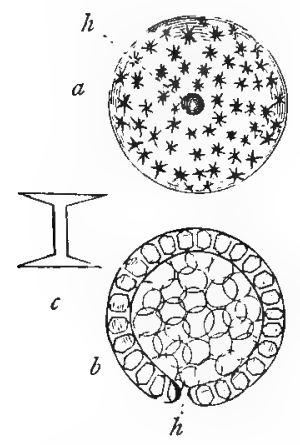

Fig. 25.-a Go:nmule of Spongilla; $h$ Hilum; $b$ Diagranmatic scetion of the germmule, showing the out(r) layer of amphidises and the inner mass of celis; $c$ One of the amplidises seen in protile. of such sponges. Lastly, in the so-called "Calcareous iponges," such as Girutir (fig. 2., A), the skeleton is composed of aggregated, but disunited, spicules of lime, instead of flint. These spicules mostly have a characteristic three-rayed form.

As regards the reproductive process in the Sponges, it will be sufficient to state very briefly the leading phenomena which have been observed in the Fresh-water Sponge (Spongilla fuviutilis). If a specimen of Spongilla be observed towards the approach of winter, its deeper portions will be found to he filled with numerous small rounded botlies like seeds, which have been called "gemmules." Each genmule (fig. 25, $a$ b) exhibits at one point a small aperture or "hilum"; and is found to be composed of a leathery membrane, surromilerl by a layer of sarcode, in which are embedded a number of spricula. These spicula are called "amphidiscs," and consist each of a central rod or axle carrying a toothed wheel or disc at each end (fig. 25, c). In the interior of the capsule thus forned is a mass of cells, of which the central ones coutain uumerous reproiluctive germs. When the spring comes, these masses are discharged into the water throngh the aperture or hilum of the gemmule, and become developed into fresh symnglille. The ahove is a non-sexual method of reproduction; but it is believed that most of the marine Sponges exhibit sexual 
reproduction also, and are capable of producing at certain seasons eggs or ova, aud sperm-celis. The impregnated ova develop themselves into embryos, which are provided with numerous cilia by neans of which they swim about freely. Finally, upon finding a suitable locality, they fix themselves to some solid object, lose their cilia, and grow up into the fixed adult. Indeed, as a general if not universal rule, the embryos of the sponges are provided with cilia, and are thus capable of active locomotion. In this way is secured the extension over a wide area of these otherwise fixed and plant-like organisms.

As to the distribution of the Sponges in space, the common Spongilloe and certain allied types are known as "fresh-water sponges," as they occur in lakes and rivers; but most sponges are inhabitants of the sea. The common Horny Sponges are mostly found attached to stones or other foreign objects between tidemarks, or in comparatively shallow water. Certain singular types (Cliona) burrow into shells, in which they form winding and branched tunnels, but the mechanism by which this is effected is not clearly known. The Glass Sponges are all marine, and are mostly found at comparatively great depths in the sea, being often anchored to the mud or sand at the bottom by longer or shorter root-fibres of flint. Lastly, the Calcareous Sponges are all marine, and are mostly confined to shallow water, or live between tidemarks. They are all small in point of size, and delicate in texture. 


\section{SUB-KINGDOM II. CELENTERATA.}

\section{CHAPTER V.}

\section{Characters of the Sub-Kingdom. 2. Divisions.}

3. General Characters of the Hydrozoa. 4. Explanation of Technical Terms.

TuE second great primary division or sub-kingdom of animals is that of the Colenterata or "hollow-entrailed" animals (Gr. koilos, hollow; enteron, intestine). This sub-kingdom embraces the Seaanemones, Corals, Sea-jellies, Sea-firs, Sea-pens, and other allied animals, all of which are characterised, amongst other things, by having their bodies built up of parts which are arranged in a more or less star-like or "radiate" manner. Hence these creatures were long known as "Radiate Animals." So many other animals of different kinds were, however, included in the old sub-kingdon Radiatr, that naturalists have generally abandoned this term. Most of the Colenterate animals would cone under the popular term of "Zoophytes" or plant-animals (Gr. zoön, animal ; phuton, plant), from the external resemblance which many of them bear to plants.

The Colenterata may be defined as radially symmetrical animals, in which the mouth opens into a simple or variously divided space, which represents the alimentary carity of the higher animals. This internal space may or may not be divided into two portions-one specially connerted with digestion, and the other corresponding with the body-cavity of the higher animals. The body-wall is composed of two fundamental layers (the "entodcrm" and "endoderm"). The nerrous system is represented by diffused ganglion-cells, or sometimes by a simple nerve-ring; but there are no circulatory organs. Distinct reprodustive organs are present at some period or another of life; but non-secual reproduetion is very generat.

The leading feature which distinguishes the Colenterata, and the one from which the name of the sub-kingdom is derived, is the peculiar arrangement of the digestive system. In the Protozoa, as 
we have seen, a mouth is only present in some groups, and in no case is there any definite internal cavity bounded by the walls of the body, to which the name of "body-cavity" or "somatic cavity" could be properly applied. In most of the higher aninals, on the other hand, not only is a permanent mouth present, but the walls of the body enclose a distinct and permanent chamber or body-cavity. Further, in most cases the mouth opens into an alimentary or diges-

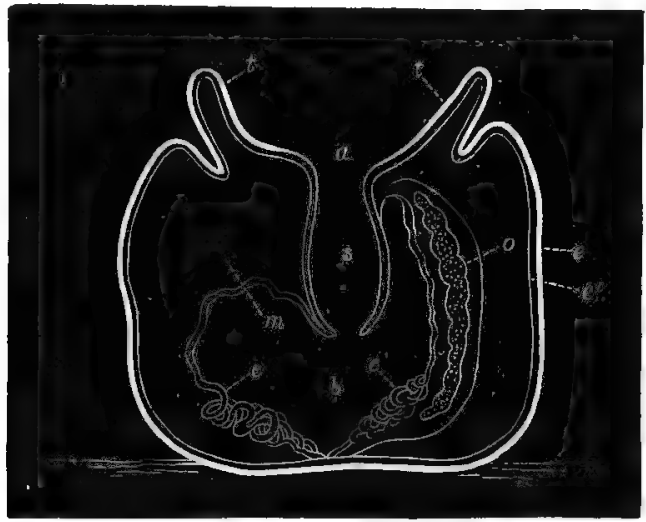

Fig. 20.-Diagrammatic vertical section of a Sea-anemone. a Mouth; $s$ Stomach ; $b$ Body-cavity ; $c$ c Convoluted cords ("craspeda") containing thread-cells, and forming the free edges of the mesentery $(m) ; t t$ Tentacles; o Reproductive organ contained within the mesentery. The ectoderm (e) is indicated by the broad external line ; the endoderm $\left(e^{\prime}\right)$ by the thin line and the space between that and the ectoderm.

tive tube, which is always distinct from the body-cavity, and never opens into it, usually passing through it to open on the surface by another distinct aperture (the anus). In most cases, therefore, the alimentary canal is a tube which communicates with the outer world by two apertures-a mouth and an anus-but which simply passes through the body-cavity without in any way communicating with it. In the Colenterata the condition of parts is intermediate in its arrangement. There is a distinct and permanent mouth, and there is a distinct and permanent cavity enclosed within the body-walls, but the mouth opens into, and thus communicates freely with, the latter. In some cases the mouth opens straight into the general body-cavity, which then serves as a digestive cavity as well (fig. 28). In other cases there intervenes between the mouth and the bodycavity a short alimentary tube, which communicates externally with the outer world through the mouth, and opens below by a wide aperture into the general cavity of the body (fig. 26). In no case is 
there a distinct intestinal tube which runs through the body-cavity and opens on the surface by a mouth at one end and an excretory aperture or anus at the other. It may be added in this connection that, though it is convenient to apply the term of "body-cavity" to the general space included within the body-walls of a C'relenterate i animal, the space does not correspond in its mode of development with what is known as the borly-cavity of the higher animals.

Another leading character of the colonterestre is the composition of the body out of two fundamental membranes (fig. 26), which are usually of a very simple structure in the embryo, but which in the adult become more or less complicated by the development of muscular fibres and other tissues. The outer of these layers or membranes is known as the "ectoderm," and it forms the whole of the
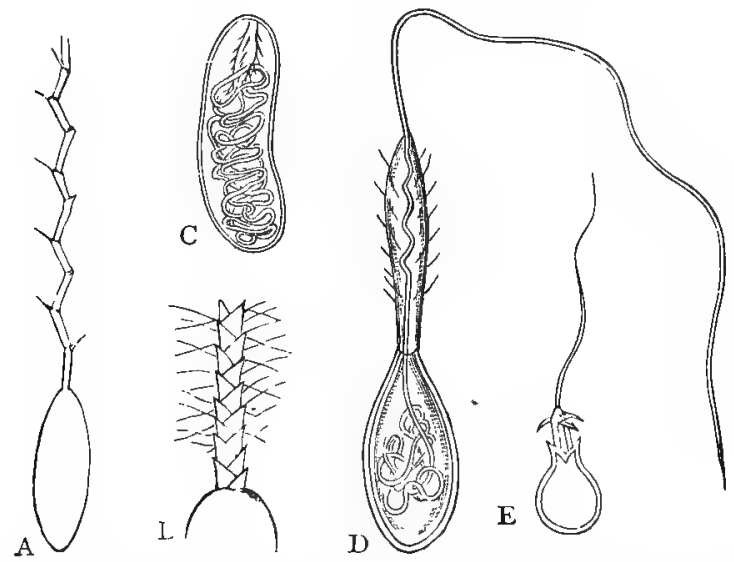

Fig. 25.-Thread-cells of Cutlenterate animals, greatly magnified. A and B, Threadcell of a coral (Caryophyllia), with the threarl everted. C and D, Threal-cell of a Sea-anemone (Corallimorphus), in its quiescent and active condition. E, Threadcell of $H y d r a$, with the thread everted.

outer surface of the hody, terminating at the margins of the mouth. The inner liyer is known as the "endoderm," and it lines the whole of the interior of the body, being prolonged into the tubular tentacles round the mouth. Both of these membranes, but especially the enilekrrm, are usually more or less richly furnished with vibrating cilia. The muscular and other tissues which are developed between the ectoderm and endoderm, constitute what is called the "mesoderm." The peculiar microscopic organs called "thread-cells," "nettle-cells," or "cnidie," which communicate to many of the Colentrintu (such is the sea-jellies) their peculiar power of stinging, are 
structures found in the integument of almost all the members of this sub-kingdom, and sometimes in interual parts as well. They are very beautiful objects of microscopical examination, and differ very considerably in the details of their structure. Each thread-cell (fig. 27) is essentially a double-walled sac or capsule filled with fluid, and containing internally a longer or shorter spirally-coiled thread or filament. The thread is pointed at its free extremity, and often barbed at its base or serrated along the edges. When the external capsule is touched it ruptures; and the coiled-up thread is thrown out, like a lasso, to a distance often equal to many times the length of the enclosing capsule. The pointed end of the thread pierces the object which it strikes-supposing the latter to be of a sufficiently soft nature--and apparently envenoms the puncture thus produced with the fluid contained in the sac, this seeming to have some poisonous or irritating character.

In accordance with the above-mentioned differences in the arrangement of the digestive system, the Colenterata are divided into two great classes, termed respectively the Hydrozoo and the Actinozoa. In the Hydrozoa, there is no body-cavity distinct from the digestive cavity-or, in other words, the body-cavity is the digestive cavity, the mouth opening directly into the body-cavity (fig. 28). In the Actinozoa, on the other hand, there is

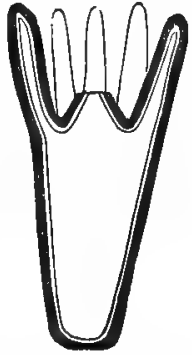

Fig. 28.-Diagrammatic section of Hydra; the dark line is the ectoderm, the fine line and clear space arjacent indicate the encloderm. a distinct digestive cavity, but this opens directly into the general body-cavity, so that the two form distinct but freely communicating divisions of the same chamber.

\section{Class I. Hydrozoa.}

The Hydrozoa are defined as Calenterata in which there is no digestive sac separate from the general cavity of the bonly. The reproductive organs are external, in the form of outward processes of the body-wall (fig. 30).

The Hydrozoo are all aquatic in their habits, and, with few exceptions, all are inhabitants of salt water. The class includes both simple and composite organisms, of which the most familiar are the Sea-firs and their allies (Hydroid Zoophytes), the Fresh-water Polype or Fydra, the Sea-jellies (Medusce), and the Portuguese Man-of-war (Physalia). Owing to the extremely complicated nature of many of the Hydrozoa, it appears advisable to preface their description by an explanation of some of the more important terms which are employed in connection with various members of the class. 


\section{General Terminology of tile Hydrozoa.}

Individurl.-In order to understand fully the meaning which is attached to the term "individual" in zoological language, it is necessary to glance briefly at the general features of reproduction as displayed in different sections of the animal kingdom. Reproduction is the process by means of which new individuals are produced and the perpetuation of the species ensured. This end nuay be attained in various ways, but these all come under the two heads of "sexual" and "non-sexual" reproduction. In sexual reproduction, by which alone cun fresh beings be produced amongst the higher animals, the essential element of the process consists in the formation of two distinct structures, a germ-cell or ovum, and a sperm-cell or spermatozoid. By the union of these distinct reproductive elements, fresh beings can be proluced. As a general rule, the gern-cell is produced by one individual (female), and the sperm-cell by another (male); but amongst the lower animals it is not unconmon for the same individual to produce both of these elements, in which case the individual is said to be "hermaphrodite." Amongst the lower animals, however, fresh beings may be produced without the contact of a sperm-cell and an ovum-that is to say, without any genuine act of reproduction. The processes by which this can be effected in different animals vary considerably, but they are all spoken of as forms of "non-sexual" reproduction. The only varieties, however, of the process which require consideration, are those in which fresh beings are produced by what is called "gemmation " or "fission."

Gemnation (Lat. gemma, a bud) consists in the production of a bud or buds, usually from the outside, but sometimes from the inside of an animal; which buils become developed into more or less completely independent beings. The fresh beings thus produced by budding are all known as zoöids, and are not spoken of as distinct animals, for reisons which will be immediately evident. When the zoöids produced by budding remain permaneutly attached to one another and to the parent organism which producel them, the case is said to be one of "continuous" gemmatim, and the ultimate result of this is to produce a colony or compusite structure, compred of a number of similis and partially independent beings, all produced by budding, but all remaining in organic comnection. This is seen very well in a great number of the Hydrosm (fig. Di). When, on the other hand, the zooids produced by budding become finally detached from the jurent organism, we have a case of what is called "discontinuous" gremmation. In this case, the detached zoöids become completely independent beings; and they are often wholly 
unlike the original zoöid in structure and in habits, so much so that they have in varions cases been described as altogether distinct animals. Discontinuous gemmation is very well seen in many. of the Hydrozoa, and in them the case is still further complicated by the coexistence of discontinuous gemmation with the continuous form of the process. Thus it is not an uncommon thing amongst the Hydrozoa tu find a composite organism or culony produced from a primordial zoöid by continuous gemmation, and having at the same time the power of giving rise to detached and completely independent beings by a process of discontinuous gemmation.

In what is called "fission" (Lat. findo, I cleave), exactly the same results are attained as in gemmation, but in a slightly different manner. In gemmation the new beings are produced by means of buds thrown ont by a primitive zoöid. In fission the new beings are produced by a cleavage or division of a prinitive zoöid into two or more parts, each of which becomes finally developed into a new and more or less completely independent being. In fission, as in gemmation, the new beings or zoöids may remain permanently in connection with one another, when the process is a continuous one, and a composite organism is produced, as in many Corals. Or, in other cases, the new zoöids produced by fission are detached to lead an independent existence, as in some of the Hydrozoa, the process thus becoming a discontinuous one.

We are now able to understand what is meant, in strict zoological language, by the term "individual," as applied to animals. Zoologically speaking, an individual is defined as "equal to the total result of the development of a single ovum." In the higher animals there is no sort of difficulty about this, for each ovum gives rise to no more than one single animal, which cannot produce fresh beings in any other way than by producing another ovum. In this case, therefore, each animal is an individual. In the lower animals, however, the being produced by an ovum has often the power of giving rise to fresh beings by a process of gemmation or fission, and these beings may either remain attached to one another so as to form a colony, or may become detached to lead independent lives. In either case, the term "individual" can only be properly applied to the whole assemblage of beings produced in this way, however much they may differ from one another in appearance, structure, or mode of life. In these cases, therefore, the individual may be, firstly, a single independent being-as, for iustance, an Amoba, or an Infusorian such as Paramocium; secondly, a colony or composite organism coniposed of a number of more or less nearly similar beings or zoöids, produced by budding from a primitive zoöid-as, for instance, is seen in many of the Infusoria (e.g., Epistylis); and 
thirdly, an assemblage of zö̈ids produced by budding or fission from a primitive being, but not necessarily remaining conuected with one

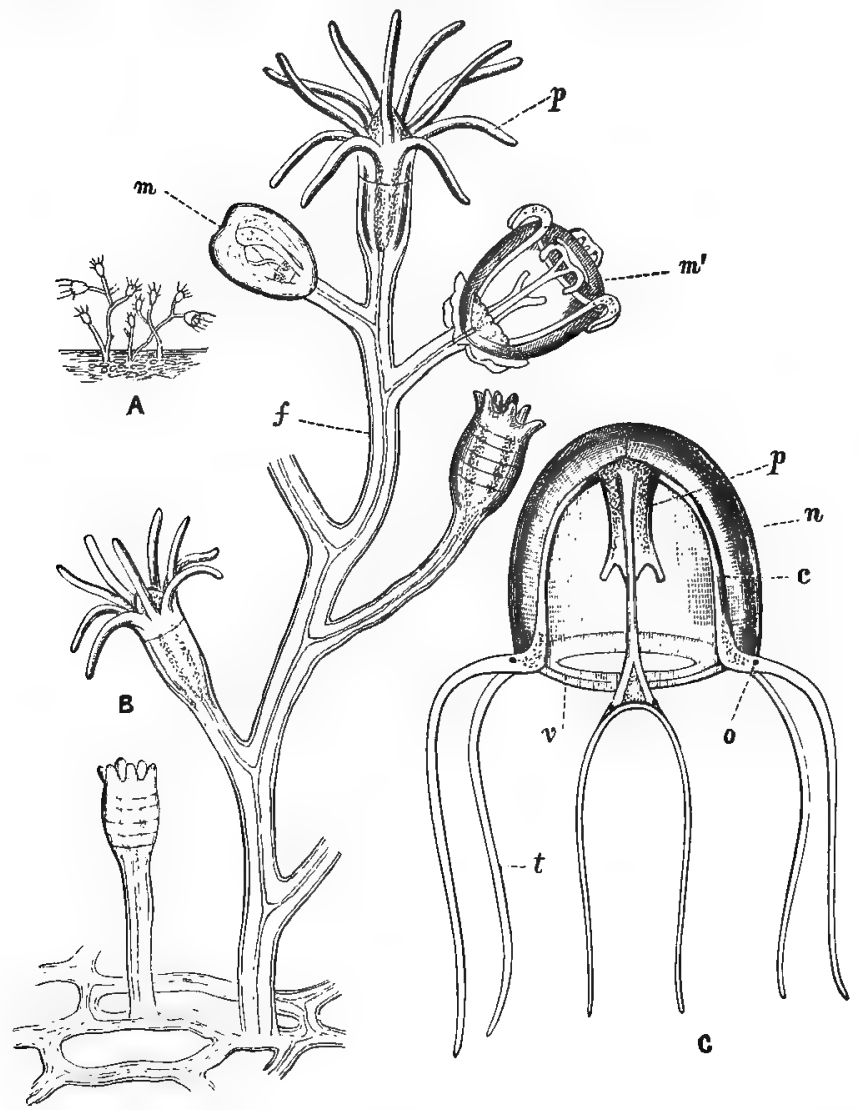

Fig. 2!. - 1, Part of the colony of Lougainsilla muscus, one of the compound Hylosm, of the natural size. B, Part of the same enlargcd: $p$. 1 polypite fully expanded; $m$ An incompletely developed remoductive bud; $m{ }^{\prime}$ A more completely developed reproductive bud; $f$ Cunosare with its investing periderun and central canal. C, A free reproductive bud or medusiform gonophore of the same : $n$ Gonocalyx; $p$ Mannlurimu; c One of the radiating gastro-vascular canals; o Ocellus; $v$ Velum; $t$ Tentaclo. (After Allmas.)

another or exhiliting any common features of likeness, as we shall see is the case in many of the Hydrozoc. Lastly, cases may occur in which the intividual consists partly of similar zoöids which 
remain permanently connected with one another, and partly of dissimilar zoöids which are detached to lead an independent life, all alike being the result of the development of a single ovum.

Zoöid.-The term "zoöid" is indifferently applied to all the more or less completely independent beings which are produced by budding, or by cleavage from a primitive organism. It does not matter, therefore, for the purposes of this definition, whether these beings remain permanently attached to the original organism, or whether they are finally separated to enjoy an independent existence.

Hydrosoma.-The term "hydrosoma" is one which is very conveniently applied to the entire organism in any Hydrozoön, whether this be simple, or whether it be composite and made up of a number of connected zoöids.

Polypite.-That portion of any Hydrozoön which is concerned with the process of digestion, or, in other words, the "alimentary region," is termed the "polypite"—-the more generally current term of "polype" being now restricted in meaning to the same region in the higher Colenterata (Actinozoa). In such of the Hydrozoa as the Fresh-water Polype or Hydra, in which the hydrosoma is sirople, the whole organism is termed a polypite ; but the term is more generally enployed to indicate the nutritive zoöids of any compound Hydruzoün.

Cenosarc.-The term "coenosare" (Gr. koinos, common; sarx, flesh) is employed to designate the common trunk or flesh by which the separate polypites of any compound Hydrozoön are united into a single organic whole.

Distal and proximal.-These are terms applied to different extremities of the hydrosoma. It is found that one extremity grows more quickly than the other, and to this free-growing end-at which the mouth is usually situated-the term "distal" is applied. To the more slowly-growing end of the hydrosoma the term "proximal" is applied. When the Hydrozoön is fixed to any solid object, it is by the proximal end that attachment is effected; but in such forms as are permanently free this mode of distinction is inapplicable. The terms may be used either in reference to a single polypite in the compound Hydrozoa, or as regards the entire hydrosoma, whether this be simple or compound.

Polypary.-The term "polypary" or " polypidom" is applied to the horny or chitinous outer covering or envelope with which many of the Hydrozow are furnished. These terms have also been not uncommonly employed to designate the very similar structures produced by the much more highly organised Sea-mats and their allies (Polyzna), but it is better to restrict their use entirely to the Hydrozoa. 


\section{CHAPTER TI.}

\section{DIVISIONS OF THE HYDROZOA.}

The Hydrozoa are dividecl into five great divisions, each of which requires some notice, is presenting points of special interest. These divisions or sub-classes are known by the names of Hydroida, Siphonophora, Lacernurida, Graptolitidee, and Iydrocurullince.

\section{SUB-CLASS HYDROIDA.}

This sub-class comprises all the Sea-firs and their allies, commonly known to naturalists as the "Hydroid Zoophytes," from their resemblance to the Fresh-water Polype $(H y d r a)$, which is also a member of this division. The Hyrlovide are defined by the fact that they consist of un alimentary region or "polypite," whirk i. f "rrished with a mouth "nd prolensile tentucles at its distal enrl, and with an adherent disc at its proximal ertrumity. In some few cases the hydrosoma consists of but one such polypite (as in the Iylridu and some of the Corynida); but generally the hydrosoma is composed of a greater or less number of similar polypites all united by a conosarc ur common trunk (as in the majority of the Comyida, and in the sistultida and Campanulaiblic). In the great majority of cases, also, the hydrosoma is not unattached, but is fixed to some solid object hy its proximal extremity or "hydrorhiza." The Hydroid Zoophytes exhibit four principal types of structure, which constitute so miany orders.

\section{Order I. Hydrild.}

In the first order we have only the well-known Fresh-water Polypes or Hydre, of which we may take the common green Hydra ( $H$. viridis) is the type. When uncontracted, the body of the Hydra is in the form of a cylindrical tule (fig. 30), composed of the two fundamental layers, the ectorlerm and endoderm, of which the former contining many thread-cells. The integument 
also contains numerous green granules, apparently identical with "chlorophyll," or the green colouring-matter of plants. At the base or proximal extremity of the cylindrical lody is a kind of discshaped sucker or hyclrorhiza, by means of which the animal can attach itself at will to any foreign body. Its favourite pisition appears to be that of hanging head-downwards, suspended from the stem of some water-plant. It is not, however, permanently fixed, but it can detach itself and change its place at will. At the opposite or distal extremity of the body is placed the aperture of the mouth, surrounded by a circle of from five to fifteen small tubular filaments, which are termed the "tentacles" (fig. 30, a). Each tentacle consists of a tubular prolongation of both ectoderm and endoderm, and encloses a canal which opens at its base into the general carity of the body. The ectoderm is richly furnished with thread-cells, which are especially abundant in the tentacles. On the inside of the ectoderm, between it and the endoderm, exists also a peculiar fibrous layer, which has been generally

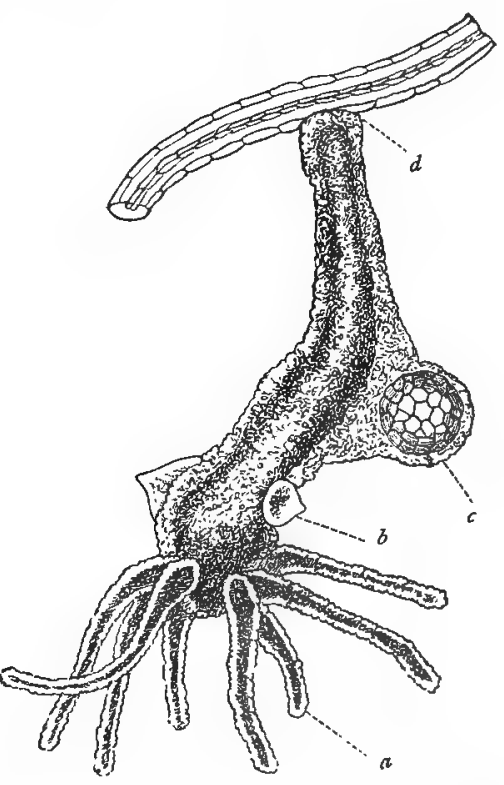

Fig. 30.-The Green Fresll-water Polype (Hydra viridis), suspended head-downwards from a piece of a stem of an aquatic plant, enlarged. $a$ One of the tentacles; $\delta$ Testis or spermarium, with spermatozoa in its interior; e A single large ovum, protruding from the side of the body; $d$ Disc of attachment ("liydrorhiza "). regarded as partly of a ner-

vous and partly of a muscular character. The tentacles exhibit the most extraordinary contractility, being capable of retraction till they appear as nothing more than so many little warts or tubercles, and of being extended to a length which is in some species many times longer than the body itself. They are the organs by means of which the Hydra obtains its food, consisting chiefly of minute aquatic organisms, such as small worms, insects, Crustacea and Rotifer'a. These are seized by the tentacles and gradually drawn into the mouth; but in 
addition to this merely mechanical action, the tentacles appear to exercise a benumbing or even fatal influence upon the animals grasped by them-this being apparently due to the thread-cells with which they are furnished. The mouth in the Hydra opens directly into a capacious cylinlrical cavity, which is excavated along the whole length of the body, and which is both the body-cavity and the stomach in one. This civity (fig. 28 ) is filled with water derived from the exterior, and also with the nutritive particles derived from the food. Indigestible fragments are rejected by the mouth, a sep arate anal opening being wanting. A striking proof of the essentially low position of the Hyel'w in the animal scale is to be found in its extraordinary capacity of resisting mutilation, or, in fact, mechanical injury of any kind short of absolute annihilation. The briefest illustration of this fact is all that can here be given, but with that the name of Trembley of Geneva must be associated. This well-known observer, in a long series of experiments, most of which have been successfully repeated by subsequent naturalists, diseoveres that the Hydra could be mechanically divided with a knife into any number of fragments, with the sole result that each and all of these possessed the power of developing themselves into fresh and independent polypites. Further, the animal could even be turned inside out, with a necessary transposition of the ectoderm and endixlerm, without any apparent inconvenience or interference with its health.

Reproduction in the Hydra is effected non-sexually by gemmation, and sexually ly the production of ova and sperm-cells; the former process being follower in summer and the latter in autumn, few individuals applparing to survive the winter. In the first or non-sexual method, the Hydra throws out one or more buds, usually from near the fixed or proximal extremity. These buts at first consist simply of a tubular prolongation of the ectoderm and endoderm, enclosing a cavity which communicates with the general cavity of the body. A new mouth and tentacles are soon developed at the distal end of this bud, and after a longer or shorter period the new Hydra, thus produced, is detacherl to leal an indepentent life. Each Hydra can produce many such buds during the summer season, and the liberated buds can also repeat the same process, so that in this way reproduction is rapidly carried on. In the second or sexual method of reproduction, ova and sperm-cells are produced towards the winter in external processes of the body-wall. The spermatozoa are developer in little conical elevations (fig. $30, b$ ), which are produced near the lases of the tentacles; anl the ova are formed in much larger elevations, of which there is orlinarily but one, placed nearer to the fixed or proximal extremity of the animal (fig. 30, c). When mature, the ovun is fertilised by the sperm-cells, both being set free into the water by the rupture of the body-wall. The embryo Hydre is at first covered with vibrating cilia, and swims freely ahout, until it meets with a suitalile locality. It then fixes itself by one extremity, the cilia lrop off, and a mouth and tentacles are developed at the distal end of the body. 


\section{ORDER II. CORYNIDA.}

In the second order of the Hydroid Zoophytes, known as the Corynida or Tubularida, we have a number of organisms which in their essential structure are closely related to the Hydra, but which differ considerably in the nature of the reproductive process. All of them are marine, with the siugle exception of the genus Cordylophoru, which inhabits fresh water. Some of the members of the order are simple, consisting of no more than a single polypite. In these cases there is an exceedingly close approach to the structure of the common Hydra, but the polypite is permanently fixed without the power of voluntarily changing its place, whilst the reproductive process is considerably different. In the majority of the Corynida, however, the hydrosoma is compound, consisting of a greater or less number of separate polypites or zoöids, all connected with one another by a common flesh or coenosartc, and all forming parts of a plant-like rooted colony. In some of the Corynida the polypites are naked, but in most cases the conosarc is protected by a horny-looking chitinous ${ }^{1}$ envelope or "polypary," as in Tubularia indivisa (fig. 31). In no case, however, is this horny covering so prolonged as to form little cups in which each polypite is contained. It always stops short at the bases of the polypites, and in this way the Corynida can always be distinguished from their near allies, the Sea-firs (Sertularida).

Good examples of the Corynida

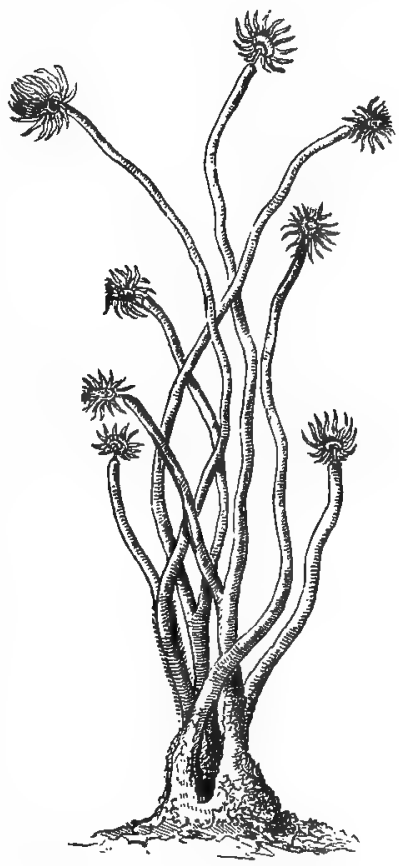

Fig. sI.-Fragment of Tubularia indivisa, natural size. are the common Pipe-corallines (Tubularia), in which the conosarc is enclosed in a horny tubular polypary (fig. 31), each tube containing a single polypite. Other

I Chitine is a substance which is nearly alliect to horn, but is distinguished from it by the fact that it is not soluble in caustic potash. 
common examples are the singular Hydractinice, which form brown prickly crusts upon the empty shells of univalve Molluscs, invariably selecting those shells which are inhabited by Hermit-crabs. Other common types belong to Eudendrium. The genus C'ordylophorc is found in fresh water; and in Coryomorplat we have a type in which the hydrosoma consists of no more than a single polypite.

As regards the generative process in the Corynida, it may be as well to consider the general phenomena of reproduction as carried on by all the Hydroid Zoophytes, the general characters of the process being of a most remarkable nature. As has been already explained, the "individual" in the case of the compound Hydrozoa consists of an aggregation or colony of partially independent beings or zoöids, produced by gemımation or fission from a primordial organisn. This is the case in all composite animals, such as Sponges, Sea-mats, Corals; and many others. In many of the compound Hydrozoa, however, the case becomes still further complicated. In many of these organisms, namely, the zoöids differ very much from one another both in structure and in function. One set of zoöids is entirely devoted to the duty of providing food for the colony, and in these no reproductive organs are ever developed. These nutritive zoöids are all like each other in form, and the whole assemblage of them has been appropriately termed the "trophosome" (Allman), from the Greek trepho, I nourish ; and soma, body. The colony or trophosome thus formed by the nutritive zooids can go on increasing by the production of fresh zoöids for an almost indefinite period; but in all cases there ultimately comes a time when it becomes necessary to produce the essential elements of reproduction in order to secure the perpetuation of the species. The nutritive zoöids, as just stated, cannot produce the ova and sperm-cells, being destitute of reproductive organs, and the colony is therefore compelled to produce a second set of buds, which have the power of producing the essential elements of reproduction. These buds are collectively called the "gonosome" (Gr. gonos, offspring; and soma, body). The generative buds have the further peculiarity that not only can they produce the generative elements, but they are altogether unlike the nutritive zoöids in appearance. This difference in external appearance and in structure is sometimes so great as to lead to a most remarkable series of phenomena. In the simplest form in which these generative buds or "gonophores" appear, they liave the form of mere protuberances of the ectoderm and endoderm (fig. 32), enclosing a cavity derived from the bodycavity. In these buds the generative elements-ova and spermatozoa-are developed. In other instances, the generative buds have a more complicated structure. They consist now (fig. $29 \mathrm{~m}^{\prime}$ ) of a 
bell-shaped disc, which is attached by its base to the parent organism, and has its cavity turned outwards. From the roof of this disc there is suspended a kind of handle, which corresponds to the clapper of the bell, and is termed the "manubrium" (Lat. for handle). From the fixed or proximal extremity of the central process or manubrium proceed four or eight canals, which extend to the margin of the bell. where they all open into a circular canal

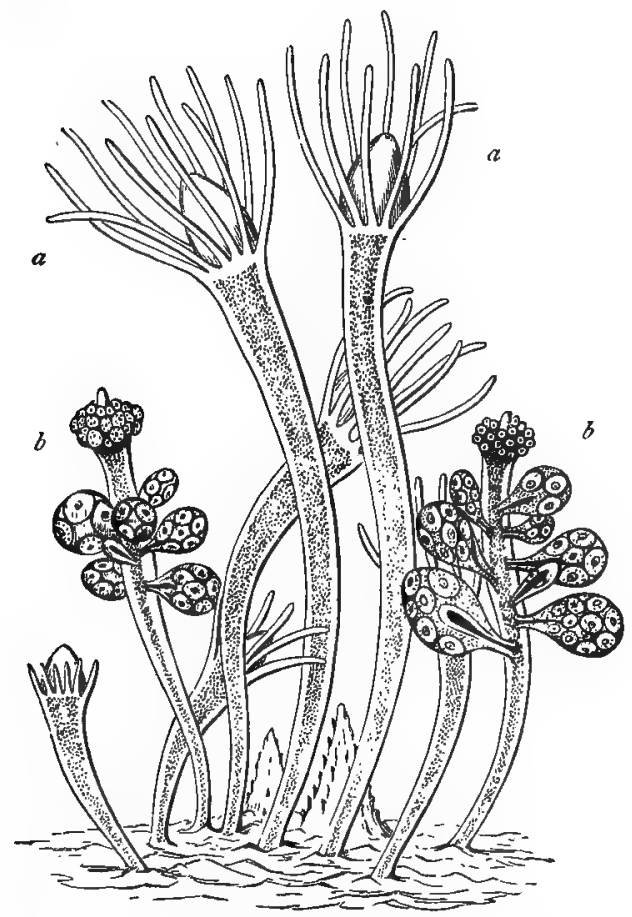

Fig. 32.-Group of zoöids of Hydractinia echinata. Enlarged (after Hincks). a a Nutritive zoöids ; $b \quad b$ Generative zoöids, carrying sacs filled with ova ("sporosacs ").

surrounding the mouth of the bell. This bell-shaped reproductive bud may attain no higher development than this, and may remain permanently attached to the parent organism from which it is produced. In other cases, however, a higher state of development is reached. The generative bud or gonophore (fig. 29, C) becomes detached from its parent colony ; the manubrium or central process develops a mouth at its free or distal extremity; the mouth of the 
bell becomes partially closed by an inward prolongation or shelf, called the "veil"; and a series of tentacles are developed from its margin. The generative burl, thus liberated, leads a wholly independent existence. The manubrium, having developed a mouth, assumes the fumctions of a true polypite, and its cavity acts as a digestive sac. The whole organism swims about freely, and has the power of assimilating food, and thus of attaining to a comparatively gigantic size. This independent existence, however, only goes on till such time as the elements of reproduction can be produced. The ovi and sperm-cells are developed in specialised portions of this generative bud, and then it ceases to exist. The ova, however, when fertilised, do not develop thenselves into the free-swimming bell-shaped organisms in which they were actually produced, but

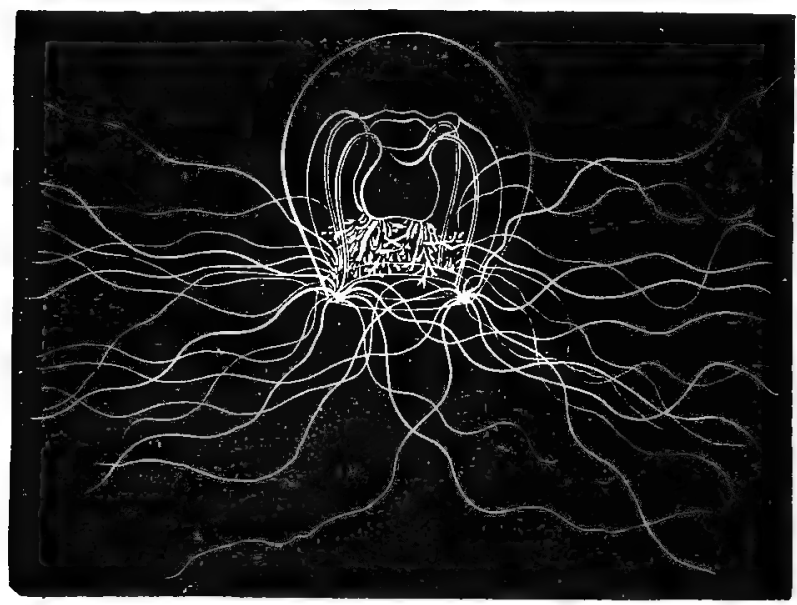

Fig. 33. Free-swimming medusiform gonophore of Bougainvillea superciliaris, a fixed Hydroid. Enlarged (after A. Agassiz).

into the plant-like, rooted, and compound zoophyte, from which the generative buds were originally given forth. These free-swimming bell-shaped reproductive buds or gonophores (fig. 33), as we shall see, are structurally identical with the smaller forms of the so called Sea-jellies or Mrilus; and it is now known that most of these Medusce, though originally described as distinct beings, are really nothing more than the free generative buds of the fixed IIyclinow. Hence, these free reproductive buds are usually spoken of as "medusiform gonophores." We have here, then, an instance of what has been, not quite appropriately, called "alternation of generations." 
We have a compound fixed animal, in many respects comparable to a plant, producing a special series of buds which are devoted to the process of reproduction. These buds are cast off as independent beings to lead an independent life, and they are furnished with the necessary organs to preserve their existence till they are able to mature the reproductive elements. When once able to consummate this, they die; but the young to which they give origin are wholly unlike themselves. The young, namely, instead of being freeswimming "medusiform" beings, become developed into the fixed plant-like colony from which the generative buds were originally produced. The term "alternation of generations" is not an aitogether good one, and does not quite express the facts of the case. There is not any alteruation of generations, but there is an alternation of generation with gemmation or budding. The only true generative act takes place in the reproductive zoöid or gonophore, in which the ova and sperm-cells are developed. The production of this gonophore from the parent organism (trophosome) is a process, not of generation, but of gemmation or budding. The whole process, therefore, is, properly speaking, not an "alternation of generations," but an alternation of generation with gemmation.

To recapitulate, then,- the process of reproduction in the Hydroid Zoophytes is carried on by means of reproductive buds or gonophores, which are produced at special seasons, and in which the reproductive elements are developed. These generative buds differ a good deal in their character, but three chief kinds may be distinguished: 1. Simple closed sacs or protuberances ("sporosacs") formed out of both ectoderm and endoderm, and having the special elements of generation developed in their interior. 2. Bell-shaped buds attached to the parent colony by their bases, and having a central process or manubrium, which is furnished with a mouth and central cavity, from which there is given off a system of canals to ramify in the substance of the disc. The reproductive elements are developed either in the walls of these canals or between the ectoderm and endoderm of the manubrium. From the resemblance of these buds in-anatomical structure to the so-called Sea-jellies or Medusee, they are usually spoken of as "medusiform gonophores," or simply as "medusoids." In this form, however, though highly organised, the buds never become detached from the parent colony. 3. Buds which become developed into bell-shaped medusiform bodies exactly similar in structure to the last, but detached to lead an independent existence. These free-swimming medusiform gonophores are anatomically indistinguishable from ordinary Medusa; and it is now known that most of the so-called "naked-eyed" Medusce, are really the detached generative buds of other orders of 
Hydrozoa. The special elements of reproduction are developed in these detached buds, but the resulting embryos are not developed into Medusce, such as produce the ova and sperm-cells, but straightway grow up into the plant-like sexless colony, from which the medusiform gonophores were originally budded fortb. In these cases, therefore, the individual Hydroid consists of a fixed, rooted colony (or trophosome), producing fresh zoöids by a process of budding, but incapable of producing the essential elements of reproduction, together with a free and independent series of generative buds (or gonosome), in which the elements of reproduction are developed.

\section{Order III. Sertularida.}

In this order of the Hydroida we have the most familiar and best known of all our zoophytes-namely, the Sea-firs and their allies. The horny plant-like polyparies of the Sertularida are
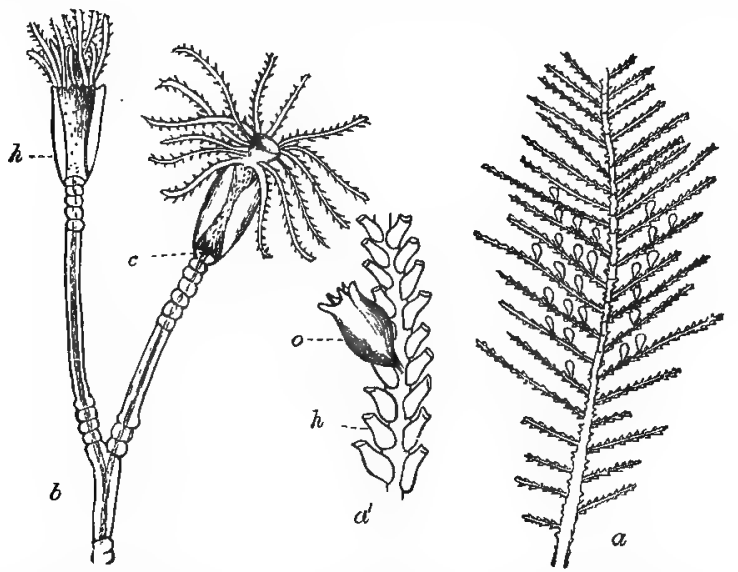

Fig. 34.-a Sertularia (Diphasia) pinnata, natural size; $a$ Fragment of the same enlarged, carrying a male capsule (o), and showing the hydrutheca $(h) ; b$ Fragment of Campanularia neglecta (after Hincks), showing the polypites contained in their hydrothecæ $(h)$, and also the point at which the conosarc communicates with the stomach of the polypite (c).

familiar to every visitor at the sea-side, and by those unacquainted with their true nature they are almost universally set down as seaweeds. The Sertularida are very closely allied to the compound forms of the Corynida, resembling them in being rooted, plant-like colonies, composed of a number of similar polypites or zoöids, produced by budding from a primitive zoöid. As in the Tubularians 
amongst the Corynida, the whole ccenosarc is enveloped in a horny or chitinous envelope or polypary (fig. $34, a$ ), and this is the structure which is most familiarly known to sea-side observers. The Sertularida, however, are distinguished from the Corynida by two points. Firstly, none of the Sertularida are simple, but all are compound, consisting of more or less numerous polypites, united by a branched cenosarc. Secondly, the polypary of the Sertularida differs from that of the Corynida in not simply reaching to the bases of the polypites, but in being prolonged to form a number of little cups or "hydrothece" (fig. $34, a, b$ ) within which the polypites are lodged. Each polypite has a hydrotheca of its own, within which it can entirely withdraw, and from which it can protrude its distal extremity.

The polypites of the Sertularida have essentially the same structure as in the Corynida, and each may be compared to a little Hydra. Each, namely, consists of a soft contractile and extensile body, which is furnished at its distal extremity with a mouth and a circlet of prehensile tentacles, richly furnished with thread-celis. The mouth opens into a chamber which occupies the whole length of the polypite, and which is to be regarded as the combined body-cavity and digestive sac. At its lower end this chamber opens by a constricted aperture into a tubular cavity, which is everywhere excavated in the substance of tho conosarc (fig. $34, b$ ). The nutrient particles obtained by each polypite thus serve for the support of the entire colony, and are distributed throughout the entire organism. The nutritive fluid prepared in the in. terior of each polypite gains access through the above-mentioned aperture to the cavity of tle conosare, which, by the combined exertions of the whole assemblage of polypites, thus become filled with a granular nutritive liquid. This conosarcal fluid is in constant movement, circulating through all parts of the colony, and thus maintaining its vitality-the cause of the movement being probably due, in part, at any rate, to the existence of vibrating cilia.

The process of reproduction varies somewhat in different niembers of the order. In all alike, however, the ordinary polypites are incapable of producing the essential elements of reproduction, and for this purpose special generative buds have to be developed. In the typical Sertularians the reproductive buds are developed at certain seasons in great numbers, and they con-

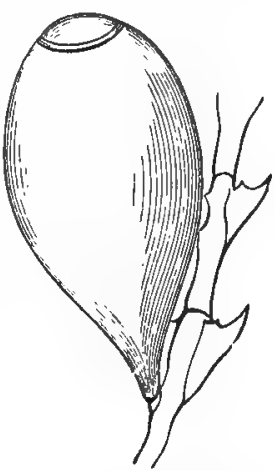

Fig. 35.-Ovarian capsule of Diphasia (Sertularia) operculata, Linn. (after Hincks). Greatly enlarged.

, stitute rhat used to be called the "ovarian vesicles" or "capsules" (fig. 35). These reproductive buds are enclosed in horny cups or receptacles, often of a very beautiful shape, and much larger in size 
than the ordinary bydrotheca. As a general rule, each capsule in the Sertularida contains a number of the reproductive buds, which are all borne upon a central axis which runs up the middle of the capsule, and is derived from the conosarc.

In one division of this group-often described as a separate order, under the name of Campanularida-some points of difference are observable. In the typical Sertularians the little cups or hydrothecæe for the polypites are placed on the sides of the branches, and they are not stalked (fig. $34, a^{\prime}$ ), whilst the reproductive elements are produced in fixed buds. In the c'umpremelaridu, on the other hand (fig. $34, b$ ), the hydrothecre are supported upon stalks, and are placed at the ends of the branches, whilst the generative buds are usually detached to lead an independent existence. In these forms the reproductive zoöids or gonophores start as simple buds; but they become gradually developed into free-swimming merlusoids, such as have been before alluded to. Each medusoid consists of a little

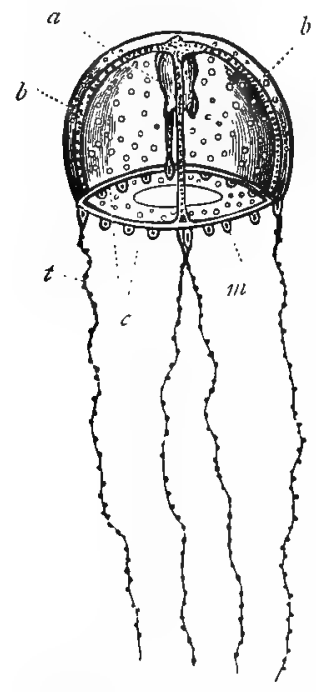

Fig. 36.-Gonophore of one of the Campenularide. trausparent glassy bell, from the under surface of which there is suspended in modified polypite, in the form of a manubrium (fig. $36, a$ ). The whole organism swims gaily through the water, propelled by the contractions of the bell or disc; and no one would suspect now that it wiss in any way related to the fixed plant-like zoophyte from which it was originally budded off. The central polypite is furnished with in mouth at its distal end, and the mouth opens into a digestive sac. From the proximal end of this stomach proceed four radiating canals which extend to the nuargins of the bell, where they all open into a circular vessel which runs round the mouth of the bell. From the circumference of the bell hang also a number of delicate extensile filaments or tentacles; and the margin is further adorned with a series of brightly coloured spots, which are probably rudimentary organs of vision and hearing. The mouth of the bell is partially closed by a delicate transparent membrane or shelf, the su-called "veil." Thus constituted, these beautiful little beings leal an independent and locomotive existence for a longer or shorter period. Ultimately, ova and sperm-cells are produced in 
special organs, which are developed in the course of the radiating canals of the disc. The resulting embryos are minute free-swimming bodies, covered with cilia, which finally fix themselves, and develop into the plant-like colonies from which the medusoids were derived.

\section{Order IV. Meduside.}

Among the most familiar and beautiful of all marine organisms are the delicate, transparent, bell-shaped creatures generally known as Jelly-fishes. All the organisms, which are generally spoken of as Jelly-fishes, belong to the $H y d r o z o a$, but they differ greatly as to their precise nature. The great gelatinous dises which are so frequently cast up on the sea-shore, and which are more especially spoken of in common language as "Jelly-fishes," are mostly the reproductive zoöids of a particular group of Hydrozoa (the Lucernarida), and will be subsequently noticed. Less familiar than these, but equally abundant, are certain, usually much smaller, Jelly-fishes which are found floating in the sea near the surface, often in vast numbers, at particular seasons of the year. Many of
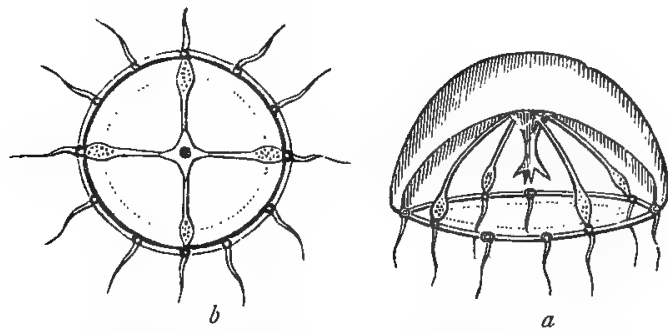

Fig. 37. - a A medusiform gonophore (Thaunantias) seen in profile, showing the central polypite, the racliating and circular canals of the disc, the reproductive organs borne in the course of the former, the marginal bodies and tentacles; $b$ The same, viewed from below. The dotted line indicates the margin of the "veil."

these comparatively minute Jelly-fishes are in reality, as previously noted, neither more nor less than the free-swimming reproductive buds of the Hydroid Zoophytes, or of other groups of Hydrozoa. That this is their true nature is shown by the fact that the eggs which they produce develop themselves not into fresh Medusoe, but into various other forms of Hydrozoa, which may be either fixed or oceanic. On the other hand, there are certain Jelly-fishes (Trochynemidce, Fgininla, \&c.) the eggs of which really give origin to fresh Jelly-fishes. These, therefore, must be considered as a special group of the Hydro:oa, to which the name of Medusidoe may be applied. 
As regards the structure of such Medusce, there is nothing to enable the observer to know for certain whether a given Jelly-fish is merely the free generative bud of some fixed Hydroid, or whether it is an independent organism. In either case, the anatomical structure is essentially the same, and may be briefly stated as follows: The hydrosoma is free and oceanic, the organism living near the surface of the sea. The body is composed of a thick, transparent, gelatinous disc or swimming-bell (the nectocalyx) by the pulsations of which the animal is driven through the water. From the under surface or roof of this bell-shaped disc is suspended

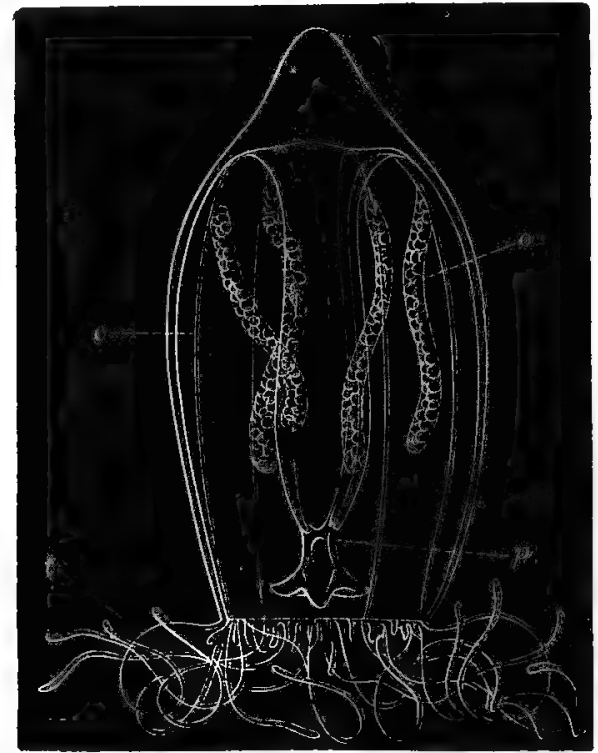

Fig. 3S. - Truchymema digitale, a naked-eyed Medusa, female, enlarged. (After A. Agassiz.) $p$ Manubrium or central polypite; $t$ One of the teutacles; $c$ One of the gastro-vascular canals; $o$ One of the ovaries.

a single polypite (the manubrium), which bears to the disc the same relative position as the clapper does to an ordinary hand-bell. The distal end of the central polypite (fig. 38) is furnished with a mouth, the lips of which are often prolonged into four longer or shorter lobes or processes. The mouth opens into a digestive sac, occupying the axis of the polypite ; and from the upper end of this proceed four radiating canals, which run in the substance of the disc to its margin, where they are united by a single circular vessel, 
the whole system constituting the so-called "gastro-vascular" or "nectocalycine" canals. The margin of the bell is narrowed by a kind of shelf, which runs round the whole circumference, leaving a central aperture, and which is known as the "veil." From the margin of the disc hang more or less numerous tentacles, which in these forms are mostly solid, instead of being hollow. Also round the circumference of the swimming-bell are disposed certain "marginal bodies," which are doubtless organs of sense. Some of these marginal bodies consist of little rounded sacs or "vesicles," filled with a transparent fluid, and containing mineral particles, apparently of carbonate of lime. These are probably rudimentary organs of hearing. Others of the marginal bodies are in the form of little masses of colouring-matter or pigment, often of a strikingly bright colour, enclosed in distinct cavities. These are known as the "pigment-spots" or "eye-specks," and they are of the nature of rudimentary organs of vision. They are placed in a conspicuous and unprotected position on the margin of the disc, and hence these organisms were termed "naked-eyed" Medusce by Edward Forbes. Round the margin of the swimming-disc there is also placed a distinct nerve-ring. The reproductive organs (fig. 38) are usually developed in the course of the radiating gastro-vascular canals, but are sometimes situated in the walls of the central polypite.

The naked-eyed Medusce, including under this name both the true Medusce and the free medusoid buds of other Hydrozoc, are all exceedingly elegant and attractive, when examined in a living condition, resembling little bells of the most transparent glass, adorned here and there with the most brilliant colours. They occur, in their proper localities and at proper seasons, in enormous numbers. They are mostly phosphorescent, or capable of giving out light at night, and they appear to be one of the principal sources of the luminosity of the sea. It does not seem, however, that they phosphoresce unles.s disturbed or irritated in some way.

Most Medusce and medusoid gonophores are of comparatively small size, but some types of the latter may grow to a diameter of eight or ten inches or more (e.g., Equorea). A single Medusoid (Limnocodium) has been found inhabiting fresh water; but this is known to be the generative bud of a fixed Hydroid. 


\section{CHAPTER VII.}

\section{SUB-CLASS SIPHONOPHORA.}

THE animals included under the name of Siphonophora are often known as the "Oceanic Hydrozoa," as they are not fixed like the Hydroid Zoophytes, but are found swimming at the surface of the open ocean, far from land. They are all singularly delicate and beautiful organisms, but they require little notice here. They are distinguished from the Hydroid Zoophytes, which we have been just considering, by the fact that the hydrosoma consists of numerous polypites, united by a common trunk or cœnosarc, which is very rarely branched, and is never furnished with any hard outer covering or polypary, so that it remains permanently soft and flexible throughout life. The proximal end of the conosarc, as already remarked, is not fixed, or capable of being fixed, to any solid olject, but is variously modified to suit the requirements of the floating colony. As in the Hydroida, the reproductive organs are in the form of special buds, which have the power of developing the essential elements of generation, and which are often detached as freeswimming medusoids.

The entire sub-class is divided into two great groups or orders, and it will be sufficient to consider shortly a typical form of each. In the first order-that of the Calycophoride - the conosarc is threadlike, cylindrical, unbranched, and highly contractile. The cavity of the ccenosinc dilates proxinally into a peculiar ciliated chamber, which is the distinguishing character of the order. The name of Calycophoride (Gr. kulux, a cup ; and phero, I bear), is, however, derived from another circumstance-namely, that the proximal end of the conosare is always furnished with a series of bell-shaped dises, which are known as "swimming-bells" or "nectocalyces." Each nectocaly $x$ consists of a bell-shaped cup (fig. $39, n$ ), attached by its base to the conosare, and having its cavity turned outwards. In the sulistance of the disc run at least four canals, which communicate with the cavity of the conosarc, and proceed to the margin of the bell, where they all open into a circular vessel. The mouth of 
the bell is also furnished with a delicate ledge, which runs round its circumference, and is known as the "veil." The structure, therefore, of the nectocalyces, is very similar to that of an ordinary medusiform gonophore, the chief difference being the absence in the former of the central polypite or manubrium. The nectocalyces are highly muscular, and have the power of alternately contracting and dilating, thus driving the whole organism through the water. In Praya (fig. 39), which may be taken as a good example of the group, the

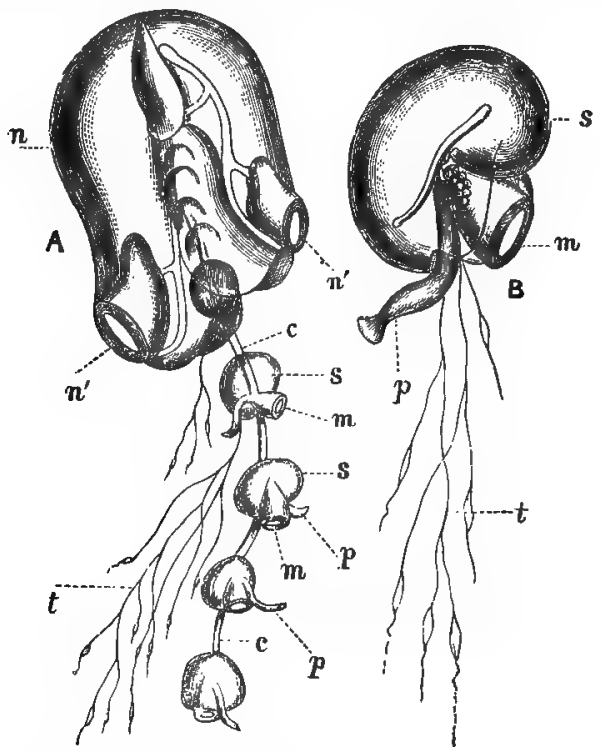

Fig. 39.-Calycoplorida. A, 'Upper portion of the colony of Fraya maxima, of the natural size: $n$ The proximal nectocalyces; $n^{\prime} n^{\prime}$ Moutls of the same; $c c$ Cnenosarc, carrying polypites $(p p)$ at intervals, along with their swimmirg-bells $(s s)$ the openings of these being indicated by the letters $m m ; t$ Tentacles. $\mathbf{B}, \mathbf{A}$ single polypite of the same $(p)$, separated from the conosare, and enlarged, with its swimning-bell (s), the opening of the bell $(m)$, and the tentacles $(t)$. (After Gegenbaur.)

nectocalyces $(n)$ are succeeded by a series of polypites. Each polypite $(p)$ is furnished with a mouth, opening into a digestive sac, which in turn communicates with the cavity of the conosarc. In this form each polypite has a little swimming-bell of its own; but in many forms, each is protected by an over-arching plate, termed a "bract." Each polypite has in general a single tentacle, rising from near its base, usually of great length, and provided with lateral branches armed with numerous thread-cells. The reprcductive organs 
of the Calycophorides are in the form of medusiform gonophores, which are budded from the stalks of the polypites, and which are mostly detached to lead an independent existence.

The second order of the Oceanic Hydrozoa is that of the Physophorida (Gr. physa, a bladder; and phero, I carry), of which the most familiar, though not the nost typical, example is the Portuguese Man-of-war, Physalia (fig. 40, a). The Physophorida are distinguished from the organisms which we have been just considering by the fact that the proximal extremity of the conosare is devel-

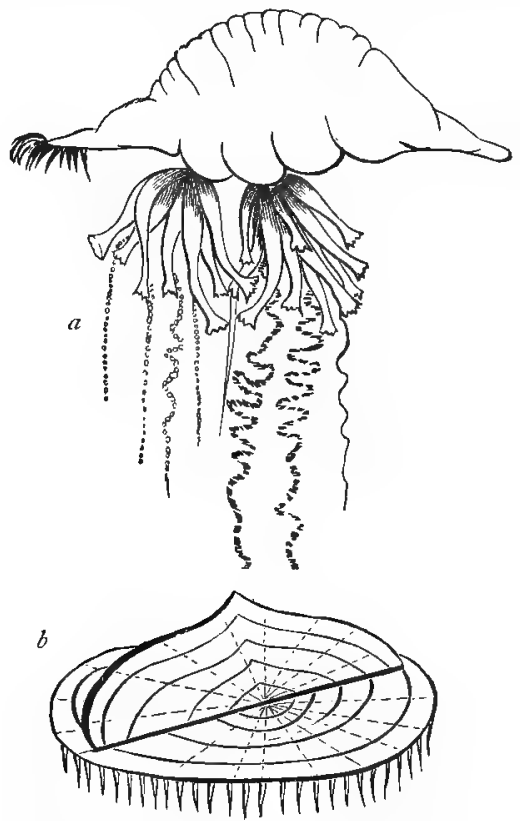

Fi: 40.-a Portuguese Man-of-war (Physalia). b Velella vulgaris.

oped into a structure which is known as the "float" or "pneumatophore." The float contains a larger or smaller sac, composed of some elastic horny substince, probably chitine, often communicating with the exteriur by one or more apertures, and always more or less completely filled with air. The function of the float is no doubt that of enabling the organism to maintain its prition at the surface of the sea. As in the Calycophoridee, the cuenosare is always perfectly flexible, contractile, and soft, and is never furnished with any 
chitinous covering or polypary. There may or may not be swimming-bells or nectocalyces, and the tentacles are very complicated in structure, and often attain a great length. The polypites present no special points of interest, but are often furnished with the protective plates which have been already spoken of as "bracts."

As a good example of the Physophorido, the Portuguese Man-ofwar may be taken (fig. $40, a$ ). It is composed of a large spindleshaped float, often of several inches in length, upon the under surface of which are arranged a number of polypites, together with highly contractile tentacles of great length, and reproductive organs. The tentacles are richly furnished with thread-cells; and it has the power of stinging very severely. Physalia is commonly found floating at the surface of tropical and sub-tropical seas.

Another very beautiful member of the Physophoridce is the Telella vulgaris, which occurs abundantly in many seas. It is about two inches in length by one and a half in height. The proximal end of the conosare is greatly expanded and flattened out into an oval dise, which carries a vertical triangular crest, running obliquely across its upper surface (fig. $40, b$ ). The whole organism is semi-transparent and of a beautiful bluish colour, and it floats at the surface of the sea with the vertical crest exposed to the influence of the wind, and thus officiating as a sail. From the under surface of the disc are suspended the various appendages of the organism, consisting of a single large central polypite; a number of processes, like polypites in shape, and carrying medusiform gonophores; and lastly, a single series of tentacles which arise from the cœnosarc quite independently of the polypites. 


\section{CHAPTER VIII.}

\section{SUB-CLASSES LUCERNARIDA, GRAPTOLITIDI, AND HYDROCORALIIN $A$.}

\section{Sub-class LUCERnarida.}

THE next group of the living IIydrozod is that of the Lucernarida,

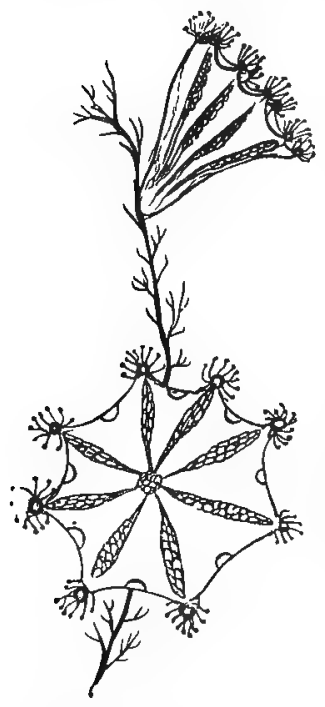

Fig. 41. - Two specimens of Lucernoria autrimala attiched to a pisce of sea-weed (after Johnston). under which name are included a considerable number of forms, differing from one another to a great extent in external appearance. It will be sufficient here to describe one or two typical forms.

One group of the Lucernarida is represented by Lucenaria itself (fig. 41), in which there is a cup-shaped body of a more or less gelatinous consistence, usually attached by its smaller extremity to sea-weeds, this end of the body being developed into a small sucker. Like the Iyylra, however, Luremaria is not fixed, but can detach itself at will, and can even swim freely by means of the alternate contraction and expansion of the cupshaped body (or "umbrella," as it is termed). Round the margin of the cup are tufts of short tentacular processes, and in its centre is fixed a single polypite, furnished with a four-lobed mouth. The essential elements of reproduction are developed within the body of Lucernaria itself, and it does not give off any generative buds, as so commonly occurs in other forms.

Another type of the Lacernarida is represented by the organisms formerly termed "hidden-eyed" Medusce, and familiarly known as 
Sea-nettles or Sea-blubbers. Every sea-side visitor is familiar with the great circular dises of jelly which are left upon the sands by the retreating tide during the summer months; and many must have noticed on a calm day the large transparent discs of these same creatures slowly flapping their way through the water. Not a few, too, must have learnt by painful experience that some of these singular organisms have the power of stinging most severely, if incautiously handled. The forms included under the old name of "covered-eyed" Medusce differ considerably from one another in their nature, and even in their structure, though they all present, in spite of their usually greater size, a decided resemblance to the naked-
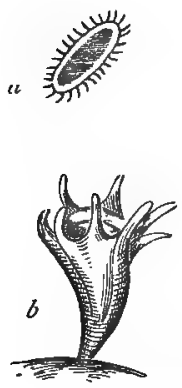
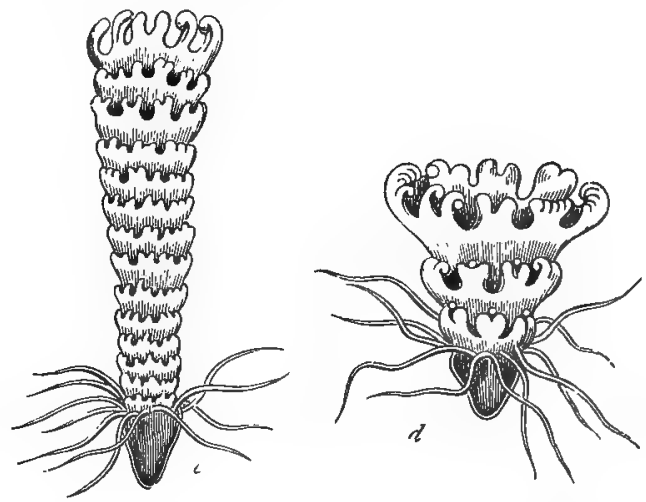

Fig. 42.-Development of Aurelia, one of the Lucernarida. a Ciliated free-swimming embryo, or "planula"; $b$ Hydra-tuba ; $c$ Hydra-tuba in which fission has considerahly advanced; $d$ Hydra - tuba in which the tission has proceeded still further, and a large number of the segments have been already detached to lead an independent existence.

eyed Medusce already described. Some of the covered-eyed Medusce produce eggs which are developed into organisms resembling themselves; but most of them are now known to be nothing more than the free-swimming reproductive buds of minute rooted IIydrozoa. It will be sufficient here to describe shortly the life-history of one of the more remarkable forms of this section.

If we commence with the young form of one of these singular animals, we find that the egg gives origin to a little microscopic ciliated body, which swims about freely by means of the cilia with which its surface is covered (fig. $42, a$ ). This little body, on finding a suitable locality, fixes itself by one end, and develops a mouth and tentacles at the otber, when it is known as a "Hydra-tuba" (fig. 42, 
b), from its resemblince in shape to the Fresh-water Polype or Hydra. The Hydra-tuba is only about half an inch in height, and it possesses the power of forming large colonies by gemmation, whilst it is incapable of developing the essential elements of reproduction. Under certain circumstances, however, reproductive zoöids are produced by the following singular process: The Hydra-tuba becomes elongated and exhibits a number of transverse grooves. These grooves go on getting deeper and deeper, and become lobed at their margins, till the whole organism assumes the aspect of a pile of saucers placed one above the other (fig. $42, c$ ). The tentacles now disappear, and a fresh circle is formed close to the base of the Hydra-tuba. Finally, all the saucer-like segments above the new circle of tentacles (fig. $42, d$ ) drop off, one by one, and present themselves in the form of independent free-swimming lfedusa. These reproductive zoöids or Medusce eat voraciously, and increase rapidly in size, becoming not only comparatively, but often actually, gigantic. Thus, in one case the reproductive zoöid has been known to attain a size of seven feet across, with tentacles one hundred feet or more in length, though the fixed organism from which it was produced was no more than half an inch in height. These gigantic reproductive bodies live an independent life until they are able to produce ova and sperm-cells, when they die. The fertilised egg, however, develops itself, not into the monstrous organism by which it was produced, but into the little fixed sexless Hydra-tuba, from which the generative bud was detached. We have, then, here another instance of the so-called "alternation of generations."

It is now known, then, that most of the great Sea-blubbers which abound around most coasts in summer are reaiy the detached reproductive buds of minute fixed Hydrozoa ; and it may be as well to mention the leading features in their structure, and the points by which they may be distinguished from the smaller or naked-eyed Medusce, to which they have a decided superficial likeness. In the commonest forms of these zoüids (such as the common Sea-blubbers Aurelia and (yanea), the body consists of a great bell-shaped gelatinous disc or "umbrella," (fig. 43), from the roof of which is suspended a single polypite, the lips of which are extended into lobed processes, often extending far below the margin of the disc. The digestive cavity of the polypite gives out from its upper extremity a series of radiating gastro-vascular canals, which proceed towards the margin of the umbrella. These radiating canals are never less than eight in number, and on their way to the margin of the disc they break up into a great number of smaller vessels, which unite with one another to form a complicated network. At the margin of the bell they all open into a circular vessel, which in turn sends processes into a 
series of marginal tentacles, which are often of extraordinary length. Besides the tentacles, the margin of the umbrella is provided with a number of marginal bodies, each of which consists of a little collection of pigment, or "eye-speck," and a little sac filled with fluid and containing mineral particles. Each of these marginal bodies is covered and concealed from view by a kind of hood derived from the ectoderm. Hence the name of "hidden-eyed" Hedusa, applied

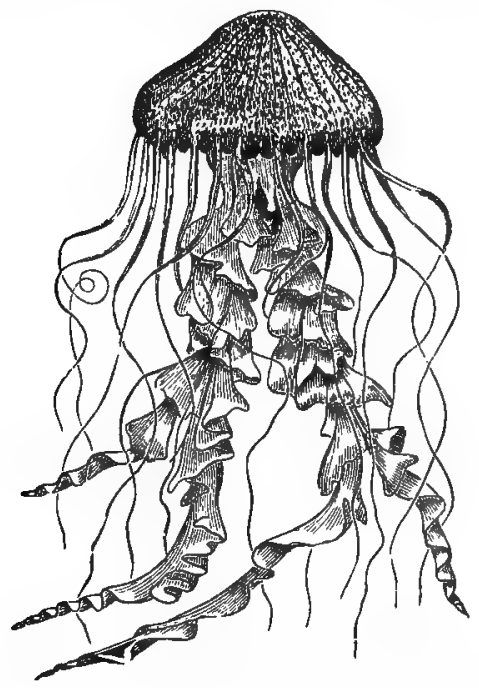

Fig. 43.-Generative zoöid of one of the Lucernarida (Chryscora hycscella). (After Gosse.)

to these forms, in contradistinction to the " naked-eyed" Medusce, in which the eye-specks are exposed to view. There is also a welldeveloped nerve-ring running round the mouth of the umbrella. The reproductive organs are usually of solue bright colour, and "form a conspicuous cross shining through the thickness of the disc."

From the above description it will be evident that there is a considerable resemblance letween the so-called "hidden-eyed" Medusce, or the reproductive zoöids of many of the Lucernarida, and the medusiform gonophores of so many of the Hydrozoa, as well as the true Medusidae or naked-eyed Medusce. The differences, however, between them are these: The swimming-disc of the naked-eyed $M$ edusae and of any medusiform gonophore is furnished at its moutl with an internal shelf or veil ; the radiating gastro-vascular canals are very. rarely more than four in number, and should they subdivide (as in rare cases 
they do), they do not form an intricate network; lastly, the marginal bodies are simply placed in an uncovered situation on the margin of the dise. In the reproductive zoöids of the Lucernarida or hidden-eyed Medusce, on the other hand, the swimming-disc or umbrella is destitute of any marginal shelf or veil; the radiating gastro-vascular canals are never less than eight in number, and they split up into numerous branches, which unite to form an intricate network; lastly, the marginal bodies are concealed from view by a kind of hood.

There still remains another family of the Lucemarida (viz., Rhizostomidce) in which the reproductive process is carried on in the same way as in the forms we have just described, but the structure of the reproductive zoöids is somewhat different. In these, as in Rhizostoma (fig. 44), the generative zoöid is much like those just men-

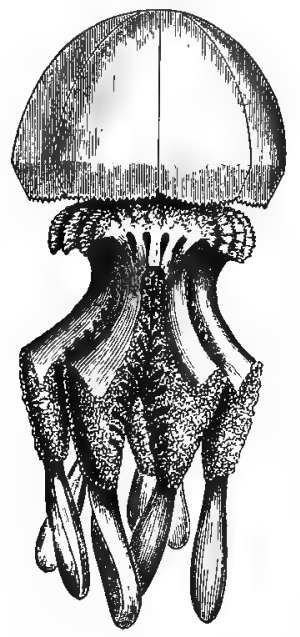

Fig. 44.-Generative zorid of Rhizostoma pulmo, resluced in size. (After Gosse.) tioned; but the umbrella is destitute of marginal tentacles; and in place of a single central polypite, there hangs from the under surface of the umbrella a complex tree-like mass, the branches of which end in, and are covered by, small polypites and club-shaped tentacles. The umbrella itself does not exhibit any difference as compared with those already described, but the ova are produced in a genital cavity which is placed on the under surface of the umbrella.

\section{Sub-Class Graptolitide.}

We may here notice very briefly a group of extinct organisms which almost certainly belong to this class, and which probably find their nearest allies in the Sertularians. The Graptolitidoe are without a single living representative, and their antiquity is, indeed, very high, since it is doubtful if they ever pass above the group of rocks known to geologists as the Silurian formation. The most typical forms of the group (fig. 45) agree with the living Sertularians in having a horny polypary, and in having the polypites protected by little horny cups or hydrothecæ, all springing from a common stem or cunosarc. The typical Graptolites, however, differ from all known Sertularians in the fact that the hydrosoma was not fixed to any solid object, but was permanently free. Most of them, also, exhibit a very anomalous and remarkable structure, termed the "solid axis" (fig. 45, B). This is a peculiar, fibrous, apparently 
hollow rod, which no doubt served to strengthen the polypary, and which is often prolonged beyond one or both ends of the polypary in a naked state. There is also good evidence that the reproductive process in the Gruptulites was carried on in manner somewhat similar to what is seen in the living Sertularians-namely, by means of reproductive buds enclosed in horny capsules. Graptolites most usually present themselves as beautiful silvery impressions, covering the surface of the black shales of various parts of the Silurian system.

\section{Sub-class Hydrocoralline.}

This name has recently been proposed by Professor Moseley for two groups of marine animals which produce a regular skeleton of carbonate of lime, and which have, therefore, been generally placed among the true Corals. Professor Moseley, however, has shown that the forms in question are really referable to the Hydrozod, though they are peculiar, as regards the members of this class, in their power of secreting a regular calcareous skeleton. The best known and most familiar of the animals placed in this group are the Millepores (Millepora), the stony skeletons of which contribute so largely to the formation of coral-reefs in the West Indies and Pacific. The skeleton of Millepora is an expanded, more or less branched, calcareous mass, studded with minute apertures of two sizes, the mouths of differently-sized tubes. These tubes are divided into chambers by a number of complete transverse partitions (the so-called "tabulæ"), and only the surface-layer of the mass is to be regarded as actually alive. The general calcareous tissue of the skeleton is open and spongy, and allows of a free communication between the different tubes. The larger tubes of the skeleton are occupied in the living condition by zoöids ("gastrozoöids"), which possess a mouth and tentacles, whilst the smaller
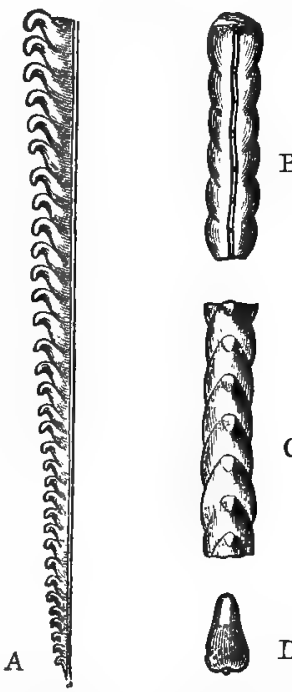

B

Fig. $45-\mathrm{A}$, Graptolites (Monograptus) priodon, Bromn, preserved in relief: lateral view slightly enlarged. $B$, Dorsal view of a fragment of the same species: considerably enlarged. C, Front view of a fragment of the same, showing the mouths of the hydrothecæ: much elllarged. $\mathbf{D}$, Transverse section of the same. All from the Silurian. (Original.) tubes are tenanted by smaller zoöids ("dactylozoöids "), which possess 
the latter organs, but are destitute of a mouth. The body-cavities of all the zoöids are placed in communication by means of canals which ramify in the spongy skeleton.

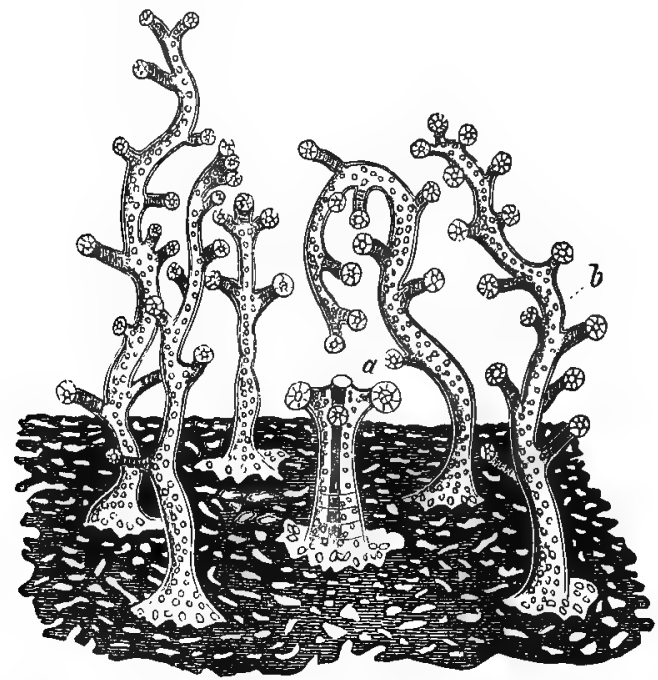

Fig. 46. - Enlarged view of a portinn of the surface of a living colony of Millepora nodosa, showing the expanded zooids of a single system. a, Central "gastrozooid"; $b$, One of the mouthless "dactylozoöids." (After Moseley.)

Other living Hydrocorallines are the coral-like Stylaster, Allopora, \&c. Closely allied to the recent types above mentioned is a great series of fossil and wholly extinct organisms, of which Stromatopora nay be regarded as the central form. 


\section{CH A P TER IX.}

\section{ACTINOZOA.}

THE second great class of the Celenterata is that of the Actinozoa, comprising the Sea-anemones and their allies, the Corals, the Seapens, the Sea-shrubs, and various other organisms. They are all defined as Colenterate animals in which there is a distinct digestive sac which opens below into the general cavity of the body, but is nevertheless separated from the body-walls by an intervening space (the "perivisceral space"), which is divided into a number of vertical compartments by a series of partitions or "mesenteries," to the faces of which the reproductive organs are attached. The Actinozoa (fig. 47), therefore, differ fundamentally from the Hydrozoa in this, that whereas in the latter the digestive cavity is identical with the body-cavity, in the former there is a distinct digestive sac, which opens, truly, into the body-cavity, but is nevertheless separated from it by an intervening perivisceral space. The result of this is, that whilst the body of a Hydrozoön exhibits on transverse section a single tube only, formed by the walls of the combined digestive and somatic cavity, the body of an Actinozoün exhibits two concentric tubes, one formed by the digestive sac and the other by the general walls of the body. Further, in the Actinozoa the reproductive organs are always internal, and are never in the form of external processes of the body-wall as in the Hydrozoa.

In their minute structure the tissues in the Actinozoa differ little from those of the Hydrozoa. The body is essentially composed of two fundamental layers-an ectoderm and endoderm; but there are often well-developed layers of muscular fibres, somewhat obscuring this simplicity of structure. Thread-cells are most commonly present in abundance. Cilia are very generally developed, especially in the endoderm lining the body-cavity, where they serve to maintain a circulation of the contained fluids. The only digestive apparatus consists of a tubular or sac-like stomach, which opens inferiorly directly into the body-cavity (fig. 47), and communicates with the outer world through the mouth. Definite nerve-centres do not 
appear to be present, as a rule; but the mesoderm is usually provided with scattered nerve-cells. No definite organs of the circulation are developed. Distinct reproductive organs are always present, and true sexual reproduction occurs in all the members of the class. In a great many forms, however, of the Actinozod, we have composite organisms or colonies, produced by a process of "continuous" gemmation or fission, the zoöids thus originated remaining attached to one another. In these cases-as in most of the Corals-the separate beings or zooids thus produced are termed "polypes," the term "polypite" being restricted to the Hydrozoa. In the simple Actinozoa, however, such as the Sea-anemones, the term "polype" is

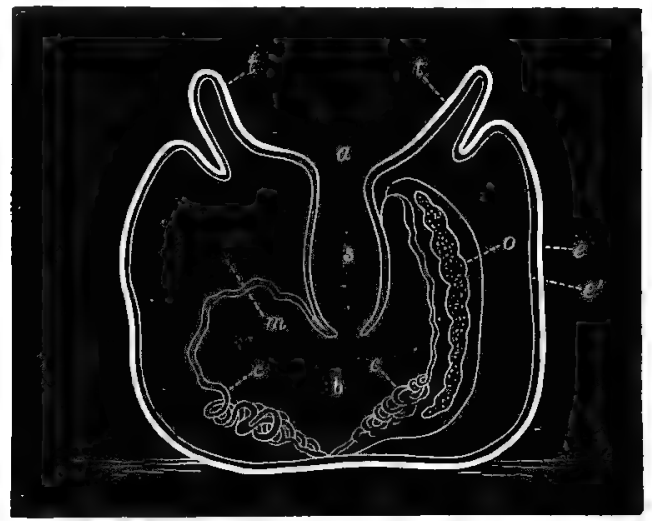

Fig. 47. - Diagrammatic vertical section of a Sea-Anemone. $\alpha$ Mouth; $s$ Stomach ; $b$ Body-cavity; $c$ c Cnnvoluted cords ("craspeda") containing thread-cells, and forming the free edges of the mesentery $(m): t \ell$ Tentacles; o Reproductive organ contained within the mesentery. The ectoderm $(e)$ is indicated by the broad external line, the endoderm $\left(e^{\prime}\right)$ by the thin line and the space lietween that and the ectorlerm.

applied to the entire organism, as consisting of no more than a single alinentary region. It follows from this, that the entire body, or "actinosoma," of any Ictinozoün, may be composed either of a single polype, or of several such, procluced by budding or cleavage, and united to one another by a common connecting structure or cenosarc. Most of the Actinuzuc are permanently fiierl, like most Corals; some, like the Aiea-anemones, possess a limited amount of locomotive power; and one order, the (fenophora, is composed of highly active free-swimning organisms. Some of them are unprovided with hard structures or supports of any kind, as the Sea-anemones and Ctenophora; but a great many secrete a calcareous or horny skeleton or framework which is known as the "coral" or "corallum." 
The Actinozoa are divided into four orders-viz, the Zurutharia, the Alcyonaria, the Rugosa, and the Ctenophora.

\section{ORDER I. ZOANTHARIA.}

The Zoantharia comprise those Actinosoa in which the polypes are furnished with smooth, simple, usually numerous tentacles, which, like the mesenteries, are in multiples of six. The Zoantharia are divided into three groups, distinguished from one another by the presence or absence of a coral, and by its structure when present.

The first of these groups is termed Zoantharia malacodermata, or "soft-skinned" Zoantharia, because the polypes are either wholly destitute of a coral, or if there is one, it consists merely of little

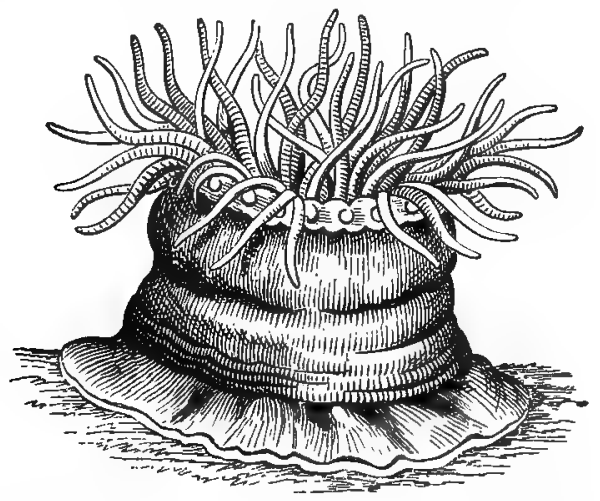

Fig. 48.-Actinia mesembryanthemum, nne of the Sea-Anemones. (After Juhnston.)

scattered spicules of carbonate of lime or grains of sand. Generally, too, the organism is simple, and consists of no more than a single polype. The best known of the members of this group are the beautiful Sea-anemones or "animal-flowers" (Actinida), which occur so plentifully on every coast (fig. 48 ). It will be as well to describe the structure of a sea-anemone somewhat in detail, as in this way a clear notion may be obtained of the general anatomy of the Actinozoa. The body of an ordinary sea-anemone (fig. 48) is a truncated cone or short cylinder, termed the "column," and is of a soft leathery consistence. The two ends of the column are termed respectively the "base" and the "disc," the former constituting a kind of sucker, by means of which the animal can attach itself at 
will, whilst the mouth is placed in the centre of the latter. The mouth is surrounded by a flat space, destitute of appendages, and the circumference of the disc is in turn surrounded by numerous simple tubular tentacles, arranged in alternating rows. The tentacles consist of both ectoderm and endoderm, enclosing a tube which communicates with the body-cavity. By the muscular contraction of the walls of the column, the fluid contained in the body-chamber can be forced into the tentacles, which can be thus protruded to a great length, whilst they can also be usually retracted. In some cases the tentacles are furnished with perforations at their extremities. The mouth (fig. 4i ) leads directly into the stomach, which is a wide membranous tube, opening by a wide aperture into the body-cavity below, and extending about half-way between the month and the base. The wide space between the stomach and body-walls is subdivided into a nunber of separate compartments by radiating vertical plates, which are called the "mesenteries," and to the faces of which the reproductive organs are attached, in the form of reddish bands, containing either ova or sperm-cells. Below the stomach, the free edges of the mesenteries are thickened, and constitute twisted threads or cords, which are filled with thread-cells, and are termed "craspeda." The Seaanemones are mostly to be found between tide-marks, in rockpools, or on ledges of stone, adhering by means of the expanded base. They are not, however, permanently fixed, but can change their place at will. In the nearly allied Ilyanthus and Arachiactis and in some related forms the base is tapering, and it appears that the animal either lives freely in the sea, or buries itself to the lips in the sand. The true Sea-anemones, as already said, are all simple, each consisting of a single polype; but there are closely related forms (such as Zounthus) in which the organism is compound, consisting of numerous polypites united by a creeping fleshy trunk or conosarc.

The second group of the Zoantharia is termed that of the Zoan1.1.ria sclerodermata, from the nature of the skeleton or coral. In "his group are all the so-called "reef-building" Corals, which are the (?rincipal makers of the well-known "coral-reefs." The members of this group all possess the power of secreting carbonate of lime within their tissues, so as to form a more or less continuous skeleton or crallum. From the fact that this corallum is secreted by the inver lityer of the polypes, and is therefore truly within the body, it is said to be "sclerodermic," in opposition to the kind of coral produced by other forms (such as the Red Coral), in which the coral forms an internal axis, over which the coenosare is spread, much as the bark encloses the wood of a tree. In this latter case the coral is said to 
be "sclerobasic." (For illustrations of these different kinds of corals, see figs. 49 and 56.) In the typical form of sclerodermic coral, the skeleton is in the form of a conical cup (fig. 49), the upper part of which is hollow, and is called the "calice." The lower part is divided into a series of compartments by vertical plates, which are called the "septa," and which correspond to the mesenteries of the living animal. Sometimes the space contained within the walls of the cup or "corallite" is broken up by horizontal plates called "tabulæ"; but when these are present, there are often no septa. In the coral just described we have a single corallite, produced by one polype, and this simple condition may be maintained throughout

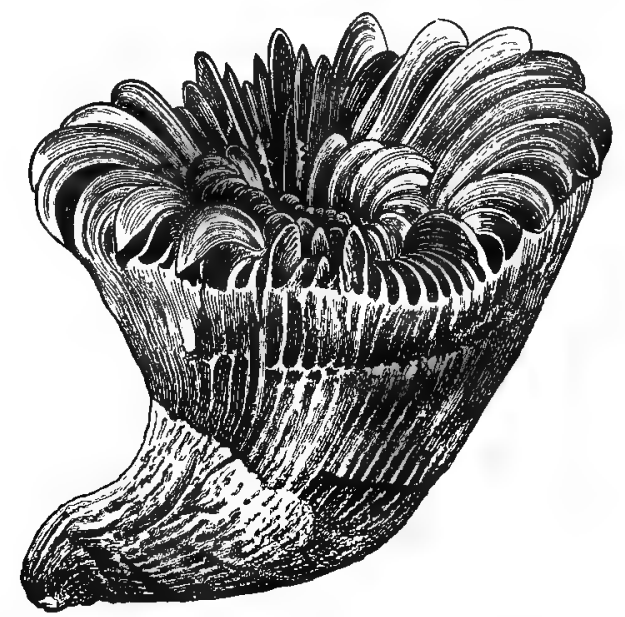

Fig. 49.-The skeleton of Caryophyllia borealis, a simple sclerodermic coral, twice the natural size. (After Sir C. Wyville Thomsin.)

I life. In the great majority of cases, hovever, the polypes bud or divide, so as to form a colony all bound together by a common flesh or conosarc. When such a colony (fig. 50), therefore, produces a sclerodermic coral, in place of a single corallite, we have a composite skeleton composed of a number of little cups or corallites, each of which was produced by one polype, and all of which are united by means of a common calcareous basis, secreted by the cœnosarc. In other cases, the colony is produced simply by the budding forth of new polypes from the sides of the old ones, or by cleavage of the original polypes; so that there is no true cœnosarc. In these cases, the compound skeleton is composed simply of the separate corallites 
belonging to the individual zoöids, without any common calcareous basis secreted by a conosare.

As before said, the "septa" are vertical partitions, which divide

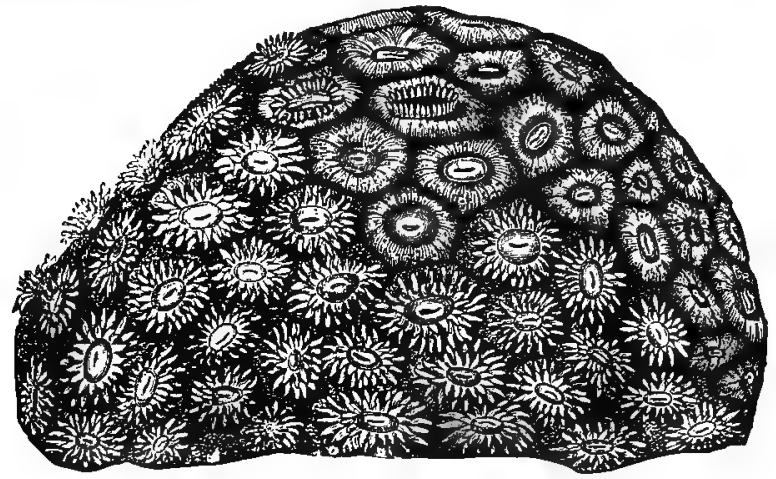

Fig. 5..-A compound Coral (Astraca pallida) in its living state. (After Dana.)

the space contained within the walls (the so-called "theca") of the coral into a series of compartments. The septa spring from the inner surface of the "theca" (fig. 51), and advance towards its

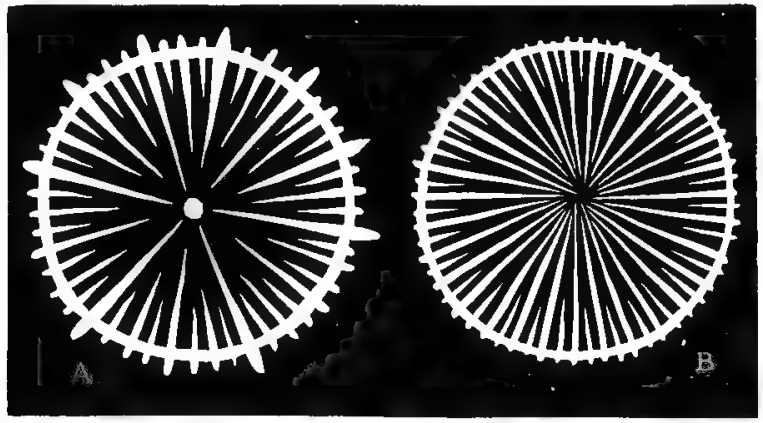

Fig. 51. $-A$, Transverse section of a simple sclerodermic coral, showing how the space included within the wall or "theca" is subdivided by the radiating septa, the centre being ocenpied by the columella; B, Transverse section of a simple Rugose coral, showing the wall and the radiating septa.

centre. Often the septa unite centrally with a calcareous pillar or rod, the "columella"; and they are of different breadths. A certain number of them extend quite to the centre of the coral, where they 
meet the columella (when this is present). These are called the "primary septa." Others, however, fall short of the centre by a greater or less distance; and these are called the "secondary" and "tertiary" septa, according to their breadth (fig. 51).

In accordance with their mode of formation, an ordinary compound sclerodermic coral may be distinguished from a sclerobasic coral by the fact that it would show a number of little cups or calices, in which the polypes were contained, whereas these cups would be absent in the latter. In accordance, also, with the fundamental character of the order Zoantharia, the corals of the present group possess septa which are some multiple of six.

When it is understood that compound corals, such as we have been speaking of, are produced by the combined efforts of a number of polypes, essentially the same in structure as our ordinary sea-anemones, it is rearlily intelligible that under favourable circumstances large masses of coral may be produced in this way. When these masses attain such a size as to be of geographical im.

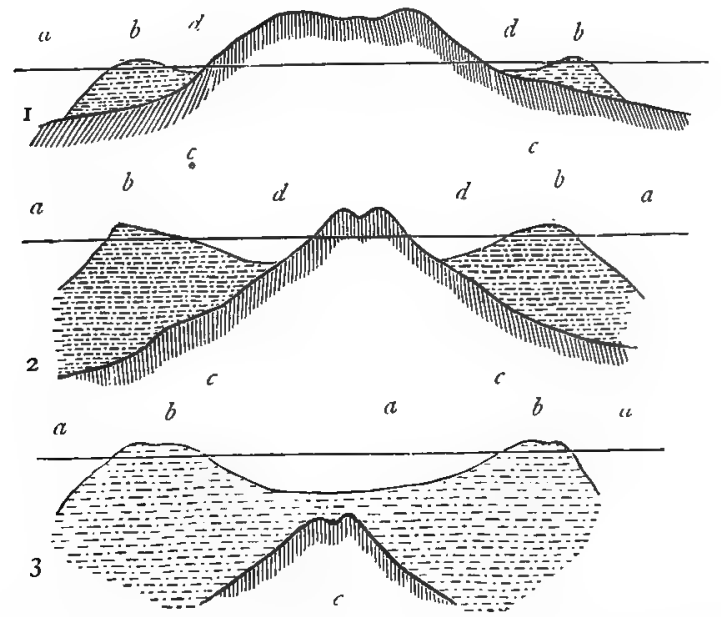

Fig. 52.-Structure of Cnral-reefs. 1. Fringing-rcef; 2. Barrier-reef; 3. Atoll : a Sealevel; $b$ Coral-reef; $c$ Primitive land; $d$ Portion of sea within the reef, forming a channel or lagoon.

portance, they are spoken of as "coral-reefs," and the phenomena exhibited by these are of such interest as to demand some notice. The coral-producing polypes require for their existence that the average temperature of the sea shall not be less during winter than $66^{\circ}$; and there are therefore no coral-reefs in temperate seac. Reefs, however, abound in all the seas not far removed from the equator, being found chiefly on the east const of Africa and the shores 
of Madagascar, in the Red Sea and Persian Gulf, throughout the Indian Ocean and the whole of the Pacific Archipelago, around the West Indian Islands, and on the coast of Florida. The headquarters, however, of the reef-building corals may be said to be around the islands and continents of the Pacific Ocean, where they often form masses of coral many hundreds of miles in length. According to Darwin, coral-reefs may be distinguished into three principal forms viz., Fringing-reefs, Barrier-reefs, and Atolls, distinguished by the following characters:-

1. Fringing-reefs (fig. 52,1).-These are reefs, usually of a moderate size, which may either surround islands or skirt the shores of continents. The e shore-reefs are not separated from the land by any very deep channel, and the sea on their outward margins is not of any great depth.

2. Barrier-reefs (fig. 52, 2). These, like the preceding, may either encircle islands or skirt continents. They are distinguished from fringing-reefs by the fact that they usually oceur at much greater distances from the land, that there intervenes a chamel of deep water between them and the shore, and soundings taken close to their seaward margin indicate considerable depths.

As an example of this class of reefs may be taken the great barrier-reef on the N.E. coast of Australia, the structure of which is on a gigantic scale. This reef runs, with a few trifling interruptions, for a distance of more than a thousand miles, with an average breadth of thirty miles, and an area of thirty-three thousand square miles. Its average distance from the shore is between twenty and thirty miles, the depth of the inner channel is from ten to sixty fathoms, and the sea outside is "profoundly deep" (in some places over eighteen hundred feet).

3. Atolls (fig. 52, 3).-These are oval or circular refefs of coral enclosing a central expanse of water or lagoon. 'They seldom form complete rings, the reef being usually breached by one or more openings. They agree in all essential particulars with those barrier-reefs which surround islands, except that there is no central island in the lagoon which they enclose.

The last group of the Zoantharia comprises composite organisms in which the cœnosarc is supported upon a central axis or sclerobasic skeleton. These Zoanthuria sclerobasica require no notice, except simply to remark that they are distinguished from other sclerobasic Corals (such as the Gorgonidce) by the fact that each polype possesses tentacles which are a multiple of six in number.

\section{Order II. Alcyonaria.}

The second great order of living Actinozoa is distinguished by the fact that the polypes are furnished with fringed tentacles, and that these, as well as the mesenteries and somatic chambers, are always eight in number. With few exceptions, the Alcyonaria are composite, their polypes being connected together by a counosarc. The body-cavities of the pulypes are connected with a system of communicating canals which are excavated in the conosarc, so that a free circulation of nutrient fluids is thus kept up. The structure of 
the polypes of the Alcyonaria is, in essential anatomical features, the same as in the Sea-anemones, but the organism commonly consists of two sets of polypes, which differ from one another in structure and in function. A regular coral may or may not be present, and when present, varies much in its character; but most Alcyonarians possess numerous microscopic spicules of lime in their tissues.

Of the various different organisms included under this order, one of the best known is the "Dead-men's-fingers," or Alcyonizm, which occurs commonly on both sides of the North Atlantic. It forms spongy-looking masses of a yellow or orange colour, attached to shells and other marine objects. The whole mass is covered with little star-shaped apertures, through which the delicate polypes can be

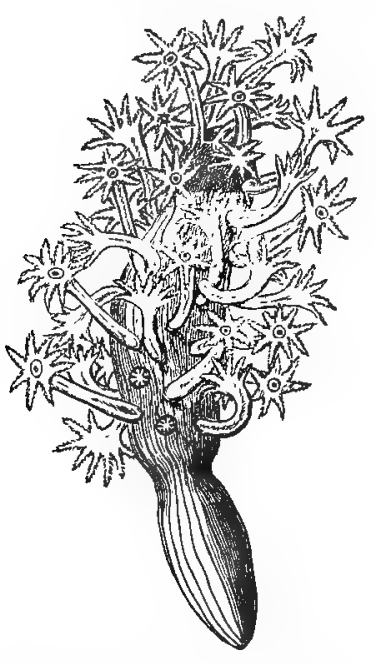

Fig. 53. - Colony of Veretillum cynomorium, of the natural size, with the polypes protruded.

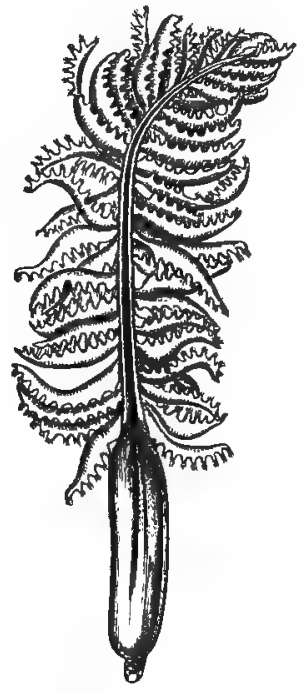

Fig. 54.-Pennatula sulcata, seen from the dorsal side. Slightly reduced, after Kölliker.

protruded and retracted at will. Another well-known member of this order-the type of another family - is the "Sea-rod" (Virgularia), which has the form of a long rod-shaped body of a light flesh colour, supported upon a calcareous rod (sclerobasis), somewhat like a knitting-needle, which is covered by the cœnosarc. From the conosarc are given out lateral processes, each of which bears numerous polypes. Closely allied to Virgularia is the "C'ock's-comb" (Pennatula); but in this the lower end of the conosarc is naked and fleshy (fig. 54), 
and the polype-bearing fringes are considerably longer, giving the whole organism very much the appearance of a feather. In Teretillım (fig. 53) the upper part of the colony is short and club-shaped, and bears the polypes all round its circumference.

Another family of the Alcyonaria is represented by the so-called "Organ-pipe corals," of which Tubipora musica is a well-known example (fig. 55). In this there is a well-developed sclerodermic coral consisting of numerous cylindrical tubes, which are not divided by vertical partitions (sejta), but which are comected by strong transverse plates. The coral is bright red in colour, and the polypes are usually bright green. In its minute structure, the corallum is composed of microscopic spicules fused together.

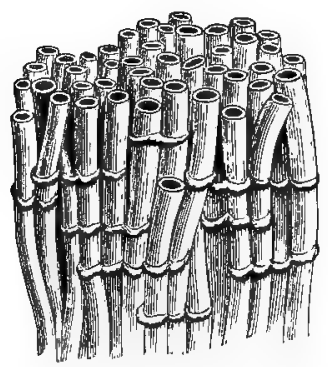

A

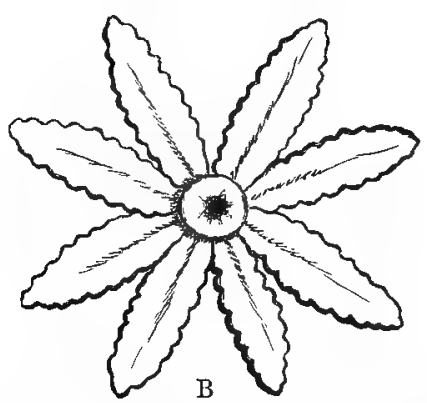

$B$

Fig. 55.-A, Portion of the corallum of Tubiporr musica, of the natural size, showing tlie tubular corallites and their connecting flours; 1 , Polype of the sane, greatly enlarged, showing the mouth and tentacles.

The best known groul, however, of the Alcyonariu is that of the (forturide, represented liy the Sea-shrubs, Fan-corals, and the Red Coral of commerce. A few of the members of this family are British, but they attain their maxinum in point of size and numbers in the seas of the tropics. In all the Gorgonidce the organism consists of a composite structure made up of numerous polypes united by a common flesh or coenosarc (fig. $56, \mathrm{~B}$ ), the whole supported by a central branched axis or coral. 'The coral varies in composition, being sometimes calcareous-as in Red Coral -sometimes borny, and sometimes partly horny and partly calcareous, as in $I$ sis. In all cases, however, the corallum differs altogether from the sclerodermic corallum, which has been described as so characteristic of the reef-building Corals. The coral in the present instance is always what is called "sclerobisic "- that is to sily, it always forms an internal axis, covered by the comosare with the prolypes proluced therefrom. It is therefore 
outside the polypes, and bears to the conosarc the same relation that the trunk of a tree bears to its investing bark. This is well shown in fig. $56, \mathrm{~B}$, where there is represented one of these sclerobasic corals in which the corallum consists of a branched horny stem. The polypes of all the Gorgonidoe agree, of course, with their order in having eight tentacles each, and by this they are distinguished from the few Zoantharia in which there is a sclerobasic coral. The tissues of the conosarc and polypes are usually charged with microscopic spicules.

The best known of the Gorgonidce is the Corallium rubrum, or "Red Coral" of commerce, which is largely imported from the Mediterranean. In this species (fig. 57) there is a bright red, finely
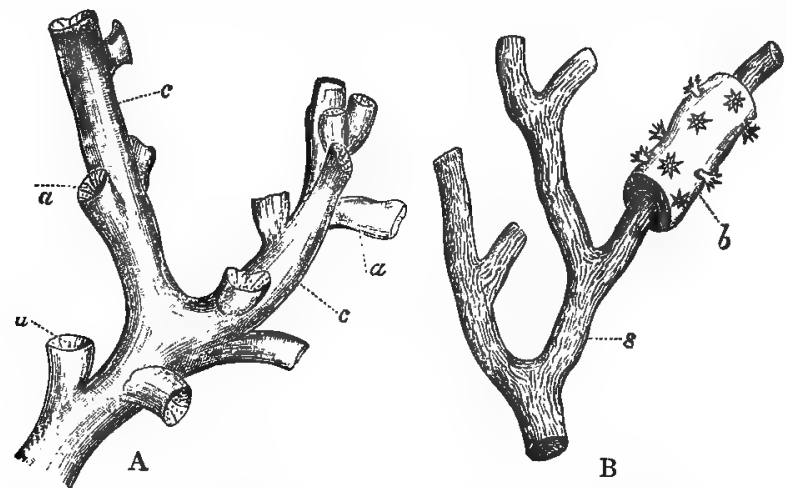

Fig. 56.-A, Portion of a compound sclerodermic Coral (Dendrophyllia), showing the cups $(a, a)$ produced by the separate polypes, united by a cominon calcareous tissue. B, Portion of a branched sclerobasic Coral (forgonia), showing the hard horny skeleton in the centre, surrounded by a fleshy bark or rind (mostly removed in the figure), in which the little polypes are embedded.

grooved, calcareous sclerobasis, usually more or less repeatedly branched. The corallum is invested by a bright red conosarc or bark, which is studded with numerous little apertures. The polypes can be protruded from these openings at will, and are milk-white in colour, with eight fringed tentacles each. The entire conosarc is excavated into a number of communicating canals, with which the cavities of the polypes are connected, the whole system being filled with a nutritive fluid known as the "milk."

Another group of the Alcyonaria has recently been constituted under the name of Helioporidee for the singular stony corals belonging to the genus Heliopora, formerly believed to belong to the Zoantharia. In this genus, the corallum is compound, and is formed 
of tubular corallites, furnished with both tabulæ and radiating septa, and separated from one another by an assemblage of smaller tabulate

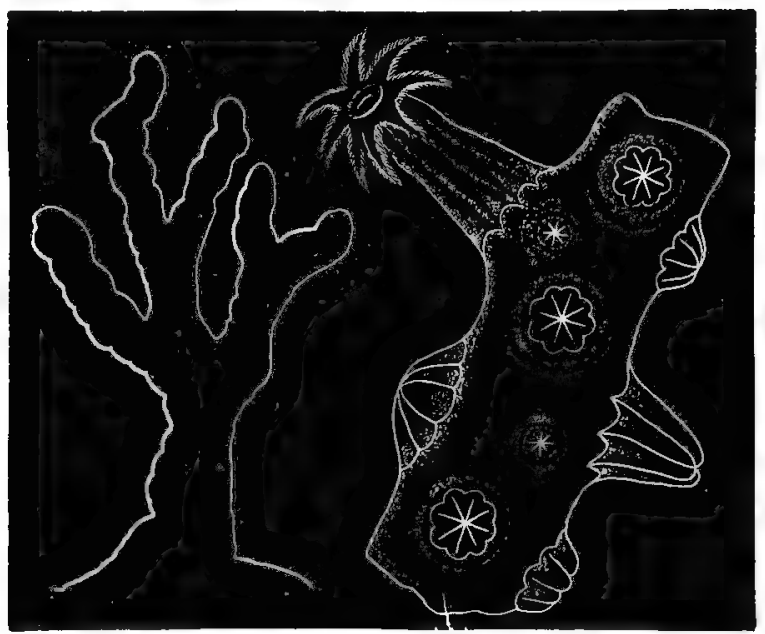

Fig. 57.-Red Coral (Corallivm rubrum), of the natural size, and a portion enlarged.

tubes, occupied by rudimentary polypes. Along with the living Heliopora of the Pacific and Indian Oceans, various ancient corals (Heliolites, \&c.) have been placed.

\section{Order III. Rugosa.}

This order merely requires mention, as almost all, or all, its members are extinct, and are therefore only known to us by their hard parts or skeletons; while the true characters and limits of the group are not completely worked out. They agree with the Zoantharia sclerodermata in having a well-developed sclerodermic corallum, but differ from them in the fact that the septa are typically in four systems; and there are generally transverse plates or tabulæ combined with the vertical plates or septa. On the other hand, they agree with the Alcyonaria in having their parts in multiples of four, but differ from them in having a well-developed sclerodermic corallum in which septa are present. They are chiefly known as fossils in the older rocks of the earth's crust, and they have no undoubted representatives at the present day. 
Order IV. Ctemophora.

The fourth and last order of the Actinozoa is that of the Ctenophora, comprising a number of free-swimming oceanic creatures, very different in appearance from any of the forms which we have hitherto been considering, and often placed among the IIydrozou. They are all transparent, gelatinous, glassy-looking creatures, which are found near the surface in the open ocean, swimming rapidly by means of bands of cilia. The cilia are arranged in a series of transverse ridges, which are disposed in longitudinal bands, the whole constituting loco-

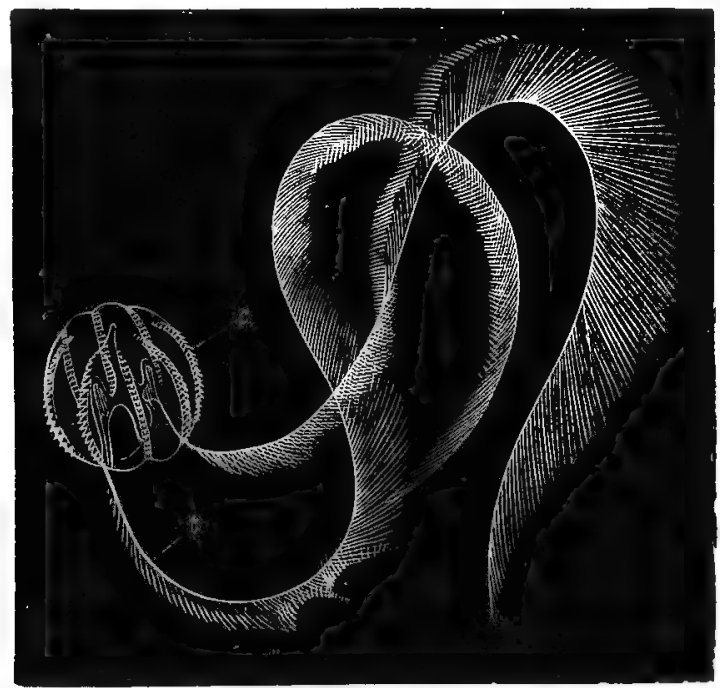

Fig. 58. - Adult of Pleurobrachia rhododactyla, in a natural attitude and of the naturul size. (After A. Agassiz.) $c$ One of the ciliated bands or ctenophores; $t$ One of the tentacles.

motive organs which are known as "ctenophores" (fig. 58, c). In none are there any traces of a corallum or skeleton, and thread-cells, or cells which represent these, are generally present. As the type of the order, we may take Pleurobrachia or Cydippe (fig. 58). The body of Pleurobrachia is transparent, colourless, gelatinous, and melon-shaped, and exhibits two poles, at one of which is placed the mouth. The globe-like body is divided into a number of crescentic lubes by eight ciliated bands or ctenophores, which proceed from near the mouth to near the opposite pole of the body. Besides the 
cilia there are two very long and flexible tentacular processes, which are fringed on one side by smaller secondary branches. The tentacles arise each from a kind of sac, one placed on each side of the body, and they can be instantaneously and completely retracted within these sacs at the will of the animal. The mouth of Pleurobrachia opens into a spindle-shaped digestive sac or stomach, which in turn opens below into a wider and shorter cavity termed the "fumel"; from this there proceed in the axis of the body two small canals, which open at the opposite pole of the body. The fumnel conmunicates with a complicated system of canals, which are ciliated internally, and are filled with a nutrient fiuid. In the angle between the two canals which run from the base of the funnel to the surface is a little vesicle or sac, believed to be a rudimentary organ of hearing, and placed upon this is a little mass which is generally believed to be of a nervous nature. The reproductive organs are developed in the walls of the canal-system.

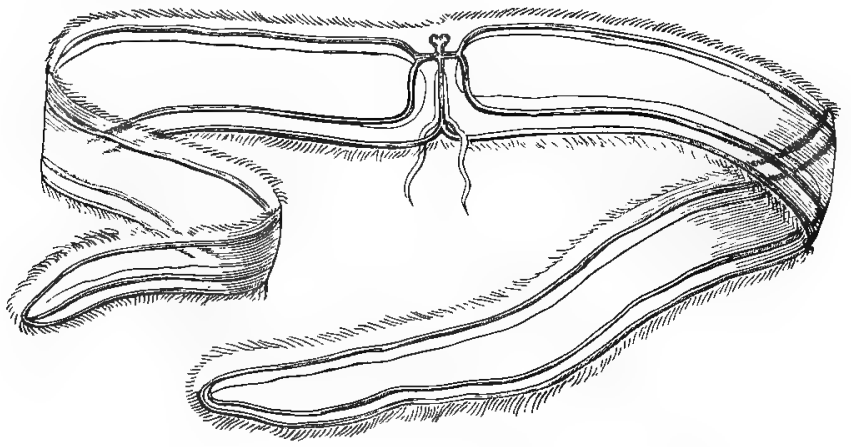

Fig. 50.-Ctenophord. Cestun Veneris, reduced in size.

The only other form of the Ctenophora which deserves mention is the "Venus's girdle" (Cestum Veneris), which agrees in essentials with Pleurobrachia, but is greatly elongated in a direction at right angles to the alimentary canal, till we have a ribbon-shaped body produced (fig. 59), four or five feet in length and two or three inches high. Cestum is not uncommon in the Mediterranean, and has the power of phosphorescence, appearing at night as a moving and twisting band of flame. 


\title{
SUB-KINGDOM III. ECHINODERMATA.
}

\author{
CHAPTER X.
}

\section{ECHINODERMATA.}

THe Echinodermata may be defined as simple marine organisms, which are mostly bilaterally symmetrical when young, but which in the adult condition have this bilateral symmetry more or less extensively masked by a radial (usually pentamerous) arrangement of their parts. An alimentary canal, with or without a distinct anus, and separate from the proper body-cavity is present. A system of water-vessels, often communicating directly with the exterior, and generally connected with protrusible tubes ("feet"), is present. The nervous system is radiate, consisting of an oesophageal ring and radiating branches. The integument is characteristically hardened by the deposition in it of carbonate of lime in the form of plates, grumules, or spicules.

The members of this sub-kingdom are popularly known as Seaurchins, Star-fishes, Brittle-stars, Feather-stars, Sea-cucumbers, \&c., and derive their name of Echinodermata (Gr. echinos, a hedgehog; and derma, skin) from the generally prickly nature of their integuments. In all, the skin is possessed of the power of secreting carbonate of lime, but in very different degrees. In the Seaurchins this goes so far that the body becomes enclosed in a kind of box, composed of numerous calcareous plates firmly jointed together. In the Star-fishes and their allies the skin is rendered prickly by grains, tubercles, or spines of calcareous matter, and the body is either destitute of regular plates or is only partially enclosed by them. In the Sea-cucumbers, again, the calcareous matter is only present in the form of minute grains scattered in the skin. When adult, they all show a more or less distinctly radiate structure, which is most conspicuous in the star-shaped Star-fishes and Sandstars, but can be detected in all the members of the class. When young, however, they almost always exhibit what is called "bilateral symmetry"-that is to say, they show similar parts on the two 
sides of the body. In all Echinoderms there is a water-vascular system of tubes, which is terned the "ambulacral system," which generally communicates with the exterior, and which in most cases is used in locomotion. An alimentary canal is always present, and is always completely shut off from the general cavity of the body. There are always distinct organs of reproduction, which are almost always placed in different individuals, so that the sexes are distinct. The nervous system is in the form of a ring surrounding the gullet and sending branches in a radiating manner to different parts of the body.

One of the most characteristic points about the Echinoderms is their mode of development. In most cases, namely, the embryo is i little oval body covered all over with cilia; but in the course of growth the cilia become restricted to transverse bands or to definite outgrowths of the body. The embryo is now often somewhat conical or pyramidal in shape, with long projecting processes, and may be supported by a provisional internal skeleton (fig. 60). An ali-

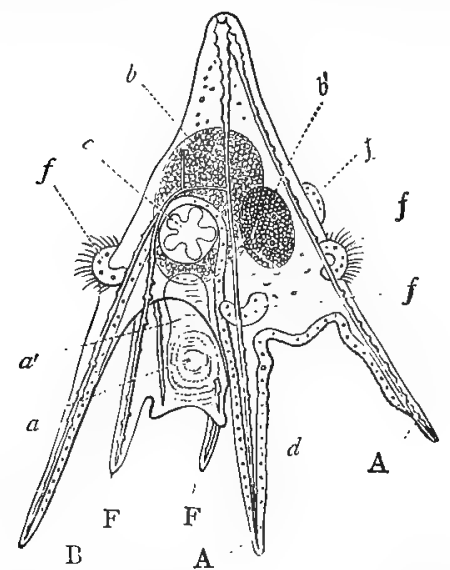

Fig. 60.-Larra of Ethirus. (1fter J. Muller.) A, A, Front arms wilh their internal skeleton; F, F, Anns of the month-process; B, Pusterior side-arms: a Mouth; $a^{\prime}$ Essophagus; $h$ Stomach; $b^{\prime}$ Intestine; $d$ Ciliated bands ; $f f$ Ciliated epaulets; $c$ Disc of the future Echinus.

mentary canal with a distinct mouth and anus is present, and the enbryo is thus divider into two bilaterally symmetrical halves. This singular embryo was originally described, in the case of the Sea-urchins, as in independent animal, under the name of "Platers." The special peculiarity of the further development of the embryo is that the adult animal is ultimately developed out of a mass of active, growing protoplasm which appears on one side of the stomach of 
the Pluteus, and finally envelops that organ; while a new month is formed, and a large part of the provisional embryo is absorbed. The adult further produces a fresh skeleton for itself, and now exhibits conspicuous radial symmetry.

The Echinodermata are divided into seven orders, as follows:-

1. Elkinsidea (Sea-urchins).

2. 1steroiden (Star-fishes).

3. Ophiuroidere (Sand-stars and Brittle-stars).

4. Crinoided (Feather-stars).

5. Cystoidea (extinct).

6. Blastoidea (extinct).

7. Holothuroidea (Sea-cucumbers).

\section{Order I. Echinoidea.}

The animals included in this order vary from the shape of a sphere or globe to that of a disc, and they are all commonly known as "Seaurchins " or "Sea-eggs." They are all characterised by the fact that the body is encased in a "test" or "shell" (fig. 61) composed of numerous calcareous plates, usually immovably jointed together so as to form a kind of box. The intestine is convoluted, and there is a distinct vent, or anal aperture.

The test of a Sea-urchin, as just said, consists of many calcareous plates accurately fitted together, and united by their edges, or, in a few cases, overlapping one another. In all living forms the test is composed of ten zones of plates, each zone consisting of a double row. In five of these zones (fig. $61, \mathrm{~A}, i$ ) the plates are of large size, and are perforated by no apertures. These are termed the "interambulacral areas." In the other five zones (fig. 61, A, a) the plates are of small size, and are perforated by little apertures for the emission of delicate locomotive suctorial tubes (the so-called "ambulacral tube-feet"). These zones are therefore called the "ambulacral areas." Besides these main rows of plates, which collectively make up the greater part of the test, there are other plates placed in the leathery skin round the mouth and vent. The most important of these form a kind of disc, which is placed at the summit of the shell. This disc (fig. 61) is composed of two sets of plates-one called the "genital plates," perforated for the ducts of the reproductive organs ; the other set smaller, carrying each a little "eye," and known by the name of "ocular plates." One of the genital plates is also larger than the others, and carries a spongy mass which is called the "madreporiform tubercle," and which protects the entrance of the water-vascular or ambulacral system. The whole of 
the test is covered with numerous tubercles of different sizes, which carry longer or shorter spines (fig. 61, E). The spines are jointed to the tubercle by a sort of "ball-and-socket" or "universal" joint, and they are completely under the control of the animal, so as to be used both in locomotion and apparently as defensive weapons. In most of our British species the spines are short, but in many tropical forms they attain a very great length. Besides the spines, the outer

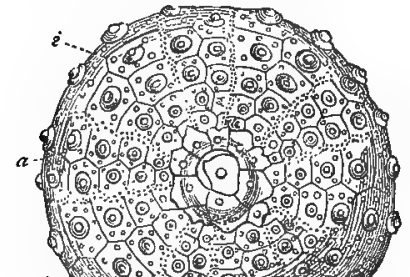

A
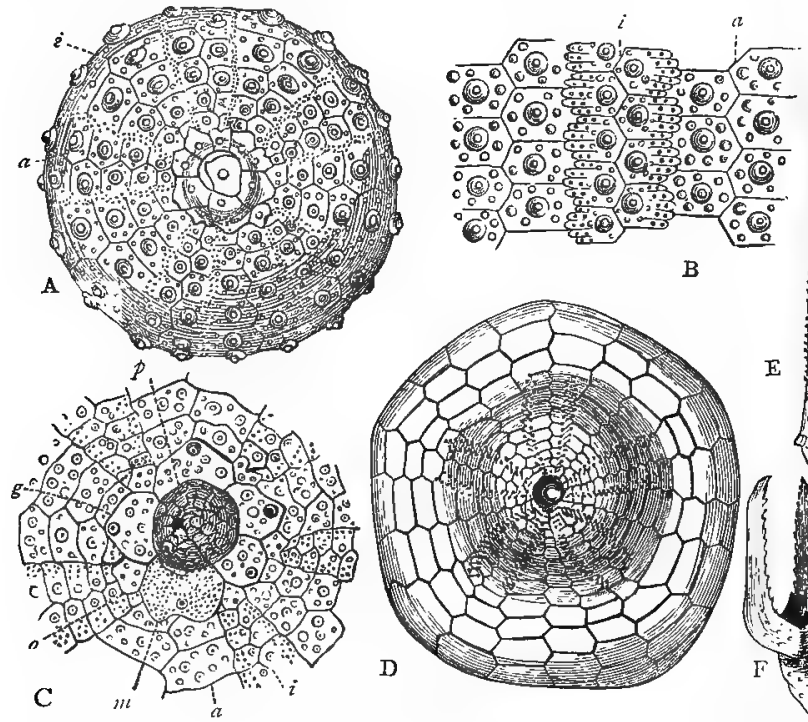

$\mathbf{E}$
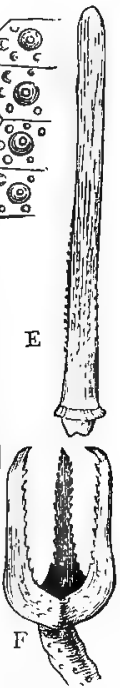

Fig. 61.-Morphology of Fchinoidea. A, Young specimen of Stronfylocentrotus Dröbachiensis, viewed from alrove; $B$, Small portion of the test of the same magnified; C, Summit of the test of Echinus spharc, magnified; D, Clypecster subdepressus, viewed from above, showing the petaloid ambulacra; E, Spine of Porocicluris purpurata; F, Pedicellaria of Toxomenstes lividus. a a Ambulacral areas ; $i$ Interambulacral areas; $g$ Genital plate; o Ocnlar plate; $m$ Madreporiform tubercle ; $p$ Nenbrane surroumling the anus. (Fiss. $A, B$, and $\mathbf{D}$ are after $\mathbf{A}$. Agassiz.)

surface of the test is furnished with curious little bodies called "pedicellariæ" (tig. 61, F), which were long believed to be parasitic. They consist of two or three blades mounted upon a flexible stalk, and constantly employed in snapping together like the beak of a bird. They occur in many other Echinodermata, and their use is obseure.

Locomotion is effected in the Sea-urchins by a curious system of contractile tubes which are known as the "ambulacral tubes" or "tube-feet," and which are appendages of the water-vascular system. 
The following is essentially the arrangement of the whole aquiferous system (see tig. 62). From the madreporiform tubercle on the largest of the genital plates there proceeds a membranous canal, the "sand-canal" (s), by which the outer water is conducted to a central tube $(r)$, which forms a ring round the gullet. The tubercle is spongy, and is perforated with little holes, and its function is probably to act as a filter, and prevent foreign particles gaining access to the interior. The "circular canal" carries five little bladders of unknown function, termed the "Polian vesicles" ( $p)$. From the "circular canal" round the gullet proceed also five "radiating canals" which take their course towards the summit of the shell, underneath the ambulacral areas (a). In its course each radiating canal gives off numerous short lateral tubes $(t)-$ the ambulacral tubes or tubefeet-which gain the exterior of the shell by passing through the apertures in the ambulacral plates of the shell, and which terminate in little sucking-discs. The tube-feet can be distended with water by means of a series of little muscular bladders or "ampullæ" $(v)$ placed at their bases, and they can thus be thrust far out beyond the shell, into which they can be

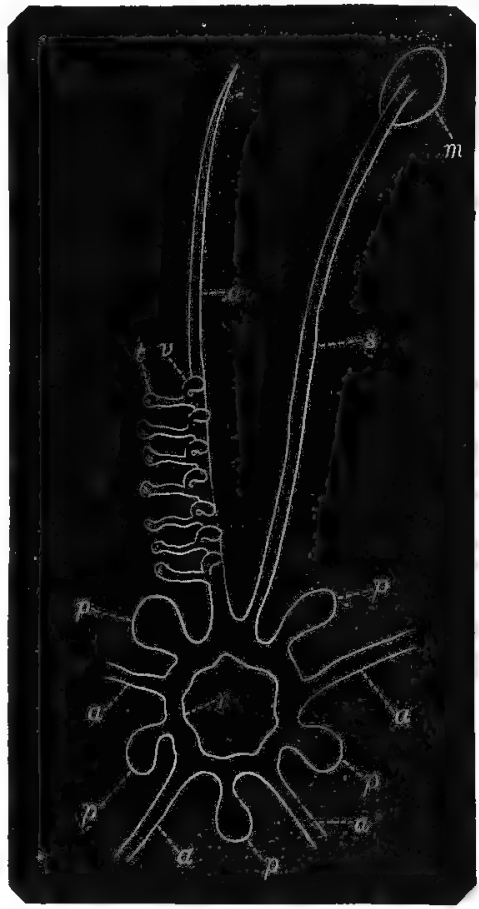

Fig. 62,-Diagram of the ambulacral system of Eelinus. $m$ Madreporiform tubercle; $s$ Stonecanal ; $r$ Central cesophageal ring ; $p p$ Polian vesicles; a a Radiating ambulacral vessels. Only the bases of four of the radiating vessels are shown; and a few of the tube-feet $(t)$, with their secondary vesicles or "ampullæ" $(v)$, are shown on one side of one of the radiating canals.

again withdrawn at the will of the animal. However long the spines may be, the animal can protrude the tube-feet to a still greater length; and by the combined action of the little suckers at their extremities locomotion is effected with moderate rapidity, considering the bulk of the body. 
The digestive system in Eitinus consists of a mouth armed with a curious apparatus of calcareous teeth, which opens into a gullet, which in turn conducts to a long intestinal tube. The teeth form a singular pyramidal structure known as "Aristotle's lantern"; but many Sicil-urchins are without teeth. The long and convoluted intestine is attached to the interior of the shell by a delicate membrane or "mesentery," and terminates in a distinct vent. The surface of the mesentery, as well as that of the lining membrane of the shell, is richly ciliated, and thus serves to distribute the fluid which fills the general cavity of the body, and

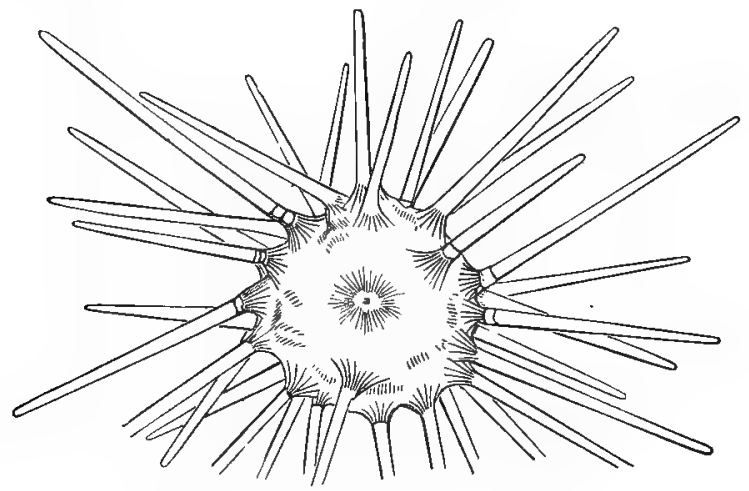

Fig. 63.-Cidaris papillata. (After Gosse.)

which corresponds with the blood, to all parts of the body. It is doubtful if any true blood-system is present, but there is present a system of tukes, of which the principal portion is a long fusiform vessel ruming parallel with the sand-canal, and which have been regarded as blood-vessels. The nervous systern consists of a gangliated com placed round the gullet, and sending five radiating branches along the ambulacral areas. The two sexes are distinct, but in both the reproductive organs are in the form of five membranous sacs placed in a radiating mamer in the interambulacral areas, and opening at the genital plates.

The majority of the Sea-urchins are found at moderate depths in the sea, especially in the neighbourhood of oyster-banks. Others spend their existence buried in the sand; and one species excavates holes for itself in the solid rock, alparently by some mechanical action. 
Order II. Asteroidea.

As the structure of the Sea-urchins may be taken as embodying the most important anatomical peculiarities of the Echinodermata, and as this has been described at some length, it will not be necessary to do more than briefly indicate the more important characteristics of the remaining orders. In the present order are included all the true Star-fishes; the Sand-stars and Brittle-stars being now regarded as a distinct group. The body in all the Asteroidea is

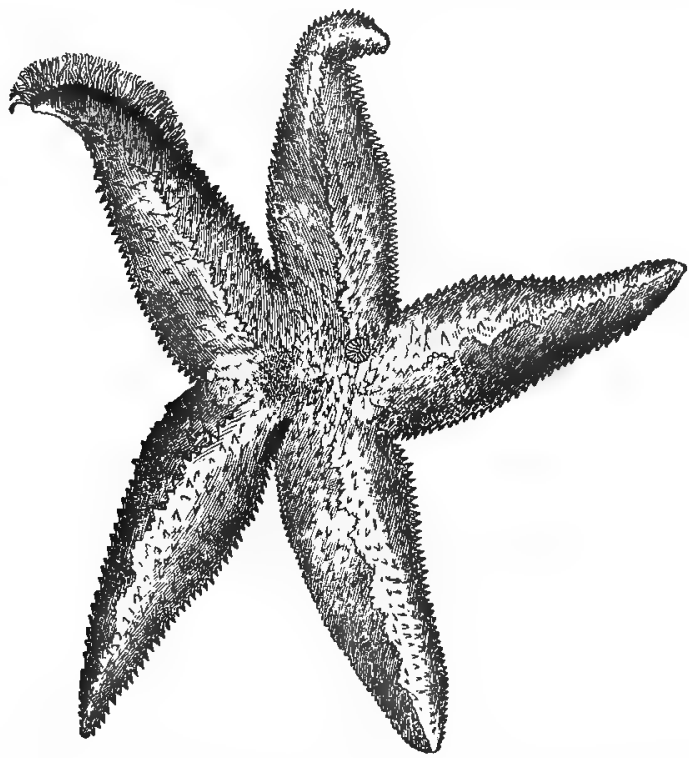

Fig. 61.-The Common Star-fish (Uraster rubens), natural size, viewed from above.

more or less obviously star-shaped (fig. 64), consisting of a central disc surrounded by five or more lobes or arms, which radiate from the body, are hollow, and contain prolongations from the stomach. The body is not enclosed in an immovable box or test, as in the Sea-urchins, but the integument is of a leathery nature, and is richly furnished with calcareous plates, tubercles, and spines. The true Star-fishes are distinguished from the nearly allied Brittle-stars (Ophizroidea) by the fact that the arms or "rays" are direct prolongations of the body, that they contain prolongations of the 
stomach, and that they are deeply grooved on their under surfaces for the radiating vessels of the water-vascular system, which are further protected by a sort of internal skeleton. The upper surface of the body and arms is richly furnished with calcareous matter, in the form of prickles, tubercles, spines, and pedicellarix, these last being peculiarly modified spines. The upper surface, also, exhibits the madreporiform tubercle in the form of a concentrically striated disc placed at the angle between two of the rays; and also the aperture of the anus, when this is present. The mouth is placed in the centre of the lower surface, and is not furnished with teeth. It leads into a pouched stomach and very short intestine, which usually terminates on the upper surface by an anal aperture; but the anus is occasionally wanting. From the upper end of the stomach in all the Asteroidea proceeds a series of much-branched membranous sacs, two of which are prolonged into each ray. These sacs are of a brown or greenish colour, and are often called the "hepatic ceca," as they are supposed to correspond with the liver. The water-vascular or ambulacral system is in most essential respects identical in structure with that of the Seaurchins, making due allowance for the different shape of the body. The madreporic plate leads into a short sand-canal, which opens into a circular ring round the gullet. The circular ring carries Polian vesicles, and gives off the radiating ambulacral vessels, one of which is prolonged to the extrenity of each ray, running at the bottom of the deep ambulicral groove on the under surface of the arms. The ambulacral groove is formed by a double row of calcareous plites (the "ambulacratossicles"), and the radiating ambulacral vessel with its tube-feet lies underneath these plates. On the other hand, the "ampullæ," or little bladders which distend the tube-feet, are situated "lunce the ambulacral ossicles, and therefore in the interior of the arm; and the ampullæ become connected with their respective tube-feet by passing through a series of pores formed between successive pairs of anbulacral ossicles. The nervous system consists of a gangliated ring surrounding the mouth and sending branches along each of the arms. The reproductive organs, like the nervous system, exhibit a radiate condition, being arranged in pairs in each ray.

The Stir-fishes are found on almost all shores, but many forms are properly inhabitants of deep water. They differ much in the general shape of the body. In the common Cross-fishes ( L'raster or $^{\top}$ dsterir(s) the dise is small, and is furnished with long finger-like rays, which are properly five in number. In the Cribelle the general shape is nuch the same. In the Sun-stars (Solaster) the dise is large and well marked, and the rays are from twelve to fif- 
teen in number, and shorter than the diameter of the disc. In the Cushion-stars (Goniaster) the body is in the form of a five-angled disc, more or less flattened on both sides, the rays being only marked out by the ambulacral grooves upon the lower surface.

\section{Order IIT. OpHituroidea.}

This order comprises the common Brittle-stars and Sand-stars (Ophioglypha, Ophiura, Ophiothrix, Ophiocoma, \&c.) The body in
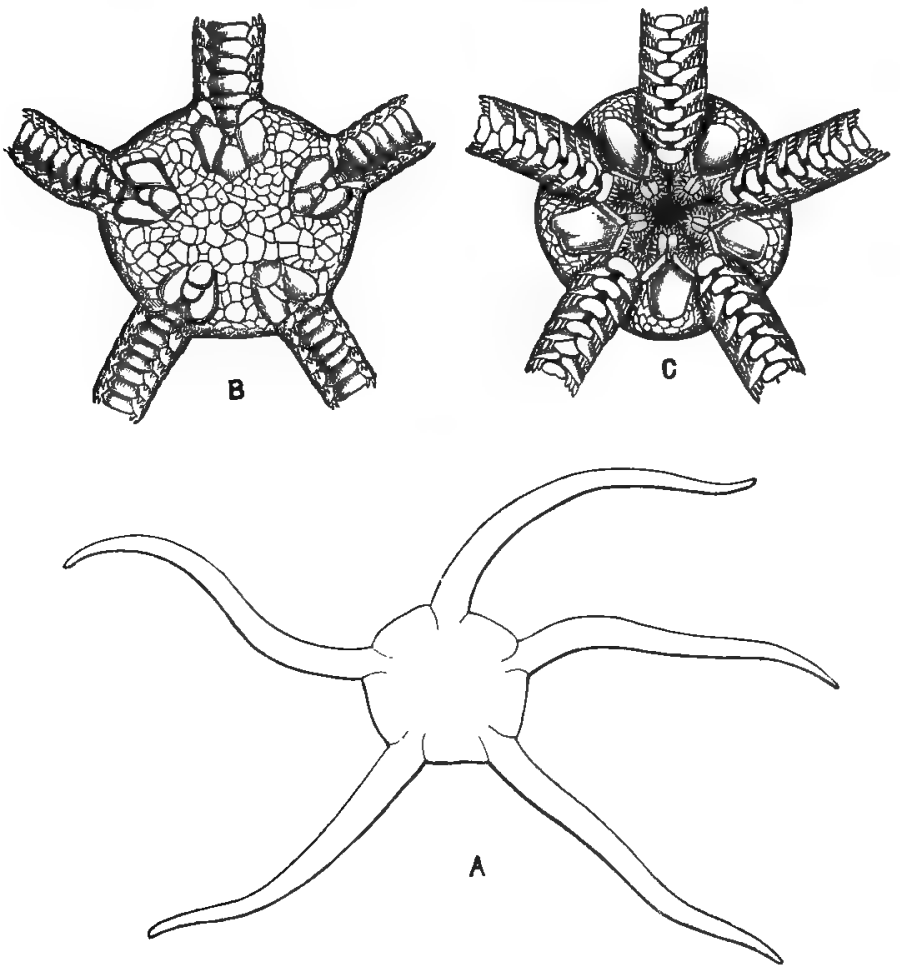

Fig. 65.-Ophiuroidea, Ophiogtypha lacertosa: A, Outline, of the natural size; $\mathrm{B}$, The disc viewed from above, twice the natural size; $C$, The disc viewed from below, showing the mouth and genital fissures, twice the natural size. (Original.)

the Ophiuroidea consists of a circular central disc covered with small calcareous plates, and giving off five long slender arms (fig. 65), 
which may be simple or branched, but which do not contain any prolongations from the stomach, nor have their under surfaces excavated into grooves for the protrusion of ambulacral tube-feet. The arms, in fact, are not jrolongations or lobes derived from the body itself, but are special appendages added for purposes of locomotion and prehension. The arms are very much longer than the diameter of the disc, and are protected by four rows of calcareous plates-one aloove, one below, and one on each side. In the centre of each arm is a row of calcareous pieces which form a kind of internal axis or skeleton, below which is placed the radiating ambulacral vessel. The main internal organs are contained within the disc, and none of them pass into the arms except the nervecords and ambulacral vessels. The mouth is placed in the centre of the under surface of the disc, and opens into a globular, simple stomach, which is not furnished with an anal aperture, all indigestible particles being got rid of through the mouth. In various points of their anatomy the Ophiuroidea differ considerably from the true Star-fishes, to which they are most nearly related, but these differences do not require further notice.

The habits of the Brittle-stars and Sand-stars are various, but many of them may be found in rock-pnols or under stones at low water on most shores. One of the most remarkable types is the Medusa-head Star, in which the arms are divided from the base, first dichotomonsly and then into many branches.

\section{URder IV. C'RINOIDEA.}

In this order are comprised Echinodernate, in which the body is fixed, during the whole or a portion of the existence of the aninal, to submarine objects by means of a jointed flexible stalk or column. The Crinoidea were formerly very numerous, both individually and in types, but they are represented at the present day by but a small number of living forms, of which one group only (viz., that of the Feather-stars) is at all of common occurrence. The body in the Crinoids consists of a central disc or cup forme:l of calcareous plates, and protecting the body of the animal. From the margins of this cup spring five or more arms which are arranged in a radiating manner, so as to form a more or less feathery crown. In one of the living groups (Comatula or intedon), the animal, when full grown, is free ; but in all other living types, and in the great majority of fossil forms, the body was attached throughout life to the seabottom by means of a jointed stalk fixed to the lower surface of the cup (fig. 67).

The commonest living group is that of the Feather-stars (Comatula 
or Antedon), species of which are found in almost all seas. In this group the organism consists of a central body or disc, from which proceed five radiating arms, which divide almost directly after their origin into two secondary branches, so that ultimately there are produced ten long and slender rays. Each arm is furnished on both sides with a number of little jointed lateral processes or "pinnæ," so as to assume a feather-like appearance, from which its

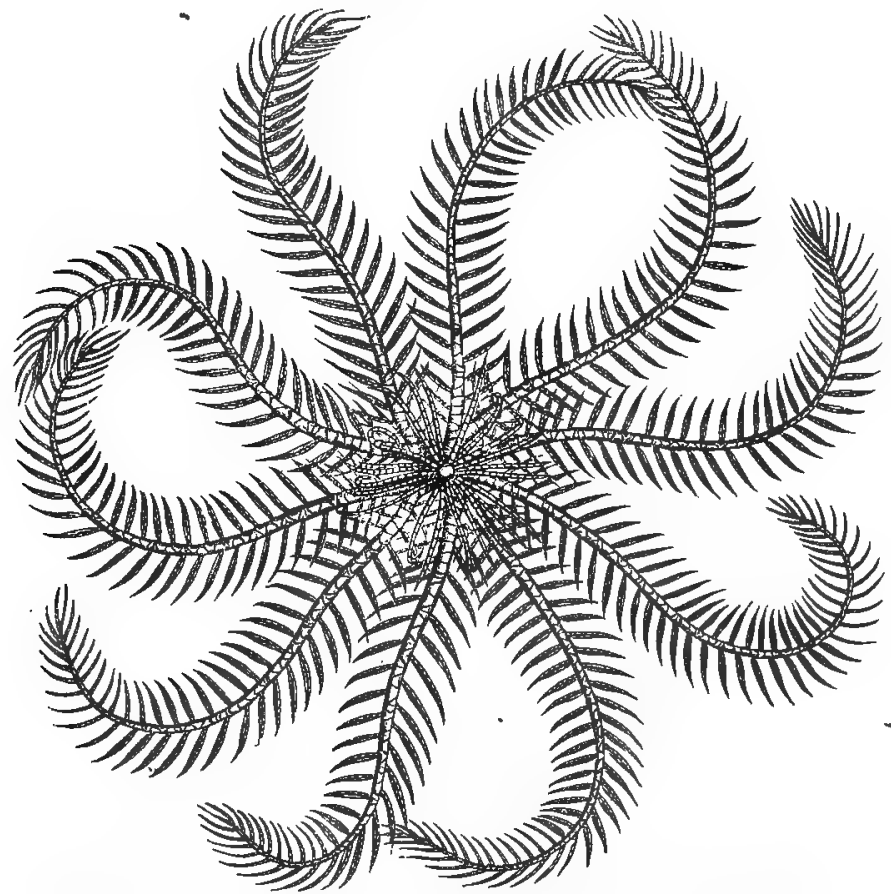

Fig. 66.-Crinoidea. Comatula rosacea, a free Crinoid, viewed from its dorsal or abord aspect.

popular name is derived (fig. 66). The digestive system is furnished with both a mouth and a vent; the water-vascular or ambulacral system appears to take no part in locomotion, and the reproductive organs are lodged in the lateral processes of the arms. The most remarkable point, however, about a Feather-star, is the manner in which development takes place. When fully grown (fig. 66) it presents no small superficial resemblance to some of the Ophiuroidea. 
When young, the Comatula is so different in appenrance from the adult, that it was originally described as a distinct animal. It consists now of a little cup-shaped disc with ten radiating arms above,

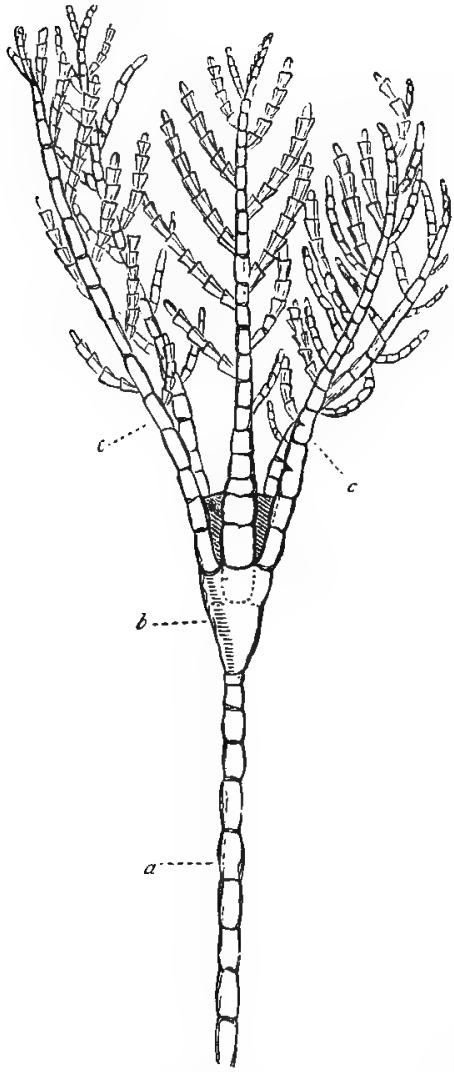

Fig. 67. - Rhizocrinus lofotensis, a living stalked Crinoid (after Wyville Thomson), four times the natural size. $a$ Stem; $b$ Cup ; c c Armis. produced by the splitting into two of five primary rays, and furnished inferiorly with a little flexible column or stalk composed of a number of calcareous joints. By this jointed stem the body is at this period of life fixed to sea-weeds or other submarine objects. When sufficiently nature, however, the body drops off its stalk, and then only requires to grow in size to become a fully developed Comatula.

The stalked condition which we have just seen to constitute a merely temporary stage in the life-history of Comatula is, on the other hand, the permanent state of parts in all the "Stone-lilies" and in most other fossil Crinoidea, and in a few living forms. Of the living stalked (rrinoids the ones with which naturalists have been longest acquainted are the species of Pentacrinus, from the seas of the West Indies. Recently a number ofstalked Crinoids have been obtained from great depths in the sea, showing that these ancient types still survive, though in much diminished numbers. One of the most interesting of these deep-sea

Crinoids is the little Rhiocrinus lofotensis (fig. 67), which seems to be distributed over the whole of the deeper portions of the North Atlantic. 


\section{Orders V. and Vi. Cystoidea ayd Blastordea.}

These orders merely require to be mentioned here, as all the forms included in them are extinct, and are unrepresented at the present day by living species. In both, the body is enclosed in a kind of box formed by jointed calcureous plates, and it was in most cases permanently fixed to the sea-bottom by a jointed stalk or column. The arms, which form so conspicuous a feature in the true Crinoidea, were either absent or very rudimentary. Both orders are in many respects closely allied to the Crinoidea, and they constitute probably the least highly developed sections of the whole class of the Echinodernuta.

\section{Order VII, Holothuroldea.}

In this order are comprised the highest of the Echinodermata, all very different in outward appearance from any of the forms we have hitherto considered. They are commonly known as Sea-cucumbers or Trepangs, but, except in warm seas, they are rare and inconspicuous animals at the best. They are all more or less worm-shaped or snail-like in form, and they are not provided with any regular shell. The skin is leathery, and generally contains calcareous matter in the form of microscopic plates or spicules, or more rarely in the form of larger overlapping plates. The body is capable of great changes of form in the way of extension or contraction, being provided with exceedingly powerful longitudinal and transverse muscles. Locomotion is effected by the alternate extension and contraction of the vermiform body, or by rows of ambulacral tube-feet, like those of the Sea-urchins, protruded through the integument. Typically, the tubefeet are arranged in five longitudinal zones, as in the Sea-urchins (fig. 68) ; but, in other cases, the tube-feet are irregularly distributed over the whole body, and in a few cases they are emitted from the lower surface of the body alone. In some forms (Synapta), there are no tube-feet, and locomotion is effected by numerous ninute anchor-shaped spicules of lime, attached to plates sunk in the skin (fig. 70). The water-vascular or ambulacral system is sometimes quite rudimentary, but in other cases its internal arrangement much resembles that of the Sea-urchins, except that the madreporiform tubercle is not placed on the outside of the body, but hangs down freely in the interior of the body. The circular cesophageal ring carries generally one very long Polian vesicle (fig. $69, p$ ); and the tube-feet are provided with "ampullæ." The mouth is situated at the anterior end of the body, and is provided with a crowu of branched tentacles 
(fig. 68). It opens into a long convoluted digestive tube, which is attached to the body-walls by a delicate mesentery, and terminates in a large muscular chamber or "cloaca" (fig. 69), which in turn communicates with the exterior by the anal aperture. Springing from the cloaca in many Holothurians are two much-branched tubes,

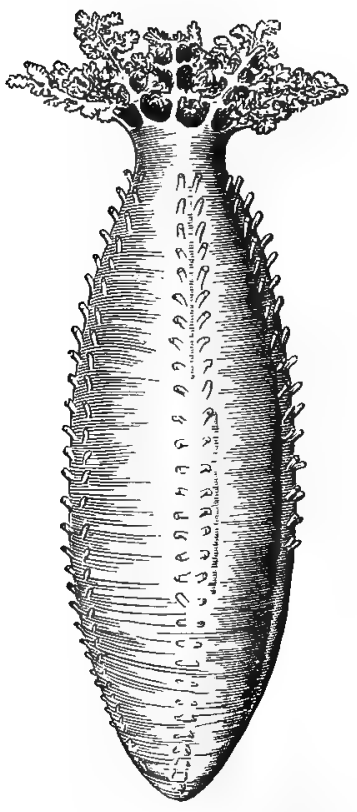

Fig. 68. - Cucumaria frondosa, showing the crown of feathery tentacles round the mouth and the rows of tube-feet.

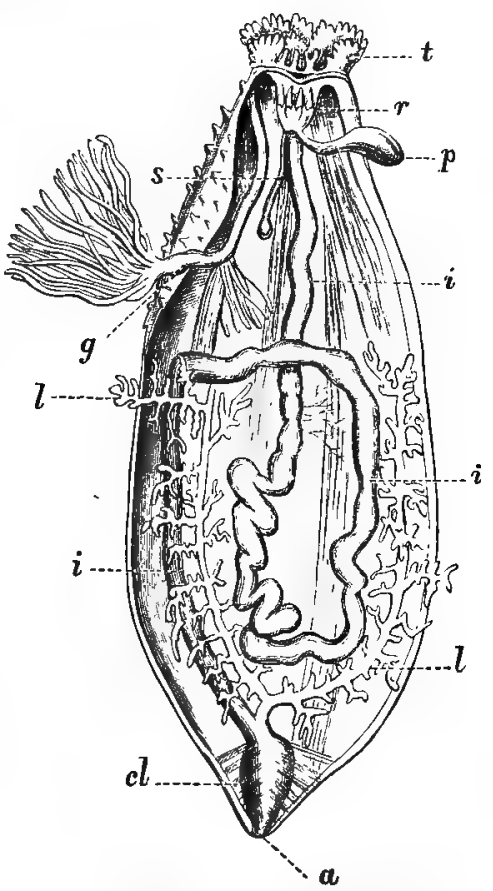

Fig. 69.-Holothuroidea. Semi-diagrammatic longitudinal section of a Holothurian, $t$ Tentacles; $r$ Calcareous ring at the base of the tentacles; $p$ Polian vesicle; $s$ Sandcarnl; $i$ i $i$ Alimentary canal; $g$ Duct of the reproductive organs; cl Cloaca; $a$ Anus; $l \imath$ Respiratory tree.

which run forward towards the anterior end of the body, and which are filled with sea-water from the exterior. These tubes seemingly act as respiratory organs, and are usually spoken of as the "respiratory tree" (fig. $69, l l$ ). The Holothurians have a nearly world-wide distribution, and are found from between tide-marks up to great 
depths in the sea. Many of the deep-sea forms exhibit singular modifications of structure. Some Holothurians (e.g., Synapta) burrow in sand or mud; others are free. Many attain a considerable size.

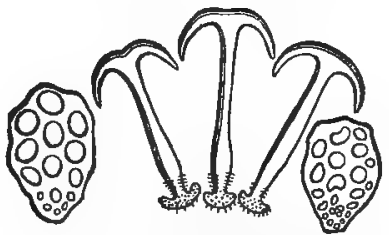

Fig. 70.-Anchor-shaped spicules of synapta, and the plates to which these are attached. Magnified greatly. 


\section{SUB-KINGDOM IV. ANNULOSA.}

\section{CHAPTER XI.}

\section{General Characters of the Annulosa-Divistons of the Annulosa-Characters and Orders of the ŚCulecida.}

THE Annulose animals are characterised by the possession of $a$ usually more or less elongated body, achich is bilaterally symmetrical, instead of being radially disposed. Commonly the body is divided into similar segments. which may be definite or indefinite, and are arranged along an antero-posterior a. is. Lateral appendages may be present or absent, and when present are bilaterally disposed. A nervous system is present, and consists of one or two ganglia placed in the anterior part of the borly, or of a ventrally placed double gangliated chain.

The sub-kingdom Annulosa may be divided into the following three primary sections, each of which admits of sufficiently definite characterisation :-

I. Scolecida.--This division includes the parasitic Worms $(E n-$ tozoct), the Wheel-animalcules, and some allied forms, and is characterised by the fact that the body is flattened, and either unsegmented or imperfectly segmented, though the integument may be anmulated. A water-vascular system is present, but the watervessels are not concerned with locomotion. There is no true bloodsystem; and the nervous system consists of one or two cephalic ganglia, and never has the form of a gangliated ventral chain. I ateral appendages are alnost universally wanting.

II. Avarthropoda. - This division includes the Spoon-worms (Gephyrea) and the Ringed Worms (Annelida), and is characterised by the fact that the body is composed of a rumber (often indefinite) of similar or nearly similar segments arranged longitudinally. A "pseudohrmal" system of vessels is generally present. The nervous system is placed ventrally, and consists typically of a double chain of ganglia, united by longitudinal commissures, and forming an œsophageal collar. Cilia are generally developed. Lateral locomo- 
tive appendages are usually present, but are never jointed or articulated to the body.

III. Arthropoda.-This division includes the Crustaceans (Crustacea), the Spiders, Scorpions, \&c. (Arachnida), the Centipedes and their allies (Myriapoda), and the Insects (Insecta). The body (fig. 71 ) is composed of a series (usually definite) of distinct rings or

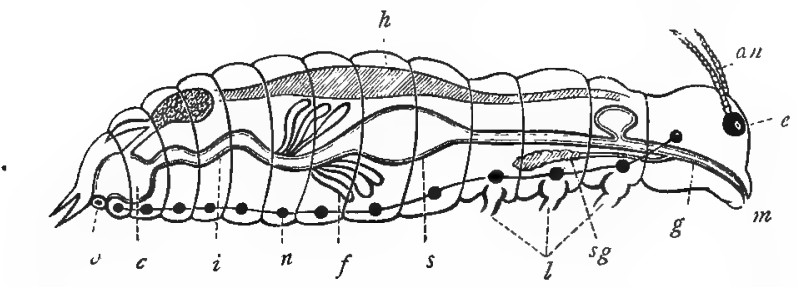

Fig. '1.-Diagram of the anatomy of an Insect. an Antennæ; $e$ Eye; $m$ Mouth; $g$ Gullet; sg Salivary gland; $s$ Stomach ; $f$ Tubes supposed to represent the kiılneys; $i$ Intestine; $c$ Clamber (cloaca) into which the intestine opens; $v$ Vent; $h$ Heart; $n$ Nervous system; $l$ Bases of the legs.

"somites," arranged along a longitudinal axis. A true blood-vascular system is normally present, and the heart is placed dursally. The nervous system consists primitively of a double chain of ganglia, placed ventrally, and traversed anteriorly by the osophagus. Limbs are almost always present, and are jointed and articulated to the body. The integument is more or less extensively hardened by the deposition in it of chitine, with or without salts of lime; and ciliated epithelium is not developed.

\section{SCOLECIDA.}

The Scoiecida are characterised, as compared with the higher Annulose Animals, by their unsegmented or imperfectly segmented bodies; by the general absence of lateral appendages; by the possession of branched water-vessels, filled with a watery fuid, and usually communicating with the exterior; and by the fact that the nervous system consists of one or two ganglia situated in the anterior part of the body.

A large number of the Scolecids are internal parasites, and are commonly known by the name of Entozod. Many forms, however, lead a permanently free existence. The Scolecida are often divided into two great sections-viz., (1) the Platyelmia or Flatworms, including the Tape-worms (Toeniada), the Fluke-worms (Trematoda), and the Turbellarian Worms; and (2) the Nematelmia 
or Round Worms, comprising the Thorn-headed Worms (Acanthocephala), the Hair-worms (Gordiacea), and the typical Round-worms and Thread-worms (Nematoidea). A third division must be constituted for the reception of the Wheel-animalcules (Rotifer $\alpha$ ).

\section{SECTION A. PLATYELIIA.}

\section{Order I. Temiada.}

This order cumprises the singular animals known as Tapeworms, all of which are found living as parasites within the alimentary canal of other animals; the young (often called "Cystic worms" or "Bladder-worms") being also parasitic, but usually inhabiting the solid tissues. As a general rule, the adult tapeworm inhabits the alimentary canal of an individual of some one species of the higher animals; while the young of the same tapeworm inhabits the tissues of an individual belonging to some nther species of animal. As a rule, therefore, each tapeworm is, at different times of its life, parasitically related to two different animals, belonging generally to different species. In its early stages each tapeworm inhabits the tissues of what may be called its "intermediate bearer," while in its adult condition it inhabits the intestine of what we may term its "final host." As a rule, the "intermediate bearer" and the "final host" are not only different individuals, but they belong to different linds of animals-the two, however, being so far related to each other that the "intermediate bearer" is liable to be eaten by the "final hort."

Many animals are infested by tapeworms; but all the leading points of interest in the order will be brought out by a consideration of one of the commonest of the tapeworms to which man is subject-namely, the Prrk-tapeworm, or 'Tinia solium. The Porktajeworm is fouml inhabiting the intestines of man, one only being generally present in the same individual. In shape (fig. 72) it is an extremely elongated, flattened, tape-like body, many feet in length, and composed of a number of flattened joints all loosely united t" one another. At one extremity the joints, technically cilled the "proglottides," become much smaller and narrower, till ultimately a point is reached where the organism is firmly fixed to the mucous membrane of the intestine by means of a minute rounded head (fig. $72, a)$. The organs ly which attachment is effected are, in this species, a crown of recurved hookis and four suckers. In other types only the suckers are present (fig. $73, e$ ). The head is in reality the true animil, and all the long, jointed, tape-like body which 
follows this is really produced by a process of budding from the head. The head contains no reproductive organs, and is not furnished with a mouth or digestive organs of any kind, its nutrition

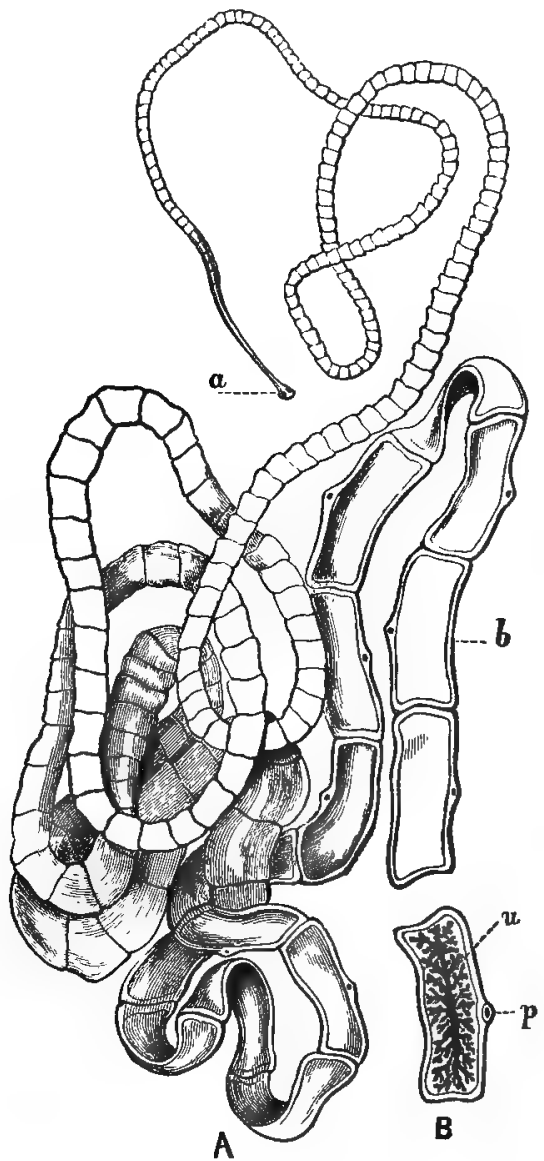

Fig. 72.-A, Tonic solium, of the natural size : $a$ "Heal" or "nurse;" $b$ One of the proglottides from the sexually mature part of the worm. B, A single mature proglottis of the same, showing the genital pore $(p)$ and the branched uterus $(u)$.

being entirely effected by imbibition of the nutritive fluids elaborated by its host. A nerrous system, in the form of two ganglia, united by a transverse conmissure, and sending filaments backwards, is 
present. The water-vascular system consists of two long vessels which run down each side of the body and communicate at each articulation by a transverse vessel, the whole opening in the last joint into a contractile vesicle. Each joint, or "proglottis," is sexually perfect, or hermaphrodite, containing both male and female reproductive organs, which open on the surface by a small raised aperture, the "generative pore" (fig. $73, h$ ). Almost the whole of each of the mature joints is filled up by a much-branched uterus. As the head is the true animal, and the numerous joints are only produced by budding, it follows that the entire organism is to be regarded as a kind of colony, constituted by a single sexless zoöid
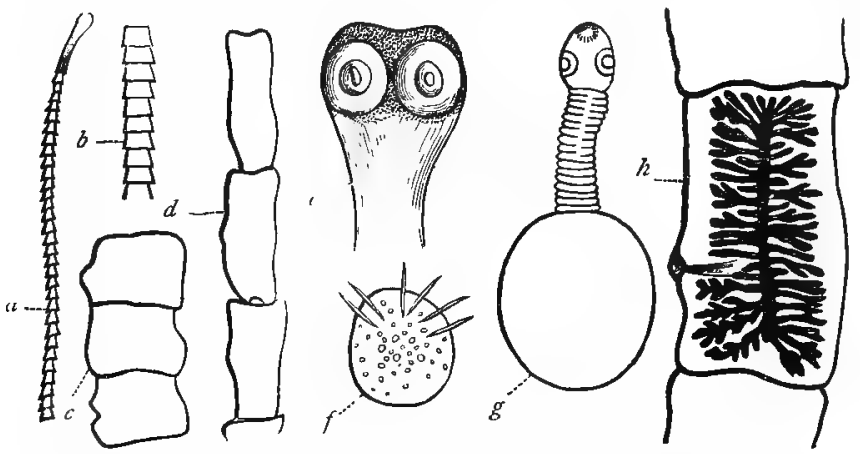

Fig. 73.-Morpholony of Taniala. a Head and a few following segments of Tanio mediocouclleter; $b$ A few serments of the same further removed from the head; $c$ and $d$ Segments progressis uly further removed from the head,-all of the natural size; $e$ Head of the same, enlarged; $h$ A single proglottis of the same, with its branched uterus and Interal genital pore, enlargerl two diameters; $f$ Embryo of Trwin bacillaris, with six honklets ; $g$ Cysticercus celluluse, the "cystic" young of Trnia solium, with its lomklets and suckers, its wrinkled neck, and its caudal vesicle, enlarged. (After Leuckart, Van Beneden, and Woinland.)

or "nurse" and numerous sexual zoöids, produced by budding from the former.

The process of development-that is to siy the process by which this composite organism, conmonly known as the tapeworm, is produced -is a very remarkable one, and is briefly as follows: Each generative segment or joint, as already said, is hermaphrodite, and contains innumerable ova. These eggs, however, cannot be developed within the body of the animal infested by the tapeworm itself, but they are compellerl to gain access to the body of some different species of animal, if development is to proceed. To secure this end, the mature joints of the colony break off, and are expelled 
from the alimentary canal of the host. The joints thus expelled die and decompose, and their contained eggs are thus set free. Each egg is covered with a little leathery capsule which protects it from injury, and contains a minute embryo in its interior. If this microscopically small egg be swallowed-as in many ways it easily may be-by another warm-blooded animal (in this particular case by the pig), then a fresh series of changes ensues. The leathery case of the ovum is dissolved in the stomach of the new host, and the embryo, or "pro-scolex" (fig. 73, $f$ ), is set free, when it bores its way through the walls of the stomach by means of little hooks or spines with which it is provided. Having reached a suitable locality, the young tapeworm proceeds to surround itself with a kind of cyst, and it develops from its hinder end a kind of bladder or vesicle filled with a clear watery fluid. The young tapeworm is now what is technically called a "scolex," and it constitutes what used to be termed a "Cystic Worm" (fig. 73, g). It consists not only of the caudal bladder, but also of a short neck carrying an oval "head," which is furnished with four suckers and a little crown of hooklets. The "scolex" of the Tcenia solium is generally about a fourth of an inch in length, and is found embedded in the muscles of the pig, when the pork is said to be "measly." When first discovered, the young tapeworm was regarded as a distinct species of worm, and was described under the name of Cysticercus cellulose (fig. 73, g). In this cystic stage the young tapeworm may remain for an apparently indefinite period, being quite incapable of developing eggs. For its further development it is necessary that it should now be introduced into the alimentary canal of man. If a portion of measly pork be eaten, with these cystic worms embedded in it, then the young tapeworm is liberated from its cyst: it fixes itself by means of its suckers and hooklets to the mucous membrane of the intestine, and its caudal bladder drops off. It is now converted into the head of the adult tapeworm. It finally commences to throw out buds from its hinder extremity, and in these buds or joints the reproductive elements are produced, so that ultimately we get the long flattened jointed colony with which we started.

A like extraordinary series of phenomena is now known to occur in other cases, but these can be merely alluded to here. Thus, another of the common tapeworms of man-viz., the Beef-tapeworm (Tenia mediocanellata)-lives as a "scolex" or "cystic worm" in the muscles of the ox. The tapeworm of the cat (Tania crassicollis) spends its "cystic" stage in the tissues of the mouse. One of the tapeworms of the dog (viz., Tonia serrata) inhabits in its early life the bodies of hares and rabbits. Another tapeworm of the dog (viz., Tenia coenurus) is found as a "cystic worm" inhabiting the brain of 
the sheep, in which animal it produces the disease known as the "staggers." Lastly, another curious tapeworm of the dog (viz., the Tcenica echinococcus) lives in its young stages in the human body, giving rise to what are known as "hydatid tumours." The adult tapeworm of this species is only about a quarter of an inch in length, and consists only of three joints besides the head. The so-called "hydatid tumour" consists of one or more bladder-like tumours, varying greatly in size, embedded in the liver, lungs, brain, or other solid organ of the human body. The bladder is filled with a watery fluid, and its inner surface carries a vist number of little buds, which are mostly similar in structure to an ordinary "cystic worm." Similar little "cystic worms" are often found floating in the fluid itself, and are commonly spoken of as "Echinococcr." In reality, the "byclatid tumour" is the result of the development of the young or "scolex" of the Tirnia crtinococcus of the dog. In this particular case the "scolex," or young tapeworn, has the power of throwing ont buds, and thus of forming a composite organism or colony. Hence, in this case, instead of remaining harmlessly embedded in the tissues, as is usual among the young of the tapeworms, the "scolex" goes on constantly growing and increasing in size, by the production of new luds in its interior. For this reason, also, "hydatid tumours" usually give rise to serious or fatal results by the pressure which they exert upon the tissues or organs amongst which they lie.

\section{Order II. Trematoda.}

The "suctorial" worms, or "flukes," as the members of this order are commonly cilled, are interual parasites, inhabiting various situations in different aninals, but especially affecting birds and fishes. They are almost all nore or less flattened and leaf-like in shape, and are furnished with one or more ventral suckers, by which they adhere. They are distinguished from the Teniulu by always possessing an alimentary canal, which is often much branched, and which is simply hollowerl out of the tissues of the body. No anal opening is present; and there is no brdy-cavity. The integument is not ciliated, and the sexes are generally united.

The best known of the Trematode worms is the common LiverHuke (Distoma hepaticum) which inhabits the gall-bladder and bile-ducts of the sheep and other domestic animals, and sometimes occurs in the same situation in man. In the sheep it gives rise to the prevalent and often fatal disease known as the "rot." In Distoma hepatirum, or in such it form as Distumu lanceolatum (fig. 74 ), the body is ovate and leaf-like, half an inch or more in length, 
and furnished with two ventral suckers. anteriorly (fig. $74, a a$ ), and is perforated by the aperture of the mouth. The hinder sucker $(a p)$ is imperforate, and is the main organ of adhesion. Between the two suckers are the openings of the male and female organs of reproduction $(o)$. The mouth opens into a short gullet, which divides into two primary branches which are continued backwards. In Distoma lanceolatum, the divisions of the intestine are simple (fig. $74, i$ ), but in D. hepaticum they are furnished with numerous secondary lateral branches. Dorsally is placed a more or less complex system of water-vessels, which open posteriorly by a caudal pore (fig. $74, p$ ), and are filled with a watery fluid. The nervous system consists of a pair of cephalic ganglia, giving off branches backwards. A large portion of the body is further occupied by the very complicated reproductive organs, the animal being hermaphrodite.

Most Trematode worms pass through a remarkable series of changes, usually accompanied by migrations, in their earlier stages; but these changes are in many cases only imperfectly known. In the case of the common Liver-fluke (Distoma hepaticum), the eggs are expelled from the intestine of the sheep which is infected by the adult worm, and give exit to a little ciliated embryo, which swims about actively in water. This bores its way ultimately into the tissues of a particular kind of Watersnail (Limnoe truncatula), where it becomes encysted. It then passes through a series of extraordinary changes, which cannot be described here, the ultimate result of which is the production of a number of little tadpole-like embryos, known as "cercariæ." These escape from the body of the snail, and swim about actively for a
One of these is placed

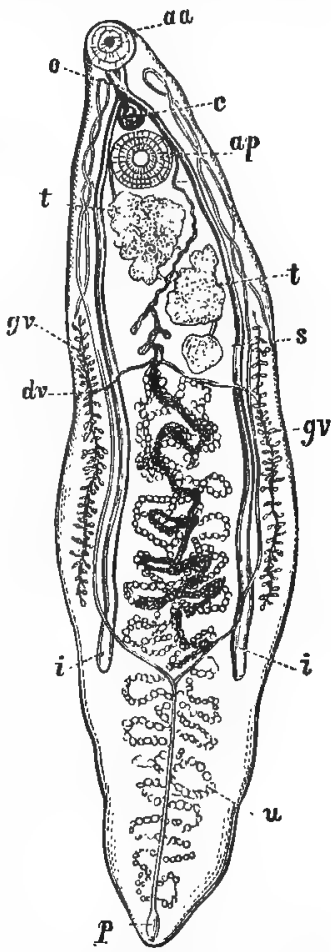

Fig. 74. - A Treinatode Worm (Distoma lanceolatum), enlarg. ed. a a Anterior sucker, with the mouth at its bottoin; $a p$ Posterior sucker; o Gullet, dividing behind into the two branches of the intestine, which are unliranched, and terminate behind in blind extremities $(i$ i) $; p$ External opening of the water-vessels, which divide above so as to cross the blind ends of the intestine. The remaining letters refer to the different parts of the reproductive organs. 
time in the water; but they finally attach themselves to a blade of grass, and surround themselves with a horny capsule. If now, the encapsulerl embryo should be swallowed by the sheep, along with

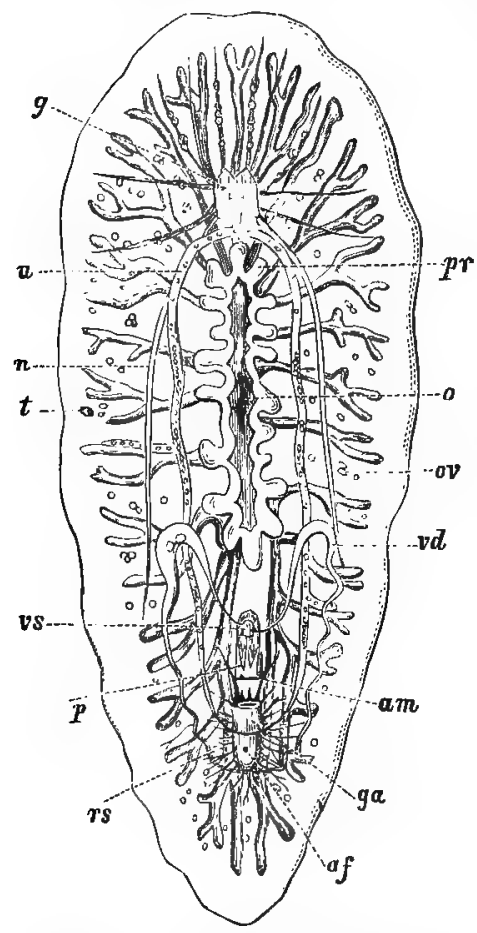

Fig. 75.-One of the Turbellarian W(irms (Lep)toplana tremellaris), enlarged. o Montl ; pr Proboscis; $g$ The irincipal nerve-ganglion, jlaced in the anterior part of the body, and giving off numerous racliating branches $(n)$; $p$ Penis; $v d$ Vas deferens; vs Vesicula semjnalis; am opening of male reproductive orans ; $t$ Testis; or Ovary ; $u$ Uterus, partly filled with pogs; of Opening of the female revituctive organs; rs Recertaculum seminis; gat Aluuniniyrarous gland.

the grass on which it feeds, the embryo escapes from its hown covering, and makes its way from the stomach of the sheep into the bile-ducts, where it becomes developed into the adult Liver-fluke.

\section{Order III. Turbellaria.}

The Turbellarian worms differ altogether from the preceding orders of Scolecids in being mostly aquatic in their habits and in being non-parasitic. They never possess sucking-discs or cephalic hooks, and their integument is always furnished with vibrating cilia. A water-vascular system is always present, but it appears simetimes not to conmunicate with the exterior. The alimentary canil is sometimes simply bollowed out of the tissues and lestitute of an anus, as in the Trematoda, and at other times suspended in a free space (body-cavity) and furnished with an anus. It may be simple or much irinched.

The best known of the members of this order are certain little, soft - bodied, ovate, or elliptical creatures, which are commonly found in fresh water or on the sea-shore, or in moist earth, and are known as flunurians. The skin in these curious little animals (fig. 75) is richly furnished with cilia, and also contains 
numerous cells which have been compared to the "nettle-cells" or "cnidre" of the Coelenterata. The intestine may be either straight or branched, but always terminates behind in blind pouches, and is never provided with an anus. The water-vascular system communicates with the exterior. The nervous system consists of two ganglia, placed in front of the mouth, and united by a cord. There are generally rudimentary eyes or pigment-spots, which vary in number from two to sixteen.

The remaining members of the Turbellaria are known as Ribbonworms (Nemertides), and are not uncommonly found in the sea, sometimes between tide-marks, sometimes at great depths, sometimes near the surface of the open ocean: occasionally they occur in moist earth. They differ from the Planarians in being worm-like in shape, by the fact that the alimentary canal is furnished with a distinct anus, and by the possession of a definite body-cavity.

\section{SECTION B. NEMATELM IA.}

\section{Order I. ACanthocephala.}

The "Thoru-headed Worms" included in this order are all internal parasites. They are worm-like in shape, marked with transverse wrinkles, and destitute of any mouth or alimentary canal. The anterior extremity of the body (fig. 76) forms a kind of proboscis or snout, which is armed with recurved hooks, and has placed at its base a single nervous ganglion. Beneath the skin is a network of canals, containing a clear fluid, and believed to represent the watervascular system. The Thornheaded Worms include some of the most formidable parasites with which we are as yet acquainted, the best known being the various forms of Echinorhynchus, which are found inhabiting the alimen-

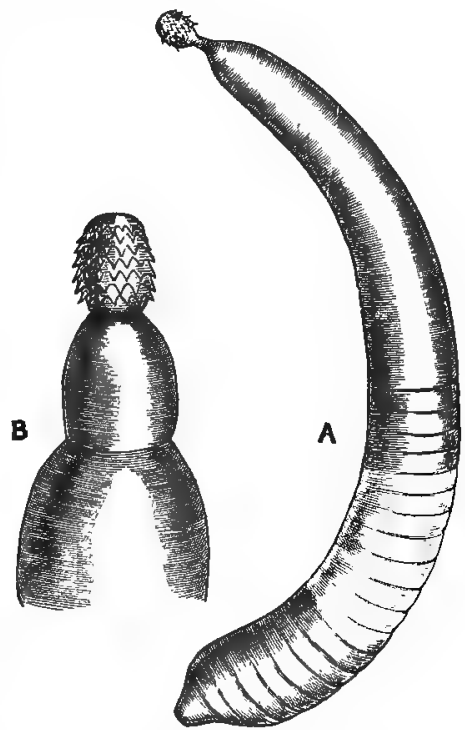

Fig. 76. - Acanthocephala. A, Echinorhynchus gigas, slightly enlarged. B, Head of the same, still further enlarged. 
tary canal in many Mammals, birds, and fishes. About one hundred and twenty species of Echinorhynchus are known, but it is doubtful if any mature example has been found in the human subject.

\section{Order TI. Gordiacea.}

The Gordiacea, or "Hair-worms," are elongated, worm-like, or hair-like Scolecids, in which the alimentary canal is without an

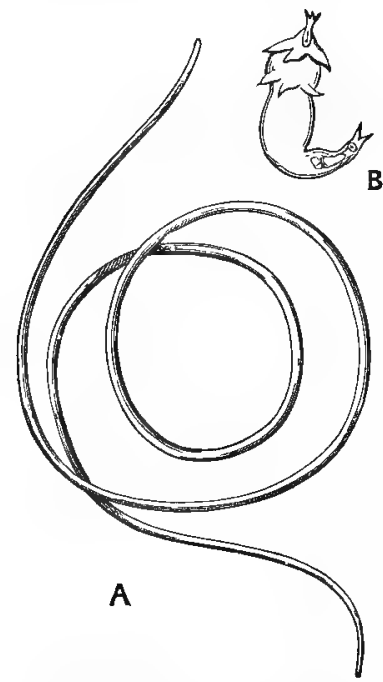

Fig. 77.-Gordiacea. A, A snuall individual of Gordius aruaticus, of the natural size. B, Larva of Gordius subjurcatis, with its piercing proboseis and two rows of hooks, enlarged. anus, and the sexes are in separate individuals.

The best known representative of this group is the common Hairworm (Gordius aquaticus, fig. 77) of Europe and North America. This curious worm is oftell found in ponds and rivers, and may be two or three feet long when mature. Other examples are found coiled up round the intestine of ground-beetles or grasshoppers; but it is not clear whether these are in a natural position, so to speak, or whether they may not be wandered individuals. In such cases, however, the worm ultimately leaves its insect-host, and betakes itself to water, where it lays long chains of white eggs. The embryo is at first free and locomotive, with three pairs of cephalic hooks (fig. $77, \mathrm{~B}$ ), and a little protrusible snout. It passes its next stage encysted in the larva of water-insects, into which it has bored its way, and then it gains access to the bodies of fishes which eat these larvie. Ultimately, however, it becomes free, and makes its way to land.

\section{Urder Ill. Nematoidea.}

The orler ltemrioidea includes the typical "Round-worms" and "Threal-worms," some of which are parasitic, while others lead a permanently free existence. The body is cylindrical, the integument being often annulated, but never ciliated. The mouth is placed anteriorly (fig. 78), and leads through a gullet $(g)$ to a strong 
muscular pharynx $(v)$. The intestine is freely suspended in the body-cavity, and a distinct anus is present. There are two lateral water-vessels which open ventrally in front by a common pore. The nervous system is a gangliated cord surrounding the gullet. The sexes are generally in separate individuals; and the males are usually fewer in number and smaller in size than the females.

Considerably more than a thousand species of Nematoid worms are known, of which a large number are permanently free. Good examples of the free Nematoids are the little "Vinegar-eel" (Anguillula aceti), the "Paste-eel" (Anguillula glutinis), and the common Anguillula fluviatilis of impure water.

A large number of the Nematoid worms are internal parasites, inhabiting the alimentary canal, the airpassages, the solid organs and tissues, or the blood-tubes of various animals; but it will be sufficient here to mention some of the commonest forms of these. The most abundant and familiar of these parasitic types is the common Round-worm (Ascaris lumbricoides), which may be six or eight inches in length, and is found inhabiting the small intestine of all races of men, but principally of children, often in great numbers. Another alnost equally common type is the small Thread-worm (Oxyuris vermicularis), which is less than half an inch in length, and is found inhabiting the large intestine, generally near its termination. It is generally found in children; but an allied type (Trichocephalus dispar)

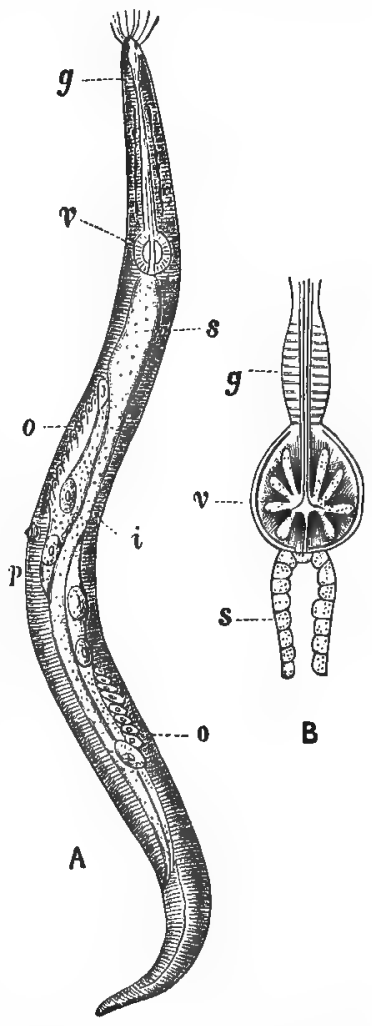

Fig. 78.-Nematoilea. A, Rhabditis bioculatu, female, enlarged. B, Portion of the alimentary tract of Oxyuris vermicularis, enlarged. $g$ Gullet; $v$ Muscular gizzard ; $s$ Chylific stomach, or anterior end of the intestine (i); $o$ o Ovaries; $p$ Genital pore. is often found in the large intestine of adults. Less common than any of the preceding is the singular Guinea-worm (Filaria medinensis), which is confined to the intertropical regions of both 
hemispheres, and which spends a portion of its existence buried in the cellular tissue which separates the muscles. It may attain a length of several feet, and has an extraordinary but still incompletely understood history. Equally famous is the little "Muscleworm " or Trirhine, which attacks man, pigs, \&c., and exists in two conditions. In one stage it is found buried in vast numbers in the muscles, each little worm-a thirtieth of an inch or less in lengthbeing enclosed in a little whitish capsule. When thus encysted, the Trinhince have no reproductive organs and are comparatively harmless. If, however, a portion of the infected muscle be eaten by another suitalle animal, the little Trichine escape from their cysts and develop reproductive organs. They then produce young, in vast numbers, within the intestine of their new host; and the young bore their way through the walls of the intestine, and travel into the muscles, where they surround themselves each with a little capsule, and lecome quiescent. When this stage has been reached, the animal attacked is in safety; but the migration of the worms from the intestine into the muscles usually gives rise to extremely serious or even fatal constitutional disturbance.

\section{SECTION C. ROTIFERA.}

The Rorijera, or "Wheel-animalcules," derive their popular name from the fact that the anterior end of the body is furnished with one or two circlets of cilia (fig. 79) which, when in motion, vibrate so rapidly as to produce the illusory inpression of a quickly rotating toothed wheel. The Rotifera are all aquatic, and are mostly inhabitants of fresh water. They are all microscopic in size, none attaining a greater length than 1-36th of an inch. In the females there is a distinct mouth, intestinal canal, and anus. A nervous system is also present, consisting of ganglia placed near the anterior extremity of the body and sending filaments backwards. There is, finally, a well-developed water-vascular system.

Most of the Rotifere are free-swimming active little animals (fig. 79, A), but sone are permanently tixed, as in Lelicerta (fig. 79, B) or in the Crowu-animalcule (Stephanoreros). They are usually simple, but they are sometimes composite, forming colonies. As a rule, the male and female Rotifera differ greatly from one another, the males being smaller than the females, devoid of any masticatory or digestive aj Juitutus, and more or less closely resembling the young forms of the sprecies. The males, in fact, merely lead a transient existence, and die as som as they have succeeded in fertilising the femaler. The body in most cases is very distinctly ringed or annulated (fig. 79, A), but is not composed of distinct rings separated by 
partitions. The integument is usually provided with bundles of muscular fibres taking. a longitudinal and transverse direction. In the free forms the anterior ciliated disc acts somewhat like the propeller of a screw-steamer in driving the organism through the water -in all cases it has the action of producing currents in the water by which particles of food are brought to the mouth. The posterior end of the body is usually developed in the free forms into a kind of tail or foot (fig. 79, A), which may take the shape of a kind of pincers or of a little suctorial disc.

As regards their internal anatomy, in the females of almost all
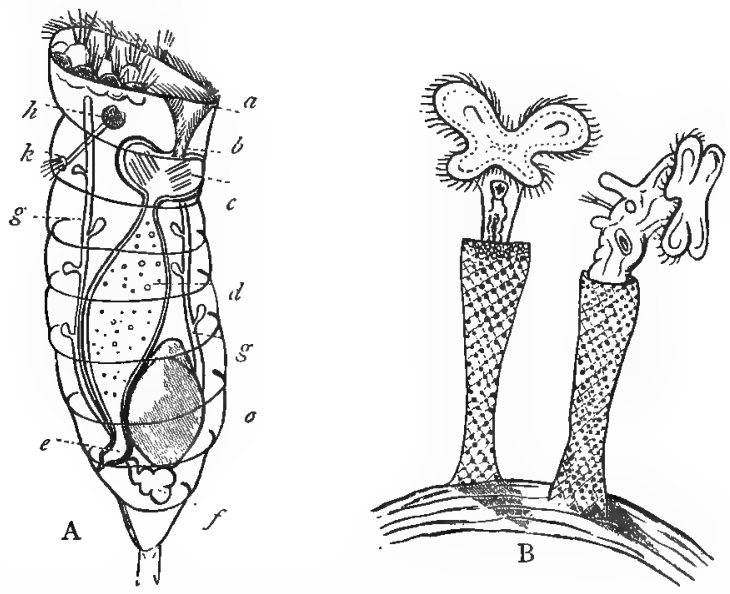

Fig. 79.-Rotifera. A, Diagrammatic representation of Hydatina senta (generalised from Pritchard): a Depression in the ciliated disc leading to the digestive canal ; $b$ Mouth ; $c$ Pharyngeal bulb with masticatory apparatus; $d$ Stomach; $e$ Cloaca ; $f$ Contractile bladder; g $g$ Respiratory or water-vaseular tubes; $h$ Nerve-ganglion, giving filament to ciliated pit (k); o Ovary. B, Melicerta ringens (after Gosse).

the Rotifera there is a well-develnped alimentary canal, which is completely shut off from the general cavity of the body. The mouth (fig. 79, $\mathrm{A}, b$ ) opens into a dilated chamber or "pharyngeal bulb" $(c)$, which contains a complicated apparatus of horny teeth. The pharynx opens into a capacious stomach $(d)$, continued into an intestine which terminates by a chamber known as the "cloaca" (e), which forms the common outlet for the water-vascular and generative systems. In both sexes there is a well-developed water-vascular system consisting of a contractile chamber or bladder $(f)$, opening into the cluaca, and giving origin to two complicated tubes which 
are known as the "respiratory tubes" $(g g)$, and which terminate near the anterior end of the body, apparently by blind extremities. The nervous system is in the form of a large double ganglion placed above the gullet, and having one or two eye-specks placed upon it. The ovaries $(o)$ crnstitute conspicuous organs in the female Rotifera, but in summer the young Rotifers appear to be produced by the females without having access to the males.

The Rotifera were long confounded with the Infusoria, in consequence of their great similarity in external appearance. They are, however, fundanentally distinguished from the Infusorians by their possession of a definite body-cavity, the presence of a well-developed alimentary canal, and the possession of a nervous system and of proper reproductive organs, while their development is also quite different. 


\section{CHAPTER XII.}

\section{ANAR'THROPODA.}

THE Anarthropoda or higher groups of the Worms have the body distinctly segmented, but the segments are generally numerous (often indefinite in number), and are mostly similar to each other except. at the two extremities of the body. Lateral appendages may be wanting; but when they are present, they are not articulated, nor are they jointed to the body. The nervous system has the form of

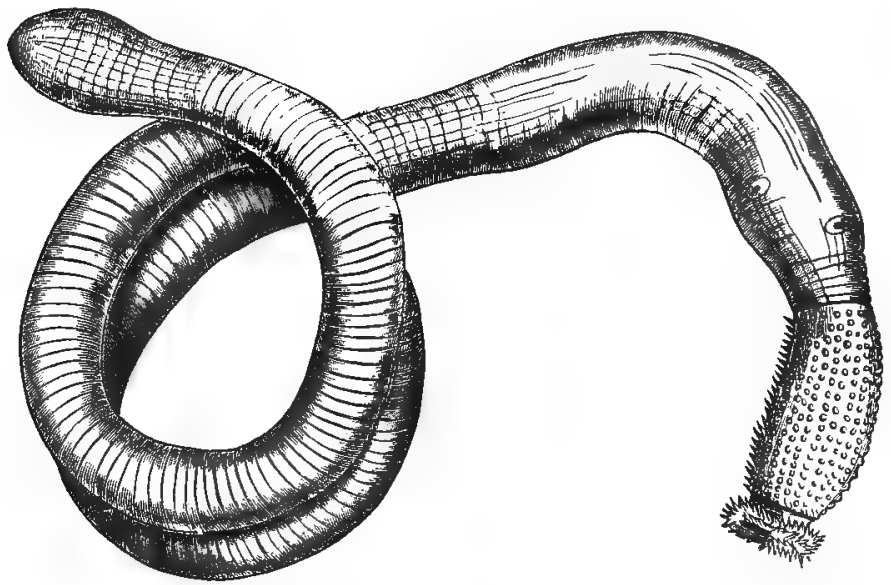

Fig. 80.-Gephyrea. Sipunculus Intlicus, of the natural size. (After Keferstein.)

a ventral chain of ganglia, the first pair of ganglia lying above the gullet. Cilia are generally developed. There is no proper heart or system of blood-vessels; but there is generally a system of tubes, filled with a coloured fluid, often furnished with contractile dilatations, and sending branches to the breathing organs, which take the 
jlace of the proper vascular system, and which are known as the "pseudohæmal" vessels.

The two principal groups included in this division of Annulose animals are the Gipleyrea (Spoon-worms) and the Innelida (Ringed Worms).

\section{Class I. Gephyrea.}

This is a small group, including a number of worm-like animals, commonly called Spoon-worms, which in many respects resemble the Annelides, and have at the same time certain relationships with the Holothurians among the Echinoderms. They differ from the Annelides in not having the body definitely segmented, though the skin is amulated (fig. 80), and also in the fact that the ventral nerve-chain is not gangliated. There are no lateral appendages, except occasionally bristles. They differ from the Holothurians in the want of an ambulacral system and the non-radiate character of the nervous system. The Spoon-worms are all marine, and the most widely distributed genus is Sipunculus (fig. 80), which ranges from between tide-marks down to a depth of 2500 fathoms.

\section{Class II. Axwelida.}

The dinelide or Aluenlato, commonly known as Ringed Worms, are distinguished by the possession of definite segmentation, the body being composed of a number of rings which are all similar to each other except at the two ends of the body. All the Annelida are more or less worm-like in shape, and in all except the Leeches, the segments are (some or all) provided with lateral appendages which mostly suliserve locomotion, but which are never jointed to the body. In the typical Innelida each segment (fig. 81) consists of two arches, termed, from their position, respectively the "dorsal arc" $(r l)$, and the "ventral arc" $(v)$. Each segment carries a lateral process on each side, which are known as the "foot-tubercles" (parapodit). Each foot-tubercle in turn may consist of an upper piece or "dorsal oar" ( 1 ), and a lower piece or "ventral oar" $(b)$, both carrying a tuft of bristles and a soft jointed filament (the "cirrus").

The nervous system consists essentially of a double gangliated chain placed along the ventral surface of the body, and traversed in front by the gullet, so that the first pair of ganglia lie above the gullet. The digestive system consists of a mouth, generally with a protrusible proboscis, and sometimes horny jaws, a gullet, stomach, intestine, and a distinct anus. As a rule, the ilimentary canal runs straight from one enl of the lorly to the other without describing 
any convolutions in its course. In almost all cases the alimentary tube is placed in a distinct perivisceral cavity, which contains a fluid with solid particles in it, corresponding to the blood of the higher animals. In most, if not all, there is further a system of vessels which carry a coloured fluid, which are contractile, and which send branches to the respiratory organs, when these exist. This system is believed not to correspond to the blood-vascular system of the higher animals, and it has therefore been termed the "pseudohæmal" system (Gr. pseudos, falsity; and haima, blood). It is believed, on the other hand, to be truly homologous with the watervascular system of the Scolecida. Respiration is effected by the general surface of the body, or by distinct gills or branchiæ. In

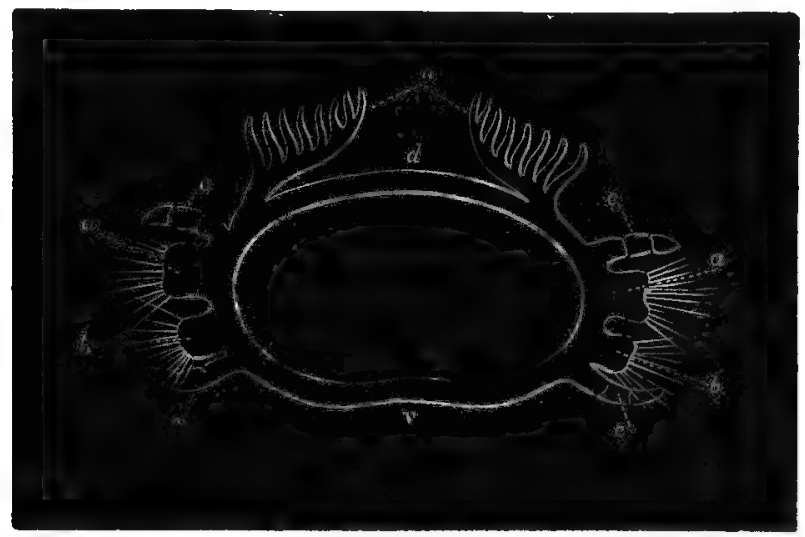

Fig. 81.-Diagrammatic transverse section of an Anneline. $d$ Dorsal are; $v$ Ventral are; $n$ Branchiæ; $a$ Notopodium, or dorsal oar; $b$ Neuropodium, or ventral oar, both carrying setæ and a jointed cirrus (c).

most cases, also, there exists a series of peculiar tubular involutions of the integument, which are known as the "segmental organs." The segmental organs open on the surface of the body by minute apertures, and generally have the form of coiled or folded tubes, which may terminate blindly internilly (Leeches), or which open at their inner ends into the perivisceral cavity. In the latter case, the internal openings of the "segmental organs" are usually funnelshaped and ciliated, and they often serve to convey the generative products to the exterior. The "segmental organs" correspond, in a general way, with the kidneys of the higher animals. The sexes in the Annelidls are sometimes distinct, sometimes united in the same 
individual. The embryos are almost always ciliated, and many of them pass through a metamorphosis.

The so-callerl "Abranchiate" Annelides are the Leeches and Earth-worms, in which respiration is carried on principally through the soft moist integument. On the other hand the marine Tubeworms and Sand-worms possess, as a rule, external processes adapted for respiration in water, and these are known as the "Branchiate" Annelides.

\section{Order I. Hirtuinea.}

The Hirudinea or Discophora are well known under the name of Leeches, some forms being marine, while others inbabit fresh water, and a few live in moist places on land. The Leeches are characterised

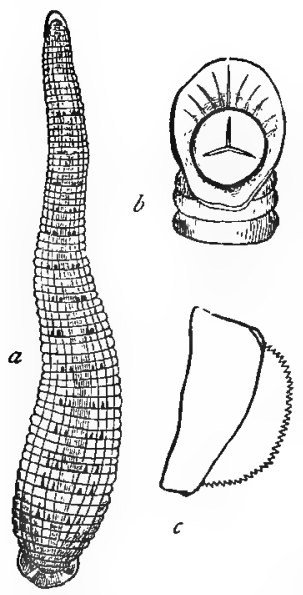

Fig. 82,-Hirudinea. a The Medicinal Leedı (San!nuisuga officinclis), natural size; 1 , Anterior extremity of the same magnified, showing the sucker and trirarliate jaws; c One of the jaws detached, sliowing the semicircular twothed margin. by the fact that the body is destitute of lateral bristles or foot-tubercles, but is provided with a sucking-disc at one or both extremities. In the typical forms, as in the common Medicinal Leech (fig. 82), there are sucking-discs at both ends of the body, and in those in which only the hinder sucker is present, the head can be converted into a suctorial cavity. Locomotion is effected either by means of the alternate fixation and detachment of the suckers, or by a serpentine bending of the body.

The body is obviously ringed or annulated, but none of the rings carry lateral appendages of any kind. The mouth is sometimes destitute of teeth, but is sometimes armed with complex jaws. The alimentary canal is short, with lateral jouches, and united to the skin by means of a spongy vascular tissue, so that the body-cavity is obliterated. The pseudohimal system is well developed, and consists essentially of four grent longitudinal ve'ssels. The segmental organs are partially tubular and partially saccular, and open on the lower surface by minute pores, while they terminate blindly internally. The nervous system has its usual form, and the ganglia in front of the gullet ("pretosophageal" ganglia) give off branches to a number of simple 
eyes which are placed on the head. The sexes are united in the same individual.

The most familiar of the Leeches are the common Horse-leech (Hamopsis), and the Medicinal Leech (Sanguisuga officinalis). The latter is provided with three semicircular toothed jaws (fig. 82, $b, c$ ), which meet in a point, and are sufficiently powerful to cut through the human skin. The Medicinal Leech is a native of fresh waters throughout the south and enst of Europe, and it is imported in large numbers from Hungary, Bohemia, and Russia.

In the Horse-leech the jaws are comparatively blunt, and the animal has only the power of cutting through the soft mucous membranes. It derives its name from the fact that it attaches itself to the mucous membrane of the mouth in horses whilst drinking at ponds or marshes.

\section{Order II. Oligochete.}

In this order are included the Earth-worms (Lumbricidce), and the Water-worms (Naïdidoe). They are all distinguished from the preceding by the fact that the body is furnished with rows of bristles (fig. 83, A), which take the place of the foot-tubercles of the higher Annelida, and which are the organs of locomotion. They are distinguished from the higher forms by the fact that the locomotive bristles are comparatively few in number, hence the modern name of the order (Gr. oligos, few ; and chaité, a bristle). In the common Earth-worm (Lumbricus terrestris, fig. 83, B), the body is cylindrical, attenuated at both ends, and furnished with eight rows of short locomotive bristles. The mouth is destitute of teeth, and opens into a gullet which leads to a muscular crop, succeeded by a second muscular dilatation or gizzard. The intestine is continued straight to the anus, and is constricted in its course by numerous transverse partitions springing from the walls of the body-cavity, and corresponding with the successive segments of the body. The pseudohæmal system is well developed, and the dorsal vessel carries a series of contractile dilatations or "hearts." The segmental organs are long coiled tubes, which open by minute apertures on the ventral surface, and communicate internally with the body-cavity. The Naididce are chiefly noticeable on account of the power which many of them possess of producing fresh individuals by a process of budding before they attain sexual maturity. One of the commonest of them is a little worm (Tubifex rivulorum, fig. 83, A), which occurs abundantly in many of our pools and streams, and which exhibits a fine red colour, owing to the 
pseudohæmal system being visible through the transparent integument.
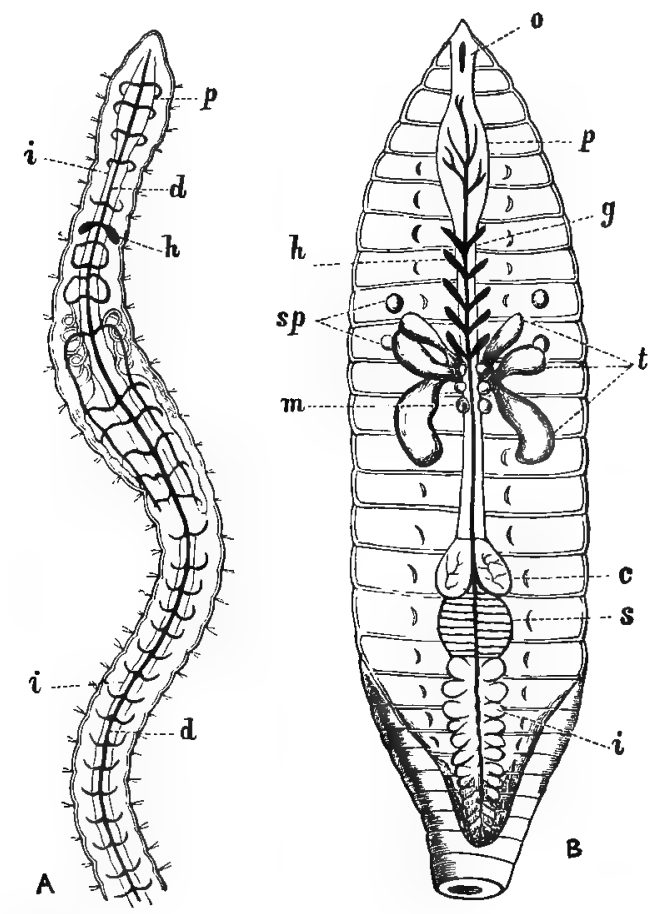

Fig. 83. - Oligrichata. A, Anterior portion of Tubifex rivulomm, enlarged: $p$ Pharynx; $i$ i Alimentary canal; $d d$ Dorsal vessel ; $h$ One of the "hearts" or contractile dilatations of the pseudohæenal vessels. B, Anterior portion of Lumbricus terrestris, laid open and enlarged : $o$ Mouth ; $p$ Plıarynx; $g$ Gullet; $m$ Esophageal glands ; $c$ Proventriculus; $s$ Gizzard ; $i$ Intestine; $h$ One of the "hearts," bome on the side of the dorsal vessel; $t$ Testes ; $s p$ Spermatheca. (After Lankester.)

\section{Order III. Polycheta.}

In the so-called Polychretous Annelides, the animal is furnished with locomotive organs in the form of "foot-tubercles," carrying tufts of bristles (fig. 81). Branchixe are generally present, in the form of outgrowths of the integument, richly supplied with branches of the pseudohæmal vessels. The Polychretous Annelides are all marine, and are of very varied halits. They may be con- 
veniently divided into two groups, according as they secrete for themselves a protective tube (Tubicola), or live a free life ( $E_{r} r-$ rantia); but the general organisation in these two sections is essentially the same.

The Tubicolous Annelides or Tube-worms derive their name from the fact that they have the power of protecting themselves by means of tubes (Lat. tuba, a tube ; and colo, I inhabit). In some cases (fig. 84) the tube is composed of carbonate of lime, and is a genuine secretion from the body. In other cases, the tube is composed of grains of sand or pieces of broken shell, cemented together by a glutinous secretion from the surface of the body. In all the Tubicola the respiratory organs are in the form of branched filamentous external gills, in which the fluid of the pseudohæmal system is subjected to the action of the outer water. They are therefore "Branchiate" Annelides. As they live in tubes,

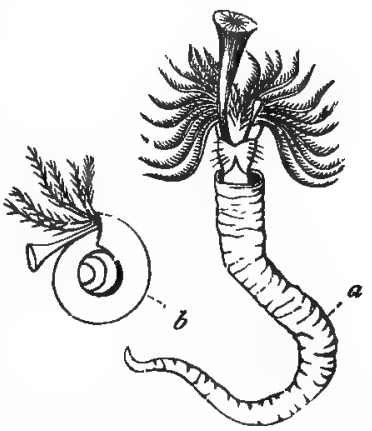

Fig. 84.-Tubicola. a Serpula contor. tuplicata, showing the branchiæ and operculuin; $b$ Spirorbis communis. however, and do not voluntarily expose more than the anterior end of the body, the branchiæ are all placed on or near the head. The filaments of which the gills are composed (fig. 84, $a$ ) are richly ciliated, and as the pseudohæmal fluid is usually red, they have generally a beautiful scarlet colour.

The most familiar of the Tubicola is the Serpula (fig. 84, a), the contorted and winding tubes of which must be known to every one as occurring on shells or stones on the sea-shore. One of the cephalic filaments in Serpula is much developed, and its extremity forms a kind of conical plug or "operculum," which serves to close the mouth of the tube when the animal is retracted within it. In Spirorbis (fig. 81, b) the shelly tube is coiled into a flat spiral, which is fixed to some solid object. It is of extremely common occurrence on the fronds of sea-weed, and on other submarine objects.

The so-called "Errant" Annelides (Tat. erro, I wander) are so called because of their "roving" habits, the animal leading a free existence, and not being confined in a tube (fig. 85). They have always lateral unjointed appendages, or foot-tubercles, which carry tufts of bristles, and a soft jointed filament or cirrus. The anterio: rings of the body are usually so modified as to form a sort of head, 
which is provided with eyes and with two or more feelers, which differ from the antemue of Insects and Crustaceans in not being jointed. The mouth is placed on the inferior surface of the head, and is sometimes furnished with one or more pairs of horny jaws which work from side to side. The upper part of the alimentary canal is muscular, and can be turned inside out, or protruded beyond the true olening of the mouth. The pseuduhiemal system is well developed, and its contained fluid is mostly red. Respiration is

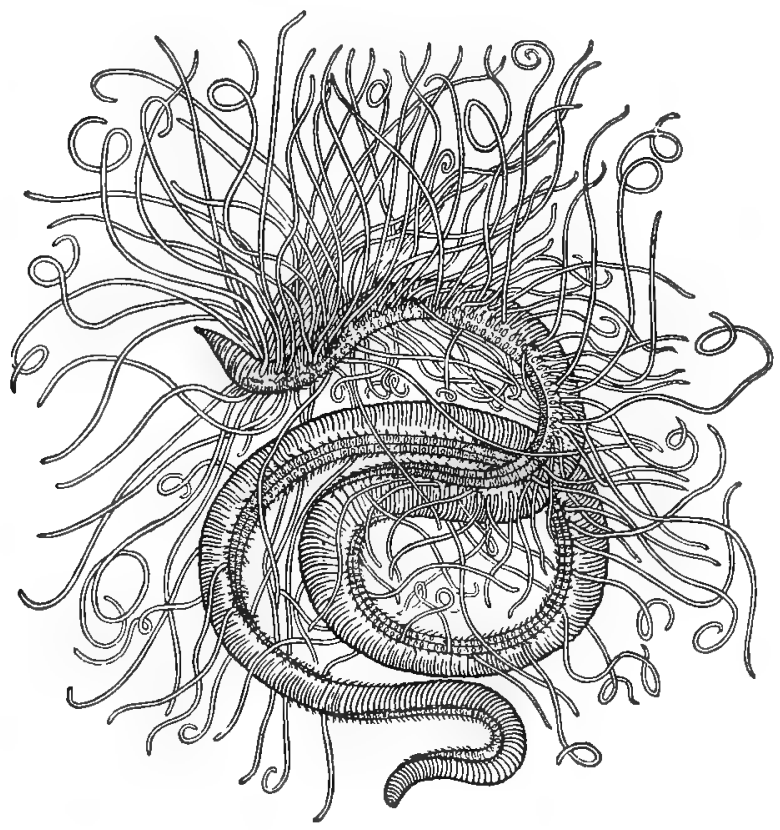

Fig. 85.-Cirrhatulus grandis, an "Errant Amnelide," in its living condition. (After Verrill.)

effected ly external processes, gills or branchiæ, arranged in tufts placed alung the silles or back of the body, and not confined to the immerliate neighbourhood of the head, as in Tubicola. The sexes are in different indivichuals, and the young pass through a metanorphosis.

Amongst the best known and commonest of the Errant Annelides are the common Lob-worm (Arenicola piscatorum); the Sea-centi- 
pedes (Nereis); and the Sea-mice (Aphrodite and Polynoe), some of which attain a large size, and are conspicuous for their iridescent bristles. Other less abundant forms may be readily obtained by searching under stones at low water. In one remarkable Annelide, from the Philippine Islands, the body is branched, and thus becomes truly composite. A few of the Errant Amnelides live in the open ocean. 


\section{CHAPTER XIII.}

\section{ARTHROPODA.}

\section{General Characters of the Arthropoda. 2. Characters}

\section{and Divisions of the Crustacea.}

THE remaining nembers of the sub-kingdom Ainnulosa are distinguished by the possession of jointed appendages, articulated to the body; and they form a great primary division-often called by the name Aiticulata. As this name, however, has been employed in a wider sense than is understood by it here, it is perhaps best to adopt the more modern term Arthropoda.

The members of this division, comprising the C'rustacea (Lobsters, Crabs, \&c.), the Aracknida (Spiders and Scorpions), the Myriapoda (Centipedes), and the Insecta, are distinguished as follows :-

The body (fig. 71) is composed of a series of segments, arranged along a longitudinal axis ; each segment or "somite," occasionally, and some almost always, being provided with articulated appendages. Both the segmenterl body and the articulated limbs are more or less completely protected by a chitinous exoskeleton, formed by a hardening of the cuticle. The appendages are hollow, and the muscles are prolonged into their interior. The nervous system in all, at any rate in the enubyonic condition, consists of a double chain of ganglia, placed along the ventral surface of the body, united by longitudinal commissures, and traversed anteriorly by the osophagus. The blood-system, when differentiated, is placed dorsally, and consists of a contractile cavity, or heart, provided with valvular ilpertures, and comnumicating with a perivisceral cavity, containing corpusculated bloor. Respiration is effected by the generil surface of the body, by gills, by pulmonary sacs, or by tubular involntions of the integument, termed "tracheæ." In no nember of the division are vibratile cilia known to be developed.

The Arthropoda are divided into four great classes-viz., the 
Crustacea, the Arachnida, the Myriapoda, and the Insecta; which are roughly distinguished as follows :-

1. Crustacea.-Respiration by means of gills, or by the general surface of the body. Two pairs of antenne. Locomotive appendages more than eight in number, borne by the segments of the thorax, and, usually, of the abdomen also.

2. Arachind.-Respiration by pulmonary vesicles, by trachea, or by the general surface of the bady. Head and thorax united into a cephalothorax. Antenna (as such) absent. Legs eight. Abdomen without articulated appendages.

3. Myriapoda.-Respiration by trachea. Head distinct; remainder of the body composed of nearly similar somites. One pair of antenna. Legs numerous.

4. INSECTA.-Respiration by trachece. Head, thorax, and abdomen distinct. One pair of antemna. Three pairs of legs borne on the thorax. Abdomen destitute of limbs. Generally two pairs of uivgs on the thorax.

\section{CLASS I. CRUSTACEA.}

The members of this class are commonly known as Crabs, Lobsters, Shrimps, Prawns, King-crabs, Barnacles, Acorn-shells, Wood-lice, \&c. They are nearly allied to the succeding class of the druchnicla (Spiders and Scorpions), but are distinguished by their adiuptation to a more or less purely aquatic life, by having jointed appendages upon the hinder segnents of the body (abdomen), and by the possession of two pairs of antennæ. As a cliss, the Crustacea are distinguished by being usually furnished with branchire, or respiratory organs adapted for breathing air dissolved in water, by having more than four pairs of legs, by having a well-developed chitinous or partially calcareous "crust" or external skeleton, by the fact that some of the appendages are generally so modified as to act as organs of mastication, and by passing through a metamorphosis before attaining their adult condition.

The body in a typical Crustacean is composed of twenty-one distinct segments or somites, placed one behind the other. These segments are distributed in three distinct divisions, known respectively as the "head," the "thorax" and the "abdomen" or tail, each of which is usually regarded as being composed of seven segments. In very many cases, however, the fourteen segments belonging to the head and thorax are amalgamated together into a single mass, which is termed the "cephalothorax," thus leaving seven segments to the abdomen.

Each segment or "somite" (fig. 86) may be regarded as com- 
posed of a convex upper plate $(t)$ and a flatter ventral arch $(s)$, and each may support a single pair of appendages. Typically, each appendage in a Crustacean consists of a short basal portion or "pro-

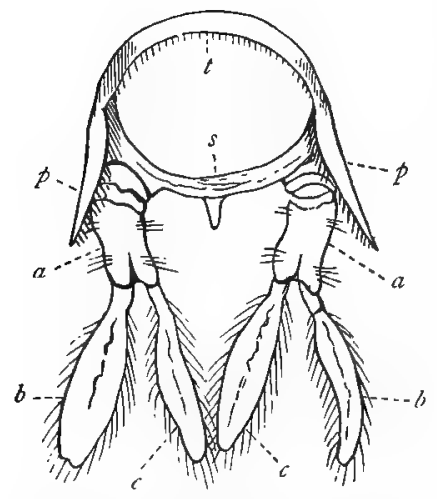

Fig. 86.-The third abdominal segment of the Lobster. $t$ Dorsal areh; $s$ Ventral arch of the segment; $a$ Protolodite; $b$ Exopodite ; $c$ Endopodite.

topodite" (fig. 86, a), which gives origin to an outer and an inner branch or division, known respectively as the "exopodite" (b) and the "endopodite" (c). Very commonly one of the two divisions of the appendage may be wanting; or in some cases both are absent, and the appendage may be reduced to the protopodite only. A certain number of the appendages of the anterior segments are usually converted into masticating organs, some of which may be proper biting jaws (mandibles and maxillæ), while others are merely limbs so far modified as to act as subsidiary jaws ("foot-jaws" or maxillipedes). The last segment of the body-known as the "telson"-carries no appendages, and is often regarded as not being properly a segment, but an umpaired appendage.

The C'rustacea form an extremely large group of animals divided into many orders, and it will be sufficient to merely notice many of these in the briefest manner. It will also be as well to commence with the cousideration of the higher sections of the class first.

\section{Order Decapoda.}

The Crustrrece included in this order derive their name from the fact that they all possess five pairs of legs (Gr. deka, ten; podes, feet). They belong to a large section known as the "stalk-eyed" Crustaceans (Podlophthalmutu), from the fact that the eyes are supported by long, novable stalks. They all further have the cephalothorax covered by a great shield or "carapace," under which the gills are carried. They include the Lobsters, Shrimps, Cray-fish, Crals, Hermit-crabs, and other forms, and are the most highly organised and most familiar of the whole class of the Crustacea. They are divided into three very well marked groups or tribes, all of which can be exemplified by familiar types. 
A. Macrura.-The name of Macrura (Gr. makros, long ; and oura, tail) is given to those ten-footed Crustaceans which have a long and well-developed tail or atbdomen. Amongst these are the Lobster, Shrimp, Prawn, and Cray-fish, of which the Lobster or Cray-fish may be selected as a good typical example.

In the Lobster or Cray-fish (fig. 87) the body is at once seen to be composed of two parts, familiarly called the "head" and "tail."

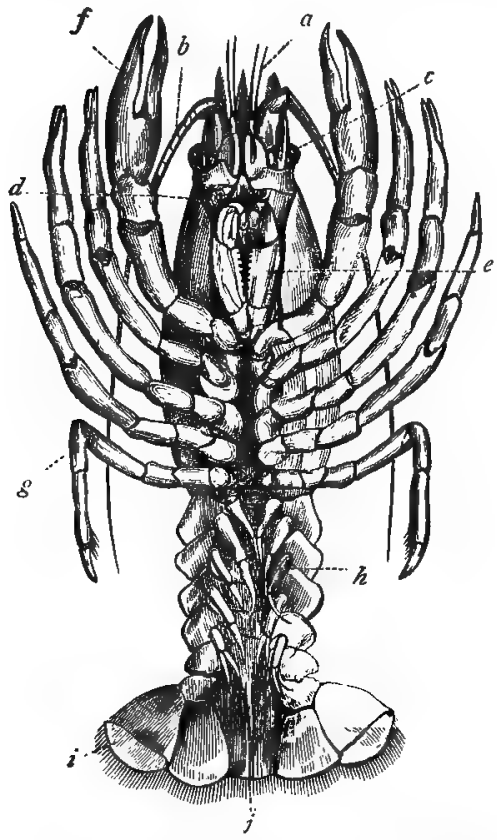

Fig. 87. -The common Cray-fish (Astacus fluviatilis), viewed from below. a Antennules; $b$ Large antennæ ; $c$ Eyes ; $d$ Opening of auditory sac; $e$ Last pair of foot-jaws; $f$ One the great chelr; $g$ Fiftl thoracic limb; $h$ Swimmerets; $i$ The last pair of swimmerets; $j$ The opening of the anns below the telson.

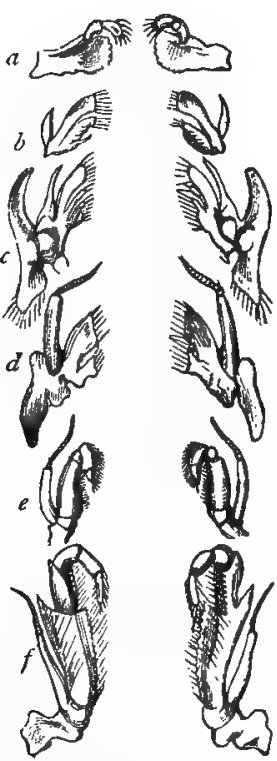

Fig. SS.-Masticatory organs of the Cray-fish (Astacus fluviaitis). a Mandibles ; $b$ Maxillæ; c Second pair of maxillæ; $a$ First pair of foot-jaws; $e$ Seeond pair of foot-jaws; $f$ Third pair of foot-jaws.

The so-called head is covered by a great shield termed the "carapace," and it is in reality the cephalothorax, being composed of the amalgamated segments which belong to the true head and to the thorax. The so-called tail is really the abdomen, and it is composed of a number of segments which are not immovably united together, 
as in the cephalothorax, but are movably jointed together. The various appendages of the animal are arranged in pairs on the under surface of the body ; and where the segments are completely amalgamated (as in the cephalothorax), their existence may nevertheless be determined by the presence of the successive pairs of appendages. The first segment of the head carries a pair of compound eyes, made up of a number of simple lenses aggregated together, and supported upon long and movalble eye-stalks. Behind these come two pairs of jointed organs of touch, which are known as the "antennæ." The front pair is much smaller than the hinder pair, and they are known respectively as the "lesser antennæ," or "antennules" (fig. 87, a), and the "great antennæ" (e). Behind these, again, comes the mouth, which is placed on the under surface of the head, and is provided with a complicated series of masticatory organs. It is umnecessary to describe these minutely, but it should be noticed that they are all modified limus, and therefore differ altogether from the jaws of the Vertebrate animals. That this is their real nature is shown most obviously in the hindermost pairs of these jaws, which are so little altered from ordinary legs that they are known as "foot-jaws" (fig. 88, $f$ ). The last five segments of the thorax carry five pairs of walking-legs, hence the name Decapoda applied to the orler. Of these legs, the first three pairs have their extremities converted into nipping-claws or "chelee," and the first pair is much larger than the others, and constitutes the wellknown great claws of the Lolster. The last two pairs of legs simply terminate in pointed extremities, and not in pincers. The segments of the abdomen, with the exception of the first and the hindmost, carry each a pair of paddle-like appendages, which are used in swimming, and are cilled the "swimmerets." The last pair of swimmerets are attached to the last segment but one, and are very greatly expanded, so as to form a very powerful tail-fin (fig. 87, $i$ ). The last segment of all is known as the "telson" $(j)$, and is not provided with any lateral appendages.

The mouth in the Lobster leals by a short gullet into a globular stomach, which is furnished with a calcareous apparatus for grinding down the food, commonly called the "lady in the lobster." The intestine is continued liak wards from the stomach without convolutions, and opens by a distinct anus placed in front of the telson. A well-developed liver is also present. The heart is placed dorsally, and is filled with aerated blood derived from the gills, which it propels through every lant of the bolly. The gills, or branchiæe, are pyramidal bodies attached to the bases of the legs, and placed in a kind of chamber formed beneath the great shield, or carapace, on each side of the body. 'They consist each of a central stem support- 
ing numerous lateral branches, and they are richly supplied with blood. The water which fills the gill-chambers is constantly renewed by the movements of the legs, and thus the gills are kept constantly supplied with fresh water. The nervous system is placed along the ventral surface of the body, and has its usual form. The organs of sense are the two pairs of feelers or anteunæ, the compound eyes, and two organs of hearing.

$B$. Anomura. -The most familiar members of this tribe are the Hermit-crabs (Pagurida) which occur so commonly on ever'y shore.

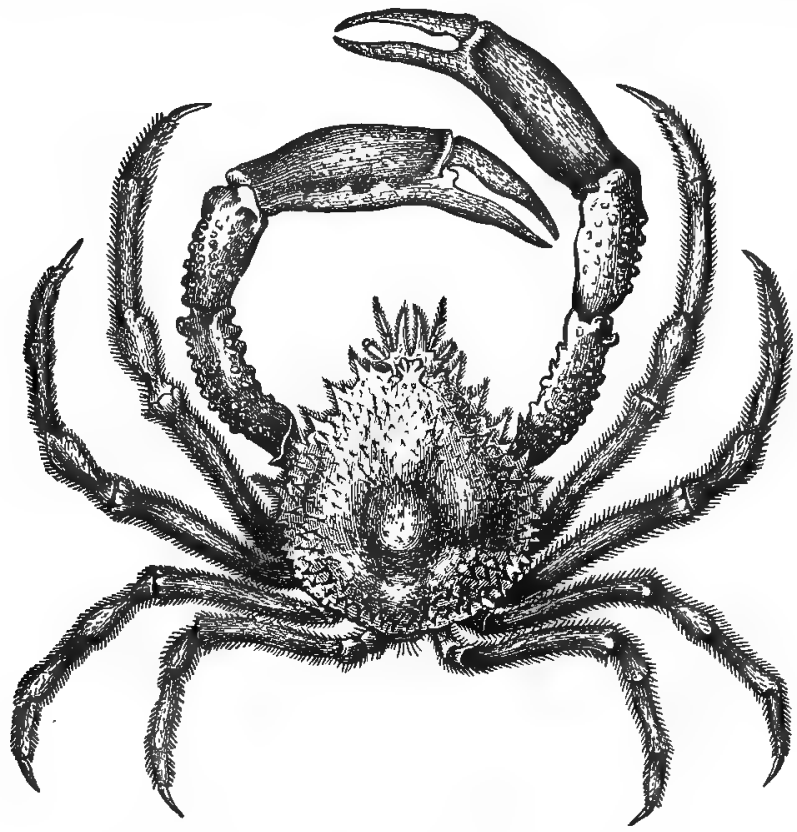

Fig. 89.-Brachyura. The Spiny Spider-crab (Maia squinado).

They are distinguished by the fact that the abdomen is quite soft, and is not protected by a chitinous crust. The animal, therefore, is compelled to protect the defenceless part of the body in some artificial manner, and this it effects by appropriating the empty shell of some dead Mollusc, such as the common periwinkle or whelk. The abdomen is provided with special appendages to enable the intruder to retain firm hold of his borrowed dwelling, at the same time that he can change it at will when too small or otherwise inconvenient. 
The first pair of legs are developed into pretty powerful nippingclaws or chelæ, and one of them is always much larger than the other, and acts as a kind of plug, blocking up the entrance of the shell when the animal is retracted within it.

C. Brachyura.-The Decapod Crustaceans inclucled in this tribe are familiarly known as Crabs, and they derive their name of Brachyura (Cir. brachus, short; and oura, tail) from the rudimentary condition of the abdomen. The abdomen, in fact, is not only extremely short, but it is always tucked up beneath the greatly developed cephalothorax, so that it is not visible at all, except when the animal is looked at from below (fig. 89). The (rrabs have very various habits, but they are mostly denizens of the shore, hiding beneath stones or sea-weel, in cracks of rock, or in pools near the line of low-water. Some of them, however, can swim with tolerable activity, and some

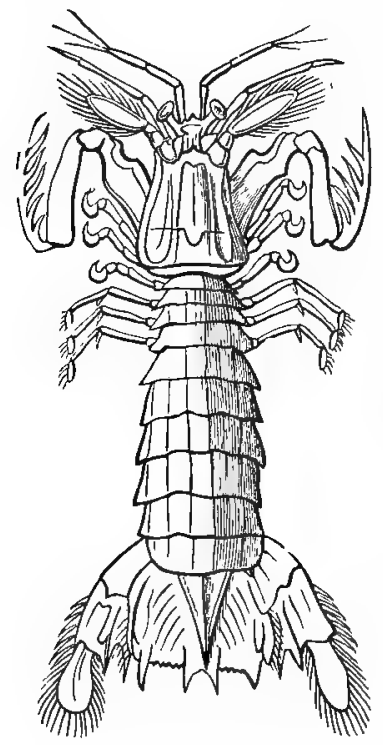

Fig. 90.-Squilla montis, the LueustShrimp. of them (the Land-crabs) even live habitually iuland. One group, that of the "Pea-crabs," is distinguished by the singular habit of living semiparasitically within the shells of bivalve Molluscs, such as the great horse-mussel or the oyster.

The young or larval Crab is exceedingly unlike the adult, and has a long and well-developed abdomen, thus approximating to the type of structure which is permanently retained in the Macrura.

\section{Order Stomapoda.}

The Stomapod Crustaceans are nearly allied to the Decapods, but they have six or eight pairs of legs, and the gills are not placed in chambers on the under surface of the thorax, but are usually suspended beneath the abdomen. They are almost all marine, and the LocustShrimp or Squilla (fig. 90) may be taken as the type of the order. In this crustacean the abdomen is well developed, and its terminal appendiuges form a broad swimming-tail. The front pairs of legs are hooked, and the gills are attached to the first five pairs of abdominal feet. 


\section{ORDER ISOPODA.}

In this order are a number of Crustaceans, of which some inlabit the sea, others are parasitic in their habits, and others are terrestrial. Of the terrestrial forms the common Wood-lice (Oniscus) are familiar examples. Of the aquatic types, the Water-slaters (Asellus) inhabit fresh waters; but the Rock-slaters (Ligia) and Box-slaters (Idotea) are marine, as are many others. The parasitic forms live upon fishes or other Crustaceans, and have often become much altered by retrograde metamorphosis.
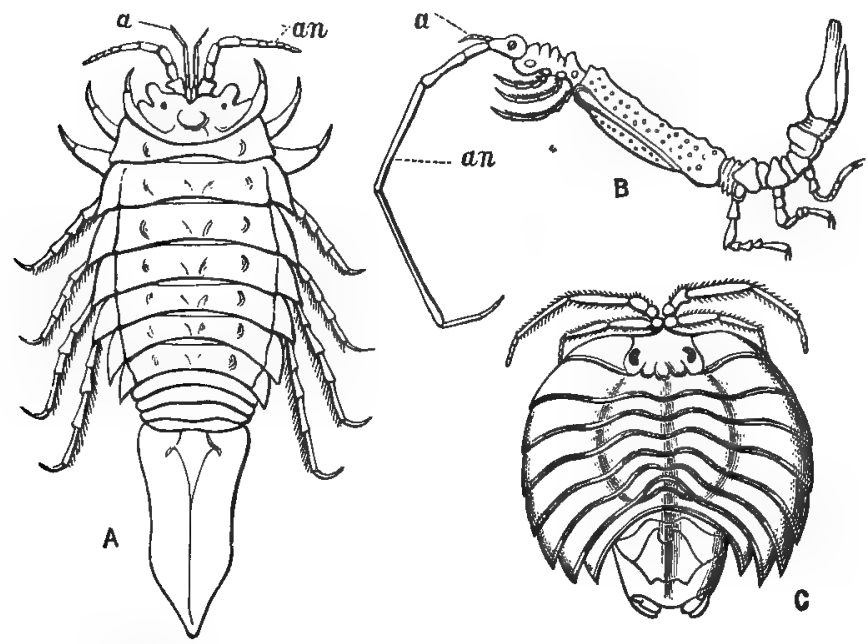

Fig. 91.-Isopoda. A, Idotea entomon, enlarged. B, Arcturns longicornis, enlarged. C, Serolis Scythei. a Antennules; an Antenna. (After Gerstreker, Spence Bate and Westwood, and Lutken.)

The Isopod Crustaceans all belong to a section of the class Crustacea, in which the eyes are not supported upon movable stalks, and they are therefore said to be "sessile-eyed" (Hedriophthalmata). The head is distinct, and the thorax carries seven pairs of legs; while the branchize are attached to the under surface of the abdomen, the segments of which are often coalescent.

\section{Order Amphipoda.}

This order comprises small Crustaceans, in which the breathingorgans are in the form of membranous vesicles attached to the bases 
of the thoracic legs. There is a well-developed abdomen, and there are seven pairs of thoracie legs, clirected partly forwards and partly bickwalids. Good examples are the Sand-hoppers (Talitrits, fig. 92, A) and the "Fresh-water Shrimps" (Gammarus, fig. 92, B).

The Sand-hoppers and Gammari swim on their side when in the water, and the former leap with great activity on land.

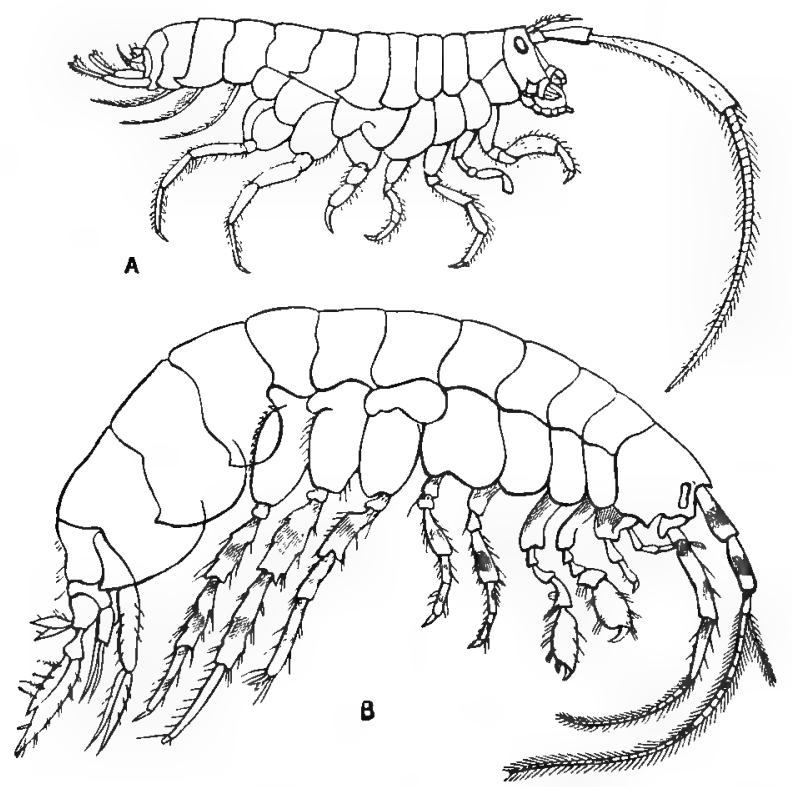

Fi:. 92. Amphiporla. A, Talitmes 7ocusta, the "Sand-hopper," enlarged. B, Gammarus locusta, enlarged about four times. (After Spence Bate and Westwood.)

Nearly related to the Amphipods are a number of little Crustaceans ( $L_{1} m$ mipold $)$, in which the abdomen is quite rudimentary. Some of these (e.g., the Whale-lice) are parasitic in their habits, and all inhavit the sea.

\section{Urder Merostomat.}

In this order are only the living King-crabs (Limulus), and some large extinct forms nearly allied to then. They are all distinguished by the fact that the appendages which are placed round the mouth act by their bases as jaws, but have their extremities developed into swimming-paddles, walking-feet, or nipping-claws. 
The King-crabs (fig. 93) constitute a special group called Xiphosura (Gr. aiphos, a sword; and oura, tail), from the fact that the end of the abdomen is furnished with a long sword-like spine (fig. 93,t). The mouth is surrounded by six pairs of appendages, the bases of which are spinous and act as jaws, whilst their free extremities are developed into nipping-claws or chelæ. The whole of the upper sur-

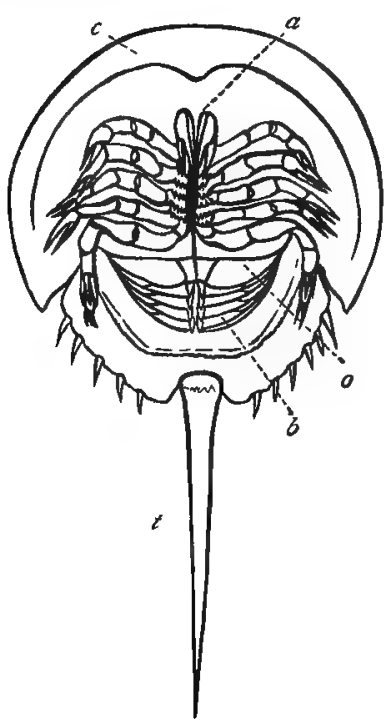

Fig. 93.-Xiphosura, Limulus polyphemus, viewed from below.

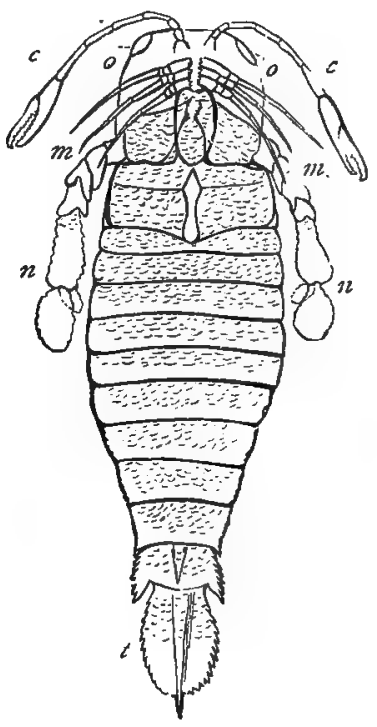

Fig. 94. - Eurypterida. Pterygotus Anglicus, restored. (After H. Woodward.)

face of the body is protected by a kind of buckler, composed of an anterior semicircular shield, and a posterior somewhat hexagonal plate, the under surface of which carries branchial plates, whilst the sword-like telson is jointed to its hinder margin. The King-crabs attain a large size, and are often called "Molucca crabs" from their occurrence in the Moluccas. Both the eggs and the flesh are eaten by the Malays.

Closely allied to the King-crabs is the extinct sub-order of the Eurypterida, an example of which is figured above (fig. 94). This particular species is supposed to have attained a length of probably six feet, but other forms were very much smaller. 


\section{Order Trilobita.}

The Trilobites constitute a wholly extinct order of the C'rustacea, and deserve a short notice from their great geological importance. They derive their name from the fact that the body exbibits a more or less conspicuous division into a central and two lateral lobes (fig. 9:5). The entire shell or crust is composed of an anterior semi-

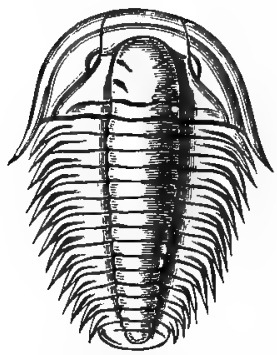

Fig. 15. Olenus micnurus. (After Salter.) circular shield, covering the head, a series of movalle rings constituting the thorax, and a tailpiece composed of amalgamated segments, and representing the abdomen. On the under surface of the shell nothing had until lately ever been discovered except the upper lip, but recently limbs and branchice have been made out. The eephalic shield usually bears a pair of compound eyes, but these are sometimes wanting. It is known that most of the Trilobites possessed the power of rolling themselves up into a ball, much as our modern wood-lice. The Trilobites are only known as occurring in the older rocks of the earth's crust, and they are chiefly characteristic of the period known to geologists as the "Silurian."

\section{Order Phyllopoda.}

This is a small order comprising a number of Clustaceans, which are principally found in inland waters, whether fresh or salt, only one form inhabiting the sea. These Crustaceans (fig. 96) have

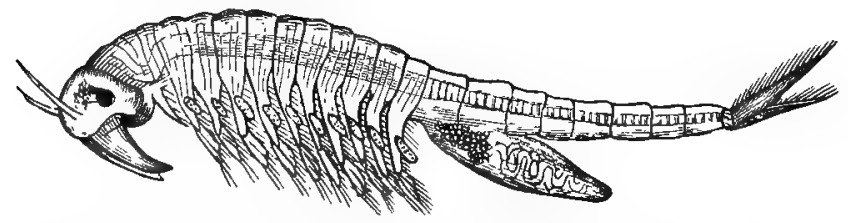

Fis. (mi.-Pliyllopoda. Fairy Shrimp (Chirocephalus, or Branchipus diaphanus). (After Bairl.)

numerous feet, never less than sixteen in number, and the feet are mostly expanded and leaf-like, and serve as gills or breathing-organs. The body may lie naked, or the head and thorax may be covered by 
a shield, or the animal may be enclosed within a bivalve shell. To this order belong the curious "Brine-shrimps" (Artemia), which are found in the brine-pans of salt-works, or in salt lakes.

\section{Orders Cladocera, Copepoda, and Ostracoda.}

These orders deserve mention more from the extreme abundance of their commoner forms than for any other reason. They include a number of minute Crustaceans, most of which are commonly called "Water-fleas," and which abound both in fresh and in salt water, in almost all regions of the globe. They are, however, mostly so small that, though visible to the eye, they can only be satisfactorily examined under the microscope. As an example of the Cladocera may be taken the "Branched-horned Water-flea" (Daphnia pulex, fig. 97, $b$ ), thousands of which may be captured in any pond in summer. In this pretty little species the whole body is enclosed in a bivalve shell, wbich is so transparent that the whole organisation
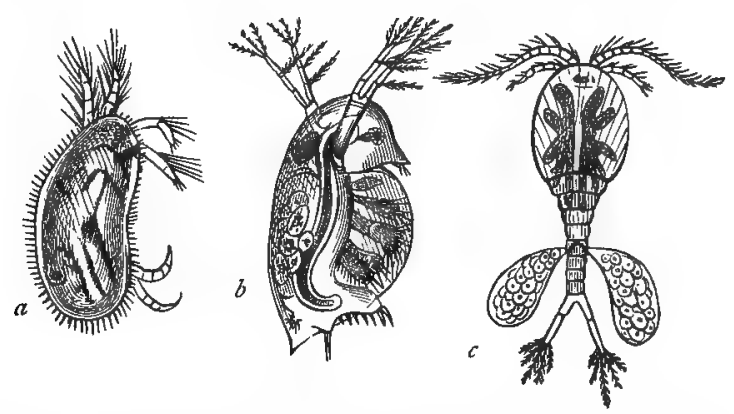

Fig. 07.-Fresh-water Entomostraca. a Cypris tris-striata; b Daphnia pulex; c Cyclops quadricornis.

of the animal is clearly visible through it. The head is distinct, and carries a single eye. The greater antenna are branched. The males are smaller than the females, and much fewer in number; and it appears to be a well-established fact that the female, when once fertilised by the male, can not. only lay eggs for the rest of her life, but can transmit the power of producing fertile ova to her young for several generations. Of the Copepoda one of the commonest is the Cyclops (fig. 97, c), in which the cephalothorax is covered by a shield, and there is a well-developed abdomen. The female carries on either side a kind of pouch or ovisac, in which the eggs remain till they hatched. The little Ostracoda (fig. 97, a), are all minute 
Crustaceans, which occur in both fresh and salt water. They are distinguished by the fact that the body is entirely enclosed in a shell, which is made up of two lateral halves or valves. The valves

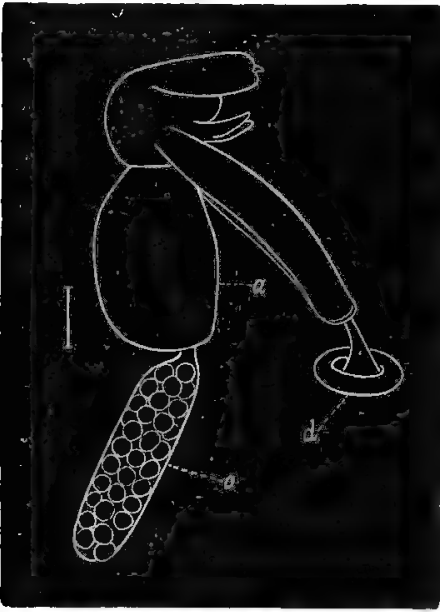

Fig. 98.-Female of Achtheres ('arpenteri, magnified. The line placed alongside of the figure slows the real size. $a \mathrm{Ab}-$ (lomen; $d$ Disc of attachment developed upon the last pair of thoracic linbs; $v$ Ovisac. the Fish-lice, however, have well-developed limbs and eyes, and lead an active locomotive existence.

\section{Order Cirripedia.}

The last order of C'rustreere is that of the Cirriperlin (Lat. cirmes, a curl ; and pw, foot), conprising the so-called Barnacles and Acornshells, buth extremely unlike Crustaceans to look at. All the Cirriperles are distinguished by the fact that, whilst they are quite free when young, and very similar to some of the little Crustaceans just described, when adult they are immovably fixed by their heads to some solid olject. In this fixed condition the body and internal argins are, in most cases, protected by means of a calcareous shell, compused of many pieces, and the only part of the body which remains movalule is the legs, which are constantly thrust out of the shell and agin drawn in in ruest of food. The ciripedia were formerly described as "multivalve" shell-fish (Kollusca), owing to 
their common possession of a regular calcareous shell. Two distinct types of structure are known amongst the (irripedio, constituting the two families of the Barnacles (Lepadida), and the Acorn-shells (Balanidce).

In the Barnacles (fig. 99), the anterior end of the body is much elongated, and is converted into a kind of stalk, by means of which the animal is attached to some solid object, such as a rock, a floating $\log$ of timber, or even some marine animal. In the Acorn-shells (fig. 100) which occur in myriads upon every solid object between tide-marks, there is no stalk, but the head is firmly cemented to the

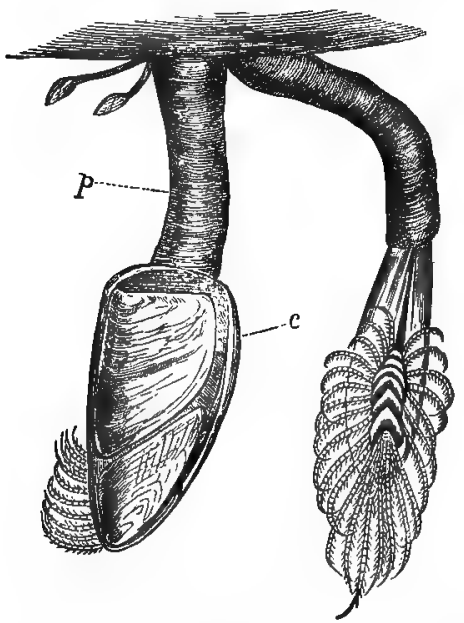

Fig. 99.-Two fully-grown individuals of the common Barnacle (Lepas anatifera), growing upon a foreign body. $p$ The stalk of attachment; $o$ The body of the animal enclosed in a shell, from which the legs can be protruded.

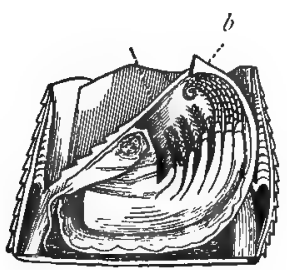

B

A

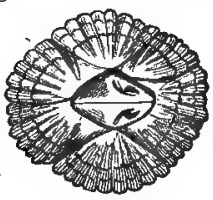

Fig. 100. - A, Acorn-shell (Balanus balanoides), of the natural size, viewed from above. B, Balanus, with the shell on one side removed, to show the animal inside; $a$ and $b$ Two of the plates forming the licl of the shell.

centre of a membranous or shelly plate. The body is enclosed in a limpet-shaped or conical shell, composed of several pieces, and having an aperture at its summit. This opening is closed by a movable lid, and from it the animal can protrude its delicate legs or "cirri," which look like a "glass hand," and are constantly employed in sweeping the water in search of food.

In accordance with the fixed condition of the adult, almost all the Cirripedia are hermaphrodite, possessing both male and female organs of reproduction. In some cases, however, males exist, but 
these are much smaller than the females, and quite different from them in appearance, and they spend their existence within the shell of the female.

Greatly as the Cirripedes are metamorphosed, when compared with the typical Crustaceans, they are not so entirely altered as are the nearly allied animals known as the Rhizocephala. These singular Crustaceans are fixed parasitically to the under side of the abdomen of crabs and hermit-crabs, the body being a mere muscular sac, with no indications of limbs or of segmentation, attached to its host by means of branched root-like processes of attachment, which sink deeply into the tissues of the latter. The young of these degraded Crustaceans have, however, limbs and organs of vision, and swim about actively in the water. 


\section{CHAPTER XIV.}

\section{ARACHNIDA.}

\section{('Lass II. Arachinida.}

This class includes the Mites, Ticks, Scorpions, and Spiders, and, as a whole, is very nearly related to the preceding. The Arachnida, however, are distinguished from the Crustacea by being adapted in most cases for a strictly terrestrial life, so that when any distinct breathing-organs are present these are never in the form of gills, but are always either pulmonary sacs or air-tubes (tracheos). In none of the Arachnida, further, are there ever more than four pairs of legs, and the segments of the abdomen never carry locomotive limbs of any sort. The eyes are sessile, and are" never supported upon stalks; the antennce are converted into jaws or pincers; and the head is always amalgamated with the thorax, so as to form a ceplealothorax.

The integument usually produces chitine more or less abundantly, so as to constitute a resistant shell; but in some cases the skin remains permanently soft. The mouth is situated in the anterior portion of the body, and in the higher forms is furnished with a pair of prehensile jaws, called "mandibles," a pair of chewing-jaws, called "maxillæ," and a lower lip. In the Scorpions an upper lip is present as well. In the true Spiders each mandible terminates in a sharp movable hook (fig. 104, B), perforated by a canal which communicates with a poison-gland situated near its base. By means of this poison apparatus the spiders kill such animals as they capture. In the Scorpions the mandibles are short, and terminate in strong pincers (fig. 101, c). In them, too, the maxillie are furnished with enormously developed nipping-claws or chelæ. In all the Arachnida the mandibles are believed to correspond to the antennæ of the Crustacea. In the lower Arachnida, such as the Ticks, the organs of the mouth are modified partly for piercing, and partly for suction.

The mouth in the Arachnida opens into a pharynx, which is of very small diameter in the true Spiders, which live simply on the 
juices of their prey. The intestinal canal is usually short and straight, and is continued without convolutions to the aperture of the anus. Salivary glands are also present, as well as ramified tubes ("Malpighian tubes") which are believed to act as kidneys.

The circulation is maintained by means of a dorsal heart, which is situated alure the alimentary canal. The typical Arachnida

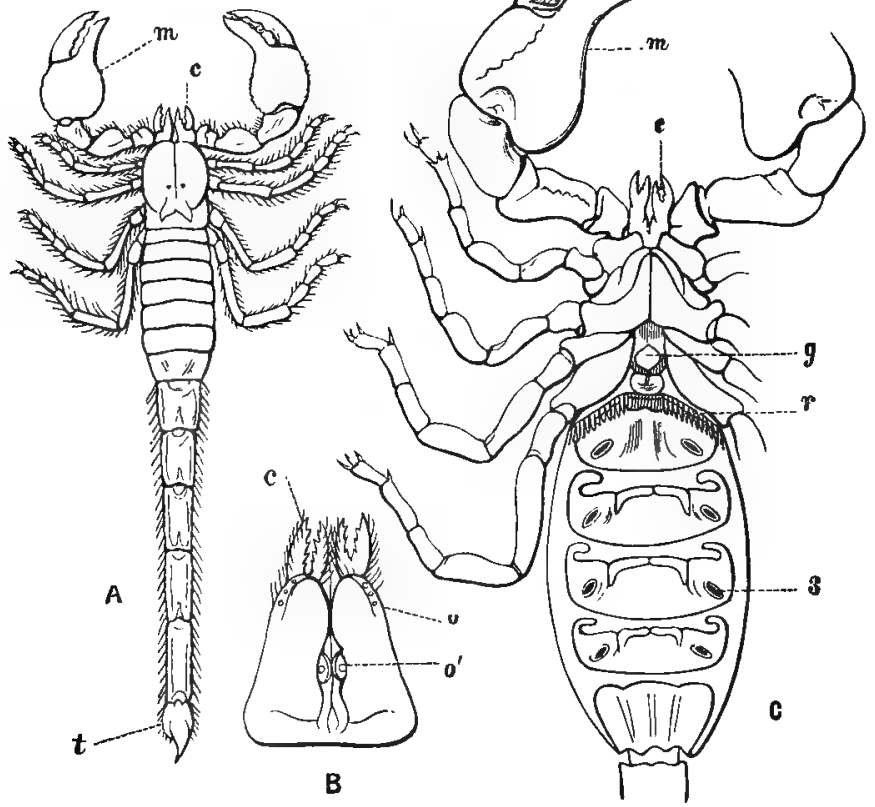

Fig. 101.-Pedipalpi. $\Delta$, Scorpin afer, viewed from above, and somewhat reduced in size. B, Front fortion of the head of the same, viewed from above, and enlarged. C, Buthus Kochii, with the terminal segments and the ends of the appendages on one sile onitterl. $m$ Maxillary palpi (behind these are the four pair of ambulatury legs); o Cheliceræ: $t$ Telson; o Lateral ocelli; $o^{\prime}$ Central, larger ocelli; $g$ Opercular plate, covering the opening of the reproductive organs; $r$ One of the "comus:" s One of the openings into the pulmonary sacs. (C is after Prof. Ray Lankester.)

breathe air directly, and the function of respiration is performed by the general surface of the boxly (as in the lowest members of the cliss), or by luanched air-tubes termed "trachex," or by distinct pulmonary chanibers or sacs, or, lastly, by a combination of tracheæ with pulmonary sacs. The trachex are essentially similar in struc- 
ture and function to the breathing-tubes of the Myriapoda and Insecta, and consist of tubes, which open on the surface of the body by distinct apertures called "spiracles," or "stigmitta," and ramify through the tissues internally. "The walls of the tubes are prevented from collapsing by means of a spirally coiled thread or filament of chitine, which is wound round their walls within their inner lining. The pulmonary sacs which occur in the Arachnida are simple chambers formed by an inversion of the skin, which constitutes a number of closely set plates or folds. The whole of the interior of the pulmonary sacs is richly supplied with blood, and air is admitted by means of external openings (fig. 101, (').

The nervous system is of the regular Articulate type, but the ganglia of the ventral chain are often massed together in particular situations. In no case are compound eyes present; and when distinct organs of vision exist, these are in the form of from two to eight or more simple eyes.

\section{ORDERS OF THE ARACHNIDA.}

\section{Order I. Podosomata.}

In this order are included the "Sea-spiders" (Pyonogonum, $N y$ mphon, \&c.), which are wholly marine, and are often regarded as referable to the Crustacea. They possess four pairs of legs, and upon this ground they have been generally placed in the Arachnida. In some forms the legs attain an extraordinary length, and contain prolongations from the stomach. They are all grotesque-looking animals, found at low water upon stones or marine plants, or parasitically attached to marine animals.

\section{Order II. Acarina.}

The most familiar members of this order are the Mites and Ticks (fig. 102). They are distinguished by the fact that the abdomen is amalgamated with the cephalothorax to form a single mass. Respiration is effected by the general surface of the body or by air-tubes (tracheæ). The mouth-organs are usually adapted for piercing and for suction (fig. 102, C), but some Mites have biting mandibles.

The habits of the Mites are extremely varied. Some are found upon different plants; others are parasitic upon water-insects when young, but swim about freely when adult; others dre parasitic upon other animals, such as sheep, dogs, insects, \&c.; and others inhabit decaying provisions, as is the case with the well-known "Cheesemite" (Acarus domesticus). Two species have a considerable medical 
interest as attacking man. One of these causes the skin-disease which is known as the "itch," and the other is found inhabiting
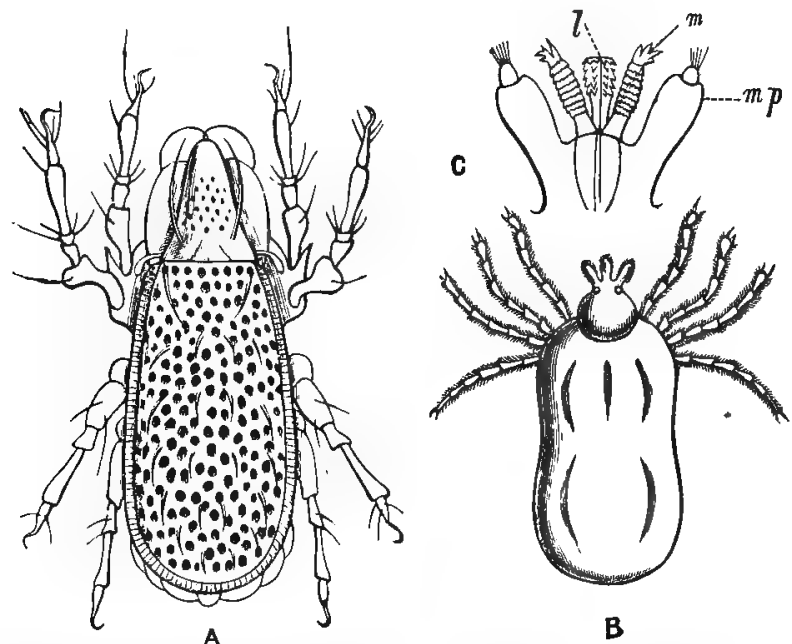

Fig. 102.-Acarina. A, Tegeocranus elongatus, one of the Mites, enlarged 65 times. B, Ixodes ricinus, one of the Ticks, greatly enlarged. C, Mouth-organs of a Tick (Ixodes albipictus), enlarged: $l$ Labium; $m$ Mandibles; $m p$ Maxillary palpi. (After Michael, Packard, and Cuvier.)

certain glandular follicles of the skin, probably without an exception even in favour of the most cleanly people.

\section{Order ill. Pedipalpi.}

In this family are the most formidable of all the Arachnidunamely, the Scorpions (fig. 101). They are all distinguished by the fact that the abdomel is divided into distinct segments, and is continued into the cephalothorax without any well-marked boundary or constriction. In the true Scorpions the end of the abdomen (fig. $101, t$ ) is composed of a hooked telson, which is perforated for the duct of a poison-gland, situated at its base. It is by means of this that the Scorpions sting; and the poisonous fluid which they secrete is sufficiently powerful to render their wounds painful or even dangerous. The mandibles in the Scorpions, as already said, are developed into pincers, and the si-called "maxillary palpi" constitute powerful nipping-claws. The respiratory organs are in the form of pulmonary sacs, four on each side, opening on the under 
surface of the abdomen by as many distinct apertures or spiracles (fig. 101, C).

The Scorpions live in the warmer regions of the temperate zone and in tropical countries, and are generally found hiding under stones or in the crevices of walls. They live upon insects, which they catch with the great nippingclaws, and sting to death with the telson.

Related to the true Scorpions, though belonging to a special group, are the little "Pseudoscorpions" or "Book-scorpions" (fig. 103, A). These are small Arachnidans, which are commonly found among old books, and which look very like Scorpions in miniature, this being due to the fact that the maxillary palpi are of great size and terminate in pincers. Related to these, again, are the "Harvest-men" (Phalangium, fig. 103, B), which are distinguished by the great length and slenderness of their legs.

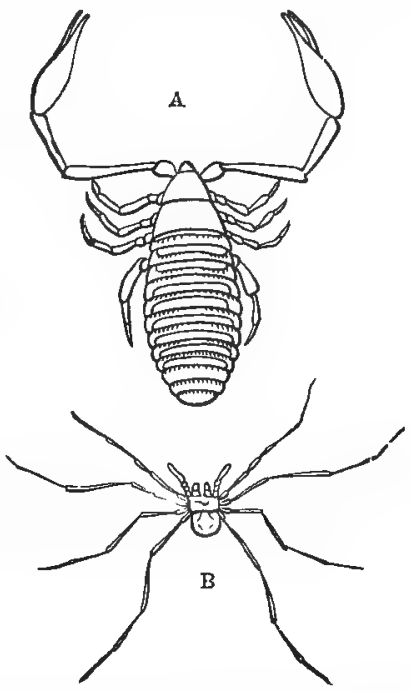

Fig. 103.-A, Book-scorpion (Chelifer), nagnified; B, Phalangiam copticum, of the natural size.

\section{Order IV. Araneida.}

In this order are the true Spiders, readily distinguished from the Insects, with which they are popularly confounded, by having four pairs of legs, as well as by other characters. In all the true Spiders (fig. 104) the segments of the thorax and head are united to form a single mass or cephalothorax, to which the soft and unsegmented abdomen is joined by a constricted stalk or neck. Respiration is effected by means of pulmonary sacs, conjoined with tracheæ. The pulmonary sacs are two or four in number, and open on the under surface of the abdomen by as many apertures. The head bears from two to eight simple eyes; the mandibles (fig. 104, B) are hooked, and carry the duct of a poison-gland; and the maxillary palpi are not developed into nipping-claws. The Spiders are all predacious and rapacious animals, and many of them possess the power of constructing webs, either for the capture of their prey, or 
simply for lining their habitations. For the production of the web, Spiders are furnished with special glands situated at the extremity of the abdomen. The secretion of these glands is a viscid fluid, which hardens rapidly on exposure to air, and which is cast into its proper thread-like shape by passing through what are called the "spinnerets." These are little conical or cylindrical organs, from

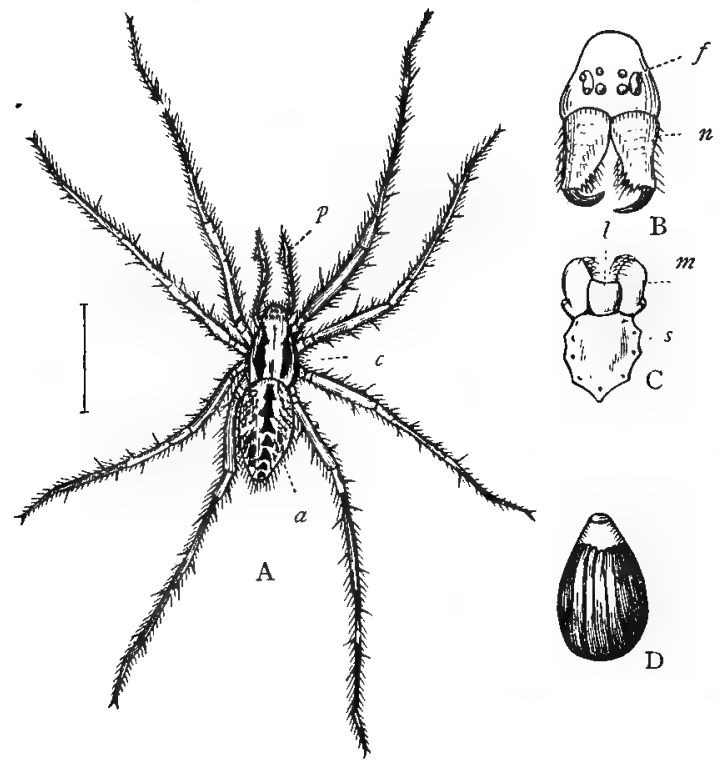

Fig. 104.-A, The male of the common Hunse-Spider (Tegenaria civilis) considerably magnified : $c$ Front portion of the bolly, cousisting of the amalgamated head and thorax; $p$ Maxillary palpi; a Abdomen. B, Front portion of the head of the samce, slowing the eight eyes $(f)$ and the mantibles $(n)$. C, Under side of the head ant trunk, showing the true jaws $(m)$, the lower lip $(l)$, and the horny plate to which the less are attached. D, Diagram of one of the air-chambers or breathingorgans. (Figs. A, B, and C are atter Blackwall.)

two to eight in number, plicerl at the end of the abdomen, and perforated ly a number of extremely minute tube, through which the secretion of the gland has to pass before reatching the air. Miny Spiders, however, do not construct any web, unless it be for their own habitations, but simply hunt their prey for thenselves.

The Spiders are oviparous, and their young pass through no metamorphosis, but they cast their skin or "moult" repeatedly before they attain the size of the adult. 


\section{CHAPTER XV.}

\section{MYRIAPODA.}

\section{Class III. Myriapoda.}

THIs class is a small one, and includes only the Centipedes and the Millepedes. In all the Myriapoda the head is distinct, and not amalgamated with the thorax. There is no clear boundary-line between the thorax and the abdomen, both being composed of nearly similar segments. The body (except in the genus Pauropus) always consists of more than twenty rings; and the hinder segments, which correspond to the abdomen, always carry locomotive appendages, whereas the abdominal rings in Arachnida and Insecta are always destitute of locomotive appendages. One pair of antennce is present, and the number of the legs is always more than eight pairs. Respiration is carried on by branched air-tubes or tracheæ.

In most of their characters the Myriapoda closely resemble the true Insects, with which, indeed, they are not uncommonly classed. The true Insects, however, always have the head, thorax, and abdomen distinct from each other, and have never more than three pairs of legs. In most of the Myriapoda the young or "larvæ" are more like insects than the adult, since they have only three pairs of legs, or are altogether destitute of feet. In some cases, however, the young Myriapod, on escaping from the egg, possesses nearly all the characters of the parents, except that the number of body-rings, and consequently of legs, is smaller, and increases with every change of skin ("moult"). The class is divided into two leading groups or orders, represented by the common Centipedes (Chilopoda) and Millepedes (Chilognatha).

The Centipedes (fig. 105) are carnivorous in their habits, and the organs of the mouth are adapted for a life of rapine. In addition to the parts of the mouth proper, they have two pairs of "foot-jaws," of which the second is hooked and perforated for the discharge of a poisonous fluid. The bite of the common European species is perfectly harmless to man, but some of the tropical forms attain a 
length of half a foot or more, and are consequently able to inflict extremely severe and even dangerous bites. The true Centipedes are further distinguished by the number of legs not being indefinitely

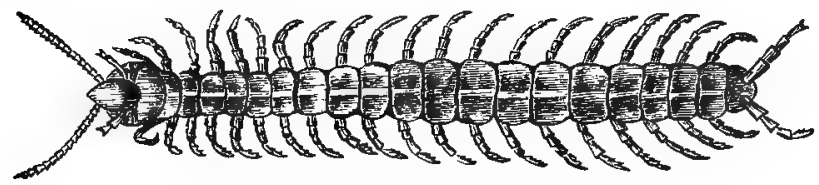

Fig, 105.-Centipede (Scolopendro).

grent (usually from fifteen to twenty pairs), and by the fact that the antenna are composed of not less than fourteen joints each.

The Millepedes (fig. 106) are repulsive-looking but perfectly innocent aninials, which feed principally upon decaying vegetable matter. The body in the ordinary Millepedes is rounded and worm-like; and the segments are so amalgamated that each apparent body-ring

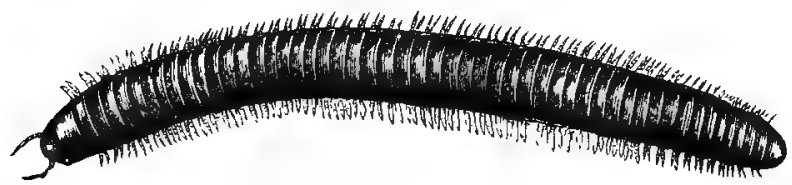

Fig. 1C6.-Millenede (Iulus maximus), a small cxample, of the natural size.

gives origin to two pairs of minute thread-like feet. The mouth is destitute of the powerful jaws which are found in the Centipedes, the legs are indefinitely numerous, and the antennæ are short, and are composed of no more than six or seven joints each.

The European Millepedes are all of smill size, but some tropical species attain a length of from six to ten inches.

A third group, under the name of l'euruporlu, has been established for a curious little creature called P'curopus. In this, the body consists of only ten segnents, and there are no more than nine pairs of legs. The antennit are five-jointed, forked, and provided with jointed appentiges. There are no trachere, and respiration is curried on by the skin. It is very small, and is found inhabiting decayed leaves and damp situations.

Lastly, a fourth group, termed Onychophora, containing only the curious aninits of the genus Peripates (fig. 107), must be admitted, provisionally at any rate, amongst the $1 / y$ riupoda. The species of Peripatus are worm-like animals found in moist situations or under 
stones in the West Indies, South Africa, South America, and New Zealand. They are so worm-like that they have often been placed among the Annelides; but the recent researches of Prof. Moseley

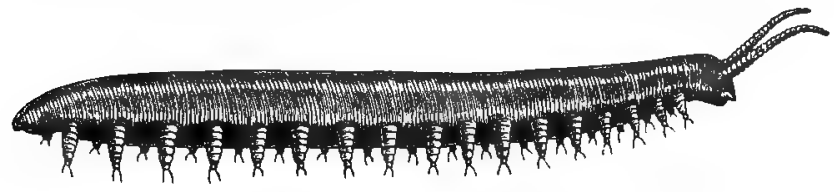

Fig. 107.-Onychogoda, Peripatus Capensis. (After Moseley.)

have shown that the animal breathes by trachex, so that it must be placed in or near the Myriapoda. 


\title{
C'HAPTER XVI.
}

\author{
INSEC'TA.
}

\section{Class IV. Insecta.}

THE true Insects are distinguished from the preceding clisses of Articulate animals by the fact that the three dicisions of the bodynamely, the head, thorux, and abdomen-are always distinct from one another; there are necer more then three pairs of legs in the aduli, and these are born! "pon the thorax; the abdomen is destitute of locomotive appendages. Respiration is effected by means of air-tubes or trachex, and in most Insects two pairs of wings are developed from the back of the second and third segments of the thorax.

The integument in insects is nore or less hardened by the deposition of chitine in it, and the body is deeply cut into segments (hence the name Insect, from the Latin insectus, cut into). The head in insects (fig. 108,a) is composed of several segments amalgamated together, and carries a pair of jointed feelers or antennæ, a pair of eyes, usually compound, and the appendages of the mouth. The thorax in insects $(b, c, d)$ is composed of three segments, which are amalgamated together, but are generally prettily easily recognised. Each of the segments of the thorax carries, in perfect insects, a single pair of jointed legs, so that there are three pairs in all. To the back of the two hinder segments of the thorax, in most insects, there are also attached two pairs of wings. In their typical form the wings are membranous expansions, supported by more or less numerous hollow tubes, known as the "nervures." One or both pairs of wings may be wanting, and when both are present the anterior pair may be much modified by the deposition of chitine in it. These modifications will be treated of in speaking of the orders of Insects. The abdomen in insects $(\epsilon)$ is properly composed of eleven segments, which are usually more or less freely movable upon one inother, and which never carry locomotive limbs, as is so commonly the case in the Crustacea. The extremity of the abdomen is, however, often furnished with appendages which are 
primarily connected with reproduction, but which are often converted into weapons of offence and defence. Of this nature are the "ovipositors" of Ichneumons, the stings of Bees and Wasps, and the forceps of the common Earwig.

The organs of the mouth in insects require a brief consideration, as being in the closest possible relation with their habits and mode

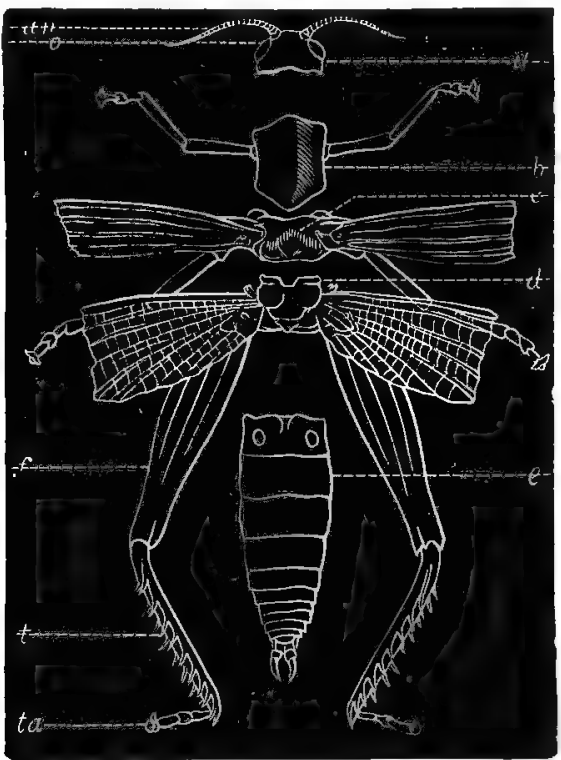

Fig. 108.-Diagram of the external anatomy of an Insect: $\alpha$ Head carying the eyes (o) and antenne $(a n) ; b$ First segment of the thorax, with the first pair of legs; $c$ Second segment of the thorax, with the second pair of legs and the first pair of wings ; $d$ Third segment of the thorax, with the third pair of legs and the second pair of wings; e Abdomen, without limbs, but carrying terminal appendages concerned in reproduction ; $f$ Fenur ; $t$ Tibia ; ta Tarsus.

of life. Two chief types of mouth are recognisable in insects, termed respectively the "masticatory" and the "suctorial," according as the mouth is fitted for biting and chewing, or simply for imbibing fluids. The masticatory mouth is seen in perfection in the Beetles, in which the following organs are present (fig. 109, A): 1. An upper lip or "labrum" (l), attached below the front of the head. 2. A pair of biting-jaws $(m)$ or " mandibles." 3. A pair of chewing-jaws or "maxillæ" ( $m x)$ provided with jointed filaments, called the 
"maxillary palpi" (mp). 4. A lower lip or "labium" (la), which also carries a pair of jointed filaments, known as the "labial palpi" (lp). In the typical suctorial mouth, as seen in the Butterflies and Moths (fig. 109, B), the following is the arrangenent of parts. The upper lip and mandibles are quite rudimentary; the maxillæ (mx) are greatly lengthened, and form a spiral tube fitted for sucking up the juices of flowers; and the labial palpi are much developed, and form two hairy cushions, between which the trunk can be coiled up when not in use. In many insects (fig. 109, C) the organs of the mouth are essentially adapted for suction, but are also fitted for piercing solid substances, such as the skin of animals or the stems
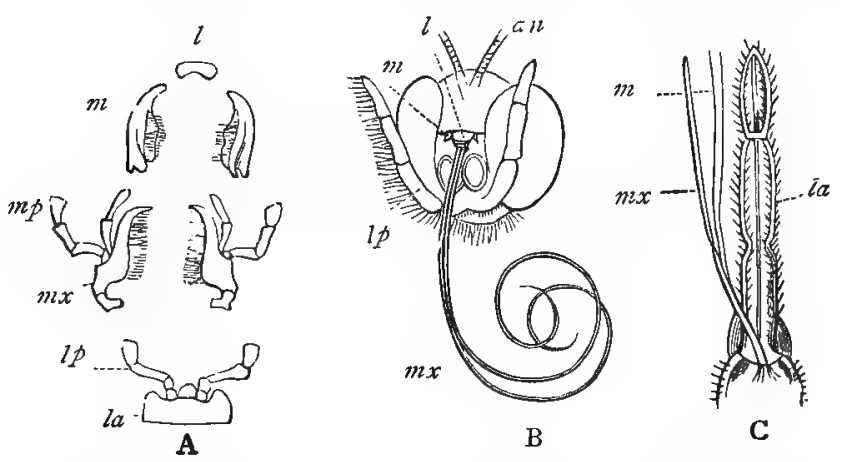

Fig. 109.-Organs of the mouth of Inserts, enlarged ; (A) of a Beetle (Carabus); (B) of the Small Calubage White Butterfy (Pontia ra, aE); (C) of the Bed-bug (Cimex lectulorius), the mandibles and maxilla being displaced to one side. $l$ Labrum ; m Mandible : $m x$ Maxilla ; $m p$ Maxillary palpus; la Labium; l Labial palpus; an Baso of one of the antennx. (Fig. B. is slightly altered from Westwood.)

of plants. In these the lower lip forms a kind of sucking-tube or sheath, within which are contained the maxille and mandibles, which are modified so as to form piercing organs or lancets. In the common Bee the masticatory and suctorial types of mouth are combined. The mandibles or biting-jaws are retained, to enable the honeycomb to be manufactured, and there is also a tubular trunk fitted for sucking up the juices of flowers. In the Butterflies, too, in which the mouth of the alult is strictly adapted for suction, the caterpillar is furnished with a masticating mouth, so that it can feed upon leaves, or other solirl substances.

The mouth in the masticating insects (fig. 110, a) leads into a membranous and often folded cavity, termed the "crop" $(b)$, from which the food passes to a second nuscular cavity or "gizzard" (c). 
The gizzard is adapted for crushing the food, and of ten has plates or teeth of chitine developed in its walls. It is succeeded by the true digestive cavity $(d)$, which is termed the "the chylific stomach." From this there proceeds an intestine $(f)$, of variable length, which usually terminates in a chamber called the "cloaca" $(g)$, into which the ducts of the reproductive organs open. The commencement of the gullet is furnished with glandular appendages, which discharge

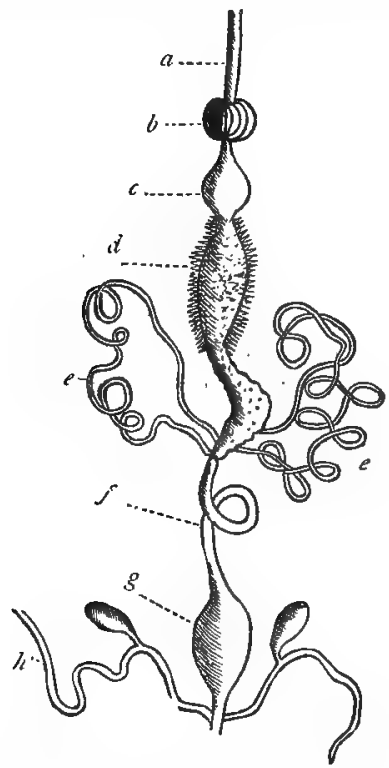

Fig. 110.-Digestive apparatus of a Beetle (Carabus aurctus). $a$ Gullet; $b$ Crop ; $c$ Gizzard ; $d$ Clylific stomach; $e$ Maipighian tubes; $f$ Intestine; $g$ Cloaca; $h$ Anal glands.

the functions of salivary glands. Immediately behind the posterior aperture of the stomach are a variable number of cæcal convoluted tubes (e), which are known as the "Malpighian vessels," after their discoverer Malpighi, and which correspond with the kidneys of higher animals.

The circulation in insects is mainly carried on by a long contractile tube placed along the back, and termed the "dorsal vessel." The blood collected from the various tissues and organs of the body, enters the dorsal vessel from behind, and is driven forwards to the anterior extremity of the body. Respiration is effected by means of 
air-tubes or tracheæ (fig. 111), which conmence at the surface by so many apertures or spiracles, and branch repeatedly as they proceed inwards through the tissues. They have the same structure as in the Arachnida, consisting of membranous tubes strengthened by

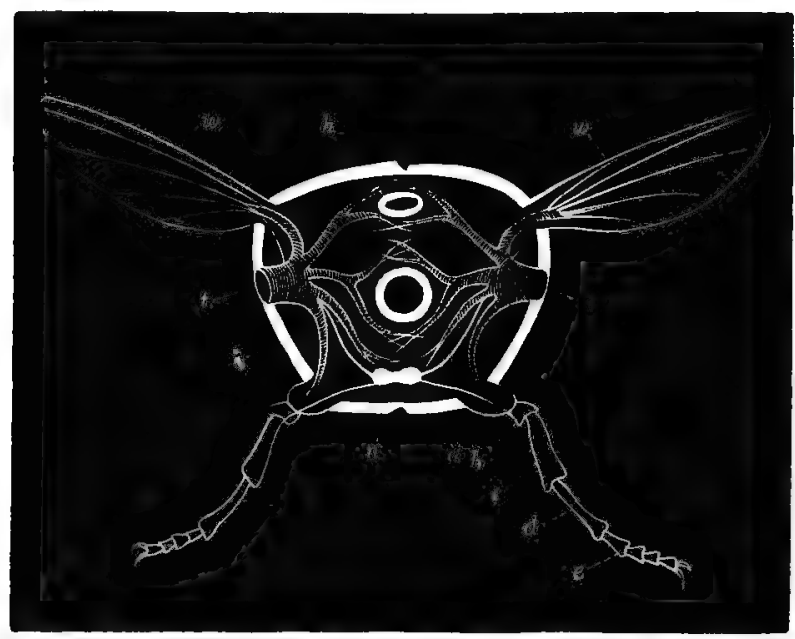

Fig. I11.-Ideal transverse section of an Insect. $\hbar$ Dorsal vessel; $i$ Intestine; $n$ Ventral nerve-cord; $t$ Stigmata leading into the branched tracheal tuhes; $w w$ wings ; $a$ Coxa of one leg; $b$ Trochanter; $c$ Fenur ; $d$ Tibia ; $e$ Tarsus. (After Packard.)

means of a spirally coiled filament of chitine. The tracheæ are prolonged into the wings, so that these structures likewise assist in respiration.

The nervous system in insects, though sometimes somewhat modified, has essentially the regular Annulose form of a ventral chain of ganglia, traversed in front ly the gullet. The organs of sense are the eyes and antennre. The eyes are usually "compound," and are composed of numerous six-sided lenses, united together, and each supplied by a separate nervous filament. As many as eight thousand of these lenses have been counted in one of the eyes of the common Cockchafer, and this number is sometimes greatly exceeded. Besides these compround eyes there are sometimes "simple" eyes, identical in structure with the single leuses of the compound eyes; and in rare cases these are the only organs of vision. The feelers or antenne, with which all insects are furnished, are jointed filaments attached close to the eyes, and assuming very different shapes in 
different insects. They appear to be certainly organs of touch, but they very probably minister to other senses as well, and there is some reason to suppose that they are connected with the sense of hearing in particular.

The sexes in insects are distinct, and most of them are oviparous. Generally speaking, the young insect is extremely different in external characters from the adult, and it requires, before reaching maturity, to pass through a series of changes which collectively constitute what is called the "metamorphosis." In some insects, however, there is no proper metamorphosis, and in some the changes which take place are not so complete and striking as in others. By the absence of metamorphosis, or by its completeness when present, insects are divided into three convenient, though perhaps not strictly natural, sections, as follows:-

Section I. Ametabolic Insects.-The insects belonging to this section are said to be "Ametabolic" (Gr. a, without; metabole, change), because they pass through no metamorphosis. The young, on their escape from the egg, resemble the adult in every respect, except in size, and they undergo no alteration in reaching maturity, except that they grow larger. All the insects of this section are destitute of wings in the adult state, and they are therefore often called "Aptera" (Gr. a, without ; pteron, a wihg).

Section II. Hemimetabolic Insects.-In the insects belonging to this section (Gr. homi, half ; and metabole, change), there is a metamorphosis consisting of three stages, but these stages do not differ much from one another in appearance (see fig. 117). The young, on escaping from the egg, is known as the "larva," and it is not only much smaller than the adult, but is destitute of wings. After several changes of skin, the larva enters into the second stage, when it is termed the "pupa." The pupa is active and locomotive, and rarely differs much from the larva, except that it is bigger, and that rudimentary wings have now appeared on the back of the thorax. After a certain period, and after some changes of skin, the wings burst from their sheaths, and the pupa is now converted into the third and final stage, when it is known as the "imago" or perfect insect. In all the insects belonging to this section-such as Grasshoppers, Dragon-flies, \&c.-the second stage, or pupa, is active and locomotive; and for this reason the metamorphosis is said to be " incomplete."

Section III. Holometabolic Insects (Gr. holos, entire; and metabolé, change).-The insects belonging to this section-such as Butterflies, 
Moths, and Beetles-pass through three stages, just as do the preceding, but these stages differ from one another very much in appearance, and the metamorphosis is therefore said to be "complete" (fig. 112). In these insects the larva is worm-like, segmented, and usually furmished with locomotive feet, which do not correspond with the three pairs proper to the adult (see figs. 1.3, 124), though these are usually present as well. Sometimes feet are wanting altogether. The larva is also provided with masticating organs, and eats voracionsly. In this stage of the metamorphosis, the larvæ constitute what are popularly known as "caterpillars" or "grubs."
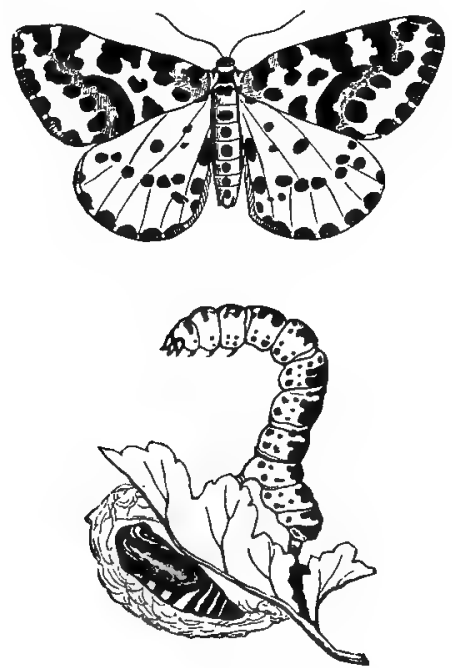

Fig. 112, -Metamorphosis of the Magpie-moth (Phalcena grossulariata).

Having remained in this condition for a longer or shorter time, and having undergone repeated changes of skin, necessitated by its rapid growth, the larva passes into the second stage, and becomes a pupa (fig. 123-see also fig. 112). In this stage the insect remains quiescent, unless irritated, and it is very often attached to some foreign object, so an to be quite incapable of changing its place. In the case of the Butterflies and Moths, the pupa constitutes what is familiarly known as the "chrysalis." The loody is protected by a chitinous pellicle, and in some cases this is still further protected by the dried skin of the larva; whilst in other cases the larva-immediately 
before entering the pupa stage-spins for itself a protective case of silken threads, which surrounds the chrysalis, and is known as the " cocoon." Having remained for a variable time in this inanimate, quiescent pupa-stage, during which rapid changes have been going on in the interior of the animal, the insect now frees itself from the envelope which obscured it, and appears as the perfect winged adult or imago. 


\section{CHAPTER XVII.}

\section{ORDERS OF INSECTS.}

The known number of insects is so enormous, their forms are so various, and their habits and instincts are not only so remarkable, but have been so fully described, that it were hopeless to attempt here to do more than give the briefest possible outline of the leading characters which distinguish the different orders. The student desirous of further information on this head must have recourse to treatises specially devoted to entomology.

Section I. Ametabolic Insects. - Young not passing through a metamorphosis, and differing from the adult in size only. Perfect insect or imagn destitute of uings; eyes simple, sometimes wanting. Owing to the fact that the adult ametabolic insects have no wings, they are often grouped together as a common assemblage, under the name of Apterc.

\section{Order I. Anopltra.}

The insects comprised in this order are parasitic upon man and other animals, and they are commonly known as Lice (Prdirulus, fig. 113, A). They are all very minute in size, destitute of wings in the adult state, having a mouth formed for suction, and having either two simple eyes or none.

\section{Order II. Mallophaga.}

These are known as "Bird-lice," and are all minute parasites on different birds or quadrupeds (fig. 113, B). They are distinguished from the true Lice by not living upon the juices of their host, but upon the more delicate and tender appendages of the skin. The mouth is, consequently, not suctorial, but fitted for biting. 


\section{Order IIJ Collembola.}

These are Apterous insects, which attach themselves to foreign bodies by means of a ventral suctorial tube. They are commonly called "Spring tails," in allusion to the fact that the abdomen carries a long forked appendage, which is employed as an elastic
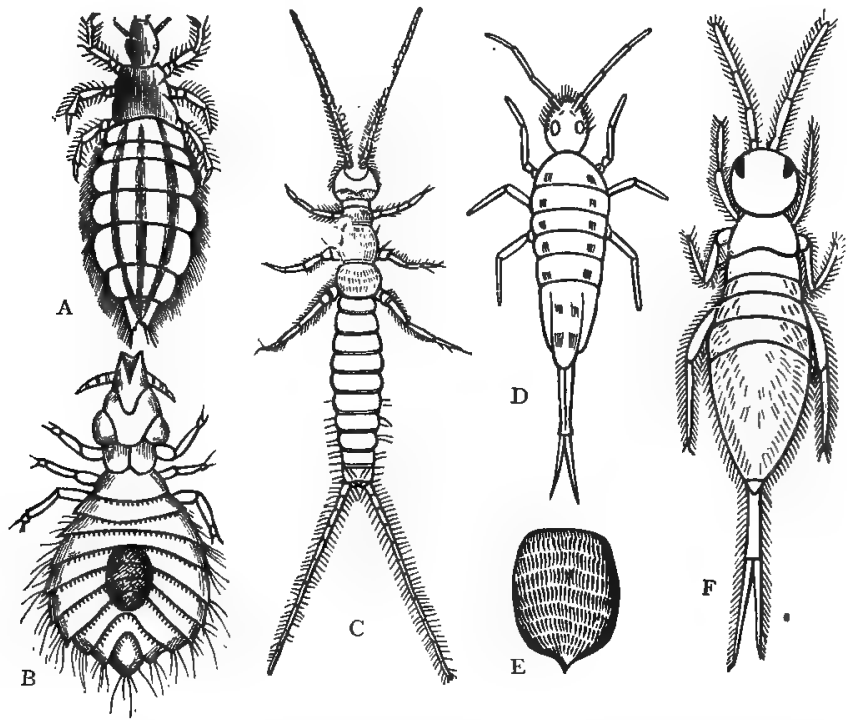

Fig. 113.-Types of Aptera. A, Pediculus humanus capitis, one of the Anoplura; B, Docophorus hamatus, one of the Bird-lice; C, Campodea, one of the Thysanura; $\mathbf{D}$, Degeeria, one of the Poduridae; E, Scale of a Podurid, as seen under the microscope; F, Degeeria purpurascens. All the figures are greatly enlarged. (A fter Packard and Gervais.)

spring, and which enables the insect to effect extensive leaps (fig. $113, \mathrm{D}$ and $\mathrm{F})$. The best-known members of the group are the Poduroe, which are generally found in moist dark places in gardens and in similar situations.

\section{Order IV. Thtranura.}

This order comprises insects such as Lepisma and Campodea (fig. $113, \mathrm{C}$ ), which are nearly related to the preceding, but are distinguished by the possession of a masticatory mouth, and by the fact 
that the bristles which terminate the abdomen do not form a "spring." The body is often covered with delicate scales, which are shown under the microscope to be beautifully marked and striated.

Section II. Hemimetabolic Insects.-Metamorphosis incomplete; the luru differing from the perfect insect shirfiy in the absence of wings and in size; pupa usully active, or, if quiescent, capable of movement.

\section{Order V. Hemiptera.}

In this order the mouth is formed for suction (fig. 109, C); the eyes are compound, but simple eyes are often present in addition. Two pairs of wings are always present.

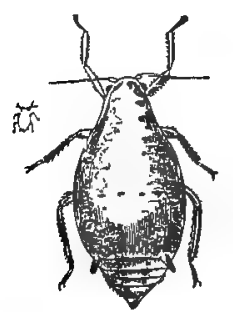

Fig. 114,-Hemiptera.

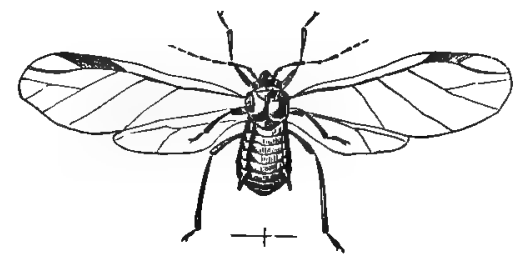

Bean Aphis $(A p h$ is $f(t h r)$; winged male and wingless fenule.
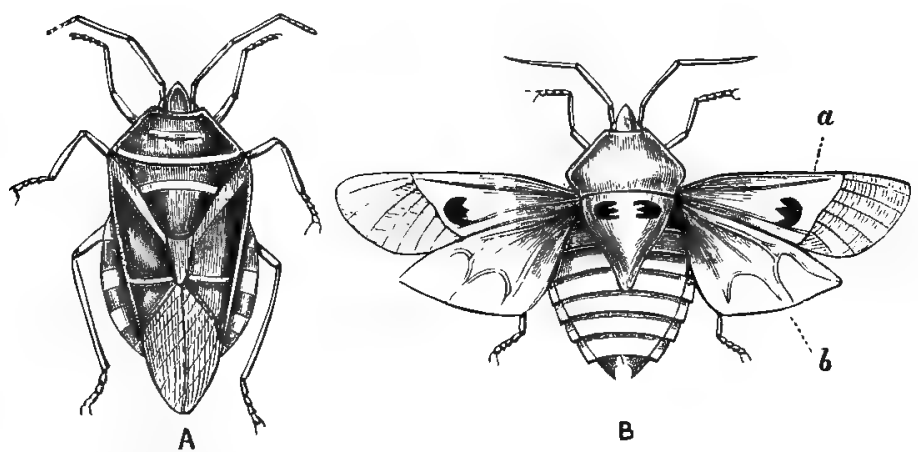

Fig. 115.-II'miptrin. A, Pentatoma rutilans, with the wings closed. B, Whaphiganter iucaruatus, with the wings expanded in flight: a Anteriol wisur (hemelytrou), with its basal portion hardened by clitine; $b$ Posterior ncmbranous wing.

The Hemiptera live upon the juices of plants or animals, which they are enabled to obtain by means of their suctorial mouths. All 
the four wings are present, but the condition of these varies in different sections of the order. In one group all the four wings are membranous (fig. 114); but in the other the posterior wings and the tips of the anterior wings alone are membranous. The inner portions of the anterior wings are hardened by chitine (fig. 115), and they are known as "hemelytra" (Gr. hemi, half; and elutron, a sheath). Amongst the more familiar examples of the Hemiptera are the numerous species of Plant-lice (Aphides), the Field-bugs (Pentatoma, fig. 115), the Boat-fly, the Nepa or Water-scorpion (fig. 116), the Cochineal insects, and the Cicadas.

The Cochineal insects are of considerable commercial importance, as the dried and powdered bodies of the female constitute the substance known as Cochineal, from which is obtained the brilliant pigment, carmine. The male insect is winged, and is smaller than the female, which is wingless. They live upon different species of Cactus (Opuntia), and are mainly imported from Mexico, Algeria, and the Canary Islands.

Numerous species of Aphides or Plant-lice (fig. 114) are known, and they are among the greatest pests of the gardener and farmer, as they are extraordinarily prolific, and live upon the juices of plants. One of the most curious points about the Plant-lice is that

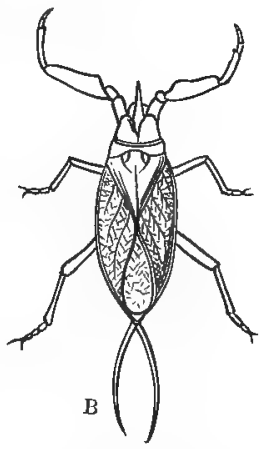

Fig. 116.-Nepa cinerea, the "Water-scorpion," showing the semi-membranous alterior wings ("home. lytra "). they secrete a sweet and sticky fluid, which is expelled from the body by two little tubular filaments placed near the end of the abdomen. Ants are excessively fond of this fluid, and hunt after Aphides in all directions in order to obtain it.

\section{Order VI. Orthoptera.}

The mouth in this order is strictly masticatory; there are foul wings present, but the anterior pair are smaller than the posterior, and of a different texture. The posterior wings are membranous and are folded lengthwise, like a fan; the anterior wings are leathery, and constitute cases (elytra) for the posterior wings. This order includes the Crickets (Achetida), Grasshoppers (Acridiidce), Locusts (Locustidoe), Cockroaches (Blattida, fig. 118), and others. Some of them are formed for running, all the legs being nearly equal in size; others have the first pair of legs greatly developed, and constituting powerful organs of prehension; whilst others, such 
as the Locusts and Grasshoppers, have the hindmost pair of legs much longer than the others, giving them a considerable power of

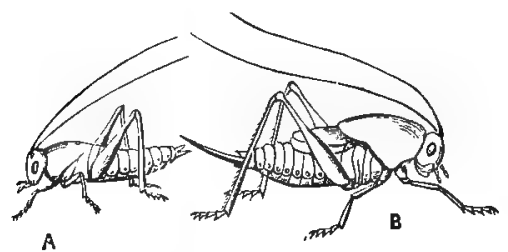

A

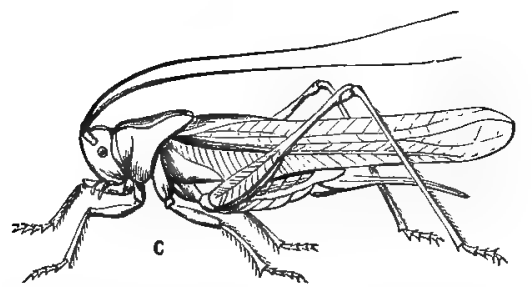

Fig. 117.-Different stages in the nictamorphosis of a Grasshopper. A, Larva; $\mathrm{B}$, Pupa, with the rudimentary wings; C, Adult or imago, with the fully developed wings. leaping. All the Orthoptera are extremely voracious, and every one is acquainted with the terrible ravages occasionally caused in hot countries by swarms of locusts.

The most destructive species is the Migratory Locust (CEdipoda migratoria), which is very abundant in Africa, India, and throughout the whole of the East. Owing to the rapidity with which they devour everything they can possibly eat, and owing to their enormous numbers, the Locustsare compelled to be constantly on the move, looking for "fresh fields and pastures new." It is from these migrations in vast bodies in search of food that the Migratory Locust
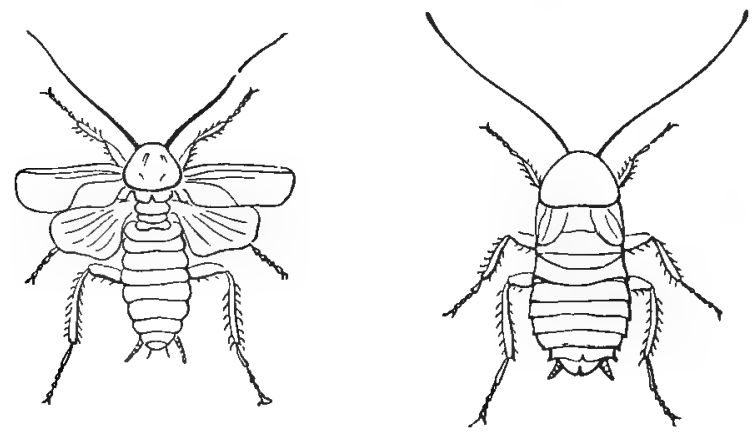

Fig. 118. -Orthoptera. The common Cockroach (Blatia orientalis), male and female.

takes its name. When one of these destructive hosts visits a district, it only needs a few hours to convert the most fertile country into a howling wilderness. In an incredibly short space of time every green 
thing on their line of march is destroyed, every leaf is stripped from every tree, every blade of grass and corn is eaten down, and it is not until the ground is utterly bare and brown that the Locusts take wing and seek out some fresh region to devastate. Nearly or quite as destructive as the Eastern Locust are various species which inhabit North America, and are particularly abundant in the far West.

\section{Order VII. NeUroptera.}

The month in this order is fitted for mastication ; the wings are four in number, generally nearly equal in size, all membranous, and traversed by numerous delicate nervures, which interlace so as to form a delicate network (fig. 119). The metamorphosis is generally incomplete, but is sometimes complete.

This order includes the well-known and rapacious Dragon-flies (Libellulidce), the Caddis-flies (Phryganeido), the May-flies (Ephemeridce), the Ant-lion (Myrmeleo), the Aphis-lion (fig. 119), Termites, \&c. The last of these-namely, the Termites or White Ants (fig.
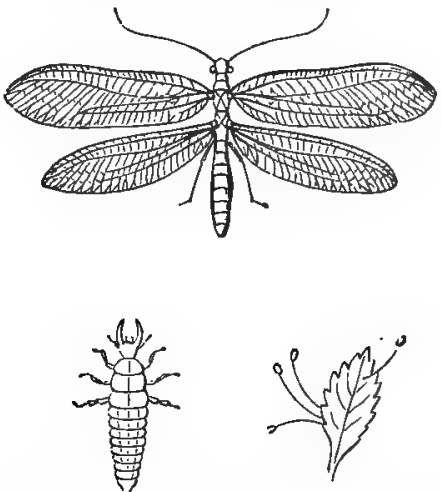

Fig. 119.-Neuroptera. Aphis-lion (Chrysopa perla), imago, larva, and eqggs.

120)-are social insects, living in organised communities, and exhibiting many remarkable phenomena. They are mostly inhabitants of hot countries, and cause immense mischief by destroying wood-work of all descriptions. Though called "White Ants," it is to be remembered that they are not related in any way to the true Ants. They build mounds of different shapes and sizes, sometimes several feet in height, formed of "particles of earth worked into a material as hard as stone." Each family of Termites possesses a king and queen, which are always kept together closely guarded in 
a chamber placed in the centre of the nest. Both are without wings and are much larger than the bulk of the community, the queen immensely so, owing to the enormous distension of her abdomen with eggs. The ordinary Termites are all sexless, incapable of laying eggs, and they are divided into two distinct sets or "castes,"

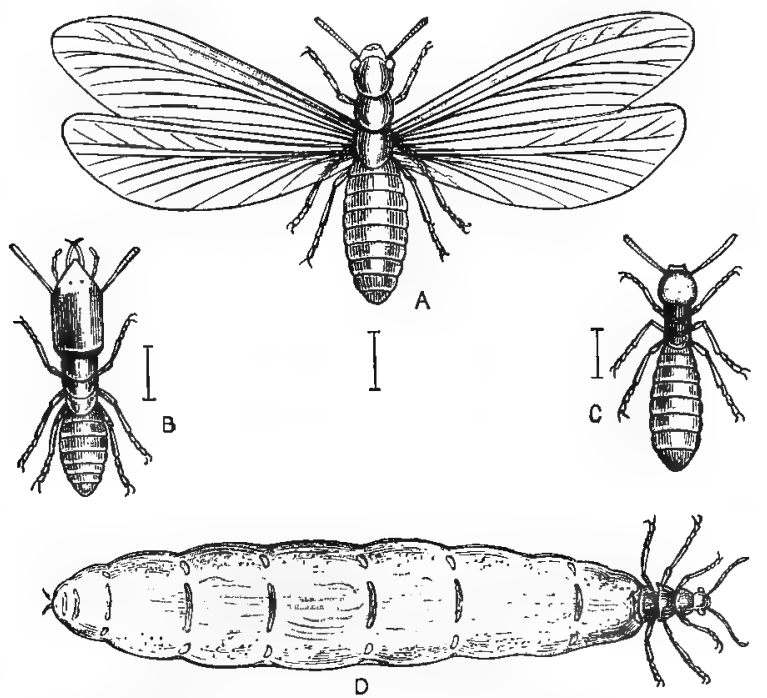

Fig. I20.-Different individuals of the colony of one of the Termitr's. A, The queen, before the wings are shed; $\mathrm{D}$, The queen, after the wings are thrown off and the abdomen has becoue greatly distended with eggs; C, Worker; B, Soldier.

both destitute of wings, and differing in the armature of the head. The one class includes the so-called "workers," who perform all the ordinary work of the colony, whilst the "soldiers" have greatly developed jaws, and are simply occupied in defending the nest against all enemies.

Section III. IIolometaboua. - Iretemorphosus complet"; the larva, I'mpre, and imago differing greatly from one ansther in external appearance. The larte worm-like, and the pupa quiescent.

\section{Order vili. Apianiptera.}

In this order are only the Fleas (Mulivile) in which the mouth is suctorial, the metamorphosis is complete, and the wings are rudi- 
mentary, being represented by four minute scales placed on the last two segments of the thorax (fig. 121). The larva of the common Flea is a footless grub, which in about twelve days spins a cocoon
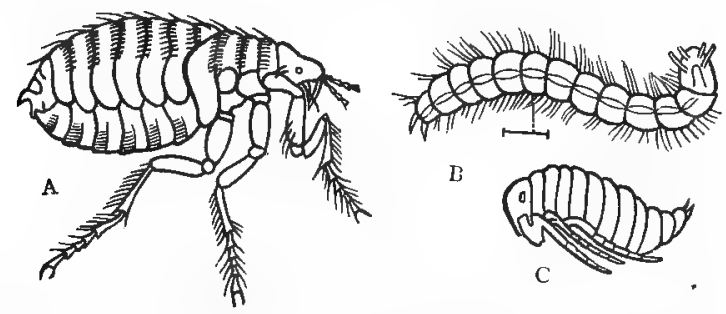

Fig. 121.-A, The common Flea (Pulex irrituns); B, Larva of the same : C, Pupa of the same. All the figures are greatly magnified. (After Westwood.)

for itself, and becomes a quiescent pupa, from which the imago emerges in about a fortnight more.

\section{Order IX. Diptera.}

The insects of this order, as implied by its name, have only a single pair of wings--namely, the anterior pair. The posterior wings are rudimentary, and are represented by two clubbed filaments called "balancers" or "poisers" (fig. 122). The mouth in the Diptera is suctorial. It consists of a tubular lower lip, enclosing the other parts of the mouth, and placed on the under surface of the head. The anteuna are generally small and three-jointed, sometimes many-jointed, sometimes feathery. The metamorphosis is complete, the larva being usually a soft fleshy grub, with an indistinct head, and generally destitute of legs.

The common Gnat (Culex pipiens) deposits its eggs upon the surface of water, the eggs being cenented together to form a sort of raft, and each having an inferior lid which allows the escape of the larva (fig. 122, A). The larval Gnat (fig. 122, B) is vermiform, with a large head and thorax, and with lateral tufts of bristles, which it uses in swimming. The last abdominal segment earries a bunch of leaf-like fins, with which the larva can keep itself suspended, head downwards, in the water; and the last segment but one carries a long tule, into which the tracheæ open, and which the larva thrusts above the surface of the water for the purpose of obtaining air. In its pupal condition (fig. 122, C) this abdominal tube has disappeared, though the abdomen still acts as a swimming-organ. The head and thorax are now fused together, and the dorsal aspect of the thorax is furnished with two tubes, which project above water when the 
insect comes to the surface, and which convey air to the trachex. Though active, the pupa does not eat; and when the time comes for the completion of the metamorphosis it approaches the surface, above which it raises its back. The skin then splits dorsally, and, drying,

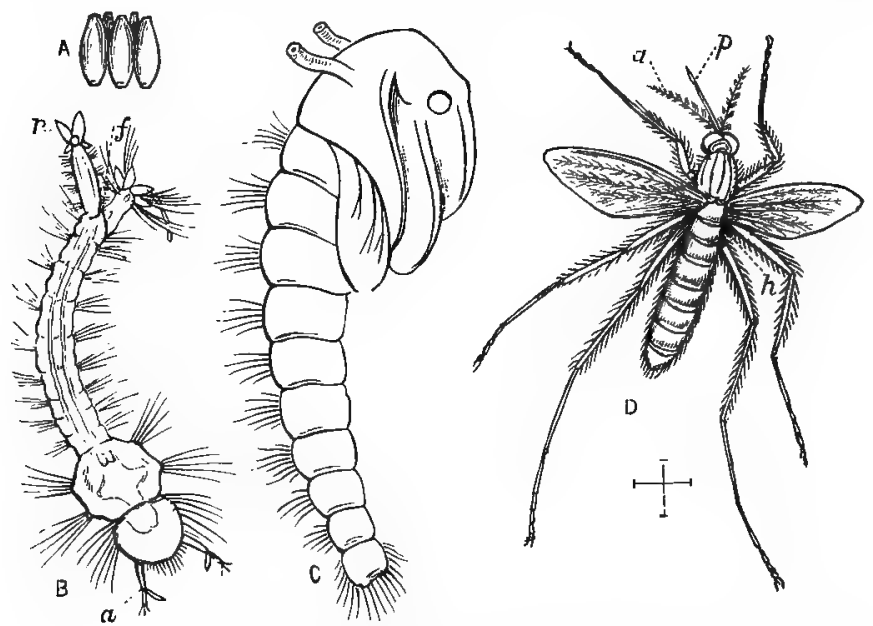

Fig. 122.--The common Gnat (Culex pipiens). A, A few of the eggs, attached together to form a raft, which floats on the water; B, The larva, suspended in the water hearl downwards, and showing the antenna $(a)$, the terminal respiratory tube $(r)$, and the fins attached to the extremity of the body $(f)$; $\mathrm{C}$, The pupa, with the two respiratory tubes attached to the thorax; $D$, The adult jusect, with the welldeveloper front wings, the rudimentary hind wings or "lalancers" $(h)$, the antennæ $(a)$, and the proboscis $(p)$. All the figures are greatly enlarged.

forms a boat, in which the insect floats until its wings are fit for use.

The lliptria constitute one of the largest orders of insects ; the House-flies and Flesh-flies ( $/ / u^{\prime} \mathbf{s}^{\prime}(t)$, the Gnats and Mosquitoes (Culicilip), the ('rane-flies (Tipula), the Forest-flies (Hippobosca), and the Gad-flies (Tabanidle) constituting good examples.

\section{Order X. Lepidoptera.}

This well-known and most beantiful of all the orders of insects comprises the Butterflies and Moths, the former being active by day (diurned ), and the latter mostly towards twilight (crepuscular), or at night (nocturul). In all the Lividoptera the mouth of the adult insect is purely suctorial, and is provided with a spiral trunk fitted for imbibing the juices of flowers, and formed ont of the elongated 
and metamorphosed maxillæ (fig. 109, B). The wings are four in number, and are covered more or less completely with modified hairs or scales, which are pretty objects under the microscope, and from which the wings derive their beautiful colours. The larvæ of the Lepidoptera (fig. 123) are generally known as caterpillars. They

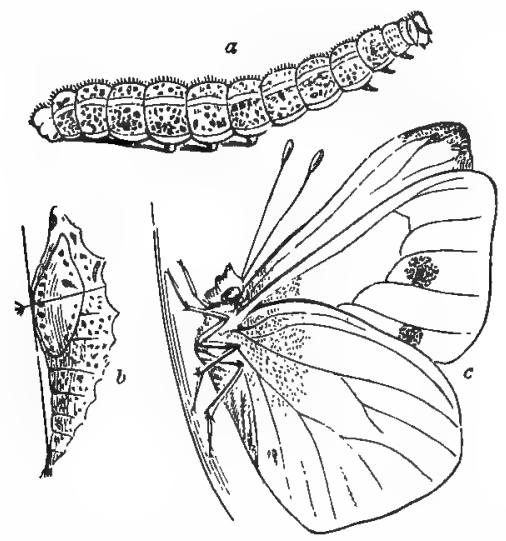

Fig. 123. -Large Cabbage White Butterfly (Pontia brassicce). $\quad a$ Larva or caterpillar; b Pupa or chrysalis ; $c$ Imago or perfect insect.

are worm-like, provided with masticatory organs fitted for dividing solid substances, possessing false legs ("prolegs") in addition to the three pairs proper to the adult, and having attached to the under lip a tubular organ or spinueret, by which silken threads can be manufactured.

The Butterfies or Diurnal Lepidoptera are characterised by being active during the daytime, by keeping their wings mostly erect when at rest (fig. 123,c), by generally having club-shaped antenuæ, and by having a chrysalis (b), which is almost always naked and angular, and is generally attached to some solid object by silken threads variously disposed.

The Moths (fig. 124) are mostly active during the night-time, when they are said to be "nocturnal." Many of them, however, are "crepuscular"- that is to say, they are active during the hours of twilight; and a few come out in broad daylight and in the brightest sunshine. The pupæ or chrysalides are never angular, as in the case of the Butterflies.

In the Crepuscular Lepidoptera, including those forms which are active during the twilight, the antennæ are usually fusiform, or grow gradually thicker from the base to the apex; the wings are 
horizontal or little inclined when the insect is at rest; and the pupx are never angular. Amongst the best known of the Crepuscular Lepidoptera are the Hawk-moths (Sphingida), comprising some of the largest examples of the whole order.

The Nocturnal Lepidopter have the antennæe setaceous, or diminishing gradually from the base to the apex, often serrated or pec-

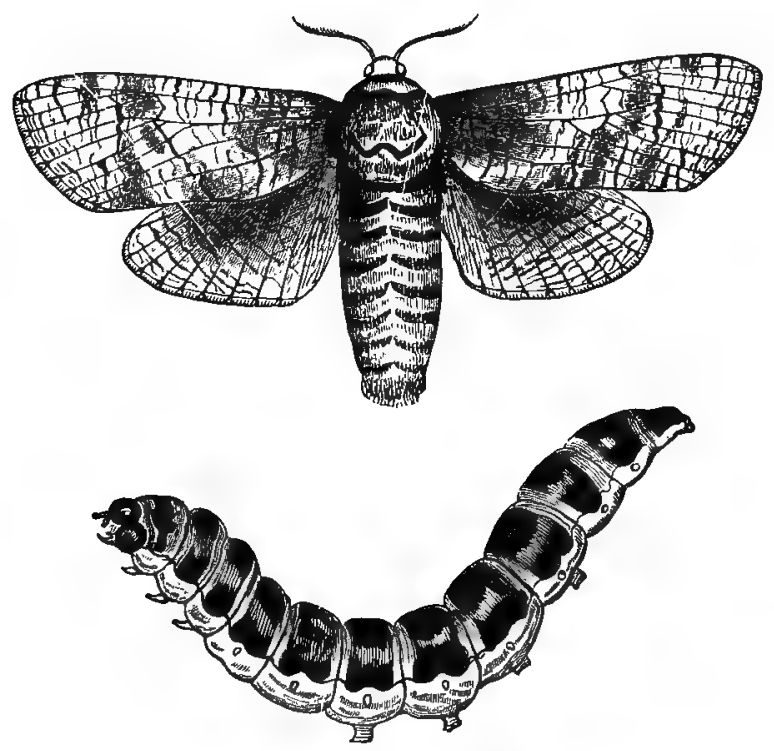

Fig. 124.-Goat-moth (Cossus ligniperda) and caterpillar.

tinated (fig. 124); the wings in repose are horizontal or deflexed; the pupæ are mostly smooth, sometimes spiny, and often enclosed in a cocoon. This group includes most of the ordinary moths. Certain groups of these comprise Moths of very small size, which are often spoken of as I/irolepidoptera.

\section{Order Xi. Hymenoptera.}

In this order all the four wings are present, as a rule, and they are all membranous in texture, with few nervures (fig. 125). The nouth is always furnished with biting-jaws or mandibles, but often is adapted for suction as well. The females have the extremity of the abdomen furnished with an instrument connected with the process of laying eggs (ovipositor); and in very many cases this becomes 
the powerful defensive weapon known as the sting. The metamorphosis is complete.

The Hymenopterc form a very extensive order, comprising the Bees (Apidoe), the Wasps (Vespidce), the Ants (Formicidce), the Gallflies (Cynipidoe), the Saw-flies (Tenthredinidre, fig. 12i), the Ichneumons, and many other forms. The Bees, Wasps, and Ants are well known as forming social communities, though solitary members of the two former families are very common.

In both groups these organised communities consist of a vast number of undeveloped females, or "neuters"-the so-called "workers" -presided over by a single fertile female, or "queen," or containing several such. The males are only produced at certain seasons,
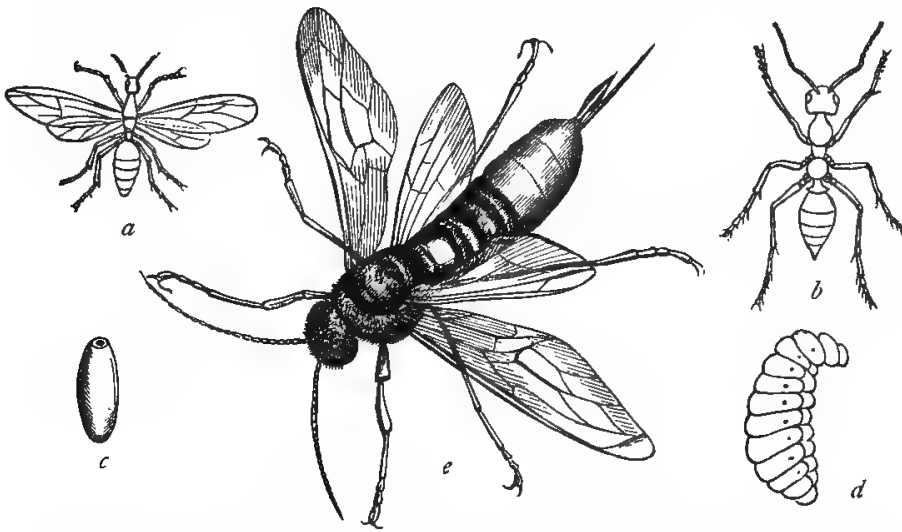

Fig. 125.-Hymenoptera. $a$ Winged male of Ant; $b$ Wingless worker of Ant ; $c$ Pul a of Ant; $d$ Larva of Ant, enlarged; $e$ The Great Saw-fly (Sirex gigas).

and they constitute the so-called "drones" of a hive of bees. The workers discharge all the duties necessary for the preservation of the colony, such as procuring food, building the nests, and feeding the young. As there is only one set, or "caste," of neuters, the duty of defending the nest falls to the lot of all the workers, and is not delegated to a special class of soldiers. The queen is the founder of the colony, and her sole function, after starting the community, is to lay eggs. The drones, or males, do no work, as a rule, and they either die, or are killed by the workers, as soon as the female is fertilised.

The Ants likewise form communities, consisting of males, females, and neuters. The males and females, like those of the very different "White Ants," or Termites, are winged (fig. 125, a), and are pro- 
duced in great numbers at particular times of the year. They then quit the nest and pair, after which the fecundated females lose their wings and form fresh societies. The workers (fig. 125, $b$ ) are sometimes all of one kind, but they are often divided into two, or even three, distinct classes or "castes." The Ants exhibit many most extraordinary and interesting instincts and babits, of which their custom of "milking" the little Plant-lice has been already mentioned. Another very singular habit of some Ants may be just alluded to-their habit, namely, of capturing the pupæ of other species of Ants and bringing them up as slaves. The relations, however, between the masters and slaves vary a good deal in different cases. In the case, for instance, of the Russet Ant (Formica rufescens) the masters are so entirely dependent upon their slaves that they cannot even feed themselves, and the only work which they perform unassisted is the capturing of fresh slaves. In the Blood-red Ant (Fornica sanguinea), on the other hand, the slaves are much fewer in number, and the masters are much less dependent upon their good offices. In all cases, the slaves exhibit the greatest devotion to their masters, and are invariably taken the greatest care of by their captors.

\section{Order XII. Strepsiptera.}

This is an extremely small order of insects, which merely requires to be mentioned. It includes only certain minute parasites, which are found on bees and other Hymenopteru. The females are desti-

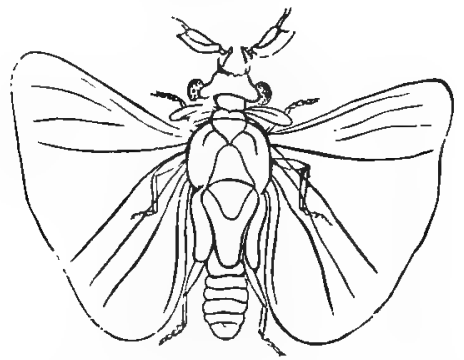

Fly. 126. - Strepsiptera. Stylops Spencii, greatly magnified (after Westwood).

tute of wings or feet, and are merely soft worm-like grubs. The males (fig. 12(i) are active, and possess a single pair of large membranous wings. Unlike the Dipter $\alpha$, it is the posterior pair of wings which is present, and the anterior pair. is quite rudimentary, and is 
only represented by curious twisted filaments, from which the name of the order is derived.

\section{Order XiII. Coleoptera.}

The twelfth and last order of insects is that of the Coleoptera, including the well-known insects familiar to every one under the name of "Beetles." The leading peculiarity of the Coleoptera is to be found in the fact, that though all the four wings are present, only the posterior pair are membranous, and perform the function of wings. The anterior pair of wings (figs. 127, 128) are no longer capable of being used in flight, but are hardened by the deposition of chitine, and constitute protective cases, which cover the hindwings, and are known as "elytra" (Gr, elutron, a sheath). The mouth in all the Beetles is masticatory, and is furnished with biting and chewing jaws (fig. 109, A).

The larvæ of the Beetles are all worm-like grubs, with masticatory mouths, and they all pass through a complete metamorphosis, generally requiring a protracted period for its completion. The known

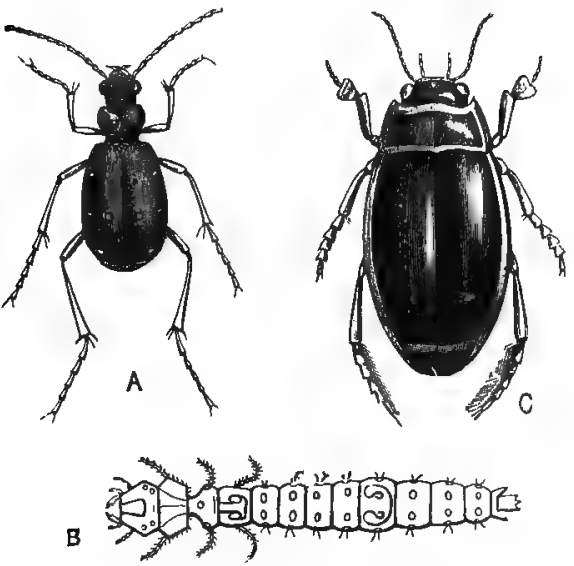

Fig. 127.-Coleoptera. A, Cicindela campestris, the Tiger - beetle, enlarged. B, Larva of the same, enlarged. C, Dyiscus marginalis, male.
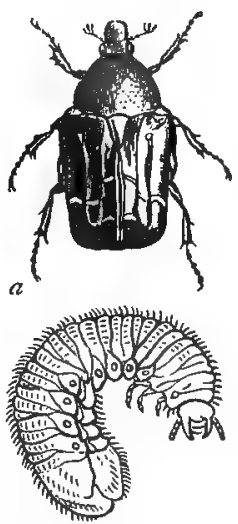

Fig. 128. - $a$, Rose-chafer (Cetonia aurata) and larva.

number of different kinds of Beetles cannot be estimated with any certainty, but it may be safely said that the order is one of the largest of all the groups of Insects. They are, as a general rule, remarkable for their hard chitinous skin, their glittering, often 
metallic, colours, and their voracious habits, though many of them feed upon vegetable matters.

Of the enormous number of known Beetles, the only one which can be said to be of any decided use to man is the so-called Blisterbeetle," or "Slanish Fly" (C'entluaris vesicatoria). This handsome insect is a native of Southern Europe, especially of Italy, Spain, and France, and lives upon the leaves of the ash, lilac, elder, and poplar. It is largely collected and exported for medicinal purposes, as it yields one of the most generally used and efficient of blisters.

Many of the Coleoptera inflict great injury upon wild or cultivated plants, some of then being most destructive in their adult condition, while others do most harm in their larval state. It is to be remembered, however, that the Coleoptera, like the Diptera, discharge important and highly beneficial functions by destroying vast quantities of decaying organic matten, which would otherwise prove injurious to man. 


\section{SUB-KINGDOM V. MOLLUSCA.}

\section{CHAPTER XVIII.}

\section{Sub-Kingdom Mollusca.}

THE Mollusca (Lat. mollis, soft), as implied by their scientific name, are mostly soft-bodied animals; but their popular name of "shellfish" expresses the fact that their soft body is usually protected by an external skeleton or "shell." All the Mollusca are furnished with a distinct alimentary canal, which is completely shut off from the general cavity of the body. There is sometimes no distinct blood-circulatory apparatus; but when there is, its central portion (i.e., the heart) is placed upon the dorsal aspect of the body. The chief peculiarity, however, of the Mollusca is found in the nature of the nervous system. In the lower forms (fig. 132, 2, $d$ ), the nervous system consists essentially of a single ganglionic mass, giving off filaments in various directions. In the higher Mollusca (fig. 129), the nervous system consists of three scattered pairs of ganglia, united to one another by nervous cords. One of these pairs is placed above the gullet or oesophagus, and is known as the "supra-oesophageal " or "cerebral" ganglia. A second pair supplies nerves to the great locomotive organ of most Molluscs, the "foot," and is therefore called the "pedal" ganglia. The third pair is known by the cumbrous name of the "parieto - splanchnic" ganglia, because it supplies nervous filaments to the walls (parietes) of the body, and also to the internal organs (splanchna). In all the higher Molluses it is this scattered condition of the nervous masses which distinguishes them so sharply from all other animals. Distinct respiratory organs may or may not be present, and they may be adapted for breathing air directly or through the medium of water. All the higher Mollusca are simple animals, and perpetuate their kind by means of the sexes; but many of the lower forms have the power of producing colonies by continuous gemmation, much as we have formerly seen in the Hydroid Zoophytes.

The digestive system in all the Mollusca consists of a mouth, 
gullet, stomach, intestine, and anus (fig. 129), with the exception of a few forms in which the intestine ends blindly. In some the

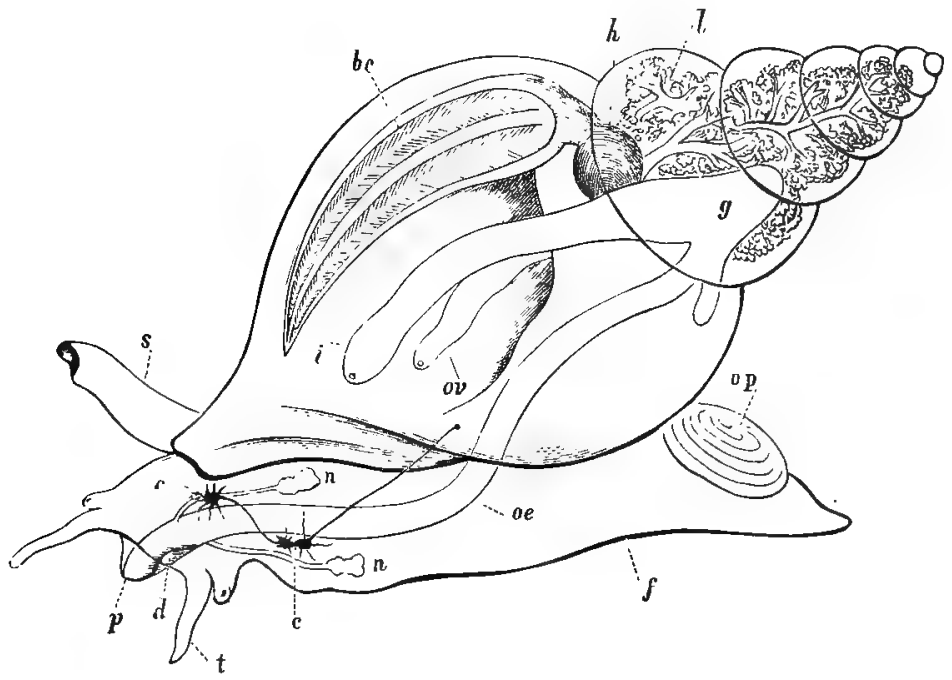

Fig. 129. -Diagram of the structure of a typical Molluse (the Common Whelk). $f$ The muscular "foot"; op The operculum; $t$ One if the tentacles, or feelers, with an eye at its base; $p$ The proboscis, retracted, with the nouth at its extremity; oe Gullet; $g$ Stomach; $i$ Intestine, terminating in the anus; $n n$ Salivary glands: $l$ The liver and the ovary; $h$ The heart; $b c$ The gill, contained in a bood of the mantle; $s$ Breathing.tube or siphon; $c$ and $c$ The main nerve ganglia, the one above the gullet being the cerebral ganglia, and the one below the gullet being the combined pedal and parieto-splanchnic ganglia.

mouth is surrounded by ciliated tentacles (Polyzox, fig. 132); in others it is furnished with two long ciliated arms (Brachiopoda, fig.
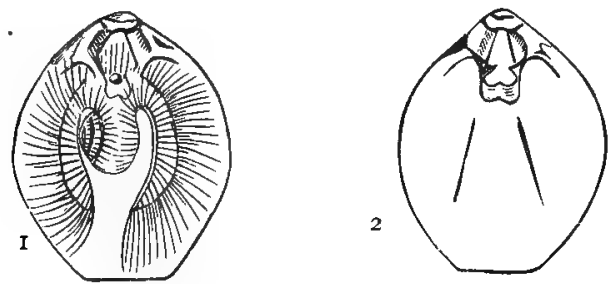

Fig. 130.-Terebratula vitrea. 1. Showing the eiliated "arms"; 2 . Showing the shell with its loop for the support of the arms. (After' Woodward.)

130); in the Bivalves (Lamellibranchiata), it is mostly furnished with four membranous processes or "palpi" (fig. 139,p); in others 
it is furnished with a complicated toothed organ or "odontophore" (Gasteropoda, fig. 141, and Pteropoda); and lastly, the Cephalopoda, in addition to an odontophore, possess horny mandibles, forming a kind of beak, very like that of a parrot.

The blood is colourless, or nearly so. In the lowest class of the Mollusca (Polyzoa) the circulation is carried on by means of cilia, and there is no distinct heart nor any definite course of the circulating fluid. In the Sea-squirts (Tunicata) there is a distinct heart, but the structure of this is very simple, consisting of a mere tube, open at both ends, so that the course of the circulation is periodically reversed. In the higher Mollusca there is a distinct heart, consisting of two chambers, of which one (the auricle) receives the aerated blood from the gills, while the other (the ventricle) drives it through the body.

Respiration is very variously effected amongst the Mollusca. In the Polyzoa (fig. 132) respiration is discharged mainly by the crown of ciliated tentacles surrounding the mouth. In the Sea-squirts (fig. 134) respiration is effected by a greatly developed pharynx, which is perforated by numerous ciliated apertures. In the Lamp-shells and their allies (Brachiopoda, fig. 135) the long ciliated arms which spring from the sides of the mouth seem to be the main agents in respiration. In the Bivalve shell-fish, the Cuttle-fishes, and most of the Univalves, the breathing-organs are in the form of gills or branchiæ, adapted for breathing air dissolved in water. In the remainder of the Univalves (e.g., Snails and Slugs) the breathingorgans are adapted for breathing air directly, and have the form of an air-chamber or pulmonary sac, produced by the folding of a portion of the mantle. The air is admitted to the chamber by a round opening situated on the side of the neck, and capable of being closed at will. The lining membrane of the chamber is richly supplied with blood-vessels, and thus the necessary purification of the blood is carried out.

In accordance with the scattered or rudimentary condition of the nervous system, the Mollusca are not characterised by acuteness of senses, nor by any great power of locomotion. Organs of sight exist in some of the lower and many of the higher Mollusca, attaining in the Cuttle-fishes (fig. 148) an extremely high type of organisation. Some of the common Bivalve shell-fish, such as the Scallop, possess numerous simple eyes placed along the margins of the mantle, but in many cases even these are absent. Locomotion is very variously effected, but seldom with much vigour or activity. The lowest classes of the Mollusca are in the great majority of instances fixed when adult. The common Univalve shell-fish, such as Whelks, Snails, Slugs, \&c., creep about slowly by means of a flattened disc, 
developed on the under surface of the body, and known as the "foot." Other Univalves and many Bivalves can effect short leaps by means of the foot; but many of the latter are permanently fixed to solid oljects, or buried in the sand. The minute Mollusca, known as the Pteropoda (fig. 147), swim freely at the surface of the ocean by means of two fins, formed by a modification of the foot, and attached to the sides of the head. The only Molluses which enjoy really active powers of locomotion are the predaceous Cuttlefishes, which swim rapidly by neans of fins, or by ejecting a jet of water from the cavity of the mantle, and which can also creep about by means of the "arnus" placed round the mouth (fig. 148).

The last feature in the $1 / 1 / l u s c a$ which requires to be mentioned is the "shell." The shell is not invariably and universally present in the Mollusca, many being either destitute of a shell altogether, or laving one so small that it would not commonly be recognised as such. In these cases, as in the common Slugs, the animal is said to be "naked." In all the llollusca which possess a shell, this is secreted by the integument, or by what is technically called the "mantle"; and in all cases it is composed of carbonate of lime. The methods in which the lime is arranged differ in different cases; but all living shells have an outer covering of animal matter, which is known as the "epidermis." In a great many of the higher $\mathbf{I} / \mathrm{l}$ lusr', such as the Whelks, Periwinkles, Snails, and others, the shell consists of only a single piece, when it is said to be "univalve." In many others, such as Oysters, Mussels, Scallops, \&c., the shell is compred "f two pieces, and is then said to be "bivalve." In a few forms the shell consists of several pieces, and it is then said to be "multivalve." The more important variations in the shells of the Hollusca will be noticed in speaking of the different classes of the sub-kingrlom.

In accordance with the nature of the nervous system, the $1 / \%$ llusca are divided into two great divisions, known respectively as

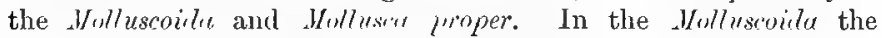
nervous nytem consists of a single ganglion, or principal pair of ganglia, and there is either no circulatory un or an inperfect heart. In this division are included the three classes of the Seamusses (Loly:or), the Sira-squirts (Turroutu), and the Lamp-shells

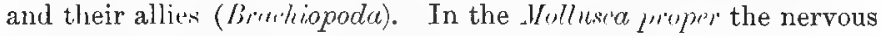
system consists of three principal pairs of ganglia, and there is a welldeveloped heart, consisting of at least two chambers. Under this head come all the ordinary forms of Shell-fish. 


\section{CHAPTER XIX.}

\section{MOLLUSCOIDA.}

\section{Class I. Polyzoa.}

Tne members of this class are the lowest of all the Mollusca, and they are generally known by the popular names of "Sea-mosses"

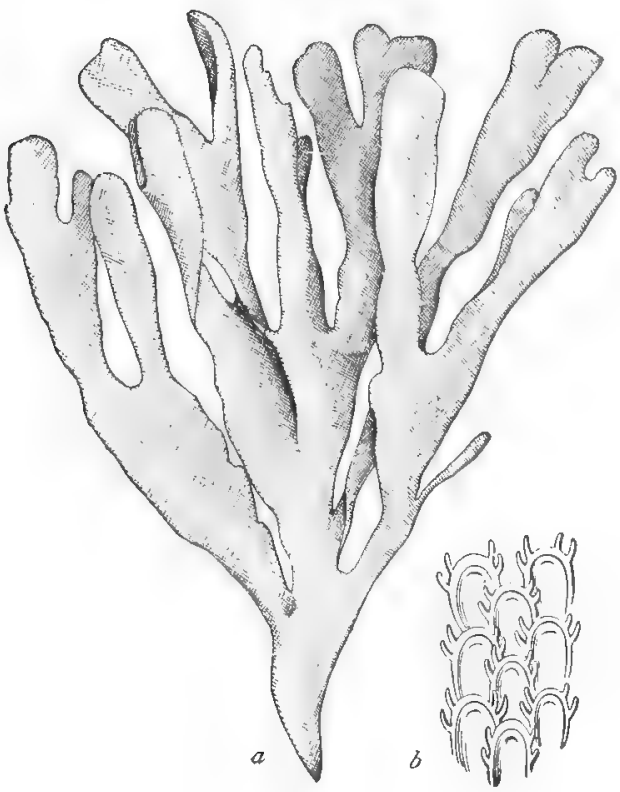

Fig. 131.-Flustra foliacea, one of the Sea-mats. a Portion of the colony, natural size; $b$ A fragment magnifier, to show the cells in which the separate polypides are contained.

and "Sea-mats." They are invariably compound, forming associated growths or colonies, often more or less plant-like in form (fig. 131), 
each consisting of a number of distinct but similar zoöids, produced by gemmation from a single primordial individual. The colonies thus produced are very generally protected by a horny or chitinous integument, and they are so like the Hydroid Zoophytes that they were lomg described as such. Indeed, the only absolute distinction between the two classes is to be found in the internal structure of the zoöids of each. The separate beings or zoöids which collectively constitute the colony of any Polyzoön are spoken of as "polypides"-the term polypite being only used in connection with the Hydrozor, and the term $1^{\prime r l y p e}$ being similarly restricted to the Lrtinozut.

Each polypide in a typical $P(y)=0 \%, n$ has the following structure (fig. 132, 2): The body of the animal is enclosed in a double-walled sac, of which the outer layer is usually chitinous or calcareous, and constitutes a "cell" in which the zoöid is contained. This outer layer is known as the "ectocyst" to distinguish it from the ecto-
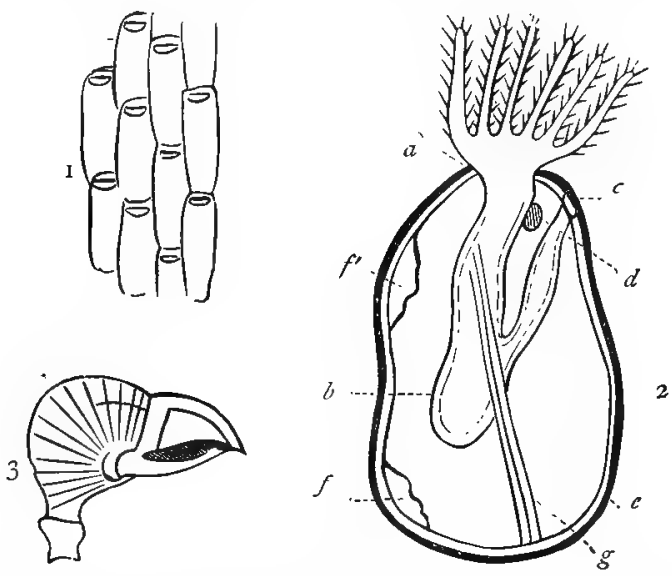

Fig. 132.-Xirpholngy of Polyzoa. 1. Fragment of one of the Sca-mats (Flustra (runcatu) matruified $t$, show the cells. 2. Diagram of a single polyplde of a Polyzom (after Allman); $a$ Mouth surrounded by the ciliated tentacles; $b$ Alimentary canal; $e$ Anus; "l Nerve-ganglion: e Investing sac or "ectocyst"; $f f$ Reproductive organs; $g$ Muscle. 3. Bird's-head process.

derm of the c'olenterata. The cell, thus formed, is lined by a much more delicate membranous layer, which is known as the "endocyst." This membranous sac, formed by the endocyst, is pierced by two openings. One of these $i s$ the mouth, and it is always surrounded by a circle or crescent of hollow ciliated processes or tentacles (fig. 
132, 2, a). These ciliated tentacles serve partly as respiratory organs, and partly to set up a current of water by which floating particles of food are brought to the mouth. The mouth and tentacular crown can be partially. or completely pulled into the sac by means of a nuscle which is fixed to the gullet $(2, g)$. The mouth leads into a gullet, and that again into a stomach, sometimes with a muscular gizzard between. From the stomach proceeds an intestine of variable length, which terniuates by a distinct anus at the upper part of the sac $(2, c)$. On one side of the gullet, between it and the anus, is placed a single nerve-ganglion $(d)$. Distinet reproductive organs $(f f)$ are also present, and the whole cavity of the sac is filled with fluid. From the above description it will be evident that the typical polypide of a Polyzoün differs from the polypite of a Hydrozoön in having a distinct alimentary canal suspended freely in a body-cavity, in having both a mouth and vent, in having a distinct nervous system, and in having the reproductive organs contained in the body.

The foregoing gives the essential structure of the polypide of any Polyzoön, but in nature this simplicity is lost. In all cases in nature the primitive polypide possesses the power of producing fresh zoöids by a process of budding; and these zociids remain attached to one another, so that ultimately there is produced a compound growth or colony. Further, in almost all the Polyzoa, the ectocyst or outer layer of the polypide is more or less hardened by the deposition in it of chitine or of carbonate of lime. The skeletons thus formed are the parts of the colony which are most familiarly known, and in the case of the common Sea-mats (fig. 131), they are very well known to seaside visitors, and are generally regarded as sea-weeds. Examined in its dead state, such a skeleton only shows a number of little horny chambers or cells (fig. 132, 1), each with a little aperture. When alive, however, each of these cells was tenanted by a single zoöid or polypide, capable of protruding its ciliated head from the aperture, and of again retiring within it if alarmed. The skeleton is, in some cases, furnished with curious organs, which are known as "bird's-head processes" (avicularia, fig. 132, 3), from their resemblance to the beak of a bird. The parts of this beak keep constantly snapping together, very much like the little pincer-like organs called "pedicellariæe" in the Sea-urchins and Star-fishes; but it is difficult to see what service they perform. They continue their movements long after the death of the polypides, and this appears, in some cases, at any rate, to be due to a peculiar system of nerves known as the "colonial" nervous system. In addition, namely, to the single ganglion with which each polypide is furnished, it has been shown that, in some forms, the zoöids composing the colony are 
united together by a well-developed nervous system, and are thus brought into organic connection with one another.

The vast majority of the $I^{\prime} \mathrm{m} / \mathrm{y} / \mathrm{wr}$ are fixed, and thus assume a very plant-like appealance. There is one fresh-water type, however (viz., ('ristatella), in which the colony can creep aloout upon a flattened base very like the foot of a slug. In this same form, also, alone of all the Polyzoa, there is not any outer covering or ectocyst to the polypides.

The P'y you are partly inhabitants of the sea and partly of fresh water, and they are thus divided into two groups which, as a
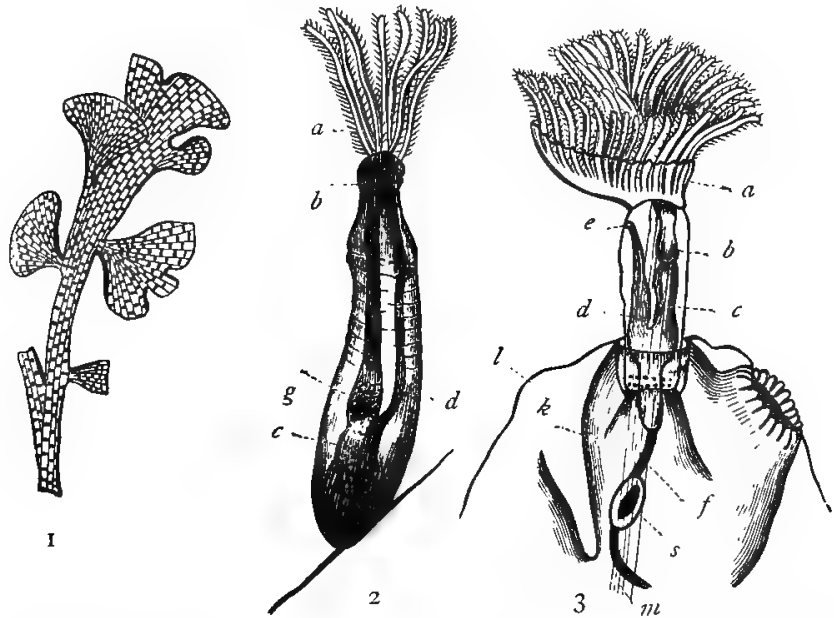

Fig. 13:3. -1. Fragment of Fustra truncata, one of the Sea-mats, natural size. 2. A single polypide of Valkerict, magnilied, slınwing the circular crown of tentacles. 3. A prlypide of Lophopus crystallinus, a fresh-water Polyzoon, lighly maguified, showing the horse-shoe-shaped crown of tentacles: $a$ Tentacular crown; $b$ Gullet; $c$ Stomach ; $d$ Intestine ; $e$ Anus ; $g$ Gizzard ; $k$ Endocyst; $l$ Ectocyst.

general rule, differ from one another considerably in anatomical structure. In most of the fresh-witter $I^{\prime}$ oly:me the tentacles are borlue upon a cremeentir lisc or stage (fig. 1333,3 ), so that the crown of tentacles assumes the shape of a horit'shoe. In almost all the marine forms, on the other hand, the tentacles (fig. 133, 2) are simply arranged in a circle.

All the Polyzor are hermaphrodite, each polypide being furnished with the reproductive organs proper to the two sexes. The eggs are simply liberated into the perivisceral cavity, where they are 
fertilised ; but it is uncertain how the fertilised ova escape into the external medium. Besides true sexual reproduction, and besides the power of producing colonies by continuous budding, fresh individuals can be produced in many cases by a process of discontinuous gemmation.

\section{Class II. Tunicata.}

The members of this class are not uncommonly called Ascidian Molluses (Gr. askos, a wine-skin), from the resemblance which many of them exhibit in shape to a two-necked leather bottle (fig. 134, C). They are popularly known as "Sea-squirts," from their power of
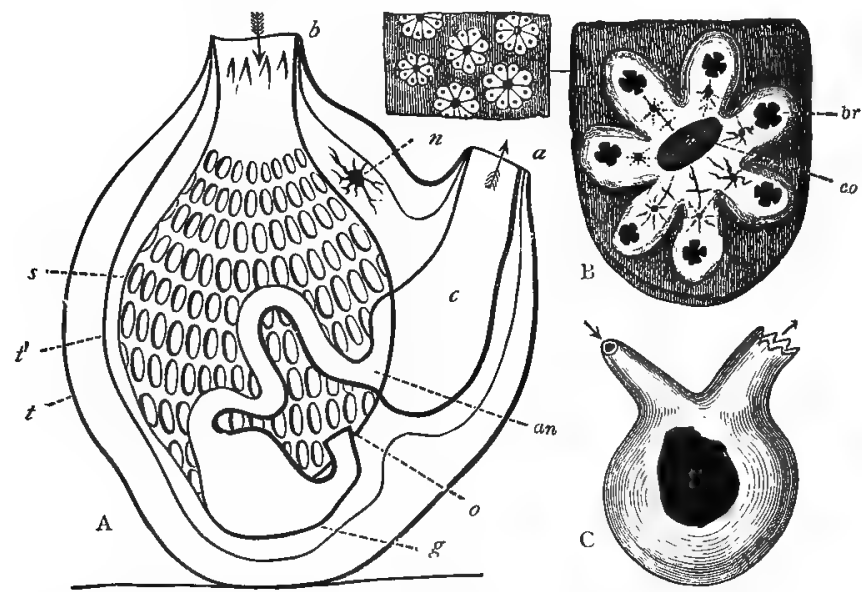

Fig. 134.-Morpholngy of Tunicata. A, Diagram of the structure of a simple Tunicate: $t$ Test; $t^{\prime}$ Second muscular tunic ; $s$ Branchial sac ; $b$ Branchial aperture; $a$ Atrial aperture ; $c$ Atrium ; o Opening of the gullet; $g$ Stomach, leading into the intestine; an Anal aperture; $n$ Nerve-ganglion. B, Botryllus smaragaus, a "compound" Tunicate-a small portion of a colony of the natural size, and a single system of the same enlarged; co Common atrial aperture; $b r$ Branchial aperture of one of the zoöids. C. Molgula Manhattensis, a simple Ascidian. The arrows in $\mathbf{A}$ and $\mathbf{C}$ show the direction of the water-currents.

forcibly ejecting water from the orifices of the bottle. Their scientific name, again, of Tunicata, is derived from the fact that the body is enveloped in a leathery elastic integument, which consists of different layers, and which takes the place of a shell. The outer covering of the animal is of a gristly or leathery consistence, and is known as the "test." It is remarkable for containing a considera- 
ble proportion of a substance apparently identical with cellulose, which is one of the most characteristic of all vegetable products. The test is lined by a second coat, which is highly muscular, and confers upon the animal its power of contracting itself and squirting out water. Of the two necks which are placed at the anterior end of a simple Ascidian (fig. 134, C), one is perforated by the aperture of the mouth, whilst the other serves as an excretory aperture. These two apertures are known respectively as the "oral," or" "branchial," and the "atrial" apertures.

The oral aperture $(a)$ is usually furnished with a circle of small non-retractile tentacles, and opens into a great chamber known by various names, but best as the "respiratory sac" or "branchial sac." This sac occupies the greater part of the cavity of the body (fig. $134, \mathrm{~A}, s$ ), and has its walls perforated by numerous apertures, the sides of which are ciliated. At the bottom of the respiratory sac is a second opening (the mouth of some writers) which leads by a short gullet into a capacious stomach $(g)$. From the stomach an intestine is continued to terminate by a distinct anus, which does not communicate directly with the exterior, but opens into a second great chamber, known as the "cloaca" or "atrium" (c). The cloaca, in turn, opens on the exterior by the second or atrial aperture in the test $(a)$. These two great clambers-namely, the respiratory sac and the cloaca-occupy the greater part of the body-cavity, and where their walls come into contact, a free comnunication is established between the two by neans of the ciliated apertures already spoken of as perforating the respiratory sac. The cilia which fringe these apertures all work towards the cloaca, and thus a constant current of water is caused to set in by the oral aperture, through the respiratory sac, into the cluaca, and out again by the atrial aperture. In this way respiration is effected, the walls of the respiratory sac being almost made up of blood-vessels. A distinct heart is present in all the Tunicita, but it has a very simple structure. It consists of a simple tube, open at both ends, and not provided with valves. In consequence of this, the circulation in the majority of Tunicaries is periodically reversed, the blood being driven for a certain number of contractions in one direction, and then propelled for a like period in an opposite direction; so that "the two ends of the heart are alternately arterial and venous."

The nervous system in the Tunicuta consints of a sirigle ganglion. placed on one side of the oral aperture (fig. 134, A, $n$ ).

With one or two exceptions all the Tunicatio are hermaphrodite, the organs of reproduction being situated in a fold of the intestine, and opening into the cloaca. The embryo is usually at first free, and swims about by means of a long tail, so that it presents con- 
siderable resemblance to the tadpole of a frog. The tail of the larval Tunicate also possesses in its interior a singular axial rod, which presents a renarkable resemblance to the embryonic backbone or "notochord" of Vertebrate animals. There are, further, other points of likeness between the embryo Tunicates and the I'ertebrata; and the Tunicates are, therefore, sometimes regarded as degenerate Vertebrate animals.

The Tunicati are all marine, but differ a good deal from one another in form. In the so-called "simple" Ascidians the animal has the shape figured above (fig. 134, C), and is fixed to some solid object by one end of the test. In the "social" Ascidians the organism consists of a number of zoöids, produced by continuous budding, and connected together by a common tube, through which the blood circulates. In the so-called "compound" Ascidians (fig. $134, \mathrm{~B}$ ) the tests are fused together into a common gelatinous mass, in which the individuals are embedded in groups. Some of the Tunicata are oceanic - that is to say, are found floating or swimming at the surface of the open ocean-and some exhibit the phenomenon of phosphorescence.

\section{Class III. Brachiopoda.}

The members of this class, sometimes called "Lamp-shells," are little known to the general public, being all marine, often inhabiting considerable depths in the sea, and being much more abundantly represented by fossil forms than by living examples. They are often placed with the ordinary Bivalve shell-fish (Lamellibranchiata), in consequence of their universally possessing a shell conmposed of two pieces or valves (fig. 135), but they are really of a much lower organisation. In their essential structure they show many points of affinity to the Polyzoa, but they are always simple aninuals, never forming colonies, and they always have a bivalve shell. The two pieces of which the shell is composed are always placed one in front and one behind, so that they are "ventral" and "dorsal," and not "right" and "left" as in the true Bivalves. The two valves of the shell are also always slightly, and sometimes greatly, different from one another in size, so that the shell is said to be "inequivalve." The ventral valve is usually the largest, and often possesses a prominent curved beak, which is generally perforated by an aperture through which there passes a muscular stalk by means of which the shell is attached to some solid object. In some cases, however, as in Lingula (fig. 136), the stalk of attachment simply passes between the valves, and is not transmitted through a distinct aperture. In other cases the shell is simply attached by the substance of the ventral valve. 
The inner surface of the valves of the shell is lined by expansions of the integument, which are called the "mantle-lobes," and which secrete the shell. The digestive organs and muscles occupy a small space near the apex or "beak" of the shell, which is partitioned off by a membranous partition, perforated by the aperture of the mouth. The remainder of the cavity of the shell is almost filled by two long processes, derived from the sides of the mouth, fringed with lateral
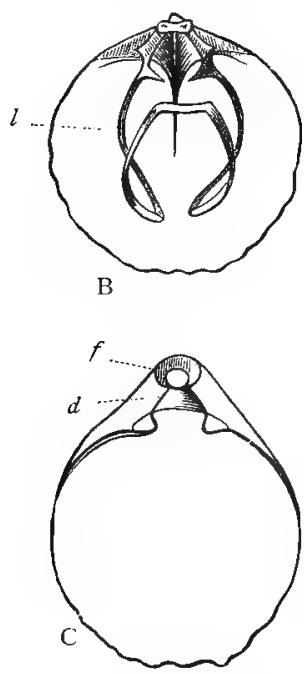
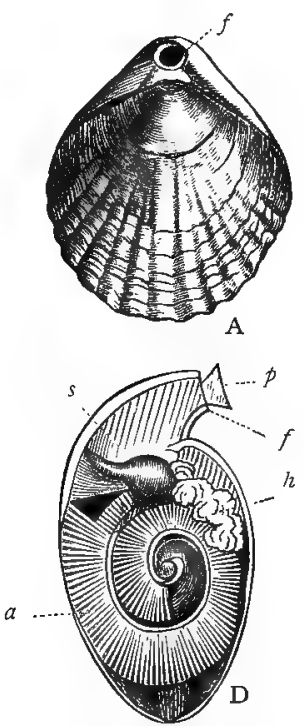

Fig. 135.-Terebratula (T'wldheimia) favescens. A, The shell viewed from behind, showing the dorsal valve, and the perforaterl summit of the rentral valve above it. $B$, Inner view of the dorsal valve, showing the shelly loop $(l)$ which supports the spiral arms. C, Inner view of the ventral valve, showing the foramen or aperture ( $f$ ) in the beak, through which the muscular stalk of attachment passes, D, Longitudinal aum vertiual sertion of the animal, showing the spiral arms (a), the stmrach (s), and thw liver $(h)$. At $f$ is the opening in the beak, with the stalk of attinchment $(p)$ passinis throluh it. (Aftr Davidson and Owen.) Some details have been omitted in liss. $B, C$, and $D$, for tle sake of clearness.

branches, and termul the "arms" (fig. 135, In). These arms are usually closely coiled un, and serve to obtain food for the animal. It is from these organs that the name of the class is derived (Gr. brachion, arm; and $l^{\prime \prime}(t, s$, feet). The arms also serve as respiratory organs, and in many forms they are supported on an internal calcareous framework or" skeleton, sometimes called the "carriage-spring apparatus." 
The mouth is placed between the bases of the arms, and is not furnished with any apparatus of teeth. It conducts by a gullet into a distinct stomach, surrounded by a well-developed granular liver. The intestine may or may not be furnished with a distinct anus, but in no case does it open into the body-cavity. Within the lobes of the mantle there is a remarkable system of branched tubes, which commence by blind extremities, and finally communicate with the mantle-cavity by means of certain organs which were formerly believed to be hearts, and are now known as "pseudohearts." This system of tubes alpuears to be mainly, if not entirely, connected with reproduction. A true heart, however, is present in most, if not in all, of the Brachiopoda.

The nervous system consists of a single principal ganglion, in some cases colnected with others so as to form a collar round the commencement of the gullet. In some cases, however, the nervous system appears to be very rudimentary.

The sexes appear to be sometimes distinct and sometimes united in the same individual. The embryo, in some cases, at any rate, is locomotive, moving from place to place by means of the ciliated arms or by ventral spines.

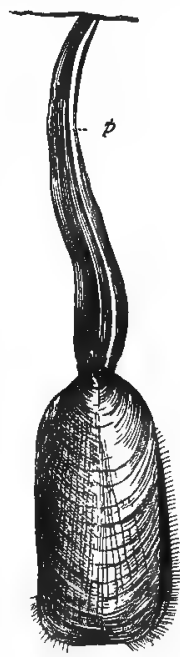

Fig. 136. - Lingula anatina, showing the muscular stalk by which the shell is attached $(p)$. (After Cuvier). 


\section{CHAPTER XX.}

\section{MOLLUSCA PROPER.}

The higher Mollusca or Mollus'a Proper comprise those members of the sub-kingdom in which the nerwus system consists of three principal puirs of yanglia; and there is always a well-developed heart consisting of at linst two chumbers.

In this division are included the following classes:-

1. Lamollihurchiuta, withont a distinct head.

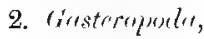

3. Pteropoda,

with a distinct bead and a masticatory

1. Cephalopoda, apparatus or "odontophore."

\section{Class I. Lamellibranchiata.}

These are well known as Bivalve shell-fish, such as Mussels, Oysters, Scallops, \&c., and they are all either marine or inhabitants of fresh water. They are distinguished from the other Molluses by having no distinct head, and by having the body protected by it bivalve shell composed of two pieces. They are called Lamellibranchiata from the fact that the organs of respiration are in the form of leaf-like gills or branchie, two of which (or sometimes one only) are placed at each side of the body, constituting what is known in the oyster as the "beard." The body of the Lrmellibrenchireta is more or less completely enclosed in an expansion of the integument which comstitutes the "mantle," and which is divided into two halves or "lobes," which are placed on the sides of the animal, and secrete the shell. The shell, therefore, of the true Bivalves is composed of two valves, which are "right" and "left," and not "dorsal" and "ventral" as in the Brrilingode. Moreover, the valves of the shell are usually of the same size, so that the shell is "equivalve"; and, lastly, the shell is more developed on one side than the other, so as to become "inequilateral" (fig. 138). The lobes of the mantle are sometimes quite free along their ventral margin; but at other times they are more or less united to each other, and leave only two 
openings. Through one of these openings (the anterior) the "foot" is protruded (fig. 137, $f$ ) ; and through the other pass the respiratory tubes or "siphons" (s). The foot in the Bivalves is a muscular organ developed upon the lower surface of the body, but not forming a creeping flattened disc as in the ordinary Univalves. In many cases it is quite rudimentary; and even when it is employed in locomotion it is usually small. Most generally it is hatchet-shaped or pointed (fig. 137, $f$ ), and serves to enable the animal to make short leaps. In many cases-as in the common Mussels-the foot is subsidiary to a special gland, which secretes a viscous fluid, that hardens rapidly on exposure to the air. This fluid is moulded by the foot into silky threads (the so-called "byssus"), by means of which the shell is firmly fixed to some solid object. Besides the muscular foot, other muscles are present as well in the Lamellibranchiata. of these the most important are the muscles which close the shell, and are called the "adductor" muscles. In one group of the Bivalves (e.g., Oyster, Scallop, \&c.), there is only one adductor muscle, but ordinarily there are two (fig. 138). These muscles leave distinct scars or " muscular impressions" in the dead shell, so that it is easy to determine how many were present in any given shell. The margin of the mantle, too, is muscular, and

leaves upon the shell a distinct line where it was attached, this

Fig. 137.-Anatomy of a Bivalve Molluse. Mya arenaria (after Woodward). The left valve and mantle-lobe, and half the siphons, are removed. \& s Respiratory siphons, the arrows indicating the direction of the currents; $a a^{\prime}$ Adductor muscles ; $b$ Gills : h Heart; o Mouth, surrounded by ( $p$ ) labial palpi ; $f$ Foot; $v$ Anus; $m$ Cut edge of the mantle. 
being known as the "pallial line" (Lat. pallium, a mantle), as shown in fig. 138.

As regards the shell of the Bivalves the following are the chief points to be noticed. Each valve of the shell (fig. 138) is to be regardel as essentially a hollow cone, the apex of which is turned more or less to one side. The apex of the valve is known as the "umbo" or "beak," and is turned towards the mouth of the animal. Consequently, the sile of the shell towards which the beaks are turned is known as the "anterior" side, and it is usually much shorter than the opposite or "posterior" side. The side of the shell at which the beaks are situated is known as the "dorsal" margin; and here the valves are united to one another for a longer or shorter

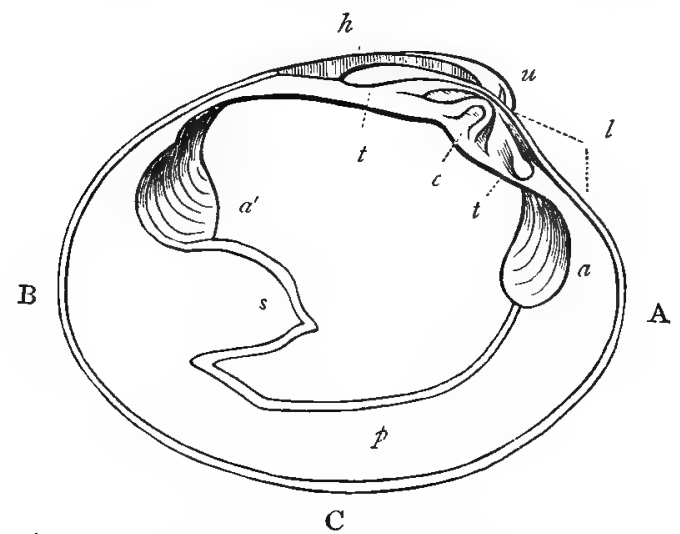

Fig. 138.-Left valve of Cytherea chiome (after Wumdward). A, Anterior margin; B, Posterior nuargin; C, Ventral margin or base; $"$ Unbo; $h$ Ligament; $c$ C'ardinal twitl ; t t Lateril teeth; a Anterior adductor; $a^{\prime}$ Posterior adductor; $p$ Pallial line; $s$ Pallial sinus caused by the retractor muscles of the siphons.

distance along a line which is known as the "linge-line." The union between the valves is usually effecter by means of interlucking parts or "teeth," and there is often a bind of horny fibres passing between the two valves just behind the beaks. In many cheses there is also a serics of homy filses placed perpendicularly between the lieiks, so as to he compressed when the shell is shut. By the elasticity of these, and of the external ligament when present, the valves of the shell are opened, without any effort of the animal, simply by relixing the arhluctor muscles. The valves are shut again by the contraction of the adductor muscle or muscles.

As illeady siald, the margin of the mantle leaves on the shell a distinct impression-the "pallial line"-and by inspection of this, 
important conclusions can be drawn in any given case as to the mode of life of the animal. In certain shells, namely-(e.g., the Scallop, the Fresh-water Mussel, \&c.) the pallial line is unbroken or "entire," and in these the mantle-lobes were either quite free, or if attached to one another and drawn out into respiratory tubes, these were not furnished with special museles by which the tubes could be retracted within the shell. In other Bivalves, on the other hand (fig. 138) the pallial line is indented to a greater or less extent, showing that the mantle-lubes were more or less united to one another, and were drawn out into long respiratory tubes or siphons, which were furnished with special muscles by which they could be withdrawn within the shell. This difference expresses a real distinction amongst the Bivalves, due to their mode of life. In all alike, the respiratory organs are in the form of membranous leaf-like gills, of which there are usually two on each side of the body. The gills are composed generally of tubular rods (fig. 137, $b$ ) richly supplied with blood-vessels, and covered with vibrating cilia. For the proper maintenance of respiration, however, it is necessary that the gills should be constantly supplied with fresh water. In those Bivalves in which the animal is free and the mantle-lobes not attached to one another, this is effected without any special mechanism. In those forms, however, in which the animal lives buried in the mud and sand, and the mantle-lobes are more or less completely united, there are two orifices, one of which admits fresh water, while the effete water is got rid of through the other. These orifices, in the shells just spoken of, are extended into two long tubes which are known as the "respiratory siphons." The water passes in by one siphon, is swept over the surface of the gills, and then reaches the mouth (fig. 137, o), when it is returned in the opposite direction to escape by the other siphon. The same current of water, therefore, both carries oxygen to the gills, and serves to convey food to the mouth. The two siphons may be quite distinct from one another, but they are very often united together so as to look like a single tube (fig. 137, s s). They are of ten very small, and then they leave no traces of their existence in the dead shell; but when they ax'e very long, they are furnished with muscles to retract them within the shell, and it is the scar left by these muscles which causes the pallial line to be indented. This indentation, therefore, as seen in the dead'shell, is an indication that the animal possessed long retractile respiratory siphons, and lived, therefore, nost probably embedded in sand or mud.

There is always a distinct heart (fig. $139, h$ ) composed of two or three chambers, and in all cases acting as a mere arterial heart. That is to say, the heart propels the aerated blood derived from the 
gills through the body, and has nothing to do with the propulsion of the non-aerated or venous blood through the gills. There is never any distinct head in any of the Bivalves, and for this reason they are sometimes called the "headless" (acephalous) Molluscs. The mouth is simply placed at the anterior end of the body, and is never furnished with teeth, though usually provided with membranous processses or "palpi" (fig. 139, lp). The mouth opens into a gullet

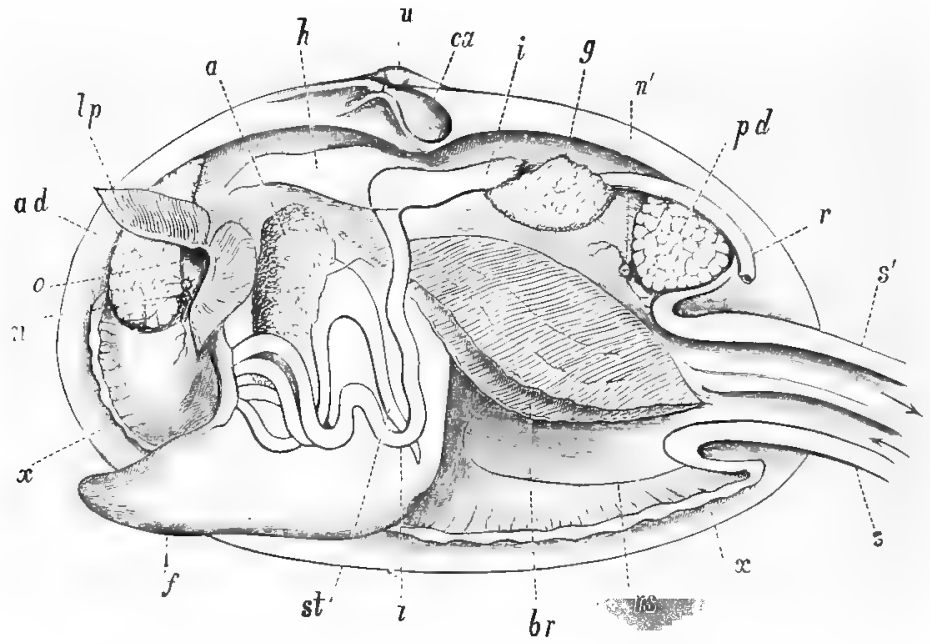

F.s. 130 - Limellubinuhiata. Diagrammatic representation of the anatomy of a s phonate Brvalve. The left valve and left mantle-lobe are removed, and the siphons are cut short. $u$ Umbo; $c a$ Cartilare-pit; o Month; lp Labial palpi; a Stomach, surrounded ly liver; st Sac containing the crystalline stylet; $i$ intestine, perforating the heart $(h) ; r$ Rectum, terminating in the anus; ad Anterior aldurtur; pri Posterior adductor ; $n$ Suprausophageal or cerebral ganglion (the mouth is a little displacel upwards, so that the ganglion comes to he below the gullet instead of alwse it): $n^{\prime}$ Parieto-splanehnic or branchial ganglion; $f$ Front; $x x$ cut eclse of the right mantle-fobe; $r$ Retractor muscle of the sifhons; br Branchire of the left sicle; $g$ Renal orsan ("Organ of Bojanus"); $s$ Inhalant siphon; $s^{\prime}$ Exhalant siphon.

which conducts to it stomach. The intestine is conroluted, and usually perforites the ventricle of the heart, ultimately terminating in a distinct anus, which is always placerl near the respiratory aperture (fig. 13:1,r). A larrge and well-developed liver is also present.

The nervous system has its normal form of three principal masses - the cerebral, the pedal, and the parieto-splanchnic ganglia.

The majority of the Bivalve Molluscs lave the sexes distinct, but they are sometimes united in the same individual. The young are 
hatched before they leave the parent, and, when first liberated, are ciliated and free-swimming.

The habits of the Lamellibranchiata are very various. Some, such as the Scallops (Pecten), habitually lie on one side, the lower valve being usually the deepest, and the fout rudimentary or wanting. Others are fixed to the bottom of the sea by the substance of one of the valves, Others, such as the common Mussel, are moored to some foreign object by a tuft of silky fibres, constituting a "byssus." Many, such as the Gapers (M $M(x)$ and Razor-shells (Solen), spend their existence sumk in the sand of the sea-shore or the mud of estuaries. Others, such as the Pholades, bore holes in rock or wood, in which they live. Finally, many are permanently free and locomotive.

\section{Class II. Gasteropoda.}

This class includes an enormous number of Molluses, such as the Land-snails, Sea-snails, Whelks, Limpets, Slugs, Sea-lemons, \&c., which agree in many fundamental characters, but nevertheless present many striking differences. From the very common occurrence of a shell composed of a single piece, the Gasteropoda are often spoken of in a general way as the "Univalve" Molluses. In many, however, there is either no shell at all, or one so small that it would not generally be recognised as such; and in a few (Chiton) the shell is composed of eight pieces ("multivalve"). In none, however, is the shell composed of two pieces or "bivalve." The large majority of the Gasteropoda are further distinguished by the great development of the foot, which constitntes a broad flattened dise upon which they creep about, as may readily be observed in the common Slugs or Snails (fig. 142). Some, however, have the foot much modified and adapted for swimming. In many cases, also, the foot carries behind a horny or shelly plate which is known as the "operculum" (fig. 140,o), and which serves to close the shell when the animal is withdrawn within it.

The head in most of the Gasteropoda, unlike the Bivalves, is very distinctly marked out, and carries two long feelers, and two eyes, often placed upon stalks (fig. 142). The mouth, also, differs from that of the Bivalves in being furnished with a singular apparatus of teeth, constituting what is known as the "odontophore" (fig. 141), or "lingual ribbon. This consists essentially of a number of chitinous teeth, of different shapes in different species, supported upon a kind of strap which can be made to work backwards and forwards over a cartilaginous cushion, thus acting like a chain-saw. In addition to the odontophore there are sometimes horny jaws as well. The mouth (see fig. 129) leads by a gullet into a distinct 
stomach, which sometimes is provided with calcareous plates for grinding down the food. The intestine is long, and always terminates in a distinct anal aperture. Distinct salivary glands are usually present, and the liver is well developed.

A distinct heart (fig. 129) is almost always present, and consists of two chamber's, an auricle and a ventricle. Respiration is very varionsly effected-one great division being constructed to breathe

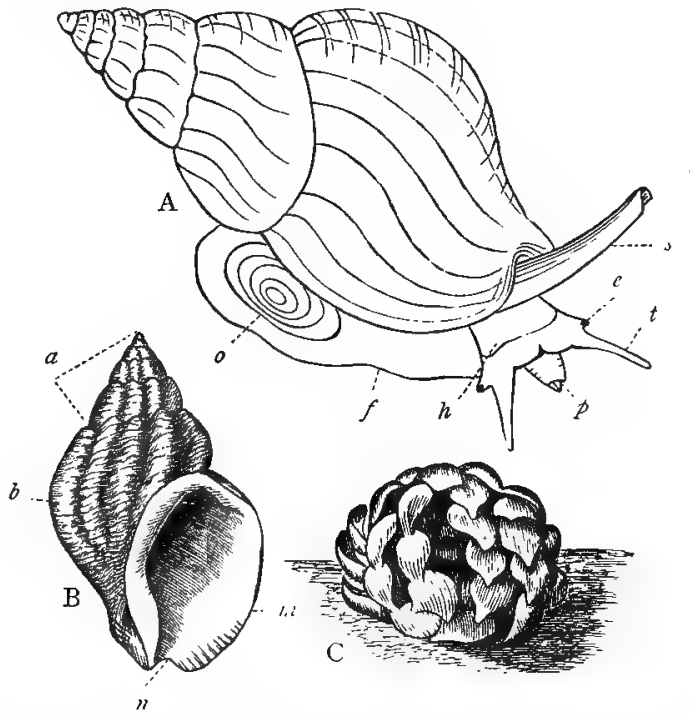

Fig. 140.-A, Sketch of a Whelk (Buccinum undatum) in motion: $f$ Foot; $h$ Head, carrying the feelers $(t)$ with the eyes (e) at their bases; $p$ Proboscis; $s$ Respiratory siphon ur tube by which water is admitted to the gills; o Operculum. B. Shell of the Whelk : $a$. Spire; $b$ Body-whorl $n$ Noteh in the front margin of the mouth of the shell; $m$ Outer lip of the mouth of the shell. This figure is half the natural size. C, A small cluster of the egg-eapsules of the whelk. (B and C are after Woudward.)

air by means of water, whilst in another section the respiration is aerial. In the former of these-often spoken of as the "branchiate" Gasteropuds-respiration may be carried on in three ways. Firstly, there nay be no special breathing-organ, the blood being simply exposed to the action of the water, as it circulates through the thin walls of the mantle-cavity. Secondly, the breathing-organs may be in the form of outward processes of the skin, exposed to view on the back or sides of the animal (fig. 144). Thirdly, the breathing- 
organs may be in the form of plume-like gills, contained in a more or less complete chamber, formed by a folding of the mantle (fig. 129). In many members of this group the water attains access to the gill-chamber by means of a tubular prolongation or folding of the mantle, forming a siphon (fig. 140, s), and often the effete water is expelled by another tube which is sinilarly constructed. In the second great section-often called the "pulmonate" Gasteropods-respiration is effected by a pulmonary chamber or lung, formed by a folding of the mantle, and having air admitted to it by a distinct aperture.

The sexes in the Gasteropoda are mostly distinct, but in some groups (e.g., the Pulmonate forms and the Sea-slugs) they are united in the same individual. The young, when first hatched, are always provided with an embryonic shell, which may be entirely lost in the adult, or may simply become concealed by a fold of the mantle. In the waterbreathing forms the young is protected by a small nautilus-shaped

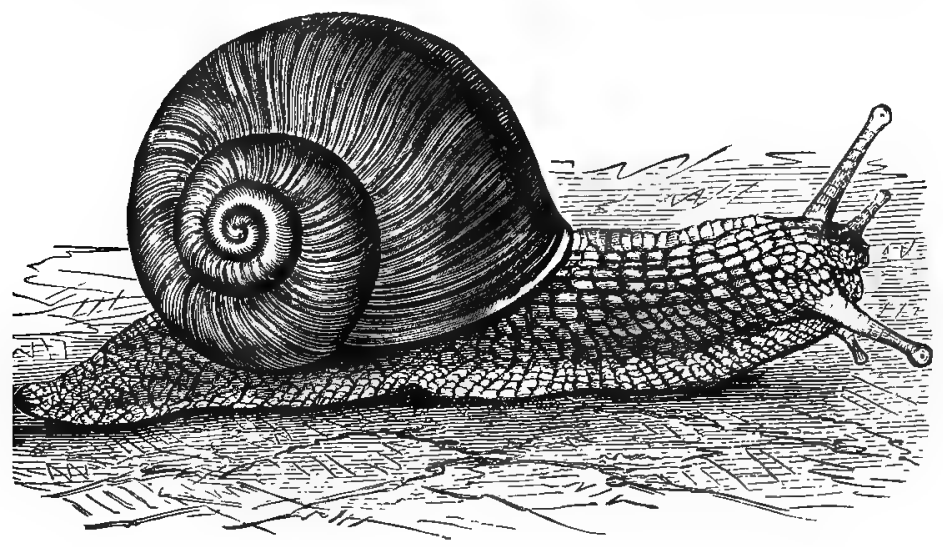

Fig 142.-Gasteropoda. The Garden Snail (Helix aspersa).

shell, within which it can entirely withdraw. At this stage, it is enabled to swim about freely by means of two ciliated lobes springing from the sides of the head, but this ciliated "veil" is soon lost.

As regards the shell of the Gasteropoda, the following points may 
be noticed. The shell is composed either of a single piece (univalve), or of a number of plates placed one behind the other (multivalve).

The univalve shell is to be looked upon as essentially a lollow cone, the apex of which is placed a little on one side. In the

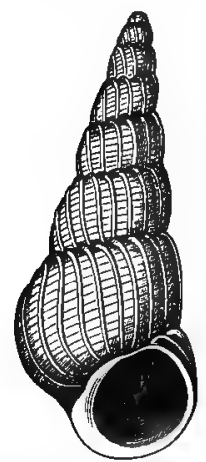

Fig. 143. - Seularia frepnlantica, a $\mathrm{H}$ olostomatous Univalve. simplest forms, as in the Limpets, the conical shell is retained throughout life without any alteration. In the great majority of cases, however, the cone is considerably elongatel, so as to form a tube, which may retain this shape (as in the "Tooth-shell"), but which is usually coiled up into a spiral. The "spiral univalve" may, in fact, be regarded as the typical form of the shell in the Gasteropoda (fig. 140, B). The coils of the spiral are termed the "whorls," and are usually more or less amalgamated on one side. In most cases, too, the whorls are wound obliquely round a central axis or pillar, increasing gradually in size to the mouth. The last whorl is the largest, and is termed the "body-whorl." The mouth of the shell in many forms is unbrokenly round or "entire" (fig. 143), and it is found that most of these forms subsist on vegetable food, as, for instance, the common Periwinkles. In others, again (fig. 140, B), the mouth of the shell is notched or is produced into a canal, as in the common Whelk, and it is found that these live upon animal food, or are "carnirurous." There may be more than one of these canals or tubes, but they do not necessarily indicate the nature of the food, as their function is to protect the respiratory siphons.

The Gusteropoda are divided into a good many groups, of which the more important nay be lriefly noticed, the foregoing applying

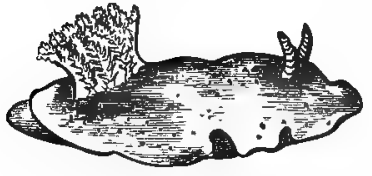

Fir. 144. - Nudibraneliata. Doris Johnstoni, one of the Sei-lemons. chiefly to the ordinary forms, which therefore need no further description. The remaining members of the waterbreathing Gasteropods are divided into two sections, differing a good deal from the typical forms of the class in many respects.

As examples of the first of these may be taken the Sea-slugs and Sealemons (Tulibrumliata), specinens of which may at any time be found creeping about on sea-weeds, or attached to the under surface of stones at low water. These slug-like animals (fig. 144) are wholly destitute of a shell when fully grown, but possess an embryonic shell when young. When there are any distinct respiratory 
organs, these are in the form of gills, placed, without any protection, upon the back or sides of the body. The head is furnished with tentacles, which do not appear to be used as organs of touch, but are more probably connected with the sense of smell; and behind the tentacles are generally two eyes. Locomotion is effected, as in the true Slugs, by creeping about on the flattened foot.

The last remaining group of the "branchiate" Gasteropods is that of the Heteropoda (fig. 145), comprising a number of curious forms which are found swimming at the surface of the open sea, instead of creeping about at the bottom of the sea. In order to adapt them for this mode of life, the foot, instead of forming a creeping disc, is modified to form a compressed fin $(f)$. The Heteropoda are to be regarded as the most highly organised of all the Gasteropoda, at the same time that they are not the most typical members of the class. Some of them can retire completely within their shells, but others

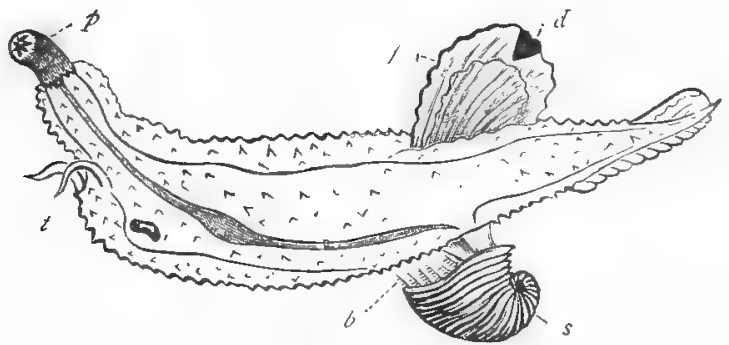

Fig. 145. - Heteropoda Carinaria cymbium. p Proboscis and nuouth; $t$ tentacles; $b$ Gills; $s$ Shell ; $f$ Foot; $d$ Disc. (After Woodward.)

have large bodies, and the shell is either small or entirely absent. In Carinaria, which may be taken as a good eximple of the group, there is a little limpet-shaped shell protecting the gills $(b)$ and heart. The aninal swims, back downwards, by means of a vertically-flattened ventral fin $(f)$, on one side of which is a little sucking-disc $(d l)$, by which the animal can adhere at pleasure to floating sea-weed. Curinaria is found in the Mediterranean and other warm seas, and is so transparent that the course of the intestine can be seen along its whole length.

The last group of the class is that of the "air-breathing" Gasteropods, so well-known as Land-snails, Pond-snails, and Slugs (fig. 146). All the members of this group are formed to breathe air directly, instead of through the medium of water, and they therefore never possess gills or branchiæ. In place of these they have a pulmonary chamber or lung, formed by a folding of the mantle, and having air admitted to it by a round hole on the right side of the 
neck, which can be opened and closed at will. Though thus adapted for breathing air directly, many of the members of this group can only live in damp or moist places, while others habitually live in fresh water. The common Pond-snails are examples of these last. The condition of the shell varies very much. Some, such as the common Land-snails (fig. 142), have a well-developed shell within

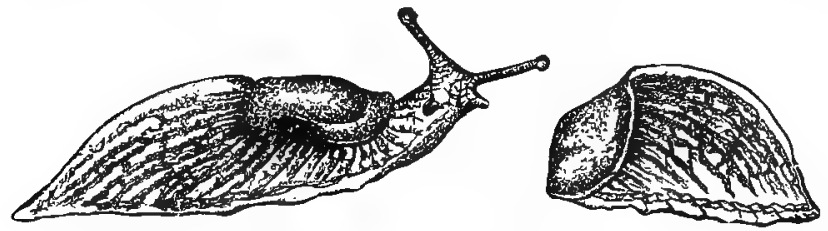

Fig. 146.-Limax Solvertyi, one of the Slugs. (After Woodward.)

which the animal can completely withdraw itself for protection. Others, such as the common Slugs (fig. 146), have a rudimentary shell which is completely concealed within the mantle. Others are entirely destitute of a shell. They all agree with the typical Gasteropods in creeping about on a broad, flattened foot.

\section{C'tiss III. Pteropoda.}

This class is a very small one, and includes a number of minute oceanic Molluses, often called "Winged Suails," which are found swimming near the surface in the open ocean, far from land, and often in enormous numbers. The organs of locomotion are two wing-like fins (fig. 147) attached to the sides of the head, and formed by a modification of a portion of the foot. The budy is usually protected hy a synmetrical glassy shell (fig. 147, D), consisting of two plates united along their edges, or in other cases forming a spiral (fig. 117, A and ('). In some, however, there is no shell, and the body is quite naked (fig. 147, B). The heal is rudinentary, and bears the mouth, which is fumished with an odontophore. The heart consists of an auricle and ventricle, and the respiratory organs are extremely rudimentary. The sexes are united in the same individual in all the Pteronurlr.

The Pteropoda occur, as already said, in the open ocean, and they are found in all sens from the tropics to within the arctic circle, sonetimes in such numbers as to discolour the water for many miles. Minute as they are, they constitute in high latitudes one of the staple articles of dict of the whale, and they themselves in turn 
are probably carnivorous, feeding upon small Crustaceans and other diminutive creatures. Though all the living forms are small, Geo-
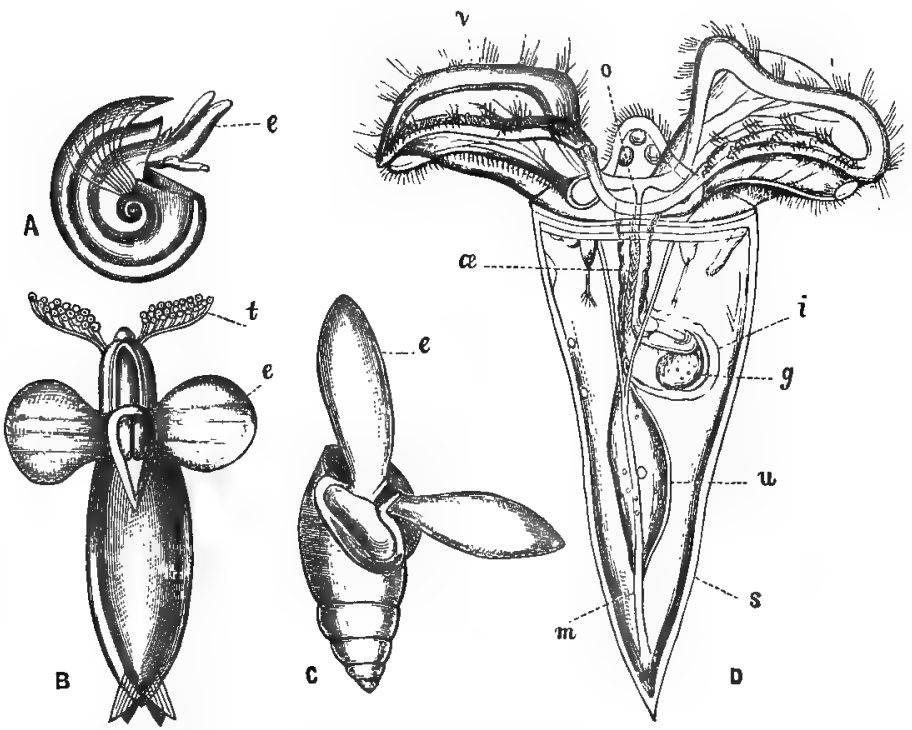

Fig. 147.-Pteropoda. A, Spirialis rostralis. B, Pneumodermon violaceum. C, Helerofusus buliminoides. All enlarged. e Epipodia or fins; $t$ Tentacles. D, Larva of Cleodora lanceolata, greatly enlarged (after Fol): $v$ Ciliated lobes; o Mouth; œ Gullet; $g$ Stomach; $i$ Intestine; $s$ Shell; $u$ Yolk-sac.

logy leads us to believe that formerly there existed comparatively gigantic forms, which appear to be truly referable to this class. 


\section{CHAPTERXT.}

\section{CEPHALOPODA.}

C'tass IV. C'epillloroda.

Tre last and highest class of the Molluse $a$ is that of the Cephalopodu, comprising the Cuttle-fishes, Calamaries, Squids, and the Pearly Nautilus. They are all inhabitants of the sea, and are all

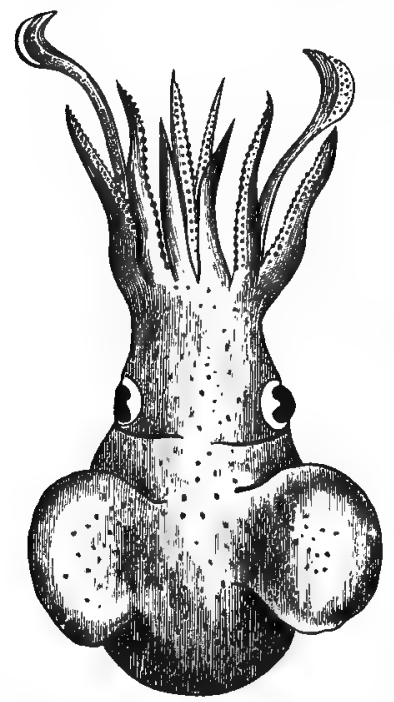

Fig. 148-Sppmire Allantirn, one of the Cuttle-fishes. (After Wooulward.) curnivorous; and they are possessed of considerable powers of locomotion. At the bottom of the sea they can walk alunt head downwards, by means of the arms (fig. 148) which surround the mouth, which are usually provided with numerous suckers, and which are really produced by a splitting up of the margins of the foot. It is from the presence of these arms that the class derives its name (Gr. kepleale, head; and podes, feet). The Cuttle-fishes can also swim rapiclly, either by means of expunsins of the skin constituting fins, or by the forcible expulsion of water from the cavity of the mantle, the reaction of which causes the animal to move in the opposite direction. The majority of the living Cephalopods are naked, possessing only an internal skeleton, and this often a rudimentary one; but the Argonaut (Paper Nautilus) and the Pearly Nautilus are protected by an external shell, though the nature of this is extremely different in the two forms.

The body in the Cephalopoda is symmetrical, and is enclosed in an 
integument which may be regarded as a modification of the mantle of the other $\mathrm{H} /$ ollusce. Ordinarily there is a tolerably distinct division of the body into an interior portion, carrying the head, and a posterior portion, in which the anternal organs are enclosed. The head (fig. 148) is very distinct, bearing a pair of large globular eyes, and having the mouth in its centre. The mouth is surrounded by a circle of eight, ten, or more, long muscular processes, or arms, which are generally provided with rows of suckers. Each sucker consists of a cup-shaped cavity, the muscular fibres of which converge to the centre, where there is a little muscular eminence or papilla. When the sucker is applied to any surface, the contraction of the radiating muscular fibres depresses the papilla so as to produce a vacuum below it, and in this way each sucker acts most efficiently as an adhesive organ. The whole of this complex mechanism of suckers is completely under the control of the animal, and the irritability of the suckers is retained even for days after death. In most of the Cuttlefishes (Octopoda) there are only eight arns, and these are nearly similar to one another. In others, however (fig. 148), there are ten processes round the mouth, of which eight are like each other, and constitute the true arms, whilst two-

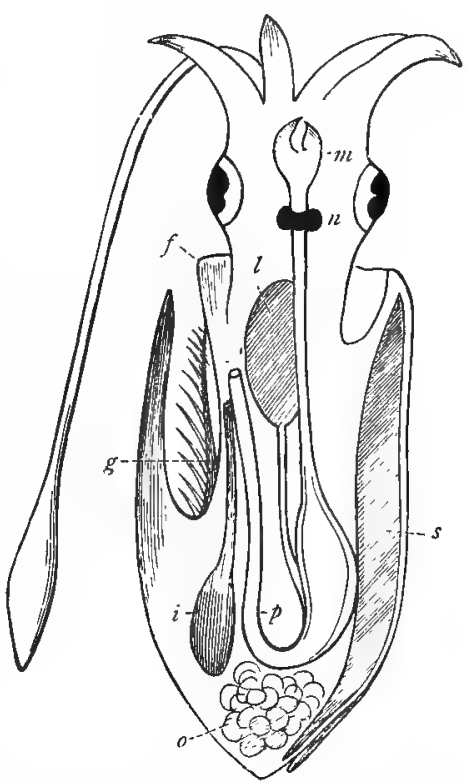

Fig. 149.-Diagrain of a Cuttle-fish (altered from Huxley): $m$ Mandibles; $n$ Cerebral ganglia ; $l$ Liver ; $p$ Intestine: o Ovary ; $g$ Gill; $i$ Ink-bag ; $f$ Funnel ; $s$ Internal skeleton, or "cuttle-bone."

called tentacles-are much longer than the others, and bear suckers only towards their extremities, which are enlarged and club-shaped. The Paper Nautilus (fig. 151) has two of the arms webbed at their extremities and secreting a shell; and the Pearly Nautilus, alone of all living Cephalopoda, has numerous arms, more than ten in number, and destitute of suckers.

The mouth leads into a cavity containing two powerful horny or partially calcareous jaws or mandibles, working vertically, very like 
the beak of a bird (fig. $149 \mathrm{~m}$ ), together with an "odontophore" or "tongue," the hinder part of which is furnished with recurved spines. This cavity leads by a gullet, furnished with salivary glands, into a stomach, from which an intestine is continued to terminate by a distinct anus, which opens on the ventral surface at the base of the so-called "fumnel." The fumel is a muscular tube placed on the under surface of the head, and communicating on the one hand with the external medium, and on the other with the cavity of the mantle. In the Nentilns alone it is simply formed of two muscular lobes, which atre in aplusition, but are not united together so as to form a tube. In many cases there is also a special gland, known as the "ink-bag" (fig. 149, i), for the secretion of an inky fluid, which the animal discharges into the witer, so as to enable it to escape when menaced or pursued. The duct of the ink-ling opens at the base of the funnel near the anus; but the Purly Nautilus and the allied fassil forms are without this me:uns of defence, which the presence of an external shell renders unnecessary.

The respinatory organs are in the form of plume-like gills, placed on the sides of the body in branchial chamber, which opens in front on the under surface of the body. In almost all the living cephalopod" there are only two gills, one on each side, and hence this section is known as that of the "Jhibromelicter." In the Pearly Nautilus alone there are four gills, two on each side, hence the name of "Tetrabrumbirata" applied to the order of which this is the only living representative. In the c'uttle-fishes, at the base of each gill is a special contractile cavity, called a "branchial heart," by which the venous libod, returnet from the bolly, is driven through the gills. In addition to these branchial hearts there is a true arterial heart, by which the aerated blood received from the gills is driven through the lonly. The almission of water to the loranchia is effected by the expansion of the mantle, which allows the entrance of the outer water into the mantle-cavity. The mantle then contracts, and the water is forcibly expelled through the funnel, which is often furnislied with a valve, allowing the passage of water outwards, but preventing its entrance inwards. By a repetition of this process both respiration ind locomotion are simultaneously effected, for the jets of water exiclled from the funnel by their reaction drive the aninul in the opposite direction. In this case, therefore, in in many other's, the more active the auinal is, the more perfectly is the respiratery puress camied on.

The nervous system is formed upon essentially the sane plan as in the other Hollusin, but the great nerve-centres are collected to form it ring round the gullet, and are protected by a cartilage, which is to be resarded as a rudinentary skull. This 
structure, therefore, is a decided approach to the Vertebrate type of organisation.

The sexes in all the Cephalopoda are in different individuals, and the reproductive process in the Cuttle-fishes is attended with some singular phenomena. The most remarkable point in this connection is the modification of one of the arms of the male Cuttle-fishes, for the purpose of conveying the male element to the female. The details of the modification vary in different species of Cuttle-fish.

In some of the Cuttle-fishes the modified arm becomes the receptacle of the spermatozoa, but is not itself actually detached from the animal. In some cases, however, as in the Paper Nautilus (Argonauta), the process goes still further. The female of this species (fig. 151), attains a considerable size, and is protected by an external shell.

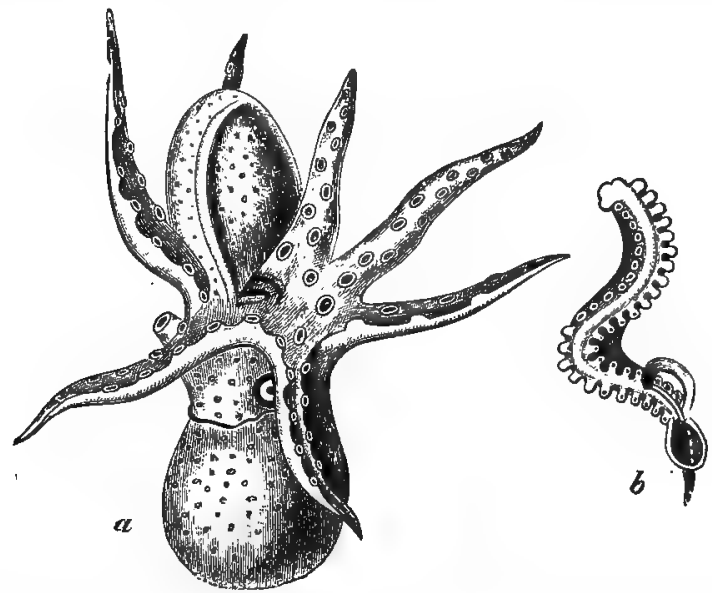

Fig. 150.- a Male of Argonauta argo, with the modified reproductive arm still contained in its enveloping cyst, four times enlarged (after H. Muller); $b$ Detached reproductive arm or hectocotylus of Tremoctopus viol "ceus (after Kölliker).

The male (fig. 150, a) is not more than an inch in length, is devoid of a shell, and has its third left arm metamorphosed. This arm is developed in a cyst, and is ultimately detached from the body, and deposited by the male within the mantle-cavity of the female. When first discovered in this position, it was described as a worm living parasitically on the Argonaut, under the name of "Hectocotylus" (Gr. hekaton, a hundred; kotulos, a cup), from the suckers or cups with which it was furnished. Subsequently it was described as the entire male Argonaut ; and it is only recently that it has been proved to be nothing more than one of the arms of the male, detached for 
the purpose of conveying the sperm-cells to the female. For the above reason, the general name of "hectocotylus" is given to the detached reproductive arm of any of the Cuttle-fishes (fig. 150, b).

The shell of the C'ephrolopoda is sometimes external, sometimes internal. The internal skeleton is seen in most of the Cuttle-fishes, in which it is known as the "cuttle-bone" or "pen." It may be either horny or calcareous, and it is sometimes complicated by the adilition of a chambered portion. The only living Cephalopods which are provided with an external shell are the Paper Nautilus (Aryomuta) and the Pearly Nantilus (Noutilus prmpilius); but not only is the structure of the animal different in each of these, but the nature of the shell itself is entirely different. The shell of the Argonaut (fig. 151) is coiled into a spiral, but it is not divided into chambers, and it is secreterl by the webbed extremities of two of the dorsal arns of the female. These arms are bent backwards, so as to allow the animal to live in the shell ; but there is no organic connection between the shell and the lorly of the animal. The shell of the Pearly Nautilus, on the other hand, is secreted by the mantle, and is organically connected to the animal. It is coiled into a spiral (fig. 155), but it differs from the shell of the Argonaut in being divided into a series of chambers by means of shelly partitions, which are connected together by a tube or "siphuncle," the animal itself living in the last and largest chanber only of the shell.

The C'ephalopoda are divided into two extremely distinct and natural orders, termed respectively Dilmumliute and Tetrubranchiata, according as they have two or four gills or branchire.

The Dibrumliritic comprise the C'uttle-fishes, Squids, Calamaries, and Paper Nautilus, and they are characterised by being almost invariably destitute of any external shell; by never having more thian eight or ten arms, which are always fumished with suckers; by having only two gills, which are provided with "branchial hearts"; ly the ponsession of an "ink-lus"; and by the fact that the "funnel" forms a cumplete tule. They are divided into two sections - Octrimule and Derripole according as they have only eight arms (fig. 150), or eight arms with two additional longer frocesses or "tentacles" (fig. 153). Amonust the Oitopoda are the Paper Nautilus and the Poulpes (Octopus). The Paper Nantilus is found in the warmer seas of various parts of the world, generally floating at the surface. The two sexes differ, as already said, greatly in extemal appearince. The female (fig. 151) inhabits a beautiful one-chaniberd cell, which is seiseterl by the webbed extremities of two of the dorsal arns. The shell is not in any way attached to the brily of the animal, but the webbed arms are turned backwards, and the animal sits in the shell with the funnel turned 
towards the keel. It swims by the jets of water emitted from the funnel, and crawls upon the sea-bottom, head downwards, carrying its shell on its back. The male Argonaut (fig. 150) is only about an inch in length, has no shell, and has all its arms alike, except the one which is metamorphosed into the "hectocotylus." The Poulpes

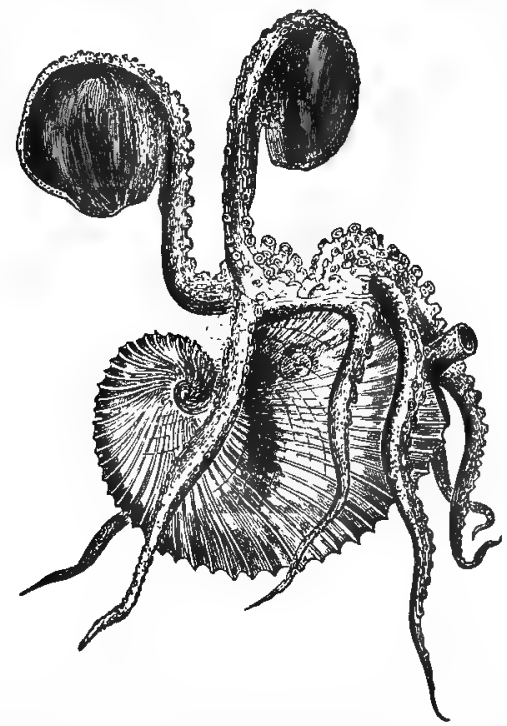

Fig. 151.-Argonauta argo, the Paper Nautilus, female. The animal is represented in its shell, but the webbed dorsal arms are separated from the shell which they secrete, and which they ordinarily embrace.

(Octopi) are universally distributed in the seas of both temperate and tropical regions. They are the "polypi" of Homer and Aristotle, and are voracious animals inhabiting rocky shores.

The Decapodra are chiefly found in the open sea, often in enormous numbers, and the best known are the Calamaries and Squids. The body is elongated, and is always furnished with lateral fins, with which they swim actively. The shell is internal, bidden in the mantle, and differs considerably in different members of the group. In the common Calamaries it forms a horny pen, with a central shaft and two lateral expansions or wings (fig. 152, b). In the genus Sepia, the skeleton is calcareous, and is sometimes called the "cuttle-bone" (fig. 152, a). In the curious Spirulce of recent seas, the shell is rolled up into an open spiral, and is divided by calcareous partitions into a succession of chambers (fig. 152, c), which are placed 
in communication with one another by a small tube or "siphuncle." The shell thus constituted is buried in the mantle at the hinder end of the body (fig. 1.54). Lastly, in the curious extinct group of the Belemuite?, which also belong here, the elongated body was supported by a long dart-like internal skeleton, the chief portion of which consisted of a cylindrical pointed fibrous body, called the "guard." In front, the guard was hollowed out into a conical cavity, in which was lodged a singular series of chambers, united by a tube or "siphuncle," and forming collectively what is called
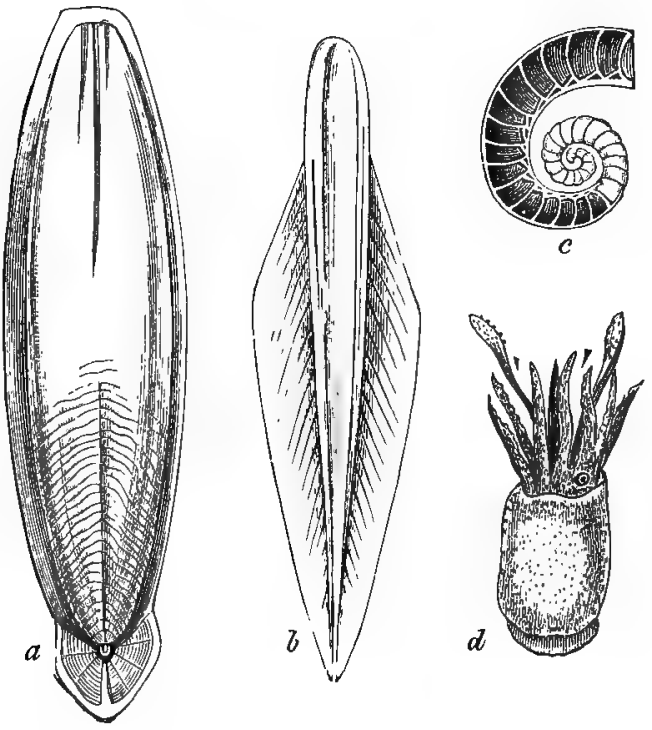

Fig. 15:-a Internal skeleton of Siria ornata; $b$ Pen of IIistioteuthis Bonelliana; c shell (" phragmacone") of Spimla fragilis; d Animal of Spimula Peronit.

the "phragmacone." In front of that, again, the skeleton was prolonged forward into " nore or lexs extensively developed horny expansion "s." "pen."

The second order of the riphalopmlin - that of the Tetrabionchiata-comprises foms chancturined by being creeping animals,

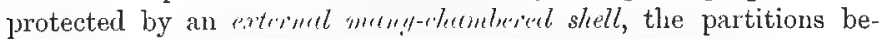
tween the chambers being perforated for the passage of a membranous on calcareous tube, termed the "siphuncle." The arms are nore than ten in number, and are devoid of suckers; the gills are 
four in number, two on each side of the body; the funnel does not form a complete tube; and there is no ink-bag.

Though abundantly represented by many and varied fossil forms; the only living member of the Tetrabranchiata with which we are acquainted is the Pearly Nautilus, which has long been known by its beautiful chambered shell. The shell of the Pearly Nautilus (fig. 155) is coiled into a spiral, and is many-chambered, the chambers being walled off from one another by curved shelly partitions or septa, perforated centrally by a foramen which transmits a mem-

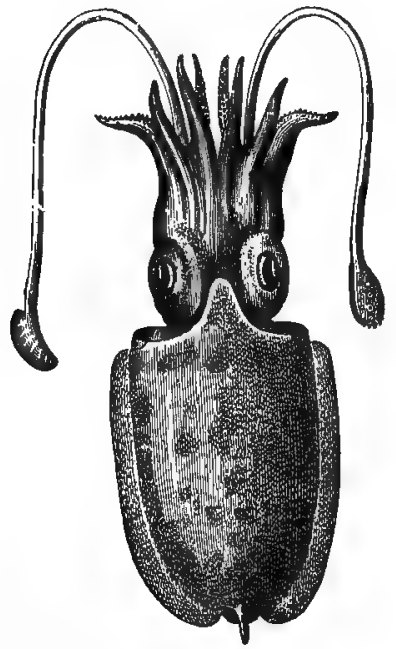

Fig. 153.-Cephalopoda. Sepia elegans.

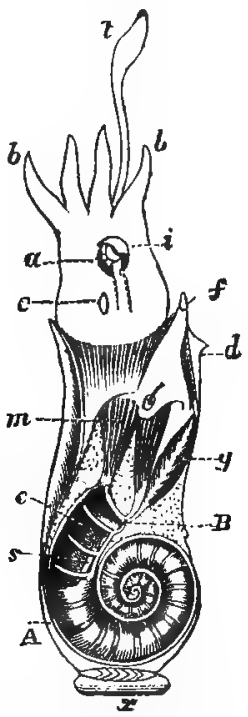

Fig. 154.-Anatomy of Spirula australis (after Owen), slow. ing the position of the skeleton.

branous tube or siphuncle. The animal inhabits only the last and largest chamber of the shell, from which it can protrude its head at will. The function of the chambers of the shell is not very clearly understood; but it appears to be that of reducing the specific gravity of the shell to near that of the surrounding water; since they appear to be filled with some gas apparently secreted by the animal. Good authorities, however, believe that these chambers are filled with water. The siphuncle does not communicate in any way with the chambers of the shell, and its functions are also un- 
known, except that it must certainly serve to maintain the vitality of the shell.

Of the fossil Tetrabranchiata the most important are the Orthocerata and the Ammonites. The Orthocerata played a very important part in the seas of the Palæozoic or Ancient-life period of the earth's history, in which they apparently filled the place now taken by the predaceous Cuttle-fishes. They agreed with the Vautitus in having a many-chambered shell, divided by curved partitions, perforated by a tube or siphuncle. The shell, however, differed from that of the Nautitus in not being curved or coiled up, but in being straight. In other nearly allied forms the shell was bent or even partially çoiled up, but never so completely as in the true Nautili. Many of the

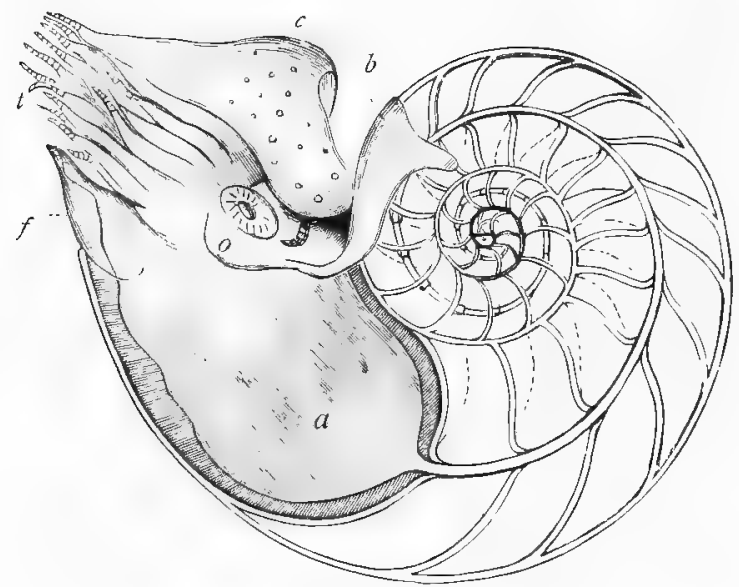

Fig. 155. -The Pearly Nautilus (Nautilus pompilius). a Mantle; b Its dorsal fold; $c$ Hood; o Eye; $t$ Tentacles ; $f$ Funnel.

Ththoceruta were of small size, but some of them were colossal, shells having been found of six or seven feet in length, and as thick as the body of a man.

The Ammonites (fig. 156), with a number of allied forms of varied shapes and beantiful structure, appear to have taken the place of the $N^{r}$ untiliclce, to a great extent, in the seas of the Secondary period; at which time, too, Dibranchiate Cephalopods first made their appearance. The true Ammonites resembled the Nautilus in having is many-chambered shell, which was coiled up into a spiral, but the position of the siphuncle was different, and the partitions or septa between the various chambers of the shell were wonderfully folded 
and lobed instead of being simply curved. The numerous beautiful shells allied to the Ammonites cannot be even mentioned here; but it is to be remembered that they are principally characteristic of the
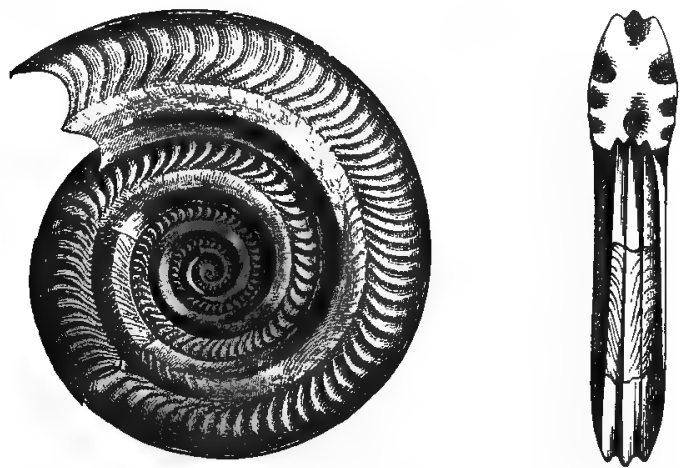

Fig. 156.-Ammonites bifrons, from the Lias.

Secondary period in geology, and that they are hardly known as occurring in the older period (Palpozoic epoch) 


\section{VERTEBRATE ANIMALS.}

\section{CHAPTER XXII.}

\section{GENERAL C'HARAC'TERS OF THE VERTEBRATA.}

TIIE five sub-kingdons which we have previously considered-viz. the Protozor, C'elenterata, Echinodermata, Annulosa, and Molluscawere grouped together hy Larnarck into one great division which he termed the Invertebsata. The remaining sub-kingdom, that of the Vertebrata, is so well-marked and compact a division, and its distinctive characters are so numerous and so important, that this mode of viewing the animal kinglom is, at any rate, a very convenient one.

The sub-kingdom Tretebrata includes the five great classes of the Fishes (Pisces), Amphibians, Reptiles, Birds (Aves), and Mammals; and the name of the sub-kingdom is derived from the very general, though not universal, presence of the bony axis known as the "vertebral column" or backbone. One of the most fundamental of the distinctive characters of Vertebrate animals is to be found in the fact thit the miain masses of the nervous system (that is to say, the brain and spinal cord) are completely shut off from the general cavity of the body. In all Invertebrate animals (fig. 157, A) the body may be rensirded as a single tuthe, enclosing all the viscera; and consequently, when it distinct nervous system and alimentary canal are present, these are in no way shut off from one another. The transverse section, however, of any Vertebrate animal (fig. 157, B) shows tro tubes, one of which contains the great nervous axis $\left(n^{\prime}\right)$, or hrain and spinil cord, whilst the other contains the alimentary canal, the chief circulatory organs, and certain portions of the nervous system (l) which an' known to anatomists as the "sympathetic" system. 
Leaving the brain and spinal cord out of sight for a moment, we see that the lower or visceral tube of a Vertebrate animal contains the digestive canal (b), the hremal or blood-vascular system (c), and a system of nervous ganglia $(n)$. Now this is exactly what is contained within the visceral cavity of any Invertebrate animal ; and it follows from this that the "cerebro-spinal" nerve-system of the Vertebrata is a structure for which no precise parallel exists among Invertebrates.

Another peculiarity which is present in all the Vertebrata is, that at an early period of life there is developed in the lower wall of the tube which contains the cerebro-spinal axis a singular structure known as the "notochord," or "chorda dorsalis" (fig. 157, B, ch). This is a semi-gelatinous rod, tapering at both ends, and extending along the floor of the cerebro-spinal tube. In some cases the notochord remains permanently in this condition, but in most cases it is replaced at maturity by the bony column or backbone, from which the Vertebrata derive their name. The general structure of the
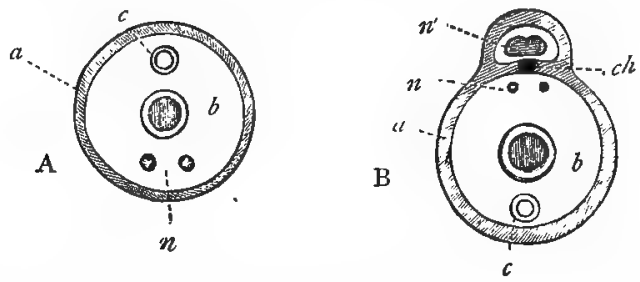

Fig. 157.-Diagrams representing transverse sections of one of the higher Invertebrata, $A-a n d$ one of the Vertebrata, B. $a$ Wall of tlie body; $b$ Alinientary canal; $c$ Hæmal or blood-vascular system ; $n$ Nervous system: $n^{\prime}$ Cerebro-spinal axis or brain and spinal cord, enclosed in a separate tube; ch Notochord, or chorda dorsalis.

vertebral column will be described shortly, and it is sufficient to state here that it consists of a series of bony or cartilaginous segments or "vertebrre," arranged so as to form a longitudinal axis upon which the spinal cord is supported. It is to be remembered, however, that all Vertebrate animals do not possess a vertebral column. They all possess a notochord, but this may remain persistent throughout life, and in many cases the development of the spinal column is very imperfect.

The skeleton of all Vertebrate animals is internal, and the muscles are attached to its several parts. The value of this character is in no way affected by the fact that many Vertebrates, such as the Tortoises, Crocodiles, and others, possess an external skeleton as well. Tlie limbs of Vutebrate animals are always articulated or 
jointed to the body, and they are always turned away from that side of the body (the "neural" side) upon which the great masses of the nervous system are placed. The limbs may be altogether wanting, or partially undeveloped, but there are never more than turo pairs, and they always have an internal skeleton for the attachment of the muscles of the limb.

A distinct blood-vascular or "hæmal" system is present in all Vertebrates, and in all except one-the Lancelet-there is a single contractile cavity or heart, furnished with valvular openings.

Lastly, the masticatory organs of all Vertebrates are modifications of parts of the walls of the head, and are never modified limbs or hard structures develined in the mucous membrane of the digestive tulue, as they are in the Invertebrates.

The above are the leading characters which distinguish the Vertebrata as a whole; and before going on to consider the different classes, it may be as well to give a short and general sketch of the anatomy of the Vertebrates, commeneing with their bony framework or skeleton.

The skeleton of the Iretebratc may be regarded as consisting of the bones which so to form the trunk and head on the one hand, and of those which form the supports for the limbs on the other hand. The bones of the trumk and head may be regarded as essentially composed of a series of bony rings or segments, arranged longitudinally. Anteriorly, these segments are much expanded and also much modified to form the bony case which encloses the brain and which is termed the cranium or skull. Behind the head, the segments enclose a much smaller eavity in which is contained the spinal cord, and they are arranged one behind the other, forming the "vertebral column." The segments which form the vertebral column are called "vertebræ," and they have the following general structure. Each vertebra (fig. 158, A) consists of a central portion known as the "buly," or "centrum" (c), placed immediately below the spinal corl, aul giving origin to certain "processes." The ends of the bulies of the vertebre are all united together in different ways, so as to give the column great flexibility. From the back of the body of the vertehra proceed two bony arches which unite behind and thus form with the centrum a bony canal in which the spinal cord is contained. For this reason these arches $(n)$ are called the "neural" arches. From the point where the neural arches unite-that is to say, from the back of the neural canal-proceeds a long process, sometimes cleft at its extremity, termed the "spinous process" (s). Springing also from each neural arch is a second whorter process ( 1 ) termed the "articular process," since liy means of these, as well as by the bodies, the vertebre are jointed or "ax- 
ticulated" together. Also arising from the neural arches at their junction with the body of the vertebra, there may be two lateral processes $(d)$ which are called "transverse processes." This is ihe

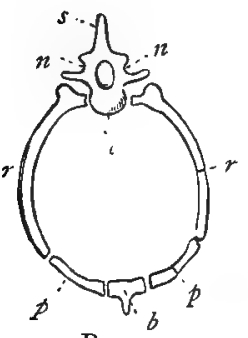

B

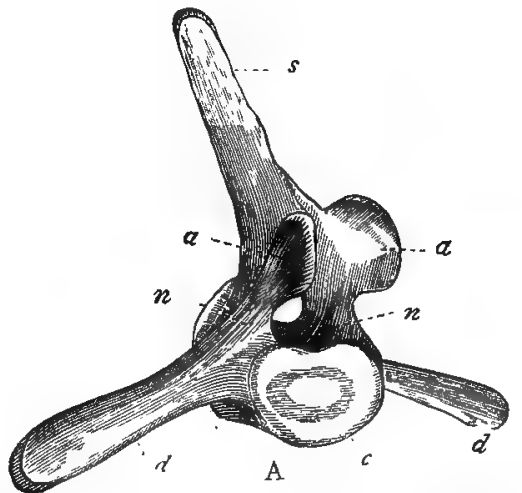

A

Fig. 158.-A, Vertebra (luntar) of a Whale: $c$ Centrum or body; $n$ Neural arclies ; $s$ Spinous process; $a$ Articular process; $d$ Transverse processes. $\mathrm{B}$, Thoracic segment or vertebra : c Centrum of vertebra; $n$ Neural arches, enclosing the canal for the spinal cord; $s$ Spinous process; $r$ Ribs ; $p$ Costal cartilages ; $b$ Breastbone or sternum. (After Owen.)

ordinary structure of the vertebra of a Mammal, and the names here used are those applied to the parts of the vertebra in human

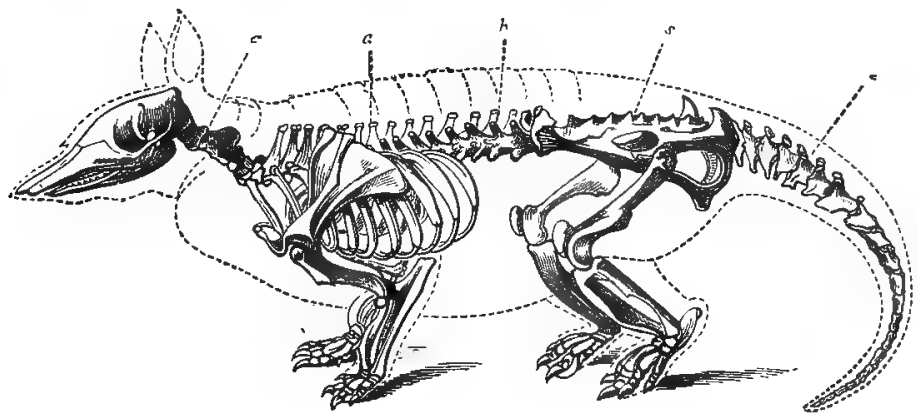

Fig. 159.-Skeleton of an Armadilln, showing the regions of the vertebral column. c Cervical region; $d$ Dorsal region; $l$ Lumbar region; $s$ Sacral region; $t$ Caudal region or tail.

anatomy. In comparative anatomy, however, these parts have proper technical names which can be employed for them in all animals alike. 
In the typical vertebra the segment is completed by a second arch, which is placed in front of or beneath the body of the vertebra, and which is known as the "hrmal' arch, as it includes and protects the principal organs of the blood-circulation (fig. 158, B). This second arch is often only recognisable with great difficulty, as

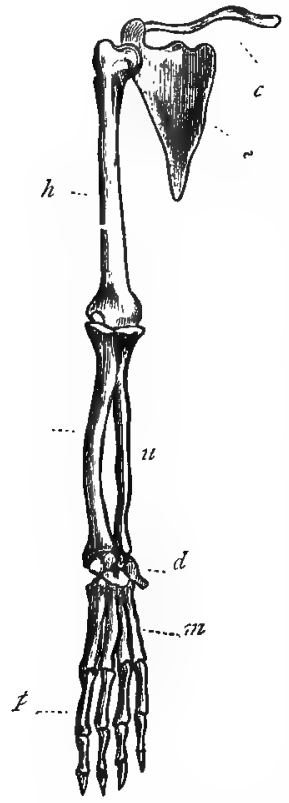

Fig. 160,-Fore-limb of the Chimpanzee. $c$ Cıllar-bone, or claricle; $s$ Shoulderblarle, or scapula; $h$ Bone of the ul'ln+r inn, or humerus ; $r$ Rallus ; $u$ Ulna ; $d$ Boules of the wrist, or carpus; $m$ Buns's of the rotot of the hand, or ntetrearpus; $p$ Bones of the dirits, or phalanges. its parts are generally much modified; but a good example may be obtained in the human thorax. Here, attached to the front of the vertebri, we find a series of bony arches, known as the ribs (r), followed by a series of cartilaginous pieces of a similar shape, termed the "costal cartilages" $(p)$, the whole united in front by a central bone, known as the breastbone or "sternum" $(b)$.

As a general rule, amongst the higher Vertebrates, the following regions may be recognised in the vertebral column: Firstly, the cervical region (fig. 159,c), comprising it variable number of vertebrie, which constitute the neck, and immediately follow the head. Secondly, the cervical region is succeeded by a variable number of vertebrie which usually carry ribs, and are known as the dorsal vertebræ $(d)$, or vertebrie of the back. Thirdly come certain vertebræ which constitute the lumbar region (l), or the region of the loins. Fourthly, there usually follows a series of vertebre which are immovably united together to form a single bone, which is termed the sucrum (s). Lastly, there comes a variable series of vertebrse which are usually free and movible upon one another, and which constitute the caudal region, "Ir the region of the tail $(t)$.

The nature of the bones which enter into the composition of the limbs varies somewhat in different Vertebrates in accordance with their mode of life; but in all the higher members of the sul)-kingdom the limbs are built upon a general and easily recognishle type. The fore-limb consists generally of the following parts: 1. A series of bones uniting the limb to the trunk, the two nlost important being the shoulder-blade (scapulu, fig. 160, s)

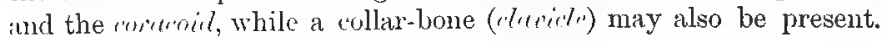


2. The bone which forms the upper portion of the limb proper, and which is known as the humerus $(h)$. 3. Two bones which form the middle portion of the limb (e.g., the fore-arm in man), and which are known as the radius and ulna ( $r$ and $u$ ), of which the former is the bone mainly concerned in carrying the hand or fore-foot. 4. A number of small bones, which form the wrist, and are termed the carpus $(d)$. 5. The cylindrical bones (usually five in number) which form the root of the hand, and are known as the metacarpus $(m)$. 6. The bones which form the fingers proper, and which are known as the phalanges $(p)$.

Essentially the same parts can be traced in the hind-limb of a typical Vertebrate aninal, but they are known by different names. The bones which unite the limb to the trunk are usually more or less completely united together, constituting a single mass, known as the innominate bone (fig. $161 ; i$ ). This is followed by a long cylindrical bone, which forms the upper portion of the hind-limb, and is known as the "thigh-bone," or femur $(f)$. Following this are the two bones of the shank, corresponding tor the redius and ulna of the fore-limb, and known as the tibia and fibula ( $t$ and $s$ ). Of these, the trbia $(t)$ corresponds to the radius, and is mainly concerned in carrying the foot. Next comes a series of small bones, which form the ankle, and are known as the tarses (r). This is succeeded by a series of cylindrical bones (usually five in number), which form the root of the foot, and which are termed the metatarsus $(m)$. Finally, the metatarsus is streceeded by the bones of the toes, which in this case are again termed the phalanges $(p)$. In both limbs the usual number of phalanges to each toe or "digit" is three.

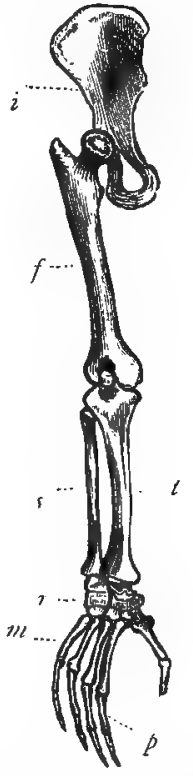

Fig. 161.-Hind-limb of the Chimpanzee. $i$ Innominate bone: $f$ Thigh-bone, or femur; $t$ Tibia; $s$ Fibula; $r$ Bones of the arkle, or tarsus : $m$ Metatarsus ; $p$ Phalanges.

The digestive system of the Vertebrata does not require a lengthened notice. The mouth is usually furnished with teeth, which have for their chief function the reduction of the food to a condition in which it can be ligested. In some animals, however, such as the snakes, the teeth are only used to hold the prey, and not for mastication; and in others, such as the turtles and birds, the jaws are not furnished with any teeth at all. The food is also usually subjected 
in the mouth to the action of a special fluid-the saliva-which acts chemically as well as mechanically upon the food, and which is secreted by special glands, known as the "salivary glands." From the mouth the food passes through a muscular tube-the gullet, or oesophregus (fig. 162,g) -to the proper digestive cavity, or stomach (s). Here it is subjected to the action of a special digestive fluidthe "gastric juice"-and is converted into a thick pasty fluid, which

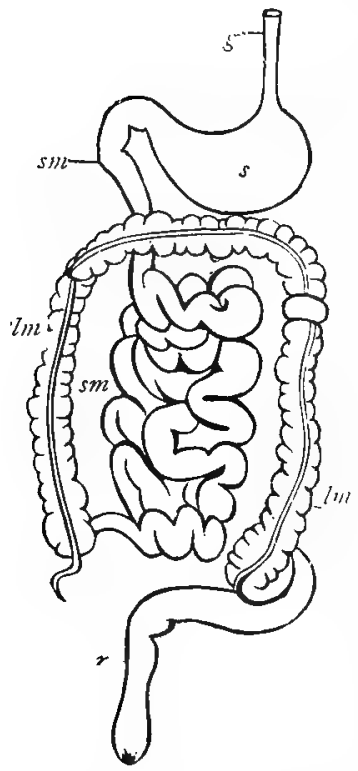

Fig. 1ij2.-Digestive system of a

Mamual. $g$ Gullet or (e'suphagus : $s$ Stomach; sm Sunall intestine; $7 m$ Large intestine; $r$ Iarge intestine terminating in its final lortion, callerl the "rectum."

is called chyme. From the stomach the chyme passes into a long convoluted muscular tube, which is called the "small intestine" (sm). Here it is subjected to the action of two other digestive fluids, called the "bile" and "pancreatic juice," as well as to the fluids secreted by the intestine itself. The bile is secreterl by a large gland, which is known as the "liver," whilst the pancreatic juice is produced by another, termed the "pancreas," both pouring their secretion into the upper part of the small intestine. By the combined action of these digestive fluids the chyme is ultimately converted into a nilky fluid, which is called chyle, when it is fit to be taken up into the blood-ressels. The small intestine finally opens into a tube of larger diameter, which is called the "large intestine" (lm), aurl this opens on the surface of the body by an anal aperture. In the large intestine the last remaining portions of the food which can be rendered useful are albsorbed into the blowl, the indigestible portions being ultinuately got rid of as useless. The fiuid prodncts of digestion (chyle) are chiefly alosorbed from

the intestinal canal by a set of ppecial vessels, which are present in all Vertebrates, and which are called the lurteds, from the milky fluid which they contain. These lacteals combine to form a large trunk, by which their contents are ultimately added to the circulating blood. Part of the products of digestion is alssorbed by the veins which ramify on the intestinal canal, and which ultimately unite to form a great vessel, cillerl the "venit korti"," which goes to the liver. 
The materials, however, which are taken up in this way also ultimately reach the circulating blood. In this way, therefore, fresh matter is being constantly added to the blood to replace the waste caused by the performance of the vital functions.

The blood is thus formed out of the materials which are taken into the alimentary canal as food; and in almost all of the l'ertebrata it is of a red colour, when viewed in mass. This is due to the presence in it of numerous microscopical particles, which are known as the "blood-corpuscles," the fluid itself being colourless. In fig. 163 are represented some of the forms of blood-corpuscles which are found in different divisions of the Tertebrata.
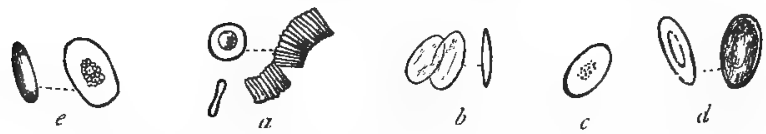

Fig. 163.-Blocd-corpuscles, nagnified. a Man; $b$ Goose ; $c$ Crocodile; d Flog; e Skate.

The blood is always distributed through the body by means of a system of closed tubes, which constitute the "blood-vessels," and with the single exception of the Lancelet, it is always propelled by means of a contractile muscular cavity or "heart." The heart and other circulatory arrangements differ considerably in different classes of the Vertebrata, but these differences will be best considered at a later period. Respiration in all the Tertebrata is effected by means of distinct breathing-organs, assisted in many cases by the skin. In the water-breathing Vertebrates, such as fishes, the respiratory organs are in the form of gills or branchiæ, which are richly supplied with blood, and are exposed to the influence of water holding oxygen in solution. In the air-breathing Vertebrates, the breathing-organs are in the form of lungs. These essentially consist of cellular or spongy organs, placed in the cavity of the chest, richly furnished with blood-vessels, and receiving constant supplies of fresh air by means of a tube which opens in the throat and is known as the "windpipe," or trachea. In the higher Vertebrates the heart becomes a double organ, one side being concerned wholly with driving the impure (venous) blood to the lungs, whilst the other side propels the pure oxygenated (arterial) blood to all parts of the body.

The waste substances of the body-of which the most important are water, carbonic acid, and the peculiar substance called urea-are got rid of by the skin and lungs, but principally by two glands which are called the kidneys. The excretion of urea from the body, as a general rule, is wholly effected by means of the kidneys alone ; and this is 
their most important function, as the retention of this substance within the body rapidly causes death. The secretion of the kidneys is sometimes got rid of by means of special canals appropriated to this alone; but in the lower Vertebrata it is discharged into the hinder extremity of the alimentary canal, and is evacuated along with the undigested portions of the food.

The nervous system varies greatly in its development in the Irertebrata. In the little fish called the Lancelet, the main mass of the nervous system consists of a cord of nervous matter, representing the spinal marrow, but not having in front any enlargement which represents the brain. In all the other lertebrata the central masses of the nervous system (termed the cerbro-spinal axis) consist of a nervous cord (the spinal cord) contained in the canal formed by the neveral arches of the vertebre, and of an anterior mass of nervous matter, which is protected by the skull, and is termed the "encephalon," or bruit. The size and development, however, of the brain vary enormously in different Vertebrates; and in the lower forms the brain is little more than an aggregation or collection of nervous masses or "ganglia," of which some are connected with the special senses, sight, hearing, taste, and smell, special organs for which are present in almost all the I'ertebrata.

Reproduction in the T'ertebrata is always truly sexual, the sexes are almost always in different individuals, and in no case are compound organisms produced by a process of budding or fission. Most are oviparous, producing eggs from which the young are developed. Some retain the eggs within the body till the young are hatched, but no direct connection is established between the young animal and the parent; anl these are sometimes said to be ovo-vivipurous. The higher Vertebrates, however, bring forth their young alive, and are said to be riciparous (Latin, vicus, living; and pario, I bring forth).

Primary Divisions of the Vertebrata. - The Vertebrata are variously divided into great primary sections by different writers, and all of these divisions have more or less merit. Here, however, the classificition proposed by Professor Huxley will be followed, and it is not necessary to enter into any consideration of the others. It his also been thought advisable to give in this place a brief account of the leading characters which separate these divisions from one another, thorugh it is not to be expected that the learner will be able to appreciate the full value of these characters till he has completed his study of the Vertebratic as a whole.

The Vertebrata are divided by Professor Huxley into the following great divisions :-

I. ICHTHYopsida (Gr. ichthus, a fish ; and opsis, appearance).-In 
this section are included the Fishes(Class $P$ isces), and the Frogs, Newts, and their allies (Class 1 mphibia). They are all characterised by the fact that they possess gills or branchiæ, either throughout life or during the earlier stages of their existence; that they possess nucleated red blood-corpuscles (i.e., blood-corpuscles with a central particle or nucleus, fig. 163, $d, e$ ), and by certain embryonic characters as well. From the temporary or permanent possession of gills they are often spoken of as the Branchiate Vertebrates.

II. Sauropsida (Gr. scuera, a lizard ; and opsis, appearance).--In this division are the Birds (Class $A$ ves), and the true Reptiles (Class Reptilia). They are characterised by the fact, that at no time of their life are they ever provided with gills; that the skull is jointed to the vertebral column by a single articulating surface (or condyle); that the lower jaw is composed of several pieces, and is united to the skull by means of a special bone (called the os quadratum); that they possess nucleated red blood-corpuscles (fig. $163, b, c$ ), and by certain embryonic characters as well.

III. Mammalia (Lat manma, the breast).-In this division are all the ordinary Quadrupeds ; characterised by the constant absence of gills; by the skull being jointed to the vertebral column by two articulating surfaces (or condyles); by the fact that the lower jaw is composed of only two pieces, and is not united to the skull by means of a special bone (the quadrate bone); by having non-nucleated red blood-corpuscles (fig. 163, $\alpha$ ): and by having special glands-the mammary glands-which secrete a special fluid-the milk-by which the young are nourished for a longer or shorter period after birth.

These three primary divisions comprise the five great classes into which the Vertebrata are divided :-

1. Pisces (Fishes).

2. Amphibia (Frogs, Newts, \&c.)

3. Reptilia (True Reptiles)

4. Aves (Birds).

5. Mammalia (Quadrupeds). 


\section{C H T H Y O P S I D A.}

\section{CHAPTER XXIII.}

\section{CLASS I. PISCES.}

Trie fishes forn the lowest class of the I'ertebrutu, and they may be broadly defined as being Vertebrate animals provided with gills, whereby they are enabled to breathe air dissolved in water; the heart, when present, comsists of a single aurisle and ventricle (with the exception of the Mul-fishes); and the limbs, when present, are in the form of fins, or a porsions of the integument.

In their external form, fishes are in most cases adapted for rapid
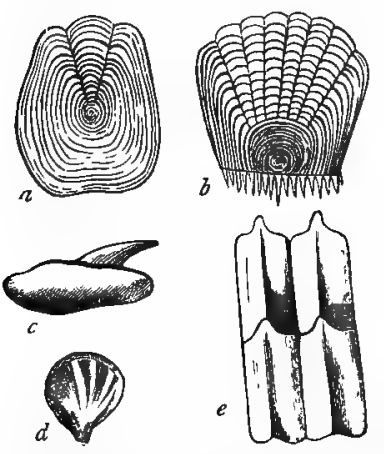

Fig. 164.-Scales of different fishes. a Cycloid scale (Pike); $b$ Ctenoid scale(Pereh); $c$ Placoid scale (Thornback); a Plaenisl scale of Rhina; $e$ Ganoid scales (Palconiscus.) locomotion in water, the shape of the body being such as to cause the least possible friction in swimming. To this end, as well as for purposes of defence, the body is generally enveloped in a species of chain-mail formed by overlapping scales, to which bony plates, tubercles, and spines are sometimes added. Valuable characters can sometimes be drawn from the nature of the scales; and with a view to this, the integumentary appentiages of fishes have been divided by Agassiz as follows (fig. 164):-

1. Cycloid scales $(a)$, consisting of thin, flexible, homy scales, which are circular or elliptical in shape, and have a smooth outline. These scales occur in most of our common fishes (e.g., the Pike).

2. Ctruid sciles $(b)$.-These resemble the cycloid scales in being thin, flexible, horny scales, but they are distinguished by having their hinder margins cut into comb-like projections, or fringed with 
spines. The common Perch supplies a good example of these scales.

3. Placoid scales $(c, d)$.-These are detached bony grains, tubercles, or plates, scattered through the skin, and sometimes armed with projecting spines, these latter being usually composed of a substance allied to dentine.

4. Ganoid scales $(e)$, composed of a layer of true bone, covered by a layer of hard polished enamel.-These scales are usually much thicker and larger than the ordinary scales; they are often oblong or rhomboidal in shape; they are often connected together by little processes; and they generally are in contact by their edges, but rarely overlap one another.

In most fishes there is also to be observed a line of peculiar scales, forming what is called the "lateral line." Each of the scales of this line is perforated by a minute tube, which leads into a longitudinal canal, supplied with special nerves; and the whole apparatus has apparently a sensory function.

As regards the true internal skeleton, fishes differ very widely from one another, but the skeleton is so complicated that only a few of the most important points can be mentioned here. In one fish-the. Lancelet-there can hardly be said to be any true skeleton, the vertebral column being represented permanently by the semigelatinous notochord (fig. 171). In others, such as the Lampreys, Sturgeons, and Rays, the skeleton remains permanently in the condition of gristle (cartilage); in others, it is partially cartilaginous and partially ossified; and lastly, in most modern fishes it is completely converted into bone. The vertebral column in a Bony Fish consists of a number of vertebræ which are hollow or cup-shaped at both ends (biconcave or "amphicoelous"), the cup-like marging being united together by ligaments. The cavities formed by the apposition of the vertebræe are filled with the gelatinous remains of the notochord. This gelatinous elastic substance acts as a ball-andsocket joint between the vertebra, thus giving the whole spine the extreme flexibility which is essential to animals living in a watery medium. The entire spinal column is divisible into no more than two distinct regions, an abdominal and a caudal. The abdominal vertebræ possess a superior or neural arch, for the passage of the spinal cord, a superior spinous process, and two transverse processes to which the ribs are attached. The caudal vertebre have no narked transverse processes; but, in addition to the other parts already mentioned, they give off an inferior or homal arch, below the body of the vertebræ, and they carry inferior spinous processes (fig. 165, $h$ ). The ribs are attached to the transverse processes or to the bodies of the albdominal vertebræ (fig. 165, r); and they do not 
enclose any thoracic cavity, or protect the organs which are usually contained in the clest-namely; the lieart and breathing-organs. The anterior or lower ends of the ribs of fishes are free, or are rarely united to hard productions of the integument; but there is never any breastbone or stumm properly so called.

The only remaining bones of the trunk proper are the so-called "interspinous bumes" (fig. 165, $i$ ). These are a series of pointed dagger-like bones, embeciled in the middle line of the body, between the great lateral muscles which form the greater part of the body of a tish. The inner ends or points of the interspinous bones are attached by ligament to the spinous processes of the vertebræ, and at their outer ends they support the framework (rays) of the so-called

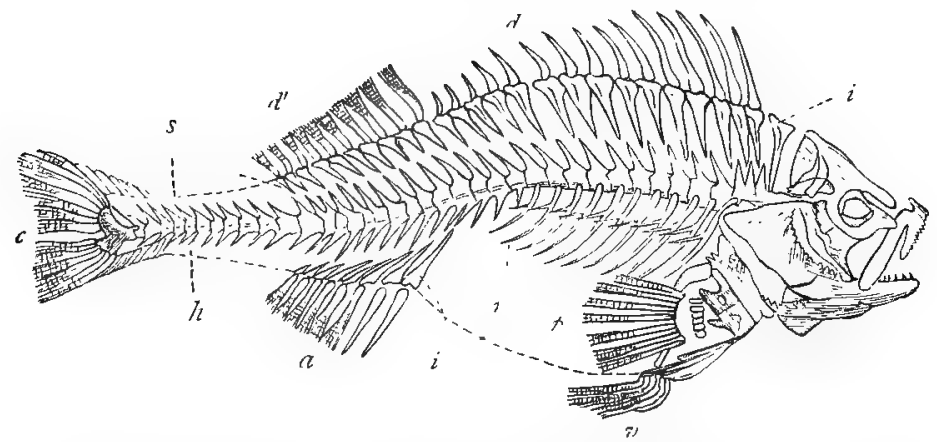

Fig. 165.-Skeleton of the common Perch (Perca fluviatilis). p Pectoral tin ; $v$ One of the ventral fins; $\alpha$ inal fin, supported upon interspinous bones (i); $c$ Caurlal fin; 17 Firnt dorsal fin: $d^{\prime}$ serond dorsal fin, lonth supported uyon interspinous lones;

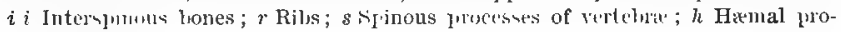
cinsers of 3interirit.

"median" fins. As a rule there is only one interspinous bone to each verteln:1, but in the Flat-fishes (Sole, Turlwt, \&c.) there are two. The limbs of tishes mily be wholly wanting, or one pair may be il)sent, lut in wu cise is the number greater than the regular Vertebrate tyle-namely, two pairs. When developed, however, the limbs of fishes are very different from those of other Tertebrates, consisting of expinsions of the integument, furnished with hony or gristly supperts on rays, and thus constituting what are called "fins" (fig. 1fifi). The prir of linbs which correpond to the arms of man and to the fore-linlss of otber Vertelorates are termed the pectorul fins, and they are attiched to a bony arch which is attached either to the bick of the the skull or to the spinal columm (fig. 165, $p$, and 166,1$)$. The hind-limb; in fishes are known as the central 
fins (figs. 165, 166, v), and are not only often wanting altogether, but when present are less developed than the pectorals and less fixed in their position. They are united to an imperfect bony arch, which represents the innominate bones, or pelvic arch, of the higher Vertebrates, but which is never joined to the spinal column. In some fishes the ventral fins are placed far back, and in these the bony arch which supports them is freely suspended in the muscles. In others the ventral fins are altogether out of position, and are placed beneath or even in front of the pectoral fins ; and in these cases the pelvic arch is attached to part of the pectoral arch. The pectoral and ventral fins represent, as just said, the fore and hind limbs, and consequently there are always two of each, when they are present at all. They are therefore spoken of as the "paired" fins. Besides

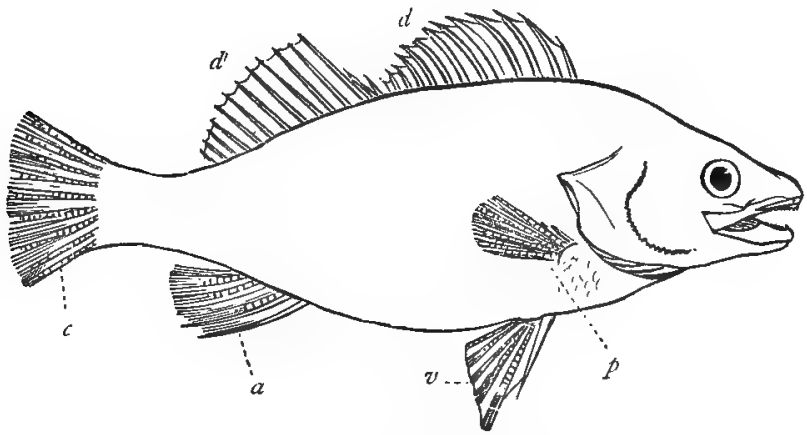

Fig. 166.-Outline of a Fish (Perca granulatu), showing the "paired" and "median" fins. $p$ Pectoral tin; $v$ Ventral fin; $a$ First dorsal fin; $d^{\prime}$ Second dorsal fin; $c$ Caudal fin ; a Anal fin.

these, however, or in the absence of one or both of these, there is also a series of what are called "median" fins; that is to say, fins which are placed in the middle line of the body, and which are unpaired, having no fellows. These median fins agree with the paired fins in being expansions of the integument, supported by bony or gristly supports or "rays," and they are carried by the heads of the "interspinous" bones, already described (fig. 165, $i$ ). They are variable in number, and in some cases there is only a single fringe running round the hinder extremity of the body. Commonly, however, the median fins consist of one, two, or three expansions of the dorsal integument, called the "dorsal" fins (fig. 165, $d d^{\prime}$ ); one or two on the ventral or lower surface near the vent, called the "anal" fins $(a)$; and a broad fin at the extremity of the vertebral column, constituting the "caudal" fin or tail (c). 
The tail in all fishes is placed vertically-that is to say, it strikes the water laterally or from silte to side, and it is the chief organ of progression in the fish. Two very distinct typess of tail are found amongst the fishes. In one of these, foumd in most living forms, the tail is comprest of twe nearly equal lobes whith suring from the end of the spine (fis. $1(i,, A)$. This form of thil is said to be "homocercil." In the other type of tiil, found in the Dog-tishes, Sharks, and other living fishes, as well as in many extinct forms, the tail is unequally lobed, and is said to be "heterocercal" (fig. 167, B). In these forms the vertebral column is prolonged into the upper lobe of the tail, and the greater portion of the tail is found below the spine.

In both the prired and the merlian fins the integument is supported by a series of spine-like bones, which are called "rays."

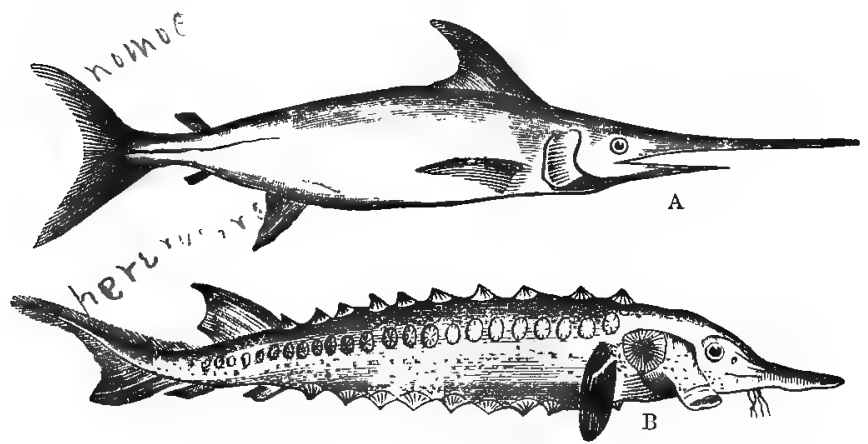

Fig. 167.-A, Sword-fish, shnwing homncercal tail; B, Sturgenn, showing leterocereal tail.

These rays are sometimes simple undivided rays or spines, when they are called "spinous rays" $(14 ., d)$; but in other "asc's they are botlı divided by triusverse juints, and split up into numerons longitndinal branches towalds their extrenities, when they are spoken "f as "soft ruys" $\left(11 ;, j, l^{\prime}\right)$. The suft rilys orenr in many fishes in different fins, but they are invariably present in the caudal tin or tail.

As regarls the dignstion system in fishes, the mouth is nsually furnished with a complicaterl system of teeth, developerl not only upun the jaws, but "um any or "very bone which enters into the composition of the oral "avity. The gnllet opens into a stomach, nsually of large size, and its hiuder aperture (the $y, h_{h}, \| s$ ) is usually furnisherl with a valve. Immediately belind the jyloric opening of the stomach there is usually a variable number of blind tubes 
(called the "pyloric crea") which open into the intestine, and which are believed to represent the pancreas. In some fishes, however, there is a well-developed pancreas, and in others even these tubes are wanting. The intestinal canal is a longer or shorter, more or less convoluted tube, and its absorbing surface is sometimes largely increased by a spiral folding of the mucous nembrane, which winds like a screw in close turns from near the pylorus to the anus. The liver is usually of large size, and saturated with oil, but in the Lancelet it is doubtfully represented by a hollow sac-like organ. The kidneys in fishes are of great comparative size, forming two elongated organs, situated beneath the spine, and extending along the whole length of the abdomen.

Respiration in all fishes is aquatic, and is effected by means of

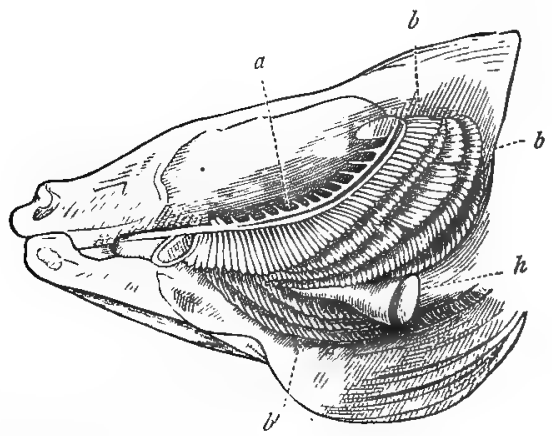

Fig. 168.-Gills and heart of the Perch exposed by the removal of the gill-cover on the left side. $a$ First of the four bony arches which carry the gills $(b b) ; b^{\prime}$ The lower edges of the gills on the right side; $h$ Heart. (After Van der Hoeven.)

gills or branchio, in all except the Lancelet, in which respiration is effected by branchial filaments placed round the pharynx, and also by a greatly developed pharynx perforated by ciliated apertures (fig. 171). The arrangement and structure of the gills in fishes vary a good deal in different orders, and the leading modifications will be noticed hereafter. In the meanwlile it will be sufficient to give a short description of the branchial apparatus in one of the Bony Fishes. In such a fish the gills consist of a single or double series of flat cartilaginous leaflets, covered by mucous membrane, richly supplied with blood, and arranged on bony or cartilaginous arches which are connected with the tongue-bone (hyoid bone) below and with the under surface of the head above (fig. 168). The branchial arches and branchire are suspended in cavities placed on the side of the neck, and in the ordinary Bony Fishes there is only one such cavity 
on each side. The water is taken in at the mouth by a process analogous to swallowing, and it gains admission to the branchial chambers by means of a series of clefts or slits which perforate the

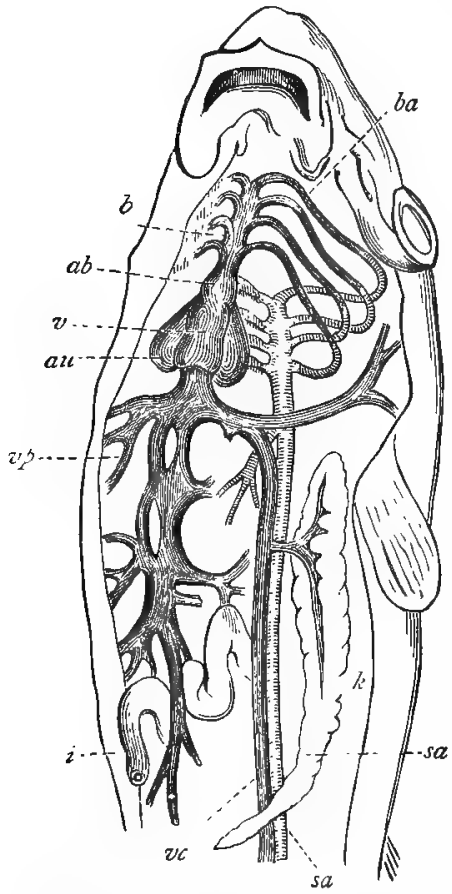

Fig. 169.-Diagram of the circulatory systinu in a Fish, the vessels contining venuus blood being longitudinally shaded, and those contajuing al'terial blood being crossshaded. vc Virna cillis; vp Vena porta ; "u Auriclo; $v$ Vuntricle, al, Bulbus arteriosus; $b$ Branchial artery; $b a$ One of the divisions of the brunehial artery going to the gills, from which proceeds one of the correspondthe suluvertebral aorta (w) is formed; $i$ Intist ine; kidney. ing bramulat vems, by the mion of which

sides of the pharynx. Having passed over the gills and lost its oxygen, the effete water makes its escape behind by an aperture called the "gillslit," which is placed on the side of the neck. The opening of the gill-slit is closed in front by a chain of flat lumes which constitute the "gillcover," and by a membrane which is supported upon a variable number of slender bony spines. This is the general mechanism of respiration in one of the Bony Fishes, but different arrangements are found in other cases, which will be subsequently noticed.

The heart in fishes may be regarded as essentially a branchial or respiratory heart, being concerned chiefly with driving the venous and impure blood to the gills. It consists in almost all cases of two cavities, an auricle and a ventricle (fig. 169). The auricle $(\alpha u)$ receives the vellous blood which has passed through all the various parts of the body, and propels it into the ventricle (ic). From the ventricle proceeds a single great vessel (the "branchial artery"), the base of which is usually developed into a muscular cavity, the "bulbus arteriosus" ( $(l)$, which acts as a kind of additional ventricle. By the ventricle and bulloss arterios"s the venous lisod is driven to the gills, where it is subjected to the action of the water. The aleated blom is not returned to the 
heart, but is driven from the gills through all parts of the body, the propulsive force necessary for this being derived partly from the heart, and partly from the contractions of the muscles between which the blood-vegsels pass. The essential peculiarity of the circulation of fishes consists in this, that the arterialised blood returned from the gills is propelled through the general vessels of the body (systemic vessels) without being sent back to the heart. In the Lancelet, alone of all fishes, there is no single heart, and the circulation is effected by means of contractile dilatations situated upon several of the vessels. In the Mud-fishes (Lepidosiren and Ceratodus) the heart consists of two auricles and a ventricle. In all cases the blood is cold, or, in ot werds, has a temperature very little, or not at all, higher than that of the surrouncling medium. The red blood-corpuscles (fig. 163,e) are always nucleated, and are oval in shape.

Whilst the respiration of all fishes is truly aquatic, most are, nevertheless, furnished with an organ which apparently corresponds to (or is homologous with) the lungs of the higher $I^{r}$ ertebrate. This is known as the "air-" or "swim-bladder," and is a sac filled with gas and situated between the alimentary canal and the kidneys. In most cases the sac contains only a single cavity, but in many instances it is variously divided by partitions. In most fresh-water fishes the gases in the swim-bladder are mainly composed of nitrogen, but in the sea-fishes it is chiefly filled with oxygen. The sac of the swim-bladder is often closed, but in other cases it opens into the gullet by means of a duct which corresponds to the windpipe. In the great majority of fishes the functions of the air-bladder are mainly hydrostatic-that is to say, it serves to maintain the necessary agreement between the specific gravity of the fish and that of the surrounding water. In the singular Mud-fishes (Lepidosiren and Ceratodus), the air-bladder is composed of two distinct sacs, divided into a number of cellular compartments, and opening into the gullet by a tube. In these fishes it acts as a respiratory organ, and is therefore, not only in structure, but also in function, the representative of the lungs of the other Vertebrates.

The nervous system of fishes is of an inferior type of organisation, the brain being of comparatively small size, and consisting of a collection of ganglia. As regards the organs of the senses, two peculiarities deserve notice. In the first place, though fishes possess the essential parts of the organ of hearing, they possess no external ears, and mostly no external auditory openings. In the second place, the organ of smell consists of a double cavity lined by a mucous membrane folded into numerous plaits, into which water is admitted, usually by two distinct apertures or nostrils. Behind, 
however, the nasal sacs are closed, and they do not communicate by any aperture with the throat, as they do in all the higher Vertebrates. The only exceptions to this rule are the Hag-fishes and their allies (1/yxinoids), and the Mud-fishes (Lepidosiren and Cerato(l's). The Hag-fishes and Lampreys are further peculiar in possessing, alone of all Vertebrate animals, a single nasal sac, opening by a single external nostril.

As restrits their reproductive system, most fishes are truly oviparous, and the ovaries are familiarly known as the "roe." Some fishes are ovo-viviparous, retaining their eggs within the body till the young are hatched. The male organs of reproduction are commonly spoken of as the "milt" or "soft roe." 


\section{CHAPTER XXIV.}

\section{ORDERS OF FISHES.}

THE number of different kinds of fishes is so enormous that nothing further will be attempted than merely to give an outline of the leading peculiarities which distinguish the different orders. The classification here adopted is the one now most usually followed, by which the class $P$ isces is divided into the following six orders:-

1. Pharyngobranchii.

2. Marsipobranchii.

3. Teleostei.

4. Girtnoidei.

5. Elasmobranchii.

6. Dipnoi.

\section{Order I. Pharyngobranchit.}

This order of fishes includes only a single animal, the anomalous Amphioxus, or Lancelet, the organisation of which differs in almost all its important points from that of all the other members of the class. In fact, the Lancelet presents us with the lowest type of organisation as yet known in the Vertebrata. The Lancelet (fig. 170)

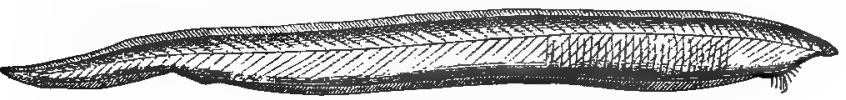

Fig. 170.-Pharyngobranchii. The Lancelet (Amphioxus lanceolatus), enIarged.

is an extraordinary little fish, from one and a half to two inches long, which burrows in sand-banks in various seas, but is especially abundant in the Mediterranean. The body is lanceolate in shape, and is provided with a narrow membranous border, of the nature of a median fin, which runs along the whole of the dorsal and a portion of the ventral surface, and expands at the tail to form a lancet-shaped caudal fin. There are no true "paired" fins, repre- 
senting the fore and hind limks. The mouth is a longitudinal fissure, placed at the front of the head, and completely destitute of jaws, but surrounded by a number of cartilaginous filaments. The throat is provided with several leaf-like filaments which are richly supplied with blond, and are believed to discharge in part the function of gills. The mouth (fig. 171, o) opens into a dilated chamber, which is considered to represent the pharynx, and is termed the pharyngeal or "branchial" sac. The walls of this chamber $(b)$ are strengthened by numerous cartilaginous filaments, between which is a series of transverse slits or clefts, and the whole is covered with a richly ciliated mucous membrane. The function of this sac is clearly respiratory, the water from without being admitted through the mouth, passing through the branchial clefts into the abdominal cavity, and finally escaping by means of an aperture placed on the ventral surface a little in front of the anus. From the hinder end of the branchial sac proceeds the alimentary canal, which has appended to

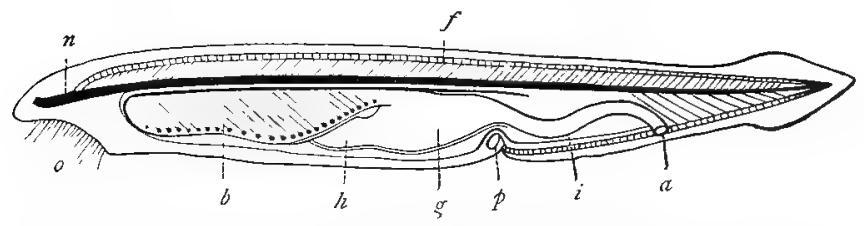

Fig. 171.-The Lancelet (Amphioxus lanceolatns), enlarged to twice its natural size. 0 Mouth; $b$ Branchial sac; $g$ Stomach: $\hbar$ Diverticulum rejoresenting the liver; $i$ Intestine; $a$ Auus; $n$ Notochord ; $f$ Rudiments of fin-rays; $p$ Abdominal pore.

it a sac-like organ believed to represent the liver, and which terminates behind in a distinct anal aperture. There is no heart, and the circulation is entirely effected by means of several contractile dilatations, developed "jom the great blood-vessels. The blood itself is colourless. No kidneys have hitherto been discovered, and the reproductive elements are enitted into the abdominal cavity, from which they escape by the pore placed upon the lower surface.

There is no skeleton properly so called. The notochord (n) remains throughout life as a semi-gelatinous rod, enclosed in a memlirinous sheath, and supporting the spinal cord. There is no skull, and the spinal corl does not expand in front to form a distinct brain or enephaton. The brain, however, may be said to be represented, as the front portion of the nervous axis gives off nerves to a pair of eyes, and another branch to a ciliated pit, which is believed to be a rudimentar! organ of smell. 


\section{Order II. Marsipobranchis.}

This order includes the Hag-fishes (1/yxinida) and the Lampreys (Petromyzonida), and it is defined by the following characters: The body is cylindrical and worm-like, and is destitute of limbs. The skull is cartilaginous, there is no lower jaw, and the notochord remains through life. The mouth is circular and cup-like. The heart is composed of an auricle and a ventricle, but there is no balbus arteriosus. The gills are pouch-like, conmunicating with the throat on the one hand, and opening externally on the other by means of apertures placed on the sides of the neck, or on the ventral surface.

The Hag-fish (Myxine) is an eel-like fish (fig. 172, A), which agrees with the Lampreys in having neither pectoral nor ventral

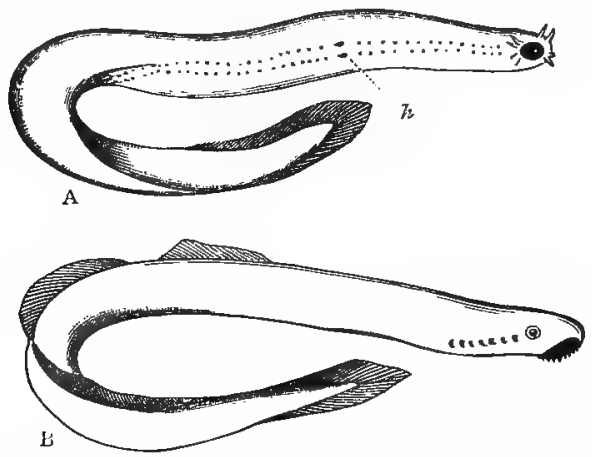

Fig. 172.-Morphology of Marsiyobranchii. A, Myxine glutinosa, the Hag-fish, showing the sucker-like mouth, and the two ventral openings $(h)$ by which the water escapes from the gills. B, The River Lamprey or Lampern (Petromyzon fuviatilis), showing the seven branchial apertures on the side of the neck.

fins, the representatives of the fore and hind himbs. The mouth is of a very remarkable character, and enables the Hag-fish to lead a very peculiar existence. It is generally found embedded in the interior of some large fish, into which it has penetrated by means of a single serrated and recurved fang attached to the centre of the palate. The month itself is destitute of jaws, and forms a sucking disc or cup. Another remarkable peculiarity of the Hag-fishes is found in the structure of the nose. In all fishes, namely, except these and the Mud-fishes (Lepidosiren and Ceratodus), the nasal chambers are closed behind, and do not communicate with the cavity of the mouth, as they do in the higher Vertebrates. In the 
Myxinoids, however, such a communication does exist. The nasal sac is placed in communication with the throat (pharynx) by means of a canal which perforates the palate. A second canal leads from the nasil cavity in front to open by an external aperture (the nostril) on the top of the head behind the mouth.

Another peculiarity, which is best considered in the Lampreys, is to be found in the structure of the respiratory organs, from which the name of the order is derived. When viewed externally, instead of the single great "gill-slit," covered hy a "gill-cover," as seen in the ordinary Bony Fishes, the sile of the neck presents seven round holes placed far back in a line on each sicle. These holes are the external apertures of the gills (tig. 172, B), which in these fishes are in the form of sices or pouches, the lining membrane of which is thrown into numerous folds or plaits, over which the branchial vessels ramify. Internally the sacs communicate with the cavity of the pharyn, ly means of a common respiratory tube into which they all open. It follows from this arrangement that the gillponches on the two sides of the neck communicate freely with one another through the pharynx. The object of this arrangement is to obviate the necesity for admitting the water to the gills through the muth, as minary fishes do. These fishes are in the habit of fixing themselves to foreign objects by means of the suctorial moutl, and when in this position, it is, of course, innossible that they can obtain the necessary water of respiration through the mouth. As the gill-sacs, however, on the two sides of the neck communicate freely with one another through the pharyx, water can readily pass in and out. The gills are not provided with cilia, but the circulation of water is assisted by a kind of elastic cartilaginous frilnework upon which the whole respiratory apparatus is supposted, and which acts somewhat like the ribs of the higher Vertelirites.

In the I I in-fishes, the structure of the respiratory organs is essentially the sime as in the Lamjeres; but the gill-pouches on each side are connected with a common tube, each of which opens on the ventral surface of the body by a small aperture placed at a considerable distance behind the head (fig. $172, \mathrm{~A}$ ).

The Lanupreys are distinguished from the Hag-fishes, not only by having separate and laterally placed apertures to the gill-pouches, but alsu lyy the fact that the nasal sac does not open behind into the throat. Sinne of them are inhabitants of rivers; but others live in the sea, and, like the great Sea-lamprey (Petromyzon muri$n \imath u s)$, betake themselves to fresh waters for the purpose of spawning. The young live in river', and pass through a curious metamorphosis. 


\section{Order III. Teleostei.}

The fishes comprised in this order, as implied in their name, have a well-ossified or bony skeleton, and they are commonly known as the "Bony Fishes." In all the Teleostei, the skeleton is bony, the skull is composed of distinct bones, and there is a lower jaw. The vertebral colunm always consists of more or less completely ossified vertebræ; and the two pairs of limbs, when present, are in the form of fins, supported by rays. The gills are free, comb-like or tufted in shape, and always protected by a bony gill-cover. The bulbus arteriosus is not capable of regular contractions, and is separated from the ventricle by only a single pair of valves.

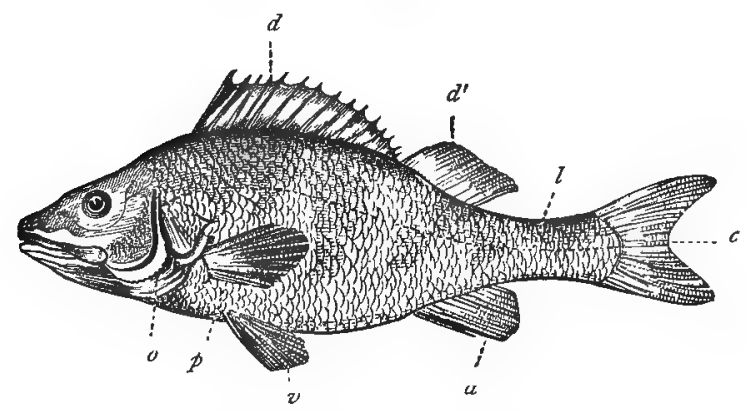

Fig. 173.-The common Perch (Perca fluviatilis). o Gill-cover, with the gill-slit behind it; $p$ One of the pectoral fins, the left; $v$ The left ventral fin; $d$ The first dorsal fin; $d^{\prime}$ The second dorsal fin; $c$ The caudal fin or tail; $a$ The anal fin; $l$ Lateral line.

The order Teleostei comprises almost all the most familiar fishes, and it will be unnecessary to dilate here upon their structure, as they were taken as the type of the class in describing the fishes generally. It may be as well, however, to recapitulate some of the leading points in the anatomy of the Bony Fishes. 1. The skeleton is always more or less completely ossified, and does not remain cartilaginous throughout life. The notochord is not permanent, and the vertebral column consists of a number of distinct vertebræ. The vertebræ, however, are "amphicœlous," or hollow at both ends, so that there is left between each pair a doubly conical cavity, which is filled with the cartilaginous or semi-gelatinous remains of the notochord. In this way an extraordinary amount of flexibility is given to the entire vertebral column. In no fish (except the Bony Pike, which belongs. 
to another order) is the conversion of the bodies of the rert(urax into bone cirried further than this.

2. The integument ustally develops scales, and these in the grmit nil jority of cases are of the forms known as "eycluid "and "ctenoid," the former being circular or elliptical horny plates, with plain margins; whilst the latter have their hinder margins cut into comb-like projections or fringed with spines (fig. 164, $1, b)$.

3. The anterior and postinior limbs (iig. 174) are usually, but nut. alwalys, present, and when develeped they are always in the form of fins. These fins nuy be supported ly "apinous rays" w "soft bays," or ly buth. The sjums rays are simple mulividerl bony spines which tinker to a print. The soft ravs are doubly divided, splitting up towarls their extrenities into a number of secondary l:y,s, and being also clivided hy transverse joints into numerous short piet'tes.

4. Muides the "pratew" fins which represent the limbs, there is

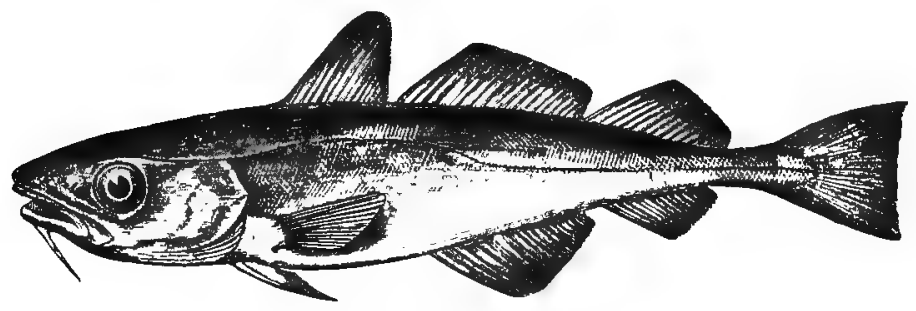

Fig. 17.4. - The Cod (Gadus mornturr).

"1 lso a series of unpairel on "median" fins, the rays of which are supprorted upon a serius of danger-shilped lmos, deeply plunged in the flesh in the middle line of the holly, and known as the "interspinous" Wones (fig. 16ii). The median fins (tig. 174) are variable in number, but when fully developed they consist of one to three fins on the bialk (the dursil fins), one or two on the ventral suffice (the anal fins), and one clothing the posterion extremity of the lwaly (the caudal fin, wr tail). In all the Tremsti, the candal fin has the shape cilled "honucereal"--that is to say, it consists of two erpial lobes -and the vartebral column is not prolongar into the upre' lobe (fig. 174).

5. The heart consists of two cavitice, an amricle ami : ventricle, but the bullous arturiosus is not rhythnically contractile, and is sepiarted from the ventricle ly only a single pair of villves.

(i. The resuintoly orins are in the form of free, comb-like, or tufted gills, enclosed in two cavities placed on the sides of the neck. 
Each of these hranchial chambers opens externally by a single aperture, the "gill-slit," which is protected by a chain of bones, forming the "gill-cover," and by a membrane supported by bony rays. Intemally the branchial chambers communicate with the throat by a series of clefts or fissures, and the water required in respiration is taken in at the mouth by a process analogous to swallowing.

7. The nasal sacs never communicate behind with the throat (pharynx).

\section{Tabular View of tife Main Divisions of the Teleostei.}

Sub-order T. Malacopteri.--Usually a complete series of fins, supportert by rays, all of which are soft, or many-jointed (with the occasional exception of the first rays in the dorsal and pectoral fins). A swim-bladder is always present, and is always connected with the gullet by a duct. The skin is rarely naked, and is mostly furnished with cycloil scales, but sometimes ganoid scales are present.

Amongst the more important families in this sub-order are the Fels (Muranida), Herrings (Clupeides), Pikes (Lsocida), Calp (Cyprinidoe), Salnon and Trout (Salmonida), and Sheat-fishes (Siluridae).

SUb-ORDer II. ANaCanthini. - Fins entirely supported by soft rays, and never by spinous rays. Ventral fins either wanting or placerl uncler the throat, beneath or in advance of the pectorals.

The two leading farmilies in this sub-order are the Corl, Ling, and Haddock family (Gadidoe), and the Flat-fishes (Pleuronectida), comprising the Sole, Turbot, Flounder, and others.

SUb-order III. ACANThOPTERI. - Fins with one or more of the first rays in the form of undivided, inflexible, spinous rays. Scales mostly ctenoid. Siwimbladder without a duct.

The leading families in this order are the Wrasses (Cyclolabritle), the Perches (Percida), the Mackerels ('somberidce), the Mullets (Mugilida,) and the Gobies (Gobiidce).

Sub-order IV. Piectognater. - Certain of the bones of the mouth (the maxillary and præmaxillary bones) immovably convected on each side of the jaw. Integumentary skeleton iu the form of ganoid plates, scales, or spines.

The chief families in this sub-order are the File-fishes (Babistidre), and the Trunk-fishes (Ostracuntida).

Sub-order V. Lophobranohit. - Gill arranged in little tufts on the branchial arches. Integumentary skeleton in the form of ganoid scales.

The two families contained in this division are the Sea-horses (IIppocampidec), and the Pipe-fishes (Syngnathide).

\section{Order IV. Ganoidet.}

The fourth order of fishes is that of the Guncidi, including few living forms, but having a great and varied development in past geological epochs. The Ganoids are distinguished by the generally imperfect development of the skeleton, which is mostly cartilaginous 
throughout life, and by having an integumentary skeleton composed of ganoid scales, plates, or spines (fig, $164, d$ ). The skull is composed of distinct hones, and there is always a lower jaw. There are usually two pairs of fins (pectoral and ventral), supported by many series of cartilages, and the ventral fins are placed very far back. The first rays in the firs are usually in the form of strong spines. The caudal fin or tail is mostly heterocercal or unsymmetrical (fig. $167, \mathrm{~B})$. The swim-blatder is always present, is often cellular, and is provided with an air-duct. The gills and gill-covers are essentially the same as in the Bony fishes. The heart has one auricle and a ventric]e; and the bulbus arteriosus is rhythmically contractile, is furnished with a distinct coat of nuscular fibres, and is provided with several transverse rows of valves.

The best known of the living Ganoids are the Bony Pike or Gar-

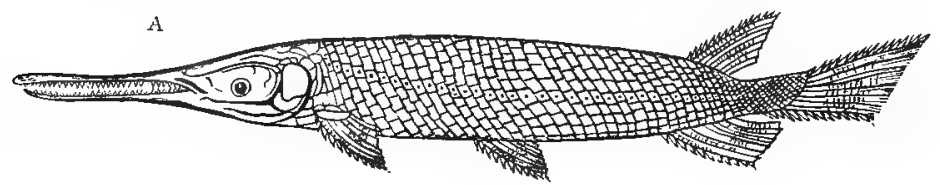

Ii

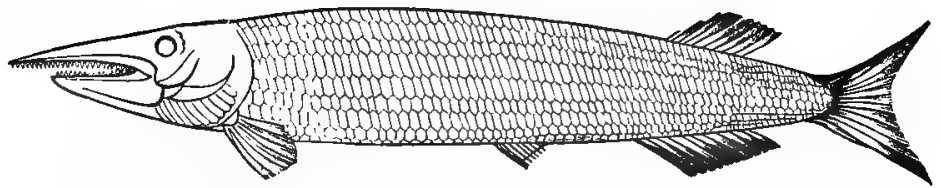

Fig. 175. -A, Lopidustenes ossous, the "Gar-Pike" of the American Lakes; B, Asyidorhynchus, restored (after Arassiz), a Jurassic Ganoid allied to Lepidostens, but having a homocercal tial.

fish (Lepidostins), the Sturgeon (Lipenser), and the Polypterus. Of these, the Fony Pike (fig. 17.5, A), is found in the rivers and lakes of North America. It is a large fish, attaining a length of several feet, and it has the boty entirely covered with an armour of ganoid scales arranged in whiquely transverse rows. The jaws form a long namow suout, armed with a double series of teeth, and the tail is heterocercal. The vertebral column is more perfectly ossified than in any other fish, the bodies of the vertebre being convex in front and concave behind (" "pistlontores"). The Polypterus inhabits the rivers Nile and simegal, and is remarkable fon the peculiar structure of the dorial fin, which is broken up into a seriess of small detached portions, eich compused of a single spine in front, with a soft fin attached to it behind. Some of the species of Polyptorus possess 
external gills when young, which they lose when grown up, thus making an approach to the Amphibia. Many of the fossil Ganoids are more or less closely allied to the living Lepidosteus and Polypterus.

Another great group of the Ganoid fishes is represented by the Sturgeons (Acipenseridoe), in which the skeleton is alway very imperfectly ossified, and the head, with more or less of the body, is protected by large ganoid plates, which are often united together at their edges by sutures (fig. 167, B). The true Sturgeons are confined to the seas and rivers of the Northern hemisphere. They mostly inhabit rivers; but some live in salt water, and ascend rivers for the purpose of spawning. They grow to a great size, and possess a toothless mouth on the under surface of the snout. A curious Ganoid found in the Mississippi is the Paddle-fish (Spatularia).

The living Ganoid fishes are essentially fresh-water types; and they are merely scattered survivors of a very extensive series of forms, most of which are now extinct.

\section{Order V. .Elasmobranchit.}

This order includes the Sharks, Dog-fishes, Rays, \&c., and is distinguished by the following characters: The skull and lower jaw
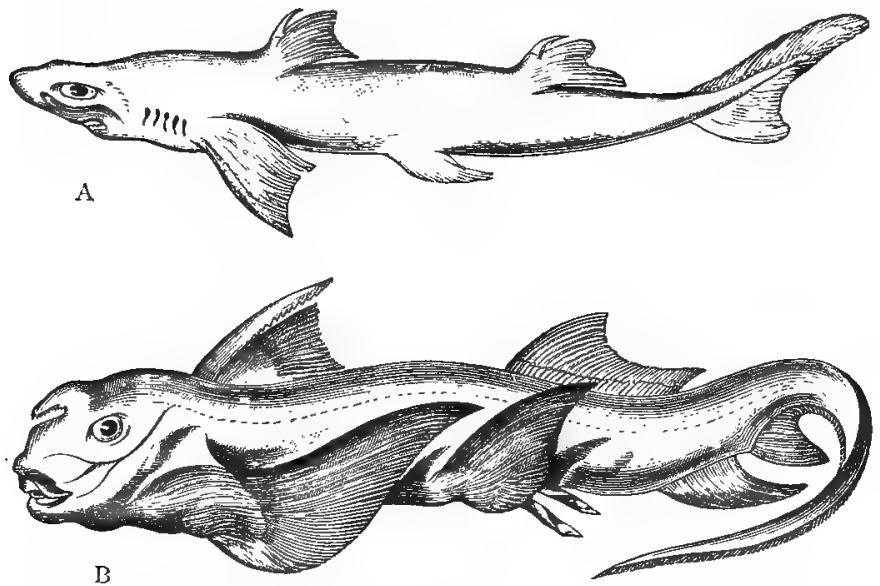

Fig. 176.-A, Spinax acunthias, one of the Dog-fishes; B, Chimcera monstrosa.

are well developed, but the skull is not composed of distinct bones, and simply forms a kind of cartilaginous box. The vertebral column is cartilaginous, but usually composed of distinct vertebræ. 
The integumentary skeleton is in the form of placoid scales (fig. $164, c)$ - that is to say, of detached grains, tubercles, or plates. There are two pairs of fins, corresponding to the fore and hiud limbs, and the ventral fins are placed far back, close to the anus. The heart consists of an auricle and ventricle; and the bullues aterios is rlytlomically contractile, is provided with a distinct coat of muscular fibres, and is furnished with several transverse rows of valves. The gills are fixed, and form a number of pouches, which open internally into the pharynx, and mostly conmunicate with the outer world by a series of apertnres placed on the side of the neck (fig. 176, A). The intestine is very short, but to compensate

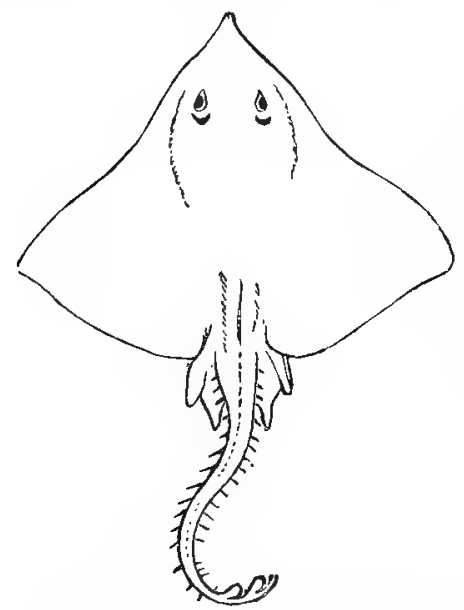

Fig. 1个7.-Batides. Rain marginaln, on of the ikates. Reduced one-sixth. (After Gosse.) for this, the mucous membrace is thrown into a fold, which winds round the intestine in close turns from near the pyloric orifice of the stomach to the anus, and which thus greatly increases its absorbing surface.

The most characteristic examples of the Elasmobranch Fishes are the Sharks, Dogfishes, Skates, and Rays, usually called Plagiostonous Fishes, because the moutll is transverse, and is placed on the under side of the head. In all these types there are five branchial pouches on each side, which open by five distinct slits on the surface of the lody. There are also two apertures ("spiracles") on the top of the heirl, just behiml the eyes, which leid ly tubes into the pharynx, and which correspond with an anterior pair of branchial prouches.

The Sharks and Dog-fishes (Selachii) have pectoral fins of the orlinary size and shaje (fig. 176, A), and hive the gill-slits placed on the sirles of the neck. They have sharp conical teeth, in several rows, and they are nearly all voracious and fierce aninals. The Sharks in particular attain a great size.

The Port Jackson Fiharks (Costr(uion) of the Pacific Ocean, resenible the true sharks in most points; but they have blunt teeth arlapted for crushing shell-fish. 
The Skates and Rays (Batides) have the branchial openings placed on the under side of the head, while the body is generally flattened out into a rhomboidal disc, the greater part of which is made up of the enormously developed pectoral fins (fig. 177). In the Skates, as in the Dog-fishes, the eggs are enclosed in leathery capsules, familiarly known as "Mermaid's Purses."

In another section of the Elasmobranchs, typified by the Chimora (fig. 176, B), though the internal structure of the gills is the same as in the ordinary examples of the order, there is only a single extemal gill-aperture. The group is therefore spoken of by the name of Holocephali.

\section{Order VI. Dipnot.}

The best-known, and until lately the only, forms included in this order, are the very singular Mud-fishes (Lepidosiren), which are of great interest from the many points of affinity which they exhibit

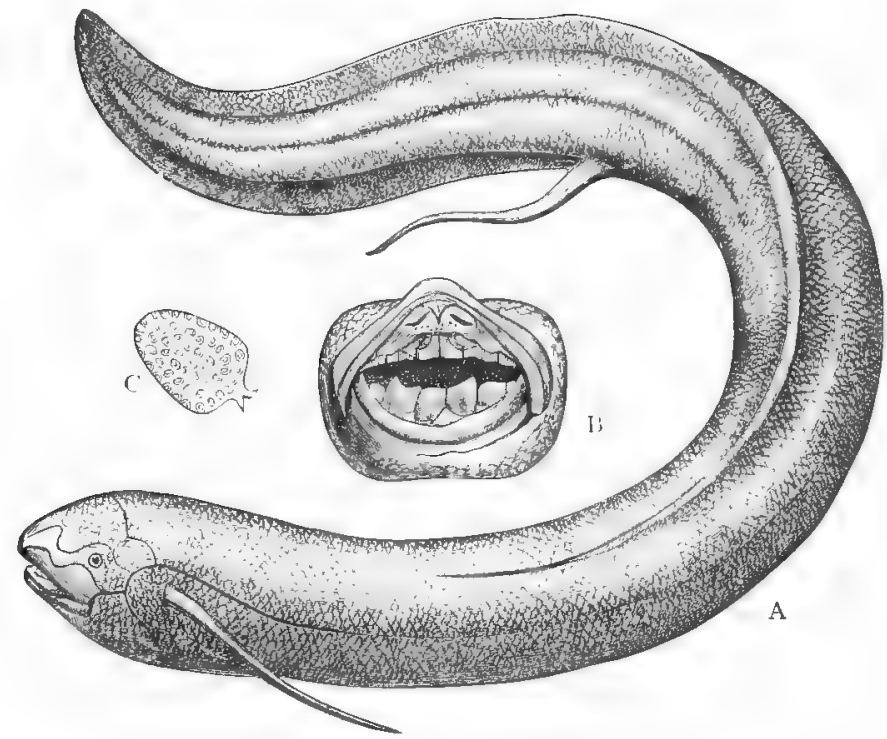

Fig. 178.-A, Lemilosiren paradnxa, one of the Mur-fishes ; B, Front of the mouth of the same, showing the teeth; C, One of the overlapping scales, enlarged.

to the Amphibia. The body of the Lepidosiren (fig. 178) is completely fish-like, and is protected by a covering of small, horny, overlapping scales, which have the cycloid characters. There are 
two pairs of limbs, but these are in the form of awl-shaped organs, each supported by a ringle, jointed cartilaginous rod. The pectoral limbs have a membranous fringe inferiorly, and the ventrals are placed very far back. There is also a median fin behind, forming a continuous fringe round the conpressed tail, and supported by cartilaginous rays.

The skull is composed of distinct bones, and there is a lower jaw ; but the notochord is persistent, and there are no bodies of vertebræ developed. The respiratory organs are twofold, consisting, firstly, of free filamentous branchix or gills, contained in a branchial chamber, which opens externally by a single vertical gill-slit; and, secondly of true lungs, in the form of a double cellular air-bladder communicating with the gullet by means of an air-duct or windpipe. Sometimes, if not alwiys, there are rudimentary external gills as well, placed on the side of the neck. The heart consists of a ventricle, and of tero auricles, divided from one another by an incomplete partition. Listly, the nasal sacs open behind into the throat, ind do not form closed chambers opening only by the nostrils, as they do in all other fishes except the Myxinoids. The two bestknown species are the Lepidosiren parador, from the Amazon, and the $L$. (Protopterus) annectens from the Gambia; but the former is

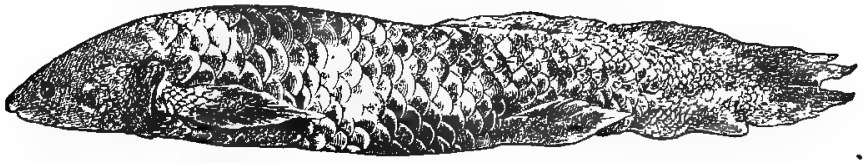

Fig. 179.-Ceratodus Forsteri, one of the Australian Mud-fishes, reduced in size.

very rare and little known. They both inhalit marshy tracts, and l,oth appear to be able in the dry season to bury themselves in the mul, and to form a kind of chamber, in which they remain dormant till the rains of the wet season set them free.

In the fr'sh waters of Queensland, Australia, are found two other remarkable Mud-fishes, belonging to the genus (crotmelns. The singular cromtorlus Forstric (fig. 179), often called the "Barramunda," grows to the length of six feet, and has the body covered with very litrge cycloid scales. The fins are not awl-like, but consist of a fringe of fin-riys surrounding a central lolke. The Barramunda seems to feed ipon leaves, which it masticates by means of curious undulated bony plates or "molars," of which each jaw carries two. It appears occasionally to come to land, at which times it doubtless breathes by means of its lungs; but it has welldeveloper gills also, and is essentially an iquatic animal. 


\section{ICH THYO P S D A.}

\section{CHAPTER XXV.}

\section{CLASS II. AMPHIBIA.}

TuIs class of Vertebrata comprises the Frogs and Toads, the Newts and Land-salamanders, the Crecilice, and some extinct forms, and it may be briefly defined as follows: In all cases gills or branchive adipted for aquatic respiration are present during a part or the whole of life; but in all cases true lungs adapted for breathing air are ultimately developed, even when the gills are retained through life. All pass through some sort of a metanorphosis after being set free from the egg. The limbs may be absent, or there may be only one pair, but in no case are they ever converted into fins. When median fins are present, as is sometimes the case, these are never furnished with fin-rays or interspinous bones, as in the fishes. The skull always articulates with, or is jointed to, the spinal column by two articular surfaces or condyles. The heart consists of two auricles and a single ventricle. The nasal sacs always open behind into the "mouth; and there is a common cavity or "cloaca" which receives not only the termination of the intestine (rectum), but also the ducts of the kidneys and of the reproductive organs. The skin is soft and glandular, and, as a rule, neither horny nor bony structures are developed in it.

The great and distinguishing character of the Imphibia is that they invariably undergo some kind of metamorphosis after birth; though in some rare cases the eggs are retained so long within the body of the parent that there is little or no obvious change. In the great majority of cases, however, the Amphibians comnence life as water-breathing larvæ, provided with gills; but in their adult state they possess two air-breathing lungs, the gills sometimes disappearing when the lungs are developed, but being sometimes retained throughout life. In most cases, and always if retained, the gills are external, placed on the sides of the neck, and not contained in a special cavity, thus differing from the gills of fishes. In the Frogs and 
Toads, and in some others, there are two sets of gills, one external aurl the other internal, of which the former is soonest lost. The lungs of the Amphibians never attain a very high state of development; and in those forms in which the gills are retained throughout life, the chief business of respiration appears to be carried on by the - gills. In accordance with the changes in the resiniratory process, corresponding alterations take place in the blood-vessels. With the developinent of the lungs the vessels which carry blood to them (the pulmonary arteries) increase in size, whilst the branchial vessels, which cary the blood to the gills, undergo a proportionate diminution. At first the condition of the circulation is rery much the same as it is in fishes, but ultimately it becomes nearly the same as in the true Reptiles.

The Implibiu are divided into three living and one extinct order as follows :-

$$
\text { Pe, }\|\| E^{\prime .1}
$$

\section{Order I. OTHTIOMORPHA.}

This order is an extremely small one, and, as its name implies, it comprises certain snake-like Amphiljians. The order includes only the curious animals known as Cocilice (fig. 180), which are found in

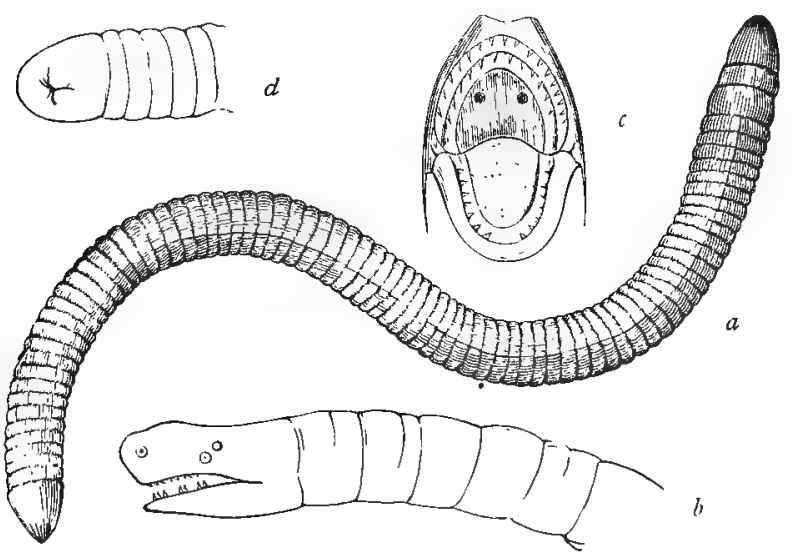

Fig. 180.-a Siphonols annulatus, one of the Creilians, much reducen; $b$ Head of the samr: o Mruth, showing the tongue, teeth, and internal openings of the nostrils; d Tail of the sane. (After Dumeril and Bibron.)

Sinthern Asia, Africa, and Sonth America. The body is entirely destitute of limb, and is enclosed in an integument which is thrown into numerous transverse wrinkles, and sometimes has numerous 
horny scales embedded in it. The eyes are concealed by the skin, and are rudimentary. There is no tail, and the anal aperture is placed almost at the extreme end of the body. When adult, respiration is carried on by means of lungs, but gills are present in the young, and there can therefore be no doubt as to their being genuiue Amphibians.

The Cocilice are found burrowing in marshy ground, and they are not unlike large earth-worms in appearance, but they sometimes attain a length of several feet.

\section{Order II. Urodela.}

In this order are a number of fish-like Amphibians, of which the Newts and Land-salamanders are the most familiar examples. In all the members of this section the skin is naked, and never develops any hard structures, and in all there is a well-developed fish-like tail, which is retained throughout life. The vertebræ are sometimes hollow at both ends (amphicoelous), sometimes hollow behind and convex or rounded in front (opisthocoelous). The ribs are rudimentary, and the bones of the fore-arm (radius and ulnu), and of the shank (tibia and fibula), are separate, and are not combined so as to form single bones.

The Lrodela are not unfrequently spoken of as the "Tailed" Amphibians, and they fall into two natural sections, according as the gills are permanently retained throughout life, or are cast off before maturity is attained. The animals belonging to the first section are often called "peremibranchiate," whilst those belonging to the second are said to be "caducibranchiate."

Among the Perennibranchiate forms, in which the gills are permanently retained after the lungs make their appearance, the bestknown examples are the Axolotl, the curious Proteus anguinus, the Menobranchus, and the Mud-eel (Siren). Axolotls inhabit various of the lakes of the Americarl continent, the best-known species being the Siredon pisciforme of the Mexican lakes. It attains the length of a foot or more, and possesses both pairs of limbs, the fore-feet having four toes, the hind-feet five toes. The branchire are in the form of three long ramified processes on each side of the head; and the tail is compressed, and fringer by a fin which is prolonged on the back between the shoulders. In a state of nature, the Mexican Axolotl is certainly peremnibranchiate, and it breeds freely in this condition. It has been shown, however, by Prof. Marsh, of New Haven, and others, that some species, when kept in confinement, lose their gills, and undergo certain other changes, becoming ultimately converted into Salamandroids, belonging to the genus $A m b l y$ - 
stonnc. Moreover, in one species (viz., Amblystoma mavortium), this change is known to occur in a state of nature; the larva being an Axolotl, with gills, and capable of breeding, but ultimately changing to a gill-less Silitmander.

The Proteus is an extraordinary Amphibian which is found inhabiting the waters of caves in Illyria and Dalmatia. It attains a length of about a foot, and is of a pale flesh-colour or nearly white. The gills, which are retained throughout life, are of a bright scarlet. Both pairs of limbs are developed, but they are only short and weak, the fore-limbs having three toes each, and the hind-limbs only two. The eyes are rudimentary, the animal spending its existence in darkness; and swimning is effected mainly by means of the tail. Allied to Protens is the Mud-puppy (Menobranchus, fig. 181, C) of
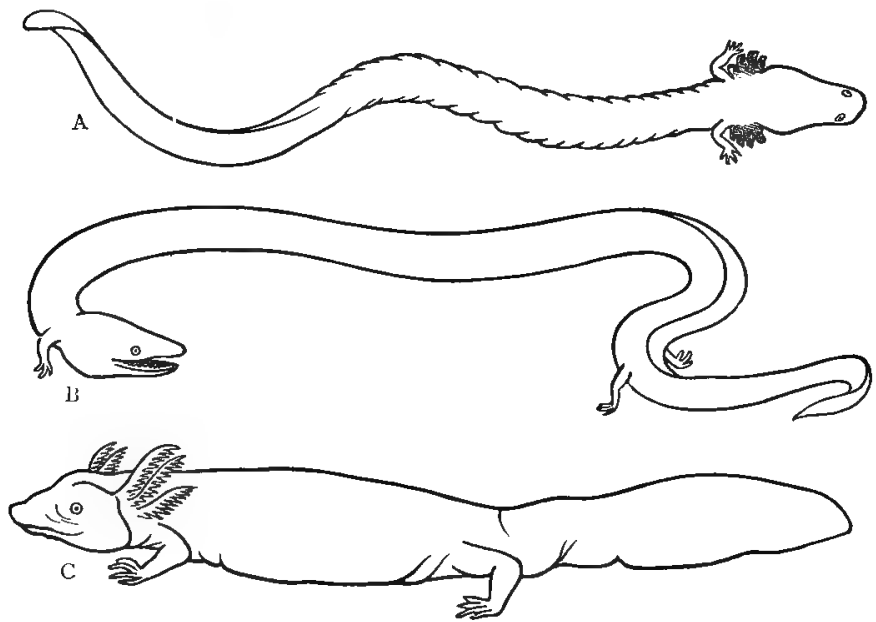

Fig. 181.-Tailed Amphibians. A, Siren lecertina; B, Amphiuma, showing the four minute limbs; C, Menobranchus maculatus. (After Mivart.)

North America, which is from six inches to a foot in length. The Siren or Mud-eel (fig. 181, A) is a large lizard-like Amphibian, which is found abunduntly in the swamps of South (arolina, and attains the great length of three feet. The external brinchize are retained throughout life, and they are the main oryans of respira. tion. The fore-limbs are present, but the hinder pair of limbs is never developerl. Another form, which occurs in the Southern United States, is the (Jongo-snake (Ampliumo). This has a suakelike body, with rudimentary two-toed limbs (fig. 181, B), and though the gill-slits remain on the side of the neck, it has no gills. 
The "caducibranchiate" section of this order is characterised by the fact that both pairs of limbs are always developed, and the branchiæe are never retained throughout life. The most familiar examples are the Water-salamanders or Newts (Triton). The Newts (fig. 182), are well known as inhabiting pools in many regions, and the young leakl a strictly aquatic life. When the lungs are developed the external gills wholly disappear; and the respiration becomes strictly aerial, though the animals still spend a great part of their time in the water. The larva or young form is at first destitute of limbs, and the fore-limbs are the first to be developed, the reverse of this taking place in the Frogs. In accordance with their mode of life, the tail is compressed and flattened, so as to form an efficient

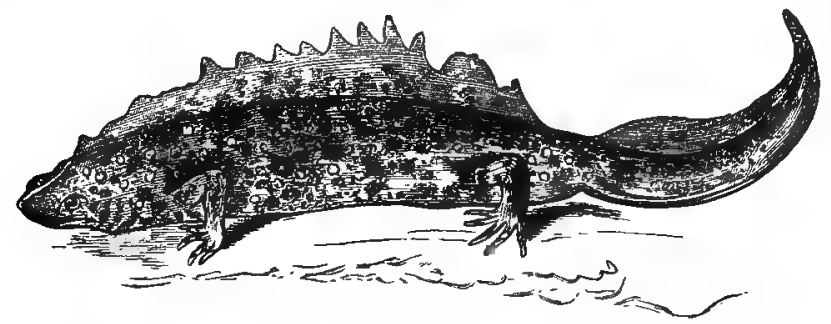

Fig. 182.-The Great Water-Newt (T'riton cristatus), male. (After Bell.)

swimming apparatus. The Water-salamanders are all oviparous, and the young are like the tadpoles of the common Frog.

The so-called Land-salamanders (Grtumandra), in the strict sense of the term, are essentially terrestrial animals, though commonly frequenting water; and they retain the larvie within the oviducts for a longer or a shorter time after the emergence of the embryo from the egg. They are, therefore, ovo-vivilatrus or even viviparous. The tail is rounded and cylindrical. A common form is the Spotted Salamander of Europe, in which the larvi have at first external gills ; but in the Alpine Salamander of Southern Europe, the larvæ are not brought forth until the gills are shed.

\section{Order III. Angura.}

This order is the highest of the Amphibia, and comprises the Frogs and Toads. It is sometimes known by the name of Batrachia (Gr. batrachos, a frog), or Anoura (Gr. $\alpha$, without; oura, a tail), the latter name being derived from the fact that the adults are "tailless."

The tailless Amphibia are characterised by the fact that whilst the larva possesses a tail, and is furnished with gills, the adult has no 
tail, and breathes wholly by lungs, and through the skin. Both pairs of limbs are always developed in the full-grown animal, and the hind-limbs are usnally considerably longer than the fore-limbs, and generally have the toes webbed, whilst those of the fore-limbs are free. The skin is soft, and there are rarely any traces of any integumentary skeleton. The spinal column is short; the dorsal vertebra are very long; and the ribs are quite rudinentary, their place being taken by greatly-developed transverse processes. The bodies of the vertebræ are hollow in front and convex behind (procolous). The bones of the fore-arm (radius and $z l u(1)$, and those of the shank (tibic and fibula), are united together to form single bones. The upper jaw is usually furnished with teeth, and the lower jaw sometimes, but there are no teeth in the Toads. The Iungs are well developed, comparatively speaking; and as there are no ribs by

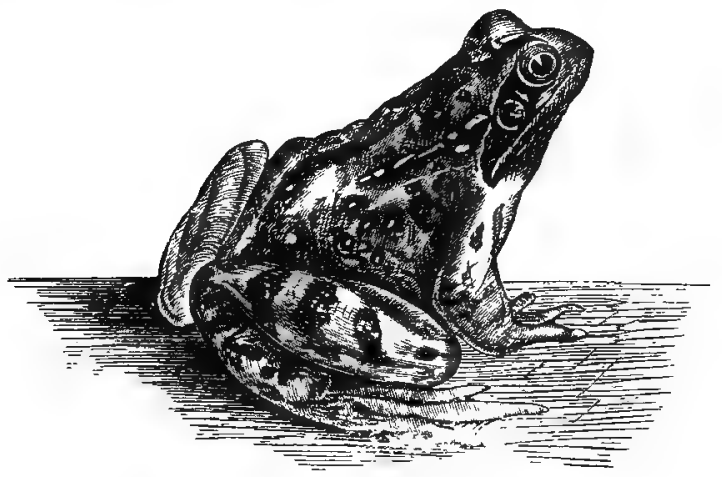

F.: 1S3.-The common Frog (Rana temporaria).

which the cavity of the chest cim be expanded, the air is taken into the luugs by a process nearly akin to that of swallowing. There can be no doubt, also, that the skin plays a very important part in the aeration of the blood, and that the frogs especially can carry on their respiration by means of the skin without the assistance of the lungs for a very lengthened period. This, however, should not lead to any credence being given to the often-repeated stories of frogs and toads being found in closed citvities in solid rock, no authenticated instance of such an occurrence being known to science. The ova of the frogs and toads are depusited, in masses or strings, in water, and the young or larve are familiar to every one as talpoles. Upon its esriape from the exis, the young frog (fig. 184) presents itself as a little fish-like creature with a broad he:ul, a sac-like belly, and a 
long compressed tail with which it swims actively. It breathes by means of gills or branchiæ, of which there are two sets, one external and the other internal. At first there are no limbs; but, as development proceeds, the limbs make their appearance-the hind-legs first, and then the fore-legs. The tail, however (fig. 184), is still retained as an instrument of progression. Ultimately, when the limbs are fully developed, and the gills have given place to lungs, the tail is alosorbed, and the animal now takes to the land as a perfect frog.

The development of the Frog is a good illustration of the general zoological law, that the transitory embryonic stages of the higher members of any division of the animal kingdom are often represented by the permanent condition of the lower members of the

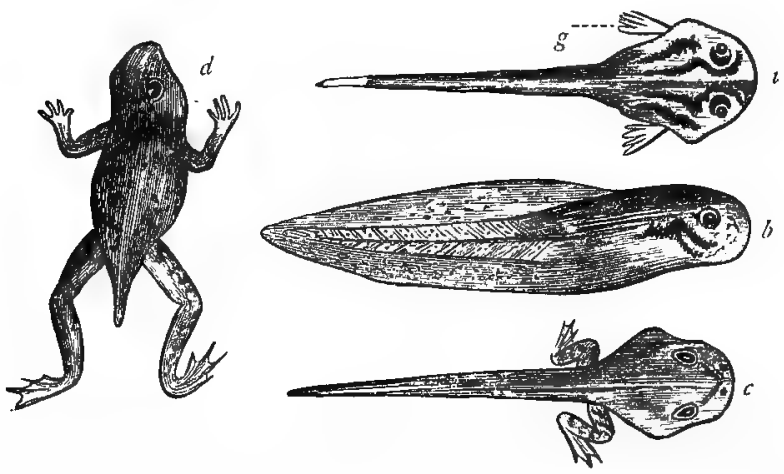

Fig. 184.--Development of the common Frog. a Tadpole, viewed from above, showing the external brancliax $(g) ; b$ side view of a somewhat older speeinen, showing the fislı-like tail ; $c$ Older specimen, in which the hind-legs have nade their aplearance; $d$ Slecimen in which all the limbs are present, but the tail has not been wholly absorbed. (After Bell.)

same division. Thus the transitory condition of the young Frog, in which it breathes by external branchie, is to a certain extent permanently represented by the permanent condition of a perennibranchiate Amphibian, such as the Proteus. The stage at which the external branchiæ have disappeared, but the tail is still present, and the limbs are developed, is permanently represented in the common tailed Amphibians, such as the Newts.

The order Anoura comprises the three families of the Frogs, Toads, and Surinam Toads. The Frngs (Ranido) are distinguished by having a tongue which is fixed to the front of the mouth, and can be protruded at will, while the upper jaw is always armed with 
teeth. The typical Frogs have enormously developed hind-legs, the toes of which are united by membrane, or are "webbed." They swim very powerfully, and can take extensive leaps. Excellent exanples are the Grass Frog (Rana temporaria) and Edible Frog (Rrime esculenta) of Europe, and the Bull-frog (Rana pipiens) of North America. The Tree-frogs, on the other hand, are adapted for a wholly different life, inhabiting trees, among which they climb with great ease by the help of suckers developed upon the ends of the toes. They are mostly found in wirm countries, especially in Americi, but one species is European.

In the equally familiar Toads (Bufonidce), the structure of the tongue is the same as in the Frogs, but the jaws are not furmished with teeth. In the Surinam Toads (Pipida) there is no tongue at all, and usually no teeth.

\section{Order IV. LabYrinthodontia.}

This, the last order of the Amphibia, is not represented by any living forms, and requires to be little more than mentioned. The Labyrinthodonts were Amphibia which were all of lirge size, and of which some must have attained absolutely gigantic dimensions, the skull of one species being three feet in length and two in breadth. They were first known to science sinply by their footprints, which were found in certain Secondary sandstones (Trias). These footprints consisted of a series of alternately placed pairs of hand-shaped impressions, the hinder print of each pair being much larger than the fore one. So like were these prints to the shape of the human band that the unknown animal which had proluced them was christened the "cheirotherium" (Gr. cheir, hand; th"r, beast). Further researches, however, showed that these footprints were produced by various species of large Amphibians, to which the name of Labyrinthodontia wats applied, in consequence of the complicated microscopic structure of the teeth. These extinct Amphibians are known to have existed at the time of the Coal, but they are most characteristic of the period known to geologists as the Trias. 


\section{SAUROPSIDA.}

\section{H A P T E P X V I.}

\section{CLASS III. REPTILIA.}

WE commence now the second great primary division of the Tertebrata-namely, that of the Sauropsida, comprising the Reptiles and the Birds. These two classes, though very unlike in external appearance, are united by the following characters: There are never at any period of life gills or branchiæ adapted for aquatic respiration; the red corpuscles of the blood are nucleated (fig. 163, b,c); the skull articulates with the vertebral colum by means of a single articulating surface or condyle ; each half of the lower jaw is composed of several pieces, and is jointed to the skull, not directly, but by the intervention of a special bone (the so-called "quadrate bone").

These being the characters by which, amongst others, Reptiles and Birds are collectively distinguished from other Vertebrates, it remains to see what are the characters by which the Reptiles are distinguished, as a class, from Birds. In all Reptiles the blood is cold-that is to say, very slightly warmer than the temperature of the external medium in which they live. The integument generally secretes scales, with or without bony plates, but in no case do the integumentiury appendages take the form of feathers. The heart consists of two auricles and a ventricle, which in most is partially divided into two chambers by anmcomplete partition, and in a few is completely divided. In any case, however, more or less of the impure venous blood is mixed with the pure arterial blood which circulates over the body. There is no division between the cavities of the thorax and abdomen, and the lungs are not connected with air-sacs placed in various parts of the body. The limbs may be wanting, or rudimentary, but in no case are the fore-limbs constructed upon the type of the "wing" of birds, and in no living Reptile is there the bone which is known in Birds as the "tarsometatarsus." 
The class Reptilia includes, among living forms, the Tortoises and Turtles (Chelonia), the Snikes (1),liclic), the Lizards (Lacertilia), and the Crocodiles (Crocodilia). With the exception of the Tortoises and Turtles, they are mostly of an elongated cylindrical form, furnished behind with a long tail. The limbs may be altogether absent or quite rudinentary, as in the Snakes, but in almost all the higher members of the class there are two pairs of limbs, which may be either ulapterl for walking or swimming, and which in some extinct forms support a flying membrane. The internal skeleton is always bony, never cartilaginous or semi-cartilaginuus as in many of the fishes. The skull is jointed to the spine by a single articulating surface (or anndyly). The lower jaw is complex, each half being composed of several pieces united by sutures. In Tortoises and Turtles, however, these separate pieces are amalgamated together, and the two halves are also united, so that the whole lower jaw appears to form a single piece. In most reptiles, on the other hand, the two hillves of the lower juw (fig. 185), are only loosely united; in the Snakes by ligaments and nuscles, in the Lizards by gristle, and in the Crocodiles by suture. In all, the lower jaw is jointed

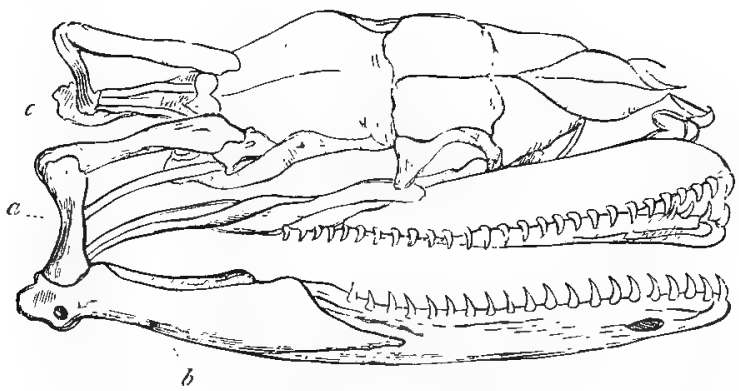

Fig. 185. - Skull of a Serpent (Python), a Quadrate bone: $b$ Lower jaw, articulating with the movalue quadlate bone (a).

to the skull by means of a special bone, called the "quadrate bone"; and as this often projects backwards, the opening of the mouth is often very extensive, and may even extend backwards beyond the base of the skull (fig. 185, a). Teeth are generally present, but these are userl chiefly to hold the pres, and not in biting or chewing the ford. Except in the Crocodiles, the teeth are not sunk into distinct sockets, and they are usually replaced as fast as shed. They likewise do not differ from one another sufficiently in form or function as to allow of their being divided into different sets, as they (an be in the Manmuls. Isually the teeth are confined to the jaws 
proper, but in some cases they are carried by other bones of the mouth. In the Tortoises and Turtles there are no teeth, and the jaws are simply sheathed in horn, so as to constitute a kind of beak, like that of a bird. The integumentary skeleton is in the form of scales, sometimes combined with bony plates. In the Tortoises and Turtles the integumentary skeleton is so united with the true skeleton as to form a kind of bony case or box, in which the body is enclosed.

The digestive system presents little wortby of special notice, except that the termination of the intestine (rectum) opens into a cavity called the "cloaca," which receives also the ducts of the urinary and generative organs.

It is, however, in the structure of the circulatory and respiratory organs that the most important characters of the Reptiles are to be looked for. The heart in all Reptiles may be regarded as being, in function, three-chambered, being composed of two auricles and a single ventricle; imperfectly divided by an incomplete partition. In the Crocodiles alone the heart is, structurally, four - chambered, the ventricle being divided into two by a complete partition. Here, however, the same results are brought about as in the other Reptiles, by means of a communication which subsists between the great vessels which spring froni the ventricles thus formed. In the ordinary Reptiles the course of the circulation is, roughly speaking, as

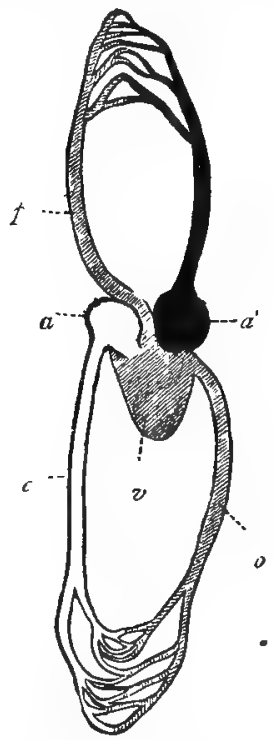

Fig. 186. - Sketch-diagram of the circulation of a Reptile. a Right auricle, receiving venous blool from the boly ; $a^{\prime}$ Left auricle, receiving arterial blood from the lungs ; $v$ Arteriovenous ventricle, containing nixed blood, which is driven by ( $p$ ) the pulmonary artery to the lungs, and by (o) the aorta to the body. (The venous system is left light, the arterial system is black, and the vessels containing mixed blood are cross-shaded.) follows (fig. 186): The impure or venous blood that has circulated through the body is poured by the great veins into the right auricle (a). The pure or arterial blood that has been submitted to the action of the lungs is poured by the pulmonary veins into the left auricle $\left(a^{\prime}\right)$. Both auricles empty their contents into the ventricle, and as the partition which divides the ventricle is an incomplete 
one, it follows that the venous and arterial streams must mix to some extent in the ventricle. From the ventricle arise the great vessels which carry the blood to the lungs and to all parts of the body, and it follows that to some extent all these parts are supplied with a mixed fluid, consisting partly of impure or venous blood, and partly of pure or arterial blood. In the (rocodiles, in which there are two ventricles completely separated from each other, the same result is brought about by means of a communication which takes place between the great vessels which spring from the ventricles, in the immediate neighbourhood of the heart.

As a matter of fact, the heart of the Reptiles is so constructed that this theoretical mixture of the arterial and venous currents in the common ventricle only takes place in practice to a limited extent. What actually occurs is that the lungs are supplied mainly with venous hlowd, and the head and fore-limbs are supplied mostly with pure arterial blood, while the body and hind-limbs are supplied with mixel blom ; but the arrangements whereby this is brought about are too complicated for description here.

As regitrits the structure of the lings, it is merely to be noted that ther'e is no partition (diaphragm or midriff) separating the two cavities of the thurax and abdomen, and that the lungs, therefore, often attain a great proportionate size, sometines extending through almost the whole length of the cavity of the trunk. There are also no air-sacs communiciting with the lungs, as in the Birds.

Lastly, all Reptiles are exsentially ovilarous, some being ovoviviparous. The egg-shell is usually parchment-like, but in other cases contains more or lent calcareous matter.

The class R'ptilia is dividert into four living and six extinct orders, as follows, but the latter require no estended notice here :-
1. Chermia (Tortuises and Turtles).
2. Opliclic ('Hakes).
3. Lerertilier (Lizards).
4. Couratilie (C'roculiles).
5. Ichthyspteryguin
6. Sorrisoleterygue
7. I'toresermint
8. Anomodontia Extinct.
9. Mrimsistererie
10. Therimlnetia 


\section{CHAPTER XXVII.}

\section{DIVISIONS OF REPTILIA.}

\section{Order I. Chelonia.}

Is this order are included the various Tortoises and Turtles, characterised by having the body enclosed in a bony case or box, and by the fact that the jaws are not provided with teeth, but are encased in horn, so as to form a kind of beak. The case in which the body of a Chelonian is protected is composed partly of integumentary plates and partly of flattened bones belonging to the true skeleton, and it is composed essentially of two pieces, one placed on the back and the other on the lower surface of the body, firmly united together at their edges. The dorsal shield is more or less convex and rounded, and is called the carapace; whilst the ventral shield is more or less completely flat or concave, and is called the plostron. The carapace and plastron, as just said, are united by their edges, but they leave two openings, one in front for the head and forelimbs, and one behind for the tail and hind-limbs. The carapace is essentially composed of the flattened and expanded spinous processes of the vertebræ, and the greatly developed ribs, covered by a series of horny plates. These are growths of the integument, and in some cases (fig. 188) they constitute the "tortoise-shell" of commerce. The plastron is also composed partly of bony and partly of horny plates, but opinions differ as to whether the bony plates are to be looked upon as formed by an expanded breastbone, or whether they are merely integumentary, the probabilities being in favour of the latter view.

The remaining peculiarities with regard to the skeleton which deserve special mention are: Firstly, that the dorsal vertebra are immovably connected together, so that this region of the spine is quite inflexible; secondly, that the heads of the ribs are articulated directly to the bodies of the vertebræ; and, thirdly, that the scapular and pelvic arches, supporting respectively the fore and hind limbs, are situated within the carapace (fig. 187), so that the 
shoulder-blade is placed inside the ribs instead of outside, as is usually the case.

The Chelonia are conveniently divided into groups, according as the limbs are adapted for swimming (natatory), or for progression on land (terrestrial); or, again, enable the animal to lead an amphibious life, sometimes on land and sometimes in the water. Of the

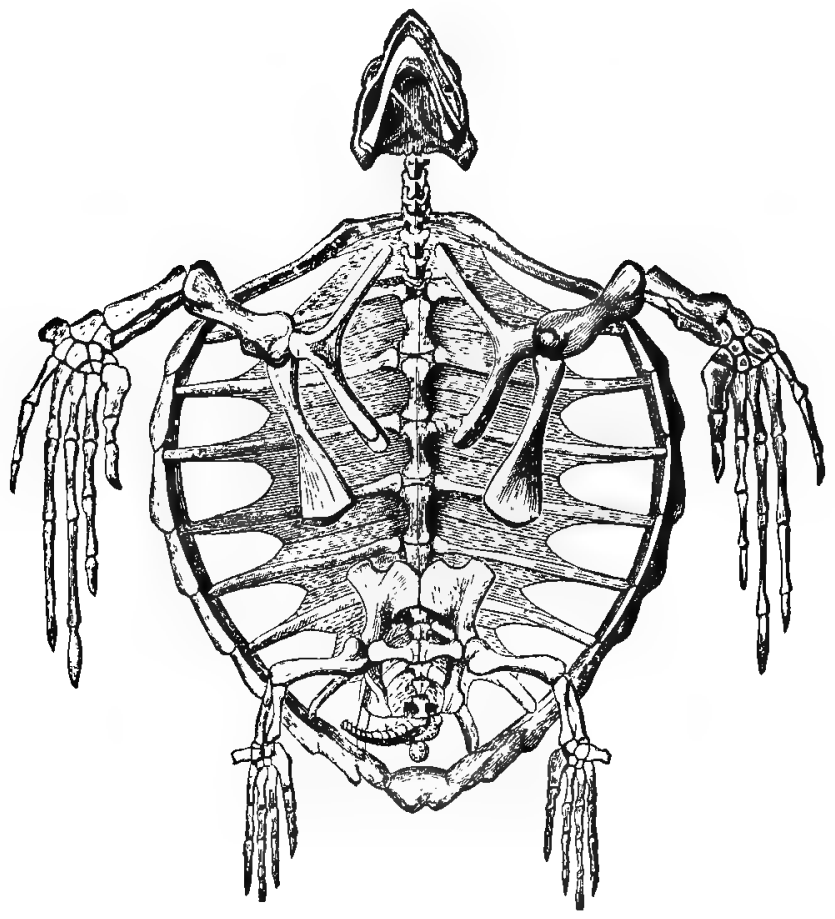

Fig. 187.-Skeleton and carnace of the Logger-headed Turtlo (Chelone caonanna), viewed from below, the plastron being removed.

strictly aquatic forms the best known are the edible Green Turtle 1thelune mydus) and the Hawks-bill Turtle (Cholone imbricta). The former is found aluudintly in many of the seas of warm climates, and is largely imported into Europe as a delicacy. The latter (fig. $1 \bar{s}_{\bar{i}}$ ) is truly a native of warm seas, though an occasional straggler his reacherl Britain. It is of conparatively small sizenot more than about three feet in length-lut is of considerable 
commercial importance, as it furnishes the "tortoise-shell" of trade, so largely used in various kinds of ornamental work.

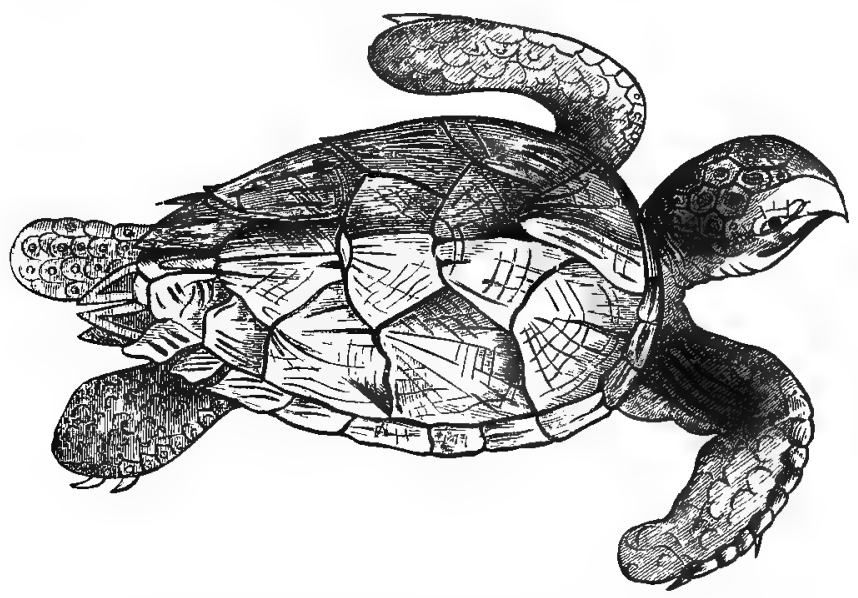

Firr. 188. - The Hawk's-bill Turtle (Chelone imbricatc). (After Bell.)

The Sea-tortoises or Turtles have the carapace much flattened, the legs of unequal length, in the form of solid fins or oars, the toes being conjoined, and hardly distinct from one another.

The Marsh, Pond, and River Tortoises are generally furnished with webbed feet, and lead an amphibions, semi-aquatic existence. The so-called "Soft Tortoises" (Trionycince) belong here, and are distinguished by the imperfect condition of the carapace, which is simply covered with a leathery skin. A good example is the Softshelled Turtle ( $T$ ferox $)$ of the Southern States. Here also belong the Snapping-turtles, so well known in the person of the common American species (Chelydra serpentina), and the Terrapins (Emydida), of which many forms are found in all parts of the United States. In the curious little Box-tortoise (Cistrudo Tirginea) the plastron is composed of two movable portions which can be brought into accurate apposition with the carapace, thus completely protecting the animal within.

The Land-tortoises have short legs of nearly equal length, the toes little distinct, and united into a sort of stump, with indistinct, horny claws. Good examples of this group are the common European Tortoise (Testudo Greca) and the Indian Tortoise (T. Indica), the last attaining a length of over three feet. 


\section{Uruer II. UPindia.}

This order includes most of the animials which would commonly be callerl slities on serpents, and is characterised by the following peculiarities: The body is always mure or less elongated, worm-like, or cylindrical, and the skin develops hony scales, but never bony plates. There is never any breast-bone (stemum), nor pectoral arch, nor fore-limbs; nor, as a rule, are there any traces of hind-limbs. In a few calses, however, rudimentary hind-limbs can be detected. The rils are always very numerous. The two halves of the lower jaw ine composed of several piteces each, and they are united to one

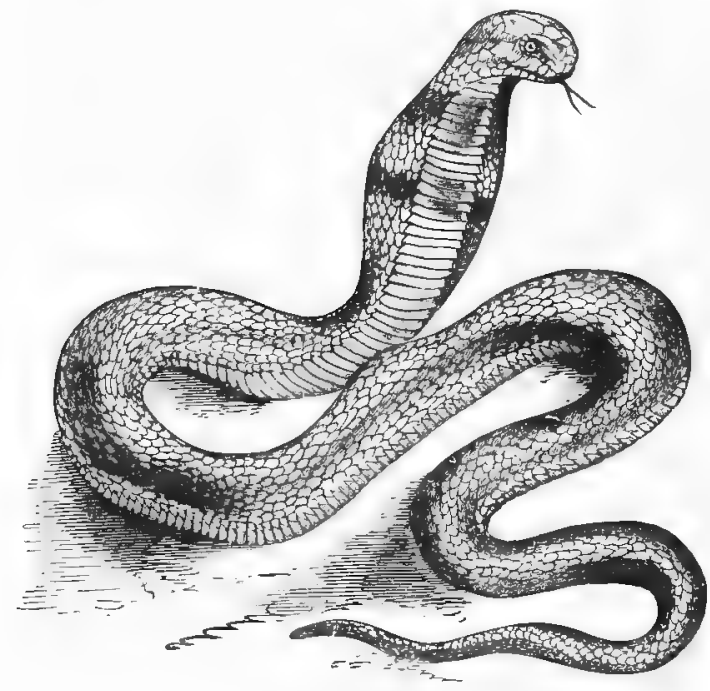

Fig, 189.-The Nuga haje, a puisonous Suake of Ligyt.

another in front only by ligaments and muscles (fig. 185). Hooked, conical teeth are always present, lut they are never lotged in distinct sockets, and ire only used to hold the prey, and not in mastication. The lumes and other fairesl organs are often not symmetrical, one of cach prit being usually smaller than the other, or altogether alisent.

The most ntrihing of these claracters of the snakes (fig. 189) is to he formel in the nature of the rroins of licomotion. The fore-limbs are invariably altogether wanting, and there is no pectoral areh nor 
breast-bone; nor, as a rule, are there any traces of hind-limbs. In a few forms, however, the hind-limbs are present in an extremely rudimentary form, never exhibiting any outward evidence of their existence, beyond the occasional presence of short horny claws or spurs. In the entire absence, then, or rudimentary condition of the limbs, the snakes progress by neans of the ribs, which are always excessively numerous, and, in the absence of a breast-bone, are also extremely movable. Their free ends, in fact, are simply attached by muscular fibres to the scales or "scutes," which cover the lower or abdominal surface of the animal. The number of ribs varies greatly, and by means of the above arrangement the snakes are able to progress rapidly, walking, as it were, upon the ends of the ribs.
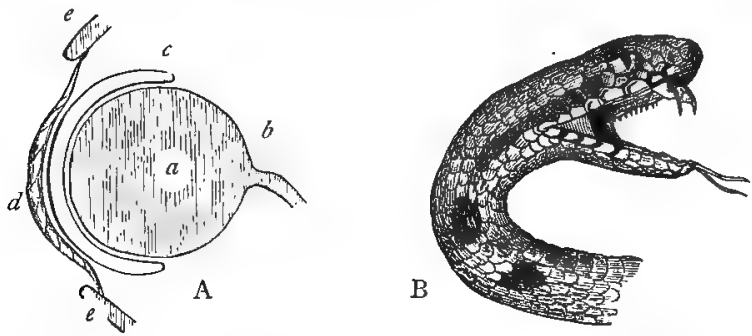

Fig. 190.-A, Diagrammatic section of the eye of a Viper (after Cloquet) : a Eycball; $b$ Optic nerve; $a$ Chamber into which the tears are poured; $d$ Epidermic layer covering the eye. B, Head of the common Viper (after Bell), showing the poisonfangs.

Their movements are also much assisted by the extreme flexibility of the whole spine, caused by the cup-and-ball articulation of the bodies of the vertebre, each of which is concave in front, and convex behind (procolous).

Of the other characters of the snakes, a few words may be said as to the tongue, the eye, and the teeth-all important structures in this order. The tongue, in serpents, is probably more an organ of touch than of taste, and consists of two muscular cylinders, which are united towards their bases. The forked organ thus formed can be protruded and retracted at will, being in constant vibration when protruded, and being in great part concealed by a sheath when retracted. The eye of serpents (fig. 190, A) is not protected by any eyelids, and hence the peculiar stony and unwinking stare for which these reptiles are celebrated. In place of eyelids, the outer layer of the skin is prolonged over the eye as a continuous and transparent film, behind which is a chamber formed by the mucous covering of the eye, into which the tears are discharged. The outer niembrane is 
periodically shed along with the rest of the external or epidermic layer of the integument, and is again renewed. The pupil is round in most serpents, but it forms a vertical slit or fissure in many venomous Snakes and in the Boas.

As regards the teeth, it is to be noticed that the snakes are not in the habit of chewing their prey, but of swallowing it whole, and the construction of their dental apparatus is in accordance with this peculiarity. The lower jaw, as before said, articulates with the skull by means of a quadrate bone (fig. 185), and this in turn is movabiy jointed to the cranium. The two halves of the lower jaw are also merely united loosely in front by ligaments and muscles. In consequence of this peculiar arrangement of parts, the serpents have the power of opening the mouth to an extraordinary width, and they can perform the most astonishing feats in the way of swallow-

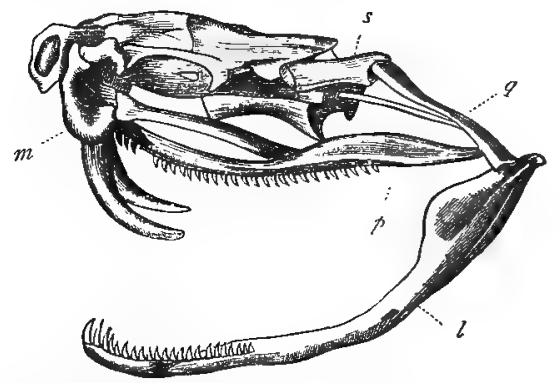

Fig. 191.-Skull of the Rattlesnake (after Dumeril and Biloron). $l$ One half of the lower jaw united to the skull by the cinarlrate bone (1); $m$ Upper jaw carrying the poisonfang : $p$ Series of teeth upon the palate.

ing. The teeth are simply fitted for seizing and holding the prey, but not in any way for chewing or dividing it. In the harmless slrakes the teeth are in the form of solid cones, which are arranged in rows round the whole of the upper and lower jaws, a double row existing on the palate as well. In the venomous rnikes, on the other hand, the ordinary teeth are usually wanting upon the upper jaws, or are few in number; and these bones are themselves much reduced in size, In place of the ortinary teeth, however, or in addition to these, the uplrer jaws carry the so-called "poison-fangs" (fig. 191). In the Viperine Snakes these are a pair of long curved fangs, one on each maxilla or upper jawbone, which, when not in use, are pointed halckwards, but can be ritised at will by special muscles, by the elevation of the movable maxilla. Each tooth is perforated by a fine canal or tube, which opens by a distinct aperture at the point 
of the fang, and is connected with the duct of the "poison-gland." This is a gland (fig. 192, a), situated under and behind the eye, secreting the poisonous fluid which renders the bites of these snakes

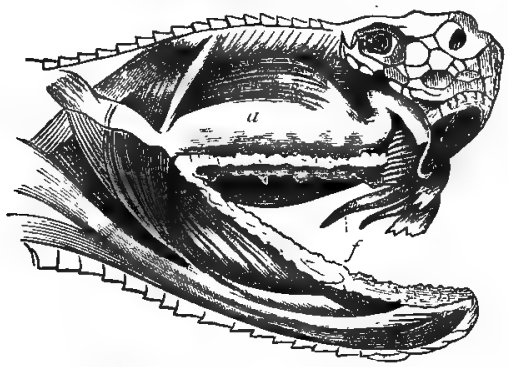

Fig. 192.-The head of the Rattlesnake, dissected to show the poison-gland (a) and poison-fangs $(f)$. (After Duvernoy.)

dangerous or fatal. When the serpent strikes at any animal, the poison is forced through the poison-fang into the wound, partly by the contractions of the muscular walls of the gland, and partly by the compressive action of the muscles of the jaws and cheeks.

The Ophidia are usually classified in accordance with the characters of their dental apparatus, and may be divicled as follows, some minor groups being omitted: (1.) The Viperina comprise the most typical of the venomous Snalses (Venenosa), and include the common Vipers (Viperida) and the Rattlesnakes (Crotalidas), the former being confined to the Old World, whilst the latter are mainly Americall. The common Viper (Pelias berus) oceurs abundantly in Europe and Northern Asia, and is capable of inflicting a severe and even dangerous bite. The rest of the true Vipers are African and Asiatic, well-known examples being the Puff-arlder of the Cape of Good Hope (Clotho), the Horned Viper (Cerastes) of North Africa, and the "Tic-polonga" (Daboia Russellii) of India.

The true Rattlesnakes (Crotalus) are exclusively natives of America, and they are highly poisonous. The extremity of the tail in the common Rattlesnake (Crotalus durissus) is furnished with a series of horny epidermic cells of an undulated pyramidal shape, articnlated one within the other, constituting an appendage which is known as the "rattle." Before striking its prey, the Rattlesuake throws itself into a coil, and shakes its rattle, as it does also when alarmed. A nearly allied form (C. horridus) is found in South America. Other American examples of the Crotalidos are the Fer-de-lance (Trigonocephalus) of the West Indies, the Copper-head (Ancistrodon contortrix), and the Watermocassin (A. piscivorus), in which there is no rattle. In India and Southern Asia there are also various Snakes belonging to the Crotalidce.

Taken as a whole, the Viperine Snakes are distinguished by having only a single poison-fang on each maxilla; while this bone is short and movable, and carries no other teeth. There are, however, one or more reserve-fangs belind 
the poison-fang. The lead is broad, somewhat triangular in shape, broadest in its middle, and showing a very distinct line of demarcation between the head and neck. The head, also, is usually covered with small scales (fig. 193, C), and rarely exhibits large plates or "scuta." The Crotalills have a deep pit between the ej'e aud the nostril, by which they are distinguished from the true Vipers, and from which they have acquired the common name of "Pit-vipers."

(2.) The Elinpina are poisonous Snakes, in which the poison-fangs are permanently fixed and erect, and have smaller solid teeth behind them. The head (fig. 193, A) is shield-shaped, and not much wider than the body, its upper surface being covered with large shields or scutil. This group comprises some of the most readly of all the Serpents, one of the best known being the Hooded Snake or Cobra di Capello (Naja tripudians), which is commonly found in

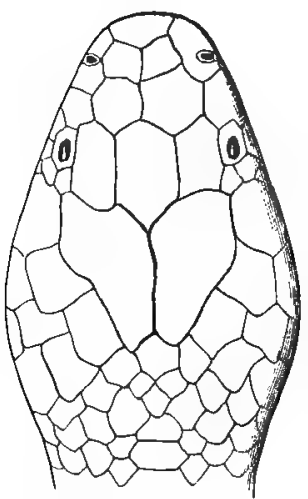

A

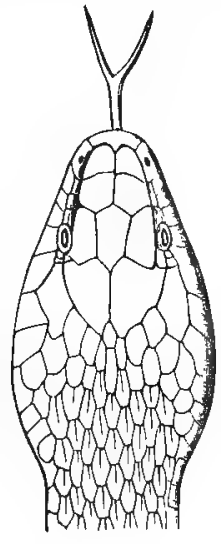

B

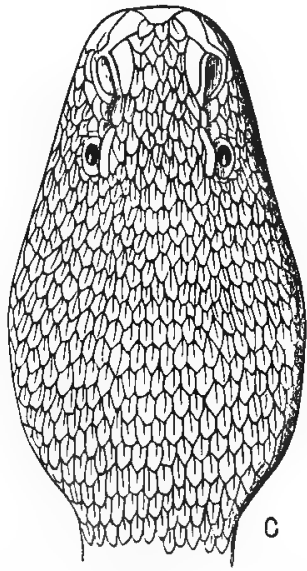

Fig. 193.-Ophidia. A, Head of an Elapine Snake (Bungamus fasciatus), viewed from above. B, I [e:tr] of a Colubrine Snake (Tropidonotus natrix). C, Head of a Viperine Snake (Daboia Russellii). (A and C are after Sir Jose 1 h Fayrer; B is after Bell.)

Hindostan, and is the snake usually carried about by the. Indian snakecharmers. It vituin' from two to six feet in length, and the neck can be extensively dilated, covering the head like a hood. A nearly allied species is the Naju haje (fig. 1S9) of Egypt. The genus Bungarus, including the deadly "Kerait" ( $B$. crileus) of India, is nearly allied to Naja, but the neck is not dilatal,le. America has representatives of this family in the beautifully marked Coral-snakes and Harleruin-snakes (Elaps); and they abound in the Australian region, a well known tylue being the Death-aclder (Acanthophis).

(3.) The Hythophithe conprise aquatic Ophiclians which have the tail ver-

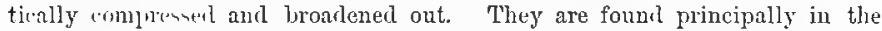
Indian and Cllinese seas, often frequenting the mouths of rivers, though sometimes ranging far from land. They are extremely poisonons, and swim with great ease and rapillity. 
(4.) The Colubrina comprise a great number of altogether innocuous Snakes, in which the superior maxillie are proviled with solid teeth only, and there are no fangs. The hend in the Colubrine Snakes is not much wider than the neck, and is covered with large shields (fig. 193, B). The Colubrine snakes are cosmopolitan in their distribution, and an excellent example is the common Ringed Snake (Coluber or Tropidonotus natrix) of Britain, a perfectly harmless animal, which is commonly found in damp situations, and which lives mainly upon frogs. Closely allied to this is the Black Snake (Bascanion constrictor) of North America, which attains a length of from three to five feet, but is perfectly harmless, so far as man is concerned.

(5.) The Pythonina comprise the well-known serpents termed the Boas, Pythons, Anacondas, and Rock-snakes. The members of this group are the largest of all living Snakes, attaining a length of certainly over twenty feet. Their bite is not venomous, but they are nevertheless highly dangerous and destructive animals, owing to their great size and enormous muscular power. They seize their prey and coil themselves round it in numerous folds, hy tightening which they gradually reduce their victim to the conclition of a shapeless bolus, fit to be swallowed. The dental apparatiss is extremely powerful giving a firm hold for the constriction of the prey. They possess rudimentary hind-limbs, terminating in horny anal spurs, which co-operate with the prehensile tail in enabling the animal to suspend itself from trees. The true Bons and Anacondas are Sonth American, but the Pythons are inhabitants of Southern Asia and Africa.

\section{Order III. Lacertilia.}

The third order of Reptiles is that of the Lacertitia, comprising all the animals which are properly known as Lizards, together with some snake-like creatures, such as the Blind-worm. They are distinguished by the following characters: Usually there are two

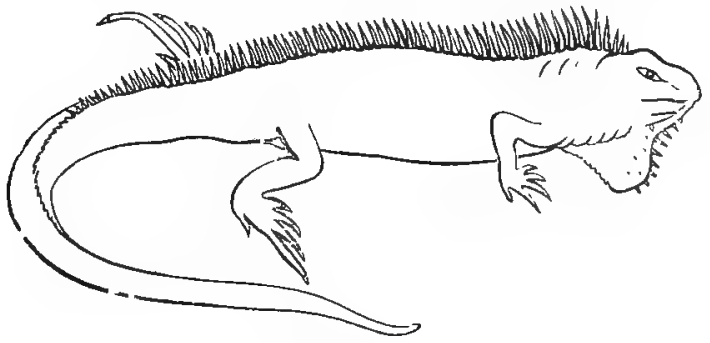

Fig. 194.-Iguana.

pairs of well-developed limbs, but there may be only one pair, or all the limbs may be rudimentary. In all cases, however, a scapular arch is present. The vertebræ are usually hollow in front (procoelous), rarely hollow at both ends (amphicelous). In no living Lacer- 
tilian are the teeth lodged in distinct sockets. The eyes are mostly furnished with movable eyelids. The integument is usually furnished with horny overlillping scales, like those of the Snakes (fig. 195).

As a general rule the animals included under this head have four well-developed legs, and would therefore be popularly called "Lizards." Some of them, however, such as the common Blindworm (1nguis fragilis) of our own country, exhibit no external indications of limbs, and would therefore be generally regarded as Snakes. These suake-like Lizards, however, can be distinguished from the true Ophidians by the consolidation of the bones of the

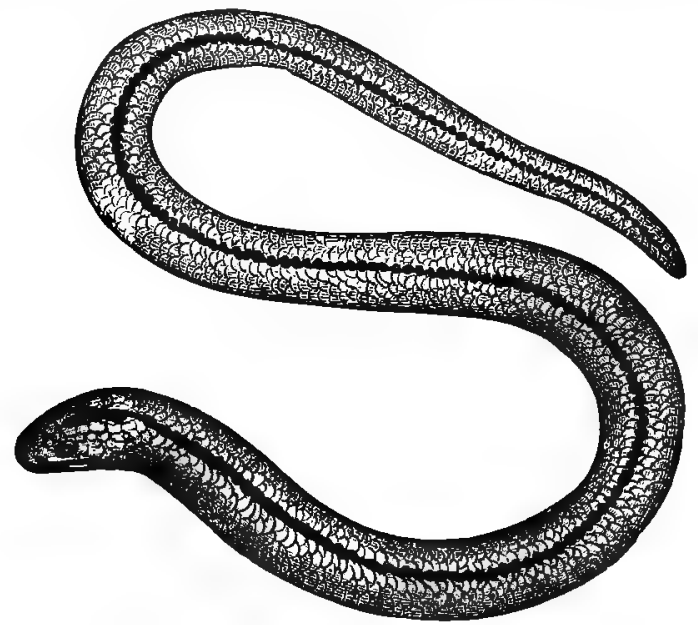

Fig. 195.-Blind-worm (.1nguis fragilis). (After Bell.)

head and jaws, and ly the fact that the eyes are generally provided with mivable eyelids. Dissection also shows that the shouldergirdle (or scapular arch) is always present in a rudimentary condition.

Few Lizards are natives of Britain ; the only forms which can be said to be at all abundant being the Blind-worm or slow-worm and the Sand-lizard (Lererte ergilis). Of the snake-like Lizards, a good example is to loe found in the common Blind-worm or Slow-worm of Europe. It is completely serpentiforn, without any external indications of limbs (fig. 19.5), and it is quite harmless. It is remarkable for the fact that, when alarmed, it stiffens its muscles to such an extent that the tail can readily be broken off, as if it were brittle. 
This same brittleness exists in the Glass-snake ( $O$ phisaurus ventralis) of the Sonthern United states, in which also there are no limbs. In other allied genera, there may be fore-feet alone, or hind-feet may be present, or all four limbs exist in a more or less rudimentary condition. In the true Lizards (Lacerta), all four limbs are present in a well-developed form; as is seen in the common Green Lizard (L. viridis) of Europe. The genus Lacerta is represented in America by the Ameiva, of which the Striped Lizard (Ameiva sex-lineata) of the Southern States may be taken as a good example. Of all living Lizards the largest are the Monitors (I'aranidac), which are exclusively confined to the Old World, and attain sometimes a length of from six to eight feet. Very large, too, are some of the Iguanas

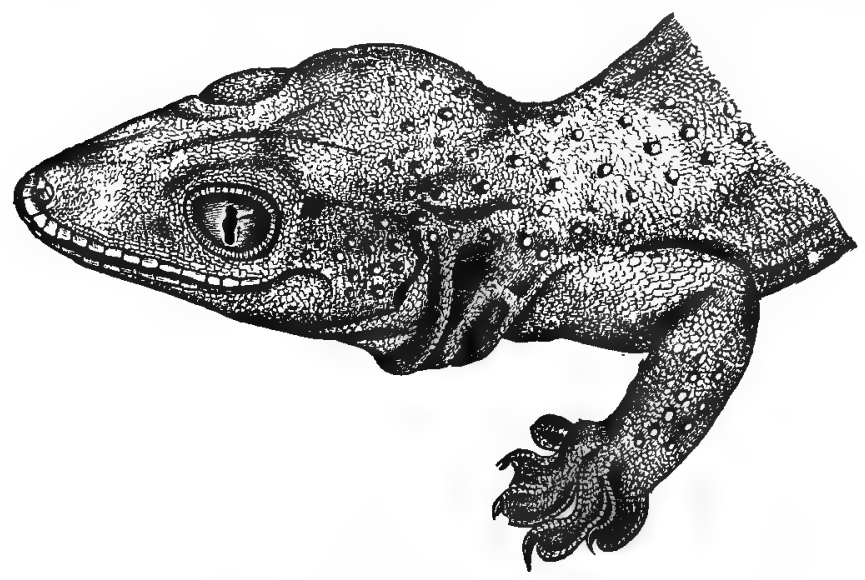

Fir. 196.-Head of Gecko stentor. (After Günther.)

(fig. 194), which occur in warm regions in various parts of the world, but especially in South America, where they are often eaten. Related to the Iguanas are the singular Lizards known as the Flying Dragons (Draco), various species of which inhabit the Indian Archipelago and the East Indies. They are all of sinall size, living in trees and feeding on insects; and their great peculiarity consists in the fact that certain of the ribs are straightened out and support a wing-like fold of the skin on each side of the boly, by means of which the animal can take very extensive leaps from tree to tree.

The Scincoid Lizards form a very large fumily, represented by numerous species in all parts of the world. One species is a common form in Egypt and Aratia, and was formerly used as a renedy in 
various discases. A nearly allied species is the bluc-tailed Lizard (Scincus furrinters) of the United States.

The Geckos ( lirikotid(e) form a litrge group of night-loving Lizards, which are found in most parts of the world, and chiefly deserve notice from the fact that their eyes are not provided with novable eyelids (fig. 1966). The Chamrelons, also, camnot be said to possess movable eyelids, for the eye is covered with a single lid, leaving only a central aperture for the pupil. The common species (Chamceleo ifricunus) occurs abundantly in the north of Africa, and has long been known for the changes of colour which it has the power of exhibiting. It is a sluggish animal, and catches insects by darting out its long and worm-like tongue with extreme rapidity.

\section{Order IV. Crocodilia.}

The last and highest order of the living Reptiles is that of the ('morudilie, comprising the Crocodiles, Alligators, and Gavials, and characterised by the following peculiarities: The outer or integu-

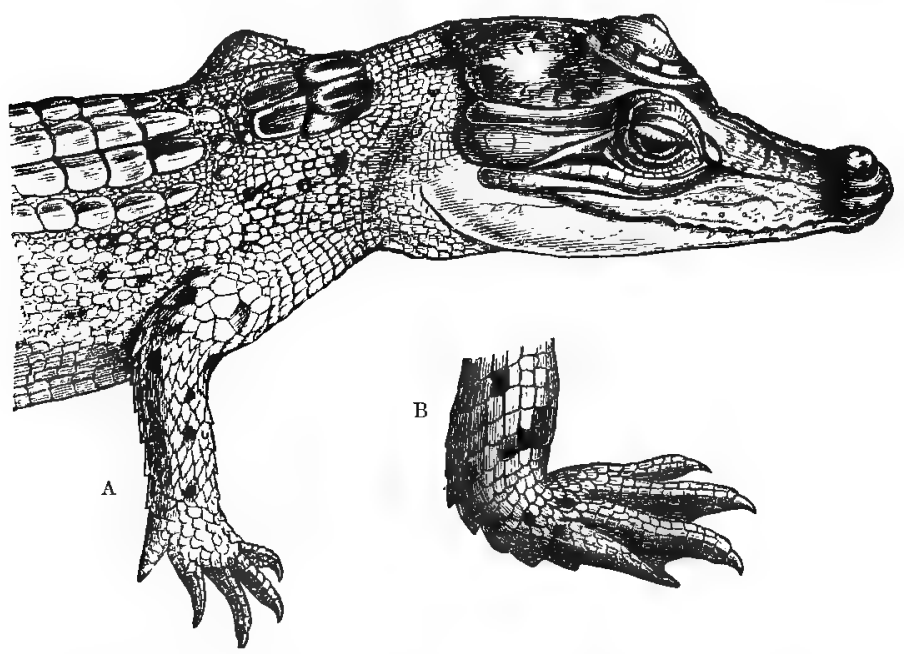

Fig. 197,-1, Hearl and anteriss portion of the brily of Crocodilus pondicerienus; B, Hind-fout of the same. (After Guather.)

mentary skeleton consists partly of horny scales developed by the outer lisyer of the skin, and pitrtly of large bony plates produced by the imer layer of the skin (fig. 197). The bones of the skull and 
face are firmly united, and the two halves of the lower jaw are joined by a distinct suture. The teeth form a single row in both jaws, and are implanted in distinct and separate sockets. The front ribs of the trunk are double-headed, and there are no collar-bones. The heart consists of four distinct chambers, two auricles and two ventricles, all completely separater from one another. The mixture of arterial and venous bloul, however, which is so characteristic of Reptiles, is provided for by a communication between the great vessels which spring from the two ventricles in the immediate neighbourhood of the heart. The eyes are protected by movable eyelids, and the ear by a movable ear-lid. The tongue is large and fleshy, and is immovably attached to the bottom of the mouth (hence the belief of the ancients that the (rocodile had no tongue). Lastly, the Crocodilia agree with the typical Lizards, and differ from the Snakes in having four well-developed limbs.

The Crocodilia abound in the fresh waters of hot climates, and are the largest of all living Reptiles, not uncommonly attaining a length of sixteen feet or upwards.

The true Crocodiles have the feet more or less webbed, the hindlegs bordered by a fringe, and the fourth tooth in the lower jaw received in a notch on the side of the upper jaw. They belong mainly to Africa and Asia, but they are also represented in Australia, in the West Indies, and in South America.

The Alligators have the hind-legs simply rounded, and the toes not completely webbed; while the fourth tooth in the lower jaw fits into a cavity in the palate, and is concealed from view when the mouth is shut. Like the Crocodiles, they are essentially aquatic in their habits, and lie dormant during the winter in cold climates, and the hot season in warm countries. They are extrenely voracious, and live upon fish and small Mammals. The best-known species are the common Alligator (A. Mississippiensis) of the Southern States, the Caiman (A. palpebrosus) of Surinam and Guiana, and the "Jacare" (A. sclerops) of South America.

The Gavial or Gangetic Crocodile occurs in India, and is distinguished by its narrow, elongated jaws, forming a kind of beak. It attains a length of more than twenty feet. Closely allied types occur in the rivers of North Australia and in Borneo. 


\section{EXTINCT ORDERS OF REPTILES.}

\section{OR.Der $V$. ICHTHYOPTERYGIA.}

In this order are includerl a number of gigantic fish-like Reptiles, which are all extinct, and are characteristic of the Secondary period of geology, and especially of the formation known as the Lias. The chief characters by which they are distinguished have reference to their purely aquatic life, for there can be no doubt that they were inhabitants of the sea. Thus the body was fishlike, without any distinct neck. The vertebre were hollow at both ends (amphicolous), and the spine thus possesser the flexibility and power of motion so characteristic of the true Fishes. The limbs also constituted powerful swimming-paddles, and it is probable that there was a vertical tail-fin.

Much has been gathered from various sources as to the habits of the Ichthyosauri, and their history is one of the most interesting chapters in the geological record. That they chiefly kept to open seas may be inferred from their

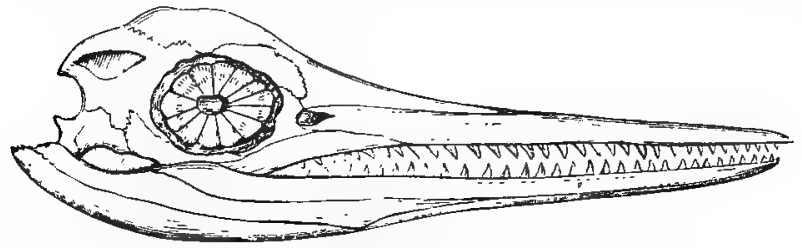

Fig. 198. -Skull of Ichthyosaurus, showing the sclerotic plates.

strong and well-developed swimming apparatus; but the presence of a powerful bony arch supporting the fore-limbs proves that they must occasionally have betaken themselves to the land. That they were tenants of stormy waters, or were in the haisit of diving in search of prey, has leeen inferred from the fact that the eyehall is protected from pressure by a ring of bony plates. That they possesser great powers of vision, especially in the dusk, seems to be rendered certain from the size of the pupil and the enormous wirth of the bony cavities (orbits) which rontained the eyes. Lastly, that they were carnivorous and predaceous in the highest degree is shown ly their wide moutlis, long jaws, and numerous powerful and pointed teeth. This is also proved by an examination of their petrified droppings, wlich are known as "coprolites," and which contain in abundance undigested fragments of fishes and other uariue animals.

\section{Order VI. Sauropterygia.}

The Reptiles helonging to this order agree with the last in heing all extinct, and in being contined to the Secondary period of geology. 'The hest known are the Plesiosauri, which resembled the Ichthyosauri in having all the linibs converted into swimming pardles, but differed in several respects, of which the most obvious is the great elongation of the neck (fig. 199). The Plesiosaur 
were gigantic marine Reptiles, chiefly characteristic of the formations known as the Lias and Oolites. As regards the habits of the Plesiosanurus, Dr Conybeare concludes: "That it was aquatic is evident from the form of its paddles; that it was marine is almost equally so from the remains with which it is universally associated ; that it may have occasionally visited the shore, the resemblance of its extrenities to those of the Turtle may lead us to conjecture; its movements, however, must have been very awkward on land; and its long neck must have impeded its progress through the water, presenting a striking contrast to the organisation which so admirably fits the Ichthyosaurus to cut

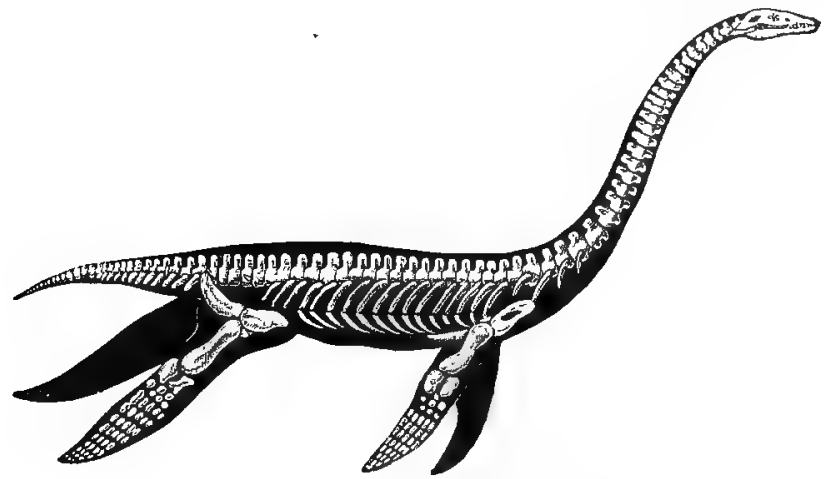

Fig. 199.-Plesiosaurus dolichodeirus. Iias.

through the waves." As its breathing-organs are such that it must of necessity have required to obtain air frequently, it may be inferred "that it swam npon or near the surface, arching back its long neck like a swan, and occasionally darting it down at the fish which happened to float within its reach. It may perhaps have lurked in shoal-water along the coast, concealed amongst the sea-weed, and, raising its nostrils to a level with the surface from a considerable depth, may have found a secure retreat from the assaults of powerful enemies; whilst thie length and flexibility of its neck may have compensated for the want of strength in its jaws and its incapncity for swift motion through the water."

\section{Order VIt. Pterosauria.}

The Reptiles of this order are all extinct, and, like those of the preceding orders, are exclusively confined to the Secondary period of geology. The most familiar examples are the so-called Pterodactyles, and the distinguishing characters of the order have reference to the fact that they were all adapted for an aerial life. They present, in fact, an extraordinary combination of the characters of Birds and Reptiles, and they make also some approach to the Marmalian order of the Bats. In the presence of teeth in distinct sockets, and, as we shall see hereafter, in the structure of the fore-limbs, the Pterodactyles differ altogether from all living birds; and there can be little doubt as to their being 
genuine reptiles. The only living Reptile which has any power of sustaining itselt in the air is the Flying Dragon (Iraco), which has been previously mentioned. In this case, however, the animal has no power of true flight, but is simply enabler to take extensive leaps ly means of a membranous expansion on each sille of the boily. In the Bats, again, the lnwer of genuine flight is present; and this given by means of a leathery membrane which is supporterl chiefly by certain of the fingers-which are greatly lengthened-and is attached to the sides of the borly and hini-limbs.

In the Pterolactyles the power of true flight was present; and this was also conditioned lyy means of a leathery expaniled membrane, attached to the hindlimbs, the sides of the body, and the fore-limbs. In this case, however, the chief support of the flying menbrane was deriver from the outermost finger of the fore-limb, which was enormously elongated (fig. 200). That the Ptero-

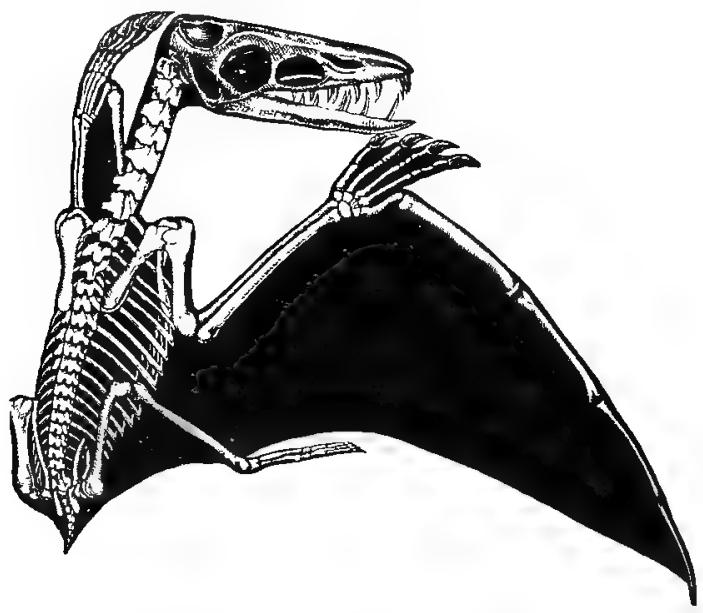

Fig. 200.-Pterodirtyluscrassirostris. From the Lithographic Slates of Solenhofen(Upper Oolite). In ancordance with the view uriginally entertained, the digits of the hand are here erroneously rinesented as fire insteal of four in number.

dactyles passerl their existence chiefly in the air, and did not simply leap from tree to tree, is shown by two characters in which they agree with the flying birds. Many of the bones, nanely, were "pneumatic"-that is to say, were hollow, and were fillecl with air. Secondly, whilst the shoulter-girdle has many of the cluaracters of that of birds, the breast-bone (sternum) is furnished with a prominent ridge or keel, serving for the attachment of the great muscles which work the wings. There can be no doubt, therefore, as to the Pterodactyles having enjoyed the power of gennine flight. Many of them attained no great size, but some of thern must have been gigantic, the expanse of wing in one species having been calculated at probably about twenty-seven feet from tip to tip. 


\section{Order VIII. ANomodontia.}

This order has been founded for the reception of a number of fossil Reptiles belonging to the period of the New Red Sandstone, all of which seem to have been adapted for walking upon the dry land. They were either destitute of teeth-in which case the jaws seem to have constituted a beak, like that of a Turtle-or they possessed two great tusk-like teeth in the upper jaw (as is the case in Vicynodon).

\section{Order IX. Deinosauria.}

The Reptiles of this order resemble the preceding in being adapted for walking upon the dry land; and they are confined to the Secondary peliod of geologists. They were mostly of large size, and the structure of the hind-limb is in some respects singularly similar to the conformation of the same part in the great wingless birds, such as the Ostrich (Cursores). The fore-limbs are in many instances so small, that these extinct Reptiles must have walked upon their hind-legs alone. The teeth are mostly adapted for an animal diet; but in some cases the animal must have lived upon vegetable food. The most important groups comprised in this order are Iguanodon, Megalosaurus, and Hadrosaurus.

\section{Order X. Theriodontia.}

This order has been recently established by Professor Owen for the reception of a number of extiact Reptiles from the New Red Sandstone. They present some singular resemblances to the ordinary Beasts of Prey (Carnivora), this resemblance being especially seen in the fact that their teeth were arranged in three distinct sets-incisors, canines, and molars; and the canine teeth were of large size and pointed, adapting their possessors for a predaceous and carnivorous mode of life. 


\section{CHAPTER XXVIII.}

\section{CIAASS IV. AVES.}

THE fourth class of the Vertebrates is that of the Birds or Aves, which may be shortly defined as being "oviparous Vertebrates, with warm blood, a double circulation, and a covering of feathers" (Owen). The other leading characters which separate the Birds from the other Vertebrata are, that the red blood-corpuscles are nucleated; the skull articulates with the spine by a single articulating surface (or condyle); the breathing-organs are in the form of lungs, which communicate with a variable number of air-sacs scattered through the body; and the fore-limbs are never terminated (in existing birds) by more than two fingers, ending in claws, and are generally modified so as to form "wings" or organs of flight.

The feathers, which form such a distinctive, character of birds, are formed by a modification of the outer layer of the skin (epidermis), and from their non-conducting nature they serve to maintain the high temperature of the body which is so characteristic of the class. A typical feather (fig. 201), such as one of the long feathers of the tail or wing, consists of the following parts: 1. A horny cylindrical tube, which forms the lowest portion of the feather, and is termed the "quill." 2. The "shaft," which forms the central axis of the feather, and which is simply the continuation of the "quill." The under surface of the shaft is always marked by a strong longitudinal groove, and it consists of a horny sheath, filled with a white spongy material, not unlike the pith of a plant. 3 . The "welos," which form the lateral expansions of the feather, and are attriched to the sides of the shaft. Each web is composed of a number of small branches, called the "barlss"; and each barb, in turn, is furnished with a series of smaller filres called the "barbules." As a rule, the barlos are all kept in comnection with one another by means of the birbules, the ends of which are hooked. Towarls the base of the shaft, however, the barls are usually more or less separate and placed at a distance from one another, con- 
stituting what is known as the "down." In the Ostriches and the birds allied to them, all the barbs are disunited and placed at a distance, and they are often not at all unlike hairs in nplearance. The feathers of Birds not only greatly conduce to the high temperature of the body, but also serve to keep out moisture, to which end there is a peculiar oil-glind at the base of the tail, with the secretion of which the bird anoints its plumage.

The skeleton of Birds exhibits many points of peculiar interest, mostly in adaptation to an aerial mode of life ; but only some of the more important of these can be noticed here. The entire skeleton is at the same time peculiarly compact and singularly light, the compacturess being due to the presence of an unusual quantity of phosphate of lime, and the lightness to the fact that many of the bones are filled with air in place of marrow. The cervical region (neck) of the vertebral column is unusually long and flexible, since the fore-limbs are useless as organs of prehension, and all these functions have to be performed by the beak. In all Birds the neck is, at any rate, sufficiently long to allow of the application of the beak to the tail, so as to permit of the cleaning and oiling of the whole plumage. The vertebræ which form the back or dorsal region of the spine are generally more or less immovably connected together, so as to give a base of resistance to the wings. In the Ostrich, however, and in other birds, in which the power of flight is either very limited or is alsent, the

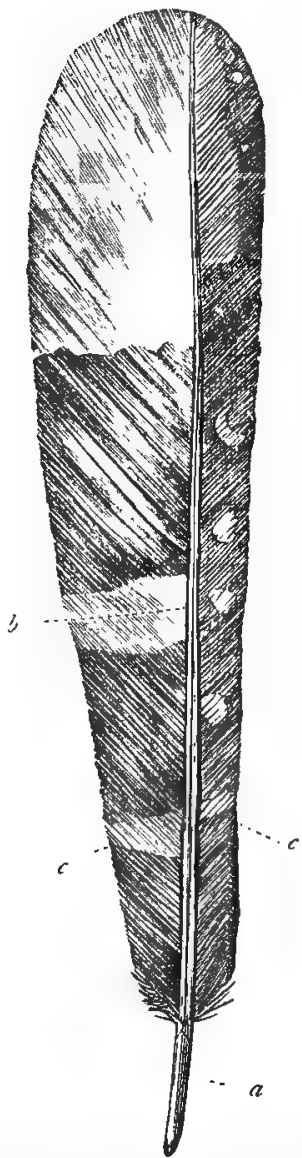

Fig. 201.-Quill-feather (Stenopsis): $a$ Quill or barrel; $b$ Shaft ; $c c$ Webs, composed of the barbs, and together forming the "vane."

dorsal vertebræ are more or less movable one upon the other. The vertebræ which follow the dorsal region of the spine are all amalgamated together to form a single bony mass, which is termed the 
"sacrum"; and this, in turn, is united on both sides with the bones which form the pelvic arch, which carries the hind-limbs. The vertebre of the tail are more or less movable upon one another; and in almost all living birds, when fully grown, the last joint of the tail (fig. $204, \mathrm{~B}, \mathrm{~s}$ ) is a long, slender, ploughshare-shaped bone, which is really commed of several vertebre united together. It is usually set on at an angle nearly perpendicular to the axis of the body, and it serves to support the great tail-feathers, which act as a rudder during flight. It also serves to support the oil-gland, which supplies the secretion with which the feathers are lubricated. The skull in Birts has its several bones generally so amalgamated in the arlult, that it forms a bony case in which the sutures can no longer be recognised. The head is jointed to the spine by no more than a single articulating surface or condyle. The beak, which forms such a conspicuous feature in Birds, is composed of two halves, an upper half or "upper mandible," and a "lower mandible." The lower mandible, like the lower jaw of all the Sunropsida, is at first composed of several pieces, but these are all undistinguishably united in the adult, and the two halves of the jaw are also analgamated together. In no living Bird are teth ever developed in either mandible; but both mandibles are sheathed in horn, constituting the "beak," and the margins of this sheath are sometimes serrated. In some curious fossil Birds, however, there are teeth in the jaws. The lower jaw is articulated to the skull by the intervention of a movable "quadrate bone." In many Birck, also, the upper mandible of the beak is so joined to the skull as to be capalle of movenent.

The most chararteristic points, however, in the skeleton of the Birds, are to be found in the structure of the limbs. The cavity of the chest or thorax is bounded behind by the dorsal vertebræ, on the sides by the ribs, and in front by the breast-bone or sternum. The ribs vary in number from seven to eleven pairs, and in must Birds most of the ribs give off a peculiar process (" uncinate process," fig. 202, B) which passes over the rib next in succession behind. In front the rils are jointed to a series of straight bones, which are called the "sternal ribs," and these, in turn, are movably articulated to the breast-bone in front. According to Owen, these sternal ribs are "the ceutres upon which the respiratory movements hinge." In front the cavity of the chest is completed by an enormously expanded breast-lone or strmum (fig. 20.2, A), which, in most birds of any powers of flight, extends more or less over the abdominal cavity as well. The sternum of all Birds which possess the power of flight is characterised by the presence of a prominent ridge ur "keel" (fig. 202, A, b), to which are attached the great 
muscles (pectoral muscles) which moze the wings. As a general rule, the size of this crest or keel gives a tolerably just estimate of the flying powers of the bird to which it belonged. The keel is, of course, most largely developed in those birds which possess the power of flight in its greatest perfection; and in certain birds which do not fly, such as the Ostrich, there is no sternal keel at all. The pectoral arch or shoulder-girdle of birds, consists of the shoulderblades (scapulce), the clavicles or collar-bones, and of two bones,

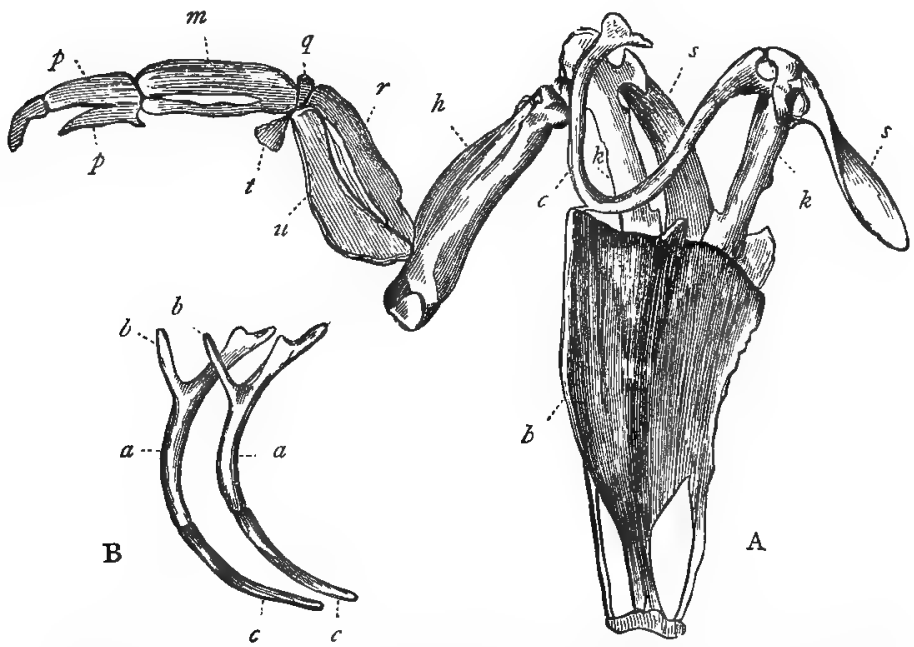

Fig. 202.-A, Breast-bone, shoulder-girdle, and fore-linb of Penguin (after Owen): $b$ Breast-bone (sternum), with its prominent ridge or keel; s s Shoulder-blades (scapules), $k k$ Coracoid bones; c Furculum or merry-thought, composed of the united collar - bones (clavicles); $h$ Bone of the upper arm or humerus, $r$ Radius, and $u$ Ulna, forming together the fore-arm; $q$ Bones of the wrist or carpus; $t$ Thumb; $m$ Metacarpus ; $p$ Phalanges of the fingers. B, Ribs of the Golden Eagle: $a$ a Ribs giving off processes $(b \quad b) ; c c$ Sternal Ribs.

which are distinct in Birds, and are called the "coracoid bones." The shoulder-blades $(s s)$ are usually long and narrow bones. The coracoid bones $(k k)$ correspond with the part of the shoulder-blade which is known in most of the Mammals as the "coracoid process"; and in Birds they are not only separate bones, but they are the strongest bones of the pectoral arch. They are more or less nearly vertical, and they form fixed points for the downward stroke of the wing. The collar-bones or clavicles $(c)$ in the great majority of Birds are united together in front, so as to form a somewhat $V$. 
shaped bone, which is technically called the "furculum," but is familiarly called the "merry thought." The function of this clavicular arch is to keep the wings asunder during their downward stroke, and the strength of the furculum varies, therefore, with the powers of flight enjoyerl by each bird. The bones which form the limb proper, or "wing," are considerably modified to suit the special function of flight, but essentially the same parts are present as in the fore-limb of the Mammals. The upper arm (fig. 203) is constituted by a single bone, the humerus $(h)$, which is generally

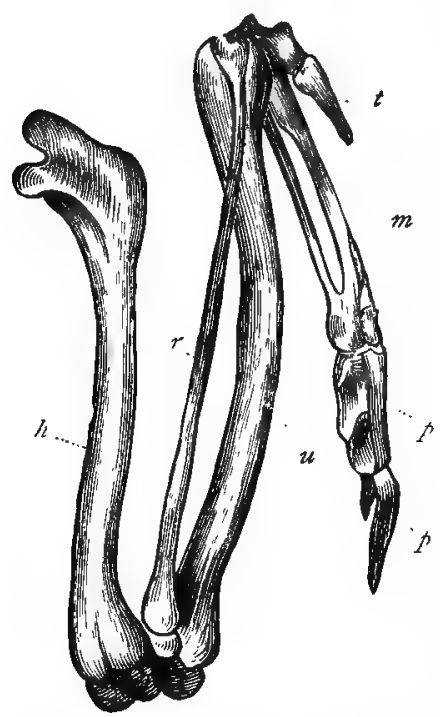

Fig. 203.-Fore-limb of the Jer-falcon. $h$ Hunerus; $r$ Radius ; $u$ Ulna ; $t$ "Thumb;" $m$ Mriarpals, anchydoed at their extremities ; $p p$ Phalanges of fingers. short and stout. The fore-arm is composed of two bones, the radius (r) and the ulna $(u)$, of which the ulna is the bigger. These are followed by the small bones, which form the wrist or carpus (q), but these are reduced to two in number. The carpus is followed by the bones which constitute the root of the hand or metacarpus ( $m$ ), but these are also reduced to two, instead of being five in number, as they are in most Mammals. The two metacarpal bones are also amalgamated together at both ends, so as to form a single piece, at the base of which, on its outer side, is a rudimentary digit, the "thumb" $(t)$, which carries a tuft of feathers, known as the "bastard wing." The nietacarpal bones, finally, support ench a single finger $(p)$, of which one is never composed of more than one bone or phalanx, whilst the other is composed of two or three phalanges. (To understand thoroughly the leading modifications of the limbs of Birds, the student will do well to refer to the general description of the limbs of Vertebrates, pp. 2222,223 , figs. 160,161 .)

As regarls the composition of the hind-limb in Birds, the two halves of the pelvic arch (i.e., the innominate bones) always form a single piece each, and they are always firmly united with the sacral region of the spine. With the single exception, however, of the 
Ostrich, they do not unite below, but remain separate. As in the higher Vertebrates, the lower limb consists of a thigh-bone (femur), a shank, composed of two bones (tibia and fibula), a tarsus, a metatarsus, and phalanges, but some of these parts are obscured by coalescence. 'The thigh-bone or femur (fig, 204, $f$ ), is generally very short, comparatively speaking; and the chief bone of the leg is the tibia $(t)$, to which a thin and tapering fibula $(r)$ is attached.

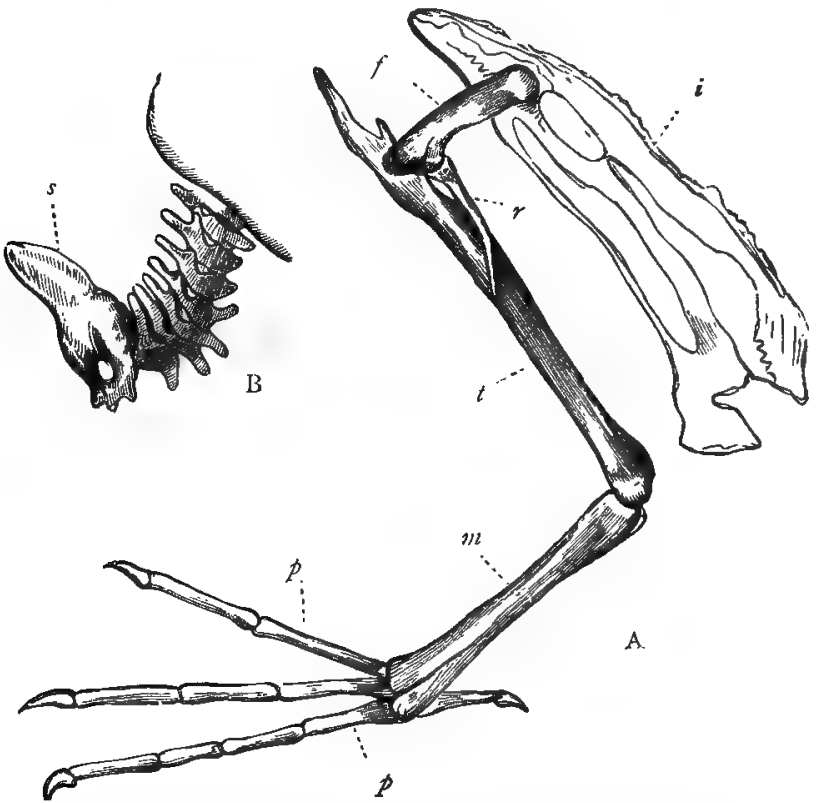

Fig. 204.-A, Pelvis and bones of the leg of the Loon or Diver (after Oweu): $i$ Innominate bone; $f$ Thigl-bone (femur); $t$ Tibia; $r$ Fibula, together forming the shank; $m$ Tarso-metatarsus; $p$ Phalanges of the toes. B, Tail of the Golden Eagle: $s$ Ploughshare-shaped bone, carrying the great tail-feathers.

In the regular typical limb of a Vertebrate animal the tibia and fibula would be followed by a series of small bones, called the tarsus, constituting the ankle-joint (fig. 161); and the tarsus would in turn be followed by a series of bones constituting the root of the foot, or metatarsus. In Birds, however, the tibia and fibula are followed by a single cylindrical bone, which is called the "tarsometatarsus" $(m)$, and which is formed by the amalgamation of the three principal metatarsal bones with the lower row of tarsal bones, 
the metatar'sal bone of the great toe being, when present, distinct and rudimentary. The upper portion of the tarsus is amalgamated with the lower end of the tibia, to which, therefore, the name of "tibio-tarsus" is often applied. The ankle-joint is thus placed in the middle of the tarsus. In most of the long-legged birds it is by the great elongation of the tarso-metatarsus that the enormous length of the legs is produced. 'The tarso-metatarsus is followed below by the foot, which consists in most birds of four toes, of which three are directed forwards and one backwards. In no wild Birds are there more than four toes; but some domesticated varieties possess a fifth. In all birds with four toes, the toe which is directed backwards (the great toe or "hallux") consists of two phalanges; the innernost of the three forward toes has usually three phalanges, the next lias four, and the outermost toe is composed of five. In many Birds, such as the Parrots, the outer toe is turned backwards, so that there are two toes in front and two behind. In the Swifts, again, all the four toes are turned forwards. In many of the siwimming Birds (Nrtatores) the hinder toe is wanting or rudimentary; and in the Ostrich both this and the next toe are absent, so that the foot consists of no more than two toes.

The digestive system in Birds consists of the beak, tongue, gullet, stomach, intestine, and cloaca, with certain accessory glands. There are no teeth, and the beak is employed, in different birds, for holding and tearing the prey, for prehension, for climbing, and in some cases as an organ of touch, being in these last instances more or less soft, and supplied with nervous filaments. In many Birds, too, the base of the bill is surroumled by a circle of naked skin, constituting what is called the "cere," and this too serves as an organ of touch. The tongue of birds can rarely lie looked upon as an organ of taste, since it is generally cased in horn, like the mandibles. It is principally (mpleyed as an organ of prelension, but it is soft and fleshy in the Parrots, and in them, doubtless, acts as an organ of taste. Salivary glands are always present, but they are rarely of large size, and are often of extremely simple structure. In accorlance with the length of the neck, the gullet is usually very long in lirds, and is generally very dilatable. In the flesh-eating and grain-eating Birds the gullet is dilated (fig. 205, c) into a ponch which is called the "crop," and is situated in the lower part of the neck, just in front of the merrythought. This may be simply a dilatation of the tube of the gullet, or it may be a single or double ponch. The function of the crop is to detain the food, for a longer or shorter leriod according to its nature, before it is submitted to the action of the proper digestive organs. In the Pigeons, the food which his been previously softened in the crop is returned to the mouth, and supplied to the young in 
a state suitable for digestion. The gullet, after leaving the crop, shortly opens into a second cavity, called the "proventriculus," which is the true digesting stomach, and is richly supplied with glands which secrete the digestive fluid or gastric juice $(p)$. This, in turn, opens into a muscular cavity which is called the "gizzard" $(g)$, and which leads into the commencement of the small intestine. The characters of the gizzard vary with the nature of the food. In the Birds of Prey, which live on an easily digested animal diet, the walls of the gizzard are thin and membranous. In the grain-eating

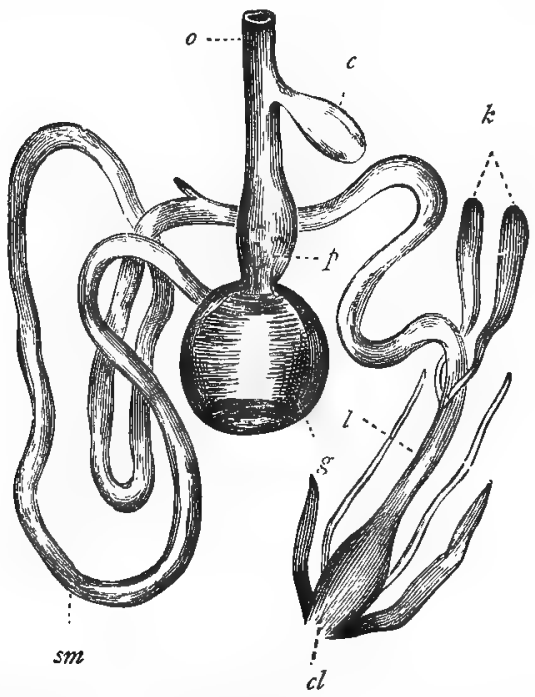

Fig. 205.-Digestive system of the common Fowl (after Owen). o Gullet; $e$ Crop; $p$ Proventriculus; $g$ Gizzard; $s m$ Small intestine; $k$ Intestinal cæca $l$ Large intestine; $\mathrm{cl}$ Closea.

Birds, such as the Fowls, whose hard food requires to be crushed before it can be properly digested, the walls of the gizzard are extremely thick and muscular, and the inner lining is hard and horny. In these Birds the gizzard constitutes a kind of grinding apparatus, like the stones of a mill; whilst the "crop" may be compared to the "hopper" of the mill, since it supplies to the gizzard "small successive quantities of food as it is wanted" (Owen). The grinding action of the gizzard is furtber assisted by the small pebbles and gravel which, as is well known, so many birds are in the habit of swallowing. These pebbles take the place of teeth, 
and there can be no doubt that they are in many cases essential to health, the bird being otherwise unable to triturate its food properly. The intestinal canal extends from the gizzard to the cloaca $(c l)$, and is compraratively short. The secretions of the liver and pancreas are poured into the commencement of the small intestine. The comnencement of the large intestine is furnished in most Birds with two blind tubes or "creca" $(k)$. These vary considerably in length in different Birds, and are sometimes wanting; whilst their exact function is still questionable. The large intestine is seldom more than a tenth part of the length of the body, and is generally conducted straight from the creca to the cloaca. The rlsece is a common cavity which in Birds, as in Reptiles, receives the termination of the intestine and the ducts of the generative and urinary organs $(\cdot l)$.

Rispiration is effected in Birds more completely, extensively, and actively than in any other class of the Vertebrata, and, as the result of this, their average temperature is higher than in any other Vertebrates. This extensive development of the respiratory process is due to the fact that air is admitted in Birds not only to the lungs, but also to a series of air-receptacles which are scattered through various jarts of the body, and to the interior of a greater or less number of the bones. The lings are two in number, of a bright-red colour, inl spoury texture, and they are confines to the back part of the chest. They differ from the lungs of Mammals in not being freely susjenderl in a membranous bag ( $\left({ }^{\prime}(n, ")\right.$ ), but in being fixed to the bick wall of the chest. The thoracic and abdominal cavities are not separated from one another by a conplete partition (midriff or diaphringm) as in the Mammals, but the common thoracicoabdominal cavity is suldivided by means of membranous partitions into a series of civities or sacs, which are termed the "air-receptacles." These air-sacs are filled with air from the lungs, and vary considerably in size in different Bircls. They not only serve greatly to reduce the s] neific gravity of the ludy, but also assist largely in the aerition of the blood. Connected with the air-receptacles, and supplementing their action in both of these respects, is a series of cavities cculying the interior of a greater or less number of the bones, and also containing air. In young birds these air-cavities in the bones do rwt exist, and the bones are simply filled with marrow, as in the Mammals. In the Penguins, which do not fly, none of the bones contain air-cavities or are "pneumatic"; and in the Wotrich mly a few of the bones contain air. In the Pelican and Gimnet all the hones of the skeleton, except the phalanges of the turn, are permeated by air; and in the Hormbill even these are pneumatic. 
The heart in all Birds consists of four chambers, and the two sides of the heart are completely separated from one another. In all essential details, as regards the structure of the heart and great vessels, and the course of the circulating fluid, Birds agree with Mammals. The impure venous blood which has traversed the body, is returned by the great veins to the right auricle. From the right auricle it passes into the right ventricle, from which it is driven by the pulmonary artery to the Iungs. Having been submitted to the action of the air contained in the lungs, and having been thereby changed into arterial blood, the blood is sent back to the left auricle by means of the pulmonary veins. Thence it passes into the left ventricle, by which it is again propelled throughout the whole body, to return again as venous blood to the right side of the heart. The heart, therefore, of Birds, differs from that of Reptiles in consisting of two sides, each composed of an auricle and ventricle, the right side being wholly concerned with sending the venous blood to the lungs, and the left side being entirely occupied with sending the arterial blood to the body. The right side of the heart is therefore venous, the left side arterial. In all Reptiles, on the other hand, the two circulations-namely, that through the lungs, and that through the body-communicate with one another, either in the heart itself or in its immediate neighbourlıood; so that both the lungs and the body are supplied with a mixture of venous with arterial blood. Though the heart of Birds resembles that of Mammals in general structure, its cavities are "relatively stronger, their valvular mechanism is more perfect, and the contractions of this organ are more forcible and frequent in Birds, in accordance with their more extended respiration and their more energetic muscular actions " (Owen). The urinary organs of Birds consist of two elongated kidneys, which open by means of their ducts (the ureters) into the cloaca, along with the termination of the intestine and the ducts of the reproductive organs. As a general rule, the female bird is provided with only a single ovary - that of the left sideand all Birds, without exception, are oviparous. The egg is always enclosed in a calcareous shell, and is mostly developed after expulsion from the body, by the process of "incubation " or "brooding"-a process for which birds are especially adapted, in consequence of their very high average temperature. The young bird, when ready for an independent existence, perforates the shell by means of a temporary calcareous excrescence developed upon the point of the upper mandible of the bill. In some Birds, mostly in the case of those which live upon the ground, the young are able to run alout and look for food directly after they come out of the egg (Aves prococes), as is seen in the common Fowl. In most Birls, however, the young 
are liberated from the egg in a perfectly helpless and naked condition, and require to be fed by their parents for a longer or shorter time, befure they are atble to take care of themselves. Most of these Birds ( 1 ves altrires), such as our common Song-birds, reside in trees, and build more or less elaborate nests.

As regards their nerous system, the brain of Birds is relatively larger than the brain of Reptiles, but it is destitute of those folds or convolutions which form so marked a feature in the brain of most Manmmals. The organs of sense, with the exception of touch and taste, are well developed in Birds, vision especially being generally extremely acute. The eyes are always well devèloped, and in no Bird are they ever wanting or rudimentary. The chief peculiarity of the eye of Birds is, that its anterior luntion (cornea) forms the segment of a nuch smaller circle than does the eyeball proper; so that the whole eye assumes a conical shilre. Another peculiarity is, that the form of the eye is maintained by means of a circle of from thirteen to twenty bony plates, which are placed in the front portion of the fibrous coat of the eye (sclerotic). Eyelashes are almost universally absent; but in addition to the ordinary upper and lower eyelids, Birds pussers a third membranous eyelid -the membrana nictitan-which is placed on the inner side of the eye. This nictitating nembrane is sometimes transparent, sometimes pearly white, and it can be drawn over the front of the eye like a curtain, moderating the too great intensity of the light. As regards the organ of hearing, the chief point to remark is, that Birds possess no external ear, by means of which the undulations of sound can be collected and transmitted to the internal ear. In some Birds, however, as the Ustrich, the external opening of the organ of hearing is provided with a circle of feithers, which can be raised and depressed at will. In the nocturnal Birds, also (such as Owli), the external opening of the ear is protected by a musculo-menbranous valve, foreshadowing the gristly external eill of Mammals. The sense of smell is apparently seldom very acute in Birds; and even the Birds of Prey appear to seek their frod mainly by the sight. The external nostrils are usually placed on the silles of the upper mandible, near its base, and form simple perforations which sometimes communicate from side to side. In the curious Aptery $x$ of New Zealand, the nostrils are placerl at the extreme end of the elongated beak. Sometimes the nostrils are defended by bristles, and sometimes by a cartilaginous scale.

Before passing on to a cmsideration of the divisions of Birds, a few worls may be said on the migrations of Birds. In temperate and cold climates, only certitin birds remain constantly in the same region in which they were originally hatehed. Those which do so are called 
"Permanent Birds" (aves manentes). Other Birds, such as the Woodpeckers, migrate from place to place without following any very definite course. These are called "Wandering Birds" (aves erraticae), and their movements are chiefly conditioned by the scarcity or abundance of food in any particular locality. Other Birds, however, at certain seasons of the year, undertake long journeys, usually uniting for this purpose into larger or smaller flocks. Such birdsof which the Swallows are a familiar instance-are properly called "Migratory Birds" (aves migratorice); and their movements are conditioned by the necessity of having a certain average temperature, without which they cannot live, and also by the necessity of finding a climate suitable for the bringing up of the young. Thus the Migratory Birds of cold regions, when the cold season comes on, travel to warmer countries ; but when the hot season of these regions approaches, they migrate back again to temperate zones. 


\section{CHAPTER XXIX.}

\section{DIVISIONS OF BIRDS.}

Birds may be variously divided, but for our present purpose it is most convenient to regard them as divided into the following three great primary divisions or sub-classes :-

1. Ratite.-This division comprises the Running Birds, which cannot fly, such as the Ostriches, Emeus, and Cassowaries. It is characterised by the fact that the sternum has no median ridge or keel for the attachment of the great pectoral muscles. The sternum. is therefore raft-like (Lat. rates, a raft), hence the name given to this section. The barbs of the feathers are separate.

2. Carinate- - This comprises all living Birds except the preceding, and is characterised by the fact that the sternum is furnished with a prominent median ridge or keel (rurina); hence the name applied to the division. Under this head are included six smaller divisions or orders.

3. Odontornithes.-This sub-class comprises three orders of fossil Birds, the essential characteristic of which is that they possessed true teeth, sunk in distinct sockets or grooves in the jaws.

\section{SUB-CLASS I. RATITÆ.}

\section{Order Cursores.}

The Running or Cursorial Birds, comprising the Ostrich, Cassowary, Emeu, Rhea, and Apteryx, are characterised by the rudimentary condition of the wings, which are useless as organs of flight, and by the compensating length and strength of the legs. In accordince with this condition of the limbs, the bones have few aircells, and the breast-bone is destitute of the prominent ridge or keel to which the great muscles of the wings are attached (fig. 206, A). The two sides of the pelvis are united together below in the Ostrich, and in al! the pelvic arch has great strength and stability. The legs 
are extremely powerful, and the hinder toe is wanting in all except the Aptery $x$, in which it is present in a rudimentary condition. The front toes (fig. 206, C and E) are either two or tlıree in number, and are furnished with strong blunt claws or nails. The feathers present the remarkable peculiarity that the barbs, instead of being connected by means of the barbules, are disconnected and separate from one another, thus coming to resemble hairs in appearance.

The African Ostrich (Struthio camelus), which is one of the bestknown members of this order, inhabits the desert plains of Africa and Arabia, and is the largest of living birds, attaining a height of

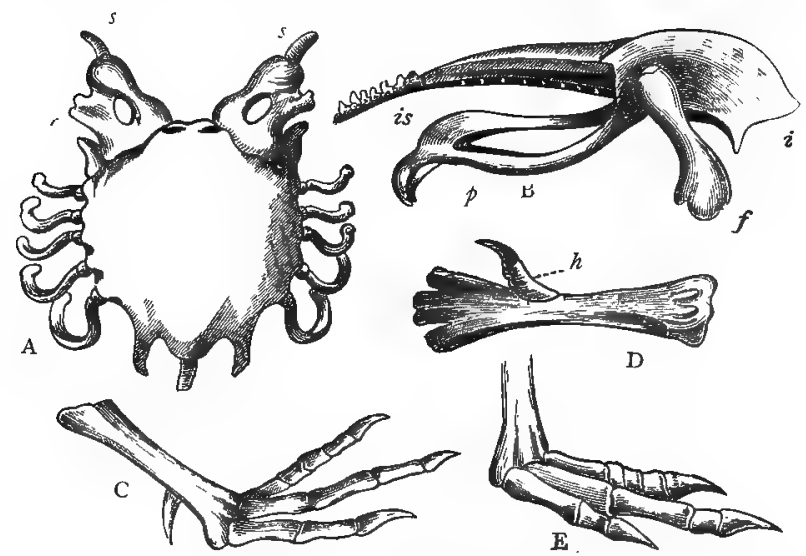

Fig. 206.-Morphology of Cursores. A, Sternum of the Ostrich (Struthio camelus) : 8 Scapula; $c$ Coracoid. B, Sidle view of the pelvis of the Ostrich : $i$ Ilium ; $p$ Pubis ; is Ischium; $f$ Femur. C, Foot of Apteryx australis. D, Tarsn-metatarsus of the Apteryx, showing the hallux placed high up on its posterior surface. E, Foot of the Rhea americana.

from six to eight feet. The head and neck are nearly naked, and the quill-feathers of the wings and tail have their barbs wholly separate, constituting the ostrich-plumes of commerce. The legs are extremely strong, and the feet have only two toes each. The Ostriches run with extraordinary speed, and can outstrip the fastest horse. They are polygamous, each male having several females, and they keep together in larger or smaller flocks. The American Ostriches or Rheas are much smaller than the African Ostrich, and have the head feathered, whilst the feet are furnished with three toes each. They inhabit the great plains of tropical America, and are polygamous. The Encu (Dronaius) is exclisively confined to 
Australia. In size it nearly equals the African Ostrich, standing from five to seven feet in height, and it is not uncommonly kept as a domestic pet. The Cassowaries are found in the Malayan Archipelago, North Australia, and New Gruinea. The best known is the Galeated Cassowary which was first brought alive to Europe by the Dutch. It stands about five feet in height, and possesses a singular Lorny crest upon the head. The last group of the living Cursorial Birds is the curious genus Apteryx of New Zealand. In the species of this remarkable genus (fig. 207) the beak is extremely long and slender, and the nostrils are placed at the extremity of the upper

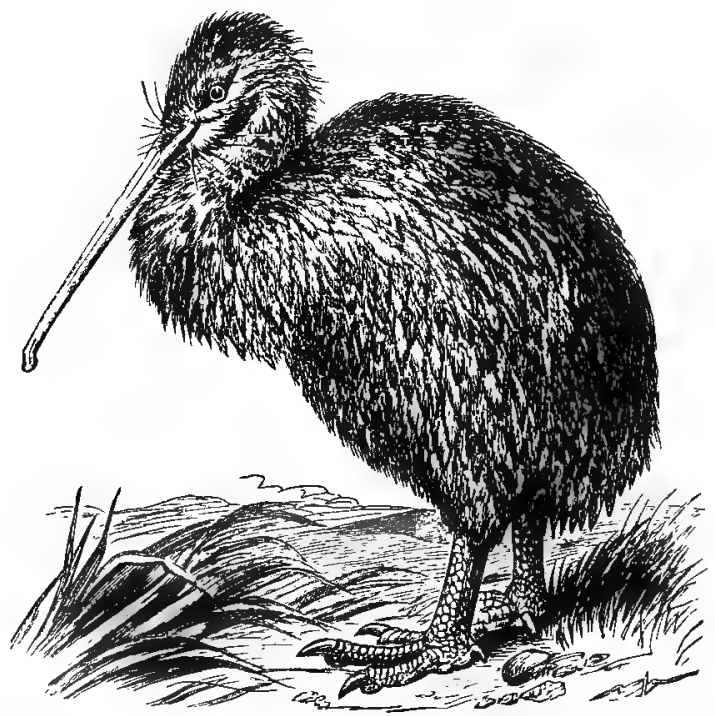

Fig. 207.-The Apteryx australis of New Zealand, showing the hair-like feathers, and the rudimentary great toe on the back of the fuot.

mandible. The legs are comparatively short, and there is a rudimentary hind-toe, provided with a claw. The feathers of the genmal plumage are long and hair-like, and the wings are altogether rudimentary.

It is worth noting that in New Zealand are found the remains of a number of gigantic Cursorial Birds which are now extinct, but which seem to have heen in existence when the island was first inhabited by mall. They are known to the Maories as "Moas," and the principal genus is Jinconis.

In very many respects the various Birds which are here included 
in the order Cursores, are so different from one another, that they may be regarded us forming divisions of equal, or nearly equal, value to the "orders" which form the sub-class Carinate.

\section{SUB-CLASS II. CARINATE.}

This sub-class includes all the living Birds which have the power of flight, and it therefore comprises the great majority of the entire class of Aves. The Carinate Birds, however, are so similar to one another in their general characters that they can with difficulty be split up into minor sections. For our present purpose, however, we may divide them into the six orders of the Swimming Birds (Natatores), the Waders (Grallatores), the Scratchers (Rasores), the Climbers (Scansores), the Perchers (Insessores), and the Birds of Prey (Raptores), which orders are more or less natural groups, with the exception of the order Scansores.

\section{Order I. Natatores.}

The order of the Swimming Birds comprises birds which are as much at home in the water as upon land, or even more so. In

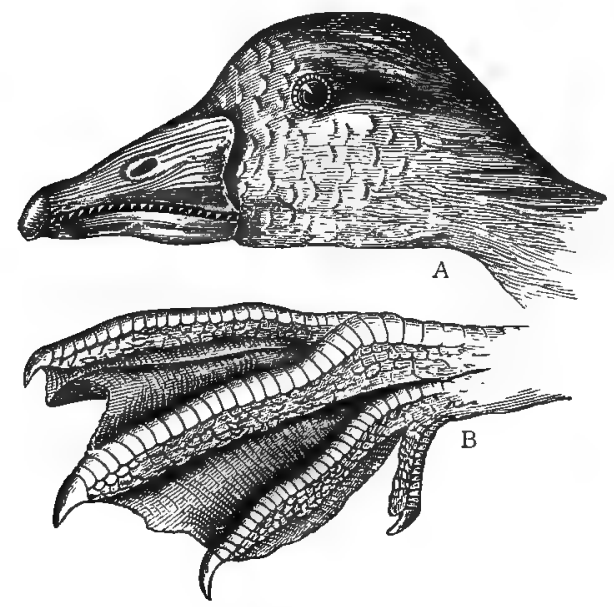

Fig. 20S.-A, Head of the Grey Lag Goose. B, Foot of the Domestic Goose

accordance with their aquatic mode of life, the Natatores have a boat-shaped body, generally elongated, and ustally having a 
long neck. The legs are short, and are placed behind the centre of gravity of the body; this position enabling then to act admirably as swimming paddles, at the same time that it renders the gait upon dry land comparatively awkward and shuffling. The toes in all the liatatores are velubed to a greater or less extent, or, in other words, are united by a membrane (fig. 208, B). In many the web or nembrane between the toes is stretched completely from toe to toe, but in others the membrane is divided between the toes, so that t're feet are only imperfectly webbed. As their aquatic mode of

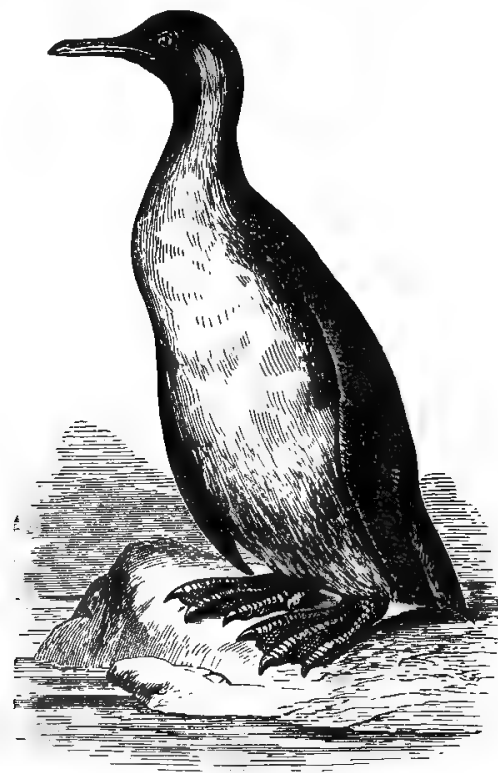

Fir. 2:a. Peltuin (At,tonotytes potugonicr).

life exposes them to great reductions of temperature, the body in the Natatorial Birds is closely covered with feathers, with a thick covering of down next the skin. They are further protected against becoming wet whilst in the water by the great development of the oil-gland at the tail, by means of which the dense plumage is kept constantly oiled. As a rule, the Natatorial Birds are polygamous, each male having several females; and the young are hatched in a (nndition not requiring assistance from their parents, being able to swim alout and procure food for themselves as soon as they are liberated from the egg. 
Amongst the more important types of the Natatores may be enumerated the Penguius (Spheniscicloc), the Auks (Alcinke), the Gulls and Terns (Larido), the Petrels (Procellaridoe), the Pelicans (Pelicanus), the Cormorants (Phalacrocorax), the Gamnets (Sula), the Ducks (Anatida), the Geese (Inserina), and the Swans (Cygnidoe).

The Penguins and Auks, with their allies the Divers, Guillemots, and Grebes, have rudimentary, or at any rate small, wings, and are all more at home in the water than upon land. In the Penguins (fig. 209), the wings are ruaimentary, and covered with a scaly skin. They are used by the bird as fins in swimming under water. The Penguins are confined to the southern hemisphere. The Gulls, Terns, and Petrels, on the contrary, are all birds of powerful flight, and some of them, such as the Albatross, are habitually found hundreds of miles from the nearest land. The Pelicans, with their allies the Cormorants, Frigate-birds, and Darters, are excellent fliers, and also not uncommonly perch on trees, which few Natatorial birds do. They are distinguished by having the hinder toe directed inward, and united to the innermost of the front toes by a contiunous membrane. The Ducks, Geese, and Swans have the bill very much flattened (fig: $208 \mathrm{~A}$ ), and covered by a soft skin. The elges of the bill are also furnished with a series of transverse plates, which form a kind of fringe or "strainer," by means of which these birds sift the mud in which they habitually seek their food.

\section{Order II. Grallatores.}

The Wading Birds for the most part frequent moist situations, such as marshes and shallow ponds, the shore of the sea or the banks of rivers or lakes, though some of them keep entirely, or almost entirely, to the dry land. In accordance with their semi-aquatic, amphibious habits, the Waders are distinguished by the great length of their legs-the increase in length being chiefly due to the elongation of the tarso-metatarsus. The legs (fig. 210, A) are also unfeathered and naked as far as the lower end of the tibia, at any rate. There are three anterior toes, and usually a short hind-toe; but the toes are never completely webbed, though they are sometimes partially palmate. The wings are long, and the power of flight is usually considerable ; but the tail is very short, and its function as a rudder is chiefly transferred to the long legs, which are stretched out behind in flight. The beak is almost always of great length, generally longer than the head (fig. 210, B), and usually more or less pointed, though it is sometimes flattened. In the Avocet (C) the bill is curved upwards, instead of being straight, or bent downwards, as is generally the case. The typical Waders, as before said, 
spend most of their time wading about in shallow water, feeding upon small fishes, shell-fish, worms, and insects. Others, such as the Storks, live mostly upon the land, and are more or less exclusively vegetable feeders.

Amongst the more important Grallatorial birds are the Rails (Rallidce), Water-hens (Giallinule), Cranes (Gruida), Herons (Ardeidre), Storks (Ciconina), Snipes (Scoloparida), Sandpipers (Tringidle), Curlews (Numenius), Plovers (Charadriida), and Bustards (Otidce).

The Rails are more or less terrestrial in their habits, but inhabit marshes and fens. Good examples are the Marsh-hen (Rallus elegans) and the Virginia Rail (R. virginianus) of North America, and

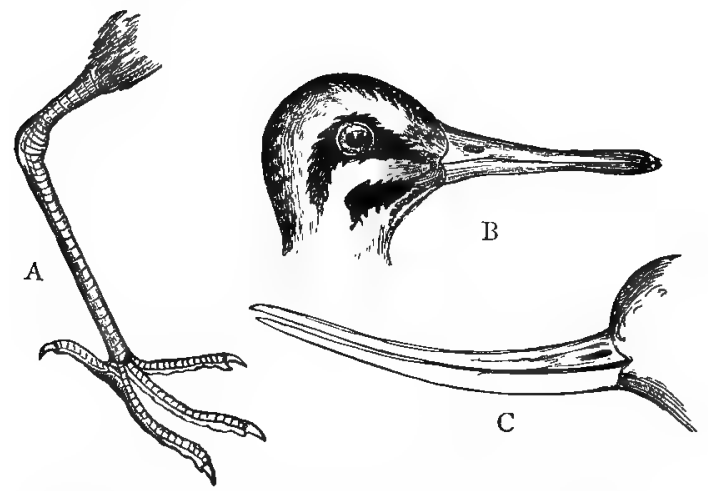

Fig. 210.-Grallatores. A, Leg and Font of Curlew; B, Head of Snipe ;

$\mathrm{C}$, Beak of Avocet.

the Corn-crake (Crex pratensis) of Europe. The Water-hens (Gallinula) and Coots (Fuliru) are aquatic or semi-aquatic, swimming and diving with the greatest ease. The C'anes are in the main vegetable-feeders, and inhabit dry plains. The Herons (fig. 211), Egrets, Bitterns, and Night Herons, form a beautiful family of Wading Binds, rejresented in almost every portion of the known world. Nearly allied to these are the lrilliantly coloured Iljises (Tantalina), which inhabit all warm countries. The Ciconince are all large birds, and comprise the intorks and Adjutant; while the Spoonbills are mainly separated from them ly their flattened, spoon-shaped bill. The Scolopacinle, comprising the Snipes and Woodcocks, the Tringidce (or Sindpipers), the (urlews (Ttemenius), and various other allied Birds, are distinguished from the preceding by the possession of a long, soft, slender bill, which is used in probing the ground for 
food. In the Charadriidoe are comprised the Oyster-catchers, Turnstones, Lapwings, Plovers, Thick-knee, and many other familiar Birds. Lastly, the Otidoe comprise only the Bustards, which are ex-

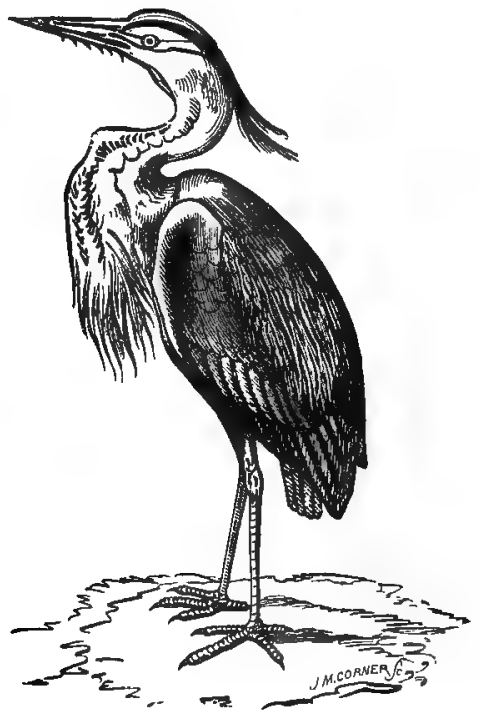

Fig. 211.-Grallatores, Common Heron (Ardea cinerea).

clusively confined to the Old World, and make a decided approach to the Rasorial Birds.

\section{ORder III. Rasores.}

The Scratching Birds-or as they are often called, the Gallinaceous Birds-are characterised by the fact that the upper mandible of the bill is convex and vaulted (fig. 213), and has a membranous space at its base, in which the nostrils are pierced. The nostrils are also covered by a cartilaginous scale. The legs are strong and muscular, and are often covered with feathers as far as the ankle-joint. There are four toes (fig. 212, A), three in front, and a short hind-toe placed on a higher level than the others. All the toes, in the typical members of the order, are provided with strong blunt claws, suitable for scratching. The food of the Rasores consists chiefly of hard grains and seeds, and in accordance with this, they have a large crop, and an extremely strong and muscular gizzard. They generally lay their eggs upon the ground, and they are mostly polygamous, 
each male having several mates. The Doves, however, pair for life. The males take no part in bulding the nest or in hatching the eggs; and the young are generally precocious, being able to run about and provide themselves with food from the moment they quit the egg. The wings are usually weak, and the flight feeble, and accompanied with a whirring sound; but many of the Pigeons are powerful fliers.

The order Rasores is divided into two very well-marked sections or sub-orders, called respectively the Gallinacei and Colambacei. In
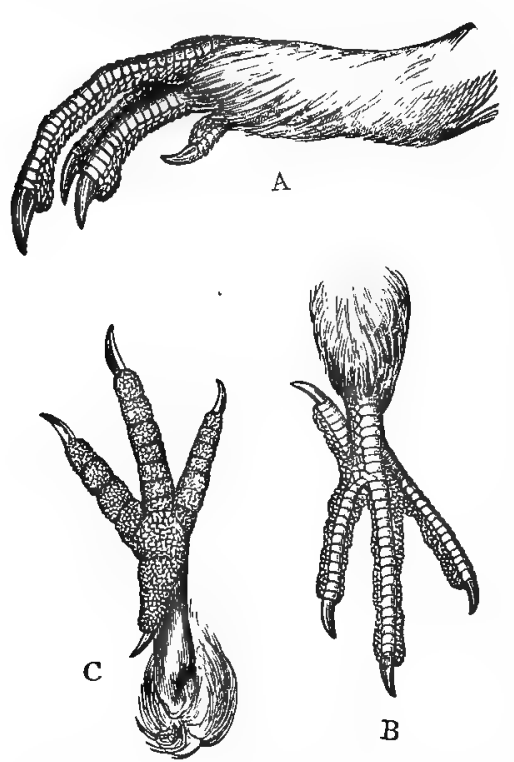

Fig. 212.-A, Foot of Black-cock (Tetrao trtrix). B and $\mathrm{C}, \mathrm{U}$,per and under views of the foot of the Wood-pigeon (Columba palumbus). the Gallinasei are all the typical forms of the order, and the characters of this section are therefore the same as those of the order itself. They are distinguished from the Columbacei mainly by being less fully adapte.t for flight, their bodies being much heavier, comparatively speaking, their legs and feet stronger, and their wings shorter. The hind-toe (great toe) is placed on a higher level than the three front toes (fig. 212, A), and merely touches the ground in walking. The foot is therefore specially adapted for living on the ground rather than for perching on trees. They are also polygamous; and the males may possess "spurs," and are usually more brilliantly coloured than the females. The leading families of the Gallinaceous Birds are: 1. The Totretonidce, or Grouse family, comprising the true Grouse and Black Game (Tetrui), the Ptarmigans (Lagopus), the Ruffed Grouse (Bon$a s a)$, \&c. 2. The Perlidille or Partridge family, comprising the Partridges (Perdix), Quails (Cotemir), Tirginian and Mountain Quails (Ortyx), Crested Quails (Lophorty $x$ ), \&c. 3. The Phasianidee, or Pheasant family, comprising the various Pheasants (Phasianus), the Domestic and Jungle Fuwls (Gallus), the Turkeys (Meleagris), 
the Guinea-fowls (Mumida), and the Pea-fowl (Pavo). 4. The Megapodide, or Mound-builders, comprising only some singular Australian and Indian birds, which build enormous mounds, in which they deposit their eggs. 5. The C'ruidle, or Curassow family, comprising the large South and Central American birds known as Curassows and Guans. 6. The Pteroctidoe, or Sand-grouse, of the Old World, which, in their long and pointed wings, make an approach to the Pigeons. 7. The Tinamida, or Tinamous, of South America, in which the tail is short, or may be wholly wanting.

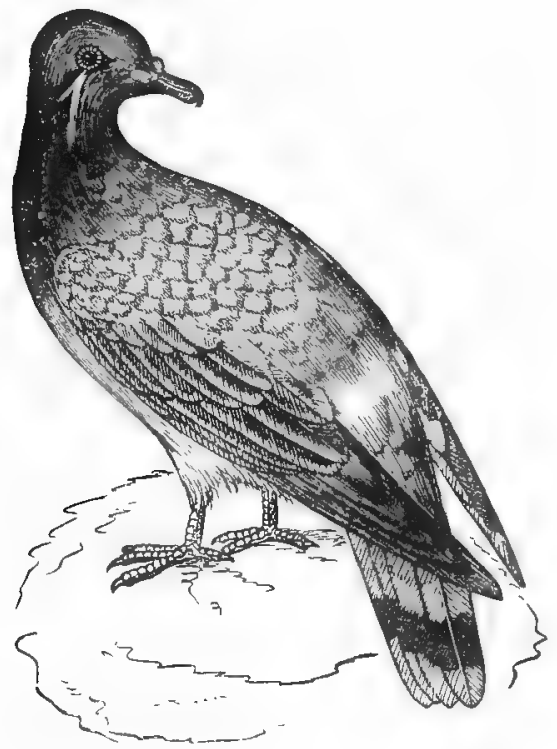

Fig. 213.-Rasores. Rock pigeon (Columba livia).

The Columbacei comprise the Pigeons and Doves, and they are separated from the typical Rasores by being much more fully adapted for flight. They are furnished with strong wings and are good fliers; and in place of being ground-birds, their habits are generally to a great extent arboreal, in accordance with which the feet are slender, and are adapted for perching, the great toe being placed on a level with the other toes (fig. 212, B). They are also not polygamous, and their voice is of a much more gentle, soft, and melancholy character. (Hence the name of Gemitores applied to this section, whilst the Gallinacei are called the Clamatores.) Besides the true 
Pigeons and Doves, this sub-order includes also the remarkable extinct bird the Dodo, which was of gigantic size, comparatively speaking, and inbabited the island of Mauritius up to the commencement of the seventeenth century.

\section{Order IV. Scansores.}

The order of Scansores or Climbing Birds is very shortly and easily defined, having no other distinctive and exclusive peculiarity, except the fact that the feet have four toes, of which two are turned backwards and two forwards (tig. 214, B). Of the two toes which are turned backwards, one is the proper hind-toe, and the other is the outermost toe. This arrangement of the toes enables the Scansorial birds to climb with great ease and readiness. Their powers of tlight are usually very moderate, and below the general average, and their food consists of insects and fruits of various kinds. Their nests are usually made in the hollows of old trees, but some (Cuckoos) have the remarkable habit of depositing their eggs in the nests of other birds. They are never polygamous, and the young are born in a naked and helpless condition.
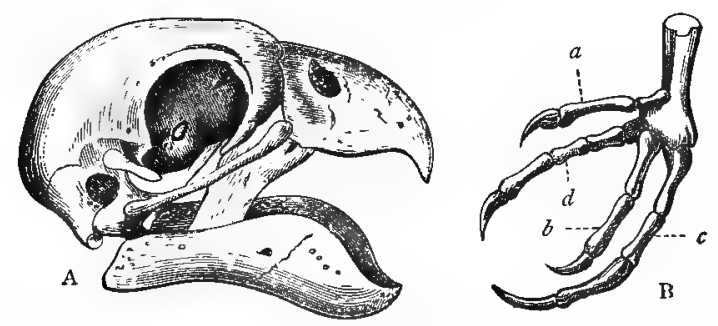

Fig 214.-A, Skull of a Parrot (Psittacus erythacus). B, Foot of the same: a Hallux: $b$ Index; $e$ Middle toe; $d$ Outer or ring toe. (After Blanchard.)

Upon the whole, we must regard the order of the Scansores as an artificial assemblage, comprising birds which have little in common save the adaptations which fit them for an essentially scansorial life. Bearing this in mind, we may include in the Scansores the following families: 1. The C'untide, or Cuckoo family, comprising the true Cucknos and some allied birds. They are remarkable for the fact that nany of them are "parasitic" ; that is to say, they lay their eggs in the nests of other lirds. The yellow-billed Cuckoo (C. ameriranns), however, of the United States, builds a nest for itself and brings up its own young, as do others of the family. 2. The Picide, or Woodpecker family. comprising many familiar 
birds, all of which climb and run up trees with the greatest facility. They live mostly on insects, which they catch by darting out their

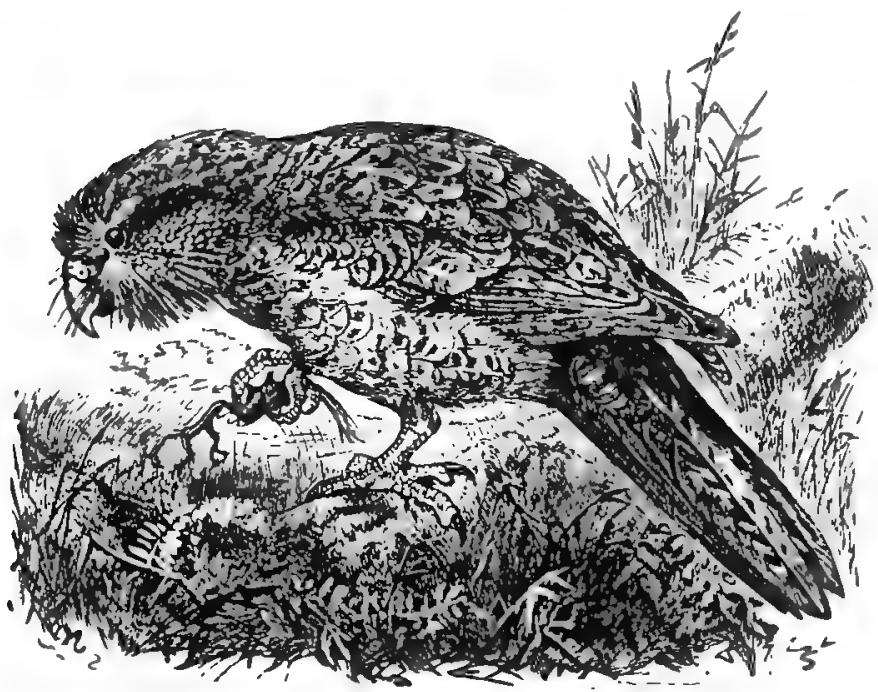

Tig. 215. - The Owl-Parrot (Strigops habroptitus), New Zealand.

long, worm-like, barbed tongue. 3. The Psittacida, or Parrot family, comprising the true Parrots, the Cockatoos, the Lories, the Parra-

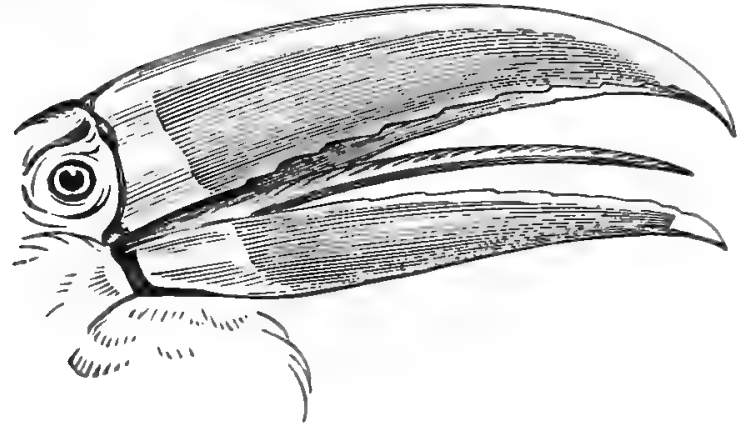

Fig. 216.-Head of Toucan.

keets, and the Macaws. They are all natives of hot climates, and are mostly remarkable for their brilliant plumage, and loud, harsh, 
and grating voices. The beak (fig. 215) is hooked, and is used as a kind of third foot in climbing, but some move about actively on the ground. 4. The Khamphastida, or Toucans, distinguished by their enormously large and cellular bills, the sides of which are serrated (fig. 216). They live in deep forests, in small flocks, and are confined to tropical America. 5. The Trogonide, or Trogons, which inhabit the most retired recesses of the forests of the intertropical regions of loth hemispheres, and are distinguished by their resplendent plumage. 6. The Barbets (Bucconidce), of the warmer parts of the New and Old Worlds; and 7. The Plantain-eaters (1/usophagid(e) of Africa.

\section{Order V. Insessores.}

The sixth order of Birds is that of the Insessores or Perchers, often spoken of as the Passerine Birds. They are defined by Owen as follows: "Legs slender, short, with three toes before and one behind, the two external toes united by a very short membrane" (fig. 217, E and F).

"The Perchers form by far the most numerous order of birds, but are the least easily recognisable by distinctive characters common to the whole group. Their feet, being more especially adapted to the delicate labours of nidification" (building the nest), "have neither the webbed structure of those of the simimmers, nor the robust strength and destructive talons which characterise the feet of the Birds of Rapine, nor yet the extended toes which enable the IIuder to walk safely over marshy soils and tread lightly on the floating leaves of aquatic plants; but the toes are slender, flexible, and moderately elongated, with long, pointed, and slightly curved claws.

"The Perchers, in general, have the females smaller and less brilliant in their plumage than the males; they always live in pairs, build in trees, and display the greatest art in the construction of their nests. The young are excluded in a llind and naked state, and are wholly dependent for subsistence during a certain period on parental care. The brain arrives in this order at its greatest proportionate size; the or yan of voice here attains its utmost complexity; and all the characteristics of the bird, as power of flight, melody of voice, and beauty of plumage, are enjoyed in the highest perfection by one or other of the groups of this extensive and varied order."

The structure, then, of the feet gives the definition of the order, lut the minor sululivisions are founded on the nature of the beak; this organ varying in form according to the nature of the food, which may be "small or young birds, carrion, insects, fruit, seeds, vegetable juices, or of a mixed kind." In accordance with this 
character, the Insessores have been divided into four great sections, as follows:-

1. Conirostres, - in which the bill is strong and on the whole con$\mathrm{ical}_{j}$ broad at the base, and tapering with considerable rapidity to the

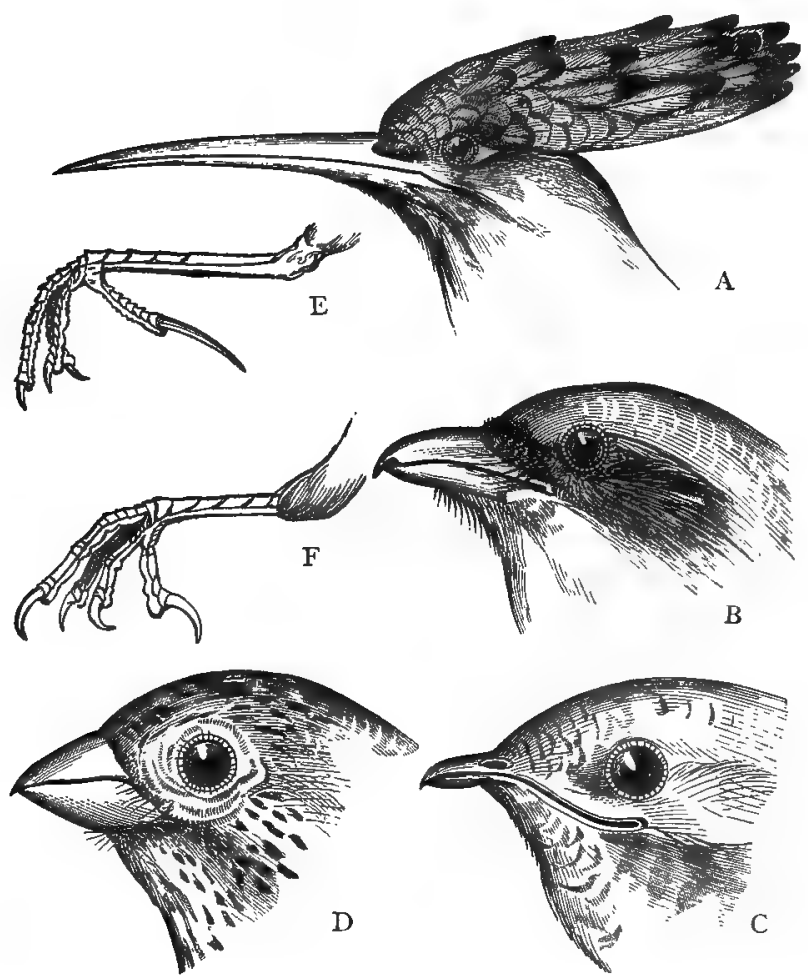

Fig. 217.-A, Head of Hoopoe (Upupa epops), showing the tenuirostral type of heak. B, Head of Red-backed Shrike (Lanius collurio), showing the dentirostral type of beak. C, Head of White-bellied Swift (Cypselus melba), showing the fissirostral type of beak. D, Head of Corn-bunting (Emberiza miliaria), showing the conirostral type of beak. E, Foot of the Yellow Wagtail (Motacilla sulphurea). F, Foot of a Finch (Fringilla).

point (fig. 217, D). The upper mandible is not markedly toothed at its lower margin. Good examples of the conirostral beak are to be found in the Sparrows, Finches, Buntings, Crows, \&c. The greater part of the Conirostres are omnivorons, eating anything which may come in their way; but some are granivorous, subsisting upon grains 
and seeds. To this section belong the (Hornbills) Buceride, the Starlings (Sturnidee), the Crows, Jays, and Magpies (Corvidce), the Crossbills (Loxiado), and the numerous Finches and Larks (Fringillidae).

2. Dentirostres.-The Birds of this section are characterised by the fact that the upper mandible of the beak is notched or toothed on its lower margin near the tip (fig. 217, B). They all feed upon animal food, especially upon insects. In this section are the Shrikes (Lanizdce), the Fly-catchers (Muscicupidce), the Thrushes (Merulida), and the Warblers (Sylviadce).

3. Tenuirostres.-In this section the beak is long and slender, gradually tapering to a point (fig. $217, \mathrm{~A}$ ). The toes are generally very long and slender, especially the hinder toe. The Hummingbirds feed upon the wing, and amongst these are some of the noost fragile and brightly coloured of all the Birds. Others, however, live upon insects, which they catch upon the ground or on the trunks of trees, and some of these approach nearly to the Dentirostres in many of their characters. Amongst the more important groups included in this section are the Creepers (Certhidce), the Honeyeaters (Meliphagide), the Humming-birds (Trochilidce), and the Hoopoes ( $C^{\top}$ pupidce).

4. Fissirostres. - The beak in the Fissirostral Perchers (fig. 217, C) is generally short, and remarkably wide in its gape, and the opening of the bill is protected by a number of bristles. This arrangement is in accordance with the habits of the Fissirostres, the typical forms of which live "1] in insects and take their prey mpon the wing. The most typical Fissirostres, in fact, such as the Swallows and Goatsuckers, fly about with their mouths open, and the insects which they catch in this way are prevented from escaping, partly from the bristles which border the gape, and partly by a sticky secretion within the mouth. The most typical Fissirostral Birds are the Swallows and Martins (Hirundinida), the Goat-suckers (Copmmulgidos), and the Swifts (Cypselidce); but to these the Bee-eaters (Meropidae) and the King-fishers are usually added.

\section{Order Vi. Raptores.}

The Birds of Prey are characterised by the form of the beak, which is adapted for tearing animal food (fig. $218, \mathrm{~B}$ ). The upper mandible is the longest, hooked at its point, "strong, curved, sharp-edged, and sharp-pointed, often armed with a lateral tooth"(Owen). The body is extremely muscular; the legs are robust, short, with three toes in front and one bebind; all the toes armed with strong, curved, crooked claws or talons (fig. $218, A$ ). They all feed upon the flesh 
of other animals, which they either kill for themselves or find dead, and their flight is generally extremely rapid and powerful. They are not polygamous, and the female is larger than the male. They usually build their nest in lofty and inacessible situations, and seldom lay more than four eggs. The young are hatched in a naked and helpless condition.

The Raptores are divided into two sections-the Nocturnal Birds
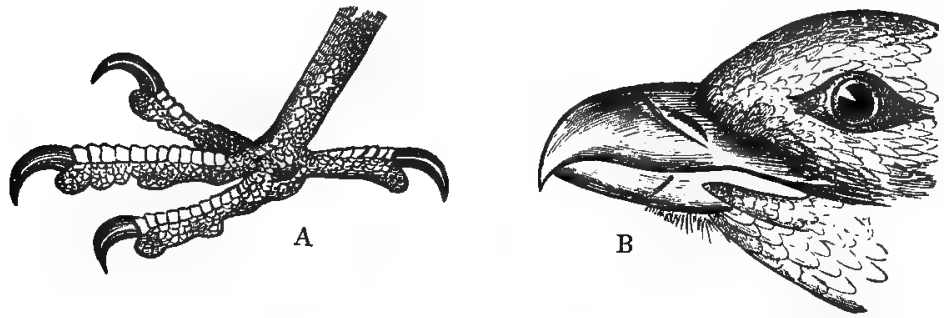

Fig. 218.-Raptores. A, Foot of Peregrine Falcon ; B, Hcal of Buzzarcl.

of Prey, which hunt at night, and the Diumal Birds of Prey, which hunt by day. In the former section is only the single family of the Owls (Strigidos), in which the eyes are large, and are directed forwards (fig. 219), whilst the plumage is exceedingly soft and loose, so as to render their flight almost noiseless. The Owls, for the most
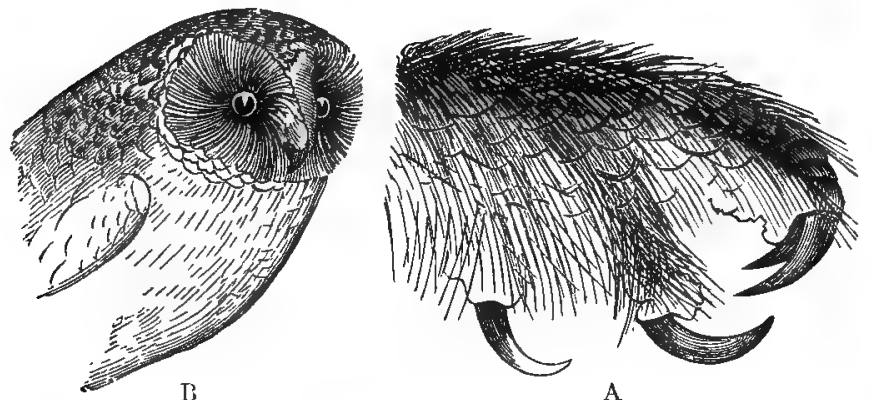

Fig. 219.-A, Foot of Tawny Owl; B, Hearl of White Owl.

part, bunt their prey in the twilight or on moonlight nights, and they live mostly upon field-nice and small birds, but they will also eat insects and frogs. In the section of the diurnal Raptores are the Falcons and Hawks, the Eagles and the Vultures. In all these the eyes are smaller than in the Owls, and are placed laterally, and the plumage is not soft. They usually possess extraordinary powers of 
flight. The wings are long and pointed, the sternal keel is greatly developed, the pectoral muscles are of large size, and many of then exhibit powers of locomotion more rapid than those enjoyed by any other members of the animal kingdom.

\section{SUB-CLASS III. ODONTORNITHES.}

\section{Order I. Saurtra.}

This order includes only the single extinct Bird, the dickoptery/x, which has been found in the Oolitic rocks of Germany. The Archaoptery $x$ was al hout as big as a common Rook, and shows many singular points of resemblance to the true Reptiles. It differs from all living birds in having two free claws to the wing, and in possessing a long lizard-like tail. Instead of the ploughshare-shaped bone which ter-

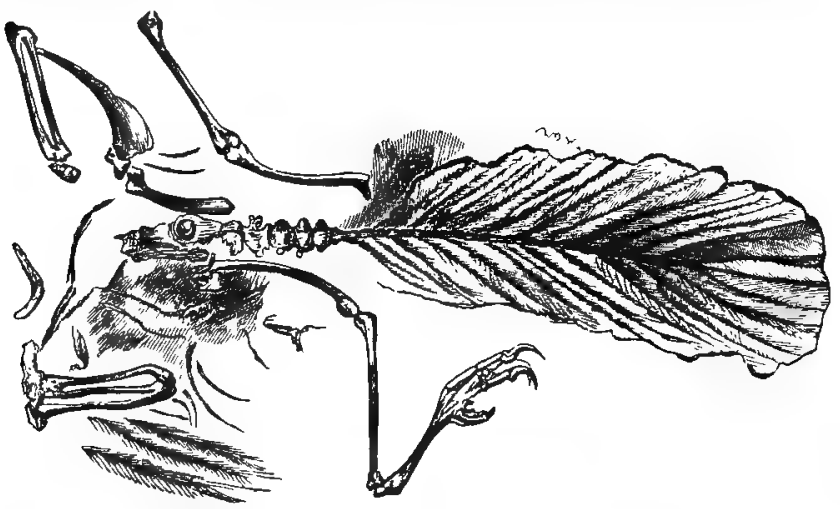

Fig. 220.-Archæopteryx. Tail and detached bones.

minates the tail in living birds (fig. 204, B), the tail in Alrcheopteryx (fig. 220) is very long, and consists of about twenty distinct and separate vertehrie, each of which supports a pair of quill-feathers. The tail, therefore, except for the presence of feathers, must have been very like thit of a Reptile. As in all the Birds of this subclass, the juws were furnished with conical pointed teeth.

\section{()RDER II. Odontolce.}

This order comprises only a single extinct Birl, the extraordinary IIsperomis refulis of the Cretaceous rocks of North America, for the discovery and description of which science is indebted to Pro- 
fessor Marsh. In this Bird (fig. 221) we have a gigantic divingbird, standing some five feet in height, but with the wings quite rudimentary, so that the power of flight was entirely absent. The tail was not elongated, as it is in Archoopteryx, but consists of about twelve vertebræ, of which the last three or four are amalgamated

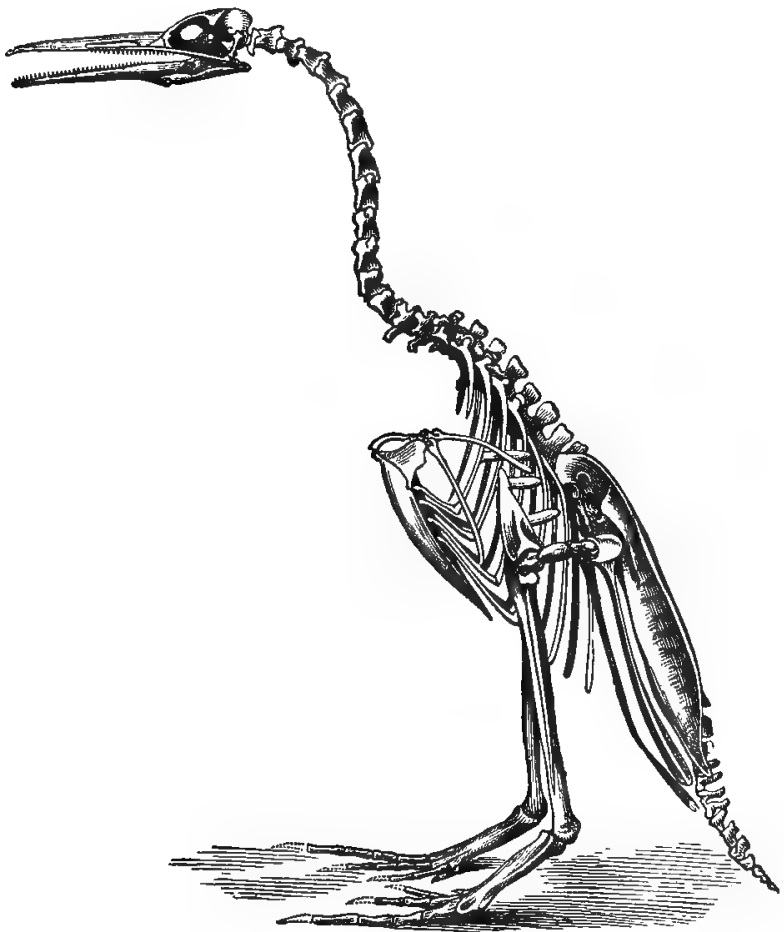

Fig. 221.-Skeleton of Hesperornis regalis, restored. (After Marsh.) About one-tenth of the natural size.

to form a single mass. The bodies of the vertebræ have the form usual among Birds. The jaws are furnished with numerous conical recurved teeth, sunk in a deep continuous groove. The metacarpal bones are wanting, and the sternum is destitute of a keel.

\section{Order III. Odontotorma.}

This order comprises only some singular fossil Birds from the Cretaceous rocks of North America, of which the genus Ichthyornis 
is the type. In Ichthyornis, as in Hesperornis, the jaws are furnished with numerous cunical teeth, but those are sunk in distinct sockets. The wings are well developed, and the bird must have possessed considerahle powers of flight. The sternum has a keel, and the metacarpal lwnes are anchylosed with one another. Lastly, there is the extraordinary character that the bodies of the vertebrce were bironsare, and in this respect resemble the vertebræ of most fishes and of many Anphibians and Reptiles. The size of Ichthyomis dispar, the only known species of the genus, seems to have been about equal to that of a Pigeon. 


\section{MAMMALIA.}

\section{CHAPTER XXX. \\ CLASS V. MAMMALIA.}

The Mammatia include all the ordinary Quadrupeds, and may be shortly defined as comprising Vertebrate Animals in which some part or other of the skin is always provided with hairs, and the young are nourished for a longer or shorter time by means of a special fluidthe milk-secreted by special glands - the mammary glands. These two peculiarities are of themselves sufficient to separate the Mammals from all other classes of the Vertebrate sub-kingdom. In addition, however, to these two leading characteristics, the following points are of scarcely less importance :-

1. The skull is united with the spinal columm by means of two articulating surfaces or condyles, instead of one, as in the Reptiles and Birds.

2. The lower jaw consists of two halves, each composed of a single piece, and united in front. The lower jaw, also, is always jointed directly to the skull, and there is no quadrate bone.

3. The heart consists-as in Birds-of four distinct chambers, two auricles and two ventricles. The right and left sides of the heart are completely separated from one another, and there is never any direct communication between the blood sent to the lungs and that sent to the body. The red corpuscles of the blood (fig. 163, $a$ ), are, in the great majority of cases, in the form of circular discs, and they never contain any internal solid particle or nucleus.

4. The cavities of the chest (thorax) and abdomen are separated from one another by a muscular partition, which is called the midriff or diaphragm, and is the chief agent in respiration.

5. The respiratory organs are in the form of two lungs, placed in the chest, and never communicating with air-receptacles situated in different parts of the body. In no case and at no period of life are gills or branchix present. 
As regards the skeleton of the Mremmalia, it is not necessary to add much to what was said in speaking of the I'ertebrata generally. With few exceptions, the spinal columm is divisible into the same regions as in man-namely, the neck or cervical region, the back or dorsal region, the loins or lumbar region, the sacral region, and the tail or caudal region (see fig, 159). In spite of the great differences observable in the length of the neck in different Mammals, the number of vertebrie which form the cervical region is extra ordinarily constant, being almost invariably seven. In this respect the Giruffe, which is the longest-necked of Mammals, agrees with the Whale, which can hardly be said to have a neck at all. The vertehrie of the back or dorsal region are mostly thirteen in number, but are often more. In man there are only twelve; and in some cases there are only eleven or ten. The lumbar vertebre are usually six or seven in number; five in Man; rarely less than four. The sacral vertebre are usually amalgamated to form a single bone-the surum-but this is wanting in the Whales. The number of vertelure in the tail or caudal region varies from four to as many as five-and-forty, and they are usually freely movable upon one another. The thoracic cavity or chest in Manmials is always enclosed by a series of ribs; the number of which varies with the number of the dorsal vertebra. As a rule, the ribs are united to the breast-bone or sternum in front, not by bony pieces, as in birls, but by cartilages. Only the front ribs reach the sternum, and these are called the "true" ribs; the hinder ribs fall short of the breast-hone, and are called the "false" ribs. The sternum is crmprserl of several pieces, placed one behind the other, but uwually amalgamated to form a single bone. It is usually long and narrow in shape, and is only rarely fumished with any ridge or keel, as it is in Pirds. The regular number of limbs in the Mammals is four, two anterior and two posterior; and for this reason the Manmals are often spoken of as Quadrupeds. Some Mimmals, however, such as the Whales and Dolphins, have only the anterior limbs, and many of the Amplbibia and Reptiles walk upon four legs. As regarrls the structure of the fore-limbs (fig. 160), the general conformation of the limb has been previously notel. The shoulderblade or sirepula is never wanting, and is generally broad and flat. The coracrill hones, which form such a marked feature in the pectoral arch of the Birds, are incomplete, and are fused with the scapula, of which they form the so-called "coracoid process." In the Monotrematous Mamnials alone are the coracoids distinct bones, sufficiently developed to articulate with the steruum. The collarbones or clivicles are often rudimentary or absent, and, when present, are never united into a single bone. The humerus presents 
nothing special; and the radius and uIna are usually present in the fore-arm, though they may be fused with one another, or the ulna may be wanting.

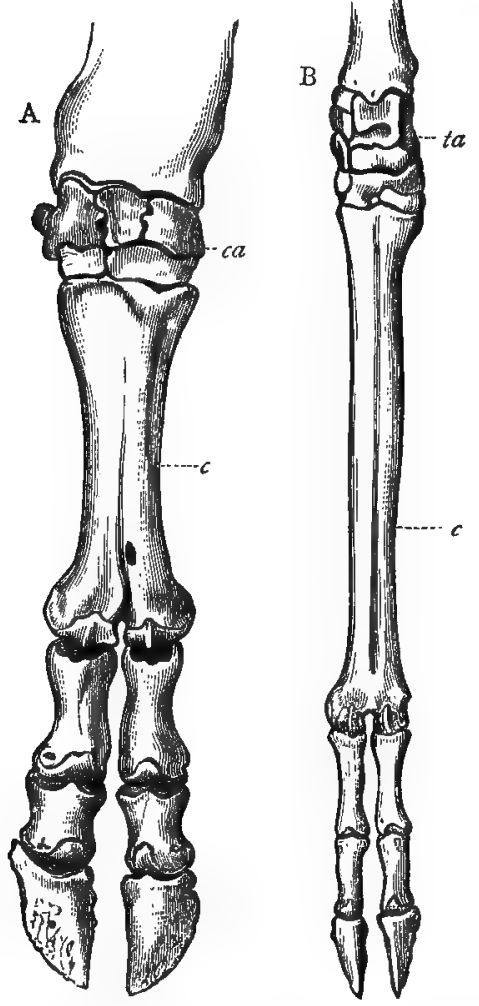

Fig. 222.-A, Fore-leg of Ox (Bos taumus), B, Hind-leg of Stag (Cervus elcupluts). ca, Carpus; ta Tarsus; $a$ "Canon-bone," composed of the united metacarpals or metatarsals of the third and fourth digits.

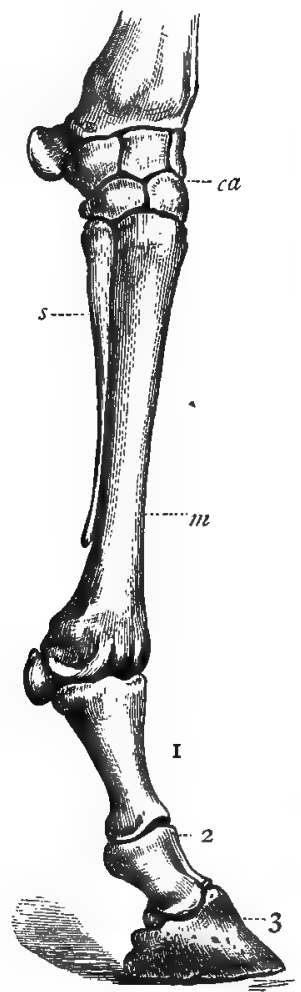

Fig. 223.-Fore-leg of Horse. ca Carpus ; $n$ Metrearjal of the third digit; s "Splintbone," or rudimentary metacarpal ; I, First phalanx or "great pastern"; 2, Second phalanx or "small pastern "; 3 Third phalanx or "coffin-bone."

The fore-arm is succeeded by the small bones which compose the wrist or "carpus." These are eight in number in Man, but vary in different Manumals from five to eleven.

The metacarpus in Man and in most Mammals consists of five 
cylindrical bones, articulating proximally with the carpus, and distally with the phalanges of the fingers. The most remarkable modification of this normal state of things occurs in the Ruminants and in the Horse. In the Rummants (fig. 222, A and B), in which the foot is eleft, and consists of two perfect toes only, there are two netacarpal bones in the embryo; but these are anchylosed together in the adult, and form a single mass which is known as the "canon. bone" (fig. 2.2, c). In the Horse (fig. 22:3), in which the foot consists of no more than a single digit, there is only a single metacarpal hone, on each side of which are two little bony spinesthe so-called "splint-bones"-which are attached superiorly to the carpus, and are to be regarded as rudimentary metacarpals.

The normal number of digits is five, but they vary from one to five. The middle finger is the longest, and most persistent of the digits of the fore-limb; and in the Horse it is the only one which is left (fig. 2:3). The thumb is very frequently absent. In the Ruminants there are only two fingers which are functionally useful, these carrying the hoofs. Normally, each digit is composed of three short bones or phalanges, the innermost digit (the thumb) having two. The extremity of the digit is usually protected by a nail, claw, or hoof.

While the fore-limbs are never wanting, the hind-limbs are absent in the so-called "Mutilated Mammals" (namely, the Cetaceans and Sirenians). The bones of the hind-limb correspond with those of the fore-limb; and the foot (pes) corresponds with the hand (manus), consisting normally of five digits, but subject to the same abortion of parts as occurs in the case of the anterior limb.

Teeth are present in the great majority of Mammals; but they are only present in the embryo of the whalebone $\mathrm{Wbales}$, and are entirely absent in the genera Echidna, Hruis, and Myrmecophaga. In the Duck-mole (1)-nithorhynchus) the so-called teeth are horny, and the same was the case in the extinct Rhytina anongst the Sirenia. In all other Manmals the teeth have their ordinary structure of dentine, enamel, and crusta petrosa, these elements being variously disposed in different cnses, and the enamel being occasionally wanting. In no Mammals are the teeth ever anchylosed with the jaw; and in all, the teeth are implanted into distinct sockets or alveoli, which, however, are very inperfect in some of the r'etacea.

Many Mammals have only a single sut of teeth thronghout life, and these are termed by Owen "monophyodont." In most cases, however, the first set of teeth-called the "milk" or "deciduous" teeth-is replaced in the course of growth by a second set of 
"permanent" teeth. The deciduous and permanent sets of teeth do not necessarily correspond to one another ; but no Mammal has ever more than these two sets. The Mammals with two sets of teeth are called by Owen "diphyodont."

In Man and many other Mammals the teeth are divisible into four distinct groups (fig. 224), which differ from one another in position, appearance, and function; and which are known respectively as the incisors, canines, prcemolars, and molars.

"Those teeth which are implanted in the promaxillary bones, and in the corresponding part of the lower jaw, are called 'incisors,' whatever be their shape or size. The tooth in the maxillary bone which is situated at or near to the suture with the premaxillary, is the 'canine,' as is also that tooth in the lower jaw which, in opposing it, passes in front of its crown when the mouth is closed. The other teeth of the first set are the 'deciduons molars'; the teeth which displace and succeed them vertically are the 'præmolars';

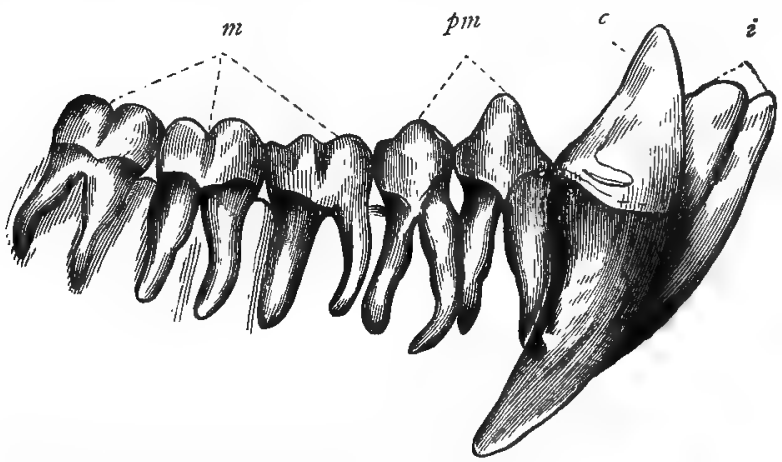

Fig. 224,-Teeth of the right side of the lower jaw of the Chimpanzee (after Owen). $i$ Incisors ; $e$ Canine tooth ; pm Promolars; $m$ Molars.

the more posterior teeth, which are not displaced by vertical successors, are the 'molars' properly so called" (Owen). The deciduous dentition, therefore, of a diphyodont Mammal cousists of only three kinds of teeth-incisors, canines, and molars. The incisor and canine teeth of the deciduous set are replaced by the teeth which bear the same names in the permanent set. The deciduous " molars," however, are replaced by the permanent "præmolars," and the "molars" of the permanent set of teeth are not represented in the deciduous series, only existing once, and not being replaced by successors.

All these kinds of teeth are not necessarily present, and the teeth furnish most important characters for separating the various orders of Mammals from one another. For this reason it is usual to express the number of the teeth in any particular animal by an arithmetical formula, called the dental formula. For example, the 
formula for the portion of the jaw of the Chimpanzee figured above (fig. 224) would be as follows:-

$$
i 2 ; c 1 ; p m 2 ; m 3 .
$$

But this is only one half of the lower jaw, and the dental formula must include both sides, so that it would be :-

$$
\text { i } 2-2 ; c 1-1 ; p m 2-2 ; m 3-3 \text {. }
$$

That this would be the formula is at once evident, when it is remembered that the two sides of the jaw of course contain exactly the same teeth. Still, the formula as given above only includes the lower jaw, and to render it perfect it must take in the teeth of the upper jaw as well. This is effected by placing the figures in two rows separated by short lines, all the figures in the upper row referring to the upper jaw, and those in the lower row to the lower jaw ; the short dashes between the figures of each row still indicating the teeth on the two sides of the mouth. The complete formula would therefore rum as follows:-

$$
i \stackrel{2-2}{2} ; s \frac{1-1}{1-1} ; p m \underset{2-2}{2-2} ; m \frac{3-3}{3-3}=32 .
$$

In this way the dentition-that is to say, the number and arrangement of the teeth-can be presented in $\pi$ mamner which can be instantly recognised by the eye. It must be remembered, however, that the formula seldom exhibits the regularity of the one of the Chimpanzee given above. The teeth are not necessiarily the same in both jaws, and in many caless some nay be altogether wanting. To show this there is subjoined the dental formula of a typical Ruminant animal, such as a sheep :-

$$
i \frac{0-0}{3-3} ; \quad c_{1-1}^{0-0} ; p m \frac{3-3}{3-3} ; m \frac{3-3}{3-3}=32.2
$$

From this formula it will be seen that the sheep has 3.2 teeth in both jaws taken together. The upper incisors and canines are wanting, and there are three præmolars and three molars on each side of the upper jaw. In the lower jaw there are six incisors, two canines, and the same number of prienolars and nolars ats in the upper jaw.

As regrurds the digestive system of Mammals, the alimentary canal and digestive glandis bave on the whole the same general structure and arrangement as in man (pp. 2223, 221). Sonie very remarkatble modifications, however, in the structure of the stomach and in the termination of the intestine, occur in certain Mammals; but these will be noticed in speaking of the orders in which they occur. 
The cavity of the abdomen in Mammals is always separated from that of the thorax by a complete muscular partition-the diaphragm. The abdomen contains the greater part of the alimentary canal, the liver, pancreas, kidneys, and other organs. The thorax contains chiefly the heart and lungs. The heart is contained in a membranous sac-the pericardium-and consists of two auricles and two ventricles. The heart consists functionally of two sides, each having an auricle and a ventricle, which communicate with one another by apertures, so guarded by valves that the bluod can pass from the auricle into the ventricle, but not, under ordinary circumstances, from the ventricle to the auricle. There is in the adult no direct communication between the two sides of the heart. The course of the circulation is indicated in the subjoined diagram (fig. 225), and is shortly as follows: The venous blood, which has become impure by passing through the tissues, is returned by the great veins to the right auricle, from which it passes into the right ventricle. From here it is driven through a great vessel, called the pulmonary artery, to the lungs, where it is submitted to the action of the air, and becomes arterial blood. It is then returned to the heart by a series of vessels called the pulmonary veins, and is poured into the left auricle, from which it passes into the left ventricle. From the left ventricle it is propelled to all parts of the body by a great systemic vessel, which is called the

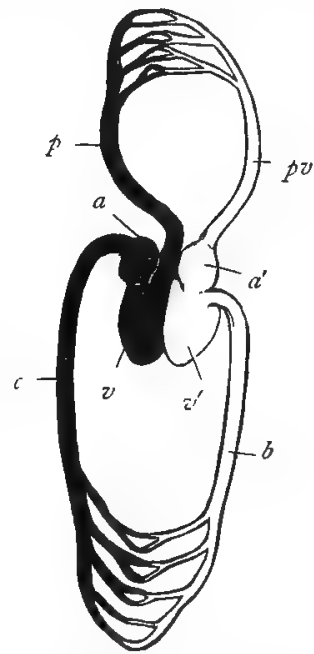

Fig. 225.-Diagram of the circulation in a Mammal. (The cavities contain. ing venous blood are marked black, those containing arterial blood are left white.) a Right auricle; $v$ Riglit ventricle; $p$ Pulmonay artery carrying venous blood to the lungs; pv Pulmonary veins carrying arterial blood from the lungs ; $a^{\prime}$ Left auricle; a' Left ventricle; $b$ Aorta carrying arterial blood to the body : $c$ Vena cava, carrying venous blood to the heart. aorta.

The lungs of Mammals are two in number, and differ from those of Birds in being freely suspended in membranous bags. They are spongy and cellular throughout, and they never communicate by apertures on their surface with air-sacs placed in different parts of the body.

The nervous system of Mammals is chiefly remarkable for the 
great proportionats development of the brain, as compared with the spinal cord.

In the higher Mammals, also, the two halves (hemispheres) of the greater brain (cerebrum) are comnected together by a great band or bridge of nervous tissue, constituting what is known as the corpus callosum. This structure is not a conspicuous feature in the two lowest orders of the Mamnalia. The senses, as a rule, attain great perfection in the Mammals; and the only sense which can ever be said to be entirely wanting is that of sight. Eyes, however, are always present, thongh they may be mdimentary; and in those Mammits which are siid to be "blind," it is not generally that the eyes are wanting, but that the skin passes unbrokenly over the eyeball. Even in these cases, however, it is not impossible that there may be some perception of light throngh the skin. An external ear for collecting sounds is usually present; lut it is wanting in the Whales and Dolphins, and in some of the Seals.

The skin is invariably furnished over a greater or less part of its surface with the epidermic apjendages known as hairs, which differ from feathers chiefly in not splitting up as they are produced. In the Scaly Ant-eater (J/fuis), the hairs are aggregated together so as to form horny scales; and in the Hedgehog, Porcupine, and other animalu, many of the hairs are develuped into long spines or prickles. $I_{11}$ the Armaldillos, again, the skin is more or less covered by an armour of bony plates. The only apparent exception to the universal presence of hair on some part or other of the integument of all Mammals is constituted by the true Cetaceans (Whales and Dolphins), many of which are without hair when grown up. Some, however, such is the Whales, have a few bristles in the neighbourhood of the mouth eve'n when adult. And the Dolphins, which are totally hairless when grown up, exhibit tufts of hair upon the muzzle before they are born.

With the exception of the singular Monotremes, which are now known to be oviparous, all Manmals produce their young alive, and the young animal is always born in a belpless condition, and is nourished for a longer or shorter time by neans of the milk of the mother. The milk is secreted by special organs, called the mammary glands, which are present in both sexes, but are normally undeveloped in the male. The number and position of the namme vary a gool deal in different cases, but they are always placed on the lower surface of the body, and their ducts almost always open upon a special eninence, called the teat or nipple. In the Monotremes, however, the mammary glands open by simple slits in the skin of the abdomen, and not by distinct nipples. In ordinary Mammals the milk is obtaincel by voluntary suction on the part of 
the young, but in the Marsupials (Kangaroos, Opossums, \&c.) the milk is forced into the mouth of the young animal by the action of a special muscle.

It will be sufficient for our present purpose to divide the Manmalia, in accordance with the way in which the young are developed, into three primary sections-viz., the Placental Mammals, the Ionplacental Mammals, and the Oviparous Mammals. In the Placental Mammals, not only are the young brought forth alive, but they are nourished within the body of the mother by means of a structure called the placenta, through which the nutrient materials of the mother's blood reach the young. In consequence of this, the young of the Placental Mammals can be retained within the body for a considerable period, and when born, they are ble to obtain their natural food-the milk-by their own exertions. This section includes all the higher groups of Mammals. In the Von-placental Mammals, on the other hand, the young are born alive, but at an extremely early period of their development, before there is any necessity that a placenta should be formed for the nourishment of the foetus. In these cases, therefore, the young, when born, are much more immature and helpless than in the case of the Placental Mammals. So helpless are they, that they are even unable to suck, and have in most cases to be fixed by the mother herself upon the teats, whilst the nilk is forced into their mouths by a nuscle which is spread over the mammary gland. This section includes only the Marsupials or Pouched Mammals. Lastly, in the Oviparous Mammals, the young are not born alive but are produced as eggs, as in the Birds and Reptiles. The young, however, are liberated from the egg at a very early period of their development, and are then nourished by the milk of the mother. This section includes only the Monotrematous Mammals-viz., the Duck-mole (Ornithorhynchus) and the Spiny Ant-eater (Echidna).

Adopting the above primary sections as practically sufficient in an elementary work, the whole class of the Mammalia may be divided into the following fourteen orders:-

\section{Division A.-Oviparous Mammals.}

Order 1.-Monotremata.

Division B.-Non-placental Mammals.

Order 2.-Marsupialia.

Division C.-Placental Mammals.

Order 3.-Edentata.

Order 4.-.Sirenia. 
Order 5.-Cetacea.

Order 6. - C'ngulata.

Order 7.-Dinocerata.

Order 8.-Tillodontia.

Order 9.-Toxodontia.

Order 10.-Hyracoidea.

Order 11.-Proboscidea.

Order 1:-Carnivora.

Order 13.-Rodentia.

Order 14.-Cheiropter $\alpha$.

Order 15.-Insectivora.

Order 16.-Quadrumana.

Order 17.-Bimana. 


\section{CHAPTER XXXI.}

\section{ORDERS OF MAMMALIA.}

\section{Order I. Monotremata.}

THE order of the Monotremes comprises only two very remarkable genera of Mammals-namely, Ornithorhynchus (the Duck-moles), and Echidna (the Spiny Ant-eaters), which are characterised by the singular combination in their structure of Reptilian or Avian peculiarities with features of a purely Manmalian type. That they are genuine Mammals is shown by their possession of hair, by the presence of mammary glands, by the nature of their red blood-corpuscles, by the structure of the lower jaw, and by the fact that the skull articulates with the vertebral column by two occipital condyles. On the other hand, they resemble the Reptiles or Birds, or both, as regards the ternination of the intestine in a clotca, the structure of the pectoral arch, and the want of true teeth, and in the still more important fact-but lately clearly established-that they produce their young in the form of eggs.

As regards their more important characters, the Nonotromatce are distinguished as follows :-

The alimentary canal termmates, as in Birds and Reptiles, in a dilated "cloaca," which not ouly receives the termination of the intestine, but also the ducts of the urinary and reproductive organs. The skull has the bones so amalgamated in the adult that the majority of the sutures are obliterated, as occurs also in Birds. There are no true teeth; but in Ornithorhyrechus the jaws carry horny plates (fig. 226, B and C), which act as teeth. The pectoral arch, which supports the fore-limbs, resembles that of Birds in several respects, but especially in the fact that the coracoid bones are distinct, and are not amalgamated with the shoulder-blade. There is no complete pouch developed on the abdomen of the females, but there are the so-called "marsupial bones." These are two small bones which arise from the front of the pelvis. They are really to be regarded as formed ly a conversion into bone of the tendons of 
one of the muscles of the abdomen. There are no external ears. The mammary glands have no nipples, but open either on a flat surface (Oruithorlynchus), or into a small "mammary pouch" (Echidnci). It has recently been shown by Mr C'aldwell that the Monotremes are not viviprarous, as all other Manmals are, but that they resenible the Reptiles and Birds in being oviparous. The Duck-mole lays two eggs-about three-quarters of an inch in length-which it deposits in the burrow in which it lives; and the Echicha lays one such egg, which it is stated to place in the small pouch of skin surrounding the openings of the mammary glands. Recent observations also show that the Monotremes further resemble the Reptiles in the fact that

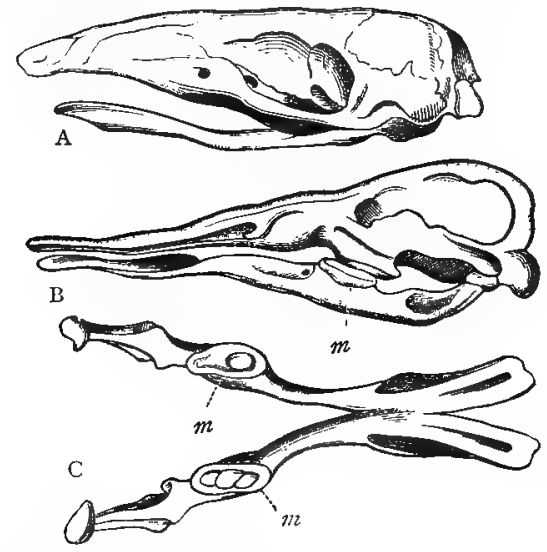

Fig. 226.-A, Skull of Echilna hystrix. B, Side view of the skull of Omithonthychus paraloxus, and $\mathrm{C}$, lower jaw of the sane, vewol from alove, showing the horny dental plates $(m)$.

the temperature of the body is much below that of the remaining types of the Mammals.

Of the two living genera of Monotremes, the Duck-mole (Ornithorlynolus) is fomnd exchusively in Australia inhabiting streans and ponds, in the banks of which it constructs burrows forty or fifty feet in length. The body is like that of a small Otter, covered with a short brown fur, and having a broal flattened tail (fig. 227). The jaws have no teeth, but cirry horny plates, which officiate as teeth (fig. 226, B and (?). The margins of the jaw are also sheathed in horn, forming a kind of flattened beak, very like that of a Duck (fig. 227). Hence the rame of "Duck-billed Animal" sometimes given to the Ornithorkynchns. The feet are webbed, and the males 
have a spur on the lind-legs. The only known species is the Ornithorhynchus paradoxus.

The other genus of Monotremes comprises the Spiny Ant-eaters (Echidna or Tachyglossus), which are not unlike large hedgehogs in appearance. The snout is very long, and is enclosed in a continuous skin till close upon its extremity, where there is a small aperture for the protrusion of a long and flexible tongue. There are no teeth, or any organs to act as teeth. The feet have five toes each, and are

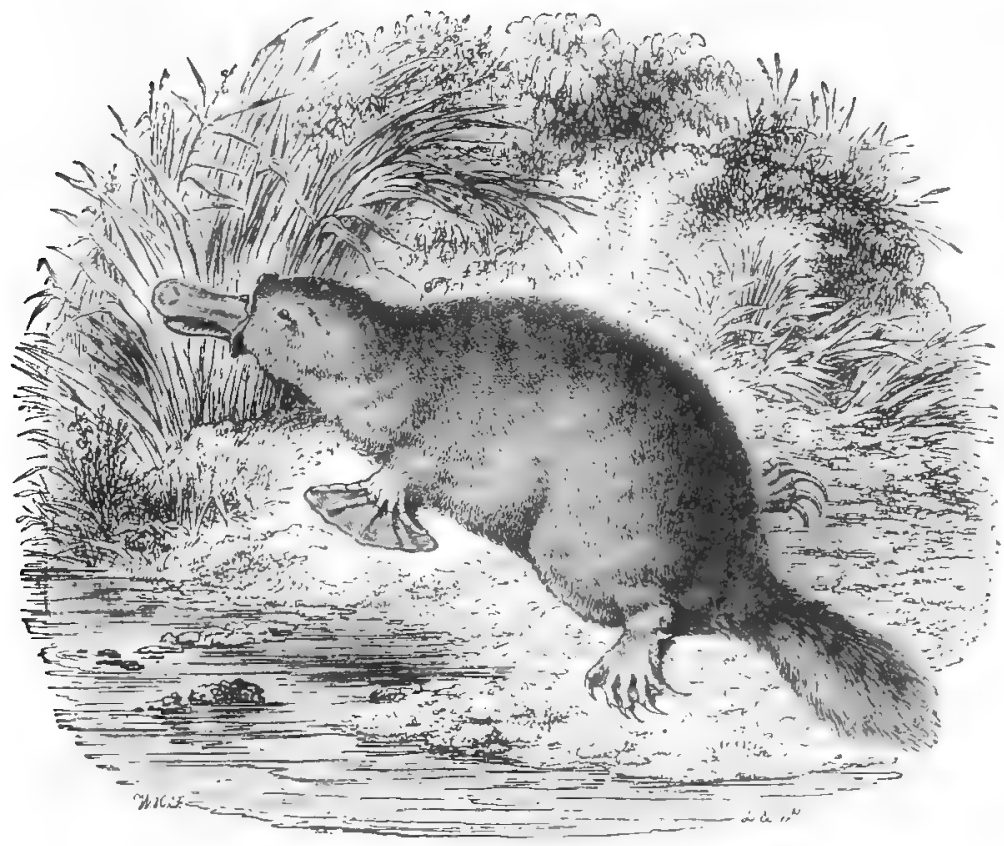

Fig. 227.-Monotremata. Ornithorhynchus paradoxus, Australia.

furnished with strong digging-claws, but the toes are not webbed. The skin is covered with strong prickly spines interspersed with bristly hair. The common Australian species (Echidna hystrix) measures from fifteen to eighteen inches in length, and is a nocturnal animal. It lives in burrows, and feeds upon insects, which it captures by protruding its long sticky tongue. Another species is found in Tasmania; and two species are known to occur in New Guinea. 


\section{Order II. Marsupialia.}

The name of lfursupials is derived from the fact that the females of this order are furnished with an abdominal pouch or marsupium (sometimes very imperfect), within which the nipples are situated. When born, the young are placed by the mother within this pouch, where they adhere to the teats, and can be carried about without injury. Even when further advanced, the young often betake themselves to the shelter of the marsupium. No placenta is present, and the young when born are therefore in a very imperfectly developed state. The so-called "narsupial bones" (fig. 228) are present, and

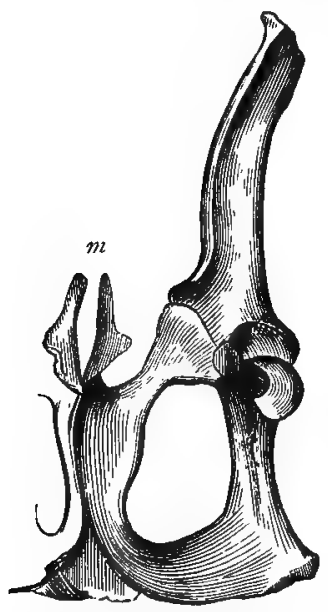

Fig. 228,-One side of the pelvis of a Kungaron, showing the "marsupial bones" (m)-aft.cr Owen. as they spring from the front of the pelvis they no doubt serve to support the pouch; but this cannot be their sole use, as they exist in the males, and also in the Montremes, in whom there is no pouch. All Marsupials possess teeth, and the pectoral arch has now the same form as in the higher Mammals, the coracoid bones being now amalgamated with the shoulder-blade. The cranial bones are distinct. The intestine does not terminate in a cloaca.

Though the I/orsupialia form an extremely natural order, sharply separated from the other Mammals, they include a large number of varied forms. In fact, this order, from its being the almost exclusive possessor of a continent so large as Australia, has to discharge, in the general econony of nature, functions which are elsewhere performed by several orders. As regards their geographical distribution, with the single exception of the family Didelphides (the true Opossums), the whole order of the Marsupials is exclusively confined to Australia, Van Diemen's Land, New Guinea, and the adjacent islands.

The Marsupials may be primarily divided into the vegetable-eating and the rapacions or carnivorous forms-the former characterised by the absence or rudimentary condition of the canine teeth, the molars having broad, grinding crowns; whilst in the latter there are welldeveloped canines, and the molars are not adapted for grinding. Of the vegetable-eating forms, the best known are the Kangaroos (Mlac- 
ropodida), distinguished by the remarkable disproportion between the hind and fore limbs, the former being by far the longest and strongest. By their long hind-legs, assisted by a powerful tail, the Kangaroos can perform astonishing jumps, and, in fact, leaping is their mode of progression when pursued.

The typical Kangaroos live on the great grassy plains of Australia; but the Tree Kangaroos spend a great part of their time in trees, and the Rock Kangaroos affect mountainous districts. The Kangaroo-bear or Native Sloth (Phascolarctos cinereus), has no tail, and has the body covered with a short, dense fur, whilst the ears are tufted. The fore-feet can be used as hands, and the toes are all

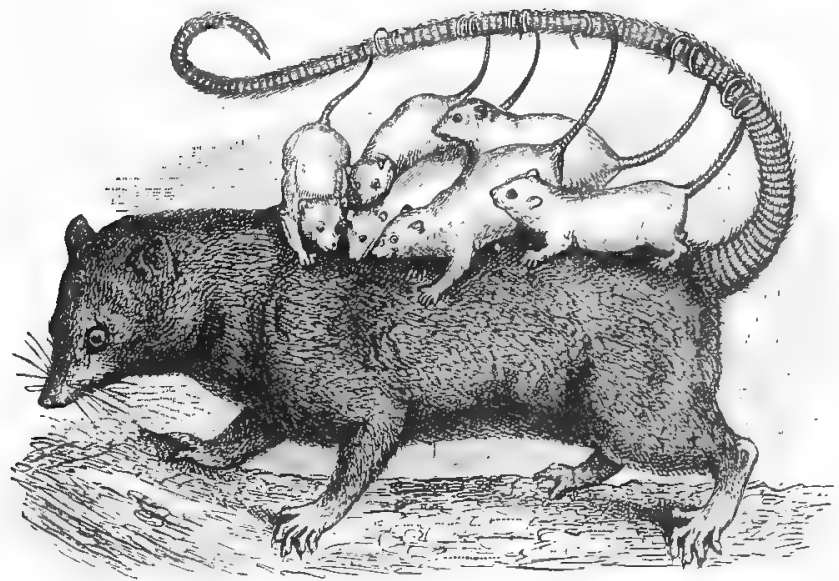

Fig. 229. - The female of Didelphys dorsigera, one of the Sonth Anerican Opossums, carrying its young upon its back.

furnished with strong curved claws. It is a harmless nocturnal animal, and spends most of its existence in trees. The typical group, however, of the vegetable-eating Marsupials is that of the Phalangers, comprising a large number of small animals which live in trees, and generally possess a prehensile tail. The most familiar example is the Australian "Opossum" (Phalangista vulpina), which is largely hunted by the natives. In the so-called "flying" Phalangers, again, the tail is not prehensile, and the animal takes extensive leaps from tree to tree, by means of a fold of skin which stretches between the body and the fore and hind limbs.

Of the carnivorous Marsupials, the Bandicoots (Perameles), the Native Devil (Dasyurus), the Native Tiger (Thylacinus), and the 
American Opossums (Didelphidce), may be mentioned. The Bandicoots are little, rabbit-like Australian animals, which live upon insects, and seem to fill the place held in the Old World by the Hedgehogs and the Shrew-mice. The species of Dasyurus, though of small size, are very ferocious; and the Thylacine grows to the size of a shepherd's dog, and is quite capable of destroying animals as big as sheep. About twenty species of Ditlelphidle are known, and they are all exclusively confined to the American continent. They are all of small size, bave prehensile tails, and mostly live among trees. The best-known species is the Virginian Opossum (Didelphys Virginiana). Another species of Opossum, the Didelphys dorsigera (fig. 229), carries its young about on its back, the young clinging to the mother by twining their prehensile tails round hers.

\section{Order ill. Edentata or Bruta.}

This order of Placental Mammals comprises the Ant-eaters, Armadillos, and Sloths, and is characterised by the fact that the teeth are not covered with enamel, have no complete roots, and are never re-

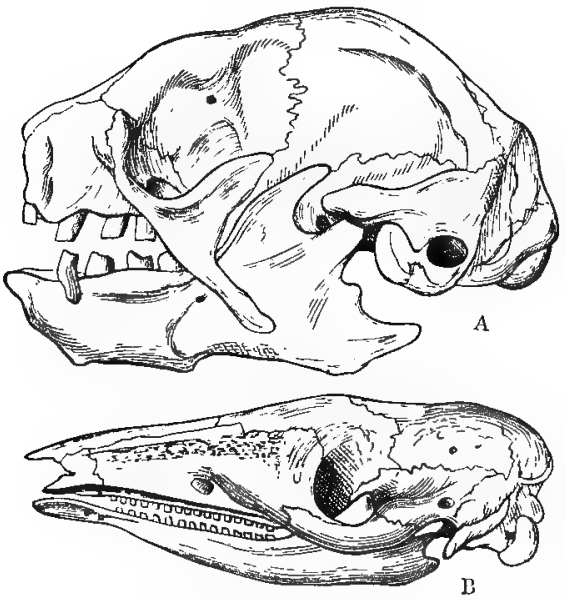

Fig. 230.-A, Side-view of the sknll of Bradypus cuculliger; B, Side-view of the skull of Dasypus gigas. (After Giebel.)

placed by a second set. As a rule, the teeth (fig. 230) are simple cylinders, placed at a little distance from each other. Further, in none of the Edentutes are there any central incisor teeth, and in all 
but one there are no incisors at all. In two genera only are there no teeth; so that the name Edentata is not a very appropriate one. In all, the toes are furnished with long and powerful claws.

The order Edentata is conveniently divided into two great sections, in accordance with the nature of the food, the one section being herbivorous, the other insectivorous. In the former section is the sing'e group of the Sloths (Bradypodidoe). In the latter are the two groups of the Armadillos (Dasypodidoe) and the various species of Ant-eaters.

The Sloths (Bradypodidae) are exclusively confined to South America, inhabiting the vast primeval forests of this continent.

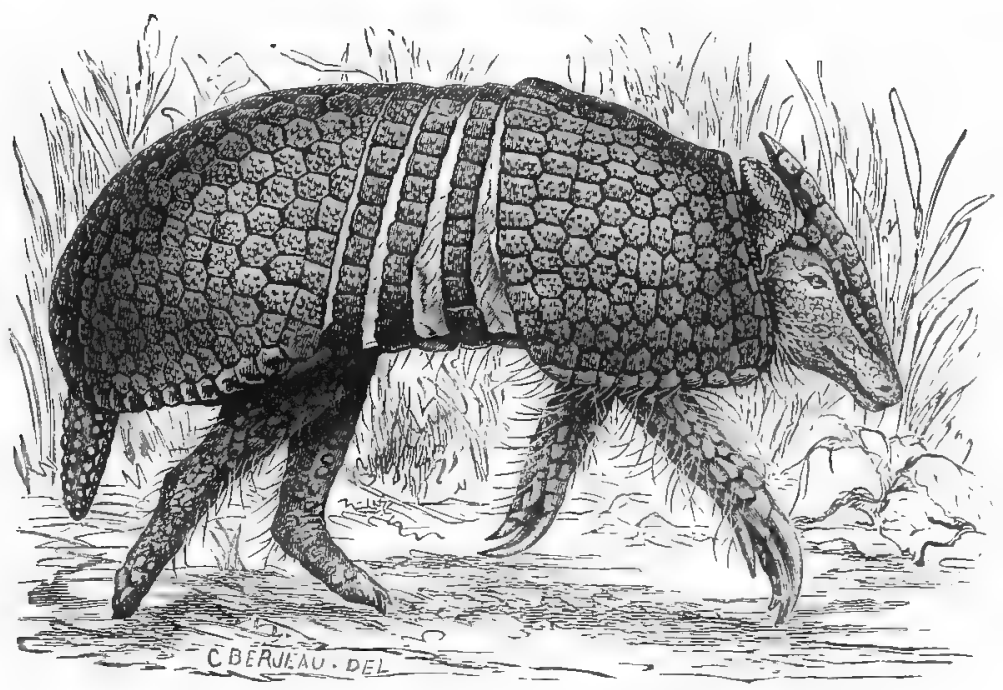

Fig. 231. -The Three-banded Armadillo (Tolypeutes conurus), one-third of the natural size. (After Murie.)

They are in every way adapted for an arboreal life, and are "destined to be produced, to live, and to die on trees." They are very awkward when upon the ground; but the feet are furnished with extremely long curved claws, so that the animal is enabled to move about freely suspended back down wards from the branches of the trees.

The second family of the Erlentata is that of the Dasypodidae or Armadillos. These are also found exclusively in South America, but they are very different in their habits. The Armadillos (fig. 231) are burrowing animals, furnished with strong digging-claws 
and well-developed collar-bones. The jaws are provided with numerous simple molars (fig. $230, \mathrm{~B}$ ), which attain the enormous number of nearly one hundred in the Great Armadillo (Dasypus gigus.s). The upper surface of the body is covered with a coat of mail, formerl of hard bony plates or shields united at their edges. A protion of this armonr covers the heal and shoulders, and another portion protects the hind-quarters; whilst between these is generally a variable number of movable bands which run transversely across the body and give the necessary flexibility to this singular integumentary skeleton. In most species this flexibility is so great that the animal can roll itself up like a hedgehog.

The remaining South American Elentates are the Hairy Ant("Iters, of which the best known is the Great Ant-eater (Myrneco-

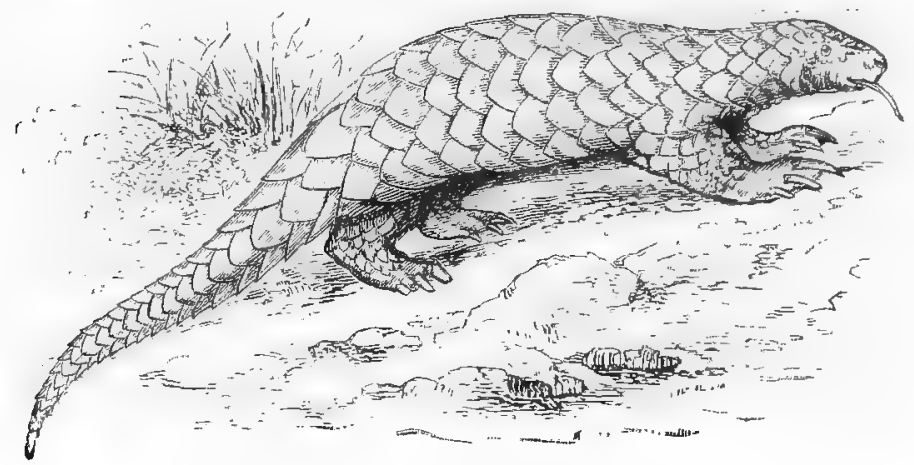

Fig. 232.-Manis pentadactyla, one of the Scaly Ant.eaters or Pangolins, showing the arinour of horny plates.

phaga jubata). The body in this family is covered with hair, the tail is lor.g, and the teeth are altogether wanting. They feed chiefly upon ants and termites, which they catch by protruding their long and sticky tongues, having previously broken into the nest by means of their strong curved claws.

The Eclentrut are represented in the Oid World by only two genera. One of these is the genus Manis, comprising the Scaly Ant-eaters or Pangolins, which are exclusively confined to Asia and Africa. In these singular animals (fig. 232) the body and tail are covered ly a flexible armour, composed of hormy plates or scales overlapping like the tiles of a roof. The other genus is 11;/teropus, compriving only the so-called Ground Hog of South Africa; which alwo lives upon insects, and burrows by means of its strong diggingclaws. 
As regards the geographical distribution of the Edentata, it is to be remembered that the order has a very limited range at the present day. The true Ant-eaters, the Armadillos, and the Sloths, are exclusively confined to South America, in which country a group of gigantic extinct Edentates existed in the later portion of the Tertiary epoch. The Scaly Ant-eaters are common to Asia and Africa; and the Ground Hog is confined to South Africa.

\section{Order IV. Sirenia.}

This order comprises only certain large marine Mammals, known as Dugongs and Manatees, which were long classed with the Whales and Dolphins (Cetacea). They agree with the Whales in the adaptation of the body to an aquatic life, especially in the facts that the anterior limbs are converted into swimming-paddles (figs. 233, 234), the hind-limbs are wholly wanting, and the hinder end of the body

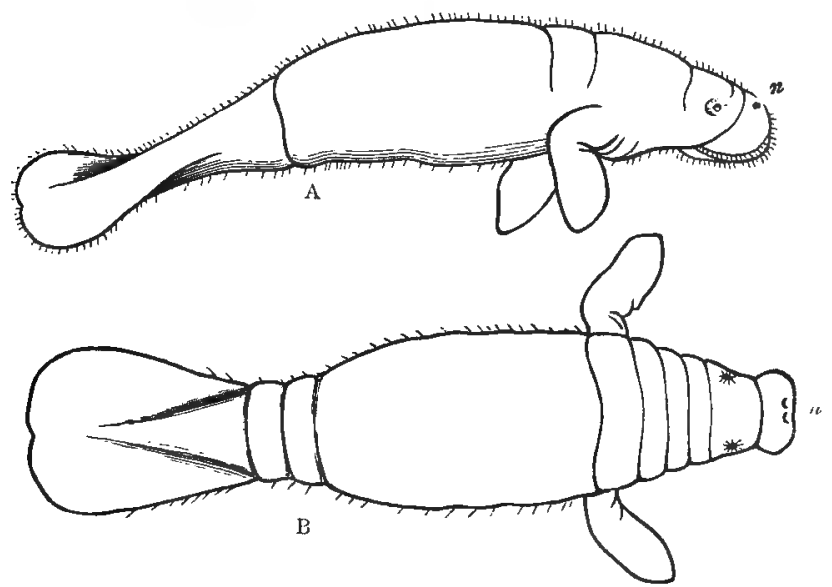

Fig. 233.-A, Side-view of young Manatus Americanus. B, the same viewed from above; $n$ Nostrils. (After Murie.)

forms a powerful candal fin, which is placed so as to strike the water horizontally, and not vertically as in Fishes. They differ from the Cetacea in having the nostrils placed at the anterior part of the head, and in having molar teeth with flat crowns, adapted for a vegetable diet. Fleshy lips are present, the upper one usually with a moustache, and the skin is covered with scanty bristles. The head is not disproportionately large as compared with the 
body, and there is a tolerably distinct neck. They are vegetableeaters, feeding chiefly upon sea-weeds, and haunting the mouths of rivers and estuaries, and sometimes ranging hundreds of miles inland.

The only existing Sirenia are the Manatees (Hanatis) and the Dugongs (Hulicore), often called "Sea-cows." The Manatees (fig. 233) are found on the east coast of America and on the west coast of Africa. They are large awkward animals, attaining a length of from eight to ten or fifteen feet, and their flesh is said to be very palatable and wholesome. The Dugongs differ little in appearance and habits from the Manatees. They are found on the coasts of the

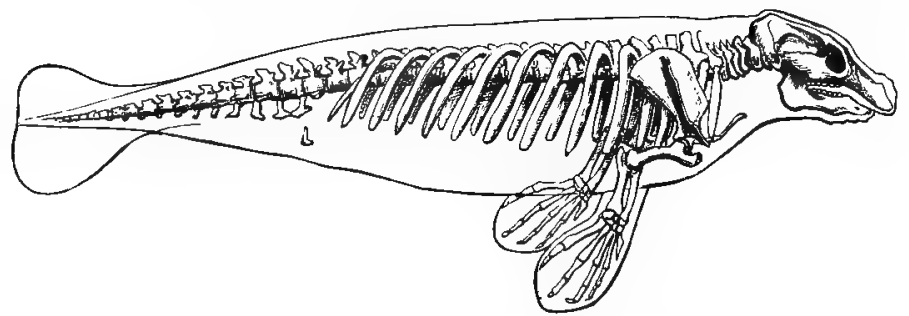

Fig. 231. -Sirenia. Skeleton of the Manatee (Manatus Americanus).

Indian Ocean and the north coast of Australia, and are often killed and eaten. They attain a lengtl of from eighteen to twenty feet. The bones of the skeleton are remarkable for their extreme hardness and density.

Besides these living forms, the Sirenia were represented by a gigantic species which formerly inhabited Behring Island on the cuast of Kantchatka. This animal was described by M. Steller who accompanied Behring on his second expedition, and he named it Rhytinu. This enormons animal attained a length of twenty-five feet, and a circumference of twenty feet, and it appears to have been completely exterminated, no specimen having been seen for nore than a century.

\section{Order T. Cetacea.}

This order comprises the Whales, Dolphins, and Porpoises, and it is characterised by the complete adaptation of its nembers to a watery life. The body (fig. 235) is completely fish-like in form, the fore-limls are converted into swinuning-paddles, and the hindlimbs are completely wanting; whilst the hinder end of the body forms an extremely powerful, horizontal caudal fin. Sometimes 
there is a dorsal fin as well. The nostrils may be single or double, but always are placed on the top of the head, constituting the "blow-hole." The body is very sparingly furnished with hairs, or is wholly without them in the adult. The head is generally of disproportionately large size as compared with the body, and is rarely separable from the trunk by any distinct constriction or neck. There is no sacrum; the pelvis is only represented in a rudimentary form; and.the hind-limbs are either wholly wanting, or are present only as rudiments, concealed within the muscles. Lastly, the adult is either wholly destitute of teeth, or possesses only a single set, which are always conical in shape, and are never divisible into distinct groups. All the true Cetacea are carnivorous, living upon animal food.

Chief amongst the Cetaceans in importance and zoological interest

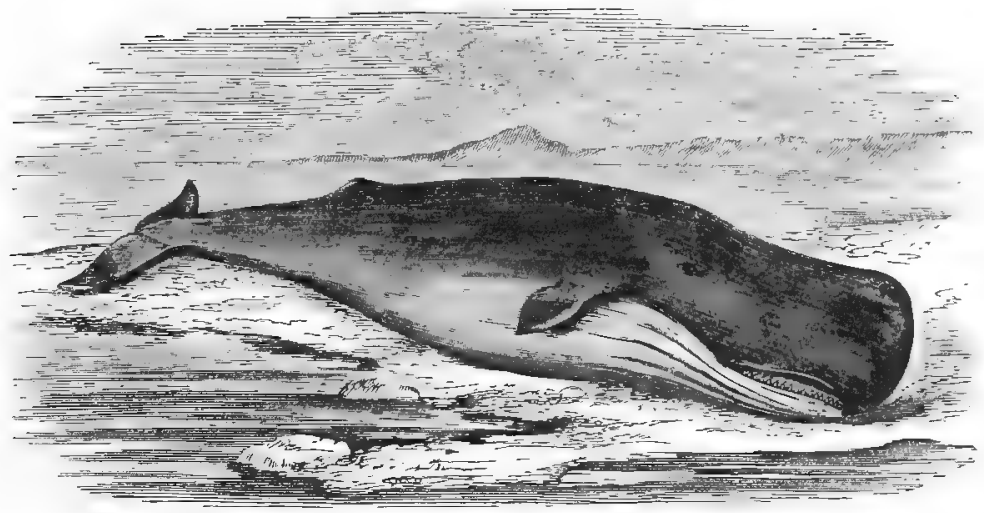

Fig. 235.- Spermaceti Whale (Physoter macrocephatus).

are the Whalebone Whales (Bulcenid(c), in which the adult is destitute of teeth, though the young Whale possesses teeth which never cut the gum. The place of teeth is taken by a series of transverse plates of whalebone or baleen, which are used as a kind of screening apparatus or filter to separate from the sea-water the minute Molluses and Jelly-fishes upon which these enormous animals live. The most important member of this family, from a commercial point of view, is the Greenland Whale (Balcena mysticetus), which yields most of the whale-oil and whalebone of commerce. The Greenland Whale attains a length of from forty to sixty feet, and of this enormous length about a third is taken up by the head alone. The oil is derived from a thick layer of fat or "blubber," which is situated 
under the skin, and serves to protect the body from cold. Though an inhabitant of the sea, the Whale is obliged to come to the surface to breathe, and in so doing it ejects from the blow-hole what looks like a column of water, the whole operation being known to the whalers as "blowing." The true nature of this act is now hardly questionable, and it appears certain that the apparent jet of water is in reality, mainly if not entirely, due to the condensation of the moisture which is contained in the air expelled from the lungs. The old view was that "blowing" consisted in the Whale ejecting through the nose the water which had previously been filtered through the baleen-plates of the mouth; but it appears to be quite certain that this view, at any rate, is not the correct one. The Rorquals or Finner Whales resemble the Greenland Whale in most respects, but the skin is furrowed with deep plaits or folds, and there is a dorsal fin, placed on the back. Some of these attain a gigantic

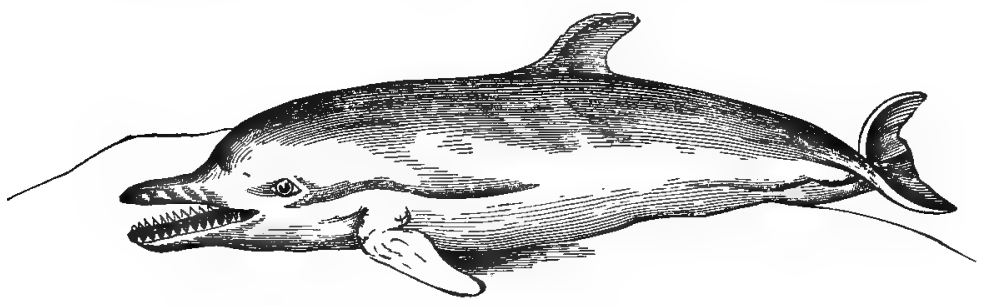

Fig. 236. - Cetacea. The common Dolphin (Delphinus delphis).

size (eighty feet or more), but they are seldom captured, as their commercial value is small.

The Toothed Whales (Odontwiti) are best known ly the Sperm Whale (fig. 235), an animal as large or larger than the (ireenland Whale, but distinguished hy having numerous conical teeth, a single blow-hole, and a curionsly truncated bead. Sperm Whales yield an excellent oil, and the singular fatty substance which is known as "spermaceti." They also yield the substance called "ambergris," which is used as a perfume; but this is probluly a product of disease.

The last fanily of the Caturere needing mention is that of the Delphinille, comprising the Dolphins (fig. 236) and Porpoises. They have numerous conical teeth in both jaws, and the nostrils open by a single aperture on the top of the head. The Dolphins are mostly inhalitants of the sea, but there are fresh-water forms which inhabit the rivers of South America and Southem Asia. The Porpoises are exclusively marine, and occur in all seas. The most remarkable of the Drphinidce is the Narwhal "Sea-micom, which is found in 
the Arctic seas, and which attains a length of as much as fifteen feet in the body alone. The chief peculiarity of the Narwhal is in the dentition. The females, as a rule, have no front teeth, the upper jaw alone having two rudimentary canines which never cut the gum. In the males, however, whilst the lower jaw is without teeth, one of the two canines of the upper jaw (the left one) is enormously developed, and grows throughout the life of the animal. It forms a tusk of from eight to ten feet in length, the whole surface of which is spirally twisted. The function of this extraordinary tooth is doubtless offensive.

\section{Order VI. Ungulata.}

This order is often spoken of as that of the Hoofed Quadrupeds, and is one of the largest and most important of the orders of Mammalia. The order is characterised by having all the four limbs, and by having that portion of the toe which touches the ground encased in a greatly expanded nail or hoof. There are never more than four full-sized toes to each leg, and owing to the presence of hoofs the limbs are useless for grasping, and are only of use in locomotion and in supporting the weight of the body. There are always two sets of teeth, and the molars have broad crowns adapted for grinding vegetable substances.

The $L^{\prime}$ ngulata are divided into two great prinary sections, according as the toes are even or odd in number:-

A. Perissodactyla, or Odd-toed l'ngulates, in which the toes are odd in number-either one or three. ${ }^{1}$ If horns are present, they are not in pairs (in any living form).

B. Artiodactyla, or Even-toed Lingulates, in which the toes are even in number-either troo or four; and if horns are present, they are in pairs.

Section A. Perissodactyla.-The living Perissodactyle Ungulates are the Rhinoceros, the Tapirs, and the Horse and its allies. The Rhinoceroses are extremely large and bulky brutes, having a very thick and nearly hairless skin, usually thrown into deep folds. The feet (fig. 237, B) are furnished with three toes each, all encased in hoofs. The nose (fig. 238) is furnished with one or two horns, composed of longitudinal fibres compacted together, and not having any central core of bone. When there is only one horn, it is, of course, unsymmetrical; and when there are two, these are not paired, but (except

1 The fore-feet of the Tapirs are even-toed, but the hind-feet are perissodactyle; and in some extinct types we find five toes to the foot. 
in some fossil forms) one is always placed behind the other in the middle line of the head, and the hinder one is much the shortest. The various species of Rhinoceros are found in India, Java, Suma-

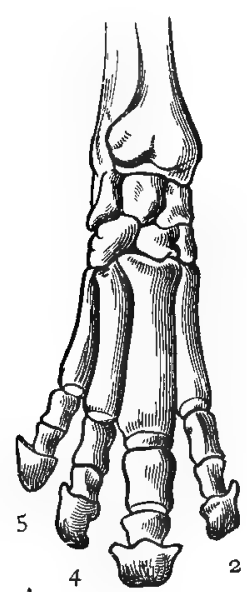

$\Lambda$

3

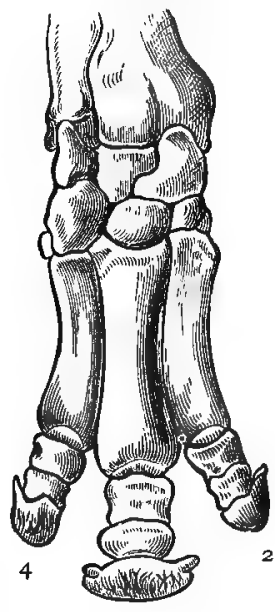

$\mathrm{B}$

3

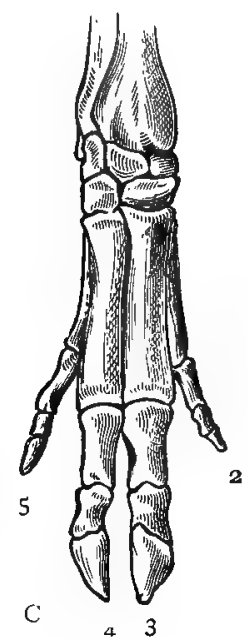

43

Fig. 237.-Feet of Ungulata. A, Fore-foot of Tapir (Tapiras Malayanus); B, Perissodactyle fore-foot of Rhinoceros Sumatrensis; C, Artiodactyle foot of Pig (Sus scrof $($ ). The figures indicate which of the normal five digits are present in each foot. (After Flower.)

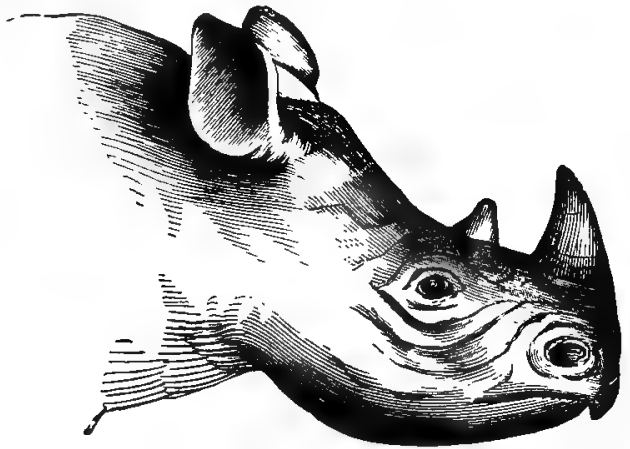

Fig. 238. - Head of two-horned Rhinoceros (R. bicornis).

tra, and Africa, inhabiting marshy places, and feeding chiefly on the foliage of trees.

The Tapirs ( Tupiridt") have four toes to each of the fore-legs, but 
only three toes on the hind-legs, so that they are really odd-toed. The nose forms a short movable proboscis, used in stripping off the leaves of trees. They are large, clurnsy, pig-like animals, which inhabit South America, Sumatra, Borneo, and Malacca.

The third and last family of the living Perissodactyle Ungulates is that of the Equidce, comprising the Horses, Asses, Zebras, and Quaggas. In this family, so far as existing types are concerned, the foot carries only a single toe (the third toe), which is furnished with a broad hoof (fig. 223). Upon the end of this toe the animal walks, and the Equidce are, therefore, often spoken of as "Solipedes." The sceond and fourth toes are present in a rudimentary form as little bony splints (the so-called "splint-bones"), hidden under the skin (fig. 223); but in certain extinct types these lateral toes are more or less developed, and carried hoofs, the foot thus becoming three-toed.

There is a continuous series of incisor teeth in both jaws, and in the males canines are present. The dental formula is-

$$
{ }_{3-3}^{3-3} ; c_{1-1}^{1-1} \text { (or none); } p m^{3-3} \begin{aligned}
& 3-3 \\
& 3-3
\end{aligned} ; \frac{3-3}{3-3}=40 .
$$

All the domestic varieties of Horses appear to be descended from the single species Equus caballus, which seems to have been primitively a native of Central Asia, in which country another species of Horse bas been recently discovered. When the American continent was discovered, it certainly possessed no living horse, but the Horse has now become completely naturalised there, and we know that America formerly possessed about twenty species of Horses, all of which are now extinct. In the genus Asinus are the Asses, Zebras, and Quaggas. The Wild Asses are natives of Asia and North Africa; but it is not quite certain from what species the domestic Ass is descended. The Zebras and Quaggas are exclusively African, and are distinguished by their beautifully striped and banded bodies.

Section B. Artiodactyla.-The Even-toed Ungulates may be divided into the two groups of the Omnivora and the Ruminantia, the former comprising the Hippopotamuses and the Swine, while the latter includes the Oxen, Deer, Camels, \&c.

Of the Omnivorous Artiodactyles, the Hippopotamuses constitute a small group, comprising massive, thick-skinned Ungulates, with four-toed feet. The common Hippopotamus amphibius inhabits all the great rivers of Africa, living upon plants, and swimming and diving with great facility. The molar teeth have flat crowns, of a peculiar double-trefoil pattern; but the canines are very large, and the lower ones in particular form enormous tusks, with a chisel- 
shaped edge (fig. 239), and these are the principal weapons by which the animal defends itself.

The Pigs, Peccaries, and Wart-hogs constitute the family Suida, and have usually four toes to each foot, though sometimes the hindfeet have only three toes. All the toes are hoofer, but it is only two which support the weight of the body, the remaining toe or toes being placed at some elevation on the back of the foot (fig. 237,

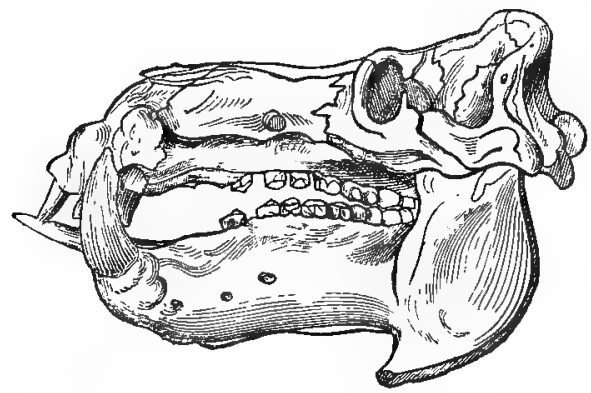

Fig. 239.-Skull of Hippopotamus amphibius, side-view.

C). The snout is truncated and cylindrical, and is capible of extensive movenent. The tail is very short, or is represented only by a tubercle. The molar and premolar teeth hive tuberculated crowns (fir. 240), and the Pigs are very miscellaneous feeders.

(I) the Kwine the most important and best known is the Wild Boar (Sizs sirufit), from which most of our domestic varieties of Swine have sprung. Another form is the Babyroussa (Sus baby-

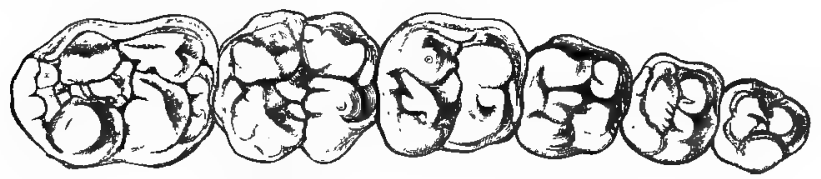

Fig. 240.-Grinding surface of the molar and præmolar teeth of a Peccary (Dicotyles labiatus). (After Giebel.)

musa), which inhabits the Indian Archipelago, and is remarkable for the great size and backward curvature of the upper canine teeth. The Wart-hogs (Phacocherus) are African, and derive their name from the possession of a Heshy wart under each eye. The Peccaries are exclusively American, the best-known species being the Collared Peccary (Dicotyles turimutus). They are not at all unlike small pigs both in appearance and habits, but they present various striking 
anatomical peculiarities, which distinguish them from the Swine of the Old World.

The Ruminantia form a most natural group of the lingulata, characterised by the structure of the foot, the dentition, and the structure of the stomach.

The foot is "cloven," consisting of a symmetrical pair of toes, encased in hoofs, and looking as if produced by the cleavage of a single hoof. The two functional toes (fig. 222) are the third and fourth toes (the middle and ring toes); but the second and fifth toes (the index and little toe) may be present in a rudimentary form on

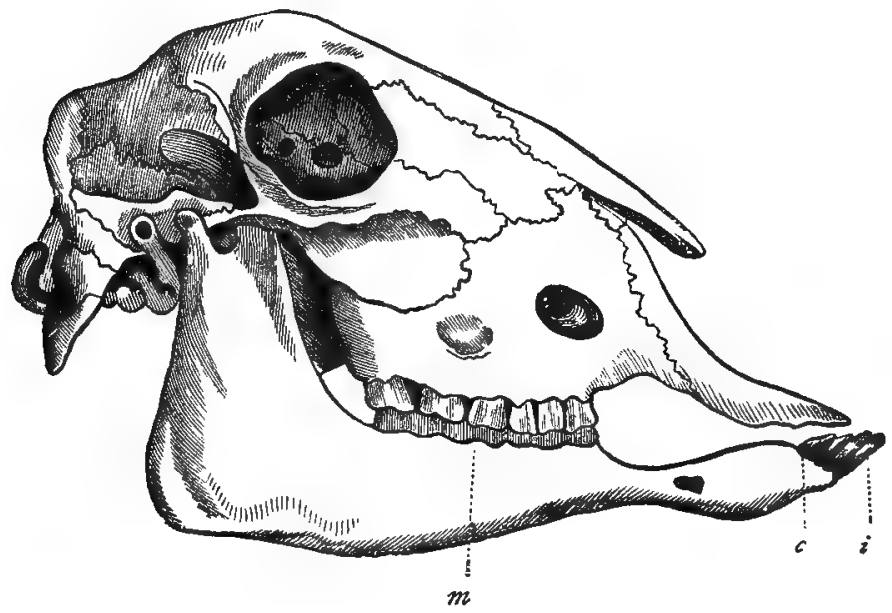

Fig. 241.-Skull of a hornless Sheep : $i$ Incisnts; $c$ Canines; n Molars and præmolars. (After Cuvier.)

the back of the foot. In no case, however, are these lateral toes so far developed as to touch the ground in walking on a hard surface.

As regards the dentition, the typical state of things is that there should be no incisor or canine teeth in the upper jaw (fig. 241), but that the lower jaw should have six incisors and two canines, which are all similar in size and form, and constitute a continuous and uninterrupted series of eight teeth placed in the front of the lower jaw. There are six back teeth (præmolars and molars) on each side of each jaw, and these have grinding surfaces, the enamel ridges of which form double crescents. The typical dental formula, therefore, for a Ruminant is-

$$
i_{3-3}^{0-0} ; c \frac{0-0}{1-1} ; \text { pm } \frac{3-3}{3-3} ; m \frac{3-3}{3-3}=32 .
$$


In the absence of incisor teeth in the upper jaw, the lower incisors bite against a callous pad of hardened gum. The Camel tribe differs in its dentition from the above typical formula, and certain exceptions likewise occur in the males of some other forms, and in one or two other less important instances.

The stomach in the Ruminants is complex, and is divided into several compartments, this being in accordance with their mode of eating. They all, namely, "ruminate" or "chew the cud"; that is to say, they first swallow their food unmasticated, and then bring it up again after a longer or shorter period in order to chew it. This is effected as follows (fig. 242 ): The gullet opens at a point between the first two compartments or stomachs, of which the largest lies to the left and is called the "paunch," whilst the smaller right cavity is called the "honeycomb bag" (reticulum). The paunch (rumen) is

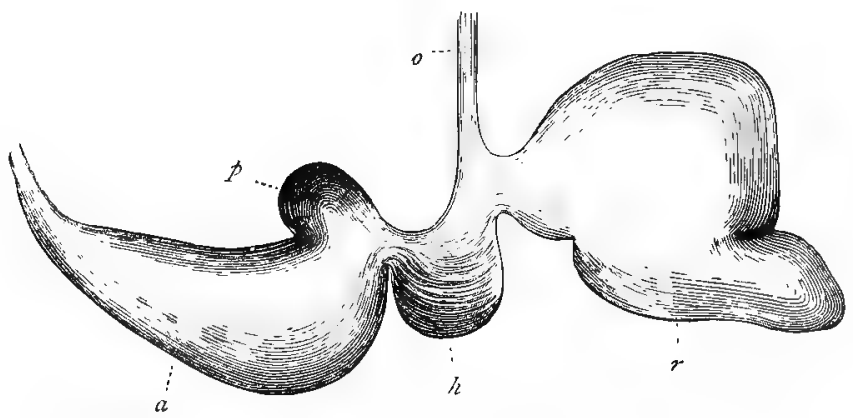

Fig. 242.-Stomach of a Sheep. o Gullet; $r$ Rumen or paunch; $h$ Honeyconb bag or reticulum; $p$ Nany-plies or psalterium; a Abomasum or fourth stomach.

the cavity into which the food is first received, and here it is moistened and allwwerl to soak for some time. After the food has lain sufficiently long in the paunch, it passes into the "honeycomb bag," from which it is ultimately returned in successive portions to the mouth by a reversed action of the muscles of the gullet. After having been thoroughly chewed, and prepared for digestion, the food is now swallowed a second time. On this occasion, however, instead of passing into the paunch, the masticated food is conveyed into the third stomach. This is known as the "many-plies " or "pselterizm," because its lining membrane is thrown into a number of longitudinal folds, like the leaves of a book. The psalterium opens by a wide aperture into the fourth and last stomach, known as the "abomasum." This is a cavity of considerable size, which secretes the true digestive fluid (gastric juice), and it is here that the food is really digested. 
The abomasum terminates, of course, in the commencenent of the small intestine.

The Rumizantia include a number of families of which it is only possible to notice the leading characters.

The family Camelide comprises the Camel and Dromedary of the Old World and the Llanas of the New, and is characterised by having no horns, by having two incisors in the upper jaw, and a pair of canines in both jaws; whilst the first præmolar tooth in both jaws (or in the upper jaw only) is conical in shape, and is placed at some distance in front of the other back teeth (fig. 243). The foot consists of only two toes, covered with imperfect nail-like hoofs, and destitute of the two supplementary toes. The soles of the feet are covered with a callous horny integument upon which the animal walks. In the Camels the toes are conjoined below by a callous pad, and the back is furnished with one or two fleshy

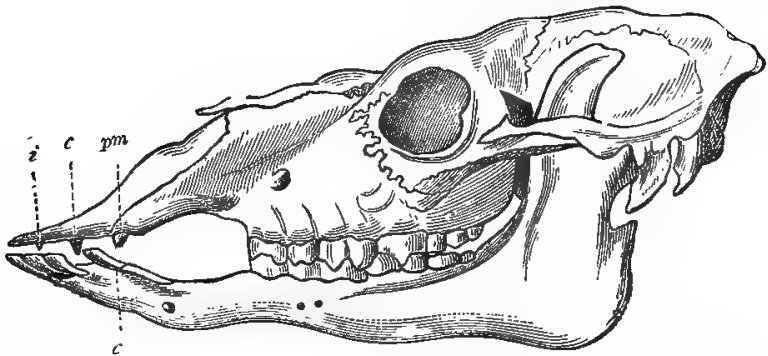

Fig. 243.-Side-view of skull of Camelus Bactrianus: $i$ Upper incisor ; $c$ e Cunines ; pm Isolated premolar. (After Giebel.)

humps. The Arabian Camel or Dromedary has but one hump, and its structure admirably adapts it for a beast of burden in the sandy deserts of Arabia and Africa. One special provision toward this end is the possession of large cells in the paunch, in which a great quantity of water can be stored up, thus enabling the animal to travel for days without drinking. The Bactrian Camel resembles the Dromedary in most respects, but it possesses two humps. The place of the Camels of the Old World is filled in South America by the Llamas and Alpacas (Auchenia), which have separate toes, and have no hump. The Llama is extensively used as a beast of burden, but the Alpaca is chiefly of value for its long wool, which is largely manufactured.

The small fanily of the Tragulida includes the little deer-like, animals which are known as "Chevrotains. These are very like the true Musk-deer (which are now placed with the Cervidee), and have 
no horus, while the canine teeth are developed in both jaws, and the upper canines of the males are tusk-like. The Tragulidce are found in India, the Indian Archipelago, and Africa.

The family c'erride includes the true Deer and the Musk-deer, and is characterised by the fact that the forehead carries two solid bony antlers, which are not hollow, and are usually much branched (fig. 214). With the single exception of the Reindeer, these appendages are exclusively confined to the males, and are deciduous; that is to say, they are only produced at certain seasons (annually, at the breeding season), and they are shed and reproduced before the commencement of the next breeding season. They increase in size and in the number of branches every time they are reproduced till in the old males they may attain an enormous size.

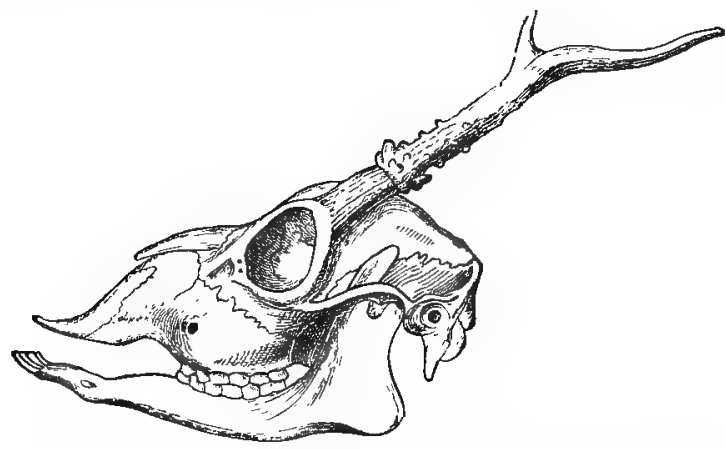

Fig. 244. - Side-view of the skull of the Roebnck (Cripreolus caproa). (After Giebel.)

Among the more familiar of the Deer may be mentioned the Elk, or Moose (Alces Americanus) of Scandinavia and North America; the Reindeer and Caribou (Cmms twandus) of Northern Europe, Asia, and North America; the Red Deer (Cerous elaplus) of Europe; the Wapiti (C'. C'cundensis) of Canada; and the Roebuck (Capreolus caproa) of Northern Europe.

Of the Giraffes or cimmetopardalider there is only a single living form, exclusively confined to the African continent. Both sexes have two pairs of short horas, carried on the forehead; but these are persistent, and are covered with a hairy skin. The neck is extremely long, and the fore-legs much longer than the hind-legs. It is the largest of living Ruminants, and measures as nuch as from fifteen to eighteen feet in height.

The Cavicornia or Hollow-homed Ruminants comprise the Oxen, 
Sheep, Goats, and Autelopes, and are characterised by having horns, which may be present in one or both sexes, and consist of a horny sheath surrounding a central bony axis, or "horn-core" (fig. 245). The horns are persistent, and are not periodically shed, and there is ustally only a single pair, though sometimes there are two pairs. In the Prong-buck Antelope alone, the horny sheath which surrounds the horn-core is annually shed and reproduced. In their dentition, and in other respects, the Cavicornia are to be regarded as being the most typical examples of the Ruminantia, and they include a number of animals which are of the highest utility to man.

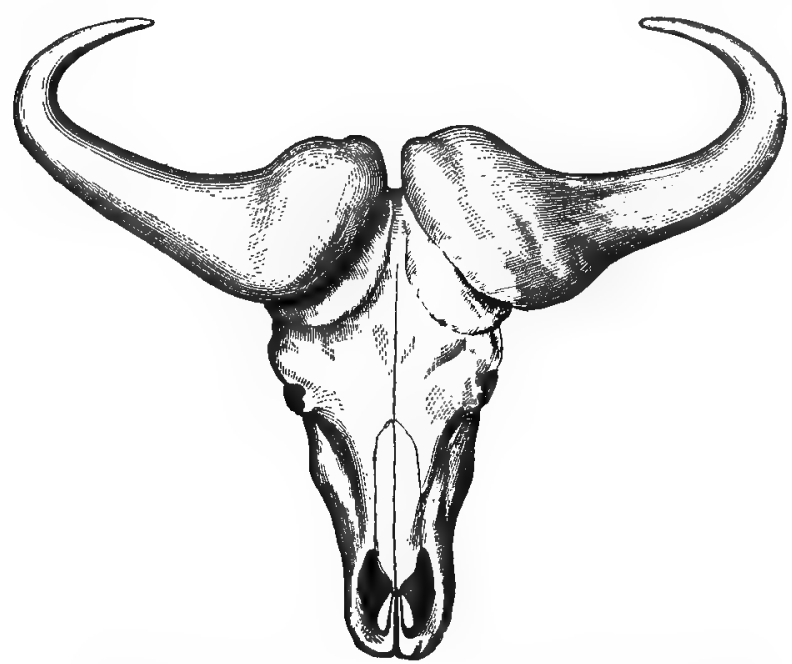

Fig. 245.-Skull of the Cape Buffalo (Bubahis caffer), viewed from above, showing the horn-cores. (After Cuvier.)

The Antelopes form a very extensive group, closely resembling the true Deer, but distinguished by the possession of hollow horns, in place of solid antlers. Most of the Antelopes are African, and there are only two European forms (the Chamois being one), while America possesses only the Prong-buck (Antilocapra furcifer). Among the more familiar African species may be mentioned the Koodoo (fig. 246), the Gnu, the Gemsbok, and the Springbok. The Sheep and the Goats (Ovidce) are closely allied to one another, and are well known by their domestic varieties, All the Sheep are natives of the Old World, with the exception of the "Big-horn" (Ovis montan $\alpha$ ) of the Rocky Mountains. Among the true Oxen 
(Bovidce) the most important species is the domestic Ox (Bos taumus) with its innumerable varieties. The true Buffalos (Bubalus) are natives of Asia and Africa, and are characterised by their wide horns united at the base (fig. 245). The American Buffalo (Bison Americanus), or Bison as it is properly called, is clistinguished by its

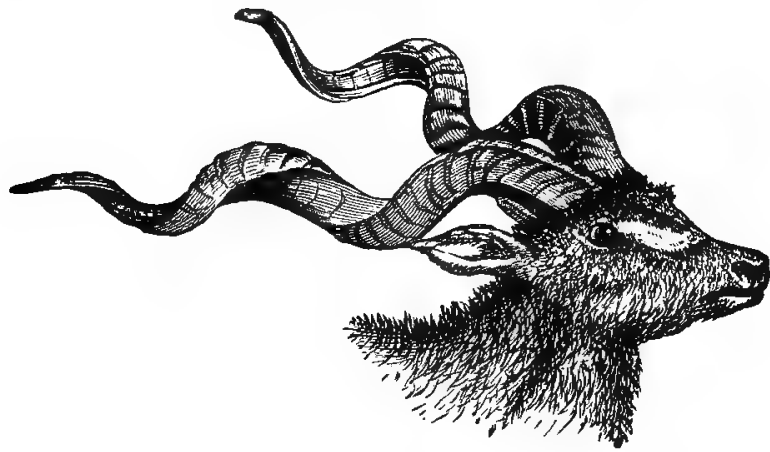

Fig. 24li,-Antelopidx. Head of the Kouloo (Strepsiceros Koodoo).

enormous head, shaggy mane, and conical hump between the shoulders. America also possesses another singular Ox (or Sheep) in the person of the Musk Ox (Ovibos moschatus), which is found north of the 60th parallel, and is remarkable for its small size an'l long woolly coat.

\section{Order VII. Dinocerata.}

This order comprises only some extraordinary extinct animals found in the Tertiary deposits (Eocene) of North America. In Dinoceras, which may be taken as the type of the group, we have an animal of large size, resembling the Elephants in most of the details of the skeleton, with five well-developed toes on the fore-feet, and with four functional toes on the hind-feet, the hallux being rudimentary. No trunk or "proboscis" was yresent, but there are three pairs of bony processes, or "cores," which seem to have carried as many horny protuberances, one pair being on the nasal bones, anotlier on the upper jaws, and the third (the largest) on the frontal bones. The upper jaw is without incisors, but carries lnge tusk-like canines; and a series of six small præmolars and molars is present on each side. In the lower jaw are six incisors, small canines, and a corresponding series of premolars and molars.

\section{Order viti. Tillodontia.}

This is another extinct order of Mammalia, comprising some singular fossil quadrupeds from the Tertiary deposits (Eocene) of North America. The animals included in this order resemble the Beasts of Prey (Carnivore) most 
closely as regards the general structure of the skeleton, and especially as to the conformation of the feet; but they possess also characters which ally them to the Ungulata and to the Rodentia. One of the most striking characters is the presence in the front of each jaw of a pair of huge incisor teeth, which resemble the corresponding teeth of the Roclent animals in having chisel-shaped crowns, and in growing throughout the life of the animal.

\section{Order IX. TOXodontia.}

This is a third extinct order of Mammals, comprising certain large fossil qualrupeds from the later Tertiary deposits of South America, the true relationships of which are quice uncertain. The nolar and præmolar teeth have flat grinding crowns, but they grow from permanent pulps, and continue growing throughout the life of the animal - a feature specially characteristic of many Rodents. The incisors resemble those of the Ungulates generally, and the canines are small, and in the upper jaw are deciduous.

\section{Order X. Hyracoidea.}

This order includes only a single small genus (Hyrax'), of which only two or three species are known. They are all gregarious little animals, mostly living in holes of the rocks, and capable of domestication. One species (IIyrax Capensis) occurs commonly in South Africa, and is known to the Dutch colonists as the "Badger." Another species (Hyrax Syriacus) occurs in the rocky parts of Arabia and Palestine, and is believed to be the "coney" of Scripture. They present many curious points of resemblance to the gigantic Rhinoceros, and are often placed in the same order, the similarity being especially great as regards the form of the molar teeth. The incisor teeth of the upper jaw are long and curved, with sharp cutting edges, and they grow from a permanent pulp, thus resembling the teeth of the genuine Rodents (such as the Rabbit or Beaver).

\section{Order XI. Proboscidea.}

The only living animals which belong to the order of the Proboscideans are the Elephants, of which there are only two well-marked existing species-namely, the Indian Elephant and the African Elephant. The name of the order is derived from the fact that the nose is prolonged into a long cylindrichl trunk, or "proboscis," which is highly muscular, and which terminates in a finger-shaped lobe, below which are placed the apertures of the nostrils (fig. 247). The proboscis is the sole organ of prehension possessed by the animal, and is employed to take up water, and also to introduce into the mouth the vegetable substances upon which the Elephant feeds. The Elephants, in fact, 
are unable to apply the mouth directly to the ground, either for feeding or for drinking, owing to the peculiar form of the incisor teeth. The upper incisors of the Elephants, namely, are two in number, and constitute long tnsks, which grow throughout the entire life of the animal, and which in old individuals may reach a length of six or seven feet (fig. 247). There are no lower incisor teeth, and canine teeth are wanting in both the upper and lower jaws. Each jaw, however, usually exhibits a pair of exceedingly large molar teeth (fig. 248), which are transversely ridged, and which are

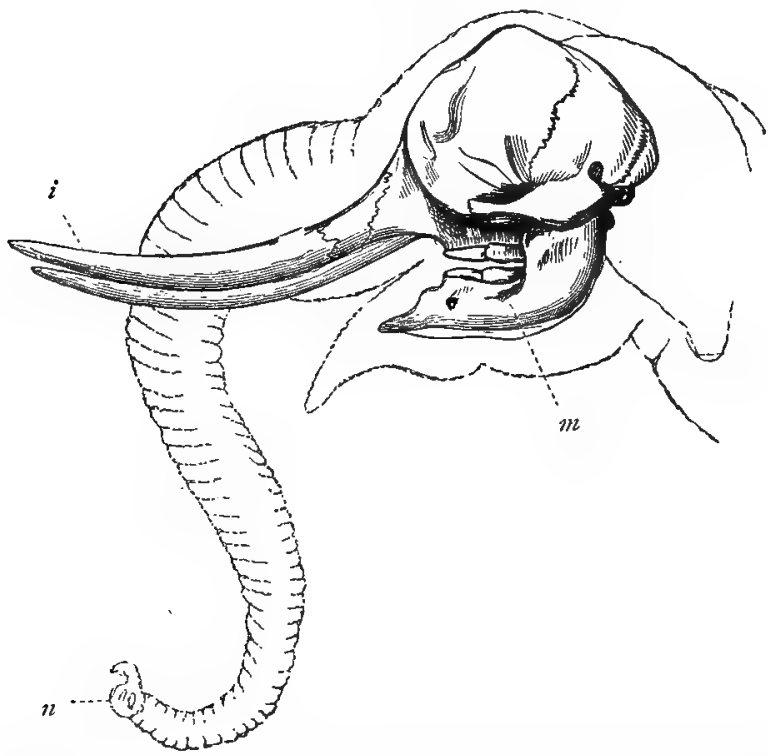

Fig. 24T.-Skull of the Indian Elephant (Elephas Indicus). $i$ Tusk-like upper incisors; $m$ Lower jaw, with grinding mulars, but without incisors; $n$ Nostrils, placed at the extrenity of the proboscis.

used in triturating the foliage or herbage on which the animal feeds. The entire structure of the Elephant is exceedingly massive, and the skin is thick, and sparingly furmished with hair. The feet have five toes each, but all the toes ch not carry hoofs, and the animal walks upon a thick pad of horny skin, which forms the lower end of each foot.

The recent Elephants are exclusively confined to the tropical regions of the Old World, in the forests of which they live in herds. Only two living species are known-the Asiatic Elephant (Elephas Indins) and the African Elephant ( $E$. Ifitomus). There can be no 
doubt, however, but that the Mammoth (Elephas primigenius) existed in Europe within the human period.

The Indian Elephant inhabits India and the Indian Archipelago, and has five hoofs on the fore-feet, but only four on the hind-feet. Like the Ceylon Elephant, which is a mere variety, the males alone possess well-developed tusks. The African Elephant has four hoofs on the fore-feet, and only three on the hind-feet, while it is smaller and darker in colour than the Indian species. Both sexes also possess tusks, though those of the males are largest.

Besides many extinct forms of Elephants, there formerly existed

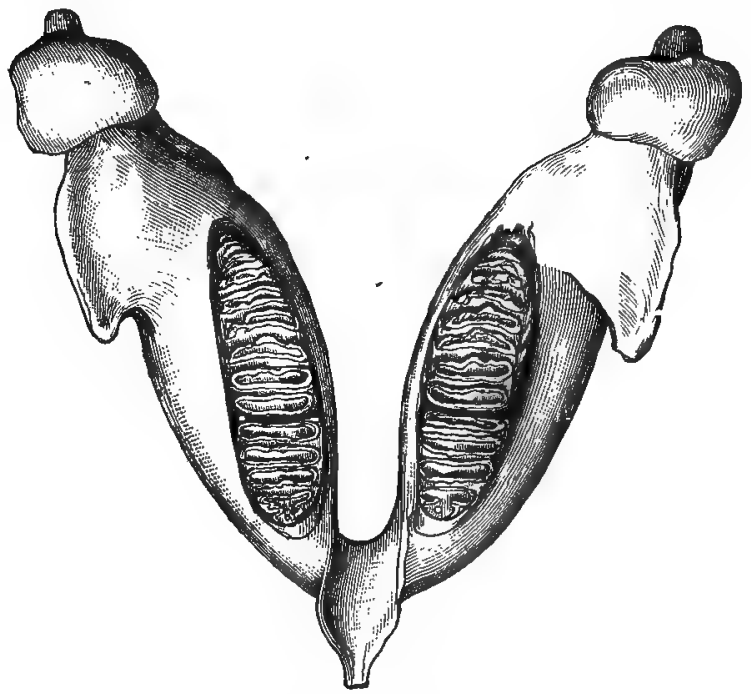

Fig. 248. - Lower jaw of the Indian Elephant (Elephas Indicus) viewed from above, showing the nolar teeth. Greatly reduced in size.

Elephantine animals belonging to two allied genera-viz, Deinotherium and Mastodon. In the Mastodons the whole structure of the animal was closely similar to that of the Elephants; but the molar teeth had tubercular and not ridged crowns; and there were sometime two tusk-like lower incisors in addition to the regular upper tusks. In Deinotherium, on the other hand, there were no tusks in the upper jaw; but there were two tusk-like incisors in the lower jaw, the front of which was abruptly bent, so that the tusks pointed vertically downwards. 


\section{Order XII. Carnivora.}

The twelfth order of Mammals is that of the Carnivora or Beasts of Prey, comprising the Lions, Tigers, Wolves, Dogs, Cats, Hyænas, Seals, Walruses, \&c. The Camivora are distinguished by possessing two sets of teeth, which are simply enamelled, and are always of three kinds, incisors, canines, and molars, differing from one another in size and shape. The incisor teeth are gellerally six in each jaw; the canines are always two in each jaw, and are much longer and larger than the other teeth. The præmolars and molars are mostly cutting teeth, furnished with sharp uneven edges, but one or more of the hinder teeth have tuberculate crowns. The molars, too, graduate from a cutting to a tuberculate form as the diet is strictly carnivorous or becomes more or less miscellaneous.

The dentition (fig. 249) differs considerably in different members of the order, but subjoined is the dental formula of the Cats (Felidce), which are the most typical examples of the Carnivora--

$$
i \frac{3-3}{3-3} ; c \frac{1-1}{1-1} ; p m \stackrel{3-3}{2-2} ; m \frac{1-1}{1-1}=30 .
$$

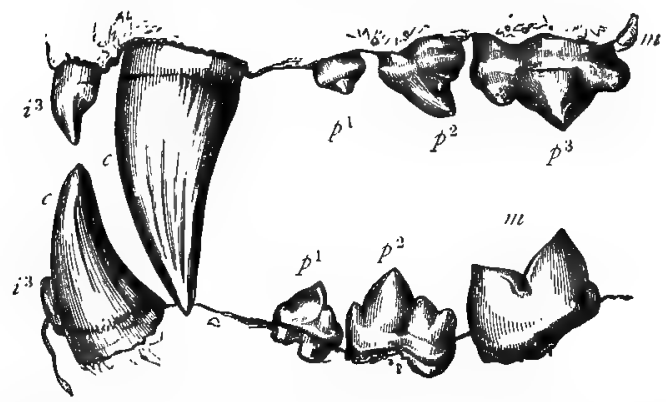

Fig. 249. -Permanent dentition of the Lion (Felis leo). In the upper jaw the letter $p^{3}$ indicates the upper carnassial, whlle in the lower jaw the letter $m$ indleates the lower carnassial.

In the typical and most highly specialised Camivores (such as the Felide), the list premolar in the upper jaw, and the first nolar in the lower jaw (fig. $249, \mathrm{pm}^{3}$ and $\mathrm{m}$ ) are specially developed, and are known as the "curnassial" teeth, having a sharp cutting-edge; whereas in other cases the corresponding teeth are blunt and "tuberculated." Even in their most trenchant condition, the carnassial tooth commonly has a more or lesis developed tuberculated process 
or heel, on the inside of its cutting edge. In various Carnivores a number, or all, of the promolars and molars may be "tuberculate," their crowns being adapted for bruising rather than cutting. As a general rule, the shorter the jaw, and the fewer the præmolars and molars, the more carnivorous is the animal. The jaws are so articulated as to admit of vertical but not of horizontal movements; and the sharp-edged back-teeth are thus enabled to act like the blades of a pair of scissors.

Besides the strictly flesh-eating dentition of the Carnivora, the order is distinguished by always having the feet provided with strong curved claws; and the collar-bones (clavicles) are either quite rudimentary, or are altogether absent. The Carnivora are divided into the following three sections, founded upon the nature of the limbs:-

1. Pinnigrada (fig. 250, B), in which both the fore and hind legs are short, and the feet form broad, webbed, swimming-paddles. The hind-feet are placed very far back, nearly in a line with the axis of the body, and they form with the hinder end of the body a powerful caudal fin. In this section are the Seals and Walruses.
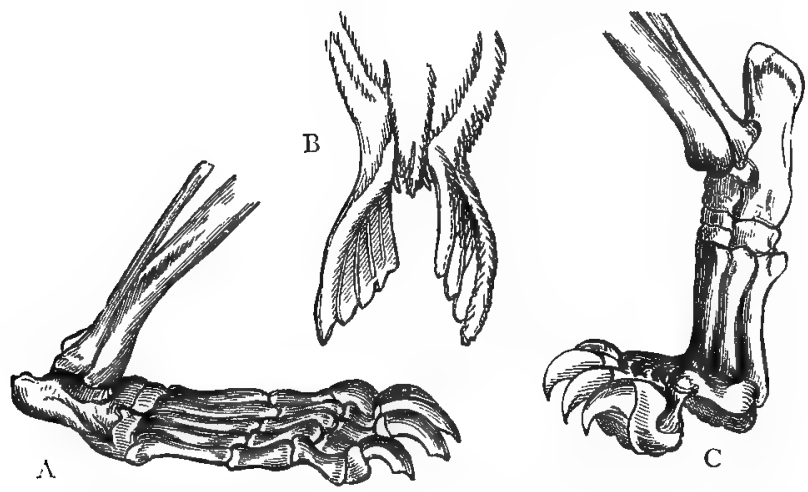

Fig. 250.-Feet of Carnivora (after Owel1). A, Plantigrada, Foot of Bear ; B, Pinnigrada, Hind-feet of Seal ; C, Digitigrada, Foot of Lion.

2. Plantigrada (fig. 250, A). comprising the Bears, in which the whole, or nearly the whole, of the foot is applied to the ground, so that the animal walks upon the soles of the feet.

3. Digitigrada (fig. 250, C), comprising the Cats, Lions, Tigers, Dogs, \&c., in which the heel is raised from the ground, and the animal walks upon tiptoe. 
The Seals and Walruses, forming the family Pinnigrada, are distinguished from the other Carnivora by their adaptation to an aquatic mode of life. In this respect they agree with the thoroughly aquatic Whales and Dolphins, but they differ from both the Cetacea and the Sirmia, not only in their dentition, but also in always having well-developed hind-limbs. The Seals (fig. 251) are characterised by having tricuspidate premolar and molar teeth, the lower incisors being- often reduced to four, and the canine teeth not being of excessive size. They form a very numerous family, of which species are found in most seas out of the limits of the tropics. They abound, however, especially in the seas of the Arctic and Antarctic regions. They are largely captured both for their oil and for their fur. The Walrus or Morse (Trichecus) is distinguished from the true Seals by the fact that in the adult only two of the

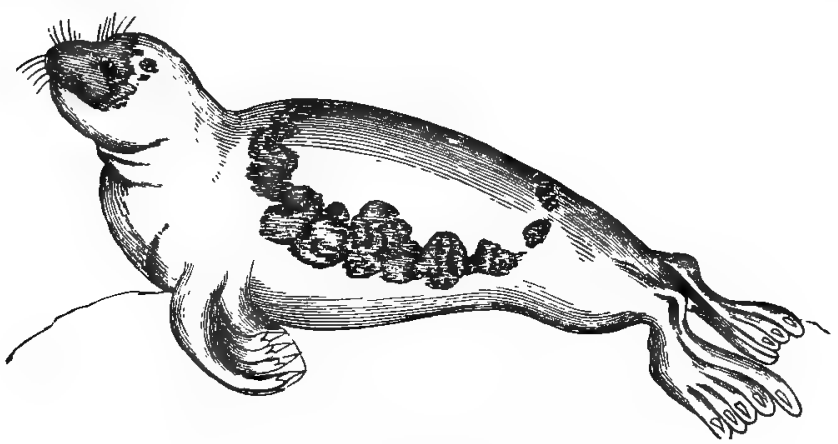

Fig. 251.-Greenland Sıal (Phoca Grocnlandica).

upper incisors are present; whilst the upper canines are enormously developed, and form two pointed tusks-fifteen inches or more in length-which are directed downwards between the small lower canines, and project considerably below the chin. The Walrus is a large heily animal, from ten to fifteen feet in length, which is found in flocks in the Arctic seas, and is hunted both for its lubber and for the ivory of the tusks.

The Plautigrale Carnieru apply the whole or the greater part of the sole of the foot to the ground in walking; and this portion of the foot is nearly or altogether destitute of hairs, except in the White Bear. The most typical members of the Plantigrada are the Bears ( $T^{\top} r$ sidee), of which the common Brown Bear and the White or Polar Bear are familiar examples. The Bears are much less purely carnivorous than the majority of the order, and, in accordance with their onmivorous habits, the teeth do not exhibit 
the typical carnivorous characters. The incisors and canines have their usual carnivorous form, but the hinder promolars and the molars are furnished with broid tubercular crowns. The claws are large, curved, and strong, but are not retractile. The tongue is smooth, the ears small and erect, the tril short, the nose mobile, and the pupil circular. Most of the Bears are only carnivorous in so far that they eat flesh when they can get it; but a great part of their fuod consists of roots, acorns, honey, and even insects.

Nearly related to the true Bears are the familiar Racoons (Procyon) of America, the Coatis (Nasua) of South America, and the Wah (Elurus) of India.

The only remaining Plantigrades of importance are the Badgers (Heles) of Europe, Asia, and America, the Gluttons or Wolverines ( $G u l_{0}$ ) of the same continents, and the Honey-badgers (Mellivora) of Africa.

Forming a kind of transition between the Plantigrada and the Digitigrada is a group of Carnivora which comprises numerous forms, such as the Weasels, Otters, and Civets, which apply part, but not the whole, of the sole of the foot to the ground.

The Weasels (Mustelidue) have short legs, and elongated worm-like bodies, with a stealthy, gliding mode of progression. Good examples are the Polecat, the Mink, the Emine, and the Sable. The three last named furnish the beautiful and valuable furs known by their names. Here also belongs the Skunk (1ephitis), celebrated for its intensely disagreeable odour when alarmed or irritated. The Otters are nearly allied to the Weasels, but have webbed feet adapted for swimming. The great Sea-otter yields a very valuable fur. The Civets and Genettes (Viverridas) all belong to the Old World. The true Civet-cat inhabits North Africa, and is furnished with a pouch which secretes the peculiar fatty substance which is used as a perfume under the name of "civet."

The typical group of the Carnivora is that of the Digitigrada, comprising the three tribes of the Dogs (Canidac), the Hyænas (Hycenidoe), and the Cats (Felido). The family Canidce comprises the true Dogs, the Wolves, the Foxes, and the Jackals, all characterised by their pointed muzzles, smooth tongues, and nonretractile claws, and by the fact that the fore-feet have five toes, whilst the hind-feet have only four. In the Hycenidce, comprising the Hyænas, there are only four toes to all the feet, the muzzle is rounded, the tongue is rough, and the hind-legs are shorter than the fore-legs. The Hyænas are ill-conditioned, ferocious animals, which occur in Africa, Asia Minor, Arabia, and Persia.

The most highly carnivorous, and therefore the most typical, group of the Carnivora is that of the Cats or Felido, comprising the Lions, 
Tigers, Leopards, Panthers, Cats, and others. In all these the animal walks lightly upon the tips of the toes, and the soles of the feet are hairy. The jaws are short, and owing to this and to the great size of the muscles which move the lower jaw, the head assumes a

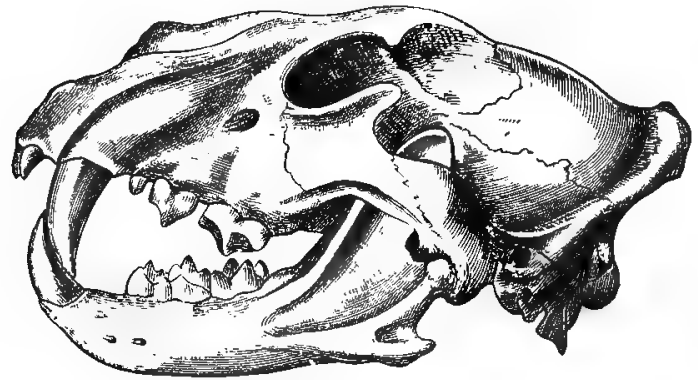

Fig. 252.-Sicle-riew of the skull of the Lion.

rounded form, with a short muzzle. The molars and præmolars (figs. 249 and 252) are fewer in number than in any other of the Carnivora-hence the shortness of the jaws: and they are all furnished with cutting edges, except the single molitr in the upper jaw,

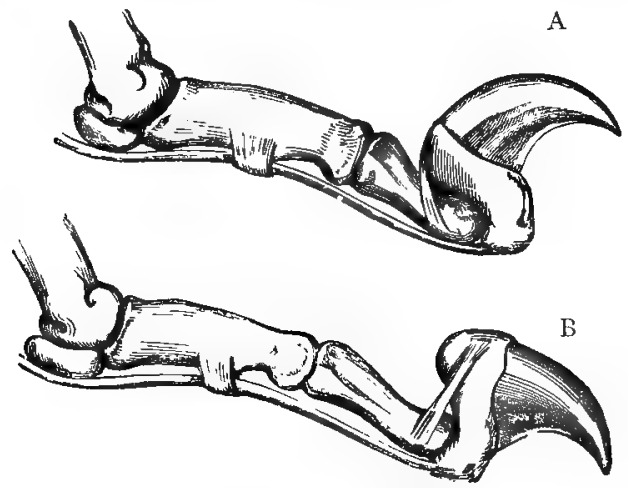

Fig. 253.-Bones and ligaments of the tre of a cit, showing the claw retiacted (A) ancl protiucled (B),

which is tuberculate. The legs are nearly of equal length, and the hind-feet have only four toes, whilst the fore-feet have five toes each. All the toes are furnished with strong curved retractile clitws, which, when not in use, are withdrawn within sheaths by the action of elastic ligaments (fig. 253). The tongrue is armed with horny 
eminences, which render it rough and prickly, and adapt it for the office of licking flesh from the bones of the prey. They are all extremely light upon their feet, and excessively muscular; and all have the habit of seizing their prey by suddenly springing upon it. In this section are the Lion (Felis leo), the Tiger (Felis tigris), the Jaguar (Felis oncu), the Puma (Felis concolor), the Leopard (Felis leopardus), the Lynxes, and the true Cats.

The Lions are entirely confined to the Old World, inhabiting Southern Asia and Africi. The males are maned, and the tail is tufted. The Royal Tiger is exclusively Asjatic, as are most of the Tiger-cats, but some of the latter are American. The Spotted Cats or Leopards are represented, among others, by the Leopard and Cheetah of the Old World and the well-known Jaguar of the American continent. The Puma is also American, but its colour is uniform. The Lynxes are distinguished by their tufted ears, and are found both in the Eastern and Western hemispheres.

\section{Order XIII. Rodentia.}

In this order are a number of small animals, characterised by the absence of canine teeth, and the possession of two long curved incisor teeth in both jaws, which are separated by a wide interval from the molars (fig. 254). There are seldom more than two incisors in the upper jow (sometimes four), but there are never more than

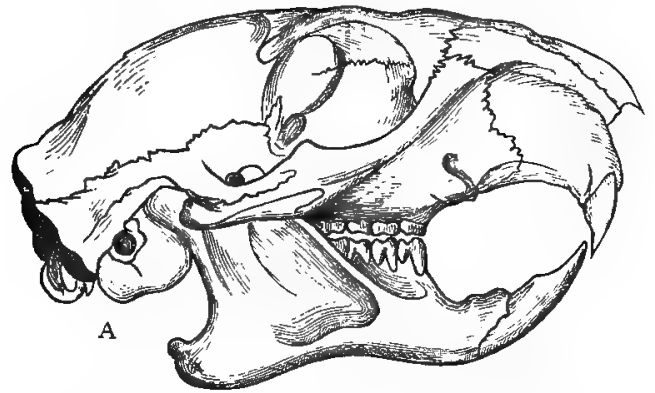

B

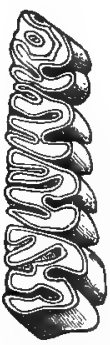

Fig. 25t.-A, Side-view of the skull of a Rnclent (Cynony's). B, Molar teeth of the upper jaw of the Beaver (Castor fiber). (After Giebel.)

two in the lower jaw. The molar teeth are few in number (rarely more than four on each side of each jaw). The feet are usually furnished with five toes each.

The most characteristic point about the Rodents is to be found in the structure of the incisor teeth, which are adapted for con- 
tinuous gnnwing. They grow from persistent pulps, and consequently continue growing as long as the animal lives. They are large, long, and curved, and are covered in front with a layer of hard enamel, so that the softer parts of the tooth are placed behind (fig. 254, A). The result of this is, that as the tooth is used in gnawing, the softer parts behind wear away more rapidly than the hard enamel in front, and thins the crown of the tooth acquires by use a chisel shape, bevelled away behind, and the enamel forms a persistent cuttingedge. The Rudents are almost all of small size, and are very prolific. They subsist principally, if not entirely, on vegetable matter's, especially the harder parts of plants, such as the bark and roots. Many possess the power of building very elaborate nests, and most of them hibernate (i.e., remain torpid throughout the winter). They are very generally distributed over the whole world.

The order Rodentia comprises a large number of families, of which

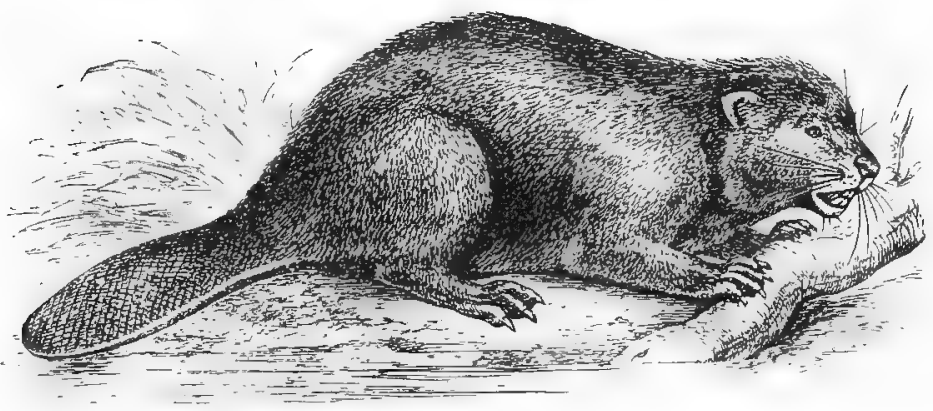

Fig. 255, - The Beaver (Castor fiber).

little more than the names of the principal ones can be nentioned. The most inportant families of Rodents are the following : 1. Leporidce, comprising the Hares and Rabbits. The Hares generally occur in temperate regions, but some are African, and one species occurs in the Arctic regions, while the common American Hare (Lepus Amricumus) extends from ('anada to Mexico. 2. Cucile", comprising the Cirpybaras, Guinea-pigs, \&c. The Cajybara is the largest of living Rodents, and is not unlike a snall pig. It is a native of Wuth America, and leads an amphibions life. Here also belong the Agontis (Dasipproctu) of Finuth America ind the West Indies, and the Paciss of Sonth America. 3. Hystricile, comprising the Porcupines, and characterised ly the fact that the boly is covered with longer or shorter spines or quills mixed with bristly hairs. Most of the Porcujpines live in burrows, and are much like the Rabbits in 
their habits, but some are furnished with prehensile trils, and live in trees. 4. Custoride or Beaver family, comprising the Beaver. The Beaver (fig. 255) has webbed feet and a scaly tail, and the fur is an article of considerable value. It inhalbits both North America and Europe. The Musquash resembles the Beaver in many respects, and is also a native of Northern America; but the Coypu is South American. 5. Wurida, comprising the Mice, Rats, Hamster, Lemmings, \&c. The Rats and Mice are too well known to require more than merely to be mentioned. 6. Dipodide, comprising the Jerboas of the Old World, and the Jumping Mice of America. 7. Myoxidxe, comprising the Dormice, which nust not be confounded with the true Mice on the one hand, or with the Shrew Mice on the other hand. 8. Sicuridee, comprising the Squirrels, Flying Squirrels, and Marmots. The Flying Squirrels do not really fly, but like the "flying" Phalangers, they take long leaps from tree to tree by means of laterally extended folds of skin. The Marmots, unlike the typical Squirrels, are ground-animals, and live in burrows. An excellent example is afforded by the Prairie-dog (Cynomys Ludovicianus) of North America.

\section{Order XIV. Cheiroptera.}

This order is undoubtedly one of the most distinctly circumscribed orders in the whole class of the Mammaliu, and comprises only the Bats. In many respects, however, it might be well to

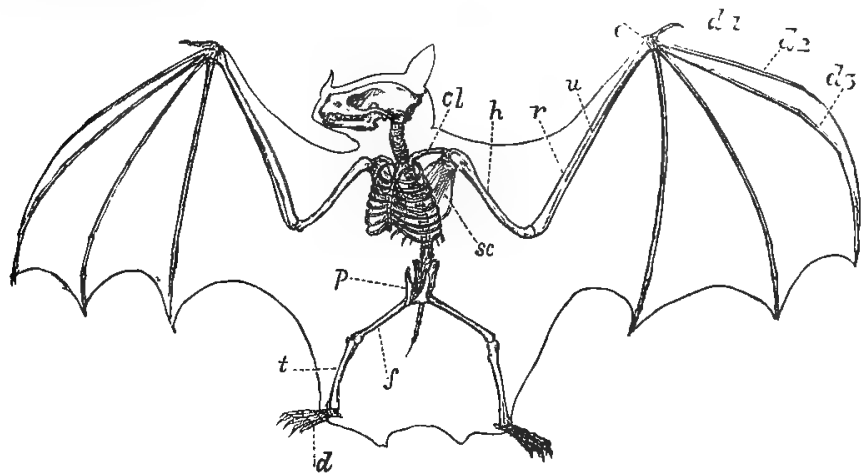

Fig. 256.-Skeleton and outline of Bat (Phyllostoma hastatum). $d_{1}$ Thumb; $d_{2}$ Foreflnger; $d_{3}$ Middle finger; $8 c$ Shoulder-blace; el Collar-bone; $f$ Thigh-bone; $t$ Tilia; $d$ Toes.

regard the order as merely a modified branch of the Insectivora, just as the Pinnigradc are regarded as a modified offshoot of the Carnivora. 
The Cheiroptera or Bats are essentially characterised by the fact that the fore-limbs are much longer than the hind-limbs, and have several of the fingers enormously elongated (fig. 256). These enormously lengthened digits are united by an expanded leathery membrane or "patagium," which not only stretches between the fingers, but is also extended between the fore and hind limbs, and is attached to the sides of the lurly (fig. 257). The patagium thus formed often includes the tail, and is nearly or quite naked or destitute of hairs on both sides. It is nsed as an organ of true flight, and, in accordance with this, there are well-developed collarbones (clavicles), and the breast-bone is furnished with a ridge for the attachment of the pectoral muscles. Of the fingers of the hand

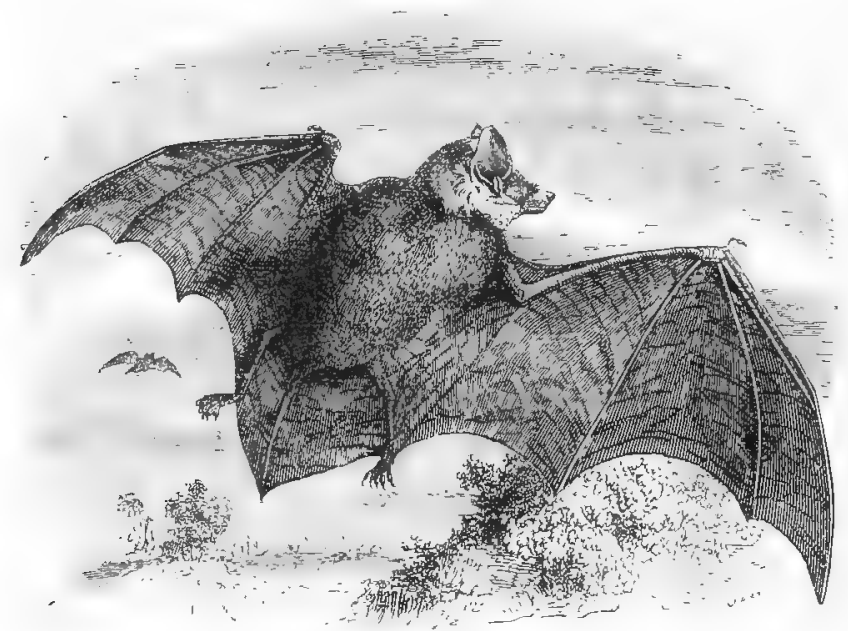

Fig. 257.-Cheirolitera. Vespertilio discolor, one-half the natural size.

at least three are destitute of nails. The mammary glands are placed upon the chest. Teeth of three kinds are always present, and the canines are always well developed.

The Bats are all twilight-loving or nocturnal animals, and they are the only Mammals which possess the power of true flight, though several others can make extended leaps from tree to tree. The eyes are snall, but the ears are very large, and their sense of touch is most acute. During the day they retire to caves or crevices in rocks, where they suspend themselves by the hind-feet, which are provided with curved claws. In their flight, though they can turn with great ease, they are by no means as rapid and active as the 
true Birds. The tail is sometimes very short, sometimes moderately long, and is usually included in a continuation of the patagium, which extends between the hind-legs. The body is covered with hair, but the patagium is usually nearly or quite hairless. Most of the Bats hibernate.

The Cheiroptera are conveniently divided into the two sections of the Insectivorous and Frugivorous Bats. In the first section are all the smaller Bats, which universally live upon insects. In this section we must also place the Vampire Bats, which are of comparatively large size, and some of which have the habit of sucking the blood of sleeping animals. In the second, or fruit-eating section of the Cheiroptera are only the Fox-bats (Pteropida), which are especially characteristic of the Pacific Archipelago, inhabiting Australia, Java, Sumatra, Borneo, \&c., but occurring also in Asia and Africa. They are amongst the largest of the Bats, one species-the Pteropus edulis or Kalong-attaining a length of from four to five feet from the tip of one wing to the tip of the other.

\section{Order XV. Insectivora.}

The next order of Mammals is that of the Insectivora, which comprises a number of small animals, very similar in many respects to the Rodents, but wanting the peculiar incisors of that order, and also being provided with clavicles. All the three kinds of teeth are present, but the dentition is very various, and the only common

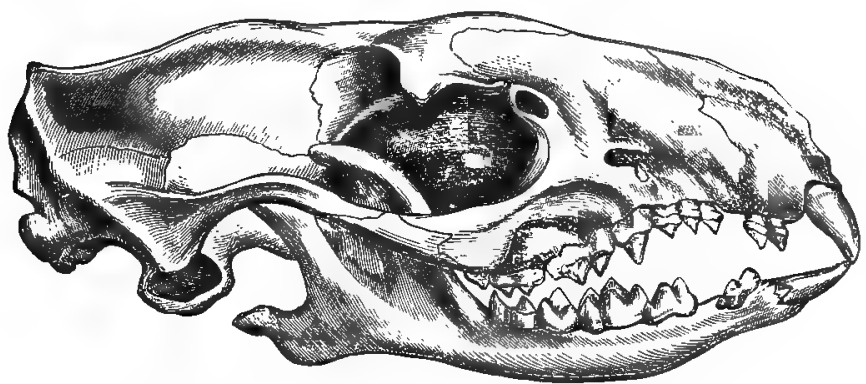

Fig. 258. -Skull of the cominon Herlgehog (Erinaceus Europoeus).

character is, that the crowns of the molar teeth (fig. 258) are furnished with small pointed eminences or cusps, adapted for crushing insects. All the toes have claws ; there are usually five toes to each foot, and most of the Insectivora are plantigrade-that is to say, walk upon the soles of the feet. They are all small, and they exist 
over the whole world, except in Australia and South America, where their place is taken by Marsupials, such as the Opossums.

The Insection are divided into several families, of which the following are the most important. The Moles (Tulpidie, fig. 259) are distinguished by having the body covered with hair, the feet short and formed for digging, and the toes furnished with strong, curved claws. There is no external ear, and the eyes are either extremely small, or are completely concealed beneath the fur. They are all nocturnal, burrowing animals. The Star-nosed Moles (Condylura) are Anerican, but their habits are like those of the European Mole (Tulpue Europoca, fig. 259). The Golden Moles (Chrysochloris) are African, and are remarkable for the iridescence of their fur. The Shrews (Simida) are very like the true Mice in external appearance, but they are really widely different. The body is covered with hair, the feet are not adapted for digging, and there are mostly extarnal ears, while the eyes are well developed. No division of the

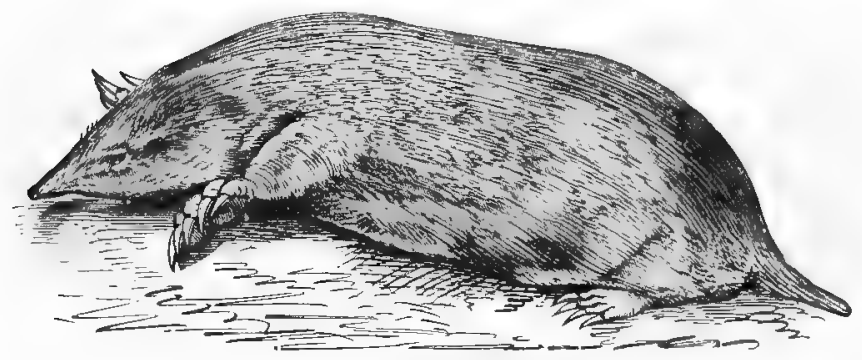

Fig. 259.-Insectivora. Mole (Talpa Europaca).

Insectivora is more abundant or more widely distributed thin the Sorivile, and one of the Shrews is probably the smallest of existing Mammals, not exceeding two and a half inches in length, counting in the tail.

The so-called "Elephant-shrews" (Mrrosirlitle) of Africa form annther family. They are distinguished by their inmensely elongated trunk-like nose, and their long Kangaroo-like hind-legs.

Another family (Erinarmide) includes the well-known Hedgehogs, which have the power of rolling themselves into a ball at the approach of danger, and which have the upper surface of the body covered with short prickly spines, forming a protective armour. The common European Hedgehog (Erinaceus Europaus, fig. 260) is the type of the family, but other species coccur in Africa and India. The "Tenres," (cintetos) of Madagascar are dosely allied to the 
Hedgehogs, but have 10 power of rolling themselves up. The "Banxrings" (Tupxia) of the Indian Archipelago have a long, compressed tail, and live mostly in trees.

Before passing on to the next order, a few words must be said about a curious transitional form, which has been alternately placed in the Cheiroptera, the Insectivora, or the Quadrumana, or has been regrarded as the type of a separate order. The animals alluded to are the so-called Flying Lemurs (Grleopithecus), of which more than

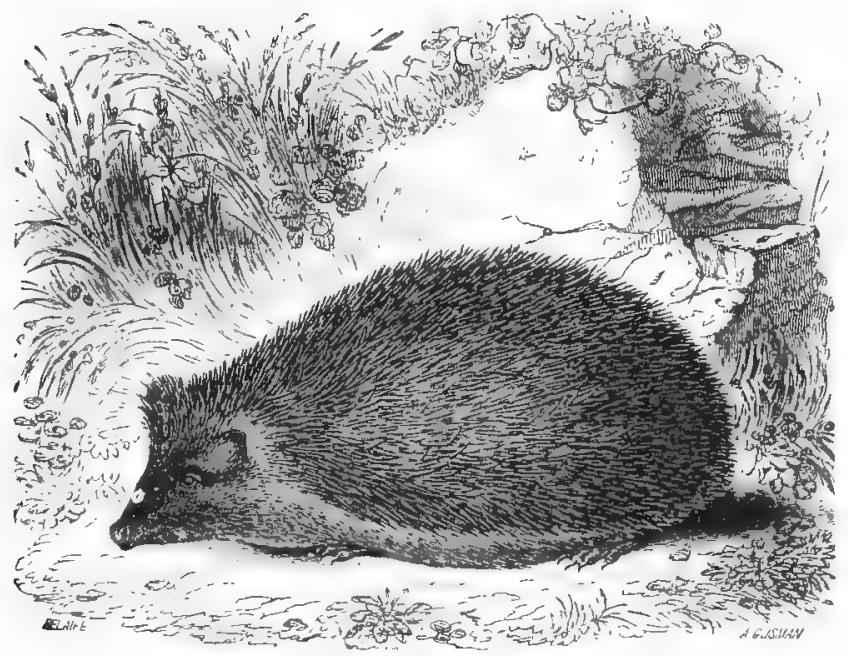

Fig. 260.-Insectivora. The Hedgehog (Erinacens Europken8).

one species is known as inhabiting the Indian Archipelago. The leading characteristic in these singular animals is the possession of a flying membrane, which extends as a broad expansion from the nape of the neck to the arms, from the arms to the hind-legs, and from the hind-legs to the tail. The fingers are not clongated, and do not support a "patagium," so that the animal has no power of true flight, but can simply take extended leaps from tree to tree. The Galeopitheci live chieffy upon small insects and birds, and they should probably be regarded as aberrant forms of the Insectivora.

\section{Order XVi. Quadrumana.}

The sixteenth order of Mammals is that of the Quadrumana, comprising the Apes, Monkeys, Baboons, and Lemurs. The charac- 
teristic of this order is, that the innermost toe (great toe) of the hind-limbs can be opposed to the other toes, so that the hind-feet become prehensile hands. The term "opposed" simply implies that the toe can be so adjusted as regards the extremities of the other toes, that any object can be grasped between them, just as the thumb of the human hand can be "opposed" to any of the fingers. The fore-feet may be destitute of a thumb, but when this is present, it, too, is generally opposable to the other digits, so that the animal becomes truly four-handed or "quadrumanous."

The Quadrumana are divided into three very natural sections, separated from one another both by their anatomical characters and their geographical distribution.

Section A. Strepsirhinu. - Characterised by having the nostrils twisted or curved, and placed at the end of the nose, whilst the second toe of the hind-feet is furnished with a claw. The Quadru-

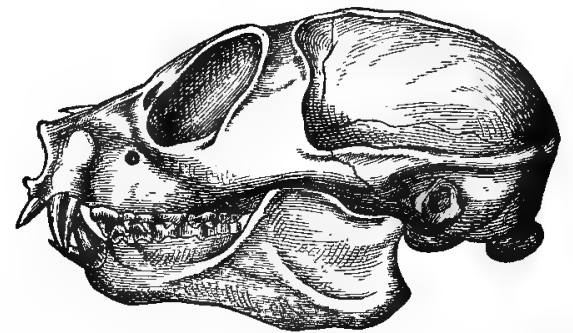

Fig. 261.-Side-view of the-skull of a Lemuroid (Nycticebus or Stenops tardigradus). (After Giebel.)

mana of this section are chiefly referable to Madagascar as their geographical centre, but they spread from Madagascar westwards into Africa, and eastwards to the Indian Archipelago. In this family are the Aye-aye (Cheiromys), the Loris (Nycticebidee), and the Lemurs (Lemuridoe).

The A ye-aye is confined to Madagasear, and is not unlike a large squirrel in appearance, having a long bushy tail. The incisors grow from permanent pulps, like those of Rodents, and there are no canines. The Loris and Slow Lemurs have either no tail or a rudimentary one, and they are confined to Southern Asia, and the great islands of the Indian Archipelago. The true Lemurs (fig. 261) are principally natives of Madagascar, and are often spoken of as "Madagascar cats." They have a soft, woolly fur, and a long tail, which is prehensile. The second toe of the hind-foot has a long and pointed claw.

Section B. Plasyrhina.-This section includes those monkeys in 
which the nostrils are simple, and are placed far apart; the thumbs of the fore-feet are wanting, or, if present, are hardly opposable; and the tail is generally prehensile. The Platyrhine Monkeys are exclusively confined to South America, occurring especially in Brazil, and they are all adapted for a more or less purely arboreal life. The best-known members of this section are the Marmosets (Hapalidoe), and the great family of the Cebidce, comprising the Spider-monkeys, the Howlers, and others. The Howlers (Mycetes) are remarkảble for having a bony drum at the summit of the windpipe, by which the voice is rendered extraordinarily resonant, and peculiarly weird and terrifying to those who hear it.

As regards their dentition, the Platyrhine Monkeys differ from the Old World Monkeys, as also from Man, in having an additional præmolar on each side of each jaw. They have, therefore, three præmolars on each side of each jaw, instead of only two. On the other hand, they have either three molars on each side, as have the old World Monkeys and Man, or they have only two. The dental formula of the Marmoset is-

$$
i \frac{2-2}{2-2} ; c \frac{I-1}{1-1} ; p m \frac{3-3}{3-3} ; m \frac{2-2}{2-2}=332 .
$$

The dental formula of the Howlers (Mycetes) is--

$$
i \frac{2-2}{2-2} ; c \frac{1-1}{1-1} ; p m \frac{3-3}{3-3} ; m \frac{3-3}{3-3}=36 \text {. }
$$

Section C. Catarhina.-In this, the highest section of the Quadrumana, the nostrils are oblique and placed close together, and the thumbs of all the feet are opposable, so that they are truly "quadrumanous." The dental formula agrees with that of Man :-

$$
i \underset{2-2}{2-2} ; c \begin{aligned}
& 1-1 \\
& 1-1
\end{aligned} ; p m \begin{aligned}
& 2-2 \\
& 2-2
\end{aligned} ; m \frac{3-3}{3-3}=32 .
$$

The incisor teeth, however, are prominent and projecting, and the canines, especially in the males, are large and pointed, whilst the teeth form an uneven series. The tail is never prehensile, and is sometimes absent. Cheek-pouches are often present. In one single instance (Colobus) the thumbs of the fore-limbs are wanting.

With the single exception of a Monkey which occurs on the Rock of Gibraltar, all the Citarhine Monkeys are confined to Africa and Asia. The most typical forms of the section are the Semnopitheci and Macaques of Asia. Less typical are the Baboons, which inhabit Africa, and are amongst the most repulsive of all the Quadrumana. In these the tail is always short, and often quite rudimentary. The head is large, and the muzzle greatly prolonged, having the nostrils at its extremity. The skull (hig. 262) is furnished with great bony 
ridges which serve for the attachment of muscles. MIore than any other of the Monkeys they employ the fore-limbs in terrestrial progression, running upon all-fours with the greatest ease.

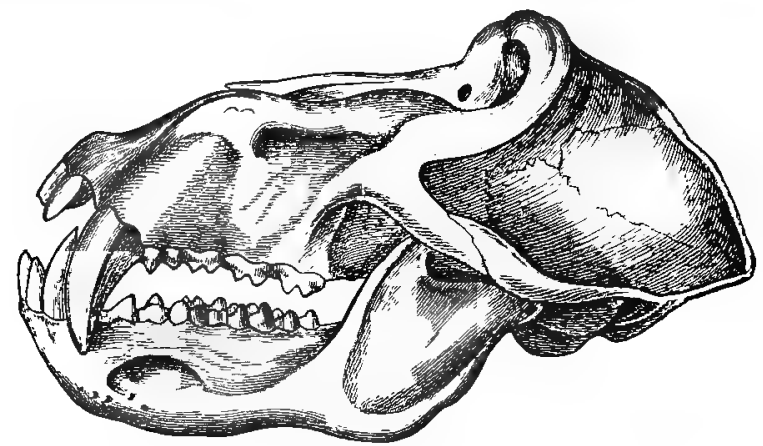

Fig. 262.-Side-view of the skull of a Baboon (Cynocephalus ursinus). (After Giebel.)

The third family of the Catarhine Monkeys is that of the Anthropoil Apes, so called from their making a nearer approach to Man in

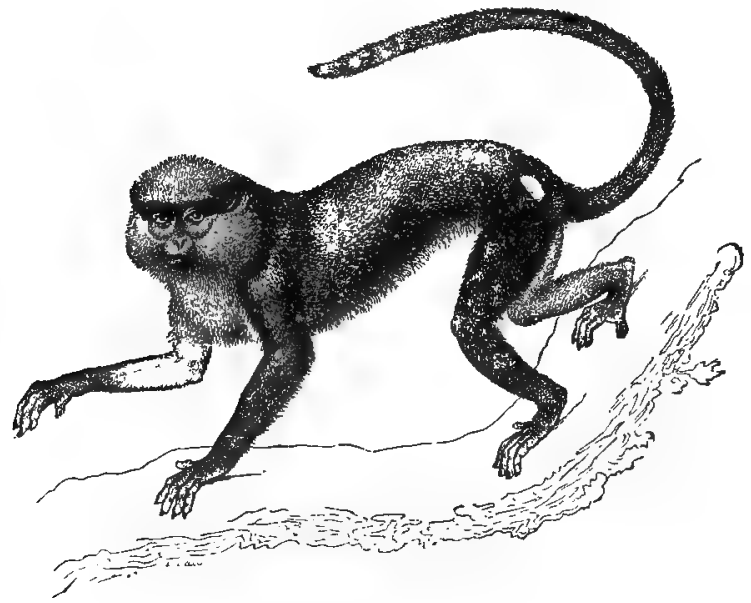

Fig. 263.-Quadrunana. Cercupithecus mona, a Catarhin. Monkey, one-serenth of the nattiral size.

anatomical structure than is the case with any otber Mammal. The Anthropoid Apes are distinguished by having no tail nor cheekpouches. The limb, are short-shorter than the fore-limbs-and 
the animal can progress in an erect or semi-erect posture. At the same time the hind-feet are strictly prehensile, since the thumbs are opposable to the other toes. The canine teeth of the males are very long, strong, and printed, but this is not the case in the females.

In this tribe are the Gibbons, the Chimpanzee, the Orang-outang, and the Gorilla. The Gibbons form the genus Hylobates, and they belong to Asia, India, and the Indian Archipelago. 'The anterior' limbs in these monkeys are extremely long, and the hands nearly or quite touch the ground when the animal stands erect. The Orangoutang (Simia) has no cheek-ponches, and the hips are covered with hair. The arms are of excessive length, and the hind-legs very short. When young, the head of the Orang-outang is not very different from that of a child, but as the animal grows, the bones of
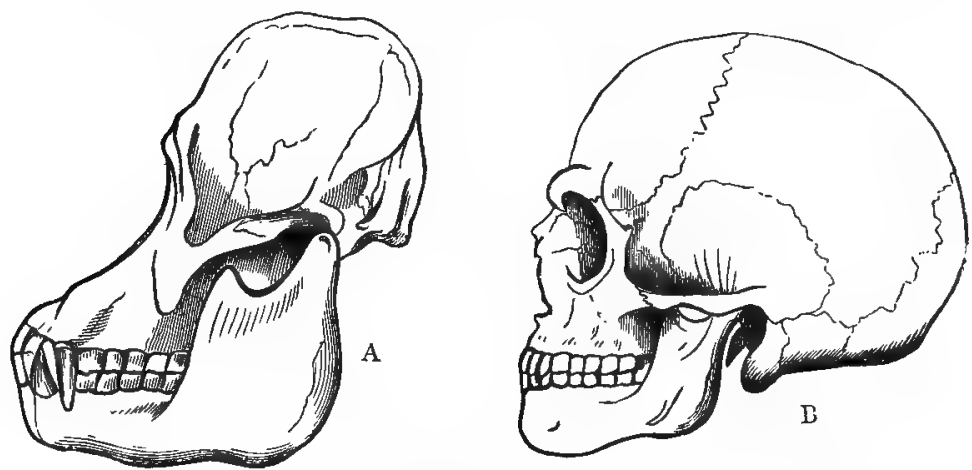

Fig. 2:4.-A, Skull of the Orang-outang; B, Skull of a European adult.

the face gradually lengthen, whilst the skull remains much about the same; great hony ridges are developed for the attachment of the muscles which act upon the jaws; the incisors project; the canine teeth of the males become long and pointed, till ultimately the muzzle becomes as pronounced and well marked as in the Carnivorous animals (fig. 264, A). The only unquestionable species of Orang is the Simia satyrus, which inhabits Sumatra, Borneo, and the other larger islands of the Indian Archipelago. The Chimpanzee and Gorilla both belong to Africa, and form the genus Troglodytes. The Chimpanzee is a native of Westeri Africa, and has the arms much shorter proportionately than in the Gibbons and Orangs. Still they are much longer than the hind-limbs, and reach below the knees. The hands are naked to the wrist, and the face is also naked 
and much wrinkled. The Gorilla is in most respects like the Chimpanzee, but is nuch larger, attaining a height of fully five feet. It is a native of Lower Guinea and Equatorial Africa, and is enormously strong and very ferocious. It is now generally looked upon as the highest of the Anthropoid Apes.

\section{Order XVII. Bimaxi.}

In this order stands Man alone, and little, therefore, needs to be said on this head. Man is distinguished zoologically from all other Manmals by his habitually erect posture and progression upon two legs. The luwer limbs are exclusively devoted to progression and to supporting the weight of the body. The fore-limbs are shorter than the legs, and have nothing to do with jrogression. The thumb can be opposed to the other fingers, and the hands are therefore prehensile. The fingers and toes are furnished with nails; but the innermost digit of the foot (the great toe) is not capable of being opposed to the otber toes, so that the foot is useless as a grasping organ. The foot is broad and plantigrade, the whole sole being applierl to the ground in walking.

The teeth are thirty-two in number, and they form a nearly even and uninterrupted series, without any gap or interval. The dental formula is-

$$
i_{2-2}^{2-2} ; c \frac{1-1}{1-1} ; p m \frac{2-2}{2-2} ; m \frac{3-3}{3-3}=32 \text {. }
$$

The lorain is more largely developed, and more richly fumished with larige and deep foldings or convolutious, than is the case in any other Mammal. Lastly, Man is the only terrestrial Mammal in which the body is not furnished with a general covering of hair.

The purely crertomird distinctions between Man and the other Mammals are thus seen to be not very striking, and of themselves they would hardly entitle Man to the position of forming a distinct order in the class Mammalia. When, however, we take into account the vast mentul differences, both intellectual and moral, between Man and the highest of the brutes, and when we reflect that this mental difference must have some physical correspondence, it becomes a question whether the group Bimann should nut bave the value of a distinct sul-kingdom, whilst there can be little hesitation in giving Mitn at least a class to hinself.

In the words of Dr Pritchard, "the sentinents, feelings, sympathies, internal consciousness, and mind, and the habitudes of mind and action thence resulting, are the real and essential characteristics of humanity." 


\section{G L O S S A R Y.}

ABDomen (Lat. abdo, I conceal ; or contracted from adipomen, derived from adeps, fat). The hinder portion of the body-cavity of the higher animals, containing the principal digestive and excretory organs.

ABERRANT (Lat. aberro, I wander away). Departing from the regular type.

Abnormal (Lat. $a b$, from; norma, a rule). Irregular; deviating from the ordinary standard.

A bomasum. The fourth cavity of the complex stomach of the Ruminants.

ABranchiate (Gr. $a$, withont; bragchia, gills). Destitute of branchiæ or gills.

ACANThOCEPHAzA (Gr. akantha, a thorn; kephale, head). A class of parasitic Worms, in which the head is armed witl spines.

ACARINA (Gr. akari, a mite). A division of the Arachnida, comprising the Mites and Ticks.

Accretion (Lat. accresco, I grow larger). The process by which inorganic bodies (such as crystals) grow larger, by the ardition of fresh particles from the ontside.

ACEPHaLOUS (Gr. $u$, without; kephale, head). Not possessing a distinct head.

Actinosoma (Gr. alitin, a ray; soma, body). Employed to designate the entire body of any Actinozoü, whether this be simple (as in the sea-anemones), or composed of several zouidis (as in most Corals).

ActinozoA (Gr. aktin, a ray; zoön, an animal). That division of the Coelenterata of which the Sea-anemones may be taken as the type.

ADductor (Lat. adduco, I bring together). The muscles which hring togetlier the valves of the shell of the Bivalve Molluscs are known as the "arlductors."

AERIAL (Gr. aër, air). Living in the air ; enjoying the powel of flight.

AMBULACRA (Lat. ambulacrum, a place for walling). The perforated spaces or "avenues" in the shell of the Eichinoidea, through which are protruded the locomotive tube-feet.

Ametabouid (Gr. $a$, without; metabolé, change). Applied to those insects which do not possess wings when fully grown, and wlich do not, therefore, pass through any well.marked metamorphosis.

AMEBA (Gr. amoibos, changing). A species of Rhizopod, so called from the numerous changes of form which it undergoes.

Amorphous (Gr. a, withont; morphé, shape). Not having any definite figure.

A MPHIBIA (Gr. amphi, both; bios, life). A class of the Vertebrata comprising Frogs, Newts, and the lilie, which have always gills when young, lut alway's develop lungs when fully grown. Most of then, therefore, live indifferently on land or in water.

AMPHICGLOUS (Gr. amphi, at both ends ; koilos, hollow). Applied to vertebræ which are doubly concave, or hollow at botl ends. 
AMPHIDiscs (ûr. amphi, at both ends; dishos, a quoit or roinel plate). The spicules which surround the reproductive "geumules" of sponyilla, and resemble two toothed wheels united by an axle.

AMPHIOxus (Gr. ampli, at both ends; oxus, sharp). The Lancelet, a curious little fish, which alone constitutes the order Pharyngobranchii.

AMPBIPona (Gr. amphi; and podes, feet). An order of the Cricstacca, so called because some of the feet are directed forwards and some backwards.

ANalogous. Applied to parts which perform the same function.

AvARTHROPODa (Gr, a, without; arthros, a joint; podes, feet). The division of Annulose animals in which there are no articulated appendages.

ANYilida (a Gallicised form of Anuulata, Lat. cnnulus, a ring). The Ringed Worms, which form one of the divisions of the Anurthropoda.

Axyulos (Lat. annulus, a ring). The sub-kingdom conprising the Scnlecida, Anarth ropoda, and the Arthropoda or Articilata, in all of which the body is more or less evidently composed of a stccession of rings.

AxOMODONTIA (Gr. anomos, irregular; odous, tooth). An extinct order of Reptiles, called by Huxley Inicynodontia.

Axomura (Gr. cenomos, irregular; oura, tail). A tribe of Decapol Crustaceans, of which the Hermit-crabs are the type.

A noplura (Gr. anoplos, unarmed; our'

Axoura or ANURA (Gr. a, without; oura, tail). An order of Amphibir, comprising the Frogs and Toads, in which the adult is destitute of a tail.

ANTENNe (Lat. antenna, a yard-arm). The jointed liorns or feelers possessed by the niajority of the Articulata.

A NTEN ULLS (diminutive of antennae). Applied to the smaller pair of antennæ in the Crustacea.

ANTHRopoIn (Gr. anthropos, man; eidos, form). Applied to those Monkeys which make the nearest approach in anatomical structure to Man.

ApHaniptera (Gr. aphanos, inconspicuous; pterom, a wing). An order of Insects comprising the Fleas.

Aplacental (Gr. a, withont; Lat. placenta, a cake). Applied to those Mammals in which the young is destitute of a placenta (see Placenta).

AxTerous (Gr. a, withont; pteron, a wing). Destitute of wings.

AQUATIC (Lat. aqua, water). Inhabiting water.

AquIFERous (Lat. aqua, water; fero, I carry). Applied to the water-carrying canal-system of the Sponges.

ARAcunida (Gr. arachné, a spider). A class of Articulute, comprising Spiders, ficorpions, and allied animals.

ARANEID. (Lat. aranea, a spider). The order of Arachnida, comprising the true Spiders.

Aachaopteryx (Gr. archaios, ancient; pterux, wing). A fossil bird, which alone constitutes the order Saururce.

ARENacisus. Saudy, or composed of grains of sand.

ArThropoda (Gr. arthros, a joint; podes, feet). 'I'he division of Annulosa, in which the boly is furnished with jointed appendiages.

Articulata (Lat. articulus, diminutive of artus, a joint). Sometimes used in the same sense as the term Arthropondr.

Artiodactyla (Gr. artias, even; duhtulus, a finger or toe). A division of the hoofed quadrupeds (Ungulata) in which eacli foot has an even number of toes (two or four).

Ascidioida (Gr. askos, a has or a leather bottle; eidos, form). Sometimes employed to designate the Tunicata, an order of the lower Mollusca, from the resemblance of the bolly in many cases to a two-necked jar.

AsExu.1L. Applied to modes of reproduction in which the sexes are not concerned (e.g., gemmation and fission).

ASTERUDEA (Gr. aster, a star; and eillos, form). An order of Echinodermata, comprising the Star-fishes, characterisel by their rayed form.

Astomatous (Gr. a, withont ; stoma, mouth). Not possessing a mouth.

ATRIum (Lat. a hall). Applied to the large chamber or "cloaca," into which the intestine opens in the Tunicata. 
A Ukicts (Lat. auricula, a little ear). Applied to the cavity of the heart wlich drives the blood into the ventricle.

Aves (Lat. avis, a bird). The class of the Birds.

BALANCERs. The knobbed filaments which represent the posterior pair of wings in Dipterous Insects; also called "poisers."

BaLANIDA (Gr. balanos, an acoru). A family of Cirripedia, commonly spoken of as "Acom-shells."

BaLeEN (Lat. balena, a whale). The horny plates which are placed in the upper surface of the mouth of the true or "whalebone" Whales.

BATRACHIA (Gr. batrachos, a frog). Generally applied loosely to any of the Amphibia, but sometimes used to designate either the entire class of the Amphibians, or the single order of the Anoura.

Bifid. Cleft into two parts; forked.

Brmans (Lat. bis, twice; manus, a hand). The order of Mammalia constituted by Man alone.

Brvalve (Lat. bis, twice; valve, folding-doors). Composed of two plates or valves; applied to the shell of the Lamellibranchiata and Brachiopoda, and to the carapace of certain Crustaces.

Blastordea (Gr. blastos, a bud; eidos, form). An extinct order of Eichinoder. mata, often called Pentremites.

BRACHIOPODA (Gr. brachion, the arm; podes, feet). A class of the lower Mollusca, often called "Lamp-shells," characterised by having two fleshy ciliated "alins" attached to the sides of the mouth.

BRACHYURA (Gr. brachus, short; oura, tail). A tribe of Decapod Crustaceans with short tails; commonly known as Crahs.

BraCT. Overlapping appendages or plates which protect the polypites in many of the Oceanic Hydrozoa.

Braschia (Gr. bragchia, the gill of a fish). A respiratory organ adapted for breathing air dissolved in water.

Branchiate. Possessing gills.

Broncht (Gr. brogchos, the windpipe). The branches of the windpipe (trachea). by which the air is conveyed to the lungs.

Brow (Lat. brutus, heavy, stupid). Sometimes used to designate the Mammalian order of the Edentata.

Buccal (Lat. bucca, mouth or cheeks). Connected with the mouth or clieeks.

Byssus (Gr. bussos, flax). The silky threads by which many Bivalve Molluscs (such as the Mussels) attach themselves to foreign objects.

Caddcibranchiate (Lat. caducus, falling off; Gr. bragchia, gills). Applierl to those Amphibians in which the gills fall off belore maturity is reached (e g., Newts and Frogs).

C.ECAL (Lat. coecus, blind). Terminating blindly, or in a closen extremity.

CACUM (Lat, coenus). A tube which ends in a blind extremity.

Calcareous (Lat. calix, lime). Composed of carbonate of lime.

Calice. The little cup in which the polype of a coral-producing Zoophyte (Actinozoön) is contained.

Calycophoride (Gr. kalux, a cup; phero, I carry). An order of the Oceanic Hydrozoa, so called from their possessing bell-shaped swimming-organs.

CaLyX (Lat. a cup). Applied to the cup-shaped body of the Bell-animalcule (Torticella), or of the Crinoidea.

Campanularida (Lat. campannila, a bell). A group of Sertularian Zoophytes.

Canine (Lat. canis, a dog). The eye-tooth in the jaw of Mammals; so called because it is particularly well developed in Logs and other carnivorous animals.

CARAPACE. A protective shield. Aprilied to the head-shield of Lolsters, Crabs, and many other Crustaceans; and to the upper half of the bony case in which the Tortoises and Turtles are enclosed.

CARINAT玨 (Lat. carina, a keel). A sub-class of birds in which the breast-bone is keeled. 
('ARxryon (Lat. caro, flesh ; voro, I devour). An orter of the Mammatia.

('ARNIVOROUS. Living upon animal food.

CARpus (Gr. karpos, the wrist). The small bones which intervene between the fore-arn and hand.

Catarhina (Gr. kata, downwards; rhines, nostrils). A group of the Monkeys. (Quadrumana).

Caudal (Lat. cauda, the tail). Connected with the tail or hinder end of the body.

Caviconna (Lat. cams, hollow; cornu, a horn). The "hollow-homed" Ruminants, in which the horn consists of a central bony "horn-core" surrounded by a sheath of horn.

CENTRUM (Gr. kentron, the point round which a circle is described by a pair of compasses). The central portion or "body" of a tertebra.

Cephalic (Gr. lephalê, head). Connected with the head.

Cephalopona (Gr. kephalé, head; podes, feet). A class of the Mollusca, comprising the Cuttle-fishes and their allies, in which there is a series of arms ranged round the head.

Cephalothorax (Gr. hephale, head; thorax, chest). The anterior division of the body in many ('rustort', and Arachnida, conjposed of the amalgamated segments of the head and thorax.

Cerebizal. Connected with the brain, or in a restricted sense with the "cerebrum."

Cermbrix. Sometimes employed in a general way to designate the entire brain ; but properly restricted to the "hemispheres" of the brain, which are believed to be concerned mainly with the discharge of the mental functions.

Cervic.. (Lat. cervix, the neck). Belonging to the neck.

Cetacea (Gr. kètos, a whale). An order of the Mammalia.

Chatogistus (Gr. chaité, a bristle; gnathos, the jaw). A class of the Anorthropuda.

Cheiroptera (Gr. cheir, hand; pteron, wing). An order of Mammalia.

CHELA (Gr. chelé, a claw). The prehensile claws with which certain of the limbs are terminated in unany of the Crustacea (such as Lobsters, Crabs, \&c.)

Chelinia (Gr. chelone, a tortoise). An order of Reptiles.

Chitune (Gr. chiton, a coat). A peculiar chemical principle allied to horn, which is found in the outer covering of many of the Invertebrata, especially in Athropwlit (Insects, Sicorpions, Crustaceans, \&c.)

Chlorophylu (Gr. clcloros, green; jhullon, leaf). The green colouring matter of leaves.

CirRYsalis (Gr. chrusos, gold). The motionless pupa of Butterfies and Moths, so called because often exhibiting a golden lustre.

Chyle (Gr. chwlos, juice). The milky fluid which is the result of the action of the various digestive fluids upon the food.

Chylffic (Gr. chulos, juice; Lat. facio, I make). Applied to one of the stomachs, when more than one is present.

CHYME (Gr. chumos, juice). The acid pasty liquid produced by the action of the gastric juice upon the food.

Cruia (Lat. cilinm, an evelash). Microscopic, hair-like filaments, which have the power of lashing backwards and forwards, thus creating currents in the surrounding fluid, or subserving locomotion in the animal which possesses them.

Cirrei (Lat, cirrus, a curl). Tendril-like appendages, such as the feet of Barnacles, and Acorn-shells (Cirripedia), the lateral processes on the arms of Brachiopods, \&c.

CIRIIPEDIa (Lat. cirrus, a curl; pes, a foot). A division of the Crustacea with curled jointed feet.

Cladocera. (Gr. klados, a branch; keras, a horn). An order of Crustacea with branched antennæ.

Clavicle (Lat. clavicula, a little key). The collar-bone of the pectoral or scapular arch. 
Cloaca (Lat. a sink). The common cavity into which open the intestinal callal and the clucts of the generative and urinary organs in many Invertebrates aud some Vertebrates.

CNID (Gr. knide, a nettle). The urticating cells ("thread-cells") whereby many of the Calenterata obtain their power of stinging.

Cocoos (Fr. cocon, the cocoon of the silli-wormi). 'The onter covering of silky hairs with which the pupa or chrysalis of many insects is protected.

CoLlenterata (Gr. koilos, bollow; enteron, the bowel). The sub-kingdom which includes the Hydrozoa and Actinozoa, the most typical members of Cuvier's division of the Radiata.

Conosare (Gr. koinos, common; sartr, flesh). The common organised medium or stem by which the separate zoöids of a compound Hydrozoön or Actinozoön are united together.

Coleoptera (Gr. koleos, a sheath; pteron, a wing). The order of Insects (Beetles) in which the anterior wings are hardened, and form protective sheatbs for the posterior membranous wings.

Columbacei (Lat. colamba, a duve). The subdivision of the Rasorial Birds containing the Doves and Pigeons.

CoNDyle (Gr. kondulos, a knuckle). The surface by wbich one hone is jointed or articulated to another. Applied especially to the articular surfaces by which the head is jointed to the vertehral columun.

Conirostres (Lat. conus, a cone ; rostrum, a beak). The division of Perching Birds with conical beaks.

COPEPODA (Gr. kopé, an oar ; porles, feet). An order of Crustacea.

CORACOID (Gr. korax, a crow; eidos, form). One of the bones which form the scapular arch in Birds, Reptiles, and Monotremata. In the majority of Mammalia it is a mere process of the scapula, and in Man its shape is something like that of the beak of a crow ; hence its name.

CORALLITE. The entire coral of a simple Actinozoön, or the portion of a compound coral which belongs to, and is secreted by, a single polype.

Colanlum (Lat. for red coral). The hard structures deposited in or by the tissues of any Actinozoön-commonly called a "coral."

CoRPOS CALLOSOM (Lat. the "firm body"). The great band of nervous matter which unites the two henispheres of the brain in the Mammalia.

Conpusculated (Lat. corpusculum, a little body or particle). Applied to fluids which, like the blood, contain floating solid particles or "corpuscles."

Cortical LAYGR (Lat contex, bark). The layer of consistent sarcorle which encloses the central " abdominal cavity" in the Infusoria and is covered by the cuticle.

Corynida (Gr. koruné, a club). An order of Hydroid Zoophytes.

Costal (Lat. costa, a rib). Connected with the ribs.

CRANIDM (Gr. kranion, the skull). The bony or cartilaginous case in which the brain is contained.

Craspeda (Gr. kraspedon, a margin or fringe). The long, convoluted cords, containing thread-cells, which are attached to the free margins of the mesenteries in a Sea-anemone.

Crepuscular (Lat. crepusculum, dusk). Applied to animals which are active in the dusk or twilight.

CrinoIdeA (Gr. krinos, a lily; eidos, form). An order of Echinodermata comprising forms which are usually stalked, aud sometirues resemble lilies in shape.

Ckocodilia (Gr. krokodeilos, a crocodile). An order of Reptiles.

Chop. A partial dilatation of the gullet, technically called "ingluvies." Sometimes it has the form of a membranous bag appended to the gullet.

Ciustacka (Lat. crusta, a crust). A class of Articulate animals, comprising Crabs, Lobsters, \&c., characterised by having a hard shell or crust, which they cast periodically.

CтENon (Gr. kteis, a comb; einlos, form). Applied to those scales of fishes, the hinder margins of which are fringed with spines or cut into comb-like projections.

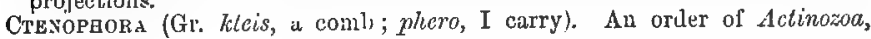


comprising oceanic creatures, wlich swim by means of "ctenophores," or bauds of cilia arranged in comb-like plates.

Cursores (Lat. curro, I run). An order of Birds, comprising birds in which there is no power of flight, but the hady is formed for ruming vigorously.

Cutrcle (Lat. cuticula, diminutive of cutis, skin). The transparent pellicle which forms the outer layer of the body in Infusoria. The outermost layer of the integument generally.

Crcloid (Gr. kuklos, a circle; eidos, form). Applied to those scales of tishes which have a regularly circular or elliptical outline.

Cystic (Gr. kustis, a bladder). Applied to the embryonic forms of the Tapeworms which were originally described as a distinct order of Parasitic Worms unter the name of Cystica, or "Blarlder-worms."

Crstordea (Gr. kustis, a bladder; eidos, form). An extinct order of Echinodermata.

Cytode (Gr. kutos, a ressel or cell; eidos, form). A minute mass of protoplasm resembling a true cell, but destitute of a nucleus, and without a proper wall.

DFCapoda (Gr. deka, ten; podes, feet). The division of Crustaced with ten legs adapted for walking (e.g., Crabs and Lobsters). Also, the family of Cuttle-lishes (Cephalopoda) in which the mouth is surrounded by ten processes or "arms."

Decrdoous (Lat. decido, I fall off). Applied to parts which fall off or are shed during the life of the animal.

Dhinogerata or Dinocerata ( $\mathrm{Gr}^{2}$. deinos, terrible; keras, hom). An extinet orfer of Tertiary Mamnials.

Deinosauria or Dinosauria (Gr. deinos, terrible; saura, lizard). An extinct order of Reptiles.

DENTAL (Lat. dens, a tooth). Connected with the teeth.

DentiRostres (Lat. dens, a tooth; rostrum, beak). The division of the Perching Birds in which the upper mandible of the bill has its lower margin toothed.

Draphragm (Gr. diaphragma, a partition). The "milriff," or the muscle which in Mammatia separates the cavity of the chest from that of the abdomen.

Dibranchiata (Gr. dis, twice: bragchia, gills). The order of Cephalopoda (comprising tlie Cuttle-fishes, \&c.) in which only two gills are present.

DicYNodontia (Gr. dis, twice; kuon, dog; odous, tooth). An extinct order of Reptiles, called by Owen Anomodonia.

Drart (Lat. digitus, a finger). A finger or toe.

Digitigrada (Iat. digitus, a finger; gralior, I walk). The division of Carnivora in which the animal walks upon the tips of the toes.

Dipnor (Gr. dis, twice; pnoe, breath). The order of Fishes represented by the Lepidosircn.

Distera (Gr. dis, twice; pteron, a wing). An order of Insects characterised by the possession of two wings only.

Discophora (Gr. diskus, a quoit, or round plate; phero, I carry). The Meduse, or Jelly-fishes, so called from their form. Also the order of the Leeches (IIimulinea), from the suctorial discs which they possess.

Distal. Applied to the quickly growing end of the hydrosoma of a Hydrozoön; also to the end of a limb, or any portion of a limb, furthest removed from the trunk.

Drurnal (Lat. diurnus, daily, by day). Applier to animals which are active during the day.

Dorsal (Lat. dorsum, the back). Connected with the region of the back.

Echinodermata (Gr. echinos, a hedgehog; derma, skin). A slass of animals comprising the Sea-urclins, Star-tishes, and others, most of which have spiny skins.

Echinoldea (Gr, echinos, a hertgehog; eidos, forn). An order of Echinodermata, comprising the Sea-urchins. 
Ecrocyst (Gr, ektos, nutside; kustis, a bladder). The external investment of the polypide of a Polyzodin.

Eстолerim (Gr. ektos, outside; derma, skin). The external integumentary layer of the Colenterata.

Edentata (Lat. $e$, without; dens, tooth). An order of Mammalia, in which some or all of the teeth are wanting Uften called Bruta.

Elasmobranchin (Gr. elasma, a strap; bragchia, gill). An order of Fishes, including the Sharks and Rays.

Elytra (Gr. elutron, a sheath). The hard chitinous anterior pair of wings in the Beetles, which form protective cases leneuth which the posterior membranous wings can lie folded.

Envocrst (Gr. endon, within; kustis, a bag). The inner membrane of the polypide of a Polyzoön.

Endoderm (Gr. endon, within ; demna, skin). The inner integumentary layer of the Coclenterato.

Endoskeleton (Gr. endon, within; skeletos, dry). The interual hard structures, such as bones, which serve for the attachment of muscles, or the protection of organs, and which are not merely produced by a liardening of the integument.

Extomostraca (Gr. entoma, insects; ostrakon, shell). Literally, "Shelled. Insects;" applied to a division of the C'rustacea.

Evтozos (Gr. entos, within; zoön, animal). Aninals which live parasiticaily in the interior of other animals.

EqTilateral (Lat. requus, equal; latus, sile). Having its sides equal. Usually applied to the shells of the Brachiopoda.

Equivalve (Lat. cequus, equal; valvoc, folding-doors). Applieil to shells which, like those of most of the Lamellibranchiata, are composed of two equal pieces or valves.

Errantia (Lat. erro, I waniler). An order of Annelula, comprising forms which are capable of active locomotion.

EurypterdDA (Gr. eurus, broad; pteron, wing). A group of extinct $C_{r}$ ) tacea.

Exoskeleton (Gr. exo, outside; skeletos, dry). Uniler this term are comprised all structures which are produced by a hardening of the integument.

Famur. The thigh-bone, intervening between the pelvis and the bones of the leg proper (tibia and fibula).

Fibula (Lat. a brooch). The outermost of the two bones of the leg in the higher Vertebrata.

Fission (Lat. findo, I cleave). Multiplication by meaus of a process of selfdivision.

Fissirostres (Lat. fiseus, cleft ; rostrum, beak). A sub-order of the Perching Birds, in which the beak can be opened to a great widtl.

FlaGellum (Lat. a whip). Vibratile filaments, allied to cilia, but differing in leing much longer, and generally present only in small numbers.

Fоoт. The muscular oryan developed on the under surface of the body in the higher Mollusca, and suberving locomotion.

FooT-JAWs. The limbs of Crustace, which are so modified as to subserve mastication.

Foot-TuBERcLes. The unjointerl lateral appendages of the Annelida, which subserve loconotion, but are not articulated to the hody.

Foraminifeks (Lat. foramen, an aperture; fero, I carry). An orter of Protozoa, usually characterised by having a shell perforated by numerous holes or "foramina," through which the pseudopodia are emitted.

Fruarvorous (Lat. frux, fruit; voro, I devour). Living upon fruits.

FunNel." The stomach sac of the Ctenophora; the muscular tube of the Cuttle-fishes by which the water filling the nantle-cavity is ejected.

Furculum, properly Furcura (Lat. diminutive of furca, a fork). The V-shaped Lone or "merry-thought" of birds, formed by the united clavicles.

Galltracer (Lat. gallina, a fowl). Often applied to the entire order of the 
Rasorial Birds, but properly restricted to that section of the Rasores of which the common fowl is a typical example.

Ganglion (Gr. gagglion, a knot). A mass of nervous matter containing nervecells, and giving origin to nerve-fibres.

Giroid (Gr. yanos, splendour; eidos, form). Applied to those scales of fishes which are composed of bone, with an outer layer of polished enamel.

GANOIDEL. An order of Fishes now mostly extinct.

Gasteropoda (Gr. gaster, helly ; podes, feet). The class of the Mollusca, comprising the ordinary Univalves, in which locomotion is usually effected by creeping about on a flattened "foot."

Gemmation (Lat. gemma, a bud). The production of fresh structures by a process of budding.

Gephyren (Gr. gephura, a bridge). A class of the Anarthropoda.

-GIzzARD. A muscular division of the stomach in Iusects, Birds, \&c.

Gonophorf (Gr. gonos, offspring; phero, I bear). The generative buds, or receptacles of the reproductive elements, in the Hydrozoa, whether these become detached or not.

Gonosome (Gr. gonos, offspring; smma, body). Applied collectively to the

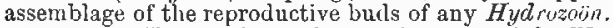

Grallatores (Lat. gralla, stilts). 'The order of the Wading Birds.

GRANIVorous (Lat. granum, a grain or seed; voro, I devour). Living upon grains or other seeds.

Graptolitide (Gr. grapho, I write; lithos, stone). An extinct sub-class of the Hydrozoa.

GRFGARINIDE (Lat. gregarizs, oecurring in numbers together). A class of the Protoñua.

GULLET. The tube which leads from the throat to the stomach.

H.esc. (Gr. haima, blood). Connected with the blood-vessels, or with the circulatory system.

Hillux (Lat. hallex, the thumb or great toe). The innermost of the five digits which normally compose the hind-foot of a Vertebrate animal. The great toe of man.

HFctocotruUs (Gr. hekaton, a hundred ; kotulos, a cup). One of the "arms" of the male Cuttle-fishes, metamorphosed for reproductive purposes.

Heliozoa (Gr. helios, sun; zoinn, animal). An order of Protozoa, with radiating pseudopodia.

HEMELYTRA (Gr. hemi, half; elutom, a sheath). The wing of certain Insects (Hemiptera), in which the inner portion of the wing is hardened by chitine, and resembles the elytron of a beetle.

Herimeta вост⿱ (Gr. hemi, half; metabole, change). Applied to those Insects which undergo an incomplete metamorphosis.

Hemiptera (Gr. hemi, half; pteron, wing). An order of Insects so called because the anterior wings are sometimes in the form of "hemelytra."

Hermaphodite (Gr. Hermes, Mercury; Aphrodite, Venus), Possessing the organs of both sexes combined.

HeTerocercal (Gr. heteros, diverse; kerkos, tail). Applied to the tail of fishes when it is unequally lobed.

Heterogkneous (Gr. heteros, diverse; genos, kinll). Unlike or dissimilar in kind.

Hetskomorphic (Gr. heteros, diverse; morphes, shape). Differing in form or shape.

Heteropoda (Gr. heteros, diverse; podes, feet). An order of Gasteroptodous Molliuses.

HiLum (Lat. a little thing). A small aperture or depression.

Hrieddinfia (Lat. limudo, a horse-leech). 'The order of Annelida comprising the Leeches.

Holockphali (Gr. holos, whole; kephale, head). A sub-order of the Elasmobranchii.

Hor.c.mlira Ont.IC (Gr. holos, whole; metaholé, change). Applied to those Insects which undergo a conplete nuetamorphosis. 
Holothuroidea (Gr. loolo'hourion). The orler of Eclinotermata, comprising the Sea-cucumbers.

Homocercal (Gr. homos, same; kerkos, tail). Applied to the tail of fishes when the two lobes are equal.

Homogeneous (Gr. homos, same; genos, kind). of like kind or nature,

Homologous (Gr. homos, same; logos, a discourse). Applied to parts which are constructed upon the same fundamental plan.

HomomorpHous (Gr. homos, same; morphé, forin). Having a similar external appearance or form.

HuMenus. The bone of the upper arm in Tertebrata.

HYDATID (Gr. hudalis, a vesicle). The bladder-worm of one of the tane-worms of the dog.

HYDRA (Gr. hudra, a water-serpent). The generic name of the Fresh-water Polypes.

HYDROLDA (Gr. hudra; and eidos, form). The sub-class of the Hylrozsa, con. taining the animals most nearly allitd to the Hydra. Often spoken of as the Hydroid Zoophytes.

HYDRoRHIZA (Gr. hudra; and rhiza, root). The adherent base or proximal extrenity of any Hydrozoön.

HrDrosoma (Gr. hudra; and soma, bolly). The entire organism of any Hydrozoön.

HYDвоTHECA (Gr. hudra; theké, a case). The little chitinous cups in which the polypites of the Sertularida and Campanularida are protected.

HydiozoA (Gr. hulra; zoön, animal). T'he class of the Ccelenterata which comprises animals constructed after the type of the Hydra.

H ymenoptera (Gr. humen, a memliane; pteron, a wing). An order of Insects (comprising Bees, Ants, \&c.) with four nembranous wings.

HYoin (Gr. $U$; eidos, form). A bone which supports the tongue, and which derives its name from its resemblance in man to the letter U.

HyRACODEA (Gr. hurax, a shrew; eidos, form). An order of Mammalia.

IснтнуомоRPhA (Gr. ichthus, a fish ; morphê, shape). An order of amphibic, comprising the tish-like Newts, \&c.

IoнтнҮорнтHria (Gr. ichthus, a fish; phtheir, a louse). An order of Cristacea.

ICHTEYOPSIDA (Gr. ichthus, fish; opsis, appearance). The primary division of the Vertebrata, which includes the two classes of the A mphibia and Pisces.

IcHTHYOPTERYGIA (Gr. ichthus, a fish; pterux, a wing). An extinct order of Reptiles.

Ichtн Yosauria (Gr. ichthus, a fish; saura, a lizarl). An extinct order of Reptiles.

Imago (Lat. an image or apparition). The perfect insect, after it has passed through all its metamorphoses.

INCISOR (Lat. incido, I cut). The cutting teeth fixed in the front of the upper jaw, and the corresponding teeth in the lower jaw, of the Mammalia.

INEquilateraL. Having the two sides unequal, as is the case with the shell of the ordinary bivalves (Lamellibranchiata).

InEquivalve. Composed of two unequal pieces or valves, as is the case with the shells of the Brachiopoda.

INFusoria (Lat. infusum, an infusion). A class of Protozoa, so called from their frequent occurrence in organic infusions.

Issecta (Iat. inseco, I cut into). The class of Articulate animals commonly known as Insects.

Ixsectrvora (Lat. insectum, an insect; voro, I devour). An order of Mammalia.

INSECTIVoRous, Living upon Insects.

INTTRAMBULACRA (Lat. inter, between; ambulacrum, a place to walk in). The rows of plates in an Echinus which are not perforated for the emission of the tube-feet.

IsTUSSUSCEPTION (Lat. intus, within; suscipio, I take up). The act of taking foreign matter into a living being. 
Invertebrata (Lat. in, without; vertebra, a bone of tle back). Animals without a spinal column or backbone.

IsOPODA (Gr. isos, equal; podes, feet). An order of Crustacen in which the feet are equal and like one another.

LABIUM (Lat. for lip). Restricted to the lower lip of Articulate animals.

LABIUM (Lat. for lip). Restricter to the upper lip in Articulate animals.

LABYRINTHODONTIA (Gr. laburinthos, a labyrinth; odous, a tooth). An extinct order of Amphibia.

Lacertilda (Lat, lacerta, a lizard). An order of Reptilia, comprising the Lizards and Slow-worms.

LAMODIPODi (Gr. Laimos, throat; dis, twice; pocles, feet). An order of Crustacea with two legs under the throat.

LAMELlibranchinTs (Lat. lamella, a plate; Gr. bragchin, gills). The class of Mollusca comprising the ordinary Bivalves with leat-like gills.

LARVA (Lat. a mask). The insect in its tirst stage atter its emergence from. the egg, when it is usually very different from the adult.

LEPIdoPTER A (Gr. lepis, a scale ; pterm, a wing). The orler of Insects, comprising the Buttertlies and Moths, characterised by liaving four wings usually covered by minute scales.

LINGUaL (Lat. lingua, tongue). Connected with the tongue.

Ilicernarida (Lat. lucerna, a lanıp). An order of the liydrozoa.

Lumbar (Lat. lumbus, a loin). Connecterl with the loins.

Macrura (Gu. maktos, long; oura, tail). A tribe of Decapol Crustaceans with long tails (e.q., the Lobster, Shrimp, \&c.)

M.idreporiforir. Perforated by sniall lioles, like a coral (or madreyore), applied to the spongy tubercle by which the water-vascular system of Echinoderms mostly communicates with the exterior.

Malacodermata (Gr. malakos, soft; derma, skin). Applied to a group of the Actnozoa, comprising the soft-skinned Sea-anemones.

Mallophaga (Gr. mallos, a fleece; phago, I eat). An orier of Insects, comprising the Bivd-lice.

Mammala (Lat. mamma, the breast). The class of Vertebrate animals which suckle their young.

Mandible (Lat. mandibulum, a jaw.) The mandibles are the first pair of jaws in Insects and Crustaceans. Iu Spiders they are the nodified antennæ. In C'ephaloporls they constitute the horny beak. The lower jaw of Vertebrates is the mandible.

MantL. The extermal integument of most of the Mollusca. which is largely developed, and forms a cloak lor the internal organs. Teclinically called the "pallium."

Manubrium (Lat. a handle). The central polyjite which is suspended from the roof of the swimming-lecll of a Medusa or medusiform gonophore amongst the IJydrozod.

Mansipobrancuis (Gr. marsipos, a ponch ; bragchia, gills). An orler of Fishes, comprising the Hag-fishes and Lampreys, with pouch-like gills.

Mirsupialis (Lat. musupium, a pouch). An order of Mamnals, in which the females are usually furn shed with an abdominal pouch in which the young are carried.

Masticatury (Lat. mastico, I chew). Adapted for chewing.

Meduse. A grony of $H_{\text {i/l }}$ wist, crimmonly known as Jelly-fishes, so called because of the resemblaice of their tentacles to the snaky liair of the Medusa.

M Edusiform. Resenbling a Medusa in shape.

Medusoid. Like a Medusa. Userl as a noun to designate the medusiform generative buds (gonopliores) of the Hydrozod.

MEMBrana Nictitans (Lat. nicto, I wink). The third eyelic present in Birds, \&c.

Meliostomata (Gr. Mèron, thigh; stoma, mouth). An order of Crustacea.

Mesenteries (Gr. mesos, intermediate; enteron, intestine). 'The membrame by which the iutestine is attacher to the walls of the abdomen. In a restricted sense, the vertical plates which divide the somatic cavity of a Seaanemone into chambers. 
Mrtac.ırpis (Gr. meta, after ; karpos, the wrist). The bones which form the "root of the hand," ant intervene between the wrist and the fingers.

Mrtamulphosis (Gr. meta, denoting change; morphó, form). Tlie clianges of form which certain animals undergo in passing from their younger to their fully-grown conditi in.

Metatarsus (Gr. meta, aftel ; tarsus, the instep). The bones which interrene between the instep (tarsus) and the digits in the hind-toot of the ligher Vertebrates.

MetazoA (G1', meta, beyond: zö̈n, animal). A name applied collectively to all animals except the Protozoa, the latter being unicellular, while all other animals are juulticellular.

Molars (Lat. mola, a mill). The "grinders" in man; or the teeth in Mammals which are not preceded by milk-teeth.

Mollusca (Lat. mollis, soft). The sub-kingdom which includes the true Shell-tish, the Polyzoa, the Sea-squirts, and the Lamp-shells.

Molloscoida (Mollusca, and Gr. eidos, form). The lower division of the Mollusca, comprising the Polyzoa, the Sea-squirts (Tunicata), and the Lamp-shells (Brachiopoda).

Muneka (Gr. monères, single). An order of Protozoa, conprising animals composed of simple undifferentiated sarcode.

Monothalamous (Gr. monos, single; thalamos, a chamber). Consisting of only a single chamber. Applied to the shells of Foraminifera and Mollusca.

Monotremata (Gr. monns, single : trèma, an aperture). The order of Mammals, comprising the Duck-mole and the Spiny Ant-eater, in which the intestinal canal opens into a "cloaca" common to the ducts of the urinary and generative organs.

MORPHOLOGY (morphé, form ; logos, discourse). The science of the external form and internal structure of the various parts and organs of different animals.

Multivalve (Lat. malius, many; valve, folding-doors). Applied to shells which are composed of nole tlian two pieces or valves.

MrriaPODA (Gr. murios, ten thousand; podes, feet). A class of Articulate animals, comprising the Centipertes and their allies, characterised liy the possession of numeruus feet. Otten, and philologically more correctly, spelt Myriopoda.

Natatores (Lat. nare, to swim). The order of the Swimming Birds.

Natatory. Adapted for swimning.

Nautrimord. Shaped like the shell of the Nautilus.

Nectocalyces (Gr. nècho, I swim; kulux, a cup). The swimming-hells of the Oceanic Hydrozoa.

Nematuda or Nematoides (Gr. néma, a thread ; eidos, fnrm). The division of the Scolecida comprising the Thread-wornis and Round-worms.

Nervures (Lat. nervus, a sinew). 'I'he ribs which support the nembranons wings of insects.

NEURAL (Gr. neuron, a nerve). Connected with the nervous system.

Neuroptera (Gr. neuron, a verve; pteron, a wing). An order of Insects in which the wings are membranous and have uumerous interlacing nervures.

Nocturnal (Lat. nox, night). Applied to animals which are active at night.

Normal (Lat. nomma, a rule). Conforming to the ordinary standard.

Notockond (Gr. nötos, the back; chordé, a string). A cellular rod which is developed iu the embryo of Vertebrates inmediately beneatli the spinal coro, and which is usually replaced in the adult by the vertebral colnmn.

NuCLEOLUS. The minte solid particle found in the interior of the nucleus of some cells. Also the minute body attached to the exterior" of the "nucleus" of certain of the Infissoria.

Nucbers (Lat, a kernel). The solid or vesicular boty found in the interior of many cells; also the solid rod, or band-shaped body, found in the interior of many of the Protozoa.

NudrBRANChiata (Lat. nudus, naked; Gr. bragchia, gills). An order of the Gasteropoda in which the gills are naked. 
OCEANIC. Applied to animals which inhalit the open ocean.

UCTOPODA (Gr. octo, eight; podes, feet). The tribe of Cuttle-fishes with eight arms round the heari.

ODONTOLCA (Gr. orlous, a tooth; halkos, a furrow). An order of extinct Birds, conprising only the genus Hesperornis, in which the teeth are sunk in a deep groove.

ODONToPHoRE (Gr. odous, a tooth ; phero, I carry). The so-called "tongue" or masticatory apparatus of the Gasteropoda, I'teropoda, C'ephalopoda.

ODWTORNITHES (Gr. oulous, tooth; ornis, bird). The extinct sub-class of Birds comprising forms with distinct teeth in sockets.

ODnNTotoRas (Gr. olloms, a tooth; tormos, a socket). An order of extinet Birds, comprising Ichthyornis only, in which the teeth are sunk in sockets.

EsophaGus. The gullet, or the tube by which the food is conveyed from the mouth to the stomach.

Obigocexta (Gr. olzgos, few; chaité, bristles). An order of the Annelida, comprising the Earth-worms.

ONASUM (Lat. hullock's tripe). The third stomach of Ruminants, commonly called the "psalterium."

OMNIVORous (Lat. omma, everything; roro, I devour). Feeding indiscrininately upon all kinds of food.

Operoubtm (Lit. a lid). The shelly or horny plate by which the shell of a Univalve Molluse is closed when the animal has retired within it; also the chain of flat bones which covers the gills in many fishes.

OPHIDI. (Gr. ophis, a serpent). The order of Reptiles comprising the Snakes.

OpH IOMORPHA (Gr. oplis, a serpent; morphe, shape). The order of Amphibria comprising the C'crilir.

OpHurrordea (Gr. ophes, a serpent; onera, tail; eidos, form). An order of Echinodermata comprising the Brittle-stars and S.ınd-stars.

Opisthocasous (Gr. opisthen, behind; koilos, holjow). Applied to vertebre, the bodies of which are bollow or concave behinel, and convex in front.

OR.IL (Lat. os, the mouth). Connected with the mouth.

ORTHOPTERA (Gr. wthos, straight; pteron, a wing). An order of Insects.

Oscula (Lat. diminutive of $o s$, mouth). The large apertures ("exhalaut apertures") by which a sponge is perforated.

Ostracoda (Gr. ostrakm, a shell; eidos, form). An orler of small Crustaceans which are enclosel in bivalve shells.

OvIPAROUS (Lat. ovum, an egr: pario, I bring forth). Applied to animals which bring forth eggs, in contradistinction to those which bring forth their young alive.

Ovipositur (Lat. ovm, an egrg; $y m m$, I place). The organ possessed by some insects, by uneans of which the egs are placed in a position suitable for their development.

OvisAc. The external bag or sac in which certain of the Invertebrata carry their eggs after they ase extruder from the body.

Ovo-virlskous (Lat, orum, an egg; vivus, alive; purio, I hring forth). Appliel to animals which retain their eggs within the body until they are hatchert.

Ovux (Lat. an egg). The germ primlucel within the ovary, and capable under certain conditions of being developed into a new indiviclual.

Pachydermati (Gr. pachws, thick; derma, skin). An old Mammalian order constituted by Cuver for the reception of the Elephant, Rlinoceros, Hippopotarnus, ice.

PaLlial. Connected with the mantle or "pallium."

P.sllium (Lat. a cloak). The "mantle" of the Mollusca.

PALPI (Lat. palpo, I tonch). Processes supposed to he organs of touch, developed from certain of the organs of the mouth in varions Articulate animals, and from the sides of the month in the Bivalve NIolnses.

Papilua (I it. for a nipple). A minute soft prominence.

PARAPODIA (Gr. pura, beside; podes, feet). The lateral locomotive processes or "foot-tubercles" of many of the Annclida. 
Parietal (Lat. paries, a wall). Connected with the walls of a cavity or of the body.

Parieto-splanchnic (Lat. paries, a wall; Gr. splagchnon, an internal organ). Applied to one of the nervous ganglia of the Mollusce, which supplies the walls of the body and the viscera.

Patagium (Lat. the border of a dress). Applied to the expansion of the integument by which Bats, Flying Squirrels, and other aninals support themselves in the air.

Pecroral (Lat. pectus, the breast). Connected with the chest.

Pedal (Lat. pes, the foot). Connected with the foot; generally used in connection with the Mollusca.

Pedickllarife (Lat. pedicellus, a louse). Curious appendages found in many Echinoderns, attached to the surface of the body, and resembling a little pair of pincers supported on a stalk.

PEdipalpi (Lat. pes, foot; palpo, I feel). An order of A rachnida comprising the Scorpions, \&c.

Pedunculated (Lat. pedunculus, a stem). Supported upon a stem or stalk.

Pelvis (Lat. basin). 'The bony arch with which the lower or posterior pair of limbs is connected in nany Vertebrata.

Perennibranchista (Lat. perennis, perpetual; Gr. bragchia, gills). Applied to those Amphibia which retain their gills throughout life.

Perissodactyla (Gr. perissos, uneven; daktulos, finger). Applied to those Hoofed Mammals (Ungulata) which have an uneven number of toes.

Perivisceral (Gr. peri, around; Lat. viscera, the internal organs). Applied to the space surrounding the viscera in most animals.

Phalanges (Gr. phalanx, a row). The small bones composing the digits of the higher Vertebrates. Normally each digit has three phalanges.

PharyngobraxchIr (Gr. pharugx, the pharynx; bragchia, gills). The order of Fishes comprising only the Lancelet.

PharynX. The upper part of the gullet.

Phyllopoda (Gr. phullon, leaf; podes, feet). An order of Crustacea.

Physophoride (Gr. phusa, bellows or air-bladder; phero, I carry). An order of Oceanic Hydrozod.

PINN\& (Lat. pinna, a feather). Lateral processes, applied especially to the processes of the arms of Crinoills, or of the tentacles of Alcyonaria.

PINNIGRADA (Lat. pinna; and gradior, I walk). The fanily of Carnivora, comprising the Seals and Walruses, adanted for an aquatic life.

Pisces (Lat. puscis, a fish). The class of the Vertebrata comprising the Fishes.

Placenta (Lat. a cake). The "after-birth," or the organ by which a vascular connection is established in the higher I'ertebrata between the mother and the young animal previous to its birth.

Placental. Possessing a placenta, or connected with the placenta.

Placold (Gr. plax, a plate; eidos, form). Applied to the irregular bony plates, grains, or spines which are found in the skin of varrous fisles.

Plagiostomi (Gr. plagios, transverse; stoma, month). The Sharks and Rays, in which the mouth is transverse, and is placed on the under surface of the head.

Planarida (Gr. plane, wandering). A group of the Scolecida.

PlantigRAda (Lat. planta, the sole of the foot; gradior, I walk). The group of the Carnivora in which the sole of the foot is applied to the ground.

Plantigrade. Walking upon the soles of the feet.

Plastron (Gr. emplastron, a plaster). The ventral shield of the case of the Tortoises and Turtles (Chelonia).

Platyrhina (Gr, platus, broad; rhines, nostrils). A group of the Quadru. mana.

Plesiosadria (Gr. plesios, near; saura, a lizard). An extinct order of Reptiles.

Puuteus (Lat. a shed). The larval form of the Sea-urchins (Echinus).

Pneumatic (Gr. pneuma, air). Filled with air. 
Pneumatophone (Gr. pnemma, air; phero, I carry). The air-bladder of the Physophorillo.

Podosomata (Gr. pous, foot; soma, body). An order of Arachnida.

Porsers. See Balancers.

PoLlex (Lat. the thunb). The innermost of the normal five digits of the forefoot of the higher Vertebrata. The thumb of man.

Polycheta (Gr. polus, many ; chaité, bristle). The order of the higher Annelides, comprising the Sea-worms, in which the foot-tubercies carry tufts of bristles.

Polycystina (G1. polus, many; kustis, a bladder). An order of Protozno.

PolYGamous (Gr. polus, nuany ; gamos, marriage). Applied to cases in which one male consorts with several females.

Polygastrica (Gr. polus, many; gastêr, stomach). The name applied by Ehrenberg to the Infusoria, under the belief that they possessed many stomachs.

Polypary. The hard chitinous covering secreted by many of the Hydrozoa.

Polype (Gr. polus, inally; pous, foot). Restricted in nodern usage to the single individual of a simple lctinozoün, or to the separate zoöids of a compound Actinozöın.

Pocvprde. The separate zooid of a Polyzoön.

POLYPIDom. Synonymous with polypary, but often applitd to the Polyzoa, as well as to the Hydrozoa.

POLYPITE. The separate zoöid of a Hydrozoön.

Polythalimous (Gr. polus, many; thalamos, chamber). Many-chambered. Applied to the shells of Firamuifera and Cephalopoda.

PolyzoA (Gr. polus, many; zoön, animal). The Sea-runsses, and Sea-mats, forming the lowest class of the Mollusca.

PORIfERA (Lat. portus, a pore ; fero, I carry). The Sponges, so called because the body is furnished with canals terminating on the surface in larger or smaller openings.

Premolars (Lat. pror, before; molares, grinders). The teeth which succeed the molars of the milli-set of teeth.

PRA-CESOPHAGEAL. Situater in front of the gullet.

Proboscidea (Gr. proboscis, the smout). The order of Mammals comprising the Elephants.

Proccelous (Gr. pro, front; koilos, hollow). Applied to vertebra, the bodies of which are hollow or concave iu front.

Protophyta (Gr. protus, first; phyton, plant). The lowest division of plants.

Protoplasm (Gr. protos, first; plasen, I moulll). The elementary basis of organised tissues. Seen in its least modified form in the "sarcode" of the Protozoa.

Protozon (Gr. protos, first; zoün, animal). The lowest clivision of the Animal Kingrlom.

Proximal (Lat. proximus, next). T'Je slowly growing, comparatively fixed extrenity of a limb or of an organism.

PSALrerium (Lat, a stringed instrument). The third stomach of the Ruminants.

Psevdoh amal (Gr. pseudos, false; haima, blood). The vascular system of the Annelida.

PSEUnO-HEARTS. Contractile cavities connected with the reproductive system of the Birerhiopoda.

Pseudopodia (Gr. pseudos, falsity ; podes, feet). The temporary extensions of the body-sulsstance which are put forth by the Rhizopuda at will, and which serve hoth for locomotion and for preliension.

PTERopoda 'Gr, pterm, a wing; podes, feet). A class of Mollusca swimming by means of fins attached to the sides of the head.

Pterosauria (Gr. pieron, a wing; saura, a lizard). An extinct order of Reptiles.

Pulmonary (Lat, pulmo, a lung). Connected with the lungs.

Pularonate. Possessing lungs. 
Pupa (Lat. a doll). The state of the nietamorplosis of an insect immediately preceding its appearance in a perfect condition. In this state the insect is very otten motionless, and is often called a "chrysalis."

PyLonus (Gr. pulōros, a gatekeeper). The valvular aperture between the stomach and the commencement of the intestine.

Quadromana (Lat. quatuor, four; manus, hand). The order of Mammalia comprising the Monkeys, Bahoons, Lemurs, \&c.

Quadrumanous. Four-handed.

Radist (Lat. radius, a ray). Formerly applied to a large number of animals which are now placed in separate sub-kingdoms $(e . g$, the Coelenterata, Lchinodermata, Infusoria, \&c.

Radiolaria (Lat. radius, a ray). An order of Rhizopoda.

RADrus. The innermost, of the two bones of the fore-arm of the higher Vertebrates. It carries the thumb, or pollex, aud corresponds with the tibia of the"hind-limb.

RAPTOREs (Lat. rapto, I plunder). The order of the Birds of Prey.

Raptorial. Applied to animals which live by preying upon other animals.

Rasores (Lat. rado, I scrape or scratch). The order of the Scratching Birds (Fowls, Pigeons, \&c.)

Ratris (Lat. rates, a raft). Applied by Huxley to the Cursorial Birds, which do not fly, and have a raft-like sternum without any median keel.

Reptilia (Lat. repto, I crewl). The class of the Vertebrata comprising the Tortoises, Serpents, Lizards, Crocodiles, \&c.

ReTiculum (Lat. a zet). The second stomach of the Ruminants.

RHIzopoda (Gr, rhiza, a root; podes, feet). 'The division of Protozod comprising all those which are capable of emitting psendopodia.

Rodextia (Lat. rodo, I gnaw). An order of the Mammalia. Often called Glires (Lat. glis, a dormouse).

Rotifera (Lat. rota, a wheel; fero, I carry). A class of the Scolecida comprising the so-called "Wheel-animalcules."

RUgosa (Lat. rugosus, wrinkled). An extinct order of Corals.

Rumar (Lat. the throat). The first stomach or "paunch" of Ruminants.

Ruminantia (Lat. ruminor, I chew the cud). A group of the Hoofed M malia.

Sacrum. The rertebræ which unite with the haunch-bones to form the pelvis.

SARCODE (Gr. sarx, flesh; eidos, form). The protoplasmic substance of which the bodies of the Protozoa are composed.

Sakcords. The separate amceba-like particles which collectively make up the "flesh" of a Sponge.

Sauropsida (Gr. saura, lizard; opsis, appearance). The name given by Huxley to the two classes of the Reptiles and Bircls collectively.

SaURopterygia (Gr. saura, a lizard; pterux, a wing). An extinct order of Reptiles.

SaURURe (Gr. saura, a lizard; oura, tail). The order of Birds comprising only the extinct Archoeopteryx.

Scansones (Lat. scando, I climb). The order of the Climbing Birds (Parrots, Woodpeckers, \&c.)

SCAPULA. The shoulder-blade of Vertebrata.

SCLERoBAsic (Gr, sklerros, hard; busis, pedestal). The form of coral which constitutes a central axis, surrounded by the soft parts of the animal (e.g., Red Coral).

SCLERodermic. Applied to those corals which are secreted within the body of the polypes which produce them.

SColecida (Gr. skotex, worm). A division of the Annulosa.

Scura (Lat. scutum, a shield). Applied to the shield-like integumentary plates developed in many Reptiles.

SEPTA. Partitions.

SerPentiform. Resembling a serpent in shape. 
Sertularida (Lat. sertum, a wreath). An oriler of the Iydrozoa.

SEssile (Lat. sedo, I sit). Not supported upon a stalk, but attached by a base. Siliceovs (Lat. silex, flint). Composed of flint.

Siphon (Gr. a tube). Applied to the respiratory tubes of nuany of the Mol lusca; also to other tubes of different functions.

Siphonophor. (Gr. siphon, a tube; phero, I carry). A suls-class of the $H y\left(l_{1} 0 z 0 \alpha\right.$.

Sirenta (Gr. seirin, a mermail). An order of Mammalia comprising the Dugongs and Manatees.

Solrdungula (Lat. solidus, solid; ungula, a hoof). The group of lloofed Mammals comprising the Horse, Ass, and Zelura.

Som ITIC (Gr. somat, body). Connected with the body.

Somite (Gr. soma). A single segment in the body of an Articulate animal.

Spicula (Lat. spicmlnm, a point). Pointed needle-shaped bodies.

Sinnerers. The organs by means of which Spiders and Caterpillars spin threads.

Spongida (Gr. spoggos, a sponge). The Aivision of the Protozoa commonly known as Sponges.

StERNum (Gr. sternon). The breast-bone.

Stomapoda (Gr. stoma, molitl ; podes, feel). An orler of ('rustacea.

Stomatode (Gr. stoma, mouth). Possessing a mouth. The Infusoria are thus often called the Stomatode Protozoa.

StrepsiptFRa (Gr. strepho, I twist; pteron, a wing). An order of Insects in which the anterior wings are represented by twisterl rudiments.

Strepsinhiva (Gr. strepho, I twist; rhines, nostrils). A group of the Quad. rumana.

Suctorial. Adapted for suction or for inbiling fluils.

SUPra-cesophageaL. Placed above the gullet or cesophagus.

TaBule (Lat. tabula, a tablet). Horizontal plates or floors which are found in many Corals.

'I'ACTILE (Lat. tango, I touch). C'onnected with the sense of touch.

T.ENIADA (Gr. tainia, a ribbon). The order of Scolecida comprising the Tapeworms.

Tarso-metatarsus. The single bone produced in Birds by the union and anchylosis of the lower part of the tarsus with the metatarsus.

Tarsus (Gr. tarsos, the flat of the foot). The small bones which form the ankle (or "instep" of nan), corresponding with the wrist (carpus) of the anterior $\operatorname{limb}$.

T'eliostre (Gir. teleios, perfect; osteon, hone). All orler of Fishes often spoken of as the Bony Fislies.

TeLson (G'r. a limit). The last joint in the abdomen of the c'rustacea.

Tenulrostris (Lat. tenuis, sleniler; rostrum, beak). A group of the Perching Birds characterised by their slender beaks.

Terrestrind (Lat. term, earth). Living upon dry land.

Test (Lat. testa, a shell). The shell of Mollusca, which are for this reason sometimes called Testacea. Also, the calcareous shell of Sea-urchins. Also, the thick leathery outer tunic of the Sea-squirts, Tunicata.

TeTrabrinchiata (Gr. tetra, four; bragchice, gills). The order of Cephalopoda characterised by the possession of four gills.

Thalassicollida (Gr. thalassa, sea; kolla, giue). A division of Protozoa.

'L'HEIIODONTIA (Gr, thèr, beast; ollous, tooth). An order of extinct Reptiles with teeth of a Mammalian type.

ThrRiomorPH i (Gr. thèr, beast; morphé, shape). Employed by Owen to designate the "tail-less Amphibians," such as Frogs and Toads.

Thorax (Gr. thorax, the breast, or a breast-jlate). In the higher animals, the thorax is that region of the body which is placed between the abdomen and the hend.

Thysanura (Gr. thusanoi, fringes; oura, tail). An order of Insects.

TIBIA. The shin-hone, corresponding to the radius of the fore-limb, and being the innermost of the two bones of the leg. 
Trachea (Gr. tracheia, the rough windpipe). The tube wlich conveys air to the lungs in the air-breathing Vertebrates. In Insects, Myriapods, and Spiders, the air-tubes which ramify througl the borly.

Trematoda (Gr. tremma, a pore or hole). An order of scolecida.

T'rilobita (Gr. treis, three; lobos, a lobe). An extinct order of Crustacea.

Tubicola (Lat. $t u b c$, a tube; colo, I inhabit). An order of Annelida.

Tubularida (Lat. tube, a tube). Often used instead of Corynida to designate an order of the Hydrozoa.

Tunicata (Lat. tunica, a cloak). The Sea-squirts, a class of the Molluscoida.

ULNa (Gr. olené, the elbow). The outermost of the two bones of the fore-arm, corresponding with the fibula of the hind-limb.

Uмво (Lat. the boss of the shield). The beak of a bivalve shell.

Umbrella. The contractile disc of one of the Lucernarida.

Ungulata (Lat. ungula, a hoof). The order of Mammalia comprising the Hoofed Quadrupeds.

UNIVAlve (Lat. unus, one; valve, folding-doors). Applied to shells composed of a single piece or valve.

URonela (Gr. oura, tail; délos, visible). The order of the "tailed" Amphibians.

VACUOLES (Lat. vacuus, enpty). The little cavities often formed in the interior of many of the Protozoa by the presence of particles of food, surrounded by a little water. Many vacuoles appear to be of a different nature, being permanent cavities in the protoplasm, and being in some cases contractile.

VunTral (Lat. venter, the stomach). Relating to the inferior surface of the body.

VENTRICLE (Lat, ventriculus, diminutive of venter, belly). One of the cavities of the heart.

VERMES (Lat, vermis, a worm). Sometimes used at the present day in the . same, or nearly the sawe, sense as Scolecida, or as Scolecida plus the Anarthropoda.

VERMIFORM. Worm-like in shape.

VERTEBRa (Lat. verto, I turu). Une of the bones composing the spinal column or backbone.

VERTEBRATA. The sub-kingdom comprising animals almost all of which have a more or less well-developed vertebral column.

Vesicle (Lat. vesica, a bladier). A little sac, blarlder, or cyst.

VIscera (Lat. viscus). The internal organs of the body.

Viviparous (Lat. vivus, alive: and pario, I bring forth). Applied to aninals which bring forth their young alive.

Xiphosura (Gr. xiphos, a sword; oura, tail). An order of C'rustacea comprising the King crabs.

Zoöin (Gr. zoön, animal ; eidos, form). The more or less completely independent organisms produced from a primitive being by gemmation or fission, whether these remain attached to one another or are detached and set free.

Zoophyт, (Gr. 20ön, animal; phuton, plant). Loosely applied to many plant-like animals, such as Sponges, Corals, Sta-anemones, Sea-firs, Seamats, \&c. 


\section{N D E X.}

Acanthccephala, 114; gcineral characters of, 12 L.

Acanthoinetra, 34.

Acanthophrs, 2 8.

A canthijp:ei, 243.

Acarina, 153.

Acarus. 153.

Accphala (Mollusca), 200.

Achetider, 171.

$A$ cipenser, 244.

Acipenserida, 245.

Acorn-shells, 145, 149.

Acrialida, $17 \mathrm{~L}$.

Actinia, 84, 85 .

Actinitido, 85 .

Actinophrys, 36 .

- Actinozoa, 53; general characters of, 83 ; orders of, 85 .

Arlutant, 296.

Almnirle", 69.

Eluru, $\$ 47$.

Iflentera, 71.

Agout1, 350.

Air-receptacles of Birds, 286.

Alces, 3:38.

Alcide, 2 , 5.

Alcyonaria, 85; genejal characters of, 90 , et ser.

Alcyonim, 91 .

Alligatrr, 272, 273

Allopora, 82.

Alpaca, 337.

A mblystoma, 251, 25:.

Ambulacral system of Echinus, 101.

Anewar, sit.

Ametabolic Insects, 165, 168.

Ammonites, 216.

A moeba. 2". 25, 28.

Amoliea, 25, 25.

Amphibia, 2z; general characters of, 249 , et ser.

Amphidisc's, 48 .

Amphioxws, 237. 238.

A mphipoda, 143 .

Anacanthini, 243.

Anzeonda, 269.

Analogy, 9, 10.

A narthropoda, 112.

Anatina, 295.

Aneistrodon, 26 个.

Anguiliula, 123.

Anouis, 270.
Animals and Plants, differences between, 2, c't seq.

Annelida, 112 ; general characters of, 128: ty pical seginent of, $2 b$.; divisions of, $131 \%$.

Anmulosa, 1 t2 ; generdl characters of, $i b$. Anomodontia, $27 \%$.

Anomura, 141 .

A nuplura, los.

A noura, 253.

A nserina, 295.

Ant-eaters, 324, 326, ₹27.

Antedun, 106, 107.

Antelopes, 339.

Antennie, 140, 160.

Anthropoid A pes, 358.

Antilocaprer, 339.

Ant-lion, 173.

Ints, 179.

A pes, $355,358$.

Aphaniptera, 174.

Aphide's, 170.

Aphis-lion, 173.

Aphrodite, 135 .

A pidae, 179.

Aplacental Mammals, 317.

A ptera, 168.

A pteryx, 288, 291. 292.

Aquiferous System (Sponges), 43.

Arachnactis, 86.

A rachnida, 113; general characters, 15l; orders of, 153 .

Aidmina, 155.

Archerepteryx, 306.

Areleit, 247.

Ardeida, 296.

A renicola, 134

Argonauta, 211, 212, 213.

Armadillos, 325, 326, 327.

Arms of Brachiopoda. 194; of Cephalopoda, 200, 211,212, 214.

Aitsmia, 147.

Arthropoda, 113; general characters of, 136.

Articulata, 138.

Arturlactyla, 331, 333.

Ascaris, 123.

Aseidinn Molluses, 191; solitary, social, and ermpound, 193.

A vellus, 143.

$A \sin u s, 333$.

Ass, 333 . 
Asierias, 104.

Asteroidea, 99, 103; general characters of, 103 , et seg.

Atolls, 89, 90 .

Atrium (Tunicata), 19:.

Auchenza, 337.

Auli, 295.

A urelia , 77, 78.

Aves, 227 ; general characters of, 278 ; feathers of, ib.; vertebral columin of, 279; beak of, 280 ; pectoral arch of, $28 \mathrm{~L}$; hind-limb of, 282 ; foot of, 284 ; digestive system of, ib.; respiratory system of, 286 ; circulatory system of, 2s7; nervous system and organs of sense of, 288 ; migrations, $i b$.; divisions of, 290 , et $\mathrm{seq}$.

A ves altrices, 288.

$A$ ves erratico, 28 .

A ves manentes. 28 ?

A ves migratoria, $2 \mathrm{~S}$ ?.

A ves proecoces, $25 i$.

A vocet, 296.

Axolotl, 251.

Aje-aye, 356 .

BABOON, 355.

Babyroussa, 334.

13ariger, 347.

Balana, 329.

Baloenida, 329

Bilancers, $17:$

Balanidoe, 149.

Balanus, 149.

Baleen, 329.

Balistidoe, 213.

Bandicoot, 323 .

Banxring, 355.

Barnacles, 149

Barramunda, 249.

Barrier-reefs, 8!.

Batides, 247.

Butrachia, 253 .

Bats, 351, 3i2.

Jiear, 346,347 .

Beaver, 350, $: 51$.

Bee-eaters, 304.

Bees, 179.

Bolemnites, 211.

Bimuna, 318 ; general rharacters of, $3 j 0$.

Biology, definition of, 2 .

Bird-lice, 168.

Birds (see Aves).

Bird's-head proress, 198, 189.

Birds of Prey, 301, 305.

Buson, 340.

Bittern, 296.

Bivalve Sliell-fish, 196

Bladder-worms (see Cystic Worms).

Blastoidea, 99, 109.

Blatta, 172.

Blattida, 171

Blind-worm, 2 \% 0.

Boa, 269

Boat-fly, 171.

Bonasa, 298.

Jony Pike, 244.

Book scorpion, 155.

Bo8, 340 .

Boviala, 340.

Brachiopoda, 184, 185, 1S6; gencral characters of, 193, et seq.
Brachyura, 141, 142.

Bracts (of octanic Hydrozoa), 73.

Braclypodidoe, 325.

Branchial hearts (Cuttle-fishes), 210.

Branchist sac (Tunieata), 19\%; (Lancelet), 220

Branchiate Vertebrates, 211.

Branchifera (Gasteropoda), 203.

Brittle-stars, 105.

Bruta, 324.

Bubalus, 340.

Buccinum, 202.

Bucerida, 304.

Buffalo, 340 .

Bufonide, 258.

Bustards, 297.

Butterflies, 176 .

Byssus (of Lamellibranchiata), 201.

\section{Caddis-Flies, 1 ל3.}

Caducubranchiata (A mphibia), 251.

Caca, intestinal (uf Birds), 286.

Cacilioe, 250, 251.

Caiman, 273.

Calamaries, 208, 212, 213.

Culice (Corals) 87.

Calycophorida, $72,74$.

Camelidx, 337.

Camelopardalida, 338.

Campanularida, 58, 69; medusiform gonophores of, 68 .

Canals, of Sponges, 46; of Aleyonaria, 90 ; of Ctenophora, 96.

Canida, 347.

Cantharis, 182.

Capreolas, 338.

Caprimulgido, 334.

Capybara, 350.

Caribols, 398.

Carinaria, 2 5.

Carinata, 290, 293.

Carnwora, 318; general characters of, 344, et seq.

Carp, 243.

Carriage-spring apparatus (Brachiopoda), 194.

Cussowary, 290, 292.

Castor, 350 .

Castorida, 351.

Catarhina, 357.

Cats, 344, 345, 347.

Cavidoe, 350 .

Cavicornia, $33 \mathrm{~s}$.

Cebidoe, 357 .

Cellulose, in Ascidians, I 2.

Centeteg, 354.

Centipedes, 157, 158.

Cephalopoda, 185, 196 ; general characters of, 208 , et seq.; respiratory organs of, 210 ; reproductinn iff, 211 ; shell of, 212 .

Cophalothorax, 137, et seq.; $15 \mathrm{~L}$.

Cerastes, 267.

Ceratium, 42 .

Ceratudus, 239, 249.

Cercopithecus, 358 .

Certhide, 304

Cervide, 338.

Cervus, 338

Cestracion, 240.

Costum, 96 .

Cetracea, 316, 319; gencral characters of, 328 , et sey. 
Cham rleo, 2:-2.

Clumois, 939.

Charadriada, 297.

Cheetah, 349 .

Cheiromys, 356.

Cheiroptera, 318 ; general characters of, 351 , at seq.

Chirotherium, 256.

Clutar, 140, 151 .

Cholifer, 155 .

Chelone, 262

Chelonea, 258, 260; general characters of, 261, etseq.

Chelydra, 263 .

Clieviotains, 337.

Chimara, 245, 247.

Chimpanzee, 359.

Chitine, 61.

Chitun, 201.

Chlorophyll in animals, 4.

Chrysaora, $7 !$.

Chrysuchloris, 354.

C'ida, 171.

Cinonince, $2 \% 6$

Cirlares, 102.

Ciliata (Infusma), 38, 42.

Cimpedia, 118,149 .

estude, thi3.

Civet, 347 .

Cladocera, 147.

Clamatures, 299

Classification, 11, et seq.

Cleodura, 207.

Climbers (Biras), 300.

Clona, 49.

Cloaca, of Rotifer $a, 125$; of Insects, 163; of Amphibia, 249; of Reptiles, 259; ol Birds, 280; of Monotremata, 319.

Clupenda, 243.

Cnidre, 5:.

Coati, :547.

Cobra, 268 .

Corhineal Insects, 171.

C'sekatons, 301.

Cockroaches, 171.

Cocoon, 107.

1:od, 243

Culentrata, 12; general characters of 50 , it seq.; thread-cells of, 52 ; divisions of, $5:$ :

Cimosare, 5 T.

Culeoptira, 181, 182.

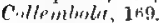

Colltisylhas ${ }^{*} a, 3$;

Collozoa, 35.

Colobus, 357.

Coluler, 2 ti9

Columbeces, 298, 290

Comulula, i06, 107, 108

Conilylura, 354.

Conwowtres, 303.

Contrutile vesicle, of Amaba, 30; of Infusoria, 45

Crot, 2!ls.

Copevorla, $1+7$.

Coral, st.

Corallite, 87

Corallium, 93, 14.

Corallum. 84. 86.

Coral-reefs, 89 , et seq.

Cirrlyliphura, 61 .

Curriorant, 295
Cortical layer, of Infusoria, 39.

Corvida, 304.

Corynida, 53 ; general characters of, 61 ; reproduction if, 62 .

Coryomorpha, 62.

Coturnix, 293.

Coypu, 351 .

Cinli, 141 .

Cracide, 209

Crane, 296

Crane-fly, 176

Craspeda, 86.

Cray tish, 133.

Creepers (Birds), 304.

Crex, 296.

Cribella, $1{ }^{n} 4$.

Cricket, 171.

Crinuter 99 , l' 6 ; general characters of, 106,107 , et $s \varphi^{2} \%$

Cristatella, 190.

Crocodilia, 25S, et seq. ; general characters of 272 , et se"l.

Crop, of Insects, 163; of Birds, 284.

Cross-bill, 314.

Crotalidae, 287.

Crotalus, 267.

Grow, 304.

Cristacea, 113; general characters of, 137 , et seq.

Ctenoid scales of Fishes, 228.

Ctenophora, 84, 85 ; general characters of, 95 .

Ctenophores, 95.

Cuckoo, 300 .

Cuculida, 300

Cucumaria, 110.

Culex, 176.

Curassow, 299.

Curlew, 296.

Cursores, 290.

Cuticle, of Infusoria, 39.

Cuttle-fishes, 186, 20S, 209, 210, 211, 212.

Cyanea, 78.

Cycloid Scales of Fishes, 228.

Cyclolabridoe, 243.

Cyclops, 147.

Cydippe, 95.

Cuynidae, 205.

Cynomys, 351.

Cyprinidre, 243.

Cypris, 147.

Cypselidoe, 304.

Cystic Worms, 117, 118.

Cystoidea, 99, 100.

Daboia, 267

Daphnia, 147.

Darters (Birrls), 295.

Dasypodida, 325 .

Dasyprocta, 350.

Davyurus, 323 .

Denil men's Fingers, ol.

Decapoda (Crustacea), 13s; (Cephalopoda), 214.

Deer, 338.

Denusauria, 277.

Delphinida, 330 .

Detphinus, 330 .

Dental formula 313 .

Dentirostres, 304.

Dibranchiata, 212.

Dicotyles. 334 
Dicynodon, 277.

Didelphido, $322,324$.

Didelphys, 324.

Diflugia, 28.

Digitigrada, 345, 347 .

Dinoceras, 340 .

Dinocerata, 340.

Dipnoi, 237; general characters of, 217 , et sen.

Dipodide, 351.

Diptera, 175.

Discophora (Medusa), 79; (Leeches), 130.

Discorbina, 30, 31.

Distal, 57.

Distoma, 118, 119.

Divers (Birds) 295.

Dodo, 3 u.

Dog, 347.

Dog-fish, 246.

Dolphin, 327, 328, 330.

Doris, 204.

Dormice, 351.

Dorsal vessel of Inuects, 164.

Doves, 299.

Draco, 271

Drigon-flies, 173 .

Dromaaus, 291.

Dromedary, 337.

Duck, 295.

Duck-mole, 319, 320 .

Dugrong, 328.

Eagle, 305.

Earth-worms, 131.

Echidna, 319, 320, 321.

Echinodermata, 97 ; general characters of 97, 98, et seg.

Echinoidea, 99; general characters of, 99 et seg.; aquiferous system of, 101 ; development of, 102 .

Echinorhynchus, 121, 122.

Ectocyst, 188.

Ectoderm, 52

Edentata, 317 ; general characters of, 324 , et seg.

Eels, 243

Elaps, 268.

Elasmobranchii, 237 ; general characters of, 245 ; sulb-orders of, 247.

Elephant, 341, 342 .

Elk, 338.

Elytra, 181.

Emeu, 291.

Emydida, 263.

Endocyst, 188.

Endoderm, 52

Entozoa, 112, 113

Ephemerida, 173.

Epistylis, 55.

Equidar, 333.

Equus, 333.

Erinaceida, 354.

Erincueus, 358, 354.

Ermine, 347.

Errant Annelide, 133, et seq.

Esocidae, 243.

Eudendrium, 62.

Euglena, 42.

Euplectella, 48.

Evorypteriàa, 145.

Euspongia, 48.

Eyes of Insects, 164.
FALCON, 305

Feather-star, 100, 10\%.

Felide, 347; dental formula, 344.

Felis, 349.

Field-bug, 171.

Filaria, 123.

Finches, 303.

Finner-whales, 330 .

Fishes (see Pisces).

Fission, continuous and discontinuous, $54,55$.

Fissirostres, $3 n 4$.

Flajellata, 38, 42 .

Flat-fish, 243.

Eleas, 174,175 .

Flesh-flies, 176

Float of Physophoridle, 74 .

Flukes, 118.

Flustra, 187, 188, 190.

Fly-catcher, 314.

Flying-Dragon, 271.

Flying-Leniur, 355.

Flying-Squirrel, 351.

Food of Animals and Plants, 4.

Food-vacuoles, 39.

Fuot of Mollusca, 186, 197, 202, 206.

Foot-jaws, 138, 189, 140 .

Foot-tubercles, 131, 132, 145.

Foraminifera, 28 ; general characters of, $t b$. : pseudopodia of, 30 ; shell of, 31 ; distribution of, in space, 32 ; presence of, in white chalk, 33 .

Forest-flies, 176.

Formicidoe, 179

Fowl, 298, 299.

Fox, 347.

Fox-bats, 353.

Frigate-bird, 295.

Fringillude, 304.

Fringing-reefs, 89, 90.

Frog, 249, 25t, 255 ; development of, 2.55.

Frulica, 296.

Fuunel of Ctenophora, 96.

GAD-FLIES, 176.

Gadida, $2+3$.

Galeopthecus, 355.

Gallinacei, 298 .

Gallinula 296.

Gallus, 298.

Gammares, 144.

Gannet, 295.

Ganoid Scales of Fishes, 229.

Ganoidei, 237 ; general characters of, I43, et seq.

Gasteropoda, 185, 196; general character's of, 201, et seq.; sliell of, 204 ; odontophure of, 241 ; development of, 202.

Gavial, 272.

Geckotida, 272.

Geese, 295 .

Gemitures, 299.

Gemmation, continuous and discontinuous, 54 .

Gemmule, of Spongilla, 48 .

Gemsbok, 339.

Generations, alternation of, 64 .

Gennette, 347.

Gephyrea, 112.

Gibbon, 359. 
Giraffe, 338.

Giz,ard, of Insects, 162; of Birds, $2 \leqslant 5$.

Globigerina, 30, 33 .

Glutton, 347 .

Gnats, 176.

Gnu, 339.

Goat, 339.

Goat-moth, 178 .

Goat-sucker, 304.

Gobiidle, 243.

Goniaster, 105.

Gonor hores, 62,63 ; medusiform, 64,65 , 68.

Gonosome, 62.

Gordiacea, 114 ; generul characters, 122.

Gorgonida, 90, 92, 93.

Gorilla, 359.

Grallatores, 293, 295, ct sc7.

Grantia, 45, 48 .

Graptolitidoe, 58, 80.

Grasshoppers, 171.

Grebe, 295.

Greenland Whate, 330 .

Gregarina, 21, 22.

Gregarinida, 21 ; reproduction of, 22.

Ground-lnng, 3:2\%.

Grouse, 298.

Gruide, 298.

Guillemot, 295.

Guinea-fowl, 299.

Guinea-pig, 350 .

Guirea-woin, 123.

Gull, 123.

Gulo, 347 .

HADDOCK, 243.

Hadimatirus, 277.

Hcemopsis, 131.

Hag-fisher, 239.

Ha15-worms, $1<2$

Halicore, 328.

Halismma, 34.

Halisarca, 48.

Halteres (see Balancers).

Hamat'sr, $35 \mathrm{l}$.

Hapalidae, 357.

Hare, 350.

Harvest-men, 155.

$H_{d w k s}, 305$.

Hectocotylus, 21?.

Hedgehog, 353, 35t.

Hedriophthalmata, 143.

IIelnolites, 94.

Heliopora, [3, 94.

Helioporide, 93.

IItlozer 35,36 .

Hemelytra, 171.

Henimetabolic Insects, $165,170$.

Heiniptera, 170.

Hermit-crabs, 141.

Heron, $296,297$.

Herring, 243

Ihespetwis, $306,347$.

Heterocercal Tall (Eislies), 232

Jeteropudif, 205.

IIiplobusea, 17i.

Hiinneampelat, 243.

Hippopotamus, $333,334$.

I irudinea, 13t; general characters of, 130.

Hirnmbitider, 304

Holocephali, 247.
Holometaholic Insects, 165, 174.

Holothicroidea, 99 , 104 ; general characters of, 109,110 , et seq.

Holtenia, 48.

Homocercal Tail (Fishes), 232.

Homology, 9.

Honey-badger, 347.

Honey-eater, 804.

Hoopoe, 304.

Horn-till, 304.

Horse, 333.

House-fly, 176.

Howlers (Monkeys), 357.

Hutaming-birds, 3,4 .

Hyonida, 347 .

Hydatids, 118.

Hydatina, 125.

Hydra, 53, 58, 59, 6n; reproduction of, 60 .

Hydractinie', 62, $\mathrm{c3}$.

Hydra-tuba, 77.

Hydrida, 58.

Hydrocorallina, 81 .

Hydroida, 58 ; reproduction of, 62 , et seq.

Hydroid Zoophytes, 58.

Hydrophido, $26 \mathrm{~s}$

Hydrorhiza, 58 .

Hydrosoma, 57 .

Hyclrothecie, 67.

Hydrozoa, 53; general eharacters of, 58 ; terminology af', $54-57$; reproduction of, 62 ; divisions of, 58 .

$H y l n b a t e s, 359$.

Hymenop'cra, 178, 179.

Hyracoidea, 318 ; gencral cliaracters of, $3+1$.

$H y+\pi x, 34 \mathrm{t}$.

Hystricida, 350 .

IBIS, 296.

Ichneumon (Insecta), 179.

Ichthyopthira, 148.

Ichthyopsida, 226 .

Ichthyopterygia, 260 ; characters of, :-7.

Ichthyornis, 307, 308 .

Ichthyosaurus, 2 it.

Idotea, 143.

Iguana, 269, 271.

Iguanodon, $27 \%$.

Ilyanthus, $80^{\circ}$.

Imago, 165 .

Inperforata (Foraminifera), 31.

Individual, detinition of, 54 , et seq.

Infusoria, 21 ; geweral characters of, 37 , ct seq.

Invera, 113; goneral characters of, $16^{\circ}$, et seq; organs of the inouth of, 161 ; digestive system of, 103; metamorphoses of, 165; orders of, 168 , et seq.

Insctivora, 318; general characters of, 353.

Insessores, 302.

Invertebrata, teneral characters of, 11.

Jsis, 92.

Isopoda, 143.

Iulus, $15 \mathrm{~S}$.

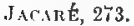

Jackal, 317 .

Jaguar, $3 \pm 9$.

Jay, 304.

Jelly-fishes, 05,63 , et seq.

Jerboa, 351. 
KALONG, 353 .

Kauguruo, 322, 823.

Kaugaroo-bears, 323 .

King-crabs, $141,145$.

Kingfisher, 304.

Koodoo, 339, 340.

Labyrinthodontia, 256.

Lacerla, 2\%0, 271.

Lacertilia, 260; general characters of, 269 , et seg.

Lamodipoda, 144.

Lagena, $30,31$.

Lrogopus, 248.

Lamellibranchiata, 194 ; general characters of, 196, et seq.

Laminarian Zone, 16 .

Lanpreys, 229. 239, 240, 257.

Lamp-shells, 193.

Lancelet, 229, 233, 235, 237.

Land-salamander's, 253.

Laniida, 304.

Lapwing, 297.

Larido, 295.

Larks, 304.

Larva (of Insceía), 166.

Ieeehes, 130,181 .

Lẻmming, 351 .

Lemuridce, 368 .

Lemurs, 355, 356.

Leopard, 348 .

Lepadido, 149.

Lepidoptera, 176, 177, 178.

Lepidosiren, 235, 236; general characters of, $247,248$.

Lepidosteus, 245.

Leporida, 350.

Lepus, 350.

Libellulida, 173.

Lice, 168.

Ligia, 143.

Limax, 206.

Limnocodium, 71 .

Limultus, 144, 145.

Ling, 248.

Lingual Ribbon (of Mollusca), 201.

Lingula, 195.

Lion, $344,345$.

Littoral Zone, 16.

Liver-fluke, 119.

Lizards, 269, et seq.

Lluma, 337.

Lobster, 138 , et ser.

Lob-worn, 134.

Locust, 171, 172.

Locustidoe, 171.

Locust-shrimp, 142.

Lophobranchi, $2 \pm 3$.

Lophopus, 190.

Lophortyx, 298.

Lories, 301.

Loxiadae, 304.

Lucernaria, 76.

Lucernarida, 58; general characters of, 76; development of, 77 ; structure of reproductive zoöids of, 78 , et seq.

Lumbricida, 131.

Lumbricus, 131.

Lynx, 349.

MACAQUE, 357.

Macaw, 301.
Mackercl, 243.

Macropodidce, 322.

Macroscelide, 354.

Macrura, 169.

Madreporiform tubercle, of Echinus, 100 ; of Star-fishes, 104 ; of Holothurians, 109.

Magpie, 804.

Maia, 141.

Malacodermata (Zoantharia), 85.

Mulacopteri, 243.

Mallophaga, 168.

Malpighian vessels of Insects, 163.

Mammalia, 309, et seq.

Marnmotl, 343.

Man, 960.

Manatee, g27, 828.

Mandibles, of Spiders, 151; of Insects, 162; of Cephalopoda, 209.

Manis, 326.

Mantle, 186, 196.

Manubrium, 63.

Marginal bodies, of Medusida, 71 ; of Lucernarida, 79 .

Marmoset, $35 \%$.

Marnot, 351 .

Marsipobranchi, 237 ; general characters, 239 , et seil.

Darsupialiu, 317 ; general characters of, 32. et seq.

Martin, 304.

May-flies, 178 .

Maxillae of Spiders, 151; of Ingecta, 162.

Measles, of Pis, 117.

Medusce, hidden-eyed, 77 , et seq.

Medusa, naked-ejed, $64,65,68,68,69$, $70,71,79$.

Medusida, 69 , et seq.

Medusoid buds of Hydrozoa, 64, 65, 66, $68,69,71$.

Megalosaurus, 277.

Megapodida, 299.

Meleagris, 298.

Meles, 347.

Melicerta, 124, 125.

Meliphagidee, 304.

Mellivora, 347 .

Menobranchus, 252.

Mephitis, 347.

Meropida, 304.

Merostomata, 144.

Merulidoe, 304.

Mesenteries (of Actinozวa), 51, 83.

Metanorphoses of Iuseets, 165, et seq.

Melazoa, 19, 43 .

Mice, 351.

Microlepidoptera, Iт8.

Miliola, 30.

Millepora, 81, 82.

Millipedes, 157, 158.

Mink, 347 .

Mites, 153.

Mole, 354 .

Mollusca, 12 ; general characters of, 183, et seq. ; shell of, 186 ; divisions of, 186.

Mollusca Proper, 196, et seq.

Molluscoida, characters of, 186 ; divisions of, 187 , et seg.

Monera, 25.

Monitors, 271.

Monkeys, 355 .

Monothalanous shells(Foraminifera), 31 . 
Monotremáa, 31t; general characters of, 319 , pt seq.

Moose, 338.

Murphology, 7:

Morse, 346 .

Moths, 177,1 \%

Mud-eel, 251.

Mud-fish, 235, 236, 248.

Nugilide, 243.

Multivalve shells, 148, 201.

Mirrenille, 213.

Mirile, 351

Musca, 176.

Muscisapidre, 304.

Milsh-ox, 340.

Mismurast, 351.

Mustelide, 347 .

M $/$ a, 197, 201.

Mucetes, 357 .

M!luxidae, 351 .

Milrapoda, 11s; general characters of, 157.

Mirnecophaga, 326 .

Myrineleo, 173.

Mixine, 239.

Myxinida, 239.

Myxinoids, 236, 210.

Naidida, 131.

$N a j a, 264,268$.

Narwhal, 330.

Fisua, 347.

Natrines. 293; general characters of, 293 et $s e \%$.

Nautiloid shells (Foraminifera), 32.

Fautilus, Pearly, 208, 209, 210, 212, 215 ; Piper, 208, 209, 211, 212.

Nectocalyces, 72,75 .

Nemalelmia, 113, $12 \mathrm{~L}$.

Nematoudea, 114 ; general characters of, 122.

Nemertide, 121.

Nereis, 195.

Nervures, 160.

Neuroptera, 173.

Newt, 251, 253.

Nodosama, 30, 31.

Nucleolus of Paramacium, 40.

Nucleus of Paramoce $\iota m, 40$.

Nuclibranchiala, 201.

Numenius, 296.

Ninida, 299.

Nimmu]ites, 33.

Nummulitic Limestone, 33.

Nycticebida, 356.

Nymphon, 153.

OCEANIC Hydruzon, 72 , ct seq.

Octopida, 212, et seq.

Optomes, 212

(hlintorete, 330 .

Gilomtalco, 306.

Glontophore of Gasteropoda, 2C1.

Glintornithes, 290, 306.

Odontotorme, 307.

Oligoch ceta, 131 ; general characters of, 131.

Omuevora (Ungulata), 333.

Oniscus, 143.

Onyehomlara, 158.

Oyurulium (if Molluses), 201.

U whitlin, 258, 260; general characters of, 'cit, c't sco.

Ophiocoma, 105.
Ophioglypha, 105.

Ophiornorpha, 250.

Ophiosaurus, 271.

Ophiothrix, 105.

Ophiura, 105.

Opheuroidea, 99, 105 ; general characters of, 105.

Opossum, 322, 323 .

Orang-outang, 359 .

Organ-pipe Cural, 92.

Organs of the mouth of Insects, 161.

Ornithorhynchus, 319, 320, 321 .

Orthoceras, 216.

Orthoptera, 171, 172 .

Ortyx, 298.

Orycteropus, 326.

Oscula of Sjonnerea, $43,46$.

Ostraciontide, 243

Ostracoda, 147.

Ostrich, 279, 281, 283, 284, 256, 288, 290, 291.

Otuda, $2 ! 7$.

Otter, 347 .

Ovarian vesicles of Sertularida, 67 .

Ovibos, 340 .

Ovidae, 339.

Ovipositor, 161 .

Ovis, 339.

Owls, 305 .

Oxen, 339

Oxyurus, 123.

Uyster-catcher, 297.

PaCA, 350.

Paddle-fish, 245.

Pagurida, 141.

Palarontology, 17

Pallial line, 198.

Pallium (see Mantle).

Pangolin, 326

Panther, 348.

Paper Nautilus, 208, 209, 211, 212.

Paramacium, 39 ; nucleus and nucleolus, 40 ; reproduction of, 41.

Parapodia, 128.

Parrakeets, 301.

Parrots, 301 .

Partridge, 298.

Passerine Birds, 322.

Patagium, 352.

Pauropoda, 158.

Pauropus, 158.

Pavo, 299.

Per-fow], 299

Pearly Nautilus, 208, 209, 210, 212, 215.

Peccary, 394.

Pecten, 201.

Pedicellario, of Echinus, 100 ; of Starfish, 104

Pidipalpi, 151.

I'rlinis, 267.

Pelicanus, 205.

Punguin, 295.

Pennatula, $9 \mathrm{I}$.

Pentacrinus, 1ne.

Printatoma, j71.

Perameles, 323.

Perchers, 302.

Percida, 243.

Perdicidie. 298.

Pralix, 2is

Perennibianchiata (Amphibia), 250. 
Perforata (Foraminifera), 31.

Peridinium, 42.

Per palus, 158.

Periss, dactyla, 331.

Petrels, 295.

Petromyzon, 239, 240.

Petromyzonidoe, 249.

Phacocharus, 334.

Phalacrocorax, 295.

Phalangers, 323.

Phalangista, 323.

Phalangium, 155

Pharyngobranchii, 237, et seq.

Pharynx, of Ascidians, 191; of Lancelet, 238.

Phascolarctos, 823.

Phasianidoe, 298.

Pheasants, 298.

Phoca, 346

Pholades, 201.

Phryganeida, 173.

Phyllopoda, 146.

Physalia, 74, 75.

Physiology, 8.

Physophorida, 74, 75 .

Picidoe, 300.

Pig, 334.

Pigeons, 299.

Pike, 243.

Pinnigrada, 345, 340.

Pipidae, 256.

Pisces, 227; general characters of, 228 ; scales of, $i b$.; skeleton of, 229 ; limbs of, 230 ; tail of, 232 ; digestive system of, $i b$, ; respiratory system of, 233 ; heart of, 234 ; swim-bladder of, 235 ; nervous system of, $i b$.; reproduction of, 236 ; orders of, 237.

Placental Mammals, 317.

Placoid Scales of Fishes, 229.

Plagiostomous Fishes, 246.

Planarians, 120.

Plantigrada, 345, et seq.

Plant-lice, 171:

Platyelmia, 113, 114.

Platyrhina, 356.

Plectognathi, 243.

Plesiosaiuries, 275.

Pleurubrachia, 95 ; canal-sjstem of, 95, 96.

Pleuronectidoe, 243.

Plovers, 297.

Pneumatophore, 74.

Podophthalmata, 138.

Podosomata, 153.

Podura, 169.

Polecat, 347.

Polychata, 132.

Polycystina, 34.

Polygastrica, 40.

Polynoe, 135.

Polypary, 57.

Polype, 87.

Polypide, 188.

Polypidom, 57.

Polypite, 57.

Polypterus, 244, 245.

Polythalamia (Foraminifera), 31.

Polyzoa, 184, 185, 186 ; general characters of, 187, et seq.

Porcupine, 350.

Pores of Sponges, 46, 47 .
Porifera, 12, 21, 43 (see Sponges).

Porpuises, 328, 330.

Purtuguese Man-of-war, 74.

Poulpe, 212, 213.

Prairie Dog, 351.

Praya, 73

Proboscidea, 318; general claracters of, 341.

Procellaridoe, 295.

Procyon, 347.

Prong-buck, 339.

Proteus, 251, 252.

Proteus-animalcule, 25.

Protophyta, 3.

Protoplasil1, 19

Protozoa, general characters of, 18, et seq.; classification, 21.

Proventriculns of Birds, 285.

Proximal, $5 \vec{i}$.

Pseudo-hæmal system (Annelida), 129.

Pseudo-hearts, 195.

Psendonavisellix, 23.

Pseudopodia, of Protozoa, 21 ; of Rhizopoda, 25; of $A$ moba, $i b$.

Pseurlo-scorpions, 155.

Psittacide, 301.

Ptarmigan, 298.

Pterocliata, 299.

Pterodactyles, 275, 276.

Pteropidas, 353.

Pteropoda, 185, 186; general cliaracters of, 206 , et seq.

Pteropus, 353.

Pterosauria, 260; general characters of, 275.

Pterygotus, 145.

Puff-adder, 267.

Pulex, 175.

Pulicida, 174.

Pulmonary sacs (A rachnida), 152.

Pulmonate Gasteropods, 2 25.

Puma, 349.

Pupa, 175.

Pyenogonum, 153.

Python, 269.

Quadrumana, 31s; general characters of, 355 , et seq.

Quagga, 333.

Quail, 298.

RABBIT, 350 .

Racoon, 347.

Radiata, 50 .

Radiolaria, 33; general characters of, 33,34 .

Rails, 296.

Rallidee, 296.

Rallus, 296.

Rana, 254.

Ranidae, 255.

Raptores, 293, 304, et seq.

Rasores, 293, 297, et seq.

Rat, 351.

Ratitoe, 290.

Rattlesnake, 267.

Rays, 245, 247.

Red Coral, 92, 94 .

Red Deer, 358.

Reindeer, 338.

Reproduction, general features of, 54 ; in Hydroid Zooplyytes, 62, et seq. 
lieptilia, 227; general characters of, 257, et seq.; jaw ot, $25 \mathrm{~s}$; teetll of, $i b$.; eir' culation of, 259; respiration of, 260; orders of, $i b$.

Respiratory trce of Bolothurians, 110.

Respiratony tubes of Roiffera, 125, 126.

Rhamphastido, 302 .

Hhea, 291

Rhinoceron, 331, 332.

Rhizocephala, 150.

Whizocrinus, 108.

lifuzripula, 21; general characters of, 24 ; divisions of, 25.

Rhizostoma, 80.

Ihizustomidlr, 80.

Rhytina, 328 .

Ribbon-worms (see Nemertide).

Rodentia, 31s; geueral characters of, $34:$, et scr.

Troebuck, 338.

Rorquals, $3>0$.

Rose-cliaftr, 181 .

Rutifera, 114; general characters of, 124 , et seq.

Riund-worms, 122,123

livgria, 85; characters of, 04.

dumbuntia, 333; dentition of, 335 ; stomach of, 336 ; families of, 337 .

Runners (Birds), 29J.

Sable, 347 .

Sillamanders, 253.

Salamandre, 253 .

Salmonidre, 243.3.

Sand-hopper, 144.

Sand-pipers, 2!ı6.

Sand-star, 105, 100.

Sand-worm, 180.

Sanquisuga, 130, 131.

Sarcorle, 250.

Sarcoids of Sponges, 43,4, .

Sauropsida, 227.

Sauropterygia, 260; general characters, 274 .

Saurirce, 9 ne.

Saw-flies, 179.

Scallop, 201.

Scansores, 293, 300, et seq.

Scincus, 272.

Sciuridee, 951.

Sclerobasica (Zoantharia), 90.

sclerobnsic Corals, 87, $! 2, ! 3$.

Selerodermata (Znamiharia), sh.

Se,lerodermic Corals, 8T.

Scolectia, 112 ; general characters of, 113.

Scolopacille, 290.

Scolopendra, 159.

Scomberida, 243.

Scurpion, 151, 154, 155.

Seratchers (Birds), 297.

Sea-anemones, 85.

Sea-blubbers, 77,78 .

Sea-cucumbers, 109 .

Sea-eggs, 99.

Sea-lemons, 204.

Seals, 346 .

Sea-mats, 187, 188, 189, 190.

Sea-mosses, 157 .

Sea-mouse, 135.

Sea-pens, 91.

Sea-rods, 1.

Sea-slugs, 204.
Sea-snakes, 268.

Sea-suriders, 153.

Sea-squirts, 141.

Sea-unicorn, 330 .

Sea-urchins, 99.

Segmental orgaus of Annelides, 129.

Selachii, 246.

Seinnopitheci, 357.

Sepia. 213, 214, 215.

Sepiola, 208.

Serpula, 133.

Sertularia, 66.

Sertularida, 5s; general characters of, 66 ; polypites of, 67 ; reproduction of', 67.

Sharks, 245, 246 .

Sheat-fish, $2+3$.

Sheep, 339 .

Shell, of Foraminifera, 30 ; of Brachiopoda, 193; of Lamellbranchiata, 198; of Gasteropoda, 204 ; of Heteropoda, 205 ; of Pternpoda, 206 ; of the Argonaut, 212 ; of Pearly Nautilus, 215.

Shrew-mice, 354 .

Shrikes, 304

Siluridor, 243.

Simia, 359.

Siphon'phora, 58 ; general characters of, 72.

Siphonops, 250.

Siphons (of Lamellibranchiata), 199.

Sipunculus, 128.

Siredon, 251

Siren, 251, 252.

Sirenia, 317 ; general characters of, $3 \pm 7$, et seq.

Skunk, 347 .

Sloths, $324,325$.

Slow-worm, 27".

Snakes, 264, et seq.

Snipes, 296.

Solaster, 104.

Solen, 201.

Soniatic cavity of Colenterata, 51.

Soricida, 351 .

Spatularia, 245.

Sperm-whale, 330 .

Spharozoum, 35.

Spheniscida, 295.

Sphingida, 178.

Sirider-crab, 141.

Spider-monkeys, $35 \%$.

Spiders, 151, 155, $15 \%$.

Spinneret, of Spiulers, 150; of Caterpillars, 177.

Spiny Aut-enter, 319.

Spirorbis, 133.

Spirula, 214, 215.

Sponges, 2l; general characters of, 43, et seq. : aquiterous system, 45,47 ; reproduction of, $4 \AA$; distribution of in space, 49.

Spongilla, 48, 49: reproduction of, 48 .

Sponn-worm, 112.

Springbok, 339.

Spring-tails, 169.

Squids, 213.

Srruilla, 142.

Squirrel, 357.

Star-fish, 103, 104.

Starling, 304.

Star-nosed Mole, 354. 
Stentor, 42.

Stephanoceros, 124.

Stomapoda, 142.

Storks, $2 y 0$.

Strepsiceros, 340.

Strepsirhina, 356.

Strepsiptera, 180.

Strigida, 305.

Stromatopora, 82.

Struthio, 291.

Sturgeon, 229, 232, 244, 2 \&5.

Sturnidae, 304.

Stylaster, 82.

Stylops, 180.

Sub-kingdoms, 12.

Suctoria (Infusoria), 38.

Suida, 324

Sula, 295.

Sun-star, 104.

Burinam Toads, 256.

Sus, 334.

Swallows, 304

Swan, 295.

Swifts, 284, 304.

Swim-bladder of Fishes, 235.

Swimmers (Birds), 293.

Swimming-bells, 72 .

Sylviadoe, 304.

Synapta, 109, 111.

Syngnathida, 213.

Syrin $x, 127,128$.

\section{Tabanida, 176.}

Tonia, 114, et seq.

Toniada, 113; general characters of, 114 ; development of, 116.

Talitrus, 144.

Talpa, 354 .

Talpidoe, 354

Tantalino, 296.

Tane-worm, 114 et seq.

Tapir, 331, 332.

Tasmanian Devil, 323.

T'egenaria, 156.

Teleostei, 237; general characters of, 211 , et seq.

Telurec, 354.

Tenthredinido, 1 个9.

Tenuirostres, 304.

Terebratula, 194.

Termites, 179.

Tern, 295.

Terrapin, 263.

Test of Foraminifera, 30; of Echino:dea, 99 ; of Tunicata, 191.

Textudo, 263.

Tetrabranchiata, 210, 212, 214, 215, 216.

Tetrao, 298.

Tetraonidae, 298.

Thalassicnlla, 35

Theriodontia, 277.

Thick-knee, 297.

Thorn-headed Worms, 121.

Thread-cells (see Cnida).

Thread-wornis, 122.

Thrusli, 304.

Thylacinus, 323.

Thysanura, 169.

Ticks, 151, 153.

Tiger, 348, 349 .

Tillodontia, 340 .

Tipula, 176.
Toads, 249, 253, 25 6, 255, 250 .

Tongue, of Gasteropods, 201; of Cephalopoda, 210.

Toothed Whales, 330 .

Tortoises, 261, et seq.

Toucan, 302 .

Toxodontia, 341

Tracher, 152, 164 .

Trachynemidae, 69.

Tragulida, $337,338$.

Tree-frogs, 256 .

Prematoda, 113 ; general characters of, 118.

Trepangs, 109.

Trichecus, 340

Trichina, 124.

Trigonocephalus, 267.

Trilobita, 146.

Tringidae, 296.

Trionycidae, 263

Priton, 253.

Trochilida, 304.

Troglodytes, 859 .

'Trogonida, 302.

Trophosome, 62.

Tuhe-feet of Echinus, 101.

Tube-worms, 130, 133.

Tubicola, 133, 134.

Trubifex, 131, 132 .

Tubipora, 92.

Tubularia, 61.

Tubularida (see Corynida).

Tunicata, 186; general characters of, 191 , et seq.

Trupaia, 355 .

Turbellaria, 120; general characters of, $i b$.

Turkey, 299.

Turn-stones, 297.

Turtles, 261, 262, 263.

UMBRELLA of Lucernarida, $76,83$.

Univalve Shells, 201.

Ungulata, 318; general characters of, 331, et seq.

Upupince, 304

Uraster, 103, 104.

Urodela, $25 \mathrm{I}$.

Ursida, 346.

Vacooles, of Amaba, 20; of Paramacium, 39 .

Vaginicola, 42.

Valkeria, 190.

Varanida, 271.

Veil, of gonophores, 64 ; of nectocalyces, 73; of naked-eyed Meduso, 79.

Velella, 74, 75 .

Venus's flower-basket, 48 .

Venus's girdle, 96 .

Veretillum, 91, 92 .

Vertebra, structure of, 22 .

Vertebrata, 11, 12, 13 ; general characters of, 218 , et seq. ; skeleton of, 220 ; digestive system, 223 : blood of, 225 ; respiration of, $i b$; nervous system of, 226 ; reproduction of, $i b$.; divisions of, $i b$.

Vesicle, contractile, of Protozoa, 19, 25, $30,40$.

Vespida, 179.

Vinegar Eel, 153.

Viperidx, 207. 
Viperina, 267.

Virgularia, $9 \mathrm{t}$.

Fivervido, 347 .

Forticella, 38, 41, 42.

Vulture, 305.

Waders (Birds), 295.

Wals, 347 .

Walins, $34 f$.

Wapitı, 398.

Warblers, $3{ }^{4} 4$.

Wirt-hog, 334.

Wasps, 179.

Water-fleas, 147.

Water-hens, 246

Weasel, 347 .

Whale, $310,312,316,327,325,329,330$.

Whalebone Whale, 529 .
Wheel-animaleules, 124.

White Ant, 173.

Wolf, 347.

Wolverine, 347 .

Woodcock, 296.

Wond-lice, 143.

Woodpeckers, 300.

Ẍiphosura, 145.

ZEBRA, 333.

Zoantharia, 85; Malacodermula, 85; ; ; Selerodermata, 86; Sclerobasica, 90.

Zoanthus, 86.

Zooid, 57.

Zoological Provinces, 15.

Zoology, definition of, 2. 


\section{APPLETONS' SCIENCE TEXT-BOOKS,}

In response to the growing interest in the study of the Natural Sciences, and a demand for improved text-books representing the more accurate phases of scientitic knowledge, and the present active and widening field of investigation, arrangements have been madc for the publication of a series of text-books to cover the whole field of sciencestudy in Figh Schcols, Academies, and all schools of similar grade.

The following are now ready. Others in preparation.

THE ELEMENTS OF CHEMISTRY. By Professor F. W. Clarke, Chemist of the United States Geological Survey. 12mo, 369 pages.

THE ESSENTIALS OF ANATOMY, PHYSIOLOGY, AND HYGIENE. By Roger S. Tracy, M. D., Sanitary Inspector of the New York Boald of Health. 12mo, 299 pages.

ELEMENTARY ZOÖLOGY. By C. F. IIOLDER, Fellow of the New York Acadeny of Science, Corresponding Member Linnæan Society, etc.; and J. B. HoLDER, M. D., Curator of \%ölogy of American Museum of Natural History, Central Park, New York. $12 \mathrm{mo}, 385$ pages.

A Compend of Geology. By Josfyh Le Conte, Profassor of Geology and Natural History in the University of California; author of "Elements of Geology," etc. 12mo, 399 pages.

APPLIED GEOLOGY. A Treatise on the Industrial Relations of Geological Structure. By Samued G. Williams, Professor of General and Economic Geology in Cornell University. 12mo, 386 pages.

DESCRIPTIVE BOTANY. A Practical Guide to the Classification of Plants, with a Popular Flora. By Eliza A. Youmans. $12 \mathrm{mo}, 336$ pagres.

Physiological Botany. By Romert Bentuet, F. L. S., Professor of Botany in King's College, London. Adapted to American Schools and prepared as a Sequel to "Descriptive Botany," by Eliza A. Youmans. $12 \mathrm{mo}, 292$ pages.

THE ELEMENTS OF POLITICAL ECONOMY. By J. Ladrence Lacghlin, Ph. D., Assistant Professor of Political Economy in Harvard University. $12 \mathrm{mo}$.

For apecimen copies, terms for introduction, catalogue, and price-list of all our publicutions, write to publishers at either adiress below.

$$
\text { D. APPLETON \& CO, Fublishers, }
$$
NEW YORK, BOSTON, CHICAGO, ATLANTA, SAN FRANCISCO. 


\section{SCIENCE.}

Huxley and Youmans's Physiology and Hygiene. By Thomas H. Hexley, LlL. D., F. R. S., and William J. Yocmans; I. D. New and revised edicion. With numerous Illustrations. 12mo. 420 pages.

Coming's Class-Book of Physiology. With 24 Plates, and numerous Engravings on Wood. 12mo. 324 pages.

Youmans's Hand-Book of Household Science, A Popular Account of Heat, Light, Air, Aliment, and Cleansing, in their Scientific Principles and Domestic Applications. With numerous illustrative Diagrams. $12 \mathrm{mo} .470$ pages.

Physiography : An Introduction to the Study of Nature. By Trowas H. Huxuer. With Illustrations and Colored Plates. 12 mo.

Nicholson's Biology. Illustrated. 12mo. 163 pages.

Nicholson's Ancient Life-History of the Earth. A Comprehensive Outline of the Principles and Lcading Facts of Paleonto. logical Science. 12mo. 407 pages.

Anthropology : An Introduction to the Study of Man and Civilization. By EDward B. TrLor, D. C. L., F. R. S. With 78 Illustrations. 12mo. 448 pagres.

Science Primers. Edited by Professors IIcxlet, Roscoe, and Bat. FOUR STEWART.

Chernistry

H. E, Roscoe.

Physics BALFOUR STEWART.

Physical Geography. A. GEIKIE.

Geology.

A. GEIKIE.

Physiology

M. Foster.

Astronomy J. N. LOCIIER.

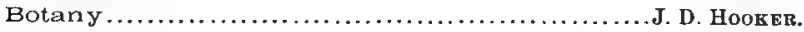

Logie. W. S. JEVONs. Inventional Geometry......................... G. SPENCER.

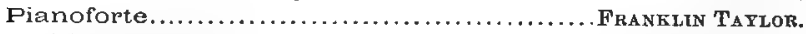
Political Economy............................... S. JEvong. Natural Resources of the United States......J. HARRIS PATtoN. Scientific Agriculture ........................... T. Lupron.

D. APPLETON \& CO., Publishers, NEW YORK, BOSTON, CHICAGO, SAN FRANCISCO. 


\section{BOTANY AND ZOOLOGY.}

First Book of Botany. Designed to Cultivate the Observing Powers of Children. By Eliza A. Yourans. 12mo. 202 pages.

Descriptive Botany. $\Lambda$ Practical Guide to the Classification of Plants, with a Popular Flora. By Eliza A. Yodmans. 12 mo 336 pages.

Henslow's Botanical Charts, modified and adapted for Use in the Cnited States. By Eliza A. Youmans. Beautifully colored. Six Charts with Key, mounted on Rollers. Per set, $\$ 15.75$.

Elements of Zoology. By C. F. Holder, Fellow of the New York Academy of Sciences, Corresponding Member of the Linnæan Society, etc. ; and J. B. HoLDER, M. D., Curator of Zoölogy, A merican Museum of Natural History, Central Park. 12mo. 385 pages.

Science Primer of Botany. 18mo.

First Book of Zoology. By Edward S. Morse, Pb. D., formerly Professor of Comparative Anatomy and Zoölogy in Bowdoin College. 12mo. 190 pages.

Nicholson's Text-Book of Zoology. 12mo. 353 pages.

Nicholson's Manual of Zoology. For the Use of Students. With a General Introduction on the Principles of Zoölogy. Revised and enlarged edition. 243 Woodcuts. 12mo. 673 pages.

Winners in Life's Race: or, The Great Backboned Family. By Arabella B. Bucketer. 12mo. 367 pagcs.

Life and her Children. Glimpses of Animal Life, from the Amœba to the Insects. With upward of 100 Illustrations. By Arabella B. Bucrley. 12mo. 312 pages.

The Crayfish. An Introduction to the Study of Zoölogy. By Tromas H. Hoxley, F. R. S. With 82 Illustrations, 12mo. 371 pages.

D. APPLETON \& CO., Publishers, NEW YORK. BOSTON. CHICAGO, SAN FRANCISCO. 


\section{THE NEW PHYSICS.}

\section{A Manual of Experimental Study for High Sohools and Preparatory Schools for College.}

By JOHN TROWBRIDGE,

PROEESBOR OF PHYSICG, HARYARD UNIVERSITY.

With IIIustrations

12mo. Cloth, $\$ 1.50$.

Prepared with special reference to the present advanced scientifio requirements for admission to the leading colleges.

The New Phrsics is intended as a class manual of experimental study in Physics for colleges and advanced preparatory schools. It involves the use of simple trigonometrical formulas in experimental demonstrations and in the discussions and mathematical computations of various forms of energy.

In The New Physics, Professor Trowbridge has so presented the subjects treated, theoretically and practically, as to furnish to the student the means of rigid and thorough mental discipline, and at the same time of acquiring that practical knowledge of the subject which will properly prepare him for subsequent and deeper study in the sciences. The modern tendency of physical seience is carefully noted and clearly shown by means of the illustrations employed and their mutual relations.

Professor Trowbridge's New Prysics is a successful and complete refutation of the fallacy which bas long prevailed among those who adhere exclusively to the classics for purposes of mental discipline. Its text shows that the mastcry of certain definite and proportionate requirements in the sciences, as requisites for college admission, calling for definite attainment before entrance upon a collegiate course of study, will furnish, in due proportion, that mental training and development which are a necessary preparation for the broader training of the college curriculum.

The New Physics is also adapted to the use of colleges and special training-schools, and will be found a convenient and practical text-book for such institutions.

For sale by all booksellers; or sent by mall, past-paid, on receipt of price.

New York: D. APPLETON \& CO., Publishers, 1, 8, \& 5 Bond Street. 


\title{
OUR PLACE IN SPACE!
}

\section{ASTRONOMY BY OBSERVATION.}

\author{
By ELIZA A. BOTVEN.
}

4to. 90 pages.

As elementary text-book for High-Schools and Academies, based on the most practical and interesting method of studying the subject-that of observation. To assist the pupil in his work, careful directions are given when, how, and where to find the heavenly bodies; also for observing, in entertaining and instructive ways, the characteristics and phenomena of the constellations. Their motions are described in familiar language, in the order in which they can be secn by an observer. The large quarto pages admit maps and views on a scale that will give a clcar conception of the vast expanse of the celestial regions.

\section{LOCKYER'S \\ ELEMENTS OF ASTRONOMY.}

Accompanied with numerous Illustrations, a Colored Representation of the Solar, Stellar, and Nebular Spectra, and Arago's Celestial Charts of the Northern and Southern Hemisphere. American edition, revised and enlarged, and specially adapted to the wants of American schools. 12mo. 312 pages.

The author's aim throughout the book has becn to give a connected view of the whole subject rather than to discuss any particular parts of it, and to supply facts and ideas founded thereon, to serve as a basis for subsequent study.

The fine STAR-MAPS OF ARAGO, showing the boundaries of the constellations and the prixcipal stars they contain, are appended to the volume.

\author{
D. APPLETON \& CO., Publishers, \\ NEW YORK, BOSTON, CHICAGO, ATLANTA, SAN FRANCISCO.
}




\section{* BOTANY BY OBSERVATION. *}

\section{SCIENCE PRIMER OF BOTANY.}

BY J. D. HOOKER, C. B., P. R.S. Fi"Lly illostrated.

18mo. Flexible cloth.

\section{FIRST BOOK OF BOTANY.}

Br ELIZA A. YOUMANS.

Designed to Cultivate the Observ. ing and Reasuning Powers of Children.

\section{DESCRIPTIVE BOTANY.}

By ELIZA A. YOUMANS.

A Practical Guide to the Classification of Plants, with a Popular Flora.

\section{PHYSIOLOGICAL BOTANY.}

BY ROBERT BENTLEY, F. L. S.,

Prof. of Botany in King's College, Lond.

Prepared as a Sequel to "Descriptive Botany," by Eliza A. Youmans.

HENSLOW'S

BOTANICAL CHARTS.

Thoroughly Modified and Adapted for Use in the United States, by Eliza A. Youmans.
A very interesting and valuable little work, designed to supply an elementary knowledge of the principal facts of plant-life, together witl the means of training beginners in the way to observe plants metlodically and accarately.

The true objective method applied to elementary science-teaching. Plants themselves are the objects of stady. The pupil is told very little, and from the beginning througbout he is sent to the plant to get bis knowledge of the plant.

Introduces the pupil to the study of Botany by the direct observation of vegetable forms.

This book takes the place of the author's "Second Book of Botany." but provides a complete course in itself, no other book being necessary.

Designed to give an elementary account of Structural and Physiological Botany, or of the inner and minute mechanism and activities of plants.

It treats of what the parts of a plant are built up, and what functions they perform in its hittory as a living being.

Six Charts monnted on rollers, containing vearly five hundred figures colored to the life, which represent twenty-four orders and more than forty apeciea of plants. An invaluable aid in making the study of Botany interesting and attractive.

New Yark: D. APRLETON \& C0., 1, 3, \& 5 Bond Street. 


\title{
FOR ELEMENTARY SCIENCE STUDY.
}

\section{HOW WE LIVE;}

Or, THE HUMAN BODY, AND HOW TO TAKE CARE OF IT. An

Elementary Course in Anatomy, Physiology, and Hygienc. By JaMes Johonnot, Eugene Bouton, Ph. D., and Henry D. Didama, M. D.

A text-book thoronghly arlapted to elementary instruction in the public schools, giving special atteution to the laws of Hygiene (including the efects of alcohol), with a special chapter on Alcohol and Narcotics by Dr. Didama.

INTRODUCTION PRICE, 40 cents.

\section{FIRST BOOK OF CHEMISTRY.}

\author{
By Mary Shaw-Brewster.
}

A course of stimple experiments for beginners, giring great prominence to practical work by the pupil. The experiments are of the most elementary character, and the simplest apparatus is employed.

INTRODUCTION PRICE, 66 cents.

\section{FIRST BOOK OF BOTANY.}

Designed to Cultivate the Observing Powers of Children. By ELzA A.

Youmans. Revised edition. 12mo. 158 pages.

In this book the true objective method is applied to elementary acienceteaching. Plants themselves are the ubjects of stady, and the knowledge thus gained becomes at once accurate and of practical value as a preparation for etudy in other departments of science.

\section{INTRODUCFION PBICE, 64 cents.}

\section{FIRST BOOK OF ZOÖLOGY.}

By Edward S. Morse, Ph. D., formerly Professor of Comparative Anatomy and Zoölogy in Bowdoin College. 12mo. 190 pages.

Professor Morse has adapted this First Book of Zoblogy to the pupils of the United States. The examples presented for study y re euch as are common and familiar to every school-boy-as snails, insects, splders, worms, molluska, etc.

\section{INTRODUCTION PRICE, 87 cents.}

Sample copies will be mailed, post-paid, to teachers or school-offcers, for examination, at the introduction price. Send for full descriptive circulars, catalogue, "Educational Notes," etc.

D. APPLETON \& CO., Publishers, New York, Boston, Chicago, Atlanta, Dan Francisco. 


\section{A GREAT WORT.}

\section{APPLETONS'}
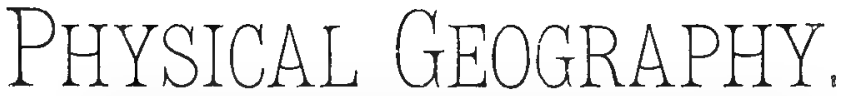

Prepared on a new and original plan. Richly illustrated with engravinirs, diagrams, and maps in color, and including a separate chapter on the geolonical history and the physical features of the United States.

$$
\mathbf{B Y}
$$

JOHN D. QUACKENBOS, A. M., M. D., Adjuuct Professor of tbe English Language and Literature, Columbin College, New York, Literary Editor.

JOHN S. NEWBERRY, M. D., LL. D., Professor of Geology and Palrontology, Columbia College.

CHARLES H. HITCHCOCK, Ph. D., Professor of Geology and Mineralogy, Dartmouth College.

W. LE CONTE STEVENS, Ph. D., Professor of Physics, Packer Collegiate Institute.

HENRY GANNETT, E. M., Chief Geographer of the United States Geological Survey.

WILLIAM H. DALL, Of the United States National Museum.

\section{HART MERRIAM, M. D.,} Ornithologist of the Department of Agriculturo.

NATHANIEL L. BRITTON, E. M , Ph. D., Lecturer in Botany, Columbia Cullege.

\section{GEORGE F. KUNZ,}

Gem Expert and Mineralogist with Messrs. Tiffany \& Co., New York.

\section{Lieutenant GEORGE M. STONEY,}

Naval Department, Washington.

The unique and valuable features embodied in Appletons' New Physical Geography place it, at once, in advance of any work of the kind heretofore issuet. The corps of scientific specialists enlisted in the preparation of this book presents an array of talent never before united in the making of a single text-book. The confidence of teachers everywhere must at once be secured when it is known that such a work is on the warket.

Price for introduction or examination, \$1.60. Specimen pagcs, etc, forwarded on application.

\section{APPLETON \& CO., Publishers,}

NEW YORK, BOSTON, CHICAGO, ATLANTA, SAN FRANCISCO. 






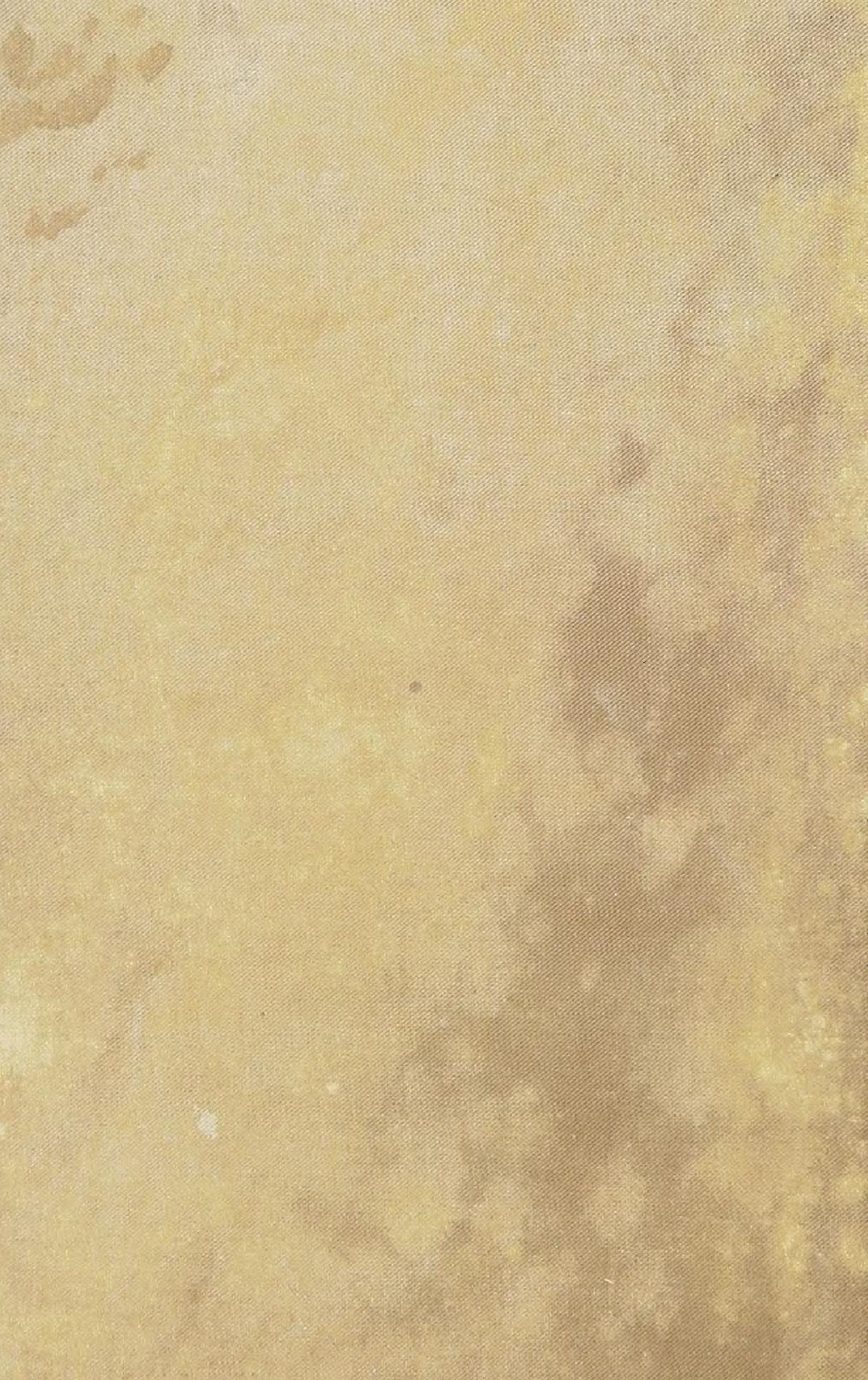

a

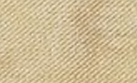

